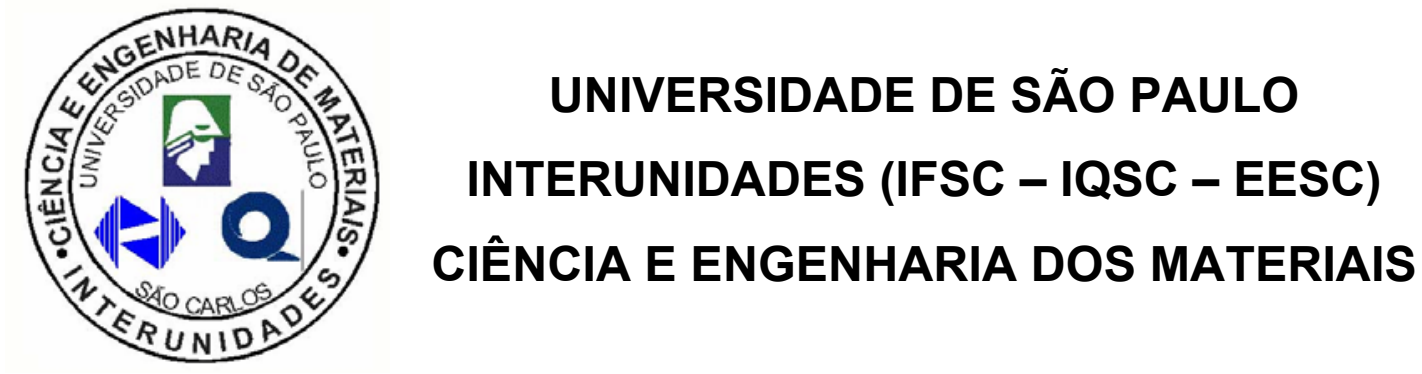

\title{
APLICAÇÃO DE CONCEITOS REOLÓGICOS NA TECNOLOGIA DOS CONCRETOS DE ALTO DESEMPENHO
}

\section{ALESSANDRA LORENZETTI DE CASTRO}

\author{
Tese apresentada à Área de \\ Interunidades em Ciência e \\ Engenharia de Materiais, da \\ Universidade de São Paulo, como \\ parte dos requisitos para a obtenção \\ do título de Doutor em Ciência e \\ Engenharia dos Materiais.
}

Orientador: Prof. Dr. Jefferson Liborio 
Castro, Alessandra Lorenzetti de C355a Aplicação de conceitos reológicos na tecnologia dos concretos de alto desempenho/ Alessandra Lorenzetti de Castro. São Carlos, 2007

Tese (Doutorado) - Escola de Engenharia de São Carlos / Instituto de Física de São Carlos/ Instituto de Química de São Carlos- Universidadede São Paulo, 2007. $302 \mathrm{f}$.

Área: Ciência e Engenharia de Materiais.

Orientador: Prof. Dr. Jefferson Benedicto Libardi Liborio.

1. Concreto de alto desempenho. 2. Reologia.

3. Trabalhabilidade. I. Título. 
Stos meus pais, Sandrave Orley, e a' minhar irmai, Renata, sempre fresentes nas minhas conquistas. 

Primeiramente, agradeço a Deus por ter me iluminado durante toda essa caminhada, dando-me força para enfrentar as dificuldades, humildade para reconhecer e corrigir os erros e sabedoria para agradecer as conquistas.

À minha amada família, Sandra, Orley e Renata, em extensão aos meus avós, Sérgio, Ruth, Orley e Marilourdes, pelo amor, apoio e incentivo dados durante toda a minha vida, permitindo o traçado de um caminho digno e correto do qual muito me orgulho.

Um obrigado especial à Dú, pelos momentos de carinho vividos desde o meu nascimento. A todos os meus familiares que torcem por mim e vibram com cada conquista.

Ao Danilo, pelo carinho, confiança, apoio, incentivo e companheirismo compartilhados desde sempre.

Aos meus amigos, Buby e Tatiana, pela convivência saudável e amizade.

Ao meu orientador Prof. Dr. Jefferson Benedicto Libardi Liborio, por ter acreditado e confiado em mim, dando-me a oportunidade de ingressar nesse maravilhoso mundo da pesquisa de tecnologia dos materiais.

À Fernanda Giannotti, Sandra, Valdirene, José Américo, Thiago, Rodrigo, Fernanda Costenaro, Vanessa, Samir e Marcelo, amigos do Laboratório de Materiais Avançados à Base de Cimento, pela troca de conhecimento e auxílios experimentais. Com certeza vivemos momentos importantes que guardaremos para sempre em nossas memórias.

Ao Laboratório de Cerâmicas Especiais e Refratários/Grupo de Engenharia de Microestruturas de Materiais da Universidade Federal de São Carlos, em especial ao Prof. Dr. Victor Carlos Pandolfelli, pelo auxílio na escolha e análise dos métodos experimentais na área de reologia dos concretos. Agradeço também aos pesquisadores Fernando e Ivone que fazem parte desse grupo de pesquisa e que muito me auxiliaram no desenvolvimento dos ensaios de reometria.

À secretaria da Interunidades, aos funcionários do Laboratório de Engenharia de Estruturas, ao Sr. Wilson e ao Jorge pelo auxílio prestado durante a realização dessa pesquisa.

À FAPESP - Fundação de Amparo à Pesquisa do Estado de São Paulo, pelo apoio financeiro dado ao desenvolvimento da presente pesquisa. 



\section{PUBLICAÇÕES}

CASTRO, A.L.; LIBORIO, J.B.L. Comportamento reológico do concreto de alto desempenho. In: SIMPÓSIO EM CIÊNCIA E ENGENHARIA DE MATERIAIS, 5., 2002, São Carlos/SP. Resumos estendidos... p. 27-28.

CASTRO, A.L. et al. Desenvolvimento tecnológico dos concretos nos últimos 50 anos. In: CONCRETO COLLOQUIA 2003, 2003, São Carlos/SP. Anais... CDROM.

CASTRO, A.L.; LIBORIO, J.B.L. Análise da trabalhabilidade da pasta de cimento fresco através do ensaio de miniabatimento. In: SIMPÓSIO EM CIÊNCIA E ENGENHARIA DE MATERIAIS, 6., 2003, São Carlos/SP. Resumos estendidos... p. 07-08.

CASTRO, A.L; LIBORIO, J.B.L. A importância da avaliação reológica de pastas com e sem sílica ativa para produção de concretos estruturais com cimento Portland para obras marítimas. In: SEMINÁRIO E WORKSHOP EM ENGENHARIA OCEÂNICA, 2004, Rio Grande/RS. Anais... CD-ROM.

CASTRO, A.L; SILVA, F.G.; LIBORIO, J.B.L. Potencialidade de uso de concretos especiais em obras marítimas. In: SEMINÁRIO E WORKSHOP EM ENGENHARIA OCEÂNICA, 2004, Rio Grande/RS. Anais... CD-ROM.

CASTRO, A.L; LIBORIO, J.B.L. Reologia de pastas e argamassas no estado fresco - Um avanço na produção de concreto de alto desempenho. In: JORNADAS SUL-AMERICANAS DE ENGENHARIA ESTRUTURAL, 31., 2004, Mendoza/Argentina. Anais... CD-ROM.

CASTRO, A.L; LIBORIO, J.B.L. A influência da sílica ativa sobre a determinação do teor ótimo de aditivo superplastificante em pastas de cimento no estado fresco. In: CONGRESSO BRASILEIRO DO CONCRETO, 46., 2004, Florianópolis/SC. Anais... CD-ROM.

CASTRO, A.L.; LIBORIO, J.B.L. A influência do procedimento de mistura sobre a trabalhabilidade de pastas de cimento. In: SIMPÓSIO EM CIÊNCIA E ENGENHARIA DE MATERIAIS, 7., 2004, São Carlos/SP. Resumos estendidos... p. 03-04.

CASTRO, A.L. et al. Concretos de alto desempenho constituídos com sílica extraída da casca de arroz. In: SIABE 2005 - SIMPÓSIO IBERO-AMERICANO "O BETÃO NAS ESTRUTURAS", 2005, Coimbra/Portugal. Anais... CD-ROM.

CASTRO, A.L. et al. Estudo do comportamento de concretos de alto desempenho. In: SIABE 2005 - SIMPÓSIO IBERO-AMERICANO "O BETÃO NAS ESTRUTURAS”, 2005, Coimbra/Portugal. Anais... CD-ROM.

CASTRO, A.L; LIBORIO, J.B.L. Avaliação da trabalhabilidade de concretos de alto desempenho em termos da tensão de escoamento. In: CONGRESSO BRASILEIRO DO CONCRETO, 47., 2005, Olinda/PE. Anais... CD-ROM. 
CASTRO, A.L. et al. Structural concretes with silica fume for the production of durable structures. In: INTERNATIONAL ACI/CANMET CONFERENCE ON QUALITY OF CONCRETE STRUCTURES AND RECENT ADVANCES IN CONCRETE MATERIALS AND TESTING, 4., 2005, Olinda/PE. Proceedings... CD-ROM.

CASTRO, A.L. et al. Demystifying the production process of high performance and high strength concretes - Design considerations. In: INTERNATIONAL ACI/CANMET CONFERENCE ON QUALITY OF CONCRETE STRUCTURES AND RECENT ADVANCES IN CONCRETE MATERIALS AND TESTING, 4., 2005, Olinda/PE. Proceedings... CD-ROM.

CASTRO, A.L.; LIBORIO, J.B.L. A influência do procedimento de mistura sobre a trabalhabilidade de concretos de alto desempenho. In: CONPAT 2005 - VIII CONGRESO LATINOAMERICANO DE PATOLOGÍA DE LA CONSTRUCCIÓN/X CONGRESO DE CONTROL DE CALIDAD EN LA CONSTRUCCIÓN, 2005, Assunção/Paraguai. Anais... CD-ROM.

CASTRO, A.L.; LIBORIO, J.B.L. Considerações sobre o processo de produção de concreto de alto desempenho para estruturas pré-moldadas. In: ENCONTRO NACIONAL DE PESQUISA-PROJETO-PRODUÇÃO EM CONCRETO PRÉMOLDADO, 1., 2005, São Carlos. Anais... CD-ROM.

CASTRO, A.L.; LIBORIO, J.B.L. Caracterização reológica inicial de concretos de alto desempenho. In: SIMPÓSIO EM CIÊNCIA E ENGENHARIA DE MATERIAIS, 8., 2005, São Carlos/SP. Resumos... p.10.

CASTRO, A.L; LIBORIO, J.B.L. A influência dos agregados sobre o comportamento do concreto de alto desempenho no estado fresco. In: CONGRESSO BRASILEIRO DO CONCRETO, 48., 2006, Rio de Janeiro/RJ. Anais... CD-ROM.

CASTRO, A.L; LIBORIO, J.B.L. A influência das adições químicas e minerais sobre a trabalhabilidade de concretos de alto desempenho. In: SIMPÓSIO EM CIÊNCIA E ENGENHARIA DE MATERIAIS, 9., 2006, São Carlos/SP. Resumos estendidos... p. 03-04.

CASTRO, A.L; LIBORIO, J.B.L. Initial rheological description of high performance concretes. Materials Research, v. 9, n. 4, Oct.-Dec. 2006. 
Lista de figuras $\quad \mathrm{V}$

Lista de tabelas $\quad \mathrm{xV}$

Lista de símbolos e abreviaturas xix

Resumo $x x i$

Abstract xxiii

1 Introdução 1

1.1 Importância e justificativa do estudo 4

$\begin{array}{ll}1.2 \text { Objetivos } & 6\end{array}$

$\begin{array}{ll}1.3 \text { Organização do trabalho } & 7\end{array}$

2 Concreto de alto desempenho 9

2.1 Definição 9

$\begin{array}{lr}2.2 \text { Histórico } & 10\end{array}$

2.3 Aplicações 11

$\begin{array}{ll}2.4 \text { Materiais constituintes } & 13\end{array}$

$\begin{array}{ll}\text { 2.4.1 Cimento } & 14\end{array}$

$\begin{array}{ll}\text { 2.4.2 Agregados } & 18\end{array}$

$\begin{array}{ll}\text { 2.4.3 Água de amassamento } & 21\end{array}$

2.4.4 Aditivo superplastificante $\quad 22$

2.4.5 Sílica ativa $\quad 26$

3 Aspectos conceituais relacionados a reologia 31

3.1 Definição de reologia 31

3.2 Tensão, deformação e viscosidade $\quad 34$

3.2.1 Conceito de tensão $\quad 35$

3.2.2 Conceito de deformação 36

$\begin{array}{ll}\text { 3.2.3 Conceito de viscosidade } & 38\end{array}$

$\begin{array}{ll}3.3 \text { Classificação dos modelos reológicos } & 40\end{array}$

$\begin{array}{ll}\text { 3.3.1 Fluidos Newtonianos } & 41\end{array}$

3.3.2 Fluidos não-Newtonianos $\quad 41$

4 Trabalhabilidade do concreto fresco $\quad 47$

4.1 Definição de trabalhabilidade $\quad 47$

$\begin{array}{ll}4.2 \text { Avaliação da trabalhabilidade } & 50\end{array}$

4.3 Fatores que influenciam a trabalhabilidade $\quad 54$

4.3.1 Tempo de manipulação das misturas $\quad 55$

4.3.2 Propriedades dos componentes da mistura $\quad 55$

4.3.3 Proporções da mistura $\quad 62$

4.3.4 Teor de ar incorporado e temperatura 66

$\begin{array}{ll}\text { 4.3.5 Processos práticos } & 67\end{array}$

$\begin{array}{ll}\text { 4.4 Perda de abatimento } & 71\end{array}$

$\begin{array}{ll}5 \text { Reologia do concreto fresco } & 79\end{array}$

5.1 Classificação reológica do concreto fresco $\quad 82$

5.1.1 Parâmetros reológicos $\quad 86$ 
$\begin{array}{lr}\text { 5.1.2 Tixotropia } & 92\end{array}$

5.2 Fatores que influenciam o comportamento reológico do concreto fresco 96

$\begin{array}{lc}\text { 5.2.1 Reologia da pasta de cimento } & 98\end{array}$

5.2.1.1 Microestrutura da pasta de cimento 102

5.2.1.2 Interação cimento-aditivo 105

5.2.1.3 Estudo do escoamento de pastas de cimento através dos $\quad 110$ ensaios de miniabatimento e cone de Marsh - compatibilidade entre os materiais

5.2.1.4 Ponto de saturação do aditivo 117

$\begin{array}{ll}\text { 5.2.2 Distribuição e empacotamento de partículas } & 119\end{array}$

$\begin{array}{ll}\text { 5.2.2.1 Segregação e exsudação } & 121\end{array}$

5.2.3 Estado de dispersão das partículas 123

$\begin{array}{ll}\text { 5.2.4 Vibração } & 127\end{array}$

5.3 Medição das propriedades reológicas do concreto fresco 130

5.3.1 Ensaios que medem apenas um parâmetro reológico 132

5.3.1.1 Ensaio de abatimento do tronco de cone 132

5.3.1.2 Consistômetro de Ve-Be 135

$\begin{array}{ll}\text { 5.3.1.3 Caixa } L & 137\end{array}$

5.3.2 Ensaios que medem os dois parâmetros reológicos $\quad 139$

5.3.2.1 Ensaio de abatimento de tronco de cone modificado 140

5.3.2.2 Reômetro 143

6 Procedimento experimental 151

6.1 Dosagem do concreto 152

6.1.1 Escolha dos traços estudados 152

6.1.2 Composição dos traços de concreto 152

6.1.3 Traço definitivo e ajustado 155

6.1.4 Procedimento de mistura do concreto de alto desempenho 155

6.2 Avaliação da trabalhabilidade pelos métodos de ensaio tradicionais $\quad 156$

6.3 Avaliação da capacidade de escoamento 157

6.4 Caracterização reológica dos concretos de alto desempenho 157

6.5 Avaliação da trabalhabilidade pelos métodos de ensaio que determinam os 157 dois parâmetros reológicos

7 Resultados e discussões $\quad 159$

$\begin{array}{ll}\text { 7.1 Dosagem dos concretos de alto desempenho } & 160\end{array}$

$\begin{array}{ll}\text { 7.1.1 Estudo da matriz pasta de cimento } & 160\end{array}$

$\begin{array}{ll}\text { 7.1.2 Estudo da fase agregado } & 167\end{array}$

$\begin{array}{ll}\text { 7.1.3 Traço definitivo e ajustado } & 169\end{array}$

7.2 Avaliação da trabalhabilidade pelos métodos de ensaio tradicionais $\quad 170$

7.2.1 Ensaio de abatimento de tronco de cone 171

$\begin{array}{ll}\text { 7.2.2 Consistômetro de Ve-Be } & 178\end{array}$

7.3 Avaliação da capacidade de escoamento do CAD fresco 185

7.4 Avaliação da trabalhabilidade pelos métodos de ensaio que determinam os 188 dois parâmetros reológicos

7.4.1 Ensaio de abatimento de tronco de cone modificado 188

$\begin{array}{ll}\text { 7.4.2 Reômetro } & 198\end{array}$ 
7.4.2.1 Identificação da natureza reológica dos concretos de alto 199 desempenho

7.4.2.2 Avaliação da trabalhabilidade dos concretos de alto desempenho através da evolução dos parâmetros reológicos

7.4.2.3 Comportamento ao cisalhamento dos concretos de alto desempenho ao longo do tempo

7.4.2.4 Influência da temperatura e do $\mathrm{pH}$ sobre o comportamento de concretos de alto desempenho

7.5 Comparação dos resultados

7.5.1 Correlação entre o abatimento e os parâmetros reológicos

7.5.2 Correlação entre o abatimento, o tempo e os parâmetros reológicos

7.5.3 Influência do misturador

7.5.4 Comparação do comportamento dos concretos produzidos com os diferentes procedimentos de mistura

\section{Conclusões}

8.1 Sugestões para pesquisas futuras

Anexo A - Caracterização dos materiais

Anexo B - Caracterização dos concretos estudados

Anexo C - Estudo da pasta de cimento

Anexo D - Caracterização reológica do concreto fresco 


\section{LISTA DE FIGURAS}

Figura 2.1 - Edifício Water Tower Place. 13

Figura 2.2 - Edifício Petronas Towers. 13

$\begin{array}{lll}\text { Figura } 2.3 & \text { - Edifício Taipei } 101 . & 13\end{array}$

$\begin{array}{lll}\text { Figura } 2.4 & \text { - Edifício e-Tower. } & 13\end{array}$

Figura 2.5 - Plataforma Gullfaks. 13

$\begin{array}{lll}\text { Figura } 2.6 & \text { - Confederation Bridge. } & 13\end{array}$

Figura 2.7 - Desenvolvimento da microestrutura durante a hidratação do cimento 16 Portland.

Figura 2.8 - Diagrama ilustrativo de como a microestrutura, as condições prévias de exposição e condicionantes do processo de fabricação do agregado determinam as suas características e como estas afetam o traço e as propriedades do concreto fresco e endurecido.

Figura 2.9 - Difratograma de raios-X da sílica de Fe-Si (a) na forma como produzida e (b) depois de aquecida a $1100^{\circ} \mathrm{C}$.

Figura 3.1 - Componentes do tensor tensão para um sistema de coordenadas 36 cartesianas.

Figura 3.2 - Conceito de deformação: (A) rotação sem deformação; (B) 36 deformação por cisalhamento; e (C) deformação por elongação.

Figura 3.3 - Deformação de um fluido. 38

Figura 3.4 - Lei de Newton para viscosidade de um fluido. 39

Figura 3.5 - Comportamento reológico de fluidos independentes do tempo. 43

Figura 4.1 - Fatores que influenciam as propriedades de um concreto. 56

Figura 4.2 - Microscopia da seção polida de um nódulo de clínquer onde: Alita = 59 $\mathrm{C}_{3} \mathrm{~S} ;$ Belita $=\mathrm{C}_{2} \mathrm{~S}$.

Figura 5.1 - Equação de Bingham para um fluido. Curva de escoamento típica para um fluido binghamiano.

Figura 5.2 - Reologia do concreto: (A) mesma tensão de escoamento e diferentes viscosidades; (B) mesma viscosidade e diferentes tensões de escoamento.

Figura 5.3 - Adaptação de uma representação gráfica da hidratação do cimento 106 pelo método da calorimetria.

Figura 5.4 - Interações entre cimento Portland, sulfato de cálcio e SP. 108

Figura 5.5 - Foto (A) e esquema com as dimensões (B) do minitronco de cone. 112

Figura 5.6 - Exemplo de execução do ensaio de miniabatimento. 113

Figura 5.7 - Foto do equipamento completo (A) e esquema detalhado do funil (B) 116 do ensaio do cone de Marsh empregado na presente pesquisa (dimensões em [mm]).

Figura 5.8 - Determinação do ponto de saturação do aditivo superplastificante 118 pelo método apresentado por Aïtcin (2000).

Figura 5.9 - Determinação do ponto de saturação do aditivo superplastificante 119 pelo método AFREM desenvolvido por de Larrard et al. (1997b).

Figura 5.10 - Ilustração dos mecanismos de estabilização de suspensões: (a) 125 estabilização eletrostática, (b) estabilização estérica e (c) estabilização eletroestérica.

Figura 5.11 - Ensaio de abatimento de tronco de cone. 9 29

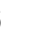


Figura 5.12 - Tipos de abatimento.

Figura 5.13 - (A) Esquema do consistômetro de Ve-Be (DNER-ME 094, 1994) e (B) 136 foto do equipamento utilizado na presente pesquisa.

$\begin{array}{ll}\text { Figura } 5.14 \text { - Caixa L. } & 138\end{array}$

Figura 5.15 - Detalhe das grades a serem utilizadas no ensaio da Caixa L. 138

Figura 5.16 - Haste para a realização do ensaio de abatimento modificado. Disco 141 deslizante no detalhe.

Figura 5.17 - Esquema do ensaio de abatimento de tronco de cone modificado.

Figura 5.18 - Ábacos para estimativa da tensão de escoamento e da viscosidade plástica do concreto a partir dos resultados do ensaio de abatimento modificado (para concretos com densidade de $2400 \mathrm{~kg} / \mathrm{m}^{3}$ ).

Figura 5.19 - Reômetro BML, baseado no conceito de cilindros coaxiais.

Figura 5.20 - Reômetro BTRHEOM, baseado no conceito placa/placa.

Figura 5.21 - Diagrama esquemático do reômetro planetário usado na presente 145 pesquisa.

Figura 5.22 - Fotografia dos reômetros usados na presente pesquisa.

Figura 6.1 - Esquema da metodologia utilizada na presente pesquisa.

Figura 6.2 - Diferentes procedimentos de mistura avaliados, onde $A M=a g r e g a d o$ miúdo, $A G=a g r e g a d o$ graúdo, $C P=$ cimento, $S A=$ sílica ativa, $A=a ́ g u a ~ e$ $\mathrm{SP}=$ superplastificante.

Figura 7.1 - Curva do tempo de escoamento versus tempo para pastas de cimento produzidas com CPV ARI Plus em função da seqüência de mistura adotada.

Figura 7.2 - Curva do tempo de escoamento versus tempo para pastas de cimento produzidas com CPV ARI RS em função da seqüência de mistura adotada.

Figura 7.3 - Curvas "logaritmo do tempo de escoamento versus teor de SP" e pontos de saturação do SP para pastas de aglomerantes incorporadas com SP.

Figura 7.4 - Curva "área de espalhamento versus tempo" para pastas de cimento com e sem a adição de sílica ativa.

Figura 7.5 - Gráfico da combinação entre os agregados versus índice de vazios para as composições estudadas.

Figura 7.6 - Curvas "abatimento de tronco de cone versus tempo" para os 171 microconcretos de alto desempenho produzidos com CPV ARI Plus.

Figura 7.7 - Curvas "abatimento de tronco de cone versus tempo" para os 172 microconcretos de alto desempenho produzidos com CPV ARI RS.

Figura 7.8 - Ensaio de abatimento de tronco de cone para microconcretos de alto desempenho: avaliação da perda da trabalhabilidade ao longo do tempo: (A) aos 10 minutos; (B) aos 60 minutos; e (C) aos 120 minutos.

Figura 7.9 - Curvas "abatimento de tronco de cone versus tempo" para os concretos de alto desempenho produzidos com CPV ARI Plus.

Figura 7.10 - Curvas "abatimento de tronco de cone versus tempo" para os 175 concretos de alto desempenho produzidos com CPV ARI RS.

Figura 7.11 - Curvas "tempo Ve-Be versus tempo" para os microconcretos de alto 179 desempenho produzidos com CPV ARI Plus.

Figura 7.12 - Curvas "tempo Ve-Be versus tempo" para os microconcretos de alto 179 desempenho produzidos com CPV ARI RS. 
Figura 7.13 - Etapas do ensaio para determinação do tempo Ve-Be: $(A)$ tronco de cone de concreto com disco transparente posicionado para o início do ensaio; e (B) concreto ocupando o formato cilíndrico da cuba do equipamento, o que caracteriza o fim do ensaio.

Figura 7.14 - Curvas "tempo Ve-Be versus tempo" para os concretos de alto desempenho produzidos com CPV ARI Plus.

Figura 7.15 - Curvas "tempo Ve-Be versus tempo" para os concretos de alto 183 desempenho produzidos com CPV ARI RS.

Figura 7.16 - Ensaio de caixa L para as misturas ensaiadas.

Figura 7.17 - Ensaio da caixa L com a aplicação de uma força vibratória para o completo adensamento do concreto. As letras indicam a seqüência da evolução do adensamento.

Figura 7.18 - Curva da "tensão de escoamento versus tempo" para microconcretos de alto desempenho produzidos com CPV ARI Plus.

Figura 7.19 - Curva da "tensão de escoamento versus tempo" para microconcretos de alto desempenho produzidos com CPV ARI RS.

Figura 7.20 - Ensaio de abatimento de tronco de cone modificado - caracterização reológica das misturas de alto desempenho: (A) aos 10 minutos; $(B)$ aos 60 minutos; e (C) aos 120 minutos.

Figura 7.21 - Curva da "tensão de escoamento versus tempo" para concretos de alto desempenho produzidos com CPV ARI Plus.

Figura 7.22 - Curva da "tensão de escoamento versus tempo" para concretos de alto desempenho produzidos com CPV ARI RS.

Figura 7.23 - Curvas ascendentes de cisalhamento dos MCAD produzidos com CPV ARI Plus e com composição variada.

Figura 7.24 - Curvas ascendentes de cisalhamento dos MCAD produzidos com CPV ARI RS e com composição variada.

Figura 7.25 - Curvas ascendentes de cisalhamento dos MCAD produzidos com CPV ARI Plus e de acordo com os procedimentos propostos.

Figura 7.26 - Curvas ascendentes de cisalhamento dos MCAD produzidos com CPV ARI RS e de acordo com os procedimentos propostos.

Figura 7.27 - Curvas de cisalhamento dos MCAD, com variações na composição, 203 produzidos com CPV ARI Plus. Obs.: as setas indicam o sentido de aplicação da velocidade de cisalhamento.

Figura 7.28 - Curvas de cisalhamento dos MCAD produzidos com CPV ARI Plus e de acordo com os procedimentos de mistura propostos na pesquisa. Obs.: as setas indicam o sentido de aplicação da velocidade de cisalhamento.

Figura 7.29 - Curvas de cisalhamento dos MCAD, com variações na composição, 204 produzidos com CPV ARI RS. Obs.: as setas indicam o sentido de aplicação da velocidade de cisalhamento.

Figura 7.30 - Curvas de cisalhamento dos MCAD produzidos com CPV ARI RS e 204 de acordo com os procedimentos de mistura propostos na pesquisa. Obs.: as setas indicam o sentido de aplicação da velocidade de cisalhamento.

Figura 7.31 - Curva do "torque de escoamento versus tempo" para os MCAD 206 produzidos com composições variadas.

Figura 7.32 - Curva da "viscosidade de torque versus tempo" para os MCAD 207 produzidos com composições variadas.

Figura 7.33 - Curva do "torque de escoamento versus tempo" para os MCAD 212 produzidos com CPV ARI Plus e de acordo com os procedimentos de mistura propostos na pesquisa. 
Figura 7.34 - Curva do "torque de escoamento versus tempo" para os MCAD 213 produzidos com CPV ARI RS e de acordo com os procedimentos de mistura propostos na pesquisa.

Figura 7.35 - Curva da "viscosidade de torque versus tempo" para os MCAD 213 produzidos com CPV ARI Plus e de acordo com os procedimentos de mistura propostos na pesquisa.

Figura 7.36 - Curva da "viscosidade de torque versus tempo" para os MCAD 213 produzidos com CPV ARI RS e de acordo com os procedimentos de mistura propostos na pesquisa.

Figura 7.37 - Curvas do torque em função do tempo para as misturas produzidas 218 com CPV ARI Plus e com composições variadas.

Figura 7.38 - Curvas do torque em função do tempo para as misturas produzidas 218 com CPV ARI RS e com composições variadas.

Figura 7.39 - Fotos do ensaio de cisalhamento contínuo ao longo do tempo: (A) no início do ensaio; (B) após 30 minutos; (C) após 60 minutos; (D) após 90 minutos e $(E)$ indicando o fim do ensaio (material sem coesão aderido na parede da cuba de ensaio - pá misturadora girando no vazio).

Figura 7.40 - Curvas do torque em função do tempo para as misturas produzidas com CPV ARI Plus e de acordo com os procedimentos de mistura propostos na pesquisa.

Figura 7.41 - Curvas do torque em função do tempo para as misturas produzidas com CPV ARI RS e de acordo com os procedimentos de mistura propostos na pesquisa.

Figura 7.42 - Evolução da temperatura ao longo do tempo para os MCAD 223 produzidos com CPV ARI Plus.

Figura 7.43 - Evolução da temperatura ao longo do tempo para os MCAD 223 produzidos com CPV ARI RS.

Figura 7.44 - Evolução do pH ao longo do tempo para os MCAD produzidos com 225 CPV ARI Plus.

Figura 7.45 - Evolução do pH ao longo do tempo para os MCAD produzidos com 226 CPV ARI RS.

Figura 7.46 - Correlação entre $g$ versus $h$ para as misturas produzidas com CPV 227 ARI Plus $\left(R^{2}=0,042\right)$.

Figura 7.47 - Correlação entre $g$ versus $h$ para as misturas produzidas com CPV 227 ARI RS $\left(R^{2}=0,050\right)$.

Figura 7.48 - Comparação entre a tensão de escoamento (determinada pelo ensaio de abatimento de tronco de cone modificado) e o torque de escoamento (determinado a partir do reômetro) para os MCAD3 produzidos com CPV ARI Plus.

Figura 7.49 - Comparação entre a tensão de escoamento (determinada pelo ensaio de abatimento de tronco de cone modificado) e o torque de escoamento (determinado a partir do reômetro) para os MCAD3 produzidos com CPV ARI RS.

Figura 7.50 - Comparação entre a viscosidade plástica (determinada pelo ensaio de abatimento de tronco de cone modificado) e a viscosidade de torque (determinada a partir do reômetro) para os MCAD3 produzidos com CPV ARI Plus.

Figura 7.51 - Comparação entre a viscosidade plástica (determinada pelo ensaio de abatimento de tronco de cone modificado) e a viscosidade de torque (determinada a partir do reômetro) para os MCAD3 produzidos com CPV ARI RS. 
Figura 7.52 - Correlação entre o abatimento de tronco de cone tradicional e a tensão de escoamento (determinada pelo ensaio de abatimento de tronco de cone modificado) para os MCAD3 produzidos com CPV ARI Plus.

Figura 7.53 - Correlação entre o abatimento de tronco de cone tradicional e o torque de escoamento (determinado a partir do ajuste da curva de cisalhamento ao modelo binghamiano) para os MCAD3 produzidos com CPV ARI Plus.

Figura 7.54 - Correlação entre o abatimento de tronco de cone tradicional e a tensão de escoamento (determinada pelo ensaio de abatimento de tronco de cone modificado) para os MCAD3 produzidos com CPV ARI RS.

Figura 7.55 - Correlação entre o abatimento de tronco de cone tradicional e o torque de escoamento (determinado a partir do ajuste da curva de cisalhamento ao modelo binghamiano) para os MCAD3 produzidos com CPV ARI Plus.

Figura 7.56 - Correlação entre o abatimento de tronco de cone tradicional e a viscosidade plástica (determinada pelo ensaio de abatimento de tronco de cone modificado) para os MCAD3 produzidos com CPV ARI Plus.

Figura 7.57 - Correlação entre o abatimento de tronco de cone tradicional e a viscosidade de torque (determinada a partir do ajuste da curva de cisalhamento ao modelo binghamiano) para os MCAD3 produzidos com CPV ARI Plus.

Figura 7.58 - Correlação entre o abatimento de tronco de cone tradicional e a viscosidade plástica (determinada pelo ensaio de abatimento de tronco de cone modificado) para os MCAD3 produzidos com CPV ARI RS.

Figura 7.59 - Correlação entre o abatimento de tronco de cone tradicional e a viscosidade de torque (determinada a partir do ajuste da curva de cisalhamento ao modelo binghamiano) para os MCAD3 produzidos com CPV ARI RS.

Figura 7.60 - Evolução da tensão de escoamento $\left(\tau_{o}\right)$ e do abatimento $(\mathrm{Ab})$ com o 233 tempo para os MCAD3 produzidos com CPV ARI Plus.

Figura 7.61 - Evolução do torque de escoamento $(g)$ e do abatimento $(A b)$ com o 233 tempo para os MCAD3 produzidos com CPV ARI Plus.

Figura 7.62 - Evolução da tensão de escoamento $\left(\tau_{0}\right)$ e do abatimento $(A b)$ com o 234 tempo para os MCAD3 produzidos com CPV ARI RS.

Figura 7.63 - Evolução do torque de escoamento $(g)$ e do abatimento (Ab) com o 234 tempo para os MCAD3 produzidos com CPV ARI RS.

Figura 7.64 - Evolução da viscosidade plástica $(\mu)$ e da viscosidade de torque $(h) 235$ com o tempo para os MCAD3 produzidos com CPV ARI Plus.

Figura 7.65 - Evolução da viscosidade plástica $(\mu)$ e da viscosidade de torque $(h) 235$ com o tempo para os MCAD3 produzidos com CPV ARI RS.

Figura 7.66 - Evolução da fluidez (diâmetro de concreto abatido - D) e do torque de 236 escoamento $(g)$ com o tempo para os MCAD3 produzidos com CPV ARI Plus.

Figura 7.67 - Evolução da fluidez (diâmetro de concreto abatido - D) e do torque de escoamento $(g)$ com o tempo para os MCAD3 produzidos com CPV ARI RS.

Figura 7.68 - Fotos do ensaio de fluidez ao longo do tempo: (A) antes do cisalhamento (no início do ensaio), (B) após o primeiro, (C) o segundo e (D) o terceiro ciclos de cisalhamento. 
Figura 7.69 - Betoneira de eixo inclinado usada na pesquisa. 239

Figura 7.70 - Argamassadeira planetária usada na pesquisa. 239

Figura 7.71 - Comparação da tensão de escoamento e do torque de escoamento 240 medidos a partir dos métodos de ensaio considerados para cada mistura.

Figura 7.72 - Comparação da viscosidade plástica e da viscosidade de torque 241 medidas a partir dos métodos de ensaio considerados para cada mistura.

Figura A.1 - Curva granulométrica da areia. 263

Figura A.2 - Curvas granulométricas das britas 0,1 e 2 . 267

Figura D.1 - Parte ascendente da curva de cisalhamento do MCAD1 produzido 278 com CPV ARI Plus (10 minutos).

Figura D.2 - Parte descendente da curva de cisalhamento do MCAD1 produzido 278 com CPV ARI Plus (10 minutos).

Figura D.3 - Parte ascendente da curva de cisalhamento do MCAD2 produzido 278 com CPV ARI Plus (10 minutos).

Figura D.4 - Parte descendente da curva de cisalhamento do MCAD2 produzido 278 com CPV ARI Plus (10 minutos).

Figura D.5 - Parte ascendente da curva de cisalhamento do MCAD3/A produzido 278 com CPV ARI Plus (10 minutos).

Figura D.6 - Parte descendente da curva de cisalhamento do MCAD3/A produzido 278 com CPV ARI Plus (10 minutos).

Figura D.7 - Parte ascendente da curva de cisalhamento do MCAD3/B produzido 279 com CPV ARI Plus (10 minutos).

Figura D.8 - Parte descendente da curva de cisalhamento do MCAD3/B produzido 279 com CPV ARI Plus (10 minutos).

Figura D.9 - Parte ascendente da curva de cisalhamento do MCAD3/C produzido 279 com CPV ARI Plus (10 minutos).

Figura D.10 - Parte descendente da curva de cisalhamento do MCAD3/C produzido 279 com CPV ARI Plus (10 minutos).

Figura D.11 - Parte ascendente da curva de cisalhamento do MCAD3/D produzido 279 com CPV ARI Plus (10 minutos).

Figura D.12 - Parte descendente da curva de cisalhamento do MCAD3/D produzido 279 com CPV ARI Plus (10 minutos).

Figura D.13 - Parte ascendente da curva de cisalhamento do MCAD3/E produzido 279 com CPV ARI Plus (10 minutos).

Figura D.14 - Parte descendente da curva de cisalhamento do MCAD3/E produzido 279 com CPV ARI Plus (10 minutos).

Figura D.15 - Parte ascendente da curva de cisalhamento do MCAD3/F produzido 280 com CPV ARI Plus (10 minutos).

Figura D.16 - Parte descendente da curva de cisalhamento do MCAD3/F produzido 280 com CPV ARI Plus (10 minutos).

Figura D.17 - Parte ascendente da curva de cisalhamento do MCAD1 produzido 280 com CPV ARI Plus (30 minutos).

Figura D.18 - Parte descendente da curva de cisalhamento do MCAD1 produzido 280 com CPV ARI Plus (30 minutos).

Figura D.19 - Parte ascendente da curva de cisalhamento do MCAD2 produzido 280 com CPV ARI Plus (30 minutos).

Figura D.20 - Parte descendente da curva de cisalhamento do MCAD2 produzido 280 com CPV ARI Plus (30 minutos). 
Figura D.21 - Parte ascendente da curva de cisalhamento do MCAD3/A produzido 280 com CPV ARI Plus (30 minutos).

Figura D.22 - Parte descendente da curva de cisalhamento do MCAD3/A produzido 280 com CPV ARI Plus (30 minutos).

Figura D.23 - Parte ascendente da curva de cisalhamento do MCAD3/B produzido com CPV ARI Plus (30 minutos).

Figura D.24 - Parte descendente da curva de cisalhamento do MCAD3/B produzido com CPV ARI Plus (30 minutos).

Figura D.25 - Parte ascendente da curva de cisalhamento do MCAD3/C produzido com CPV ARI Plus (30 minutos).

Figura D.26 - Parte descendente da curva de cisalhamento do MCAD3/C produzido com CPV ARI Plus (30 minutos).

Figura D.27 - Parte ascendente da curva de cisalhamento do MCAD3/D produzido com CPV ARI Plus (30 minutos).

Figura D.28 - Parte descendente da curva de cisalhamento do MCAD3/D produzido com CPV ARI Plus (30 minutos).

Figura D.29 - Parte ascendente da curva de cisalhamento do MCAD3/E produzido com CPV ARI Plus (30 minutos).

Figura D.30 - Parte descendente da curva de cisalhamento do MCAD3/E produzido com CPV ARI Plus (30 minutos).

Figura D.31 - Parte ascendente da curva de cisalhamento do MCAD3/F produzido 282 com CPV ARI Plus (30 minutos).

Figura D.32 - Parte descendente da curva de cisalhamento do MCAD3/F produzido 282 com CPV ARI Plus (30 minutos).

Figura D.33 - Parte ascendente da curva de cisalhamento do MCAD1 produzido com CPV ARI Plus (60 minutos).

Figura D.34 - Parte descendente da curva de cisalhamento do MCAD1 produzido com CPV ARI Plus (60 minutos).

Figura D.35 - Parte ascendente da curva de cisalhamento do MCAD2 produzido com CPV ARI Plus (60 minutos).

Figura D.36 - Parte descendente da curva de cisalhamento do MCAD2 produzido com CPV ARI Plus (60 minutos).

Figura D.37 - Parte ascendente da curva de cisalhamento do MCAD3/A produzido com CPV ARI Plus (60 minutos).

Figura D.38 - Parte descendente da curva de cisalhamento do MCAD3/A produzido com CPV ARI Plus (60 minutos).

Figura D.39 - Parte ascendente da curva de cisalhamento do MCAD3/B produzido 283 com CPV ARI Plus (60 minutos).

Figura D.40 - Parte descendente da curva de cisalhamento do MCAD3/B produzido 283 com CPV ARI Plus (60 minutos).

Figura D.41 - Parte ascendente da curva de cisalhamento do MCAD3/C produzido 283 com CPV ARI Plus (60 minutos).

Figura D.42 - Parte descendente da curva de cisalhamento do MCAD3/C produzido 283 com CPV ARI Plus (60 minutos).

Figura D.43 - Parte ascendente da curva de cisalhamento do MCAD3/D produzido 283 com CPV ARI Plus (60 minutos).

Figura D.44 - Parte descendente da curva de cisalhamento do MCAD3/D produzido 283 com CPV ARI Plus (60 minutos).

Figura D.45 - Parte ascendente da curva de cisalhamento do MCAD3/E produzido 283 com CPV ARI Plus (60 minutos). 
Figura D.46 - Parte descendente da curva de cisalhamento do MCAD3/E produzido 283 com CPV ARI Plus (60 minutos).

Figura D.47 - Parte ascendente da curva de cisalhamento do MCAD3/F produzido 284 com CPV ARI Plus (60 minutos).

Figura D.48 - Parte descendente da curva de cisalhamento do MCAD3/F produzido 284 com CPV ARI Plus (60 minutos).

Figura D.49 - Parte ascendente da curva de cisalhamento do MCAD1 produzido 284 com CPV ARI RS (10 minutos).

Figura D.50 - Parte descendente da curva de cisalhamento do MCAD1 produzido 284 com CPV ARI RS (10 minutos).

Figura D.51 - Parte ascendente da curva de cisalhamento do MCAD2 produzido 284 com CPV ARI RS (10 minutos).

Figura D.52 - Parte descendente da curva de cisalhamento do MCAD2 produzido 284 com CPV ARI RS (10 minutos).

Figura D.53 - Parte ascendente da curva de cisalhamento do MCAD3/A produzido 284 com CPV ARI RS (10 minutos).

Figura D.54 - Parte descendente da curva de cisalhamento do MCAD3/A produzido 284 com CPV ARI RS (10 minutos).

Figura D.55 - Parte ascendente da curva de cisalhamento do MCAD3/B produzido 285 com CPV ARI RS (10 minutos).

Figura D.56 - Parte descendente da curva de cisalhamento do MCAD3/B produzido 285 com CPV ARI RS (10 minutos).

Figura D.57 - Parte ascendente da curva de cisalhamento do MCAD3/C produzido 285 com CPV ARI RS (10 minutos).

Figura D.58 - Parte descendente da curva de cisalhamento do MCAD3/C produzido 285 com CPV ARI RS (10 minutos).

Figura D.59 - Parte ascendente da curva de cisalhamento do MCAD3/D produzido 285 com CPV ARI RS (10 minutos).

Figura D.60 - Parte descendente da curva de cisalhamento do MCAD3/D produzido 285 com CPV ARI RS (10 minutos).

Figura D.61 - Parte ascendente da curva de cisalhamento do MCAD3/E produzido 285 com CPV ARI RS (10 minutos).

Figura D.62 - Parte descendente da curva de cisalhamento do MCAD3/E produzido 285 com CPV ARI RS (10 minutos).

Figura D.63 - Parte ascendente da curva de cisalhamento do MCAD3/F produzido 286 com CPV ARI RS (10 minutos).

Figura D.64 - Parte descendente da curva de cisalhamento do MCAD3/F produzido 286 com CPV ARI RS (10 minutos).

Figura D.65 - Parte ascendente da curva de cisalhamento do MCAD1 produzido 286 com CPV ARI RS (30 minutos).

Figura D.66 - Parte descendente da curva de cisalhamento do MCAD1 produzido 286 com CPV ARI RS (30 minutos).

Figura D.67 - Parte ascendente da curva de cisalhamento do MCAD2 produzido 286 com CPV ARI RS (30 minutos).

Figura D.68 - Parte descendente da curva de cisalhamento do MCAD2 produzido 286 com CPV ARI RS (30 minutos).

Figura D.69 - Parte ascendente da curva de cisalhamento do MCAD3/A produzido 286 com CPV ARI RS (30 minutos).

Figura D.70 - Parte descendente da curva de cisalhamento do MCAD3/A produzido 286 com CPV ARI RS (30 minutos). 
Figura D.71 - Parte ascendente da curva de cisalhamento do MCAD3/B produzido 287 com CPV ARI RS (30 minutos).

Figura D.72 - Parte descendente da curva de cisalhamento do MCAD3/B produzido 287 com CPV ARI RS (30 minutos).

Figura D.73 - Parte ascendente da curva de cisalhamento do MCAD3/C produzido 287 com CPV ARI RS (30 minutos).

Figura D.74 - Parte descendente da curva de cisalhamento do MCAD3/C produzido com CPV ARI RS (30 minutos).

Figura D.75 - Parte ascendente da curva de cisalhamento do MCAD3/D produzido com CPV ARI RS (30 minutos).

Figura D.76 - Parte descendente da curva de cisalhamento do MCAD3/D produzido com CPV ARI RS (30 minutos).

Figura D.77 - Parte ascendente da curva de cisalhamento do MCAD3/E produzido com CPV ARI RS (30 minutos).

Figura D.78 - Parte descendente da curva de cisalhamento do MCAD3/E produzido com CPV ARI RS (30 minutos).

Figura D.79 - Parte ascendente da curva de cisalhamento do MCAD3/F produzido com CPV ARI RS (30 minutos).

Figura D.80 - Parte descendente da curva de cisalhamento do MCAD3/F produzido 288 com CPV ARI RS (30 minutos).

Figura D.81 - Parte ascendente da curva de cisalhamento do MCAD1 produzido 288 com CPV ARI RS (60 minutos).

Figura D.82 - Parte descendente da curva de cisalhamento do MCAD1 produzido 288 com CPV ARI RS (60 minutos).

Figura D.83 - Parte ascendente da curva de cisalhamento do MCAD2 produzido 288 com CPV ARI RS (60 minutos).

Figura D.84 - Parte descendente da curva de cisalhamento do MCAD2 produzido com CPV ARI RS (60 minutos).

Figura D.85 - Parte ascendente da curva de cisalhamento do MCAD3/A produzido com CPV ARI RS (60 minutos).

Figura D.86 - Parte descendente da curva de cisalhamento do MCAD3/A produzido com CPV ARI RS (60 minutos).

Figura D.87 - Parte ascendente da curva de cisalhamento do MCAD3/B produzido com CPV ARI RS (60 minutos).

Figura D.88 - Parte descendente da curva de cisalhamento do MCAD3/B produzido com CPV ARI RS (60 minutos).

Figura D.89 - Parte ascendente da curva de cisalhamento do MCAD3/C produzido 289 com CPV ARI RS (60 minutos).

Figura D.90 - Parte descendente da curva de cisalhamento do MCAD3/C produzido 289 com CPV ARI RS (60 minutos).

Figura D.91 - Parte ascendente da curva de cisalhamento do MCAD3/D produzido 289 com CPV ARI RS (60 minutos).

Figura D.92 - Parte descendente da curva de cisalhamento do MCAD3/D produzido 289 com CPV ARI RS (60 minutos).

Figura D.93 - Parte ascendente da curva de cisalhamento do MCAD3/E produzido 289 com CPV ARI RS (60 minutos).

Figura D.94 - Parte descendente da curva de cisalhamento do MCAD3/E produzido 289 com CPV ARI RS (60 minutos).

Figura D.95 - Parte ascendente da curva de cisalhamento do MCAD3/F produzido 290 com CPV ARI RS (60 minutos). 
Figura D.96 - Parte descendente da curva de cisalhamento do MCAD3/F produzido 290 com CPV ARI RS (60 minutos). 
Tabela 2.1 - Grau de hidratação necessário para desconexão de poros, em função da relação água/cimento e teor de sílica ativa.

Tabela 4.1 - Esquema da nomenclatura para trabalhabilidade.

15

Esquema da nomenclatura para trabalhabilidade.

49

Tabela 4.2 - Influência do aumento da proporção dos materiais constituintes da mistura sobre a trabalhabilidade.

Tabela 5.1 - Equações que relacionam a tensão e a taxa de cisalhamento para descrever o comportamento ao escoamento de concretos no estado fresco.

Tabela 5.2 - Evolução dos parâmetros reológicos durante a utilização do concreto fresco. Interpretação e correção do problema encontrado.

Tabela 5.3 - Relação entre as forças entre as partículas, o estado de dispersão e 105 a reologia das suspensões.

Tabela 6.1 - Traços a serem analisados na pesquisa.

Tabela 6.2 - Procedimentos de mistura avaliados para a produção das pastas de cimento.

Tabela 6.3 - Exemplo da determinação da composição ideal entre dois agregados de granulometrias diferentes através da massa unitária no estado compactado.

Tabela 7.1 - Variação do procedimento de mistura e os correspondentes tempos de escoamento para as pastas de cimento produzidas com sílica ativa.

Tabela 7.2 - Tempos de escoamento para pastas de aglomerantes incorporadas com SP determinados através do ensaio de cone de Marsh.

Tabela 7.3 - Áreas de espalhamento obtidas a partir do ensaio de miniabatimento para pastas de cimento com e sem a adição de sílica ativa.

Tabela 7.4 - Características das matrizes pasta de cimento e/ou de aglomerantes a serem incorporadas às misturas de concretos de alto desempenho.

Tabela 7.5 - Composição ideal entre areia e brita 0 (microconcreto). 167

Tabela 7.6 - Composição ideal entre britas 1 e 2 (concreto). 167

Tabela 7.7 - Traços definitivos e ajustados para as misturas de alto desempenho 170 estudadas na pesquisa.

Tabela 7.8 - Resultados do ensaio de abatimento de tronco de cone para os microconcretos de alto desempenho. Abatimentos em [mm].

Tabela 7.9 - Resultados do ensaio de abatimento de tronco de cone para os 175 concretos de alto desempenho. Abatimentos em [mm].

Tabela 7.10 - Resultados do ensaio de consistômetro de Ve-Be para os 178 microconcretos de alto desempenho. Tempos em [s].

Tabela 7.11 - Resultados do ensaio de consistômetro de Ve-Be para os concretos de alto desempenho. Tempos em [s].

Tabela 7.12 - Resultados obtidos e observações feitas para a avaliação da capacidade de escoamento de MCAD produzidos com CPV ARI Plus através da caixa $L$.

Tabela 7.13 - Resultados obtidos e observações feitas para a avaliação da capacidade de escoamento de MCAD produzidos com CPV ARI RS através da caixa $L$. 
Tabela 7.14 - Resultados obtidos e observações feitas para a avaliação da 186 capacidade de escoamento de CAD produzidos com CPV ARI Plus através da caixa $L$.

Tabela 7.15 - Resultados obtidos e observações feitas para a avaliação da capacidade de escoamento de CAD produzidos com CPV ARI RS através da caixa $\mathrm{L}$.

Tabela 7.16 - Parâmetros reológicos para os MCAD estudados.

Tabela 7.17 - Parâmetros reológicos para os CAD estudados.

Tabela 7.18 - Área de histerese das curvas de cisalhamento dos MCAD estudados.

Tabela 7.19 - Parâmetros reológicos obtidos a partir do ajuste das curvas de 206 cisalhamento dos MCAD estudados.

Tabela 7.20 - Parâmetros reológicos obtidos a partir do ajuste das curvas de 212 cisalhamento dos MCAD produzidos de acordo com os procedimentos de mistura propostos na pesquisa.

Tabela 7.21 - Valores da fluidez medida antes e após o ciclo de cisalhamento pra os MCAD produzidos com CPV ARI Plus e CPV ARI RS.

Tabela 7.22 - Valores dos fatores considerados na avaliação do comportamento dos MCAD a partir do ensaio de abatimento de tronco modificado (para um intervalo de 30 minutos entre a mistura e o lançamento do material).

Tabela 7.23 - Pontuação dos fatores considerados na avaliação dos comportamentos dos MCAD a partir do ensaio de abatimento de tronco de cone modificado (para um intervalo de 30 minutos entre a mistura e o lançamento do material).

Tabela 7.24 - Valores dos fatores considerados na avaliação do comportamento dos MCAD a partir do reômetro (para um intervalo de 30 minutos entre a mistura e o lançamento do material).

Tabela 7.25 - Pontuação dos fatores considerados na avaliação dos comportamentos dos MCAD a partir do reômetro (para um intervalo de 30 minutos entre a mistura e o lançamento do material).

Tabela 7.26 - Valores dos fatores considerados na avaliação do comportamento dos MCAD a partir do ensaio de abatimento de tronco modificado (para um intervalo de 60 minutos entre a mistura e o lançamento do material).

Tabela 7.27 - Pontuação dos fatores considerados na avaliação dos comportamentos dos MCAD a partir do ensaio de abatimento de tronco de cone modificado (para um intervalo de 60 minutos entre a mistura e o lançamento do material).

Tabela 7.28 - Valores dos fatores considerados na avaliação do comportamento dos MCAD a partir do reômetro (para um intervalo de 60 minutos entre a mistura e o lançamento do material).

Tabela 7.29 - Pontuação dos fatores considerados na avaliação dos 252 comportamentos dos MCAD a partir do reômetro (para um intervalo de 60 minutos entre a mistura e o lançamento do material).

Tabela A.1 - Propriedades químicas e composição potencial dos cimentos 260 utilizados na pesquisa.

Tabela A.2 - Propriedades físicas dos cimentos utilizados na pesquisa. 261

Tabela A.3 - Composição granulométrica do agregado miúdo. 263

Tabela A.4 - Composição granulométrica do agregado graúdo (brita 0). 266

Tabela A.5 - Composição granulométrica do agregado graúdo (brita 1). 266

Tabela A.6 - Composição granulométrica do agregado graúdo (brita 2). 267 
Tabela A.7 - Massa unitária, massa específica, absorção, teor de materiais pulverulentos, número de angulosidade e índice de forma (agregados graúdos).

Tabela A.8 - Composição química e perda ao fogo da SFS empregada na 269 pesquisa.

Tabela B.1 - Massa específica e consumo de materiais para microconcretos de 270 alto desempenho produzidos com CPV ARI Plus.

Tabela B.2 - Massa específica e consumo de materiais para microconcretos de 271 alto desempenho produzidos com CPV ARI RS.

Tabela B.3 - Tempos de início e fim de pega das pastas de cimento que compõem 271 os microconcretos de alto desempenho (em [min]).

Tabela B.4 - Resistência à compressão, resistência à tração e módulo de 271 elasticidade dos microconcretos de alto desempenho produzidos com CPV ARI Plus.

Tabela B.5 - Resistência à compressão, resistência à tração e módulo de elasticidade dos microconcretos de alto desempenho produzidos com CPV ARI RS.

Tabela B.6 - Massa específica e consumo de materiais para concretos de alto 273 desempenho produzidos com CPV ARI Plus.

Tabela B.7 - Massa específica e consumo de materiais para concretos de alto 273 desempenho produzidos com CPV ARI RS.

Tabela B.8 - Tempos de início e fim de pega das pastas de cimento que compõem 273 os concretos de alto desempenho (em [min]).

Tabela B.9 - Resistência à compressão, resistência à tração e módulo de 274 elasticidade dos concretos de alto desempenho produzidos com CPV ARI Plus.

Tabela B.10 - Resistência à compressão, resistência à tração e módulo de 274 elasticidade dos concretos de alto desempenho produzidos com CPV ARI RS.

Tabela C.1 - Tempos de escoamento determinados a partir do ensaio de cone de 275 Marsh para as pastas de cimento incorporadas com sílica ativa.

Tabela C.2 - Diâmetros das pastas de cimento abatidas, com e sem a adição de 276 sílica ativa, determinados através do ensaio de miniabatimento.

Tabela D.1 - Valores dos abatimentos de tronco de cone e dos tempos de 276 abatimento parcial determinados através do ensaio de abatimento de tronco modificado para os MCAD.

Tabela D.2 - Valores dos abatimentos de tronco de cone e dos tempos de 277 abatimento parcial determinados através do ensaio de abatimento de tronco modificado para os CAD.

Tabela D.3 - Resumo dos coeficientes de ajuste dos modelos reológicos 290 considerados. 


\section{LISTA DE SÍMBOLOS E ABREVIATURAS}

$\tau$ - Tensão de cisalhamento

$\tau_{0}-$ Tensão de escoamento

$\mu$ - Viscosidade plástica

$\dot{\gamma}$ - Taxa de cisalhamento

$\alpha$ - Teor ideal de argamassa

a/agl - Relação água/aglomerante

a/c - Relação água/cimento

Aft - Etringita

AFm - Monossulfoaluminato de cálcio hidratado

ASTM - American Society for Testing and Materials

B.E.T. - Brunauer-Emmett-Teller

BS - British Standards

$\mathrm{Ca}(\mathrm{OH})_{2}-$ Hidróxido de cálcio

$\mathrm{C}_{2} \mathrm{~S}$ - Silicato dicálcico

$\mathrm{C}_{3} \mathrm{~A}$ - Aluminato tricálcico

$\mathrm{C}_{3} \mathrm{~S}$ - Silicato tricálcico

$\mathrm{C}_{4} \mathrm{AF}$ - Ferroaluminato tetracálcico

CAA - Concreto auto-adensável

CAD - Concreto de alto desempenho

CAR - Concreto de alta resistência

CPV ARI Plus - Cimento Portland de alta resistência inicial

CPV ARI RS - Cimento Portland de alta resistência inicial e resistente a sulfatos

C-S-H - Silicato de cálcio hidratado

$D_{\text {máx }}$ - Dimensão máxima característica do agregado

DNER - Departamento Nacional de Estradas de Rodagem

$g$ - Torque de escoamento

$h$ - Viscosidade de torque

MCAD - Microconcreto de alto desempenho

NBR - Norma Brasileira Registrada

NM - Norma Mercosul

PS - Ponto de saturação do aditivo superplastificante

RPM - Rotações por minuto

RPS - Rotações por segundo

SFS - Sílica ativa de ferro-silício ou silício metálico

SP - Aditivo superplastificante 
CASTRO, A. L. Aplicação de conceitos reológicos na tecnologia dos concretos de alto desempenho. Tese (Doutorado) em Ciência e Engenharia de Materiais, Universidade de São Paulo. São Carlos/SP, 2007.

Do ponto de vista reológico, o concreto fresco flui como um líquido. Sendo assim, o seu comportamento no estado fresco deve ser estudado a partir dos conceitos da reologia, ciência voltada para o estudo das deformações e escoamento de um fluido sob a influência de tensões. As estruturas bem planejadas, dependendo do processo adotado para sua confecção, são executadas em tempo muito pequeno após a mistura dos materiais que irão constituir os concretos. Assim, a trabalhabilidade do concreto é um parâmetro importante a ser estudado, tanto por facilitar o lançamento do material quanto pelas decisões relacionadas com a forma desse lançamento. Tradicionalmente, a trabalhabilidade do concreto está associada à sua consistência, expressa em termos de abatimento obtido no ensaio de tronco de cone, que, apesar de ser um método de ensaio bastante utilizado, não a quantifica totalmente. Isto porque o concreto se comporta como um fluido binghamiano, sendo, então, caracterizado por dois parâmetros reológicos: a tensão de escoamento e a viscosidade plástica. Assim, o presente trabalho determina alguns parâmetros de medida, a partir de conceitos reológicos, para a verificação do comportamento de alguns tipos de concreto de alto desempenho no estado fresco, com adição de sílica ativa. Para isso, foram usados tanto os métodos de ensaios tradicionais - ensaio de abatimento de tronco de cone e consistômetro de $\mathrm{Ve}-\mathrm{Be}$ - quanto equipamentos mais modernos - reômetro. Uma modificação do ensaio de abatimento tradicional também foi usada como uma tentativa de simplificar a determinação dos parâmetros reológicos que caracterizam o comportamento dos concretos frescos. A capacidade dos concretos escoarem sob influência do seu peso próprio foi avaliada através do ensaio da caixa L. A identificação da natureza reológica dos concretos foi feita com o auxílio de um reômetro. A trabalhabilidade dos concretos foi avaliada a partir dos métodos de ensaio que medem os dois parâmetros reológicos e sua perda ao longo do tempo foi associada à evolução dos parâmetros medidos. Apesar de terem sido classificadas como misturas fluidas, nenhum concreto apresentou escoamento suficiente que o caracterizasse como um material auto-adensável, porém apresentou bom escoamento sob a energia de um vibrador. A natureza reológica dos concretos foi identificada como sendo realmente semelhante a um fluido binghamiano. A trabalhabilidade, bem como sua perda ao longo do tempo, foram associadas à evolução dos parâmetros reológicos: observou-se um aumento da tensão de escoamento (ou torque de escoamento), enquanto a viscosidade plástica (ou viscosidade de torque) permaneceu praticamente constante durante os 60 minutos em que o comportamento foi acompanhado. Conclui-se que para a trabalhabilidade dos $C A D$, há inúmeros outros fatores importantes a serem considerados no prosseguimento da pesquisa, os quais deverão levar em conta parâmetros associados à produção, ao transporte e ao lançamento do material. 
CASTRO, A. L. The application of rheological concepts on the high performance concretes technology. Ph.D. Thesis - Ciência e Engenharia de Materiais, Universidade de São Paulo. São Carlos/SP, 2007.

From the rheological point of view, the fresh concrete flows as a liquid. In such case, its fresh behavior should be studied from the concepts of rheology, the science which concerns the study of deformation and flow of a fluid under stress influence. The well designed structures, depending on the process considered in their production, are performed in a very short time after the mixture of the materials that will constitute the concretes. Thus, the concrete workability is an important parameter to be studied, even for facilitating the material placement and for the decisions related with the method of this process. Traditionally, the concrete workability is associated to its consistency, expressed in terms of the slump value measured by the slump test that, in spite of being a quite used test, does not quantify it totally. It happens because the concrete behaves as a Bingham fluid, being described by two rheological parameters: the yield stress and the plastic viscosity. Thus, the present research determines some measure parameters from rheological concepts to verify the behavior of some types of fresh high performance concrete (with silica fume addition). For this, both traditional test methods - slump test and Vebe consistometer - and more recent equipments - rheometer - were used. A modification of the traditional slump test was also used as an attempt to simplify the determination of the rheological parameters that describe the fresh concretes behaviors. The capacity of the concretes flow under the influence of their own weight was evaluated by the L-box test. The identification of the concretes rheological behavior was made with a rheometer. The concretes workability was evaluated from test methods that measure the two rheological parameters and its loss over time was associated to the evolution of the measured parameters. In spite of being classified as fluid mixtures, none of the concretes presented enough flow to describe it as a self-compacting material; however they presented a good flow under vibration energy. The concrete rheological behavior was identified as being similar to a Bingham fluid. The workability, as its loss over time, was associated to the evolution of the rheological parameters: an increase of the yield stress (or flow resistance) was observed, while the plastic viscosity (or torque viscosity) stayed practically constant during the 60 minutes in which the behavior was followed. It is concluded that for the high performance concretes workability, there are other several important factors to be considered in the research pursuit, which should consider the parameters associated to the material's production, transport and placement. 



\section{CAPÍTULO 1 INTRODUÇÃO}

A utilização do concreto de alto desempenho (CAD) iniciou-se no exterior nos anos 70. No Brasil, a sílica ativa só foi introduzida em 1984, sendo a primeira utilização registrada em 1985 (EESC-USP). Desde então, seu uso vem se multiplicando. Esse aumento na aplicação de concretos especiais em obras da construção civil se dá pela procura de concretos duráveis que prolongam a vida útil das estruturas e, conseqüentemente, reduzem os custos com manutenção.

O concreto é considerado um material composto, tendo como componentes principais o cimento, os agregados miúdo e graúdo e a água. No caso do CAD, aditivos químicos e adições - minerais ou não - são incorporados à mistura "tradicional" para que a obtenção de uma variedade de propriedades e características melhoradas seja possível.

Em termos reológicos, o concreto pode ser entendido como uma concentração de partículas sólidas em suspensão (agregados) em um líquido viscoso (pasta de cimento). A pasta de cimento, por sua vez, não se configura como um líquido homogêneo, sendo composta por partículas (grãos de cimento) e um líquido (água). De um ponto de vista macroscópico, diz-se que o concreto flui como um líquido (FERRARIS, 1996; 1999).

Assim, sendo o concreto um líquido, para se estudar o seu comportamento à deformação no estado fresco, parece muito adequado buscar os conceitos da reologia, ciência voltada para o estudo da deformação e escoamento de um fluido sob a influência de tensões.

Desde que Powers e Wiler introduziram seu "plasticizômetro" em 1941, diversas tentativas têm sido feitas para se aplicar uma aproximação mais fundamental ao estudo das propriedades do concreto fresco. Porém, a maioria dessas tentativas resultou apenas em protótipos de equipamentos. Os métodos mais comumente utilizados são baseados em métodos de ensaio empíricos, como 
o ensaio de abatimento de tronco de cone introduzido por Abrams em 1918. Um grande avanço na avaliação da trabalhabilidade do concreto foi obtido em 1973, quando Tattersall introduziu o ensaio de dois pontos da trabalhabilidade. Esse equipamento, que esteve comercialmente disponível por mais de uma década, está bem documentado na literatura (WALLEVIK \& GJØRV, 1990b). Desde então, a investigação do comportamento reológico do concreto fresco tem ocorrido continuamente.

Nos últimos anos, a reologia do concreto fresco tem sido estudada com determinações que variam entre métodos de ensaio simples e práticos, como o ensaio de abatimento de tronco de cone, até equipamentos mais sofisticados que determinam as curvas de cisalhamento do material, como os reômetros. Porém, ainda não é muito comum o uso dessa ciência para se estudar as propriedades de escoamento do concreto fresco.

A dificuldade da aplicação de medidas reológicas em concreto está relacionada com as grandes partículas de agregado graúdo que compõe a mistura, que impossibilitam o uso de reômetros tradicionais, tais como o viscosímetro capilar ou o viscosímetro cilíndrico. Porém, equipamentos com dimensões suficientemente grandes têm sido construídos, possibilitando a construção das curvas de cisalhamento desses materiais.

Como o concreto fresco é um material extremamente heterogêneo, com descontinuidades mecânicas internas extremas, a consideração de um meio contínuo torna-se inaceitável. Assim, as curvas de cisalhamento têm sido plotadas dando o torque como uma função da velocidade de rotação. Como o torque é um valor mecânico dependente do material estudado e da geometria do equipamento utilizado no estudo, qualquer modelação matemática elaborada para transformar esse parâmetro em tensão se torna sem sentido. O mesmo se aplica se a tentativa for feita para a obtenção da taxa de cisalhamento a partir da velocidade de rotação (LEGRAND, 1994).

Assim, a dificuldade apresentada pelo estudo reológico pode ser verificada, mas qualquer tentativa em mascarar o nível de complexidade introduzido pela consideração da heterogeneidade ao longo do desenvolvimento das determinações globais em concreto é destituída de qualquer significado prático.

Porém, isso não significa dizer que tal aproximação é inútil (LEGRAND, 1994). Em termos práticos, essa aproximação leva aos ensaios de trabalhabilidade que constituem a única maneira de obtenção de dados essenciais sobre a capacidade do material apresentar o desempenho esperado, de maneira simples e 
direta. É importante não buscar obter características reológicas globais e intrínsecas por meio desses ensaios e deve-se manter em mente que os resultados obtidos dependerão do material estudado, da geometria do equipamento utilizado e das condições de ensaio adotadas.

No entanto, a simples consideração de que a trabalhabilidade seja o único parâmetro importante deve ser visto com cautela. As dificuldades passam pelas considerações que envolvem desde os próprios materiais já na fabricação de concretos - grande variabilidade da matéria-prima (retirada de regiões variadas dentro das próprias jazidas), disponibilidade e forma de estocagem desses materiais - até a correção de suas partes na escala do processo industrial envolvido, nos equipamentos de mistura, nas considerações de transporte, redosagem, lançamento e adensamento do material. Dessa forma, entende-se a trabalhabilidade final, que seria a característica última do concreto a ser lançado em moldes, como uma suplantação de problemáticas envolvidas até esse estágio.

Assim, ao projetar um bom método de ensaio para a avaliação da trabalhabilidade, deve-se considerar a caracterização do concreto sob condições bem próximas das condições que seriam ideais de lançamento e medir parâmetros que estejam ligados com a qualidade do material.

O presente trabalho apresenta um estudo sobre a trabalhabilidade de concretos de alto desempenho a partir de conceitos reológicos. Para isso, foram usados tanto os métodos de ensaio tradicionais - ensaio de abatimento de tronco de cone e consistômetro de Ve-Be - quanto equipamentos mais modernos reômetro. Uma modificação do ensaio de abatimento tradicional também foi usada como uma tentativa de simplificar a determinação dos parâmetros reológicos que caracterizam o comportamento dos concretos frescos.

Consideram-se tempos de 30 e 60 minutos como aqueles máximos que estariam envolvidos desde a produção até o lançamento de concretos em obras efetivamente planejadas, verificando-se os diversos parâmetros envolvidos nesse planejamento.

Como a trabalhabilidade de uma mistura de concreto pode ser influenciada por diversos fatores, alguns desses fatores foram considerados na pesquisa: os materiais constituintes da mistura (tipo de cimento, dimensão máxima característica do agregado graúdo e a incorporação de adições química e mineral) e o procedimento de mistura empregado na produção das mesmas. 
A natureza reológica dos concretos foi identificada como sendo semelhante a um fluido binghamiano ${ }^{[1.1]}$. Com isso, duas constantes reológicas são necessárias para a caracterização do comportamento do material no estado fresco: tensão de escoamento e viscosidade plástica, ou ainda, em unidades de torque, torque de escoamento e viscosidade de torque.

A trabalhabilidade, bem como sua perda ao longo do tempo, foram associadas à evolução dos parâmetros reológicos que caracterizam o comportamento das misturas no estado fresco: observou-se um aumento da tensão de escoamento (ou torque de escoamento), enquanto a viscosidade plástica (ou viscosidade de torque) permaneceu praticamente constante durante os 60 minutos em que o comportamento foi acompanhado.

Também foram estudadas correlações entre os vários parâmetros medidos, como uma tentativa de associar os diversos métodos de ensaio usados na avaliação da trabalhabilidade dos concretos. Observou-se que a tensão de escoamento e o torque de escoamento apresentaram uma boa correlação com o abatimento, porém para a viscosidade plástica e para a viscosidade de torque a correlação com o abatimento não foi tão boa assim (menores coeficientes de correlação), mostrando que o abatimento é mais sensível à tensão de escoamento ou torque de escoamento do que à viscosidade plástica ou viscosidade de torque. Os parâmetros medidos pelos métodos de ensaio que determinam os dois parâmetros reológicos que caracterizam o comportamento do concreto fresco ensaio de abatimento de tronco de cone modificado e reômetro - mostram boas correlações tanto entre a tensão de escoamento e o torque de escoamento quanto entre a viscosidade plástica e a viscosidade de torque.

\subsection{Importância e justificativa do estudo}

O comportamento de misturas de alto desempenho no estado fresco é sempre crítico para a execução de uma construção com sucesso e um desempenho satisfatório do material a longo prazo. Porém, as informações sobre a trabalhabilidade dessas misturas tendem a ser dispersas em publicações sobre o material no estado endurecido. Tais fontes geralmente mencionam o método de produção para um tipo de concreto em particular, mas os parâmetros relacionados

[1.1] Fluidos binghamianos ou plásticos - fluidos que se comportam como um sólido até que uma tensão mínima seja excedida; em seguida, a relação entre a tensão de cisalhamento e a taxa de cisalhamento torna-se linear. 
com a trabalhabilidade do material são escolhidos arbitrariamente e raramente são investigados (BARTOS, 1994).

Por um processo contínuo no qual o custo da mão-de-obra tem aumentado com relação ao custo dos materiais, existe uma tendência em considerar os materiais agrupados como uma suspensão concentrada e não como um empacotamento granular (De LARRARD et al., 1994). Assim, dada a diversidade dos concretos existentes na atualidade, é especialmente importante caracterizar suas propriedades de trabalhabilidade a fim de se determinar corretamente os materiais constituintes da mistura e os métodos de lançamento do material.

Omitindo-se a evolução do comportamento das pastas de cimento, relacionado com a atividade química inicial do cimento na presença de água, esses materiais são caracterizados por um comportamento binghamiano e, mais particularmente, pseudoplástico ou dilatante dependendo da concentração de cimento na mistura. A tensão de escoamento é explicada pela floculação entre as partículas, sobre a qual é possível agir tanto pela incorporação de aditivos superplastificantes quanto pela aplicação de uma força vibratória. As pastas de cimento também exibem alguma tixotropia e sua estrutura é geralmente modificada pelo fenômeno da exsudação (De LARRARD et al., 1994). O comportamento das pastas de cimento exibe um grau de complexidade que é normal em reologia e, dessa maneira, não é resistente à descrição científica.

O mesmo não é verdade para o concreto, pelo menos por duas razões: a instabilidade intrínseca do material durante o escoamento e os efeitos de aglomeração relacionados com a dimensão limitada da parte de concreto (efeito parede) (De LARRARD et al., 1994). A fim de descrever o comportamento reológico do concreto fresco, é necessário ter certeza se o teor de ar incorporado não muda significativamente à medida que o concreto escoa e se a amostra permanece suficientemente homogênea.

De qualquer maneira, a caracterização reológica do concreto tem muitas aplicações que podem interessar na estimativa das seguintes características: energia de mistura; capacidade de bombeamento do concreto e a taxa de escoamento esperada com relação às instalações e às pressões de trabalho; velocidade de escoamento do material sob o efeito da gravidade; velocidade de escoamento sob o efeito combinado da gravidade e da vibração; intervalo de tempo durante o qual o concreto pode ser lançado; inclinação máxima da superfície livre no concreto fresco além da qual problemas de estabilidade podem aparecer; 
qualidade da superfície do concreto após a remoção da fôrma, ligada ao aparecimento de bolhas de ar no material fresco etc.

Dessa forma, o presente trabalho assume uma grande importância na análise do comportamento de concretos de alto desempenho no estado fresco, pois apresentará os conhecimentos adquiridos de maneira a viabilizar a mistura, o transporte e o lançamento, em função da sazonalidade regional. A metodologia a ser estabelecida poderá ser facilmente adaptada para as outras regiões.

\subsection{Objetivos}

O presente trabalho tem como objetivo geral apresentar os principais conceitos relacionados à reologia no que diz respeito à sua definição, à medição dos parâmetros reológicos e à aplicação às misturas de alto desempenho, comparando-os com situações reais.

De maneira mais específica, o presente trabalho tem como objetivo avaliar a trabalhabilidade de concretos de alto desempenho a partir de conceitos reológicos. Com isso, a influência de alguns fatores pode ser observada com uma maior precisão.

Para isso, pretende-se determinar o melhor comportamento para as misturas de alto desempenho, ou seja, a mistura que apresenta a menor perda da sua trabalhabilidade ao longo do tempo. A trabalhabilidade será associada aos parâmetros medidos em cada método de ensaio, enquanto sua perda ao longo do tempo será associada com a evolução dos parâmetros medidos (aumento ou redução).

Serão consideradas as influências do tipo de cimento, dimensão máxima característica do agregado, incorporação de adições químicas e minerais, além do procedimento de mistura empregado na produção dos concretos.

Com a utilização de um reômetro, pretende-se identificar a natureza reológica das misturas de alto desempenho e, com isso, verificar se o concreto realmente se comportava como um fluido binghamiano - como amplamente estabelecido na literatura - ou se algum outro comportamento poderia encontrado para as misturas de concreto produzidas, por exemplo, com os materiais disponíveis na região de São Carlos/SP.

Como diversos métodos de ensaio serão utilizados para a avaliação do comportamento de concretos no estado fresco, pretende-se estudar correlações entre os parâmetros medidos como uma tentativa de facilitar o estudo reológico 
dessas misturas, uma vez que a utilização do reômetro não é comum na prática das construções.

\subsection{Organização do trabalho}

O trabalho apresentado nessa tese está estruturado em 8 capítulos. Neste primeiro capítulo, uma breve introdução sobre o assunto estudado é apresentada, bem como a importância e justificativa da presente pesquisa e os objetivos a serem alcançados.

O segundo capítulo aborda uma revisão dos principais aspectos relacionados com o concreto de alto desempenho: definição, histórico e aplicações desse material e os materiais que o compõe.

O terceiro capítulo apresenta os principais conceitos relacionados com a reologia: sua definição e conceitos de tensão, deformação e viscosidade. Neste capítulo também são apresentados os tipos de fluidos existentes e as características de cada um deles.

Como o comportamento do concreto no estado fresco está relacionado com sua trabalhabilidade, a definição, os métodos de avaliação e os fatores que influenciam essa propriedade do material são apresentados no capítulo quatro.

O capítulo cinco apresenta a revisão bibliográfica sobre a reologia do concreto fresco. Os pontos abordados incluem a classificação reológica do material - com detalhamento dos parâmetros que caracterizam esse comportamento - os fatores que influenciam sua reologia e os métodos de ensaio empregados na avaliação do comportamento do material.

O procedimento experimental adotado na pesquisa é apresentado no capítulo seis.

No capítulo sete, são apresentados os resultados obtidos e as discussões do estudo experimental realizado. As conclusões do estudo, bem como as sugestões para futuras pesquisas são apresentadas no capítulo oito.

$\mathrm{Na}$ seqüência, anexo a este trabalho, são apresentados os dados complementares para a elaboração da pesquisa. Esses dados incluem a caracterização dos materiais constituintes das misturas, as características das misturas estudadas (consumo de materiais, características mecânicas e tempos de início e fim de pega da pasta que as constituem) e os resultados de ensaios com o reômetro que auxiliaram no desenvolvimento do estudo experimental. 
Por último, as referências bibliográficas consultadas para a elaboração do trabalho são apresentadas. 


\section{CAPÍTULO 2 CONCRETO DE ALTO DESEMPENHO}

\subsection{Definição}

Segundo Aïtcin (2000), um concreto de alto desempenho (CAD) é essencialmente um concreto que apresenta uma relação água/aglomerante baixa. O valor de 0,40 é sugerido como limite entre um concreto convencional e um de alto desempenho. Apesar de ser um valor arbitrário, adota-o como limite ao considerar muito difícil, se não impossível, trabalhar e lançar um concreto com relação água/aglomerante menor ou igual a 0,40 produzido com o cimento Portland comum encontrado no mercado e sem o uso de aditivos superplastificantes. Além disso, esse valor se aproxima do valor teórico que garante a completa hidratação do cimento proposto por Powers (1968).

Ao aceitar esta definição, uma pequena variação da relação água/aglomerante torna-se possível. Porém, à medida que essa relação se afasta significantemente de 0,40 , os concretos convencionais e os de alto desempenho não apresentam apenas uma diferença quanto à resistência mecânica, mas também em relação à microestrutura.

A expressão "relação água/aglomerante" começou a ser usada na Europa e corresponde à expressão francesa rapport eau/liant, traduzida como a relação água/materiais cimentícios. Nesta definição, o termo aglomerante representa qualquer material finamente moído - com finura menor ou igual a do cimento usado na mistura de concreto.

A relação água/aglomerante não dispensa o cálculo da relação água/cimento $(\mathrm{a} / \mathrm{c})$; ela apenas a substitui, uma vez que o CAD é produzido com um cimento moderno que pode conter pequenas quantidades de adições minerais. Além disso, o uso de materiais cimentícios suplementares tornou-se uma prática comum, de maneira que os cimentos modernos incorporam cinzas volantes, escórias de alto- 
forno, pozolanas, sílica ativa, fíler calcário etc., dando ao conjunto o nome de "cimento composto".

A relação água/cimento é muito importante durante a pega e o endurecimento inicial do concreto, pois a maioria dos materiais cimentícios suplementares incorporados à mistura são bem menos reativos que o cimento. Essa importância está relacionada com a resistência inicial e a permeabilidade do concreto em endurecimento, que são quase que inteiramente função das ligações criadas pela hidratação inicial do cimento contido no aglomerante. Assim, do ponto de vista tecnológico, as duas relações devem ser calculadas.

O conceito de CAD é bastante variado. Diversas definições vêm sendo apresentadas desde que esse material foi proposto e variam de acordo com cada país ou centro de pesquisa. No grupo de pesquisa junto ao qual a presente pesquisa foi desenvolvida, a definição empregada é dada por Liborio (2002): "material cientificamente produzido, que atende as expectativas do cliente do ponto de vista estrutural, da estética, de durabilidade frente ao meio ambiente atual e futuro, para fins pré-determinados. Deve ser econômico (custo/benefício) e propiciar vantagens frente a outras alternativas tecnológicas". Essa última observação é feita a fim de se evitar a panacéia.

Assim, o que é necessário em todos os lugares é um concreto à la carte, isto é, uma mistura que alcance uma ampla lista de exigências usando materiais locais a um custo mínimo (De LARRARD \& SEDRAN, 2002), relacionando a idéia de se fazer um CAD com um concreto durável, com a satisfação do usuário e com o seguro de vida da empresa.

\subsection{Histórico}

A utilização do CAD, mais precisamente do concreto de alta resistência (CAR), se deu no início dos anos 60, na cidade de Chicago, Estados Unidos, quando pequenas quantidades desse concreto foram usadas em estruturas importantes que estavam sendo construídas: uma ou duas colunas principais da edificação eram executadas com o concreto experimental, isto é, com concreto de resistência à compressão de $10 \mathrm{MPa}$ a $15 \mathrm{MPa}$ maiores que do concreto até então utilizado. Usando esse estratagema, triplicou-se a resistência à compressão dos concretos usados nos edifícios da cidade de Chicago devagar e progressivamente durante dez anos, aumentando a resistência de 15MPa/20MPa para 45MPa/60MPa (AÏTCIN, 2000). 
Ao atingir $60 \mathrm{MPa}$, uma barreira técnica foi encontrada e ela só poderia ser ultrapassada com a utilização de novos materiais. Porém, no início dos anos 70 era impossível vencê-la, uma vez que os aditivos existentes na época não eram capazes de reduzir ainda mais a relação água/aglomerante.

Durante os anos 80 , as dosagens dos aditivos químicos utilizados foram aumentadas aos poucos, até que se percebeu que eles poderiam ser usados como excelentes redutores de água, sem que nenhum retardamento significativo da pega pudesse ocorrer e sem que fosse incorporado ar em quantidades excessivas ao concreto.

Nessa época, a relação água/aglomerante de 0,30 era considerada uma "barreira psicológica", ou seja, esse valor correspondia à relação água/aglomerante mínima adequada à hidratação do cimento usado na mistura. Entretanto, com uma seleção cuidadosa do cimento e do aditivo permitiu-se, inicialmente, a redução dessa relação para 0,30 , depois para $0,27,0,25$, e por fim 0,23 , a qual permitiu obter um concreto com resistência à compressão de $130 \mathrm{MPa}$ [GODFREY (1987) apud AïTCIN (2000)] $]^{[2.1]}$.

Atualmente, a aceitação e o uso do CAD estão crescendo em todo o mundo, porém sua utilização corresponde a uma porcentagem muito baixa no mercado do concreto. Dentre os países que lançaram importantes programas de pesquisa específicos sobre esse material no final da década de 80 estão os Estados Unidos, Noruega, Canadá, França, Suíça, Austrália, Japão, Coréia, China e Taiwan.

A fabricação e a utilização do CAD não são mais um desafio, pois já existem muitas informações disponíveis em seminários, simpósios, cursos de curta duração e artigos publicados em diversos jornais e revistas especializados.

\subsection{Aplicações}

A utilização de concretos especiais iniciou-se no exterior durante os anos 70 , quando a resistência à compressão dos concretos usados nos pilares de alguns edifícios era maior do que a dos concretos comumente usados na construção "concreto de alta resistência". Com a incorporação de novos aditivos (superplastificantes - SP), descobriu-se que era possível obter outras características melhoradas e, assim, a expressão "concreto de alto desempenho" passou a ser mais utilizada.

[2.1] GODFREY, K. A. Jr. Concrete strength record jumps 36\%. Civil Engineering, v. 10, n. 57, p. 84-86, Oct. 1987 apud AIITCIN, P. C. Concreto de alto desempenho. Tradução Geraldo G. Serra. São Paulo; PINI, 2000. 667p. 
No Brasil, essa questão começou a ser tratada em 1985, ocasião em que foram produzidos os primeiros elementos estruturais de alto desempenho (pilares, vigas e lajes) para a então CDH - Companhia de Desenvolvimento Habitacional, atual CDHU - Companhia de Desenvolvimento Habitacional e Urbano (LIBORIO, 1985). Isso foi possível pela introdução da então "microssílica" no país pelo Eng. Epaminondas Melo do Amaral Filho em 1984.

Desde então, o uso do CAD vem se multiplicando em todo o mundo. Esse aumento na aplicação em obras de construção civil se dá pela procura por concretos mais duráveis que prolongam a vida útil e, conseqüentemente, reduzem os custos com manutenção das estruturas.

O CAD transforma o concreto convencional em um material com melhor desempenho, o que permite aos projetistas usarem-no eficientemente em estruturas cada vez mais esbeltas. Os arquitetos o utilizam em edifícios altos com a intenção de projetar lajes menos espessas e colunas esbeltas, além de ser esteticamente mais interessante. O gosto dos empreiteiros pelo seu uso deve-se à desmoldagem mais rápida dos elementos estruturais.

Segundo Aïtcin (2000), o CAD mantém a versatilidade do concreto convencional, porém sua resistência e durabilidade se assemelham a uma rocha natural que, nesse caso, pode ser facilmente modelada, reforçada com barras de aço protendidas ou pós-tensionadas com cabos ou misturada com todos os tipos de fibras.

Nas aplicações que envolvem o sucesso do CAD citam-se diversas obras internacionais, tais como a plataforma submarina Gullfaks (Noruega - 1971), o edifício Water Tower Place (Chicago/EUA - 1976), a Confederation Bridge entre Prince Edward Island e New Brunswick (Canadá - 1997), o edifício Petronas Towers (Kuala Lampur/Malásia - 1998), o edifício Taipei 101 (Taipei/Taiwan 2004 ) etc. No Brasil, na cidade de São Paulo, o edifício e-Tower, considerado um recorde em concreto colorido de alto desempenho (resistência à compressão de $125 \mathrm{MPa}$ e relação água/cimento de 0,19 - HELENE, 2003), foi concluído em 2005. 


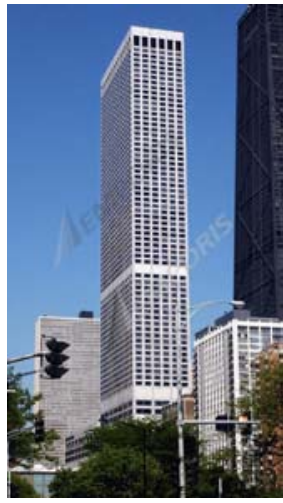

Figura 2.1 Edifício Water Tower Place ${ }^{[2.2]}$.

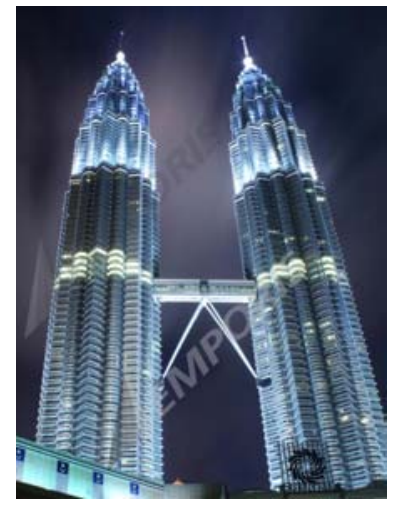

Figura 2.2 - Edifício Petronas Towers ${ }^{[2.3]}$.

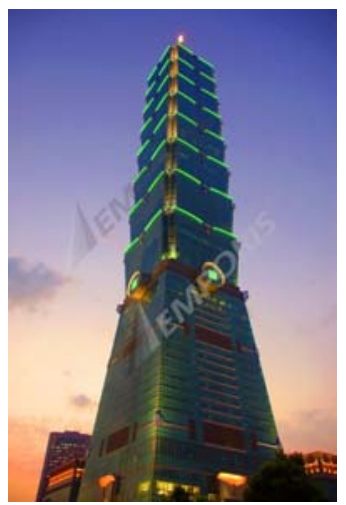

Figura 2.3 - Edifício Taipei $101^{[2.4]}$.

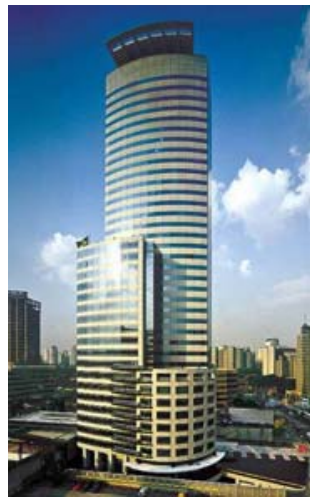

Figura $2.4-$ Edifício eTower ${ }^{[2.5]}$.

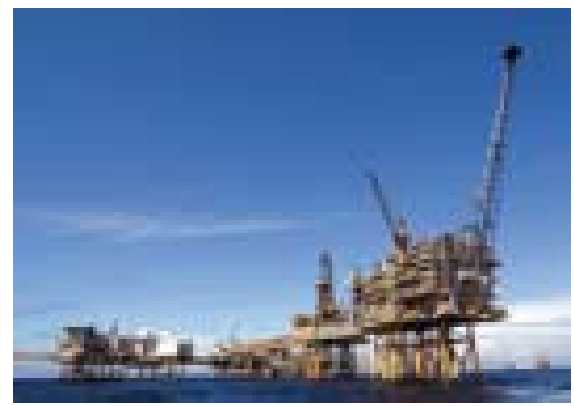

Figura 2.5 - Plataforma Gullfaks ${ }^{[2.6]}$.

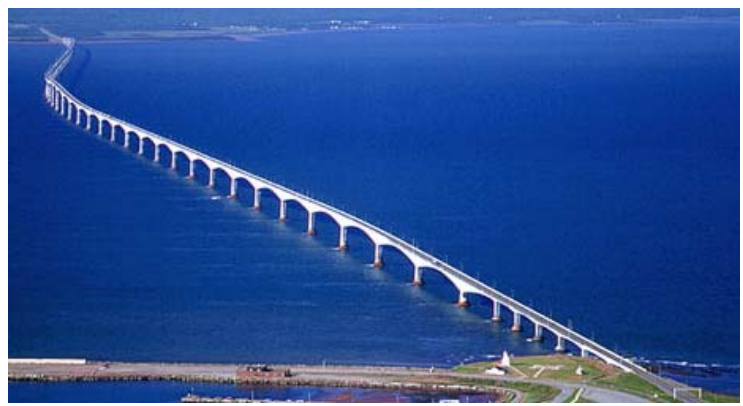

Figura 2.6 - Confederation Bridge ${ }^{[2.7]}$.

Os critérios para a decisão da utilização de um determinado material estrutural estão relacionados com a tipologia estrutural, a função, a localização e as considerações econômicas locais, dentre outros, após serem considerados os prós e os contras de cada alternativa possível. Nos projetos citados anteriormente, diferentes fatores foram considerados, incluindo a resistência à compressão, que tem interferido no uso do CAD por razões econômicas.

\subsection{Materiais constituintes}

Os componentes de um CAD não são apenas os quatro materiais básicos que compõem um concreto convencional - cimento, água, areia e agregado graúdo. Para se alcançar as características mecânicas, a durabilidade e as propriedades reológicas desejadas, aditivos superplastificantes, sílica ativa ou fílers

\footnotetext{
[2.2] Fonte: http://www.emporis.com/en/il/im/?id=200730. Acesso em 08/10/2006.

${ }^{[2.3]}$ Fonte: http://www.emporis.com/en/il/im/?id=489518. Acesso em 08/10/2006.

${ }^{[2.4]}$ Fonte: http://www.emporis.com/en/il/im/?id=387936. Acesso em 08/10/2006.

${ }^{[2.5]}$ Fonte: http://www.emporis.com/en/il/im/?id=436177. Acesso em 08/10/2006.

[2.6] Fonte: http://www.noruega.cl/business/oil/oilproduction.htm. Acesso em 08/10/2006.

${ }^{[2.7]}$ Fonte: http://www.confederationbridge.com/en/media gallery/photo gallery.php. Acesso em 08/10/2006.
} 
são utilizados para o controle da densidade de empacotamento desses concretos (CHOPIN, De LARRARD \& CAZACLIU, 2004).

\subsubsection{Cimento}

Segundo a norma brasileira NBR 5732/91, o cimento Portland comum é definido como o aglomerante hidráulico obtido pela moagem de clínquer ao qual se adiciona, durante a operação, a quantidade necessária de uma ou mais formas de sulfato de cálcio. A norma também permite que materiais pozolânicos, escórias de alto-forno e/ou materiais carbonáticos sejam incorporados em quantidades limitadas, dando origem aos cimentos compostos.

Porém, hoje em dia, existe a possibilidade de se produzir novos cimentos a partir de um material fornecido por uma fábrica de cimento. Assim, é possível obter um novo cimento com características específicas para uma determinada utilização.

O novo aglomerante hidráulico poderá ser constituído com partes de materiais como o clínquer $\left(\mathrm{C}_{3} \mathrm{~S}, \mathrm{C}_{2} \mathrm{~S}, \mathrm{C}_{3} \mathrm{~A}\right.$ e $\left.\mathrm{C}_{4} \mathrm{AF}\right)$, gipsita (controlador de pega), escória de alto-forno, cinzas volantes, sílica ativa de ferro-silício ou silício metálico, cinza e sílica extraídas da casca de arroz, metacaulinitas, terras diatomáceas, argilas calcinadas, pós de concreto reciclado, cerâmica moída, vidros, microfibras, fíler calcário etc. (LIBORIO et al., 2005). Assim, inicialmente, as características desejadas para o concreto deverão ser estabelecidas para, então, escolher os materiais que irão compor o aglomerante hidráulico.

Atualmente, os concretos produzidos com os cimentos comerciais permitem estabelecer certa durabilidade, mas isso muitas vezes é insuficiente. Para que seja correta, a produção de concretos deve estar relacionada a um sistema de cura eficiente, a uma relação água/cimento ou água/aglomerante muito reduzida e a uma intensidade de cura muito prolongada (LIBORIO, CASTRO \& SILVA, 2004).

Simulações nesse sentido foram realizadas por Bentz e Garboczi (1991), que buscaram determinar qual o grau de hidratação necessário que as pastas de aglomerantes deveriam atingir para que fosse obtida a desconexão dos poros. Os resultados obtidos encontram-se na tabela 2.1. 
Tabela 2.1 - Grau de hidratação necessário para desconexão de poros, em função da relação água/cimento e teor de sílica ativa (BENTZ \& GARBOCZI, 1991).

\begin{tabular}{c|c|c|c|c|c|c|c|c|c|c}
\hline \multirow{2}{*}{$\begin{array}{c}\text { Relação } \\
\text { água/cimento }\end{array}$} & \multicolumn{10}{|c}{ Quantidade de sílica ativa (\%) } \\
\cline { 2 - 12 } & $\mathbf{0}$ & $\mathbf{2 , 5}$ & $\mathbf{5}$ & $\mathbf{7 , 5}$ & $\mathbf{1 0}$ & $\mathbf{1 2 , 5}$ & $\mathbf{1 5}$ & $\mathbf{2 0}$ & $\mathbf{2 5}$ & $\mathbf{3 0}$ \\
\hline $\mathbf{0 , 2 2 5}$ & 0,31 & 0,27 & 0,23 & 0,22 & 0,22 & 0,22 & 0,21 & 0,20 & 0,20 & 0,19 \\
\hline $\mathbf{0 , 2 5 0}$ & 0,36 & 0,32 & 0,27 & 0,26 & 0,26 & 0,25 & 0,25 & 0,24 & 0,23 & 0,23 \\
\hline $\mathbf{0 , 2 7 5}$ & 0,41 & 0,37 & 0,32 & 0,30 & 0,29 & 0,29 & 0,29 & 0,28 & 0,27 & 0,26 \\
\hline $\mathbf{0 , 3 0 0}$ & 0,46 & 0,42 & 0,37 & 0,33 & 0,33 & 0,32 & 0,32 & 0,32 & 0,31 & 0,30 \\
\hline $\mathbf{0 , 3 2 5}$ & 0,51 & 0,47 & 0,42 & 0,37 & 0,37 & 0,36 & 0,36 & 0,35 & 0,35 & 0,34 \\
\hline $\mathbf{0 , 3 5 0}$ & 0,56 & 0,52 & 0,47 & 0,42 & 0,41 & 0,40 & 0,40 & 0,39 & 0,38 & 0,38 \\
\hline $\mathbf{0 , 3 7 5}$ & 0,61 & 0,57 & 0,52 & 0,47 & 044 & 0,44 & 0,44 & 0,43 & 0,42 & 0,41 \\
\hline $\mathbf{0 , 4 0 0}$ & 0,66 & 0,62 & 0,57 & 0,52 & 0,48 & 0,47 & 0,47 & 0,47 & 0,46 & 0,45 \\
\hline $\mathbf{0 , 4 2 5}$ & 0,71 & 0,67 & 0,62 & 0,57 & 0,53 & 0,51 & 0,51 & 0,50 & 0,50 & 0,49 \\
\hline $\mathbf{0 , 4 5 0}$ & 0,76 & 0,72 & 0,67 & 0,62 & 0,58 & 0,55 & 0,55 & 0,54 & 0,53 & 0,53 \\
\hline $\mathbf{0 , 4 7 5}$ & 0.81 & 0,77 & 0,72 & 0,67 & 0,63 & 0,59 & 0,59 & 0,58 & 0,57 & 0,56 \\
\hline $\mathbf{0 , 5 0 0}$ & 0,86 & 0,82 & 0,77 & 0,72 & 0,68 & 0,63 & 0,62 & 0,62 & 0,61 & 0,60 \\
\hline $\mathbf{0 , 5 2 5}$ & 0,91 & 0,87 & 0,82 & 0,77 & 0,73 & 0,68 & 0,66 & 0,65 & 0,65 & 0,64 \\
\hline $\mathbf{0 , 5 5 0}$ & 0,96 & 0,92 & 0,87 & 0,82 & 0,78 & 0,73 & 0,70 & 0,69 & 0,68 & 0,68 \\
\hline $\mathbf{0 , 6 0 0}$ & --- & --- & 0,97 & 0,92 & 0,88 & 0,83 & 0,78 & 0,76 & 0,76 & 0,75 \\
\hline $\mathbf{0 , 6 5 0}$ & --- & --- & --- & --- & 0,98 & 0,93 & 0,88 & 0,84 & 0,83 & 0,82 \\
\hline $\mathbf{0 , 7 0 0}$ & --- & --- & --- & --- & --- & --- & 0,98 & 0,91 & 0,91 & 0,90 \\
\hline
\end{tabular}

A cura de um concreto é realizada por duas razões: para hidratar tanto quanto possível o cimento presente na mistura e para minimizar a retração (AÏTCIN, 2000). Ela deve ser iniciada logo após o lançamento do material, lembrando-se que a umidade do ambiente onde o concreto foi lançado deve ser mantida elevada nas primeiras horas; só após adquirir resistência suficiente, deve-se realizar, por exemplo, seu umedecimento (LIBORIO, CASTRO \& SILVA, 2004).

O desenvolvimento da microestrutura durante a hidratação do cimento Portland pode ser visualizada através da figura 2.7 .

A consideração da cura é importante, pois se há poros abertos e a cura não está sendo realizada, então poderá ocorrer uma evaporação da água livre e, ainda, uma interrupção na hidratação do material cimentício e na reação entre produtos hidratados do clínquer e as adições que compõem o cimento.

Assim, a ausência da cura ou a cura incorreta propicia uma hidratação inadequada do cimento, sem o refinamento dos poros. Isso também pode ocasionar uma dessecação interna, causando retrações com fissuração visível e, conseqüentemente, comprometendo o elemento estrutural. Pela ausência da formação das fases indicadas na figura 2.7, há também uma perda da resistência mecânica. O processo de cura interfere na quantidade e distribuição dos poros no concreto e promove grandes perturbações na sua microestrutura. 


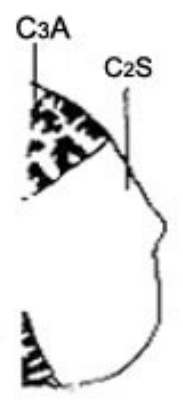

$10 \mu \mathrm{m}$

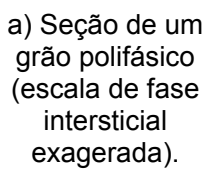

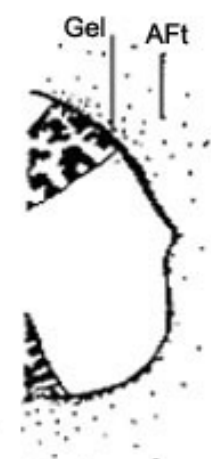

b) 10 minutos

$\mathrm{C}_{3} \mathrm{~A}$ inicia a sua reação com sulfato em

solução. Formase um gel amorfo na superfície e bastões curtos iniciam a sua formação na interface gelsolução.

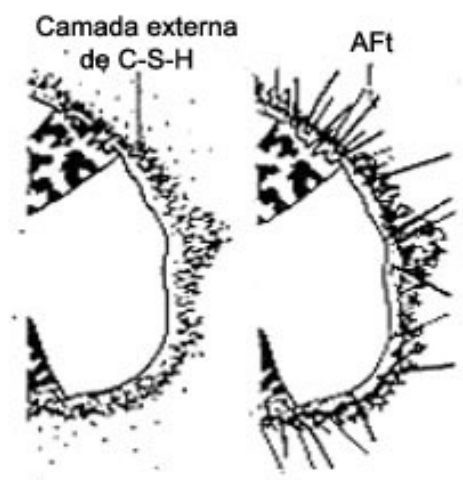

c) 10 horas

Reação do $\mathrm{C}_{3} \mathrm{~S}$ com formação da camada externa de C-S-H (outer shell) sobre os bastões de AFt. Forma-se um vazio de 1,0 $\mu \mathrm{m}$ entre a superfície do grão e a camada externa. d) 18 horas Hidratação secundária de $\mathrm{C}_{3} \mathrm{~A}$ produzindo bastões longos de Aft. O C-S-H interno (inner shell ) começa a se formar

internamente pela continuação da hidratação do $\mathrm{C}_{3} \mathrm{~S}$.

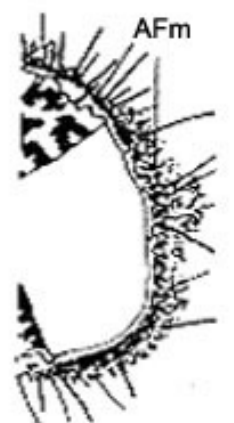

e) 1 a 3 dias

$\mathrm{C}_{3} \mathrm{~A}$ reage com Aft da camada interna formando placas

hexagonais de

AFm. A formação de produto interno reduz a separação entre o grão anidro e a camada externa.

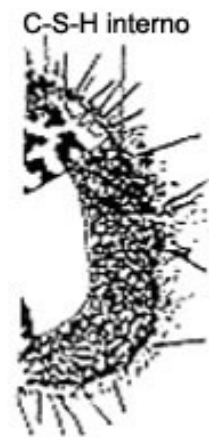

f) 14 dias

Formou-se C-S$\mathrm{H}$ suficiente para preencher o espaço vazio ao redor do grão. $A$ camada externa torna-se fibrosa.

Figura 2.7 - Desenvolvimento da microestrutura durante a hidratação do cimento Portland (SCRIVENER, 1989).

Quando se vai produzir uma pasta, argamassa ou concreto, especialmente de alto desempenho, a primeira escolha a ser feita é quanto ao tipo de cimento a ser empregado, mesmo quando um ou mais materiais cimentícios suplementares são incorporados à mistura. Isto porque seu desempenho em termos de reologia e de resistência torna-se um item crítico à medida que a resistência à compressão desejada aumenta (AÏTCIN, 2000).

Os diferentes tipos de cimento existentes não apresentam o mesmo desempenho quando se produz um CAD. Alguns possuem bom desempenho em termos de resistência mecânica, mas um péssimo comportamento reológico, o que dificulta o lançamento e o adensamento do material produzido; outros apresentam um ótimo desempenho em termos de reologia, porém seu desempenho quanto à resistência mecânica deixa a desejar. Assim, devido à grande variabilidade nas propriedades químicas e físicas do cimento, deve-se esperar que diferentes cimentos se comportem de diferentes maneiras na presença de um mesmo aditivo.

As características reológicas de traços com relação água/aglomerante muito baixa estão relacionadas com a fase intersticial da hidratação do cimento, enquanto o desenvolvimento da resistência é dependente da fase silicato. Dessa forma, o desempenho final do cimento na produção de misturas de alto desempenho dependerá da maneira pela qual o comportamento reológico e o desenvolvimento da resistência podem ser simultaneamente otimizados (AÏTCIN, 2000). 
Dentre as características físicas do cimento, a finura e a distribuição granulométrica são as mais importantes em termos de fluidez da mistura (OKAMURA, HARADA \& DAIMON, 1998). Dentre os parâmetros químicos, aqueles que têm exercido maior influência sobre as propriedades das misturas incorporadas com SP são a perda ao fogo, o teor e a morfologia do $\mathrm{C}_{3} \mathrm{~A}$, o teor de álcalis e a forma do sulfato de cálcio adicionado ao clínquer (AÏTCIN, JOLICOEUR \& MacGREGOR, 1994).

Segundo Suhr (1990), a quantidade total de $C_{3} A$ não é responsável pela reatividade desse componente do cimento; o ponto decisivo é a proporção que reage imediatamente e a quantidade de $\mathrm{C}_{3} \mathrm{~A}$ que reage nos primeiros minutos. Cimentos com menores teores de $\mathrm{C}_{3} \mathrm{~A}$ são menos influenciados pela modificação do sulfato de cálcio e a sensibilidade para a disponibilidade de sulfatos desses clínqueres é diferente. Quanto à influência sobre os parâmetros reológicos, o autor verificou que tanto a tensão de escoamento quanto a viscosidade das misturas aumentaram à medida que o teor de $\mathrm{C}_{3} \mathrm{~A}$ foi aumentado.

$A$ morfologia do $\mathrm{C}_{3} \mathrm{~A}$ na fase intersticial ${ }^{[2.8]}$, controlada pela quantidade de álcalis aprisionada no cimento, é muito importante do ponto de vista reológico dos traços com relação água/aglomerante muito baixa. Sendo o comportamento reológico de um dado cimento determinado pelo controle do $\mathrm{C}_{3} \mathrm{~A}$ através da formação da etringita, quanto mais cúbico for esse componente, mais fácil será o controle de sua reologia [VERNET \& NOWORYTA (1992) apud AÏTCIN (2000)] $]^{[2.9]}$. Assim, com o objetivo de se produzir um clínquer com o $\mathrm{C}_{3} \mathrm{~A}$ cúbico, a maioria dos álcalis deve ser combinada na forma de sulfatos de álcalis durante o período de clinquerização, o que torna o grau de sulfatação do clínquer um parâmetro importantíssimo no controle das propriedades reológicas de um cimento empregado na produção de misturas de alto desempenho.

De acordo com Claisse, Lorimer e Al Omari (2001), a eficiência do gesso como um agente controlador da pega é reduzido quando se utiliza um clínquer altamente reativo, isto é, um clínquer composto por $\mathrm{C}_{3} \mathrm{~A}$ de morfologia ortorrômbica

\footnotetext{
[2.8] Se a quantidade de $\mathrm{Na}_{2} \mathrm{O}$ for inferior a 2,4\%, o $\mathrm{C}_{3} \mathrm{~A}$ mantém a sua estrutura cúbica; quando o teor de $\mathrm{Na}{ }_{2} \mathrm{O}$ fica entre $2,4 \%$ e $3,8 \%, \circ \mathrm{C}_{3} \mathrm{~A}$ torna-se parcialmente ortorrômbico e, próximo dos 3,8\%, ele torna-se ortorrômbico; quando o teor de $\mathrm{Na}_{2} \mathrm{O}$ é superior a $5,3 \%, \mathrm{o} \mathrm{C}_{3} \mathrm{~A}$ torna-se triclínico (situação que nunca ocorre no cimento comum) (REGOURD, 1978 apud AïTCIN, $2000^{\circ}$ ).

${ }^{\infty}$ REGOURD, M. Cristallisation et réactivité de l'aluminate tricalcique dans les ciments Portlands. // Cimento, n. 3, p. 232-235. 1978 apud AÏTCIN, P. C. Concreto de alto desempenho. Tradução Geraldo G. Serra. São Paulo: PINI, 2000. 667p.

${ }^{[2.9]}$ VERNET, C.; NOWORYTA, C. Interaction des adjuvants avec I'hydratation du $C_{3} A$ : points de vue chimique et rhéologique. Personal communication, 56 p. 1992 apud AÏTCIN, P. C. Concreto de alto desempenho. Tradução Geraldo G. Serra. São Paulo: PINI, 2000. 667p.
} 
e um alto teor de álcalis, pois a reatividade do $C_{3} A$ é aumentada pelos álcalis (potássio).

O papel crítico dos sulfatos sobre a reologia de materiais à base de cimento tem sido a disponibilidade ou a taxa de dissolução dos íons $\mathrm{SO}_{4}{ }^{2-}-$ que deve ser balanceada com a reatividade química do $\mathrm{C}_{3} \mathrm{~A}$ - e não a quantidade total de $\mathrm{SO}_{3}$ no cimento (AÏTCIN, JOLICOEUR \& MacGREGOR, 1994).

A influência do teor de sulfato sobre a tensão de escoamento e a viscosidade desses materiais pode ser descrita aproximadamente como (SUHR, 1990): o excesso de sulfato promove um aumento da tensão de escoamento e da viscosidade através da recristalização do sulfato de cálcio; porém, a deficiência de sulfato aumenta a tensão de escoamento, mas diminui a viscosidade, porque o desenvolvimento do monossulfato aumenta, enquanto o desenvolvimento de etringita diminui. Daí os dois parâmetros reagirem independentes um do outro.

Em qualquer situação, quanto menor a quantidade de $C_{3} A$ presente no cimento, mais fácil será o controle de sua reologia. Dessa forma, ao se produzir misturas de alto desempenho, deve-se optar por cimentos com baixos teores de $\mathrm{C}_{3} \mathrm{~A}$ e $\mathrm{C}_{3} \mathrm{~S}$ (AÏTCIN \& NEVILLE, 2003), sendo o $\mathrm{C}_{3} \mathrm{~A}$ de forma cúbica ou, pelo menos, uma mistura de formas cúbicas (predominante) e ortorrômbicas. Além disso, esse cimento deve conter certa quantidade de sulfatos solúveis com o objetivo de controlar rápida e eficientemente a formação da etringita (AÏTCIN, 2000).

Segundo Suhr (1990), o grau de coerência e mobilidade das partículas de cimento é decisivo para o comportamento do escoamento de materiais à base de cimento, assim como os produtos de hidratação ou grupo de produtos de hidratação dependentes do sulfato disponível, da proporção de $\mathrm{C}_{3} \mathrm{~A}$ imediatamente reagente e da temperatura.

\subsubsection{Agregados}

A escolha do agregado é de fundamental importância para a preparação do concreto de alto desempenho ou de elevadíssima resistência: no estado fresco, os agregados têm papel fundamental na determinação do custo e da trabalhabilidade das misturas de concreto; no estado endurecido, eles podem influenciar a resistência, a estabilidade dimensional e a durabilidade do material. Assim, é necessário conhecer macroscopicamente sua forma e sua textura superficial, 
visando melhorar e aumentar a aderência entre o agregado e a pasta de cimento, além de buscar a resistência mecânica adequada para o uso afim.

De acordo com Mehta e Monteiro (1994), o conhecimento de algumas características dos agregados é uma exigência para a dosagem do concreto, enquanto outras são responsáveis pela determinação das propriedades do material no estado fresco. A composição mineralógica dos agregados afeta sua resistência à compressão, dureza, módulo de elasticidade e durabilidade que, por sua vez, interferem nas propriedades do concreto no estado endurecido. A partir do ponto de vista da tecnologia dos concretos, ao analisar o diagrama da figura 2.8 , pode-se determinar como características importantes dos agregados as decorrentes da microestrutura do material, das condições prévias de exposição e do processo de fabricação.

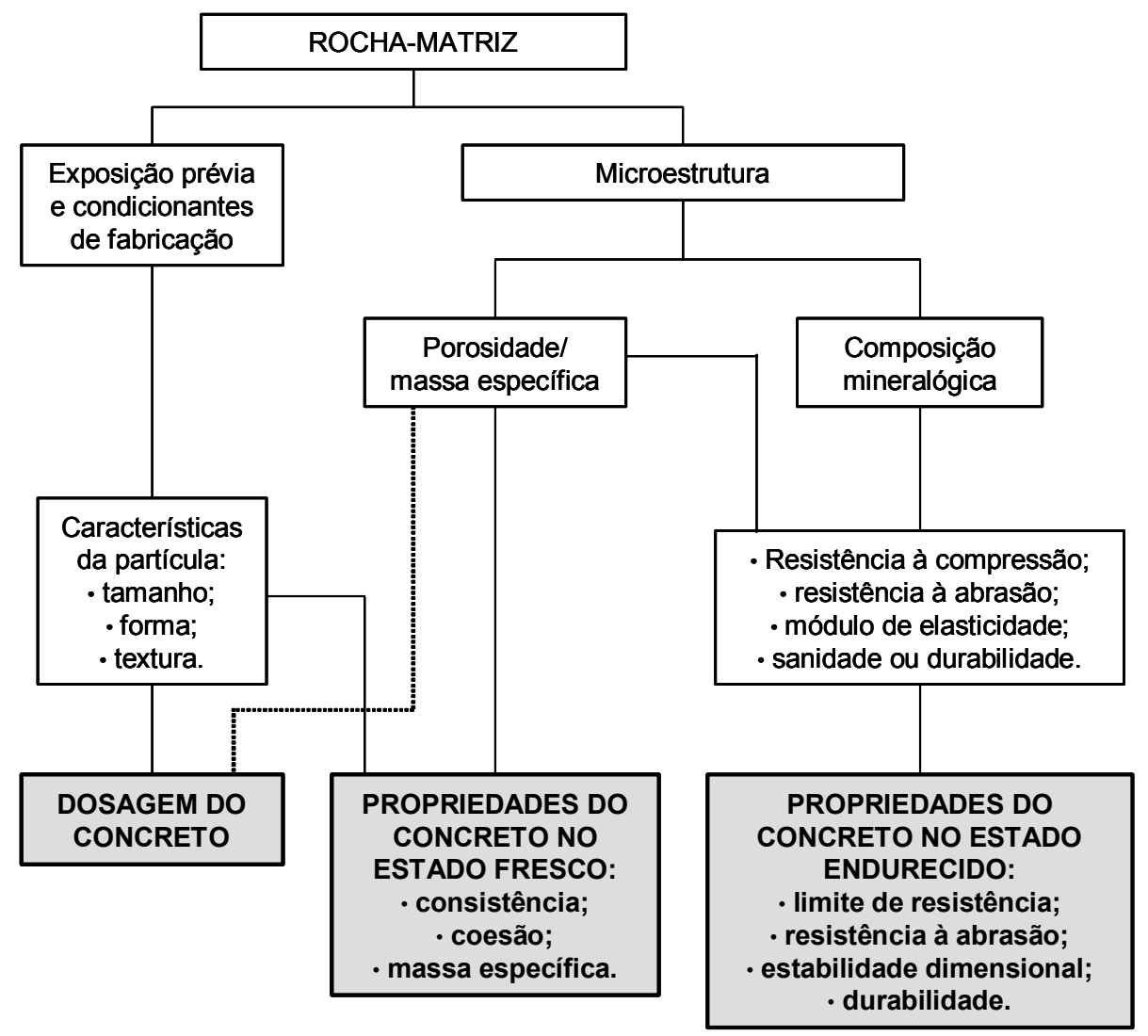

Figura 2.8 - Diagrama ilustrativo de como a microestrutura, as condições prévias de exposição e condicionantes do processo de fabricação do agregado determinam as suas características e como estas afetam o traço e as propriedades do concreto fresco e endurecido (MEHTA \& MONTEIRO, 1994).

A influência dos agregados no concreto começa no ato da mistura: a granulometria, a forma e a textura desses agregados definirão a compacidade e o consumo de água para uma dada trabalhabilidade. Com o avanço da hidratação, outras propriedades importantes do concreto, como porosidade, permeabilidade, 
resistência à tração, estrutura cristalina, coeficiente de expansibilidade térmica, dureza e composição química também serão influenciadas pelos mesmos.

No CAD e CAR, o agregado constitui a parte mais frágil do sistema, isto porque esses concretos se comportam como compósitos, onde a tensão é compartilhada por seus dois componentes: agregados e pasta de cimento. Sob essas circunstâncias, a fase agregado se torna um fator limitante (SILVA, 2000), de maneira que o agregado a ser empregado na produção desses concretos deverá ser resistente, isento de alterações mineralógicas e provido de características cristalinas finas.

Quanto à dimensão máxima do agregado a ser empregado na produção de um concreto, muitos pesquisadores recomendam agregados com dimensão máxima característica inferior a $12,5 \mathrm{~mm}$ e com índice de forma adequado, argumentando que o uso de agregados com dimensões características maiores $\left(D_{\text {máx }} \geq 19 \mathrm{~mm}\right)$ influencia a resistência mecânica de várias maneiras. Porém essa é uma situação que deve ser analisada com bastante cuidado. No Laboratório de Materiais Avançados à Base de Cimento (LMABC/SET/EESC/USP) tem-se produzido, satisfatoriamente, $C A D$ com agregados de dimensão máxima característica igual a $25 \mathrm{~mm}$ e com resistência à compressão acima de $100 \mathrm{MPa}$ medida em corpos-de-prova cilíndricos.

Por outro lado, Neville (1997) afirma que a resistência de um concreto plenamente adensado, com determinada relação água/cimento e/ou água/aglomerante, é independente da granulometria do agregado utilizado. Em primeira aproximação, ele relaciona a granulometria com a trabalhabilidade do concreto, que tem influência sobre importantes propriedades do concreto, tanto no estado fresco quanto no estado endurecido.

Além de se empregar uma granulometria adequada, deve-se mantê-la constante: de outro modo, resulta em variações na trabalhabilidade que, ao serem corrigidas, variam a quantidade inicial de água da mistura que, por sua vez, implicam na produção de concretos com resistências variáveis.

A forma e a textura superficial das partículas de agregado influenciam mais as propriedades do concreto no estado fresco do que no estado endurecido. Devido ao entrelaçamento mecânico, a ligação da matriz pasta de cimento e agregado é de responsabilidade da textura superficial do agregado graúdo (SILVA, 2000).

No caso do agregado miúdo, sua forma e textura têm um efeito significativo sobre a demanda de água de uma mistura; enquanto a lamelaridade e a forma do 
agregado graúdo geralmente têm um efeito apreciável sobre a trabalhabilidade do concreto (NEVILLE, 1997).

\subsection{3 Água de amassamento}

A água é um componente fundamental para o concreto, pois possui duas funções importantíssimas: uma química, que consiste em produzir as reações de hidratação; e outra física, onde estabelece determinadas características reológicas ao concreto para sua manipulação.

Aïtcin e Neville (2003) subdividiram a relação água/cimento em duas partes: a primeira representa a quantidade de água necessária para a completa hidratação do cimento; e a segunda representa a quantidade de água adicional necessária para se obter uma trabalhabilidade adequada (água de trabalhabilidade). Dessa maneira, o concreto ideal deve conter água suficiente para desenvolver a resistência máxima do cimento e, ao mesmo tempo, fornecer as propriedades reológicas necessárias ao seu lançamento (GRZESZCZYK \& KUCHARSKA, 1990).

A qualidade da água de amassamento desenvolve um papel importante na produção do concreto: impurezas contidas na água podem influenciar negativamente a resistência do concreto, causar manchas na superfície concretada e desenvolver um processo de corrosão da armadura (NEVILLE, 1997). Dessa maneira, deve-se dar atenção tanto à qualidade da água de amassamento quanto à da água utilizada na cura do concreto.

A água pode estar presente de várias formas na pasta de cimento endurecida e sua classificação é feita de acordo com o grau de dificuldade com o qual ela pode ser removida do concreto [MEHTA \& MONTEIRO (1994); MELO (2000)]:

- a água capilar é considerada como o volume de água que está livre da influência das forças de atração exercidas pela superfície sólida. É subdividida em água livre e água retida. A água livre corresponde àquela encontrada nos vazios grandes (diâmetros superiores a $50 \mathrm{~nm}$ ), sendo sua remoção isenta de alterações de volume. A água retida por tensão capilar é encontrada nos pequenos capilares (diâmetros variando entre $5 \mathrm{~nm}$ e $50 \mathrm{~nm}$ ) e sua remoção causa a retração do sistema;

- a água adsorvida se localiza próxima à superfície do sólido, isto é, fica sob a influência das forças de atração. As moléculas de água estão fisicamente adsorvidas na superfície dos sólidos da pasta, sendo perdida quando a 
umidade relativa estiver em torno de $30 \%$. A perda desta água gera a retração por secagem do sistema;

- a água interlamelar, também conhecida como água de gel, está associada à estrutura do silicato de cálcio hidratado (C-S-H), ligada por pontes de hidrogênio. Só ocorre a perda dessa água caso a umidade relativa caia para abaixo de $11 \%$, o que pode causar uma retração considerável na estrutura do C-S-H;

- a água quimicamente combinada, também denominada água de cristalização, corresponde à água considerada como parte definitiva da estrutura de vários produtos da hidratação do cimento. Ela não é perdida durante a secagem, sendo liberada apenas quando os produtos hidratados são decompostos por aquecimento.

\subsubsection{Aditivo superplastificante}

Os aditivos superplastificantes (SP) foram utilizados pela primeira vez em concreto no final dos anos 60 , simultaneamente no Japão e na Alemanha. Durante os anos 80 , suas dosagens foram aumentadas pouco a pouco, até que se percebeu que eles poderiam ser usados como excelentes redutores de água (AÏTCIN, 2000).

Assim, com o avanço da tecnologia dos concretos, o uso de adições químicas se tornou essencial para a produção de misturas de alto desempenho. Esses aditivos melhoram as propriedades do concreto nas primeiras idades sem apresentar efeitos adversos em idades avançadas.

Segundo a NBR $11768 / 92$ os aditivos superplastificantes (tipo SP), também chamados de aditivos redutores de água de alta eficiência pela norma americana ASTM C-494/92, são definidos como produtos que aumentam o índice de consistência do concreto mantendo-se a quantidade de água de amassamento constante, ou ainda, como os produtos que possibilitam a redução mínima de $12 \%$ da água de amassamento na produção de um concreto com uma dada consistência.

Os SP são polímeros orgânicos hidrossolúveis obtidos sinteticamente através de um processo de polimerização complexo utilizado na produção de moléculas longas e de massa molecular elevada, sendo, portanto, relativamente caros. Porém, ao serem produzidos para um fim específico, suas características, em relação ao comprimento das moléculas, são otimizadas para um mínimo de entrelaçamento necessário, tornando, assim, a aplicação do produto viável (NEVILLE, 1997). 
O efeito redutor de água promovido pela incorporação dos aditivos em argamassas e concretos no estado fresco é verificado pelo aumento da fluidez dessas misturas. A adição desses aditivos orgânicos produz uma camada de adsorção com cargas de mesmo sinal sobre as partículas de cimento e de hidratos, dispersando-as por meio de repulsão eletrostática (UCHIKAWA et al., 1992).

O efeito fluidificante do SP depende de vários fatores, tais como a natureza e a concentração do aditivo, a composição e a temperatura da mistura fresca, o procedimento de mistura e o tempo de adição do polímero (CHIOCCHIO \& PAOLINI, 1985). O peso molecular de um SP também é de fundamental importância para sua eficiência na redução de água das misturas à base de cimento: polímeros com baixo peso molecular tendem a permanecer nas soluções dos poros, enquanto polímeros com pesos moleculares maiores são adsorvidos sobre as partículas de cimento (BONEN \& SARKAR, 1995). O aumento do peso molecular influencia tanto as propriedades de dispersão quanto a morfologia dos produtos de hidratação do $C_{3} A$; porém, deve-se observar que existe um peso molecular máximo além do qual o efeito dispersante é reduzido (AÏTCIN, JOLICOEUR \& MacGREGOR, 1994). A eficiência do SP não está condicionada apenas por sua compatibilidade com o cimento, mas também pelas técnicas de mistura e transporte, pela correta dosagem, pela metodologia de incorporação, pelas condições ambientais e por uma total compreensão de todas as vantagens que podem ser obtidas com o seu uso.

O tempo de ação de um SP é limitado pela reação entre o $C_{3} A$, a água e o íon sulfato para a produção da etringita e pelo crescimento da camada de minerais hidratados na presença de aditivos. A eficiência de um aditivo diminui devido à formação dos produtos de hidratação na camada, enquanto a exigência global, em termos de área superficial disponível para a adsorção e a dispersão, aumenta (TATTERSALL \& BANFILL, 1983).

Uma vez que um aditivo aumente a densidade potencial da superfície e esse efeito seja perdido após um determinado período de tempo, a adição de tal aditivo não prejudicará a pega e o endurecimento do cimento, salvo quando são usados na presença de cimentos com baixo teor de $\mathrm{C}_{3} \mathrm{~A}$ (neste caso, pode-se observar um retardamento excessivo da pega do sistema). Além disso, esses aditivos não têm influência sobre a retração, a fluência, o módulo de elasticidade, as resistências ao gelo/degelo e aos sulfatos do concreto, assim como não apresentam qualquer efeito sobre a durabilidade do mesmo (NEVILLE, 1997). 
A reologia do CAD é influenciada por dois fenômenos contrapostos: a velocidade com a qual os diferentes componentes do cimento fixam as moléculas de água e a velocidade com que as moléculas de SP são fixadas pelos novos compostos que se formam nos primeiros instantes, isto é, logo após o início da hidratação do cimento [BUCHAS \& BUCHAS (1995) apud SILVA (2000)] ${ }^{[2.10]}$. Neste caso, há a necessidade de se considerar dois conceitos fundamentais: a reatividade reológica de um cimento, definida como a rapidez com que suas partículas consomem a água nos primeiros instantes que seguem a mistura; e a compatibilidade cimento/SP, relacionada com a quantidade de moléculas de SP consumidas durante a hidratação.

Segundo Chiocchio e Paolini (1985), películas em torno das partículas de cimento e/ou dos produtos hidratados são formadas pelas moléculas do polímero ou pelos produtos da hidratação entre o polímero e os constituintes do cimento (particularmente $\circ \mathrm{C}_{3} \mathrm{~A}$ ). Essas películas reduzem a taxa de hidratação, reduzindo, assim, a quantidade de água ligada ao cimento durante os primeiros instantes da hidratação. Uma maior quantidade de água livre explica a maior fluidez de misturas à base de cimento na presença de aditivos.

Se uma camada de moléculas adsorvidas se forma ao redor de cada partícula, as superfícies dessas partículas não podem se aproximar fisicamente como antes. Assim, a camada adsorvida forma uma barreira estérica para evitar essa aproximação. Caso essa camada seja mais espessa que a distância para a energia potencial mínima, as partículas não poderão se aproximar o suficiente para se aderirem uma às outras, de maneira que a floculação é evitada (TATTERSALL \& BANFILL, 1983).

Qualquer aditivo capaz de se adsorver na superfície das partículas de cimento em quantidade suficiente para produzir essas mudanças reduzirá a tensão de escoamento pela defloculação. Adicionalmente, como a função do SP é promover a repulsão eletrostática dos ânions adsorvidos sobre a superfície da pasta de cimento, ele conduzirá a uma redução da viscosidade aparente (YEN et al., 1999).

Usualmente o CAD apresenta um comportamento pegajoso devido à sua coesão, o que representa, em parte, uma redução da taxa de escoamento. A incorporação de SP reduz a demanda de água e ajuda as misturas a alcançar

\footnotetext{
${ }^{[2.10]}$ BUCHAS, F.; BUCHAS, J. Consideraciones sobre el uso de superfluidificantes en HAP (hormigones de alta performance) para la industria del hormigón elaborado. Cemento Hormigón, n. 749, p. 1131-1142. 1995 apud SILVA, I. J. Contribuição ao estudo dos concretos de elevado desempenho: propriedades mecânicas, durabilidade e microestrutura. 2000. 279p. Tese (Doutorado) em Interunidades em Ciência e Engenharia de Materiais, Universidade de São Paulo. São Carlos. 11/10/2000.
} 
maiores fluidez e plasticidade, o que também melhora o empacotamento do concreto pela melhoria da variação granulométrica dos finos, especialmente dos aglomerantes (ZAIN, SAFIUDDIN \& YUSOF, 1999).

A pasta de cimento deve ser suficientemente fluida para ser despejada no seu estado fresco, enquanto uma compacidade ótima, com teor de água limitado, tem que ser alcançada para a obtenção de uma alta resistência mecânica. O aperfeiçoamento do empacotamento de partículas obtido pela adição de agregado miúdo pode ser neutralizado pelo teor de água necessário para se obter uma pasta com a trabalhabilidade desejada. Neste caso, deve-se fazer a incorporação de aditivos para ajustar a dosagem do concreto à sua finalidade (moldagem, bombeamento, vibração). Assim, é necessário controlar a influência dos aditivos sobre o comportamento reológico do concreto fresco.

Para garantir que a pasta esteja sob uma boa condição de escoamento para uma dada relação água/aglomerante e uma dada combinação de materiais cimentícios, é necessário encontrar a dosagem apropriada de SP a ser incorporado. Quando o teor de SP é suficiente para exibir um escoamento adequado, o efeito de uma adição posterior é insignificante e poderá até diminuir o escoamento. Este valor, conhecido como ponto de saturação, é tomado como a dosagem máxima de SP.

A escolha do SP deve ser baseada na relação custo-eficiência obtida por meio de comparações entre a curva "tempo de escoamento versus dosagem de SP" e através da determinação do ponto de saturação desse aditivo (AGULLÓ et al., 1999).

Para fins práticos, as várias complicações do uso de um SP devem ser supridas ensaiando-se a mistura produzida com a concentração de aditivo recomendada pelo fabricante e, então, padronizando-se o método, o tempo e a taxa de adição, bem como o tempo total de mistura.

Deve-se ressaltar que nem todos os cimentos que cumprem as especificações regulamentares têm o mesmo comportamento reológico com um dado SP quando se trabalha com baixas relações água/aglomerante. Da mesma maneira, nem todos os SP que cumprem as normas interagem da mesma forma com um dado cimento. Assim, nunca se deve perder de vista o objetivo final da produção de concreto, que é cumprir as especificações exigidas pelo cliente, otimizando os recursos existentes e utilizando os materiais disponíveis na região. 


\subsubsection{Sílica ativa}

A sílica ativa é um material cimentício suplementar do concreto relativamente novo. Ela começou a ser utilizada no final dos anos 70 na Escandinávia; na América do Norte, sua utilização como tal material se deu apenas no início dos anos 80 . No Brasil, a sílica com características adequadas de qualidade quanto à composição química e características físicas só começou a ser coletada em 1989, porém, desde 1984, essa adição mineral era importada pelo Eng. Epaminondas Melo do Amaral Filho.

A utilização de adições minerais com o objetivo de se melhorar a durabilidade do concreto tem aumentado bastante nos últimos anos. Fatores econômicos e ambientais também têm um papel importante no crescimento do uso dessas adições. Eles fornecem um conforto ambiental, pois subprodutos industriais são reciclados, emissões perigosas lançadas na atmosfera durante a produção do cimento são reduzidas, matérias-primas são preservadas e energia é economizada (NEHDI, MINDESS \& AIITCIN, 1998). Assim, existe um duplo benefício ambiental através da utilização das adições minerais.

Segundo Aïtcin e Neville (2003), nas primeiras idades, a sílica ativa pode ser considerada um inerte, um material muito fino, mas não um aglomerante, uma vez que suas reações químicas não ocorrem na mesma taxa que as reações do cimento. Porém, a situação é complicada devido aos efeitos físicos provocados pela sílica sobre o empacotamento de partículas e, dessa maneira, sobre as forças que controlam a distância entre as partículas de cimento no início do processo de hidratação.

A sílica, quando finamente subdividida e na presença de água, reage quimicamente com o hidróxido de cálcio (liberado pela hidratação do cimento), formando silicatos estáveis que têm propriedades cimentícias (NEVILLE, 1997). Essa reação entre a pozolana (sílica ativa) e o hidróxido de cálcio é denominada reação pozolânica. O efeito fíler corresponde ao processo de refinamento dos poros associado à reação pozolânica: os produtos da reação são bastante eficientes no preenchimento dos espaços capilares grandes, melhorando, assim, a resistência e a impermeabilidade do sistema (MEHTA \& MONTEIRO, 1994).

O papel químico da sílica ativa no processo de hidratação é governado pela disponibilidade de hidróxido de cálcio $\left(\mathrm{Ca}(\mathrm{OH})_{2}\right)$ originado pela hidratação do $\mathrm{C}_{3} \mathrm{~S}$ e $\mathrm{C}_{2} \mathrm{~S}$ no cimento (AÏTCIN \& NEVILLE, 2003). Acima de uma quantidade limite de aglomerante, a sílica não participa das reações químicas, de maneira que a 
quantidade em excesso se comporta realmente como um inerte e não como um aglomerante. Assim, os efeitos benéficos da sílica ativa na microestrutura e nas propriedades mecânicas do concreto ocorrem devido à reação pozolânica e ao efeito fíler, além de seu efeito químico relacionado com o desenvolvimento de cristais de portlandita (AÏTCIN, 2000).

De uma maneira geral, o efeito da incorporação das adições minerais sobre as propriedades do concreto no estado fresco depende principalmente da forma de suas partículas e de sua distribuição granulométrica. Sobre as propriedades do concreto no estado endurecido, seu efeito depende da maneira com que a mistura no estado fresco foi influenciada e também das propriedades químicas que interferem no desenvolvimento da resistência e da durabilidade (TATTERSALL, 1991b). Como resultado da presença de partículas de sílica ativa na pasta de cimento, argamassa ou concreto, Silva (2000) cita o grande aumento da compacidade que provoca os seguintes efeitos: a mistura se torna muito mais densa; a velocidade do fluxo interno de líquido na pasta é reduzida; e a coesão interna, o número de sítios de nucleação e a ligação dos grãos de cimento e das partículas de sílica com os produtos de reação são aumentados.

O uso de sílica ativa resulta em concretos mais coesos (sem exsudação ou segregação) e é muito eficiente na produção de concretos fluidos. As pequenas partículas de sílica agem como esferas rolantes no concreto e passam a fazer parte da solução de água do poro, o que, conseqüentemente, promove o aumento da fluidez da mistura. Embora o concreto incorporado com sílica pareça ser pegajoso, ele é muito mais fluido que qualquer outro concreto quando lançado em um molde (ZAIN, SAFIUDDIN \& YUSOF, 1999).

Assim, com a introdução de sílica ativa nos concretos, as propriedades mecânicas e a trabalhabilidade dos mesmos são melhoradas, enquanto a permeabilidade e a porosidade capilar são reduzidas. Com o refinamento dos poros, a zona de interface entre o agregado e a pasta de aglomerantes (cimento e sílica) é drasticamente reduzida e a exsudação interna e superficial da mistura é minimizada. Tudo isso leva a um alto desempenho do concreto com conseqüente aumento de sua durabilidade.

A incorporação de sílica ativa implica no aumento da demanda de aditivo. A grande área superficial da sílica pode não ser o principal fator que acarreta esse aumento e a idéia de que essa adição mineral pode ter uma afinidade pela adsorção das moléculas de SP é sustentada por Nehdi, Mindess e Aïtcin (1998). De acordo com Zain, Safiuddin e Yusof (1999), as partículas de sílica estão em uma 
variação granulométrica sobre a qual as forças de floculação atuam. A floculação das partículas reduz a fluidez da mistura ou, reciprocamente, aumentam a demanda de SP.

\section{Sílica ativa de ferro-silício ou silício metálico}

A sílica ativa de ferro-silício (SFS), também conhecida como fumos de sílica condensada, sílica volatilizada, sílica amorfa ou microssílica, é um subproduto da fabricação de silício metálico ou de ligas de ferro-silício. O silício e suas ligas são produzidos em fornos de arco elétrico imerso onde o quartzo é reduzido na presença de carvão (e ferro durante a produção das ligas de ferro-silício). Durante a redução do quartzo puro, um subóxido de silício, SiO, se desprende na forma de gás, se oxida e condensa em um material composto de partículas esféricas extremamente pequenas, com aspecto vítreo e muito reativas: dióxido de sílica amorfa $\left(\mathrm{SiO}_{2}\right)$.

A SFS é comercialmente encontrada de três formas: não densificada ou no estado natural (material proveniente diretamente do filtro coletor), densificada (partículas beneficiadas pela aglomeração) e lama (suspensão aquosa com teor de sólidos de $50 \%$ ).

A qualidade da SFS depende de vários fatores, dentre eles o processo de produção, da forma de operação da fabricação, do processo de coleta do pó, dos meios de redução, da matéria-prima e do tipo de forno utilizado.

A sílica, dependendo da natureza do material e do processo de produção empregado, pode ser considerada um material altamente pozolânico, de mediana e até de baixa atividade pozolânica. A pozolanicidade é uma função de sua característica amorfa, de sua granulometria e de sua área específica.

Em termos de composição química, a SFS pode ser qualificada como quase pura, pois suas partículas possuem altos teores de sílica amorfa quando comparado à presença de pequenas quantidades de alumina, ferro, cálcio, álcalis, carbono, dentre outros. O teor de sílica amorfa no subproduto é função do teor de sílica contido nas ligas e/ou metais produzidos nas indústrias: quanto maior for o teor de silício da liga, maior será o teor de $\mathrm{SiO}_{2}$ da SFS. Uma vez que as matériasprimas usadas na fabricação do silício e das ligas de ferro-silício são muito puras, a SFS coletada num dado forno tem, usualmente, uma composição consistente.

Através do ensaio por difração de raios-X, comprova-se que a composição básica da SFS é de sílica amorfa (figura 2.9). Segundo Aïtcin (2000), o resfriamento do vapor de $\mathrm{SiO}$ e a sua oxidação para $\mathrm{SiO}_{2}$ acontecem tão rapidamente que o tetraedro do $\mathrm{SiO}_{2}$ não tem tempo de se organizar de maneira ordenada para 
constituir a forma da sílica cristalina. Dessa maneira, ao analisar um gráfico de ensaio por difração de raios- $\mathrm{X}$, quanto mais achatada for a crista observada, mais amorfa será a sílica ativa.

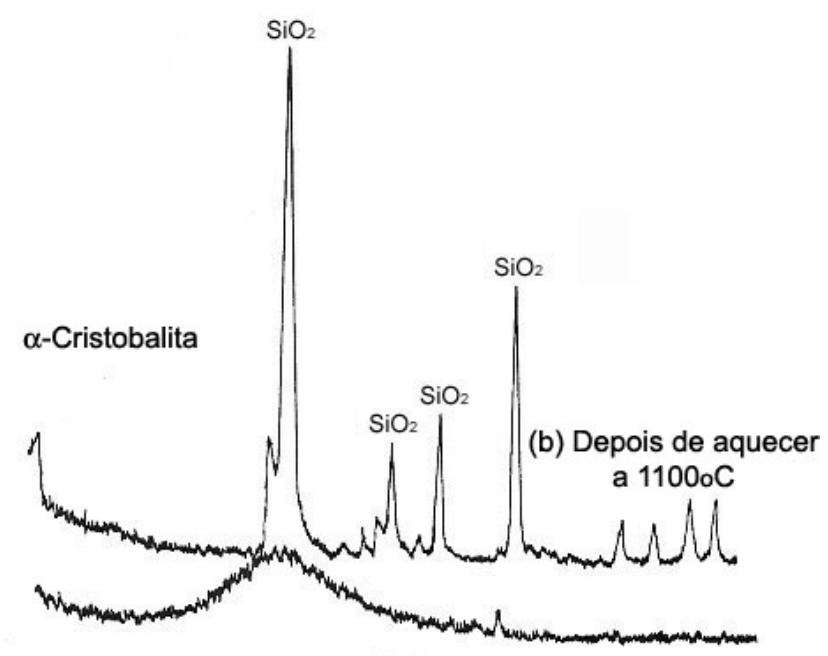

(a) Sílica ativa como produzida

Figura 2.9 - Difratograma de raios- $X$ da sílica de Fe-Si (a) na forma como produzida e (b) depois de aquecida a $1100^{\circ} \mathrm{C}$ (AÏTCIN, 2000).

As propriedades físicas também são de fundamental importância para um bom desempenho da sílica como uma superpozolana. Os efeitos benéficos estão associados à área específica, à granulometria e à sinergia da sílica com outras adições químicas e minerais.

Em relação à granulometria, a sílica é um material extremamente fino, cujo tamanho das partículas apresenta um valor médio de cerca de $0,15 \mu \mathrm{m}$, podendo variar de $0,01 \mu \mathrm{m}$ a $1 \mu \mathrm{m}$ - como esse valor não pode ser medido com precisão, considera-se que a sílica apresenta diâmetros médios de cerca de 50 a 100 vezes menores que os diâmetros médios das partículas de cimento. Segundo Mehta e Monteiro (1994), é por esse motivo que o material, por um lado, é altamente pozolânico, enquanto que, por outro lado, cria problemas de manuseio e aumenta consideravelmente o consumo de água do concreto (isso quando não é feita qualquer adição de SP).

Devido aos diâmetros extremamente pequenos dos grãos, a área específica da SFS é elevada (os valores típicos variam entre $15.000 \mathrm{~m}^{2} / \mathrm{kg}$ e $25.000 \mathrm{~m}^{2} / \mathrm{kg}$ ), sendo que sua ordem de grandeza varia de acordo com o processo de medida utilizado - atualmente, o mais adotado é o método B.E.T. ${ }^{[2.11]}$. Portanto, quanto maior a área específica e menor a granulometria, maior a eficiência da ação da sílica.

[2.11] B.E.T. - Equação de Brunauer-Emmett-Teller: método usado para determinar a área específica a partir da adsorção física de um gás sobre a superfície de um sólido. 
Quanto à massa unitária, a SFS apresenta um valor muito baixo, variando entre $200 \mathrm{~kg} / \mathrm{m}^{3}$ e $700 \mathrm{~kg} / \mathrm{m}^{3}$. Já em termos de massa específica, o valor médio varia entre $2.150 \mathrm{~kg} / \mathrm{m}^{3}$ e $2.650 \mathrm{~kg} / \mathrm{m}^{3}$. 


\section{ASPECTOS CONCEITUAIS RELACIONADOS À REOLOGIA}

\subsection{Definição de reologia}

Embora o conhecimento da reologia por Newton e Hooke date do século XVII, foi somente em 1920, quando o comportamento mecânico de materiais industriais como a borracha, o plástico, a cerâmica, as tintas e os fluidos biológicos - passou a ser do interesse da física, da mecânica, da matemática e, inclusive, da química dos colóides, que surgiu a necessidade do estudo da reologia (TANNER, 1988).

O termo reologia foi definido por E.C. Bingham em 1929. É originado da palavra grega rhein que significa "escorrer" e corresponde ao estudo da deformação e do escoamento da matéria [VAN WAZER et al. (1966); TANNER (1988); MANRICH \& PESSAN (1987)], ou seja, a reologia analisa as respostas de um material provocadas pela aplicação de uma tensão ou de uma deformação, o que significa dizer que ela tem interesse nas relações entre tensão, deformação, taxa de deformação e tempo (TATTERSALL \& BANFILL, 1983). É o ramo da física que se preocupa com a mecânica de corpos deformáveis, os quais podem estar no estado sólido, líquido ou gasoso.

Em outras palavras, a reologia tem por finalidade predizer a força necessária para causar uma dada deformação ou escoamento em um corpo ou, reciprocamente, predizer a deformação ou o escoamento resultante da aplicação de um dado sistema de forças em um corpo (MANRICH \& PESSAN, 1987). Ainda, a reologia pode ser definida como a ciência que estuda o fluxo e a deformação dos 
materiais quando submetidos a uma determinada tensão ou solicitação mecânica externa [STEIN (1986) apud PANDOLFELLI et al. (2000)] $]^{[3.1]}$.

$\mathrm{Na}$ prática, a reologia está preocupada com materiais cujas propriedades do escoamento são mais complicadas do que as de um fluido simples (líquido ou gás) ou as de um sólido elástico ideal, embora possa ser observado que um material, com um comportamento considerado simples sob uma restrita variação da condição de ensaio, poderá exibir um comportamento muito mais complexo sob outras condições (TATTERSALL \& BANFILL, 1983).

Apesar da maioria das teorias de reologia, qualitativas ou quantitativas, tratar de fenômenos reversíveis, a irreversibilidade é geralmente encontrada. Às vezes, as propriedades reológicas de uma substância exibem mudanças consideráveis com o tempo ou com uma deformação prolongada, o que ocasiona tanto a reversibilidade quanto a irreversibilidade.

A reologia quantitativa está relacionada com as relações entre a tensão, a deformação, o tempo e a influência de fatores, como a temperatura, sobre os materiais.

O efeito da temperatura sobre as propriedades de um material é significativo e, muitas vezes, pode "mascarar" os efeitos não-newtonianos no escoamento (TANNER, 1988). Dessa maneira, é importante considerar as variações de temperatura, as quais podem ser causadas por fontes externas de calor ou pelo auto-aquecimento devido à dissipação viscosa. Em muitos casos, o efeito da elevação da temperatura tem um efeito relevante sobre a reologia como função da viscosidade. Tattersall e Banfill (1983) também consideram uma dependência da pressão, mas na maioria das situações práticas isso não é importante.

De acordo com Van Wazer et al. (1966), as curvas de escoamento da reologia deverão sempre ser usadas para medidas envolvendo escoamento laminar, condição em que a velocidade varia apenas na direção da altura da lâmina líquida considerada e não nas duas direções perpendiculares a essa altura. Como o conceito de escoamento laminar se refere a um meio contínuo, às vezes é difícil entender como ele pode ser aplicado a um sistema multifásico, no qual as partículas das fases dispersas são grandes. Porém, o problema da descontinuidade do escoamento devido às partículas é superado pelo uso de instrumentos de medida suficientemente grandes.

[3.1] STEIN, H.N. Rheological behavior of suspensions. Encyclopedia of fluid mechanics: slurry flow technology, Houston, v. 5, p. 3-47. 1986 apud PANDOLFELLI et al. Dispersão e empacotamento de partículas. São Paulo: Fazendo Arte, 2000. 195p. 
Com o objetivo de se determinar as propriedades reológicas de um material, é importante investigar uma ampla extensão da curva de escoamento, dando maior ênfase às baixas taxas de cisalhamento. Às vezes, é conveniente observar a presença de um limite de escoamento em uma operação separada da determinação da variação da taxa de cisalhamento com a tensão de cisalhamento.

Segundo Manrich e Pessan (1987), se o corpo em consideração for um fluido, a aplicação de qualquer sistema de forças anisotrópico (diferentes forças aplicadas em diferentes direções) e heterogêneo (diferentes forças aplicadas em diferentes posições), mas pequeno, resultará em escoamento. Além disso, a relaxação do sistema de forças não resultará no retorno do corpo ao seu estado não-deformado.

Por outro lado, se o corpo for um sólido, a aplicação de qualquer sistema de forças não-homogêneo, isotrópico ou anisotrópico, resultará em uma deformação e não em escoamento. Com a relaxação do sistema de força, o corpo retornará ao seu estado original, não-deformado. No caso de um corpo considerado plástico, ele escoará como um fluido quando a força aplicada exceder um valor crítico; caso contrário, o corpo deformará como um sólido elástico.

Um fenômeno importante ligado ao escoamento é a existência de um limite de escoamento. Alguns materiais que escoam rapidamente sob uma determinada tensão de cisalhamento não escoarão totalmente se essa tensão for reduzida a um valor abaixo do limite de escoamento. Uma vez que esse limite tenha sido excedido, a taxa de cisalhamento poderá ser proporcional à tensão de cisalhamento, como no caso dos fluidos newtonianos; materiais que exibem esse comportamento são chamados de substâncias plásticas ou fluidos binghamianos.

Um limite de escoamento real nunca é encontrado em um líquido de fase simples. Ele está sempre associado às emulsões e às pastas semifluidas, onde uma ou mais fases estão dispersas, assim como partículas ou bolhas em uma fase contínua. À medida que a concentração de uma fase dispersa é reduzida, o limite de escoamento também é reduzido, podendo até ser eliminado.

A presença de um limite de escoamento introduz dificuldades experimentais nas medidas do escoamento de todas as geometrias nas quais a taxa de cisalhamento não é uniforme ao longo do corpo do fluido (VAN WAZER et al., 1966).

Segundo Tanner (1988), os efeitos da elasticidade e da viscosidade são observados para a maioria dos materiais sob circunstâncias apropriadas e, caso esses efeitos não sejam posteriormente complicados pelo comportamento 
dependente do tempo, diz-se que esses materiais são viscoelásticos. É o caso dos materiais poliméricos sólidos, fundidos ou em solução.

De acordo com Bretas e D’Ávila (2000), são considerados materiais viscoelásticos aqueles que apresentam, ao mesmo tempo, características tanto de materiais sólidos como de materiais líquidos. Porém, a distinção entre um sólido e um líquido normalmente é feita com base em uma comparação subjetiva do tempo de relaxação e do tempo de observação.

Geralmente, de início, a tensão diminui rapidamente e, então, gradualmente até se aproximar de um valor limite (TANNER, 1988). O valor limite é, até certo ponto, uma questão subjetiva devido a problemas de medida, mas é uma idéia conveniente. Se esse valor limite não for zero, classifica-se o material como sólido e, caso ele seja zero e se aproxime rapidamente de zero, o material é classificado como líquido. Evidentemente essa classificação depende de uma interação entre a natureza do material e a natureza da observação.

O comportamento viscoelástico, sob condições de estado estacionário, muitas vezes não é distinguível e, quando observado, é difícil de ser interpretado em termos de constantes físicas do material ensaiado (VAN WAZER et al., 1966). Isto significa que as medidas viscoelásticas são melhor desenvolvidas em estudos que envolvem a aceleração ou a desaceleração de uma tensão ou de uma deformação aplicada sobre o material ensaiado. Resumidamente, o problema experimental no estudo do comportamento viscoelástico está em determinar a relação entre a tensão, a deformação e o tempo.

No caso do concreto no estado fresco, o mesmo comporta-se como um fluido. Neste sentido, os conceitos reológicos relacionados ao mesmo são descritos na seqüência.

\subsection{Tensão, deformação e viscosidade}

No caso dos fluidos, a reologia está relacionada a um sistema de forças que faz com que os mesmos escoem. Portanto, para a compreensão deste fenômeno, há a necessidade de se estudar o conceito de tensão, de deformação e, por fim, de viscosidade. 


\subsubsection{Conceito de tensão}

Segundo Bretas e D'Ávila (2000), quando um fluido está em movimento, vários tipos de forças atuam sobre ele. Essas forças surgem devido ao seu movimento (forças de convecção), à ação da gravidade (forças de campo), aos gradientes de pressão e às interações entre as moléculas do fluido (forças de superfície).

Por definição, a tensão é uma força por unidade de área e é dada pela equação:

$$
\tau=\lim \frac{\Delta F}{\Delta A}
$$

onde $\Delta F$ é a força que atua em $\Delta A$. Assim, todas as forças que atuam em um fluido estão relacionadas à tensão.

Ao considerar que tanto a força quanto a área na qual esta força é aplicada são grandezas vetoriais, ou seja, a força está associada a uma dada orientação, podemos definir a tensão de uma maneira mais rigorosa.

Associando um escalar a uma direção obtém-se um vetor e, ao associar um vetor (força) a uma direção obtém-se um tensor tensão $(\overline{\bar{\tau}})$, definido como:

$$
\vec{F}=\hat{n} \times \bar{\tau}
$$

onde $\vec{F}$ é o vetor força e $\hat{n}$ é o vetor unitário normal à superfície onde a força é aplicada. O tensor tensão representa as tensões em um elemento de fluido sem considerar a pressão hidrostática ou termodinâmica atuando no elemento.

Ainda, segundo Bretas e D'Ávila (2000), cada componente do vetor força está associada a uma direção. Assim, em coordenadas cartesianas, o tensor tensão tem nove componentes, usualmente representados na forma de matriz:

$$
\bar{\tau}=\tau_{i j}=\left[\begin{array}{lll}
\tau_{x x} & \tau_{x y} & \tau_{x z} \\
\tau_{y x} & \tau_{y y} & \tau_{y z} \\
\tau_{z x} & \tau_{z y} & \tau_{z z}
\end{array}\right] .
$$

As componentes do tensor tensão $\tau_{i j}$, com $i=j$, ou seja, $\tau_{x x}, \tau_{y y}$ e $\tau_{z z}$, são denominadas componentes normais de tensão (tensões normais). Já as componentes $\tau_{\mathrm{ij}}$, com $i \not j$, são chamadas componentes de cisalhamento (tensões de cisalhamento) e atuam na direção paralela a uma dada face do elemento do fluido.

A figura 3.1 ilustra as componentes do tensor tensão para um elemento de fluido no sistema de coordenadas cartesianas. $O$ índice " $i$ " representa o paralelismo 
da componente com determinado eixo, enquanto o índice "j" representa o plano perpendicular a um determinado eixo onde a componente atua.

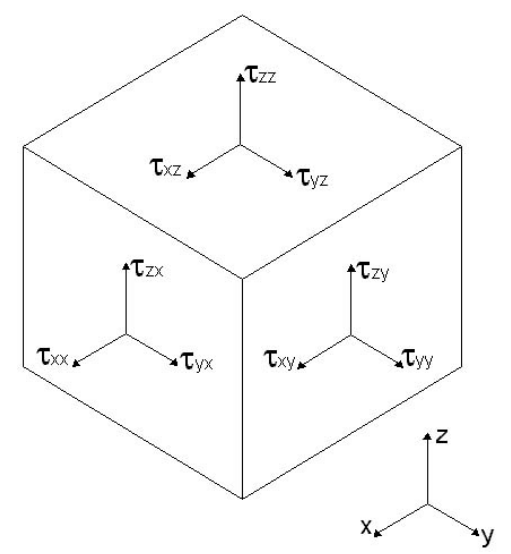

Figura 3.1 - Componentes do tensor tensão para um sistema de coordenadas cartesianas (BRETAS \& D'ÁVILA, 2000).

O tensor tensão possui a propriedade de simetria, ou seja, $\tau_{i j}=\tau_{j j}$. Assim, para se determinar o estado de tensão de um corpo é necessário conhecer seis componentes do tensor tensão: três componentes normais e três componentes de cisalhamento.

No Sistema Internacional de Unidades (SI), a tensão é dada em [Pa].

\subsubsection{Conceito de deformação}

A partir de uma análise física, pode-se dizer que a deformação está associada à mudança de posições relativas das partes de um corpo. Na figura 3.2 são apresentados três movimentos diferentes onde pode ou não ocorrer a deformação do corpo.

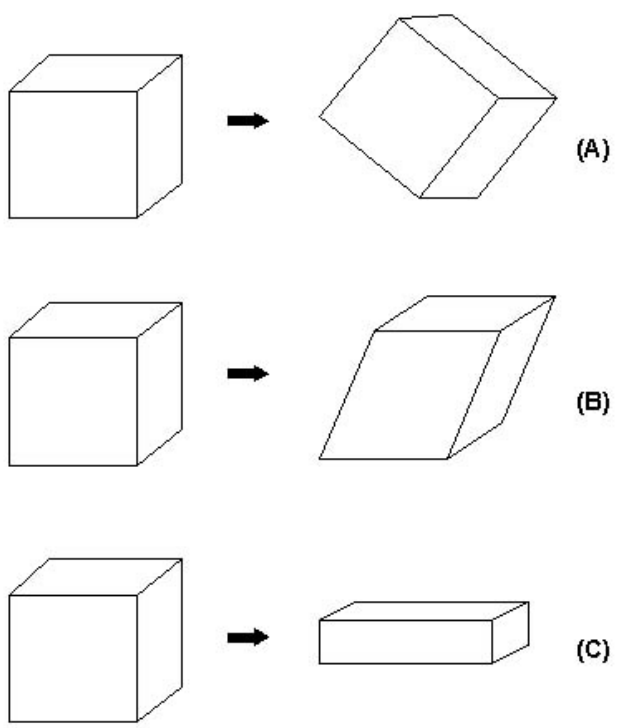

Figura 3.2 - Conceito de deformação: $(A)$ rotação sem deformação; $(B)$ deformação por cisalhamento; e (C) deformação por elongação (BRETAS \& D'ÁVILA, 2000). 
A deformação de um corpo pode ser arbitrariamente dividida em dois tipos: elasticidade ou deformação espontaneamente reversível; e escoamento ou deformação irreversível (VAN WAZER et al., 1966). O trabalho empregado na deformação de um corpo perfeitamente elástico é recuperado quando o corpo retoma sua forma original, enquanto que o trabalho empregado na manutenção do escoamento é dissipado na forma de calor, não sendo recuperado mecanicamente (SCHRAMM, 2006). Assim, a elasticidade corresponde à energia mecanicamente recuperada e o escoamento à conversão da energia mecânica em calor.

Do ponto de vista da reologia, as propriedades mecânicas de todos os materiais são descritas em termos de contribuições elásticas, viscosas e inerciais (VAN WAZER et al., 1966). A deformação elástica é usualmente expressa em termos de deformação, definida de maneira elementar como uma deformação relativa. A deformação viscosa é expressa em termos de taxa de cisalhamento, que corresponde à mudança na velocidade do escoamento com uma distância medida em determinados ângulos em relação à direção do fluxo.

No caso dos fluidos, estes podem ser definidos como matéria ao se deformarem continuamente sob a ação de uma tensão de cisalhamento, sendo que, na ausência desta, não haverá deformação. De uma maneira geral, os fluidos podem ser classificados de acordo com a relação entre a tensão de cisalhamento aplicada e a taxa de cisalhamento (FOX \& McDONALD, 1998), pois ao submetê-los a qualquer tensão externa, eles se deformam continuamente até encontrar uma barreira física capaz de impedir seu escoamento (PANDOLFELLI et al., 2000). Assim, a caracterização reológica dos fluidos envolve a determinação da taxa de cisalhamento do material com o tempo ao invés da deformação absoluta do mesmo.

A tensão de cisalhamento conduz o líquido para o seu perfil de escoamento. A velocidade de escoamento é máxima na camada superior da figura 3.3 e vai diminuindo à medida que atravessa o corpo-de-prova até chegar a zero na camada ligada à placa estacionária. O gradiente de velocidade na amostra é chamado de taxa de cisalhamento e é definido como um diferencial da velocidade pela distância (dv/dy) (SCHRAMM, 2006).

$\mathrm{Na}$ literatura científica, a taxa de cisalhamento é representada por $\dot{\gamma}$. O ponto acima de $\gamma$ indica que a taxa de cisalhamento é derivada do tempo da deformação causada pela ação da tensão de cisalhamento sobre a lâmina de um líquido (SCHRAMM, 2006). 
No Sistema Internacional de Unidades, a taxa de cisalhamento é dada em $\left[\mathrm{s}^{-1}\right]$.

Baixa taxa de cisalhamento Alta taxa de cisalhamento
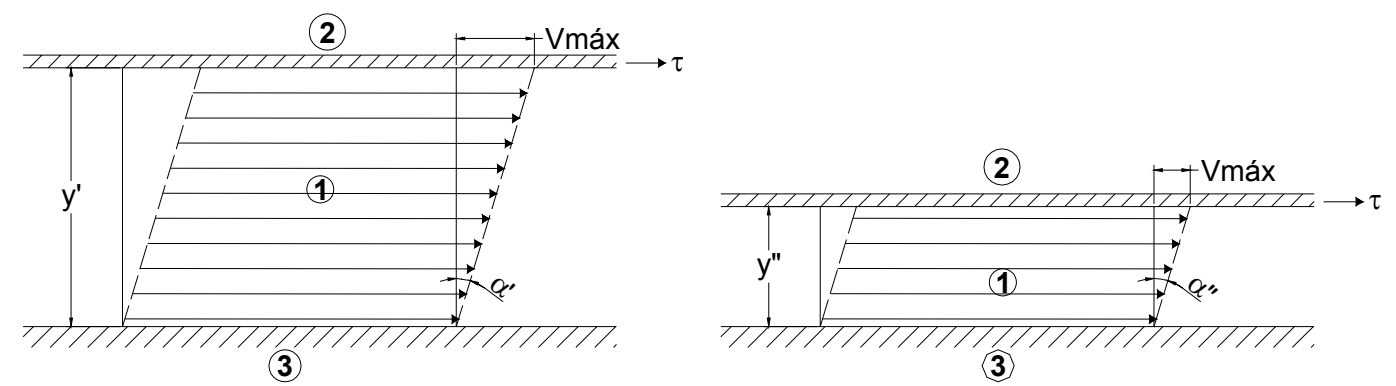

1 Líquido cisalhado

(2) Placa em movimento com área de cisalhamento $A$ em contato com o líquido

3 Placa estacionária

Figura 3.3 - Deformação de um fluido (SCHRAMM, 2006).

\subsubsection{Conceito de viscosidade}

Um corpo viscoso exibe um fluxo com a taxa de escoamento sendo função da tensão de cisalhamento. Segundo Van Wazer et al. (1966), existem dois tipos de escoamento possíveis: um deles é o escoamento no cisalhamento e, o segundo, correspondente a um fenômeno pouco conhecido, pode ocorrer quando o volume de um corpo é mudado com a aplicação ou atenuação da compressão.

Matematicamente, a viscosidade pode ser entendida como a relação entre a tensão de cisalhamento e a taxa de cisalhamento de um material. De acordo com a equação 3.4, quanto menor a viscosidade de um fluido, menor a tensão necessária para submetê-lo a uma dada taxa de cisalhamento constante.

$$
\mu=\frac{\text { tens } \tilde{a} o_{\text {cisalhamento }}}{\text { taxa }_{\text {cisalhamento }}}=\frac{\tau}{\dot{\gamma}}
$$

Fisicamente, a viscosidade nada mais é do que a velocidade de deformação de um corpo, ou ainda, um indicativo da coesão entre as moléculas que constituem as lâminas adjacentes de um fluido. Nos concretos e argamassas, a viscosidade está ligada às pastas e, conseqüentemente, ao teor de água, à origem mineralógica, dimensão e forma dos agregados e ao efeito lubrificante das partículas finas [BLOMBLED (1967) apud RAGO (1999)] $]^{[3.2]}$.

[3.2] BLOMBLED, P.J. Comportement rhéologique des pâtes, morties et bétons: mesure, évolution, influence de certains paramètres. Revue des Matériaux de Construction "Ciments et Bétons", v. 617, Fev. 1967 apud RAGO, F. 
De acordo com Bretas e D'Ávila (2000), a viscosidade pode ser definida como a propriedade que mede a resistência do material ao escoamento. Assim, quanto maior a viscosidade do material, maior sua resistência ao escoamento e vice-versa.

Schramm (2006) denomina viscosidade a resistência de um fluido a qualquer mudança irreversível de seus elementos de volume e considera ainda que, para a conservação do escoamento, deve-se adicionar energia continuamente ao fluido.

Para Ferraris (1996), a viscosidade é definida como o fator de proporcionalidade entre a força de cisalhamento e o gradiente de velocidade do líquido induzido (figura 3.4).

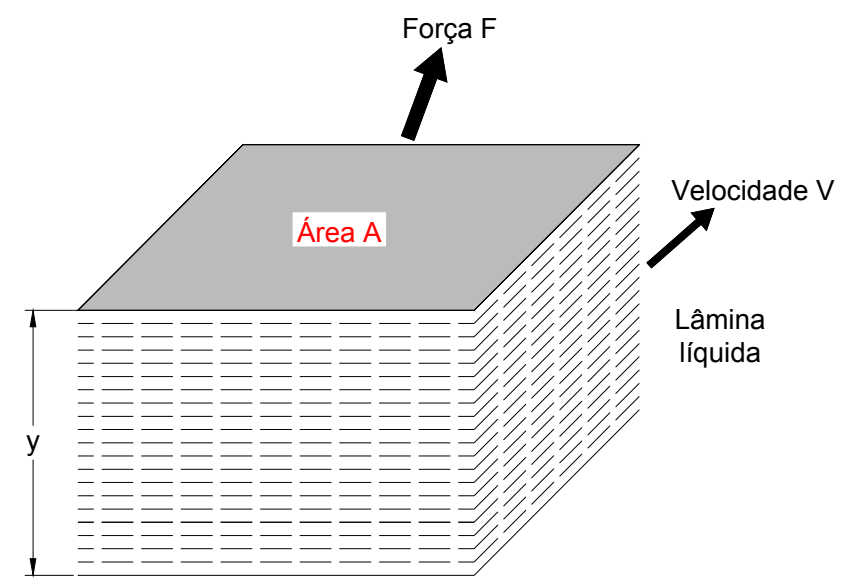

Figura 3.4 - Lei de Newton para viscosidade de um fluido (FERRARIS, 1996).

De acordo com Tattersall (1991b), a viscosidade é um termo que pode ser usado qualitativamente, assim como o termo consistência, para se referir à propriedade do material em resistir crescentemente à deformação com o aumento da taxa de cisalhamento. Quando o termo é usado quantitativamente, ele é definido como a tensão de cisalhamento dividida pela taxa de cisalhamento, quando esta for constante. Assim, este termo somente é aplicado a fluidos newtonianos e seu uso para outros materiais está incorreto.

Segundo Van Wazer et al. (1966), a viscosidade - ou coeficiente de viscosidade - é definida como a razão entre a tensão de cisalhamento aplicada e a taxa de cisalhamento para corpos viscosos ideais. Os autores dividem a viscosidade em: viscosidade diferencial, que corresponde à inclinação de um dado ponto da curva "tensão de cisalhamento versus taxa de cisalhamento"; e viscosidade aparente, termo mais usual aplicado às curvas "tensão de cisalhamento versus taxa de cisalhamento" não-lineares, que é obtida a partir da inclinação de uma reta ligando um ponto particular da curva com a origem.

Características reológicas de pastas de cales hidratadas normalizadas e de cimento. 1999. 207p. Dissertação (Mestrado) em Engenharia de Construção Civil e Urbana - Escola Politécnica, Universidade de São Paulo, São Paulo. 10/02/1999. 
O corpo viscoso ideal mais conhecido é o fluido newtoniano, para o qual a viscosidade é constante. Assim, fornecendo a condição de escoamento laminar, a constante de viscosidade é suficiente para caracterizar completamente as propriedades ao escoamento desse fluido (sob temperatura constante) e a determinação de um único par tensão de cisalhamento/taxa de cisalhamento é suficiente para a determinação da viscosidade do fluido (TATTERSALL \& BANFILL, 1983).

No caso dos fluidos não-newtonianos, a viscosidade pode variar em muitas ordens de magnitude com a mudança da taxa de cisalhamento ou da tensão de cisalhamento para as diversas classes de fluidos.

De acordo com Pandolfelli et al. (2000), a viscosidade pode ser considerada a principal propriedade reológica de um fluido, pois indica sua facilidade de escoar continuamente sob a ação de uma tensão de cisalhamento externa.

Segundo Schramm (2006), a viscosidade, que descreve a propriedade física de um líquido resistir ao escoamento induzido pelo cisalhamento, pode depender de seis parâmetros independentes. São eles: a natureza físico-química do fluido; a temperatura do fluido; a pressão, porém esse parâmetro não é testado tão frequentemente quanto a temperatura; a taxa de cisalhamento, que constitui um fator decisivo (o aumento da taxa de cisalhamento pode aumentar ou diminuir a viscosidade do material); o tempo, que indica a dependência da viscosidade das suspensões da história de cisalhamento, ou seja, do tempo em que uma dispersão foi submetida ao cisalhamento contínuo ou se ela foi mantida parada antes de ser ensaiada; e o campo elétrico, relacionado com uma família de suspensões cujo comportamento ao escoamento é fortemente influenciado pela magnitude de campo elétrico atuante. Assim, para definir a viscosidade em função de um desses parâmetros, os outros cinco devem ser mantidos constantes e bem definidos.

No Sistema Internacional de Unidades, a viscosidade é dada em [Pa.s].

\subsection{Classificação dos modelos reológicos}

As relações entre tensão e deformação, que caracterizam reologicamente um material, podem apresentar-se de diferentes formas (BRETAS \& D'ÁVILA, 2000). Assim, em função deste comportamento, os fluidos são caracterizados em Newtonianos e não-Newtonianos. 


\subsubsection{Fluidos Newtonianos}

São considerados fluidos newtonianos aqueles que apresentam uma relação constante entre a tensão de cisalhamento e a taxa de cisalhamento, independente da deformação e do tempo, isto é, a tensão de cisalhamento é diretamente proporcional à taxa de cisalhamento.

$$
\tau \propto \dot{\gamma}
$$

A constante de proporcionalidade $(\propto)$ presente na equação 3.5 é denominada de viscosidade absoluta ou dinâmica $(\mu)$ e, de acordo com a Lei de Newton da viscosidade para um escoamento unidimensional, ela é dada pela expressão:

$$
\tau=\mu \dot{\gamma}
$$

Assim, a curva de escoamento de um fluido newtoniano é uma linha reta que passa através da origem e tem uma inclinação cujo inverso é igual ao coeficiente de viscosidade. Dessa maneira, para um fluido newtoniano, mas apenas para um fluido newtoniano, uma determinação experimental simples, isto é, um ensaio que mede apenas um dos parâmetros reológicos é suficiente para a caracterização do seu comportamento ao escoamento (TATTERSALL \& BANFILL, 1983).

\subsubsection{Fluidos não-Newtonianos}

São caracterizados como fluidos não-newtonianos aqueles em que a relação entre a tensão de cisalhamento e a taxa de cisalhamento não é linear, isto é, a viscosidade de um fluido não-newtoniano não é constante sob uma dada temperatura e pressão, mas dependente da taxa de cisalhamento ou, de maneira mais geral, da sua prévia história de cisalhamento [TATTERSALL \& BANFIL (1983); TANNER (1988)]. Tais comportamentos são ilustrados por curvas de escoamento que não correspondem a linhas retas passando através da origem e cujas propriedades do escoamento não podem ser caracterizadas por uma única constante.

Estes fluidos são divididos em três grupos, classificados de acordo com o seu comportamento:

- fluidos independentes do tempo $\rightarrow$ fluidos em que a taxa de cisalhamento em qualquer ponto é função apenas da tensão de cisalhamento naquele ponto; 
- fluidos dependentes do tempo $\rightarrow$ sistemas mais complexos em que a relação entre a tensão de cisalhamento e a taxa de cisalhamento depende do tempo em que o fluido foi cisalhado;

- fluidos viscoelásticos $\rightarrow$ sistemas que apresentam tanto características de sólidos quanto de líquidos e que exibem uma recuperação elástica parcial após a deformação.

Os fluidos não-newtonianos independentes do tempo são subdivididos em [VAN WAZER et al. (1966); TATTERSALL \& BANFILL (1983); TANNER (1988); FOX \& McDONALD (1998); PANDOLFELLI et al. (2000); SCHRAMM (2006)]:

- fluidos pseudoplásticos $\rightarrow$ a curva de escoamento típica desses materiais indica que a razão entre a tensão de cisalhamento e a taxa de cisalhamento denominada viscosidade aparente - diminui progressivamente com o aumento da taxa de cisalhamento; diz-se que esses fluidos tornam-se mais delgados sob tensões tangenciais. Observa-se que a taxa de cisalhamento aumenta mais que a tensão de cisalhamento na curva "tensão de cisalhamento versus taxa de cisalhamento". Dentre os fatores que causam este tipo de comportamento estão as características físicas das partículas, o tipo de interação entre as partículas e a concentração, o peso molecular e a conformação das moléculas do dispersante presente no meio líquido. Exemplos: soluções poliméricas, suspensões coloidais e polpa de papel em água;

- fluidos dilatantes $\rightarrow$ a curva de escoamento típica desses materiais indica que sua viscosidade aparente aumenta progressivamente com o aumento da taxa de cisalhamento; diz-se que esses fluidos tornam-se mais espessos sob tensões tangenciais. Observa-se que a taxa de cisalhamento aumenta menos que a tensão de cisalhamento na curva "tensão de cisalhamento versus taxa de cisalhamento". Como este comportamento é característico de suspensões altamente concentradas, todos os fatores que contribuem para a redução da distância de separação entre as partículas e que dificultam o deslocamento relativo entre as partículas no meio líquido - como a presença de partículas com elevada rugosidade superficial, formato assimétrico e distribuição granulométrica bastante estreita e a existência de pronunciadas forças de repulsão entre elas - podem ser considerados. Exemplos: suspensões de amido e areia, PVC e alguns polímeros carregados;

- fluidos binghamianos ou plásticos $\rightarrow$ fluidos que se comportam como um sólido até que uma tensão mínima seja excedida; em seguida, a relação entre 
a tensão de cisalhamento e a taxa de cisalhamento torna-se linear. $\mathrm{Na}$ maioria das vezes, esses fluidos são dispersões que podem formar uma rede interpartículas mantida por forças ligantes quando em repouso. Essas forças restringem mudanças de posição dos elementos, resultando em um material de caráter sólido com uma alta viscosidade. As forças externas, se menores do que aquelas que formam a rede, deformarão elasticamente o material sólido. Somente quando as forças externas são fortes o suficiente para superar as forças de ligação entre as partículas é que estrutura entra em colapso. Quando isso acontece, os elementos podem mudar de posição irreversivelmente, isto é, o sólido se transforma em um líquido. A curva de escoamento típica desses materiais apresenta uma linha interceptando o eixo "tensão de cisalhamento", determinado, assim, a tensão de escoamento. Exemplos: sangue, lamas de perfuração de poços de petróleo, graxa, massas para batom, pasta de dente e borrachas naturais.

Alguns exemplos de comportamentos de fluidos independentes do tempo são apresentados no diagrama reológico da figura 3.5 .

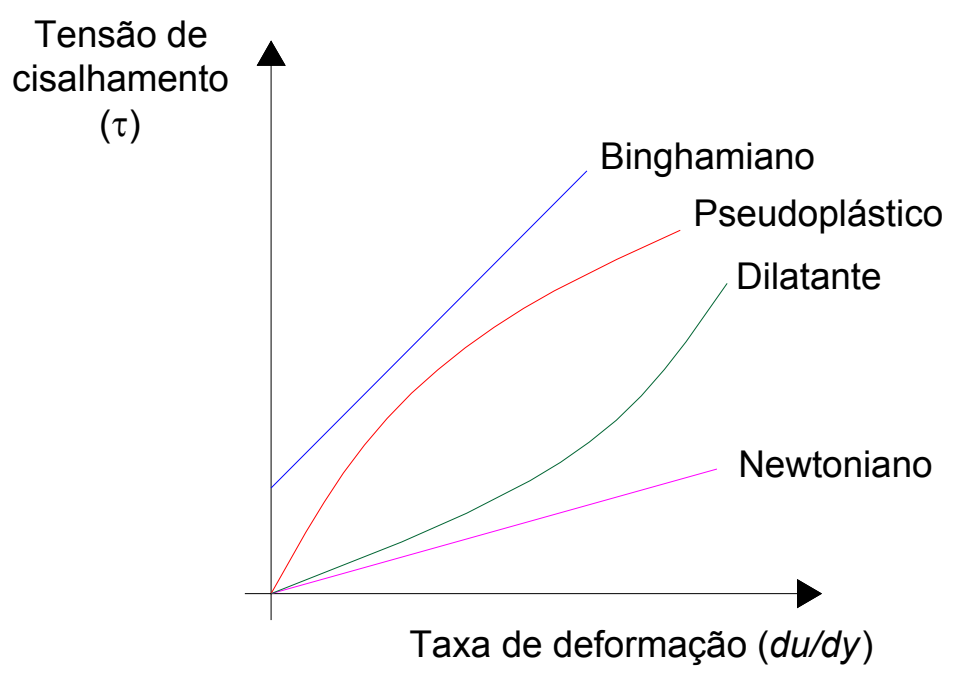

Figura 3.5 - Comportamento reológico de fluidos independentes do tempo (FOX \& McDONALD, 1998).

Numerosas equações empíricas têm sido propostas para elaborar o modelo matemático das relações observadas entre a tensão de cisalhamento e a taxa de cisalhamento para fluidos independentes do tempo. Para muitas aplicações da engenharia, elas podem ser corretamente representadas pelo modelo exponencial:

$$
\tau=k \dot{\gamma}^{n}
$$

onde o $\tau$ é a tensão de cisalhamento, $\dot{\gamma}$ a taxa de cisalhamento, $n$ o índice de comportamento do escoamento e $k$ o índice de consistência. Para $n=1$ e $k=\mu$, esta equação reduz-se à Lei de Newton (fluidos newtonianos). 
Vários outros modelos têm sido propostos para representar outros tipos de comportamento do escoamento como, por exemplo, o modelo de Herschel-Bulkley (equação 3.8 - De LARRARD, FERRARIS \& SEDRAN, 1998). Esse modelo descreve o comportamento de um fluido com tensão de escoamento $\left(\tau_{0}\right)$ e com uma relação não-linear entre a tensão de cisalhamento e a taxa de cisalhamento. Quando o expoente $n$ for menor ou maior a 1 , o fluido exibe um comportamento pseudoplástico ou dilatante, respectivamente. Esse modelo resulta no modelo de Bingham quando $n$ for igual a 1 , com $k$ representando a viscosidade plástica do fluido (YAHIA \& KHAYAT, 2003).

$$
\tau=\tau_{o}+k \dot{\gamma}^{n}
$$

Da mesma forma, os fluidos dependentes do tempo são subdivididos em [VAN WAZER et al. (1966); TATTERSALL \& BANFILL (1983); TANNER (1988); FOX \& McDONALD (1998); PANDOLFELLI et al. (2000); SCHRAMM (2006)]:

- fluidos tixotrópicos $\rightarrow$ considerado a quebra da estrutura pelo cisalhamento. São fluidos cuja consistência depende tanto da duração do cisalhamento quanto da taxa de cisalhamento. Apresentam uma diminuição da viscosidade aparente com o tempo sob uma taxa de cisalhamento constante, ou seja, tornam-se mais fluidos com o aumento do tempo de escoamento sob condições de estado estacionário. É um comportamento considerado reversível. Exemplo: tintas, produtos alimentícios, cosméticos, farmacêuticos etc. ;

- fluidos reopéticos $\rightarrow$ considerado a formação gradual da estrutura pelo cisalhamento. São fluidos que apresentam um aumento da viscosidade aparente com o tempo sob uma taxa de cisalhamento constante, isto é, o material exibe maior resistência ao escoamento com o aumento do tempo de escoamento quando sujeito ao cisalhamento no estado estacionário. Líquidos reopéticos podem permanecer em um ciclo infinito entre o aumento da viscosidade dependente do tempo de cisalhamento e a diminuição da viscosidade relacionada com o tempo de repouso. Geralmente, existe um valor crítico de cisalhamento além do qual a reestruturação do material não é induzida e a ruptura acontece; porém, existem outros materiais cuja estrutura se forma apenas sob cisalhamento e se desintegra gradualmente quando em repouso, observado apenas sob taxas de cisalhamento moderadas. É considerado um comportamento reversível e contrário à tixotropia. Exemplos: suspensão aquosa diluída de pentóxido de vanádio e oleato de amônio. 
Pandolfelli et al. (2000) ressaltam que os comportamentos dependentes do tempo são bastante influenciados pela história de cisalhamento do material, o que consiste na seqüência e duração das taxas aplicadas anteriormente à avaliação reológica. Os autores consideram a história de cisalhamento como o diferencial entre esses dois comportamentos.

De acordo com Van Wazer et al. (1966), as constantes de tempo para os efeitos tixotrópicos e reopéticos poderão variar consideravelmente, sendo virtualmente impossível determinar as mudanças que ocorrem em intervalos de tempo extremamente pequenos durante o escoamento de um material. Com base em estudos realizados, os autores argumentam que o escoamento pseudoplástico (sem limite de escoamento) resulta de um comportamento tixotrópico imediatamente concluído (exibindo um intervalo de tempo infinitamente curto para ir do valor de viscosidade inicial para um valor de viscosidade limite final), enquanto que o escoamento dilatante resulta do comportamento reopético também imediatamente concluído.

O termo "corpo falso" é freqüentemente encontrado em discussões sobre tixotropia. Segundo Tanner (1988), ele foi introduzido para distinguir os tipos de comportamento tixotrópico de fluidos binghamianos. Um verdadeiro material tixotrópico se rompe completamente sob a influência de altas tensões de cisalhamento e se comporta como líquidos, mesmo após a retirada da tensão aplicada, até que se atinja o tempo necessário para a reestruturação do material. Por outro lado, os materiais de "corpo falso" não perdem suas propriedades sólidas por completo e ainda podem exibir uma tensão de escoamento, embora ela possa ser reduzida; a tensão de escoamento original pode ser novamente alcançada após o fluido permanecer em repouso por um longo período. 



\section{CAPÍTUL口 4 TRABALHABILIDADE DO CONCRETO FRESCO}

Tradicionalmente, o comportamento do concreto no estado fresco é resumido em uma única palavra: trabalhabilidade, que não corresponde a uma propriedade intrínseca do material. Ela está relacionada ao tipo de construção e aos métodos de lançamento, adensamento e acabamento do material.

$\mathrm{Na}$ tecnologia dos concretos, esse termo tem sido freqüentemente usado para abranger todas as qualidades necessárias a uma mistura, o que pode incluir, sob a mesma denominação geral, o requisito estabilidade, que significa dizer que a mistura é capaz de resistir à segregação e à exsudação (TATTERSALL \& BANFILL, 1983). Obviamente, o nível de trabalhabilidade exigido para um concreto depende da situação para a qual o material será empregado.

\subsection{Definição de trabalhabilidade}

A palavra trabalhabilidade é um termo que se refere às propriedades do concreto no estado fresco, isto é, às propriedades do concreto antes que se inicie a pega e seu endurecimento. Obviamente, é uma palavra que significa "capacidade de ser trabalhado (a)", mas definí-la de tal maneira é apresentar uma tautologia ${ }^{[4.1]}$ sem nenhum valor prático (TATTERSALL, 1991b).

Como qualquer outra propriedade física, a trabalhabilidade pode ser formalmente definida como sendo descrita por um conjunto de uma ou mais constantes que devem satisfazer certos critérios como segue [TATTERSALL \& BANFILL (1983); TATTERSALL (1991b)]:

- a trabalhabilidade é só uma propriedade do concreto;

[4.1] Tautologia significa "vício ou figura retórica que consiste em repetir a mesma idéia utilizando termos diferentes". 
- a trabalhabilidade será expressa quantitativamente em termos de uma ou mais constantes físicas;

- todas as constantes físicas devem ser expressas em termos de unidades fundamentais de massa, comprimento e tempo ou de unidades derivadas delas, tais como tensão de cisalhamento e taxa de cisalhamento. Em outras palavras, os resultados devem ser independentes do equipamento utilizado para determiná-los;

- as constantes devem ser tais que os valores de todas elas sejam numericamente os mesmos para dois ou mais materiais. Esses materiais se comportarão exatamente da mesma maneira para qualquer circunstância prática, ou seja, se dois concretos têm os mesmos valores numéricos para todas as constantes necessárias, seus comportamentos deverão ser iguais em qualquer situação.

Não existe dúvida de que, no campo de medida da trabalhabilidade, muita confusão tem sido feita pelo uso descuidado e impreciso da terminologia e pela formulação de definições arbitrárias que estão em conflito com outras definições igualmente arbitrárias ou com o uso já estabelecido.

A menos que, e até que seja possível definir a trabalhabilidade com o rigor dos critérios listados anteriormente, o termo deve ser restrito ao uso mais geral, sem qualquer quantificação. Dessa maneira, é válido referir-se à alta, média ou baixa trabalhabilidade e, em situações particulares, fazer declarações do tipo "esse concreto é mais trabalhável que aquele", mas não tentar impor números à descrição.

Assim, duas classes de termos têm sido consideradas: uma geral ou qualitativa; e uma específica ou quantitativa relacionada aos resultados dos ensaios empíricos. Existe, ainda, uma terceira e importante classe que incorpora os termos de quantidades fundamentais rigorosamente definidos e que não devem ser usados em qualquer outra situação (tabela 4.1) [TATTERSALL \& BANFILL (1983); TATTERSALL (1991b)]. 
Tabela 4.1 - Esquema da nomenclatura para trabalhabilidade [TATTERSALL \& BANFILL (1983); TATTERSALL (1991b)].

\begin{tabular}{|c|c|c|}
\hline Classe de termos & Termos abrangidos & Aplicação da classe de termos \\
\hline $\begin{array}{c}\text { Classe I } \\
\text { Qualitativa }\end{array}$ & $\begin{array}{c}\text { Trabalhabilidade } \\
\text { Capacidade de escoamento } \\
\text { Compactabilidade } \\
\text { Estabilidade } \\
\text { Acabamento } \\
\text { Lançamento etc. }\end{array}$ & $\begin{array}{l}\text { Usada apenas em uma } \\
\text { descrição geral sem qualquer } \\
\text { tentativa de quantificação. }\end{array}$ \\
\hline $\begin{array}{l}\text { Classe II } \\
\text { Quantitativa e } \\
\text { empírica }\end{array}$ & $\begin{array}{c}\text { Abatimento } \\
\text { Fator de compactação } \\
\text { Tempo Ve-Be } \\
\text { Mesa de consistência e de } \\
\text { espalhamento etc. }\end{array}$ & $\begin{array}{l}\text { Usada como uma manifestação } \\
\text { quantitativa simples do } \\
\text { comportamento de um conjunto } \\
\text { particular de circunstâncias. }\end{array}$ \\
\hline $\begin{array}{l}\text { Classe III } \\
\text { Quantitativa e } \\
\text { fundamental }\end{array}$ & $\begin{array}{c}\text { Viscosidade } \\
\text { Mobilidade } \\
\text { Fluidez } \\
\text { Tensão de escoamento etc. }\end{array}$ & $\begin{array}{c}\text { Usada estritamente em } \\
\text { conformidade com as definições } \\
\text { da norma BS } 5168 / 75^{[4.2]} \text {. }\end{array}$ \\
\hline
\end{tabular}

As principais definições de trabalhabilidade, segundo Iwasaki (1983) apud Ferraris $(1999)^{[4.3]}$, são:

- American Concrete Institute $\rightarrow$ propriedade do concreto ou argamassa no estado fresco que determina a facilidade e a homogeneidade com as quais o material pode ser misturado, lançado, adensado e acabado;

- British Standards Institution $\rightarrow$ propriedade do concreto, argamassa ou semelhante no estado fresco que determina a facilidade com a qual o material pode ser manipulado e completamente adensado;

- Association of Concrete Engineers (Japão) $\rightarrow$ propriedade do concreto ou argamassa no estado fresco que determina a facilidade com a qual o material pode ser misturado, lançado e adensado devido à sua consistência, a homogeneidade com a qual o concreto pode ser feito e o grau com qual o material pode resistir à separação de materiais.

De acordo com a ASTM C-125 apud Mehta e Monteiro (1994) $)^{[4.4]}$, a trabalhabilidade pode ser definida como "a propriedade que determina o esforço necessário para manipular uma quantidade de concreto fresco com uma perda mínima de homogeneidade", sendo que, o termo manipular inclui todas as

[4.2] BRITISH STANDARDS INSTITUTION. British Standard BS 5168 - Glossary of rheological terms. 1975.

[4.3] IWASAKI, N. Estimation of workability - Why has the slump remained being used so long. Concrete Journal, v. 21, n. 10, p. 4-12. 1983 apud FERRARIS, C.F. Measurement of the rheological properties of high performance concrete: state of the art report. Journal of Research of the National Institute of Standards and Technology, v. 104, n. 5, p. 461-478, Sep.-Oct. 1999.

${ }^{[4.4]}$ AMERICAN SOCIETY FOR TESTING AND MATERIALS. Definitions of terms relating to concrete and concrete aggregates. ASTM C-125. In: Annual Book of ASTM Standards. Philadelphia, 1993 apud MEHTA, P.K.; MONTEIRO, P.J.M. Concreto: estrutura, propriedades e materiais. São Paulo: PINI, 1994. 573p. 
operações das primeiras idades como lançamento, adensamento e acabamento do material.

A trabalhabilidade é uma propriedade composta de pelo menos dois componentes principais: fluidez, que descreve a facilidade de mobilidade do concreto fresco; e a coesão, que descreve a resistência à exsudação ou à segregação (MEHTA \& MONTEIRO, 1994).

A qualidade do concreto fresco é determinada por sua homogeneidade e pela facilidade com a qual esse material pode ser misturado, transportado, adensado e acabado. Capacidade de escoamento, capacidade de moldagem, coesão e compactabilidade são propriedades da trabalhabilidade que estão associadas à qualidade do material. A capacidade de escoamento está relacionada com a consistência, uma vez que essa determina a facilidade com que um concreto escoa; porém, concretos com consistências semelhantes podem exibir diferentes características de trabalhabilidade [POPOVICS (1982) apud CHIDIAC et al. $(2000)]^{[4.5]}$. A coesão, que é uma medida da compactabilidade e da capacidade de acabamento, é geralmente avaliada pela facilidade de alisamento e pelo julgamento visual da resistência à segregação (MEHTA \& MONTEIRO, 1994).

Dessa maneira, a importância da trabalhabilidade na tecnologia dos concretos é bastante óbvia. Independente da sofisticação usada nos procedimentos de dosagem e de outras considerações, tais como o custo, uma mistura de concreto que não pode ser lançada facilmente ou adensada em sua totalidade provavelmente não apresentará as características de resistência e durabilidade inicialmente desejadas (MEHTA \& MONTEIRO, 1994).

\subsection{Avaliação da trabalhabilidade}

A avaliação da trabalhabilidade através da análise subjetiva da aparência do material e de suas qualidades de manipulação, apesar de ser um método tão antigo quanto o próprio concreto, é ainda bastante utilizada hoje em dia.

Porém, mesmo não existindo dúvidas de que a avaliação subjetiva seja um guia útil quando realizada por um operador experiente, ela apresenta severas limitações. Segundo Tattersall (1991b), essa avaliação não pode ser imediatamente quantificada, fazendo com que a informação não seja facilmente passada adiante; deve-se notar também que a descrição "experiente" de um operador não implica em

[4.5] POPOVICS, S. Fundamentals of Portland cement concrete: a quantitive approach. In: FRESH CONCRETE (vol. 1). New York: John Wiley \& Sons, 1982 apud CHIDIAC, S.E. et al. Controlling the quality of fresh concrete - a new approach. Magazine of Concrete Research, v. 52, n. 5, p. 353-363, Oct. 2000.

Aplicação de conceitos reológicos na tecnologia dos concretos de alto desempenho 
uma vasta experiência geral, mas sim em uma experiência bastante específica sobre componentes e proporções de misturas de concreto.

Devido às limitações óbvias da avaliação subjetiva, métodos de ensaio mais objetivos tornaram-se necessários. Além disso, a definição de trabalhabilidade, a natureza composta desta propriedade e a sua dependência do tipo de construção e dos métodos de lançamento, adensamento e acabamento são as razões pelas quais nenhum método de ensaio único pode ser projetado para medir essa propriedade.

Muitos métodos de ensaio foram desenvolvidos para medir a trabalhabilidade do concreto no estado fresco. Entre eles estão: o ensaio de abatimento de tronco de cone (NBR NM 67/98), a mesa de consistência (NBR 7215/96) ${ }^{[4.6]}$, o fator de compactação ( $\mathrm{ACl}$ Standard 211.3) ${ }^{[4.7]}$, o consistômetro de Ve-Be (DNER-ME 094/94) e o ensaio de penetração Kelly ball (ASTM C 360/92) ${ }^{[4.8]}$. Embora esses métodos de ensaio sejam úteis como ferramentas para o controle de qualidade do concreto, eles são, em grande parte, medidas qualitativas baseadas em escalas definidas arbitrariamente (SAAK, JENNINGS \& SHAH, 2004).

Além disso, praticamente todos esses métodos dependem da consideração implícita de que o número de constantes no conjunto de variáveis é apenas um, de maneira que a trabalhabilidade possa ser expressa em termos de um valor unitário. Para Tattersall e Banfill (1983), é óbvio que os resultados obtidos a partir desses ensaios não satisfazem nenhuma das condições estabelecidas para a definição de trabalhabilidade, isto é, os resultados obtidos são bastante dependentes do equipamento utilizado e os ensaios são capazes de considerar dois concretos idênticos mesmo quando eles se comportam de maneiras diferentes em outras circunstâncias.

A maioria das normas nacionais especifica vários métodos de ensaio diferentes para a avaliação da trabalhabilidade e a razão para isso é que nenhum deles é capaz de abranger a grande variação de trabalhabilidade utilizada na prática. Os resultados obtidos a partir de ensaios empíricos devem ser citados quantitativamente, mas com referência ao ensaio. Tais ensaios não medem a trabalhabilidade e é um engano citar os resultados como se eles a medissem (TATTERSALL, 1991b).

\footnotetext{
[4.6] ASSOCIAÇÃO BRASILEIRA DE NORMAS TÉCNICAS. NBR 7215 - Cimento Portland - Determinação da resistência à compressão.1996.

${ }^{[4.7]}$ AMERICAN CONCRETE INSTITUTE. Standard practice for selecting proportions for normal, heavy weight and mass concrete: reported by ACI Committee 211. In: _. ACI Manual of Concrete Practice. Detroit, 1991. v.2.

${ }^{[4.8]}$ AMERICAN SOCIETY FOR TESTING AND MATERIALS. Standard test method for ball penetration in freshly mixed hydraulic cement concrete. ASTM C 360. In: Annual Book of ASTM Standards. Philadelphia, 1992
} 
Como os vários ensaios de trabalhabilidade avaliam tal propriedade em escalas diferentes, não existe qualquer correlação entre os resultados obtidos. Essas correlações dependem de fatores como a forma dos agregados, a quantidade de areia e a presença de ar incorporado.

Estabilidade, mobilidade e compactabilidade são três componentes separadamente distinguíveis do que é comumente chamado de trabalhabilidade. $A$ trabalhabilidade do CAD é avaliada principalmente pelo ensaio de abatimento de tronco de cone, que é uma medida da estabilidade ou da coesão da mistura sob condições estáticas de ensaio e cuja análise de resultados não passa de uma avaliação qualitativa [JOHNSTON (1990); SAAK, JENNINGS \& SHAH (2004)]. Ele assume pouca relevância com relação à estabilidade ou com a compactabilidade, especialmente sob condições dinâmicas (vibração) de lançamento frequentemente empregadas na prática e, óbvio, isso é inútil para misturas extremamente secas ou extremamente fluidas.

A validade desse ensaio é recomendada para concretos com abatimentos variando entre $25 \mathrm{~mm}$ e $175 \mathrm{~mm}$, o que corresponde a consistências variando entre os estágios de baixa e média plasticidade; dessa maneira, esse método de ensaio não parece caracterizar corretamente a trabalhabilidade dos CAD com alta capacidade de escoamento, uma vez que seus abatimentos geralmente são maiores que $200 \mathrm{~mm}$. Além disso, sabe-se que, na prática, concretos com mesmo abatimento ou mesmo escoamento poderão apresentar diferentes trabalhabilidades (YEN et al., 1999). Assim, para avaliar as propriedades reológicas do concreto baseado apenas nesse ensaio, é extremamente difícil, se não impossível, compreender tais propriedades usando descrições qualitativas, fazendo com que os resultados sejam mal interpretados.

Para que avanços sejam feitos na compreensão e no controle da trabalhabilidade do concreto fresco, procedimentos de ensaio e normas industriais devem ser direcionados para bases quantitativas mais fundamentais. Com isso, nos últimos anos, a demanda pela estimativa da trabalhabilidade do concreto fresco em termos de constantes reológicas no lugar de valores obtidos a partir de ensaios empíricos vem aumentando bastante.

Muitos pesquisadores acreditam que essa estimativa promoverá tanto a sistematização quanto a automatização da construção das estruturas de concreto. Contudo, existem problemas associados a esse tipo de construção que ainda precisam ser resolvidos, tais como a designação de um método para o cálculo das proporções dos materiais constituintes que irão compor uma mistura com as 
constantes reológicas predeterminadas. Como uma tentativa para solucionar esse problema, é necessário considerar as argamassas e os concretos como suspensões altamente concentradas e suas constantes reológicas em termos da concentração das partículas suspensas e das propriedades dessas partículas e da matriz (NISHIBAYASHI et al., 1996).

Qualquer concreto projetado para utilização em campo ou para a indústria de pré-moldados deverá ter uma trabalhabilidade no exato momento em que ele for moldado, o que corresponde a vários minutos após a mistura (às vezes, várias horas). Vários fenômenos fazem com que a trabalhabilidade evolua logo que o cimento entra em contato com a água.

Dessa maneira, é importante fornecer ensaios capazes de avaliar a trabalhabilidade do concreto fresco por um determinado período de tempo. Antigamente, o único jeito era produzir um lote com pelo menos 50 litros de material, amostrá-la de tempos em tempos e, então, desenvolver sucessivos ensaios. Este processo necessitava de uma grande quantidade de materiais, tempo e força de trabalho. Sempre houve discussão se o concreto deveria ser continuamente misturado ou não e se os resultados poderiam ser significativamente influenciados pela evaporação, uma vez que a superfície livre do lote era relativamente grande se comparada ao seu volume. Finalmente, era difícil dizer qual era a causa da perda de trabalhabilidade, pois a medida da consistência era feita através de um ensaio simples, fornecendo apenas um valor (De LARRARD et al., 1996). Com o desenvolvimento de reômetros, a avaliação da trabalhabilidade em função do tempo foi muito simplificada. Apenas uma pequena amostra precisa ser preparada, a qual é colocada no equipamento para sucessivos ensaios sob cisalhamento. O reômetro permite ao usuário não apenas detectar perdas de trabalhabilidade, mas também conhecer a origem do fenômeno.

Segundo De Larrard et al. (1996), a finalidade de se utilizar um reômetro não é apenas medir o maior número de parâmetros possíveis, mas avaliar quantidades físicas que possam estar cientificamente relacionadas aos vários estágios de utilização do concreto, como por exemplo:

- a tensão de escoamento, que indica a tensão mínima que deve ser aplicada para deformar o concreto fresco logo após o cisalhamento. O ângulo de equilíbrio do material poderá ser calculado a partir da tensão de escoamento. Também, a tensão de escoamento está diretamente relacionada com o ensaio de abatimento de tronco de cone; 
- a viscosidade plástica, que expressa o acréscimo de tensão necessário para fornecer uma determinada taxa de cisalhamento. A taxa na qual o concreto se abate no ensaio de abatimento de tronco de cone é uma ilustração direta da viscosidade plástica. Na prática, a viscosidade plástica pode desempenhar um papel importante: ela controla a taxa de bombeamento e a facilidade de acabamento da superfície do concreto.

A especificação dos níveis de trabalhabilidade em termos de valores médios obtidos através de ensaios padrões só pode ser feita com base experimental. A avaliação da trabalhabilidade em termos dos parâmetros reológicos, tensão de escoamento e viscosidade plástica, pode estabelecer uma ferramenta poderosa para o controle da produção do concreto. Essa avaliação não possui apenas o papel de dizer se o resultado obtido no ensaio é adequado ou não - fato que os ensaios padrões existentes são incapazes de fazer - mas ela também pode indicar quais são os fatores causadores da falha no ensaio para se alcançar a trabalhabilidade desejada (TATTERSALL, 1991c).

Assim, os parâmetros reológicos também devem ser determinados a partir de situações práticas, mas de uma maneira sistemática. Além disso, quando os valores desejados e as variações permitidas são conhecidos, a situação não se torna confusa pela necessidade de se usar todos os valores para a precisão do ensaio, como acontece nos ensaios padrões, pois um erro experimental pode ser calculado para cada determinação (TATTERSALL, 1991b).

\subsection{Fatores que influenciam a trabalhabilidade}

A trabalhabilidade de um concreto é influenciada por diversos fatores, como:

- o tempo decorrido desde a mistura;

- as propriedades e as características dos cimentos e dos agregados;

- a presença de qualquer adição mineral em substituição ao cimento;

- a presença de qualquer adição química;

- as proporções relativas dos materiais constituintes da mistura.

Assim, existem diversos fatores a serem considerados e a situação é posteriormente complicada pelo fato de que existem interações entre eles, isto é, os fatores não são independentes um dos outros em seus efeitos. Do ponto de vista reológico, Aïtcin (2000) considera a trabalhabilidade dependente essencialmente dos fatores relacionados ao esqueleto dos agregados e da quantidade e fluidez da pasta usada quando da mistura de concreto. 


\subsubsection{Tempo de manipulação das misturas}

O concreto fresco pode ser manipulado, lançado e adensado durante o período de indução da hidratação do cimento. Depois de completado esse período, os parâmetros relacionados com a resistência mecânica e durabilidade começam a ser evidenciados.

No entanto, a trabalhabilidade diminui com o tempo e, consideravelmente, logo nos primeiros minutos após a mistura. Mudanças nas propriedades reológicas com o tempo podem ocorrer devido a fatores físicos (coagulação e reestruturação da microestrutura) e a fatores químicos (hidratação do cimento e redução da quantidade de água livre). Segundo Tattersall (1991b), a redução da trabalhabilidade com o tempo acontece devido à ocorrência de alguma hidratação adicional, à qualquer perda de água por evaporação e à absorção de água da matriz por qualquer partícula de agregado que não tenha sido completamente saturada no momento da mistura. Assim, parâmetros-chave influenciando as mudanças com o tempo incluem a temperatura, a composição da mistura e a interação entre o aglomerante e o SP utilizado (PETIT, KHAYAT \& WIRQUIN, 2006).

Portanto, o tempo no qual o ensaio é desenvolvido torna-se muito importante em relação ao tempo no qual a mistura foi executada e o tempo no qual ela será utilizada.

A perda da trabalhabilidade com o tempo, geralmente relacionada à perda de abatimento, pode ser muito importante na prática, principalmente se a distância entre a usina de concreto e a obra for considerável ou, ainda, se algum atraso imprevisto ocorrer. No caso de regiões onde a temperatura ambiente é alta, o problema da perda da trabalhabilidade é particularmente agudo (TATTERSALL, 1991b).

\subsubsection{Propriedades dos componentes da mistura}

Os componentes de uma mistura de concreto podem variar tanto com relação à quantidade quanto com relação à qualidade de um lote de concreto para outro, resultando em uma conseqüente variação nas propriedades do material nos estados fresco e endurecido. Na figura 4.1 são apresentados os fatores que, para uma determinada dosagem, podem variar e influenciar as propriedades de um concreto. 


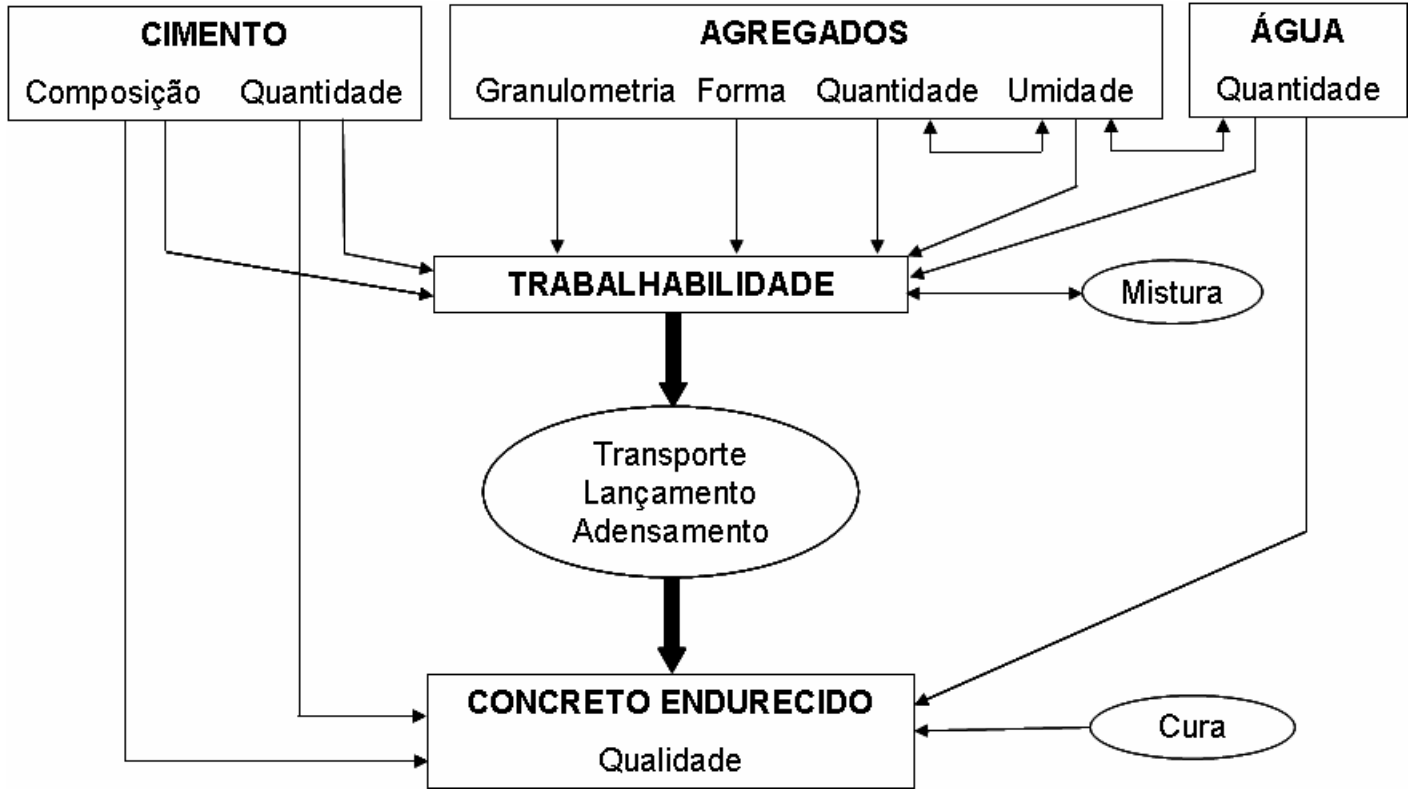

Figura 4.1 - Fatores que influenciam as propriedades de um concreto (TATTERSALL \& BANFILL, 1983).

A trabalhabilidade é influenciada principalmente pelas quantidades de pasta $\mathrm{e}$ de agregados, pela plasticidade da pasta de cimento e pelas características dos agregados (CHIDIAC et al., 2000).

Segundo Aïtcin e Neville (2003), uma maneira de se garantir a trabalhabilidade adequada para uma mistura é fornecer uma água de trabalhabilidade, isto é, disponibilizar grandes espaços entre as partículas de cimento não-hidratadas. Parte da água em um concreto fresco é consumida para o preenchimento da porosidade do esqueleto granular (aglomerantes e agregados); somente a outra parte poderá contribuir com a trabalhabilidade da mistura. Melhorando o empacotamento do esqueleto granular, menos água será utilizada para uma mesma trabalhabilidade ou uma melhor trabalhabilidade será obtida para um teor de água constante (SEDRAN et al., 1996). Assim, a diferença entre o teor de água e a demanda de água da mistura é considerada muito importante para a trabalhabilidade do concreto (HANKE, 1991).

A quantidade total de agregados presente no traço, as proporções relativas de agregado miúdo e graúdo, a respectiva granulometria, a forma e a textura superficial das partículas são os principais fatores relacionados aos agregados que afetam a trabalhabilidade do concreto, seja do tipo convencional ou de alto desempenho (AITCIN, 2000).

O concreto geralmente é idealizado por um modelo de esferas. Nele, todos os componentes sólidos se aproximam de esferas envolvidas por camadas de água. Dessa maneira, a trabalhabilidade dessas misturas depende da mobilidade de 
todas as partículas sólidas assim como do teor de água. Considerando a distribuição granulométrica das partículas finas e a granulometria dos agregados, o índice de forma tem uma influência sobre a mobilidade dos sólidos (HANKE, 1991).

De uma maneira geral, pode-se dizer que quanto mais esféricas forem as partículas de um agregado, mais trabalhável será a mistura na qual esse agregado é incorporado, considerando-se constante as demais características e materiais. Esse efeito deve-se a duas propriedades da esfera: o efeito de rolamento e a área superficial. O chamado efeito de rolamento evidencia a facilidade com que esferas acumuladas realizam movimentos relativos umas às outras quando comparado às partículas de formas irregulares, até mesmo no estado seco. Quanto à área superficial, a esfera é a forma geométrica que possui a menor área superficial, considerando-se a mesma massa. Assim, quanto mais esféricas forem as partículas de um agregado, menos argamassa será necessária para revestí-las e preencher os vazios entre elas, de maneira que mais argamassa ficará disponível para contribuir com a fluidez da mistura.

O tamanho das partículas de um agregado apresenta uma óbvia e considerável influência sobre a trabalhabilidade do concreto. Uma descrição adequada do tamanho das partículas é dada por sua distribuição granulométrica, que mostra a proporção de partículas dentro das possíveis variações de tamanho.

O efeito da classificação deve ser considerado em termos de área específica. Para uma dada partícula, a área específica é inversamente proporcional à sua dimensão linear, de maneira que quanto mais finas as partículas em um pó, maior a área específica para uma determinada massa. No concreto, isso significa que a área superficial a ser revestida e lubrificada pelas partículas mais finas e pela pasta de cimento será maior e, com isso, quanto mais finas as partículas do agregado miúdo, menos trabalhável será o concreto, considerando-se constante as demais características e materiais [TATTERSALL \& BANFILL (1983); TATTERSALL (1991b)]. Isso também sugere que mudanças na proporção do material retido nas peneiras de aberturas menores terão um maior efeito sobre a trabalhabilidade da mistura do que mudanças semelhantes em proporções retidas nas peneiras de aberturas maiores.

Partículas menores têm que estar presentes na mistura de concreto em quantidade suficiente para preencher os vazios entre as partículas maiores e uma escolha inadequada da distribuição granulométrica global pode produzir vazios ou segregação. Dentro da variação normal das misturas, é esperado que um aumento no teor de partículas menores reduzirá a trabalhabilidade, mas na prática, tem-se 
observado que existe um teor ótimo dessas partículas que permite alcançar uma máxima trabalhabilidade, tal que um aumento ou uma redução dessa quantidade diminui a trabalhabilidade (TATTERSALL \& BANFILL, 1983).

Além do efeito da classificação, existe o efeito da dimensão máxima característica do agregado graúdo. Em um estudo desenvolvido por Lydon (1972) apud Tattersall (1991b) ${ }^{[4.9]}$ - onde foram produzidos concretos com resistências e trabalhabilidades semelhantes usando agregados com partículas de formas semelhantes, mas com dimensões máximas características diferentes - o autor observou que à medida que a dimensão máxima do agregado diminuía, era necessário adicionar mais água à mistura a fim de se manter a mesma trabalhabilidade e, conseqüentemente, adicionar mais cimento para se manter a resistência desejada.

Do ponto de vista prático, as propriedades do cimento têm menor influência sobre a trabalhabilidade do concreto do que as propriedades do agregado, mas elas deverão ser consideradas especialmente no caso de misturas ricas [TATTERSALL \& BANFILL (1983); TATTERSALL (1991b)]. Além disso, a mudança no comportamento do concreto fresco ao longo do tempo deve-se especialmente ao cimento, que constitui o principal componente reativo da mistura (HANKE, 1991). Assim, existem diversos parâmetros durante o processo de produção e envelhecimento do cimento que podem exercer efeitos importantes sobre a reologia do concreto fresco. Dependendo desses parâmetros, o resultado pode ser o endurecimento do concreto e este fenômeno está diretamente relacionado com um comportamento reológico anormal da pasta de cimento (CHAPPUIS, 1991).

As pesquisas mais recentes indicam que os fatores mais importantes na composição do cimento que interferem na trabalhabilidade do concreto são o teor de $\mathrm{C}_{3} \mathrm{~A}$ e a quantidade e condição dos sulfatos, além da proporção de partículas com tamanhos entre $10 \mu \mathrm{m}$ e $30 \mu \mathrm{m}$ (TATTERSALL, 1991b). De acordo com Aïtcin e Neville (2003), para misturas com baixas relações água/aglomerante, como o $C A D$, deve-se dar preferência para a utilização de cimentos que contêm baixos teores de $\mathrm{C}_{3} \mathrm{~A}$ e $\mathrm{C}_{3} \mathrm{~S}$.

\footnotetext{
[4.9] LYDON, F.D. Concrete mix design. London: Applied Science Publishers, 1972. 148p. apud TATTERSALL, G.H. Workability and quality control of concrete. London: E \& FN SPON, 1991b. 262p.
} 


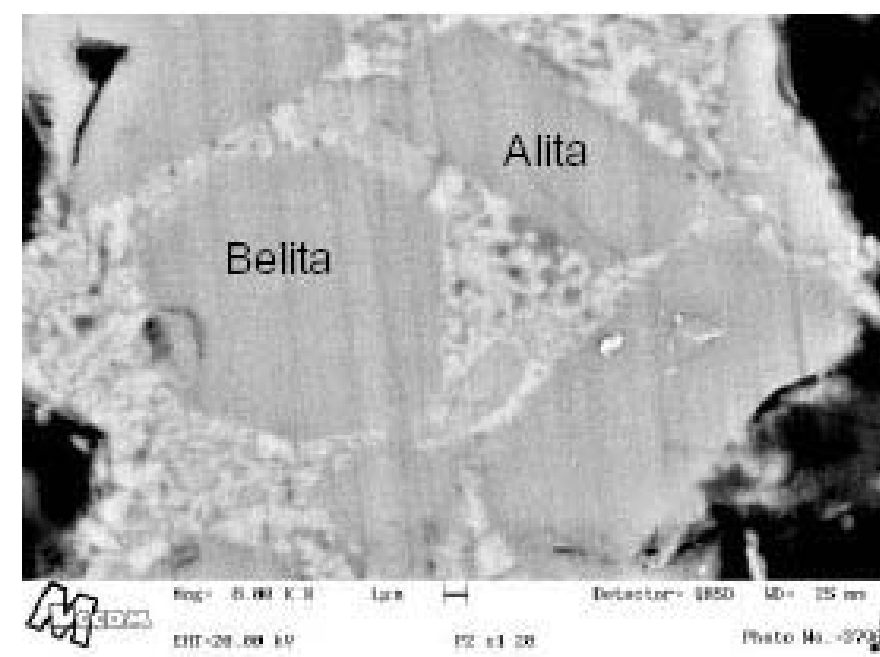

\author{
Fase intersticial: \\ $\mathrm{C}_{3} \mathrm{~A}$ - pontos claros \\ $\mathrm{C}_{4} \mathrm{AF}$ - pontos brilhantes
}

Figura 4.2 - Microscopia da seção polida de um nódulo de clínquer onde: Alita $=C_{3} S$; Belita $=C_{2} S(M E L O, 2000)$.

Embora pareça racional pensar que cimentos mais finos, com maiores reatividades, estejam associados a menores trabalhabilidades, existe evidência do contrário. Experimentos feitos em laboratórios de pesquisa de indústrias produtoras de cimento mostraram que concretos produzidos com cimento Portland de alta resistência inicial foram mais trabalháveis que os produzidos com cimento Portland comum, apesar do ensaio de consistência padrão em pastas de cimento indicar que a exigência de água do primeiro cimento é maior que a do segundo (TATTERSALL, 1991b).

Devido a uma nova geração de aditivos químicos tem sido possível ajustar a trabalhabilidade de um concreto em termos de seu comportamento do escoamento e de sua plasticidade, assim como de sua coesão e viscosidade. A trabalhabilidade desejada é obtida tanto pela ação desse novo aditivo quanto pelo completo envolvimento dos agregados pela pasta, que consiste de uma mistura de pequenos grãos e água (VIEIRA et al., 2005).

Em termos de reologia, os SP são considerados interferências positivas nas propriedades do concreto no estado fresco. Eles são utilizados para aumentar a trabalhabilidade desse material de tal forma que se obtenham misturas bastante fluidas, com tensões de escoamento tão reduzidas que pouca ou nenhuma vibração se torna necessária.

A trabalhabilidade de um concreto fresco, bem como sua perda ao longo do tempo dependem, até certo ponto, das características do SP usado. O comportamento apresentado pela mistura sob determinadas condições - seja do tipo binghamiano, tixotrópico, dilatante ou newtoniano - dependerá da presença e da concentração das adições, da taxa de cisalhamento, da relação 
água/aglomerante e do tempo decorrido após a adição da água. A eficiência de um SP é influenciada pelo tempo de mistura e seus efeitos não dependem apenas da quantidade de material adicionado, pois outros fatores - como a composição da mistura, a variação na composição e as propriedades do cimento, o procedimento de mistura e o equipamento utilizado na produção da mistura, dentre outros (AÏTCIN, JOLICOEUR \& MacGREGOR, 1994) - podem interferir nas situações em que o SP é adsorvido pelas partículas de cimento. Assim, as taxas de variação dos parâmetros reológicos com o tempo dependem tanto do tipo de aditivo quanto do tipo de cimento empregados na mistura.

Diferentes SP dão diferentes tempos de trabalhabilidade para diferentes combinações de aglomerantes e uma maneira de melhorar esses tempos é selecionar um aditivo compatível com uma determinada combinação de aglomerantes. Em estudos feitos por Penttala (1990), tempos de trabalhabilidade mais longos, variando entre 45 e 50 minutos, foram alcançados pela correta seleção de SP compatíveis com a combinação de aglomerantes dos CAD estudados.

Se a trabalhabilidade de materiais à base de cimento está relacionada com o efeito dispersante do aditivo e se esse efeito, por sua vez, está relacionado com a taxa de adsorção do polímero e com a taxa de hidratação do cimento com e sem a presença de aditivos, é possível, então, explicar as mudanças na fluidez desses materiais como uma variação tanto do tempo de adição do SP quanto do tempo total de mistura. Considerando que o agrupamento de partículas aumenta com o aumento do tempo de mistura, enquanto o revestimento do polímero se torna desprezível durante o período de indução da hidratação do cimento, observa-se que existe um tempo ótimo para a adição do SP. De acordo com um estudo feito por Chiocchio e Paolini (1985), esse tempo corresponde ao início do período de indução da hidratação do cimento sem a presença de SP e isso dependerá da composição do cimento, da temperatura e do procedimento de mistura.

As propriedades reológicas de pastas de cimento avaliadas por Aiad (2003) foram reduzidas pela adição atrasada de SP, tanto para um pequeno intervalo de tempo (30 minutos), quanto para períodos de tempo mais longos (120 minutos). Segundo o autor, a adição atrasada pode melhorar a fluidez de pastas de cimento devido ao: $\mathrm{C}_{3} \mathrm{~A}$, que é responsável pela redução da fluidez devido à sua rápida e instantânea hidratação, isto é, o teor de $\mathrm{C}_{3} \mathrm{~A}$ é reduzido pela hidratação durante os 10 primeiros minutos; e adsorção de aditivo sobre o $\mathrm{C}_{3} \mathrm{~S}$ e $\mathrm{C}_{3} \mathrm{~A}$ não-hidratado é maior do que os mesmos para as fases hidratadas. Em outras palavras, os pontos 
decisivos das fases aluminato $\left(\mathrm{C}_{3} \mathrm{~A}\right.$ e/ou $\left.\mathrm{C}_{4} \mathrm{AF}\right)$, que são responsáveis pelo consumo do SP, são reduzidos com o decorrer da hidratação. A adição atrasada de SP age como uma barreira de repulsão adicional entre as partículas de cimento, com uma posterior contribuição para a melhoria da fluidez das pastas de cimento.

A presença de SP na mistura de concreto não impede a perda da trabalhabilidade com o tempo e, no caso de concretos com trabalhabilidade muito alta, essa perda poderá ser maior do que a perda considerada aceitável. Na prática, um concreto que contém SP pode apresentar mais variações na trabalhabilidade do que o esperado. Segundo Tattersall (1991b), esse problema pode ser melhorado pelo atraso na adição do SP, pela dosagem repetida ou pela mistura de um aditivo retardador de pega ao SP.

Mantendo-se o volume da concentração de sólidos constante em um concreto, a incorporação de adições minerais melhora o seu desempenho, porém reduz sua trabalhabilidade (FERRARIS, OBLA \& HILL, 2001). A principal razão para essa menor trabalhabilidade deve-se à adição de materiais muito finos que aumentam a demanda de água em função do aumento da área específica.

O efeito benéfico da adição de sílica ativa é observado quando suas minúsculas partículas esféricas estão bem dispersas no sistema água-cimento, o que promove o deslocamento das moléculas de água vizinhas aos grãos de cimento. Com isso, as moléculas de água presas entre as partículas de cimento floculadas podem ser liberadas e, assim, contribuir com a fluidificação da mistura [BACHE (1981) apud AÏTCIN (2000)] ${ }^{[4.10]}$.

O uso da sílica ativa facilita o controle do comportamento reológico do concreto fresco: o controle da reologia de qualquer sistema torna-se mais fácil quando se substitui uma parte do cimento por um material cimentício suplementar que não contém $\mathrm{C}_{3} \mathrm{~S}, \mathrm{C}_{3} \mathrm{~A}$ ou $\mathrm{C}_{4} \mathrm{AF}$, desde que a granulometria e a forma das partículas desse material sejam semelhantes às do cimento (AÏTCIN, 2000). Porém, até agora, somente em casos bastante específicos tem-se defendido o uso de material cimentício suplementar com base exclusivamente em considerações reológicas, o que tende a mudar no futuro.

Geralmente, estruturas de concreto duráveis com altas resistências estão associadas com microestruturas densas, que são bastante dependentes das propriedades reológicas do material fresco. As adições minerais influenciam

[4.10] BACHE, H. H. Densified cement/ultrafine particle-based materials. In: INTERNATIONAL CONFERENCE ON SUPERPLASTICIZERS IN CONCRETE, 2., 1981,Ottawa. Proceedings... Aalborg Denmark: Aalborg Cement Aalborg, 1981. 12p. apud AïTCIN, P. C. Concreto de alto desempenho. Tradução Geraldo G. Serra. São Paulo: PINI, 2000.667p. 
significantemente a reologia dos concretos quando no estado fresco, o que está diretamente relacionado com o desenvolvimento de suas propriedades no estado endurecido (PARK, NOH \& PARK, 2005). A incorporação dessas adições produz uma matriz com fluidez satisfatória no estado fresco e com maior compacidade e resistência no estado endurecido quando comparada às matrizes dos concretos convencionais. Como conseqüência, o CAD apresenta menor permeabilidade e maior integridade mecânica (AGULLÓ et al., 1999). Dessa maneira, a otimização da matriz ou pasta de um concreto se torna uma etapa importante no cálculo de sua composição.

A partir da literatura pode-se concluir que a escolha de uma adição mineral para melhorar a trabalhabilidade de um concreto não é problema insignificante. Atualmente, esta seleção não pode ser predeterminada a partir das características físicas e químicas da adição, mas através de ensaios corretamente planejados (FERRARIS, OBLA \& HILL, 2001).

Park, Noh e Park (2005) estudaram a sílica ativa como uma adição mineral para materiais à base de cimento. Eles verificaram que essa adição afeta a capacidade de escoamento do concreto fresco e observaram uma grande liberação de calor de hidratação, resultando na retração por secagem das estruturas quando no estado endurecido. Assim, como as adições minerais têm suas propriedades particulares, as propriedades reológicas dos materiais à base de cimento devem ser controladas pela dosagem dessas adições.

\subsubsection{Proporções da mistura}

Muitos CAD incorporam aglomerantes que consistem de misturas de cimento, adições minerais, fílers inertes e aditivos. Assim como para o concreto convencional, os constituintes aglomerantes e suas proporções são geralmente escolhidos de acordo com as necessidades do material no estado endurecido (por exemplo, a resistência mecânica) e em endurecimento (por exemplo, o calor de hidratação). Porém, o uso de baixas relações água/aglomerante e de teores relativamente altos de aglomerantes leva à necessidade pela consideração rigorosa das propriedades no estado fresco e torna mais exigente a produção de concretos com trabalhabilidades adequadas (DOMONE \& HSI-WEN, 1997).

Relativo à trabalhabilidade, a demanda de água, incluindo as ligações física e química da água, é uma característica muito importante dos concretos. Do ponto de vista físico, a água é ligada pela tensão de superfície e resistência de absorção. De 
acordo com Hanke (1991), ao utilizar um agregado com superfície úmida, a influência da resistência de absorção passar a ser igual para todos os ensaios e pode ser desconsiderada, enquanto a tensão de superfície depende do diâmetro e da área específica das partículas. Dessa maneira, a demanda de água é influenciada principalmente pela distribuição granulométrica dos materiais. Além disso, os componentes reativos, principalmente o cimento, têm a propriedade de ligar a água do ponto de vista químico.

Os efeitos das mudanças nos teores de cimento, de agregado e de finos estão interligados e a alteração de um deles depende dos outros. Além disso, a relação entre a trabalhabilidade e qualquer uma dessas três variáveis não é necessariamente uniforme, isto é, pode haver um mínimo na curva de dosagem de forma que o aumento no teor de qualquer um deles poderá resultar tanto no aumento quanto na redução da trabalhabilidade do concreto.

A redução da tensão de escoamento é maior à medida que o teor de cimento da mistura é aumentado. A mudança acompanhante na viscosidade plástica varia de um aumento para uma redução no teor de cimento da mistura, porque, quando o concreto com baixo teor de areia e, conseqüentemente, com maior teor de cimento escoa, é o cimento floculado na mistura que separa as partículas de agregado graúdo; se o cimento estiver defloculado, as partículas maiores se aproximam e se tocam, gerando uma maior resistência ao escoamento. Isso aumenta a viscosidade plástica do concreto mesmo quando a viscosidade da pasta de cimento é reduzida. Por outro lado, o concreto com alto teor de areia conta com menos cimento, pois existe areia suficiente para preencher os vazios entre o agregado graúdo, de maneira que a dispersão do cimento não aproxima as partículas de agregado e o efeito na viscosidade plástica do concreto é dominado pela redução da viscosidade plástica da pasta de cimento (TATTERSALL \& BANFILL, 1983).

Apesar de algumas declarações afirmarem, por exemplo, que o efeito da mudança no teor de finos é menor para misturas com altos teores de cimento ou menores relações água/aglomerante, não é possível uma generalização satisfatória dos efeitos das mudanças na composição da mistura sobre a trabalhabilidade, pois o seu comportamento é muito complicado (TATTERSALL, 1991b). Existem interações entre as variáveis, ou seja, o efeito de alterar um dos fatores depende dos outros fatores, de forma que qualquer regra se torna específica para uma mistura em particular.

Visando a tomada de decisão em obras, a influência da variação da proporção entre os materiais constituintes de uma mistura de concreto pode ser 
resumida de acordo com a tabela 4.2. Nela, as informações são apresentadas de maneira bem simplificada, mas fornece uma base satisfatória para a prática das construções (TATTERSALL, 1991b). Pode-se observar que os três primeiros fatores (água, SP e ar incorporado) possuem efeitos semelhantes para todas as misturas, enquanto os outros fatores possuem efeitos cuja intensidade e direção dependem da mistura considerada. Assim, um aumento no teor de água sempre reduz tanto a tensão de escoamento quanto a viscosidade plástica, enquanto um aumento no teor de finos poderá diminuir ou aumentar ambos os parâmetros ou, ainda, aumentar um e reduzir o outro dependendo da mistura considerada (TATTERSALL, 1991c).

Tabela 4.2 - Influência do aumento da proporção dos materiais constituintes da mistura sobre a trabalhabilidade (TATTERSALL, 1991b; 1991c).

\begin{tabular}{c|c|c}
\hline \multirow{2}{*}{$\begin{array}{c}\text { Causa: aumento no } \\
\text { teor de }\end{array}$} & \multicolumn{2}{|c}{ Resultado: mudança na } \\
\cline { 2 - 3 } & Tensão de escoamento & Viscosidade plástica \\
\hline Água & Diminui & Diminui \\
\hline Superplastificante & Diminui & Nenhuma \\
\hline Ar incorporado & Nenhuma & Diminui \\
\hline Finos & Depende da mistura considerada \\
\hline Cimento & \multicolumn{2}{|c}{ Depende da mistura considerada } \\
\hline
\end{tabular}

Do ponto de vista reológico, deve-se considerar também a influência da pasta de cimento. Seu comportamento reológico está essencialmente relacionado com a relação água/aglomerante (AITCIN, 2000). Quanto mais alta for essa relação, mais diluídas em água estarão as partículas finas e, assim, fisicamente, a água desempenha um papel-chave na reologia da pasta de cimento quando a relação água/aglomerante é alta (maior que 0,50). Com uma relação tão alta, as partículas de cimento e de materiais cimentícios suplementares estão tão afastadas uma das outras dentro da pasta de cimento que suas interações durante a hidratação não afetam de modo particular a trabalhabilidade do concreto.

À medida que a relação água/aglomerante diminui e a dosagem de SP aumenta, a situação torna-se cada vez mais complexa em termos reológicos, porque a própria água não desempenha mais o papel-chave de antes. O cimento e as partículas cimentícias interagem fisicamente, o que é influenciado pela sua forma, pela sua granulometria e pela sua reatividade química [AITCIN, JOLICOUER \& MacGREGOR (1994); HUYNH (1996) apud AITCIN (2000) $\left.{ }^{[4.11]}\right]$. Além disso, o SP usado para deflocular as partículas do cimento interage com as partículas em

[4.11] HUYNH, H.T. La compatibilité ciment-superplastifiant dans le bétons à hautes performances - synthèse bibliographique. Bulletin des Laboratoires des Ponts et Chaussés, n. 296, p. 63-73, Nov.-Dec. 1996 apud AITCIN, P.C. Concreto de alto desempenho. Tradução Geraldo G. Serra. São Paulo: PINI, 2000. 667p. 
hidratação, de maneira que um conjunto mais complexo de fatores passa a influenciar a reologia e a trabalhabilidade do CAD.

Naturalmente, quanto mais baixa for a relação água/cimento e/ou a relação água/aglomerante, mais complexa a situação se torna, de tal modo que termos como "pegajoso" e "tixotrópico" são usados para descrever o comportamento de alguns CAD no estado fresco (AITCIN, 2000).

A trabalhabilidade do concreto também depende do teor de argamassa presente na mistura. Em um concreto, o teor de argamassa deve ser o mínimo necessário para preencher os vazios entre o agregado graúdo e ligá-lo de maneira a formar um material resistente quando no estado endurecido (YEN et al., 1999). Porém, um concreto trabalhável requer uma quantidade suficiente de argamassa para preencher os vazios entre os agregados e para lubrificar a superfície dos mesmos durante o seu lançamento. Caso não exista argamassa suficiente, o concreto resultante apresentará uma trabalhabilidade pobre. Quanto maior o teor de argamassa no concreto, maior será seu abatimento e sua extensão de fluxo (slump flow).

A trabalhabilidade de um concreto é resultado das propriedades inerentes de seus constituintes, das proporções da mistura e das interferências física e química entre eles. A maneira mais simples de modelagem deste sistema complexo é considerar o concreto como um material bifásico composto por uma matriz e uma fase sólida ou, ainda, descrito por suas propriedades como um material fluido e um material de friç̧ão (M\$RTSELL, MAAGE \& SMEPLASS, 1996). Este modelo é considerado satisfatório para a maioria dos concretos usados, inclusive o CAD.

Essa idéia é compartilhada por diversos pesquisadores. De acordo com Wallevik (2006), por exemplo, como o concreto consiste de partículas com uma ampla variação de massa, dimensão, forma e textura superficial, a distinção entre matriz e partículas suspensas se torna uma escolha, em contraste com a idéia tradicional de uma suspensão de esferas submergidas em um líquido newtoniano (água).

Assim, o desafio básico é descrever e determinar as propriedades das fases que compõem um concreto de maneira consistente e simples e, posteriormente, modelar o impacto dessas propriedades quando combinando as fases em diferentes proporções da mistura de concreto. 


\subsubsection{Teor de ar incorporado e temperatura}

Quando os SP são usados sem um agente incorporador de ar, poucos vazios são criados no concreto. Porém, uma quantidade correta de ar pode ser facilmente incorporada em concretos compostos com SP quando um aditivo incorporador de ar de boa qualidade é usado (AÏTCIN, JOLICOEUR \& MacGREGOR, 1994).

O teor de ar recomendado para um concreto no estado fresco depende da finalidade para a qual o material será designado, da localização e das condições climáticas. Outros fatores, como o tipo e a qualidade do aditivo, o tempo de mistura, a temperatura, o tipo de agregado (dimensão máxima característica do agregado graúdo) e o tipo e o teor de cimento (riqueza da mistura) também influenciam a quantidade de ar incorporado em um concreto para uma determinada quantidade de aditivo [TATTERSALL \& BANFILL (1983); ZAIN, SAFIUDDIN \& YUSOF (1999)]. Normalmente, o valor utilizado varia entre $3 \%$ e $6 \%$.

Segundo Tattersall e Banfill (1983), os aditivos incorporadores de ar mudam significantemente as propriedades de um concreto. Eles reduzem a resistência à compressão em cerca de $20 \%$ a $30 \%$, aumentam a trabalhabilidade e a coesão da mistura (permitindo uma redução de aproximadamente $5 \%$ no teor de areia) e, ainda, reduzem a densidade do material. Além disso, eles fornecem um aumento de cerca de dez vezes no número de ciclos de gelo/degelo antes da destruição do material.

Teoricamente, os CAD utilizados em ambientes mais quentes não necessitam da incorporação de ar; porém, para melhorar o manuseio, o lançamento e o acabamento do mesmo, sugere-se a incorporação de uma pequena quantidade de ar [AÏTCIN (1997) apud ZAIN, SAFIUDDIN \& YUSOF (1999)] ${ }^{[4.12]}$. Vale ressaltar que a incorporação de ar melhora a trabalhabilidade do concreto, mas, em excesso, pode atrapalhar a capacidade de escoamento do mesmo.

A qualidade do CAD também é função da temperatura. Quanto maior for a temperatura, maior será a evaporação, maior será a perda de água e o teor de ar incorporado e, conseqüentemente, menor será a trabalhabilidade do material. Assim, Aïtcin (1993) apud Zain, Safiuddin e Yusof (1999) ${ }^{[4.13]}$ recomenda que a temperatura do concreto deve ser mantida entre $15^{\circ} \mathrm{C}$ e $25^{\circ} \mathrm{C}$.

[4.12] AïTCIN, P.-C. Sherbrooke mix design method. In: ONE-DAY SHORT COURSE ON CONCRETE TECHNOLOGY AND HIGH PERFORMANCE CONCRETE: PROPERTIES AND DURABILITY, 1997, Kuala Lumpur. Proceedings... apud ZAIN, M.F.M; SAFIUDDIN, M.; YUSOF, K.M. A study on the properties of freshly mixed high performance concrete. Cement and Concrete Research, v. 29, n. 9, p. 1427-1432, Sep. 1999.

${ }^{[4.13]}$ AIITCIN, P.-C. Durable concrete: current practice and future trends. In: V.M. MALHOTRA SYMPOSIUM (ACI SP-144), 1993. Proceedings... p. 85-104 apud ZAIN, M.F.M; SAFIUDDIN, M.; YUSOF, K.M. A study on the 
Em um estudo desenvolvido por Ravina e Soroka (1994), os autores avaliaram a trabalhabilidade de CAD sob temperaturas de $21^{\circ} \mathrm{C}$ e $32^{\circ} \mathrm{C}$. A quantidade de água necessária para conferir o mesmo abatimento para as misturas estudadas foi $4 \mathrm{~kg}$ maior para os concretos produzidos sob maiores temperaturas $\left(32^{\circ} \mathrm{C}\right)$. Eles também verificaram que a taxa de perda de abatimento foi maior a $32^{\circ} \mathrm{C}$ do que a $21^{\circ} \mathrm{C}$, ou seja, ela aumentou com a temperatura. A taxa de hidratação e a taxa de evaporação aumentaram com a temperatura e, conseqüentemente, a taxa de redução da quantidade de água livre da mistura foi acelerada. A redução na quantidade de água livre aumentou $\mathrm{O}$ atrito entre as partículas de cimento e de agregado e ocasionou um correspondente endurecimento da mistura.

As mudanças na temperatura podem influenciar a reologia de materiais à base de cimento por meio de vários mecanismos, tais como a taxa de adsorção do SP. No estudo feito por Petit, Khayat e Wirquin (2006), a eficiência do SP sobre a dispersão das partículas de cimento mostrou-se dependente da temperatura da mistura. Tal temperatura pode ter um efeito marcante sobre a taxa de adsorção desse SP sobre os grãos de cimento, o que em termos é influenciado pela taxa de hidratação do cimento e pela concentração de íons sulfato presente na solução aquosa. Dessa maneira, dependendo da temperatura da mistura, parece existir uma competição entre a adsorção do aditivo e a concentração de íons sulfato na solução. O primeiro pode promover a dispersão das partículas de cimento e melhorar a manutenção da fluidez, enquanto o último pode contribuir com a retração da intensidade do efeito estérico do polímero, resultando em um aumento exponencial da tensão de escoamento da mistura.

\subsubsection{Processos práticos}

O sucesso econômico de uma construção de concreto é determinado, acima de tudo, pela racionalização e automatização dos estágios envolvidos no processo de mistura, transporte e lançamento do concreto fresco (BEITZEL, 1994).

Uma das tarefas mais importantes na produção e na entrega de um concreto é garantir que, no momento da entrega, a trabalhabilidade desejada seja alcançada em qualquer situação. Entre outras coisas, as influências decorrem dos

properties of freshly mixed high performance concrete. Cement and Concrete Research, v. 29, n. 9, p. 1427-1432, Sep. 1999. 
constituintes do concreto, da composição da mistura, do processo de mistura, da temperatura do material e do tempo (RESTORFF, 1990).

O custo de lançamento de um concreto é extremamente dependente de sua trabalhabilidade e boas propriedades uniformemente distribuídas na estrutura endurecida só são possíveis com uma fluidez adequada e ausência de segregação. Uma boa dosagem de concreto leva em consideração as quantidades de agregado, de água e do teor de ar incorporado; porém, quase sempre é necessário testar a fluidez em lotes de amostragem, pois ela é muito sensível à fração volumétrica de pasta de cimento presente na mistura (maiores frações podem levar à segregação) (FERRARIS \& GAIDIS, 1992).

Um estudo da relação entre a trabalhabilidade e o processo de mistura de um concreto é importante em três aspectos: consideração das exigências de energia em usinas de concreto; possível aplicação para o controle da produção de concreto; e estudo da eficiência de misturadores específicos (TATTERSALL \& BANFILL, 1983). Para os fabricantes de misturadores essa relação pode ser valiosa no processo de desenvolvimento dos mesmos, mas para o produtor e o usuário de concreto, o interesse está relacionado com a eficiência do misturador que eles possuem e nas possibilidades de introduzí-lo como um meio de controle da produção (TATTERSALL, 1991b). Porém, mesmo quando todo o cuidado necessário é tomado, ainda assim poderá haver uma variação da trabalhabilidade dentro de um lote de concreto considerado.

Geralmente, a influência das diferentes energias de mistura sobre o comportamento reológico de materiais à base de cimento tem que ser estudada em termos qualitativos. De acordo com Yang e Jennings (1995), pesquisas realizadas demonstraram que o escoamento desses materiais é sensível à história do cisalhamento e à intensidade de mistura. Misturas à base de cimento produzidas com misturadores de alta velocidade exibiram tensão de escoamento, viscosidade plástica e quebra estrutural menores do que aqueles produzidos segundo os procedimentos estabelecidos em normas.

Segundo Tadmor e Gogos (1979) apud Yang e Jennings (1995) $)^{[4.14]}$, dois princípios físicos básicos são vigentes em uma operação de mistura: mistura intensiva ou dispersão, que reduz eficientemente o tamanho dos aglomerados de partículas ou das gotículas ligadas pela tensão de superfície; e mistura extensiva ou

[4.14] TADMOR, Z.; GOGOS, C.G. Principles of polymer processing. New York: John Wiley \& Sons, 1979. p. 434438 apud YANG, M.; JENNINGS, H.M. Influences of mixing methods on the microstructure and rheological behavior of cement paste. Advanced Cement Based Materials, v. 2, n. 2, p. 70-78, Mar. 1995. 
combinação, que incorpora fases miscíveis simplesmente pela deformação do fluido, cujo processo é governado pela história de cisalhamento do material.

A escolha de um misturador depende da natureza dos componentes a serem misturados. Em uma mistura ideal de pasta de cimento, o material deve estar isento de aglomerados, cada partícula deve estar envolvida com água e a mistura deve apresentar uma baixa viscosidade. Uma mistura homogênea de materiais à base de cimento pode ser obtida através de um processo de mistura que forneça tensão suficiente para quebrar esses aglomerados.

O grau de uniformidade de um lote de concreto não depende apenas do projeto do misturador empregado na sua produção, mas também do método de incorporação dos vários materiais constituintes da mistura [TATTERSALL \& BANFILL (1983); TATTERSALL (1991b)]. Assim, as propriedades reológicas dos materiais à base de cimento são sensíveis à seqüência e intensidade de mistura, o que pode ser observado tanto sobre sua trabalhabilidade, quanto sobre sua fluidez (AGULLÓ et al., 1999).

A taxa de cisalhamento aplicada durante a mistura pode variar entre $10 \mathrm{~s}^{-1} \mathrm{e}$ $60 \mathrm{~s}^{-1}$ e constituir uma das variáveis que mais interferem nas propriedades reológicas dos materiais à base de cimento. Além disso, como a energia disponível para o equipamento de mistura diminui desde a produção do concreto (misturador da usina) até o local de construção (caminhão-betoneira), a floculação do material aumentará e sua fluidez diminuirá (ROUSSEL, 2006). Estudos realizados em pastas de cimento sob taxas de cisalhamento constantes indicam que a estrutura aglomerada pode ser quebrada à medida que a taxa de cisalhamento é aumentada, mas sob taxas de cisalhamento muito altas, os produtos de hidratação são liberados na fase líquida, resultando em piores propriedades relacionadas ao escoamento (WILLIANS, SAAK \& JENNINGS, 1999).

A maioria das influências importantes sobre a trabalhabilidade do concreto fresco tem sido investigada através de ensaios em laboratório. Os resultados dessas investigações têm dado a impressão de que, em muitos casos, algumas influências são tão evidentes que uma produção de concreto sem problemas não é realmente possível, embora o sucesso da utilização do concreto usinado ter demonstrado o contrário no passado. Isso significa que as influências mais evidentes encontradas por meio dos ensaios de laboratório devem ser compensadas durante a produção na usina. A fim de alcançar o objetivo de seu programa de pesquisa, Restorff (1990) utilizou condições de contorno comparáveis 
entre uma usina de concreto e um laboratório, porém isso não foi possível para o processo de mistura do material.

$\mathrm{Na}$ prática, durante o transporte do concreto fresco em um caminhãobetoneira, a pasta de cimento está submetida à moagem pelos agregados (como em um moinho de bolas). Assim, as propriedades do escoamento e a microestrutura de uma pasta de cimento em campo são bem diferentes das propriedades de uma pasta produzida em laboratório com o auxílio de uma argamassadeira (YANG \& JENNINGS, 1995). Além disso, nenhum dos reômetros disponíveis para ensaios em laboratório é capaz de quebrar completamente o estado de floculação do material após um período de repouso e devolvê-lo ao seu estado de floculação em um misturador, uma vez que a taxa de cisalhamento máxima que eles podem aplicar no material é sempre menor que a taxa de cisalhamento durante o processo de mistura; isso significa que o comportamento reológico observado imediatamente após a mistura não será medido novamente caso a amostra permaneça no reômetro entre as determinações (ROUSSEL, 2006). Assim, como a maioria dos procedimentos de mistura empregados na produção de pastas de cimento em laboratório segue seqüências normalizadas, deve-se tomar cuidado quando aplicar os resultados obtidos em laboratório no campo.

O tempo necessário para se obter uma dispersão uniforme do material granular em uma mistura está relacionado com o diâmetro médio do material considerado [JOHANSSON apud CHOPIN, De LARRARD \& CAZACLIU (2004)] ${ }^{[4.15]}$. Isso implica que a homogeneização do agregado graúdo é obtida mais rapidamente do que a homogeneização da areia ou partículas menores. Assim, como um CAA e um CAD contêm muito mais partículas finas do que um concreto convencional, um maior tempo de mistura torna-se necessário.

Sabe-se que o tempo de mistura de um determinado concreto está ligado aos seus teores real e máximo de sólidos, os quais estão relacionados com a dosagem de um concreto. Como, na prática, o efeito da densidade de empacotamento pode ser controlado conhecendo-se os efeitos de alguns dados da dosagem sobre esse parâmetro, o tempo de mistura pode então ser reduzido pelos seguintes meios: aumentando-se o teor de partículas finas, para uma relação água/aglomerante constante; aumentando-se a quantidade total de água (a resistência à compressão será modificada); a otimização do esqueleto granular levará a um teor máximo de

[4.15] JOHANSSON, A. The relationship between mixing time and type of concrete mixer. In: HANDLINGAR SWEDISH CEMENT AND CONCRETE RESEARCH INSTITUTE. Proceedings... Stockholm apud CHOPIN, D.; De LARRARD, F.; CAZACLIU, B. Why do HPC and SCC require a longer mixing time? Cement and Concrete Research, v. 34, n. 12, p. 2237-2243, Dec. 2004. 
sólidos maior, para um teor total de agregado constante; e a substituição de parte do cimento por sílica ativa terá o mesmo efeito (redução da densidade de empacotamento) (CHOPIN, De LARRARD \& CAZACLIU, 2004). O uso de diferentes formas de sílica (não densificada, densificada ou pré-misturada) também poderá ter um pequeno efeito sobre o tempo de mistura.

A vibração tem um efeito considerável sobre o comportamento do concreto no estado fresco. Assim, o objetivo de se aplicar uma força vibratória no concreto é aumentar sua trabalhabilidade $\mathrm{e}$, durante décadas, isto tem sido uma prática comum em obras para auxiliar nos processos de lançamento e adensamento do material.

Da mesma maneira que a observação em obra indica que o concreto fresco não vibrado possui uma tensão de escoamento, ela também indica que a aplicação da vibração reduz consideravelmente essa tensão ou, pelo menos, até um ponto em que o material possa escoar sob a influência do seu peso próprio (TATTERSALL, 1991a; 1991b).

\subsection{Perda de trabalhabilidade}

A perda de trabalhabilidade é o principal problema na indústria do concreto, pois ela afeta a eficiência de lançamento do material e, conseqüentemente, a qualidade do mesmo. Ela pode ser definida como a perda de fluidez do concreto fresco com o passar do tempo e ocorre quando a água livre de uma mistura é consumida pelas reações de hidratação, por adsorção na superfície dos produtos de hidratação e por evaporação (MEHTA \& MONTEIRO, 1994). A redução da trabalhabilidade é um fenômeno normal em todos os concretos porque resulta do enrijecimento gradual e pega da pasta de cimento hidratada, que está associada à formação de produtos de hidratação (etringita e C-S-H).

Sob condições normais, na primeira meia hora após o contato entre a água e o cimento, a perda de trabalhabilidade é insignificante em função do pequeno volume de produtos de hidratação formados no período (MEHTA \& MONTEIRO, 1994). Na seqüência, o concreto começa a perder sua trabalhabilidade sob uma taxa que é função da hidratação, da temperatura, da composição do cimento e dos aditivos presentes na mistura. Sob elevadas temperaturas, o endurecimento é acelerado e o acréscimo da taxa da perda de trabalhabilidade poderá apresentar sérios problemas. 
Tattersall e Banfill (1983) consideram a perda de trabalhabilidade como um endurecimento que ocorre devido às lentas reações químicas que acontecem durante o período de indução da hidratação do cimento. Como é esperado que os aditivos mudem a natureza da membrana que envolve as partículas de cimento e a composição da solução aquosa, eles também mudarão a taxa de endurecimento, o que é bem evidente no caso da utilização de SP. Essa mudança está relacionada com a finura do cimento e com a reatividade dos constituintes do cimento, especialmente $\circ \mathrm{C}_{3} \mathrm{~A}$ e o sulfato de cálcio, que resultam em uma taxa de perda da trabalhabilidade influenciada principalmente pelas proporções relativas entre esses dois componentes do cimento - devido às diferenças nas taxa de solubilidade do sulfato de cálcio, várias taxas de reação do $\mathrm{C}_{3} \mathrm{~A}$ com os íons sulfato registram o surgimento de perdas de trabalhabilidade variáveis (BONEN \& SARKAR, 1995). De acordo com Penttala (1990), a taxa de perda da trabalhabilidade também pode ser dependente do tipo e da dosagem de SP, da temperatura do concreto e do tipo de cimento.

Como possíveis causas dos problemas da perda de abatimento no concreto fresco, Mehta e Monteiro (1994) apontam: o emprego de um cimento de pega anormal; o tempo extraordinariamente longo de mistura, transporte, lançamento, adensamento e/ou acabamento; e a alta temperatura do concreto devido ao calor de hidratação excessivo e/ou uso de materiais que tenham sido estocados a uma temperatura ambiente muito elevada.

Segundo Ravina e Soroka (1994), o endurecimento do concreto fresco é ocasionado principalmente pela hidratação do cimento e, em alguns casos, a evaporação da água de mistura e a absorção de água pelos agregados poderão constituir causas adicionais. Todos esses efeitos reduzem a quantidade de água livre presente na mistura o que, conseqüentemente, aumenta $\circ$ atrito entre as partículas sólidas, reduzindo a fluidez.

Para Aiad (2003), a perda de trabalhabilidade, dada em termos de perda de abatimento, ocorre devido à formação de alguns hidratos nos primeiros instantes da mistura e à coagulação de partículas de cimento, engrossando a fase líquida e aumentando a viscosidade do material.

Como a etringita necessita de $C_{3} A$ para a sua formação, espera-se que uma maior quantidade desse produto seja obtida em um cimento rico em $\mathrm{C}_{3} \mathrm{~A}$. Porém, a perda de fluidez parece estar mais relacionada com a química da solução dos poros do que com o teor de $\mathrm{C}_{3} \mathrm{~A}$ do cimento. Segundo Bonen e Sarkar (1995), a pega está relacionada com a hidratação do $\mathrm{C}_{3} \mathrm{~S}$ e não com a formação da etringita ou 
com a recristalização da etringita secundária, que forma uma estrutura tridimensional comprimindo as agulhas de etringita que detêm a fluidez.

De acordo com Lim et al. (1999), as principais causas da perda de trabalhabilidade podem ser amplamente divididas em duas partes: solidificação química, produzida pela reação entre a adição química e os componentes do cimento à medida que a hidratação ocorre; e a física, causada pela colisão entre as partículas de cimento. A perda de trabalhabilidade da pasta de cimento que compõe o concreto também poderá resultar de uma redução da capacidade dispersante do SP com o decorrer do tempo.

Aiad, El-Aleem e El-Didamony (2002) consideram a fluidez e a pega do concreto fresco influenciadas pelo tipo e pela adição do aditivo orgânico incorporado à mistura: quanto menor a quantidade de aditivo adsorvido pelas partículas de cimento, maior o escoamento da mistura. Os pesquisadores observaram que o abatimento e a manutenção desse parâmetro estão relacionados com a quantidade de SP "livre" ou em excesso disponível na solução intersticial da pasta de cimento fresca. Além disso, parece existir uma relação inversa entre a quantidade de SP adsorvido e a taxa de perda de trabalhabilidade, relacionada com a reologia do material.

O efeito dispersante do SP pode ser de curta duração e resultar em uma rápida perda de trabalhabilidade dependendo da combinação de um par cimentoSP em particular. Um aumento na dosagem desse aditivo poderá atenuar esse problema; porém, certamente resultaria em efeitos secundários como a exsudação, o aumento no teor de ar incorporado, o retardamento excessivo da pega e o maior custo (JIANG, KIM \& AïTCIN, 2000).

De acordo com Erdogdu (2005), a perda de trabalhabilidade de um concreto pode ser considerada como a perda de consistência desse material com o tempo e está diretamente relacionada com a redução da água livre na mistura. A duração que decorre no curso das operações de mistura, transporte, lançamento, adensamento e acabamento do concreto é considerada como um dos principais parâmetros que influenciam a perda de trabalhabilidade. A redução da água livre no concreto fresco aumenta à medida que o tempo para a entrega se estende, uma vez que a hidratação do cimento e a evaporação estão diretamente relacionadas com o tempo decorrido (RAVINA \& SOROKA, 1994).

Misturas prolongadas em um caminhão-betoneira aceleram o endurecimento do concreto, de maneira que a taxa de perda de trabalhabilidade e o seu aumento trazem algumas inconveniências, particularmente quando longos períodos de 
transporte estão envolvidos (caso de entregas de concretos usinados) (ERDOGDU, 2005). O aumento da temperatura no interior do tambor do caminhão-betoneira devido à mistura prolongada é outro parâmetro que deve ser considerado com relação à redução da água livre no concreto fresco.

Segundo West (1990), as causas da perda de trabalhabilidade podem ser divididas naquelas que alteram a relação água/cimento final da mistura e naquelas que não alteram tal relação. A água livre, que entra em contato com o cimento na reação inicial e no período da hidratação, não altera a relação água/cimento. Por outro lado, a absorção de água pelos agregados não-saturados diminui a quantidade de água livre, porém, devido ao maior controle existente nas usinas de concreto, esse efeito deve ser relativamente menor. Já a quantidade de água que evapora da mistura pode reduzir a relação água/cimento significativamente, sendo muito influenciada pelas temperaturas do concreto e do ambiente, pela umidade relativa e pelo tempo decorrido antes do seu lançamento. No entanto, a contribuição individual de cada fator sobre a perda total de água livre em um intervalo de tempo específico para uma determinada mistura ainda não está claro e varia bastante de caso para caso.

As manifestações mais visíveis da perda de trabalhabilidade em um concreto incluem a dificuldade de manuseio e manipulação durante o lançamento e o adensamento do material, a redução da resistência mecânica e uma menor durabilidade [AL-GAHTANI, ABBAS \& AL-AMOUDI (1998) apud ERDOGDU $(2005)]^{[4.16]}$. Como resultado dessa perda, o concreto começa a endurecer imediatamente, o que resulta em perdas apreciáveis de suas propriedades reológicas, como a consistência, a trabalhabilidade e a fluidez (ERDOGDU, 2005).

Para a produção do CAD, que é caracterizado por uma baixa relação água/aglomerante e um alto teor de SP, a perda da trabalhabilidade poderá ocorrer mais rapidamente do que nos concretos convencionais. Segundo Nehdi, Mindess e Aïtcin (1998), existem dois aspectos relacionados com esse fenômeno: primeiro, o cimento deve ter uma menor reatividade reológica, isto é, a quantidade de água fixada imediatamente após a mistura deve ser mínima; e segundo, o SP não deve concorrer com o sulfato de cálcio para neutralizar o $\mathrm{C}_{3} \mathrm{~A}$.

Além disso, o procedimento de mistura também tem se mostrado muito importante e, em particular, o tempo para a adição do SP. A quantidade de SP

[4.16] AL-GAHTANI, H.J.; ABBAS, A.G.F.; AL-AMOUDI, O.S.B. Concrete mixture design for hot weather: experimental and statistical analyses. Magazine of Concrete Research, v. 50, p. 95-105. 1998 apud ERDOGDU, S. Effect of retempering with superplasticizer admixtures in slump loss and compressive strength of concrete subjected to prolonged mixing. Cement and Concrete Research, v. 35, n. 5, p. 907-912, May. 2005. 
também é um fator importante, particularmente em combinação com a sílica ativa, que afeta de maneira significativa a superfície total de partículas sólidas em um sistema de partículas (PUNKKI, GOLASZEWSKI \& GJØRV, 1996).

Em um concreto convencional, que não contém qualquer adição química e/ou mineral, as propriedades reológicas são controladas principalmente pela quantidade de água de amassamento, sulfato de cálcio e reatividade do cimento. Assim, os problemas da perda de trabalhabilidade são relativamente raros e acidentais (falsa pega). Porém, em concretos contendo SP e com baixa relação água/aglomerante $(C A D)$, as propriedades reológicas são controladas principalmente pela dosagem desse aditivo e pela interação entre ele e o cimento (JIANG, KIM \& AÏTCIN, 2000). Contanto que os mecanismos de interação cimento-SP não sejam completamente esclarecidos, as propriedades reológicas desses concretos são dificilmente predeterminadas em alguns casos.

Geralmente, as mudanças na trabalhabilidade do concreto, em termos de sua consistência, até o momento de sua utilização são perfeitamente controladas, sendo feitos ajustes adequados para garantir uma trabalhabilidade suficiente para o seu lançamento, adensamento e acabamento. Porém, sob certas condições, a mistura que apresenta uma perda de trabalhabilidade incomum durante a primeira meia hora ou uma hora de idade, pode dificultar ou mesmo impossibilitar todas as operações envolvidas.

Atualmente muitos métodos têm sido sugeridos para controlar a perda de trabalhabilidade das pastas de cimento e dos concretos. Um método seria controlar a fluidez do sistema cimento-água com o decorrer do tempo utilizando a combinação de um aditivo SP com um retentor de fluidez para compensar a perda de trabalhabilidade; um outro método seria manter estável a dispersão da pasta de cimento pela prevenção da solidificação das partículas de cimento através dos efeitos específicos da adsorção e estérico do SP adsorvido na superfície das partículas de cimento (LIM et al., 1999).

Segundo Tattersall e Banfill (1983), o uso de um SP retardador de pega reduz a perda de trabalhabilidade e prolonga o tempo de trabalhabilidade, pois ele atrasa o processo de pega do material (a absorção de água através da membrana gera pressão hidrostática para rompê-la). Existe uma correlação geral entre o efeito retardador dos aditivos e seus efeitos sobre a perda de trabalhabilidade, sujeita a algumas exceções. Sendo assim, os autores apresentam três maneiras de melhorar o problema da perda de trabalhabilidade: a adição atrasada do aditivo; a dosagem repetida de SP; e a mistura de um SP com um retardador de pega. 
Esses métodos também são considerados por Aiad (2003). Segundo o autor, além da adição atrasada do SP e da utilização de um outro tipo de aditivo, a dosagem parcelada do SP e a utilização de materiais cimentícios suplementares também constituem uma boa alternativa para contornar o problema da perda da trabalhabilidade em um concreto. Pelo atraso na adição de aditivos à mistura de concreto, as moléculas de água são rapidamente adsorvidas pelas partículas cimentícias reativas e a envoltória hidratada nesses elementos é formada antecipadamente: o $\mathrm{C}_{3} \mathrm{~S}$ e $\circ \mathrm{C}_{2} \mathrm{~S}$ podem adsorver moléculas de SP suficientes para sua dispersão.

Segundo Penttala (1990), o uso simultâneo de um SP e um retardador de pega tem um efeito bem pequeno sobre o tempo de trabalhabilidade dos CAD. Naturalmente, os tempos de pega desses concretos aumentam, mas o endurecimento da mistura, que comanda o tempo de trabalhabilidade, acontece quase que ao mesmo tempo em que as misturas sem a incorporação de aditivos retardadores.

A perda de trabalhabilidade também pode ser superada pela adição de água extra e/ou aditivo à mistura de concreto logo antes de sua descarga; essa operação é conhecida como redosagem. Uma quantidade de água de redosagem limitada e cuidadosamente considerada pode ser adicionada sem qualquer perda da resistência e essa quantidade varia de uma maneira complexa, dependendo da contribuição particular de fatores que reduzem a relação água/cimento devido à redução global da água livre [SASIADEK \& SLIWINSKI (1990); WEST (1990)].

Apesar do potencial de redosagem com água ser reconhecido há bastante tempo e ser uma prática comum, ele tem sido muito criticado pelos textos de normas, artigos e códigos de prática dentro da engenharia. A redosagem com água só pode ser feita com a permissão do engenheiro e de maneira que a quantidade de água extra adicionada não exceda os limites especificados para a relação água/cimento máxima (AL-KUBAISY \& PALANJIAN, 1990).

Dessa maneira, a redosagem com aditivos é considerada mais vantajosa [SASIADEK \& SLIWINSKI (1990); RAVINA (1995) apud ERDOGDU (2005) ${ }^{[4.17]}$; porém, indiscutivelmente, o uso de aditivos para redosagem necessita de mais atenção com relação a seus possíveis efeitos adversos sobre as propriedades

\footnotetext{
[4.17] RAVINA, D. Slump retention of fly ash concrete with and without chemical admixtures. ACl Concrete International, v.17, p. 25-29. 1995 apud ERDOGDU, S. Effect of retempering with superplasticizer admixtures in slump loss and compressive strength of concrete subjected to prolonged mixing. Cement and Concrete Research, v. 35 , n. 5 , p. $907-912$, May. 2005.
} 
reológicas e características mecânicas do concreto, o que depende da quantidade e do tipo de aditivo usado.

Do ponto de vista prático, usar materiais cimentícios suplementares funciona bem para resolver problemas de grandes perdas de trabalhabilidade, o que vem sendo feito desde o desenvolvimento do CAD (AITCIN, 2000). A única limitação da utilização desses materiais refere-se ao desenvolvimento da resistência inicial e à durabilidade quanto ao gelo/degelo.

Normalmente, a perda da trabalhabilidade é dada em termos de perda de abatimento. Além da perda de abatimento, a mudança na trabalhabilidade é descrita em termos de viscosidade plástica e tensão de escoamento, que expressam a resistência do concreto ao início do escoamento e ao aumento da taxa de escoamento, respectivamente (PUNKKI, GOLASZEWSKI \& GJØRV, 1996).

Para garantir um comportamento reológico estável por um determinado período, uma caracterização adequada da evolução da trabalhabilidade é importante. O processo da perda de trabalhabilidade é geralmente refletido por um aumento da tensão de escoamento (e uma redução correlativa do abatimento); porém, na maioria dos casos, a viscosidade plástica permanece praticamente constante durante o período de ensaio (geralmente menor que 90 minutos) (HU \& De LARRARD, 1996). 



\section{CAPÍTUL口 5 REOLOGIA DO CONCRETO FRESCO}

De uma maneira geral, os concretos são materiais compostos, tendo como principais componentes o cimento, os agregados e a água. Assim, esse material pode ser entendido como uma concentração de partículas sólidas em suspensão (agregados) em um líquido viscoso (pasta de cimento). A pasta de cimento, por sua vez, não se configura como um líquido homogêneo, sendo composta por partículas (grãos de cimento) e um líquido (água). Em uma escala macroscópica, o concreto fresco flui como um líquido (FERRARIS, 1996; 1999).

Termos como trabalhabilidade, consistência, capacidade de escoamento, mobilidade e capacidade de bombeamento têm sido usados para descrever o comportamento do concreto no estado fresco. Porém, esses termos refletem mais pontos de vista pessoais do que precisão científica (WALLEVIK, 2006).

Assim, sendo o concreto um líquido, para se estudar o seu comportamento no estado fresco, nada mais adequado do que buscar os conceitos da reologia, ciência voltada para o estudo da deformação e do escoamento de um fluido sob a influência de tensões.

As propriedades reológicas do concreto no estado fresco são importantes principalmente no período em que o material é lançado nas fôrmas e podem ser determinadas em qualquer momento durante o período de indução da hidratação do cimento (CHAPPUIS, 1991).

Freqüentemente, as propriedades nas primeiras idades de pastas de cimento, argamassas e concretos são definidas como aquelas relacionadas com qualquer parte do período compreendido entre o momento logo após a mistura e o momento em que as propriedades no estado fresco - tal como a trabalhabilidade - começam a ser alteradas para o desenvolvimento da resistência total ou quase total do material (28 dias). De acordo com Domone e Thurairatnam (1991), para a maioria das finalidades, as três partes mais importantes do comportamento desses 
materiais no estado fresco são: a taxa de perda de fluidez ou de trabalhabilidade para o início de pega, que representa o fim da vida útil de uma mistura fresca; o início e a subseqüente taxa de ganho de resistência, quando carregamentos e tensões podem ser aplicados; e o período de movimentação térmica devido aos efeitos do calor de hidratação.

A investigação reológica direta do concreto não é difícil apenas devido à escala envolvida (necessidade de uma grande quantidade de material), mas também porque dispositivos de leitura para tais operações em grande escala nem sempre são muito sofisticados - o equipamento usado para ensaios em campo deve ser relativamente barato, de fácil utilização e suficientemente pequeno - e a falta de reprodução das matérias-primas (especialmente dos agregados) acarreta uma grande dispersão nos resultados. Vale ressaltar também que a dificuldade em se desenvolver ensaios e equipamentos capazes de caracterizar reologicamente um concreto está relacionada ao agregado graúdo que compõe a mistura, pois as distâncias mínimas exigidas entre as superfícies de cisalhamento devem ser iguais a 2 ou 3 vezes a dimensão máxima característica desse agregado [FERRARIS \& GAIDIS (1992); SAAK, JENNINGS \& SHAH (2004)].

Assim, não é muito comum o uso da reologia para se estudar a trabalhabilidade do concreto. Geralmente, o abatimento é o único parâmetro medido e, mesmo em laboratório, os estudos raramente fornecem informações adicionais sobre o comportamento do escoamento desses materiais. Sabe-se que o abatimento está relacionado com a tensão de escoamento, mas nenhuma informação sobre o comportamento sob maiores taxas de cisalhamento é obtida. Além do mais, o ensaio de abatimento de tronco de cone é uma avaliação empírica.

Dessa maneira, uma completa caracterização do comportamento do escoamento do concreto fresco oferece muitas vantagens sobre o ensaio de abatimento de tronco de cone. Como exemplo, Tattersall e Banfill (1983) descobriram uma linearidade da relação entre o torque e a velocidade de rotação utilizando um equipamento descrito como Mk I, que mede a trabalhabilidade em termos de dois parâmetros relacionados com a tensão de escoamento e com a viscosidade plástica do concreto. Isso foi possível porque as taxas de cisalhamento utilizadas foram baixas, assim como as taxas envolvidas nos processos práticos de lançamento do concreto. Essa descoberta foi bastante encorajadora, porque embora a experiência prática já tivesse convincentemente demonstrado que a trabalhabilidade não seria satisfatoriamente representada por um valor único, agora 
apenas dois parâmetros seriam suficientes e o problema prático poderia ser resolvido.

Como a reologia dos materiais à base de cimento está diretamente relacionada com o desenvolvimento do desempenho do concreto, ela é considerada um dos fatores mais importantes para um CAD. Recentemente, uma metodologia quantitativa fundamental foi desenvolvida para avaliar a reologia no estado fluido. Este método introduziu parâmetros reológicos, como a tensão de escoamento e viscosidade plástica, para a quantificação da capacidade de escoamento (PARK, NOH \& PARK, 2005). Pesquisas recentes indicaram que a tensão de escoamento da pasta de cimento mostrou a mesma tendência do abatimento de tronco de cone no concreto e a viscosidade plástica foi associada com o lançamento, bombeamento, acabamento e segregação do material. Assim, com a determinação desses parâmetros reológicos fundamentais, pode-se tirar vantagens do vasto conhecimento sobre a reologia das suspensões (STRUBLE et al., 1998).

De acordo com Banfill (1991), a reologia dos materiais à base de cimento é importante por diversas razões. O controle da qualidade de produção desses materiais pode ser feito simultaneamente à sua utilização, ao invés de esperar por resultados de ensaios realizados no estado endurecido: uma correta definição de sua reologia permite que métodos de ensaio de controle simples, perfeitamente fundamentados e informativos sejam inventados. Uma consideração reológica das condições de utilização pode fornecer informações úteis àquelas envolvidas na dosagem dos concretos. Na prática, a reologia de uma mistura deve estar correta para sua aplicação; caso contrário, o trabalhador fará um trabalho incorreto: provavelmente o material poderá ser alterado pela adição de mais ou menos água, com conseqüentes mudanças no seu desempenho.

Infelizmente, em função da complexa composição do concreto, não existe nenhum método definido para predizer o escoamento do material a partir de seus componentes. Até a determinação dos parâmetros reológicos não é facilmente executada devido à ampla variação do tamanho das partículas encontradas em uma mistura. Então, o escoamento de um determinado concreto é normalmente medido usando-se um dos vários ensaios padrões disponíveis, onde as propriedades de escoamento intrínsecas do material são medidas parcialmente (TATTERSALL, 1991b). 


\subsection{Classificação reológica do concreto fresco}

Apesar das diversas pesquisas que estão sendo desenvolvidas para a definição das propriedades de escoamento do concreto fresco, os métodos de ensaio existentes ainda não determinam propriedades reológicas semelhantes para um mesmo concreto (CHIDIAC et al., 2000). As variações devem-se principalmente às diferenças quanto às técnicas experimentais empregadas e aos equipamentos utilizados. Além disso, a maioria dos métodos de ensaio é geralmente complicada, requer habilidade e não é facilmente realizada em campo.

Todos os ensaios normalizados, bem como quaisquer outros ensaios empíricos, tentam avaliar a trabalhabilidade em termos de quantidade única, seja ela um valor de abatimento, um tempo Ve-Be etc., de maneira que todos eles abrangem a consideração implícita de que o concreto se comporta da maneira mais simples possível, como a água. Porém, a observação mais casual do comportamento desse material mostra que essa suposição não pode ser verdade.

Observa-se que o concreto exige a imposição de uma tensão ou força mínima para que ele inicie seu escoamento, o que indica a existência de uma tensão de escoamento (TATTERSALL \& BANFILL, 1983) e, conseqüentemente, que sua curva de escoamento não passará pela origem. Dessa maneira, o concreto não pode ser caracterizado por uma constante única. Para se descobrir qual a forma da curva de escoamento desse material é necessário desenvolver alguns experimentos nos quais as medidas são feitas para uma série de velocidades de escoamento diferentes (TATTERSALL, 1991b).

A maioria das equações usadas para suspensões concentradas, como o concreto, tenta relacionar a concentração da suspensão com a sua viscosidade ou a tensão de cisalhamento com a taxa de cisalhamento, assumindo, assim, que existe apenas um valor de viscosidade para todo o sistema (FERRARIS, 1996; 1999). As equações que relacionam a concentração com a viscosidade são usadas para descrever o comportamento do escoamento de pastas de cimento, não sendo aplicáveis ao concreto em função da complexidade da suspensão. As equações que relacionam a tensão de cisalhamento com a taxa de cisalhamento, comumente usadas para descrever o comportamento do escoamento do concreto fresco, são apresentadas na tabela 5.1 . 
Tabela 5.1 - Equações que relacionam a tensão e a taxa de cisalhamento para descrever o comportamento do escoamento de concretos no estado fresco (FERRARIS, 1996; 1999).

\begin{tabular}{|c|c|}
\hline Nome do modelo & Equação desenvolvida \\
\hline Newton & $\tau=\mu \dot{\gamma}$ \\
\hline Bingham & $\tau=\tau_{o}+\mu \dot{\gamma}$ \\
\hline Herschel-Bulkley & $\tau=\tau_{o}+K \dot{\gamma}^{n}$ \\
\hline Lei das potências & $\begin{array}{c}\tau=A \dot{\gamma}^{n} \\
n=1 \text {, para fluido newtoniano } \\
n>1, \text { para fluido dilatante } \\
n<1 \text {, para fluido pseudoplástico }\end{array}$ \\
\hline $\begin{array}{l}\text { Vom Berg, } \\
\text { Ostwald-de-Waele }\end{array}$ & $\tau=\tau_{o}+\operatorname{Bsen}^{-1}(\dot{\gamma} / C)$ \\
\hline Robertson-Stiff & $\tau=a(\dot{\gamma}+C)^{b}$ \\
\hline Eyring & $\tau=a \dot{\gamma}+\operatorname{Bsen}^{-1}(\dot{\gamma} / C)$ \\
\hline Atzeni et al. & $\dot{\gamma}=\alpha \tau^{2}+\beta \tau+\delta$ \\
\hline \multicolumn{2}{|c|}{$\begin{array}{l}\text { Obs.: } \begin{aligned} \tau & =\text { tensão de cisalhamento; } \\
& \\
\tau_{o} & =\text { tensão de escoamento; } \\
\mu & =\text { viscosidade; } \\
\dot{\gamma} & =\text { taxa de cisalhamento; } \\
\mathrm{A}, & a, B, b, C, K, \alpha, \beta, \delta=\text { constantes. }\end{aligned}\end{array}$} \\
\hline
\end{tabular}

A reologia do concreto no estado fresco é muito complexa devido à sua composição e às mudanças químicas acompanhantes. Vários pesquisadores já descreveram o concreto fresco como um material não-newtoniano complexo que possui uma tensão de escoamento e uma viscosidade dependente da taxa de cisalhamento, sendo que ambos mudam com o tempo: à medida que o concreto endurece, a tensão de escoamento e a viscosidade plástica aumentam (PETROU et al., 2000a; 2000b).

$\mathrm{Na}$ literatura, devido a uma vasta evidência experimental das propriedades de escoamento do concreto no estado fresco, concluiu-se que o material se comporta como um fluido binghamiano [TATTERSALL \& BANFILL (1983); TATTERSALL (1991b); FERRARIS (1996; 1999)] para o intervalo das taxas de cisalhamento envolvidas no processo prático do material, isto é, o material não apresenta escoamento até que uma tensão em particular seja excedida. Assim, a tensão necessária ao escoamento do material - tensão de cisalhamento $(\tau)$ - é igual à soma da tensão de escoamento $\left(\tau_{\circ}\right)$ e de outro termo proporcional à taxa de cisalhamento $(\dot{\gamma})$ (equação 5.1). A constante de proporcionalidade no segundo termo é denominada viscosidade plástica $(\mu)$ e o seu inverso, fluidez ou mobilidade. 


$$
\tau=\tau_{o}+\mu \dot{\gamma}
$$

Um fluido binghamiano apresenta uma curva de escoamento onde uma linha reta intercepta o eixo tensão de cisalhamento (figura 5.1). O ponto onde ocorre a interseção é denominado tensão de escoamento e corresponde à tensão que deve ser excedida para que o escoamento inicie. Quando submetidos a valores de tensão inferiores à tensão de escoamento, tais fluidos se comportam como sólidos elásticos rígidos (PANDOLFELLI et al., 2000).

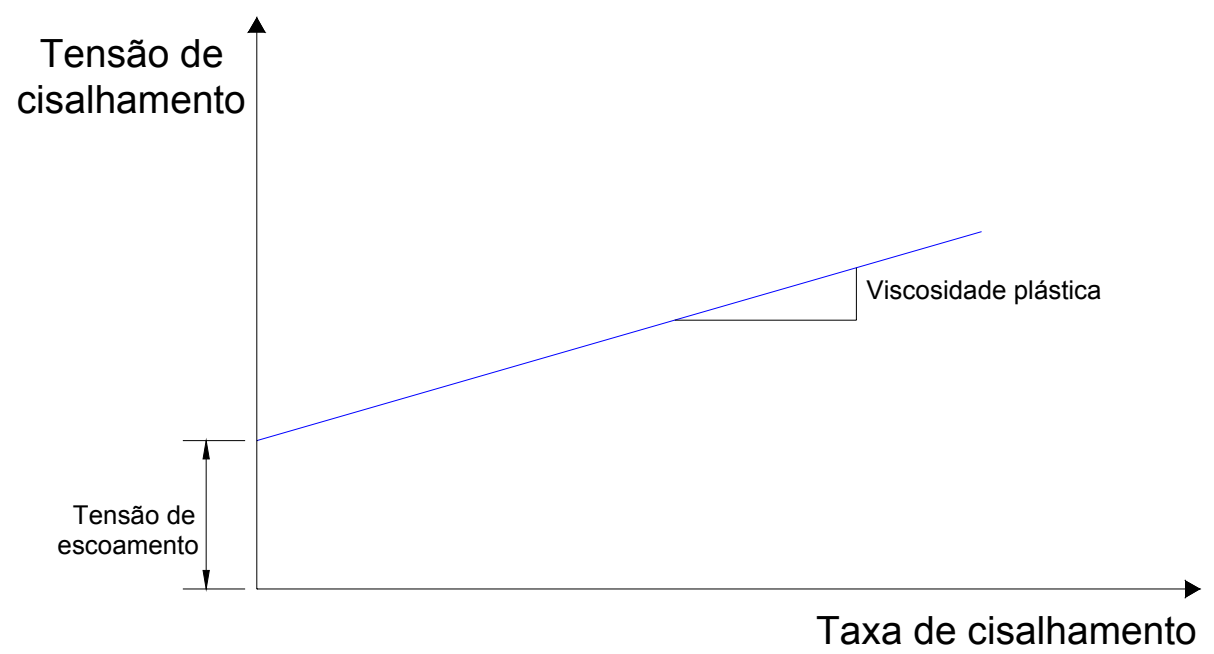

Figura 5.1 - Equação de Bingham para um fluido. Curva de escoamento típica para um fluido binghamiano (FERRARIS, 1996; 1999).

De acordo com Tanner (1988), a explicação para o comportamento de um fluido binghamiano é que o fluido, em repouso, contém uma estrutura tridimensional com rigidez suficiente para resistir qualquer tensão inferior à tensão de escoamento. Caso a tensão de escoamento seja excedida, a estrutura se desintegra e o sistema se comporta como um fluido newtoniano sob uma determinada tensão de cisalhamento. Quando a tensão de cisalhamento que age sobre o sistema for reduzida e atingir valores inferiores à tensão de escoamento, a estrutura tridimensional é recuperada.

Como o principal fator responsável pela formação da estrutura tridimensional é a atração entre as partículas de uma suspensão, todas as variáveis que favorecem a atuação de tais forças também contribuem para o aparecimento da tensão de escoamento em uma suspensão (PANDOLFELLI et al., 2000).

A partir de uma análise reológica dos processos de mistura, transporte, lançamento e adensamento de um concreto, Szwabowski (1991) observou que a razão tensão de cisalhamento/tensão de escoamento, determinante da possibilidade de escoamento, é a primeira condição da trabalhabilidade. Por essa 
razão, o estudo da relação entre a condição da estrutura e a tensão de escoamento do concreto fresco é necessário para o controle de sua trabalhabilidade.

Assim, não existe dúvida de que as propriedades de escoamento do concreto no estado fresco se aproximam de um fluido binghamiano. Sendo assim, o material deve ser avaliado em termos de duas constantes: tensão de escoamento e viscosidade plástica. O primeiro parâmetro reológico está relacionado com o abatimento, enquanto o segundo faz a diferença entre um concreto facilmente trabalhável e um tendo um comportamento "pegajoso", difícil de ser bombeado e apresentando vazios na superfície quando a forma for retirada (De LARRARD \& SEDRAN, 2002).

Segundo Tattersall e Banfill (1983), não se deve esquecer que o modelo binghamiano é de fato um modelo e que não há porque se surpreender caso o comportamento real de um material não se ajuste tão adequadamente a ele. De fato, a equação descreve satisfatoriamente as propriedades de escoamento de muitas suspensões concentradas para taxas de cisalhamento dentro de um limite mais ou menos estabelecido, mas Whorlow (1980) apud Tattersall e Banfill $(1983)^{[5.1]}$ diz que, de acordo com sua experiência, o comportamento real dos materiais se afasta significantemente do modelo em pelo menos um dos seguintes aspectos: as curvas ascendente e descendente do cisalhamento não coincidem; a tensão de escoamento não é bem definida; e a curva de escoamento não é linear, exceto para uma variação bastante limitada da taxa de cisalhamento.

Geralmente, durante o período de indução da hidratação de um cimento, caso essa hidratação não ocorra muito rapidamente, o concreto poderá se parecer com um material tixotrópico (HU \& De LARRARD, 1996). Do ponto de vista prático, um efeito importante da tixotropia do concreto é o grande aumento da tensão de escoamento durante o repouso. A tixotropia é anulada pela aplicação de uma força vibratória, mas é recuperada posterior e rapidamente.

Ainda pode-se observar um comportamento dilatante das misturas de concreto. Segundo Hu e De Larrard (1996), a dilatância observada em um concreto deve ser relacionada principalmente aos materiais constituintes da mistura do que ao método de ensaio utilizado. A dilatância mostrou-se mais evidente em concretos cujo diâmetro máximo característico do agregado graúdo é maior e quando agregados mais angulosos são utilizados na produção dessas misturas. De acordo com esses autores, uma boa maneira de limitar o efeito da dilatância em concretos

[5.1] WHORLOW, R.W. Rheological Techniques. Wiley, Chichester, 1980 apud TATTERSALL, G.H.; BANFILL, P.F.G. The rheology of fresh concrete. London: Pitman, 1983. 347p. 
é aumentar o volume de finos da mistura, ou seja, o volume de partículas com diâmetros menores que $400 \mu \mathrm{m}$.

\subsubsection{Parâmetros reológicos}

A tensão de escoamento é definida como a tensão mínima para iniciar o escoamento de um material (TATTERSALL, 1991b), ou seja, ela corresponde à tensão que deve ser excedida para que o escoamento inicie. Para um modelo binghamiano, a viscosidade plástica é definida como a diferença entre a tensão de cisalhamento e a tensão de escoamento dividida pela taxa de cisalhamento (BS 5168/75 apud TATTERSALL \& BANFILL, 1983) $)^{[5.2]}$ ou, simplesmente, como a constante de proporcionalidade entre a tensão de cisalhamento e a taxa de cisalhamento. Relacionando-as com as aplicações práticas, a tensão de escoamento indica a resistência ao escoamento para baixas velocidades de rotação, enquanto a viscosidade plástica indica como a resistência ao escoamento aumenta com o aumento da velocidade de rotação (CLAISSE, LORIMER \& AL OMARI, 2001).

A tensão de escoamento é uma característica comum do concreto fresco e de materiais granulares secos (como os solos), enquanto a viscosidade plástica tende a relacionar o concreto fresco com corpos viscosos como os óleos ou a água (De LARRARD \& SEDRAN, 2002). Dessa maneira, deve-se considerar que a tensão de escoamento é resultado do atrito intergranular durante o cisalhamento do concreto, enquanto a viscosidade plástica é uma assinatura macroscópica do escoamento da água dentro dos poros no sistema granular.

A viscosidade plástica é governada pela concentração relativa de uma mistura, definida como a razão entre a proporção de materiais sólidos (em volume) e sua densidade de empacotamento (De LARRARD \& SEDRAN, 2002). A contribuição das várias frações de grãos com a viscosidade plástica se dá apenas na extensão em que esses grãos contribuem com a densidade de empacotamento da mistura seca correspondente.

A presença de uma tensão de escoamento nas misturas de concreto não tem sido explicada em termos da microestrutura desse material e apenas recentemente alguns estudos foram realizados nesse sentido [LEI \& STRUBLE (1997) apud

\footnotetext{
[5.2] BRITISH STANDARDS INSTITUTION. British Standard BS 5168 - Glossary of rheological terms. 1975 apud TATTERSALL, G.H.; BANFILL, P.F.G. The rheology of fresh concrete. London: Pitman, 1983. 347p.
} 
PETROU et al. (2000b)] ${ }^{[5.3]}$. Como a concentração de sólidos em um concreto é muito alta e o tamanho e a morfologia desses sólidos podem variar, a tensão de escoamento de um concreto poderá ter origem a partir de três fontes contribuintes: o imbricamento mecânico do agregado graúdo (de forma irregular) que compõe o concreto (FERRARIS \& De LARRARD, 1998a); as forças de atração entre o cimento e outras pequenas partículas que promovem a floculação [LEI \& STRUBLE (1997) apud PETROU et al. (2000b)] ${ }^{[5.4]}$; e o gel coloidal de silicato de cálcio hidratado que se forma ao redor das partículas de cimento como resultado da sua reação de hidratação, bem como outros contribuintes do endurecimento final das misturas à base de cimento [DOUBLE \& HELLAWELL (1977) apud PETROU et al. $(2000 b)]^{[5.5]}$.

Segundo Szwabowski (1991), a tensão de escoamento do concreto fresco, sob uma temperatura constante, depende da condição da estrutura da mistura e seu valor varia dentro de um limite amplo. Para um fator de dispersão da pasta de cimento constante, a tensão de escoamento da mistura depende dos fatores de dispersão do agregado e da mistura de concreto e, mais precisamente, da razão entre os fatores de dispersão da mistura e do agregado. $O$ tipo de influência desses fatores sobre a tensão de escoamento está de acordo com o efeito fenomenológico da capilaridade da mistura e, no caso da não existência de tensões normais, a tensão de escoamento do material depende apenas da coesão dos capilares.

Para Ferraris (1996; 1999), a relevância em se medir as duas constantes reológicas pode ser observada ao comparar os parâmetros reológicos de dois concretos quaisquer. A partir da figura 5.2, verifica-se que dois concretos podem ter um dos parâmetros reológicos idênticos, enquanto o outro pode ser totalmente distinto, o que implica no fato destes materiais apresentarem comportamentos reológicos muito diferentes.

Tattersall (1991c) também ressalta esse fato. Segundo ele, a determinação dos dois parâmetros reológicos permite a diferenciação imediata de concretos que poderiam ser erroneamente considerados idênticos por um dos ensaios padrões existentes, proporcionando uma facilidade que é essencial até mesmo para o desenvolvimento de sistemas de controle mais rudimentares. Além disso, existe uma outra vantagem decorrente do fato de que os vários fatores que compõem uma

\footnotetext{
[5.3] LEI, W.G.; STRUBLE, L.J. Microstructure and flow behavior of fresh cement paste Journal of the American Ceramic Society, v. 80, n. 8, p. 2021-2028. 1997 apud PETROU, M.F. et al. Influence of mortar rheology on aggregate settlement. ACI Materials Journal, v. 97, n. 4, p. 479-485, Jul.-Aug. 2000 b.

[5.4] Op cit. nota de rodapé [5.3].

[5.5] DOUBLE, D.D.; HELLAWELL, A. The solidification of cement. Scientific American, p. 82-90, July. 1977 apud PETROU, M.F. et al. Influence of mortar rheology on aggregate settlement. ACl Materials Journal, v. 97, n. 4, p. 479-485, Jul.-Aug. 2000b.
}

Aplicação de conceitos reológicos na tecnologia dos concretos de alto desempenho 
mistura e que interferem na sua trabalhabilidade influenciam a tensão de escoamento e a viscosidade plástica de maneias diferentes. Assim, um estudo da natureza das mudanças que ocorrem na mistura pode fornecer informações que indicam o fator responsável por elas.
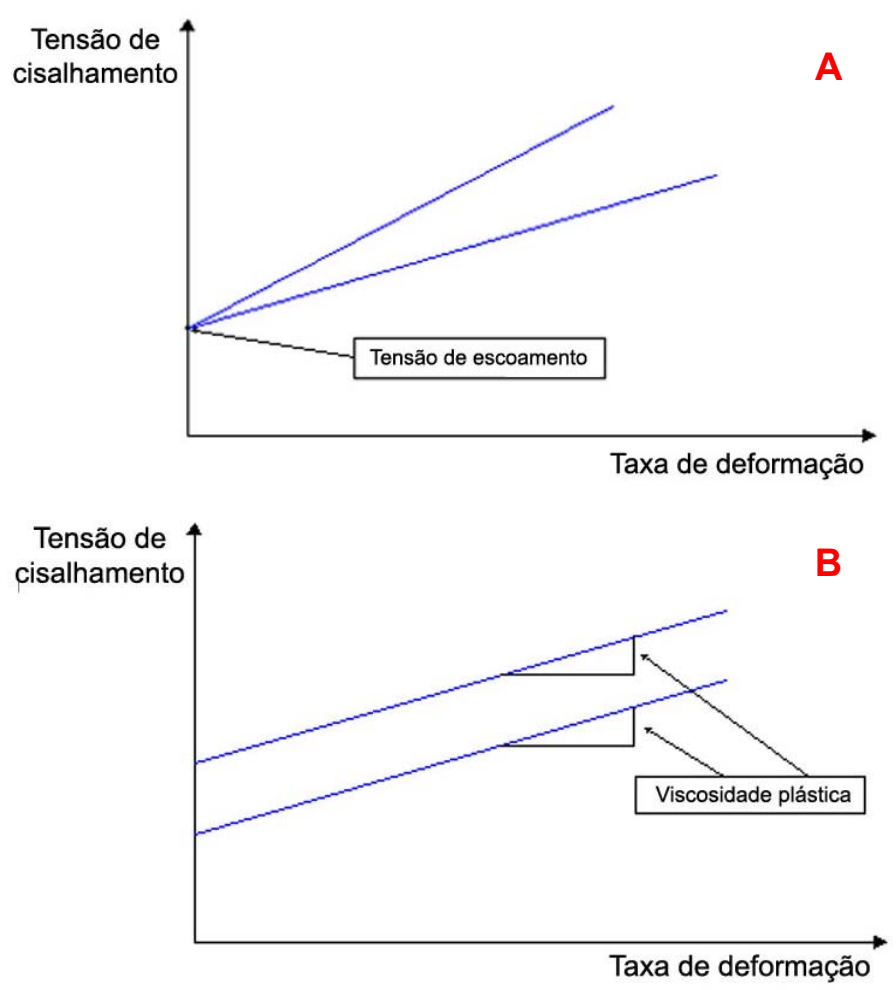

Figura 5.2 - Reologia do concreto: (A) mesma tensão de escoamento e diferentes viscosidades; (B) mesma viscosidade e diferentes tensões de escoamento (FERRARIS, 1996; 1999).

O CAD possui baixa tensão de escoamento e alta viscosidade plástica comparado com o concreto convencional (YEN et al., 1999). Uma menor tensão de escoamento significa que esse material está apto a escoar sob seu peso próprio, enquanto uma maior viscosidade plástica é necessária para evitar a segregação dos agregados.

Dependendo da dosagem de um concreto, um aumento no teor da água de amassamento pode resultar em um aumento de sua trabalhabilidade, com uma redução uniforme tanto da tensão de escoamento quanto da viscosidade plástica da mistura. Para um determinado conjunto de materiais, o teor de água pode ser um parâmetro para o controle da viscosidade do material (SEDRAN et al., 1996), enquanto a tensão de escoamento está diretamente relacionada com o seu abatimento: quanto maior a tensão de escoamento, menor o abatimento.

A influência dos agregados sobre as propriedades reológicas do concreto fresco está relacionada principalmente com a quantidade de agregado que compõe a mistura e com sua a granulometria. Em um estudo desenvolvido por Struble et al. 
(1998), os autores observaram um aumento na tensão de escoamento e na viscosidade plástica - de $50 \mathrm{~Pa}$ e 20 Pa.s (pastas) para $370 \mathrm{~Pa}$ e $90 \mathrm{~Pa} . \mathrm{s}$ (concretos), respectivamente - quando agregados foram incorporados à pasta de cimento para a produção do concreto. Esses acréscimos são maiores à medida que o teor de agregado aumenta; porém, ambos os parâmetros são reduzidos quando a granulometria do agregado se torna mais densa.

Em um outro estudo sobre a influência do agregado sobre a reologia do concreto, Nishibayashi et al. (1996) verificaram que as constantes reológicas aumentaram à medida que a fração volumétrica de agregado graúdo também aumentava e que o tipo de agregado graúdo utilizado interferiu nas constantes reológicas do material. Quanto à influência do agregado miúdo, um estudo desenvolvido por Chidiac et al. (2000) mostrou que o aumento da fração desse agregado teve um efeito direto sobre as propriedades reológicas da mistura, sendo a viscosidade plástica mais influenciada que a tensão de escoamento.

No caso do cimento, a influência mais significativa está relacionada com sua composição química, isto é, com o retardamento do processo de hidratação dos aluminatos causado pelo sulfato de cálcio (BOMBLED, 1980 apud GRESZCZYK \& KUCHARSKA, 1991) ${ }^{[5.6]}$. As grandes diferenças nos comportamentos reológicos de materiais com e sem a adição de gesso estão relacionadas principalmente ao tipo do produto de hidratação e à sua influência sobre a modificação da superfície dos grãos de cimento (forças de interferência intergranular, formação da estrutura de coagulação, imobilização física da água etc.). Dentre os vários produtos de hidratação que podem ser formados, o mais vantajoso para as propriedades reológicas dos materiais à base de cimento é o cristal de etringita (KUCHARSKA, 1991).

Devido às altas taxas de reação da fase aluminato, elas são muito importantes quando da determinação das características reológicas dos materiais à base de cimento nos primeiros estágios da hidratação e também influenciam o desenvolvimento das propriedades reológicas desses materiais. Segundo o estudo feito por Kucharska (1991), o efeito dos produtos de hidratação sobre a tensão de escoamento se mostrou mais evidente do que sobre a viscosidade plástica, sendo essa influência maior na medida em que diminui a disponibilidade de sulfatos para a formação dos cristais de etringita.

[5.6] BOMBLED, J.P. Influence of sulphates on the rheological behaviour of cement pastes and their evolution. In: INTERNATIONAL CONGRESS ON THE CHEMISTRY OF CEMENT, 7., 1980, Paris. Proceedings... Paris: Editions Septima, 1980. Vol. III e IV, p. 164-169 apud GRESZCZYK, S.; KUCHARSKA, L. The influence of chemical composition of cement on the rheological properties. In: RHEOLOGY OF FRESH CEMENT AND CONCRETE, 1990, London. Proceedings... London: E \& FN Spon, 1991. p. 27-36. 
De acordo com os efeitos sobre a reologia do concreto, as adições químicas podem ser divididas em dois grupos: plastificantes e superplastificantes, que possuem um efeito predominante sobre a tensão de escoamento do material; e os agentes incorporadores de ar, cuja influência principal se dá sobre a viscosidade plástica do concreto (TATTERSALL \& BANFILL, 1983).

As adições do primeiro grupo interagem com as partículas de cimento, introduzindo uma camada de adsorção que evita a aproximação entre elas por meio de uma combinação de repulsões eletrostática e estérica, enfraquecendo a estrutura que pode se formar quando a mistura permanece em repouso e, consequentemente, reduzindo a tensão de escoamento do material. Como as partículas estão dispersas, existe uma pequena mudança da viscosidade plástica, porém isso depende da distribuição granulométrica global da mistura. As adições do segundo grupo introduzem bolhas de ar esféricas na mistura de concreto que agem como esferas rolantes para permitir que as partículas maiores escoem mais facilmente sobre as demais partículas. Assim, essas bolhas de ar têm uma maior influência sobre a viscosidade plástica do que sobre a resistência da estrutura formada quando o material é deixado em repouso.

Embora existam algumas exceções, a adição de SP às pastas de cimento e aos concretos possui duas conseqüências principais: uma redução significativa da tensão de escoamento e um pequeno ou nenhum efeito sobre a viscosidade plástica, atribuídas à defloculação das partículas de cimento [ASAGA \& ROY (1980); TATTERSALL (1991b); PETROU et al. (2000b)]. Assim, como o efeito principal da dispersão pela ação do SP se dá sobre a tensão de escoamento, esse efeito é observado por um maior aumento desse parâmetro reológico com o tempo quando comparado com a viscosidade plástica (TATTERSALL \& BANFILL, 1983).

Do ponto de vista da reologia, a sílica ativa produz efeitos intensos sobre a trabalhabilidade dos concretos a que é incorporada. Quando a sílica é incorporada à mistura, uma maior quantidade de superfícies sólidas é introduzida. Como a sílica possui partículas muito pequenas e, consequentemente, uma área superficial muito alta, suas partículas são muito reativas quimicamente e adsorvem moléculas de SP [PUNKKI, GOLASZEWSKI \& GJøRV (1996); PARK, NOH \& PARK (2005)]. Como resultado, a tensão de escoamento e a viscosidade plástica tendem a aumentar.

Porém, a substituição de parte do cimento por uma adição mineral também pode resultar em uma redução de ambos os parâmetros reológicos do concreto. A granulometria melhorada do aglomerante e o efeito lubrificante concedido pelas pequenas partículas de sílica possivelmente reduzem o imbricamento entre os 
agregados e, consequentemente, a tensão de escoamento e a viscosidade plástica do material. Quanto mais finas e mais esféricas forem as partículas da adição mineral, maior a redução observada para os parâmetros reológicos [NEHDI, MINDESS \& AÏTCIN (1998); ZHANG \& HAN (2000)].

Segundo o estudo feito por Ivanov e Roshavelov (1991), o grau de influência da sílica ativa sobre as propriedades reológicas dos materiais à base de cimento, em termos de valor absoluto, é mais do que o dobro da influência de outros fatores, tais como a relação água/cimento, o teor de $\mathrm{SP}$ e as quantidades de $\mathrm{C}_{3} \mathrm{~A}$ e de sulfatos do cimento. De acordo com Wallevik apud Tattersall $(1991 \mathrm{~b})^{[5.7]}$, a incorporação de sílica ativa em substituição ao cimento até um determinado valor limite - que depende do teor de cimento e que diminui com a redução do teor de água - reduz a viscosidade plástica em até $50 \%$; a tensão de escoamento é praticamente constante até que o valor limite para substituição de cimento por sílica ativa seja alcançado e, a partir daí, ela aumenta consideravelmente.

O teor de um componente em particular da pasta de cimento influencia os valores de suas propriedades reológicas de maneiras diferentes e depende dos demais fatores. De acordo com um estudo feito por Ivanov e Roshavelov (1991), todos os cinco fatores considerados - relação água/cimento, teores de SP e de sílica ativa e quantidades de $\mathrm{C}_{3} \mathrm{~A}$ e de sulfatos - foram significativos, indicando que cada fator (componente) tem uma contribuição substancial para o comportamento do escoamento e para as propriedades reológicas dos materiais à base de cimento.

Apesar da reologia de fluidos binghamianos não ser muito sensível à temperatura, a taxa de mudança da reologia com o tempo em um sistema quimicamente reativo contendo cimento é influenciada por esse fator (CLAISSE, LORIMER \& AL OMARI, 2001). Assim, o mesmo deve ser considerado. Em um estudo feito por Petit, Khayat e Wirquin (2006), os autores observaram diferentes mudanças na tensão de escoamento com o tempo, que variaram em função da temperatura da mistura. Eles verificaram que existe uma temperatura abaixo da qual a mistura apresentou uma tensão de escoamento constante, ou até mesmo houve sua redução, durante cerca de $30 \%$ do período de indução da hidratação do cimento, sendo observado um grande aumento dessa tensão após esse período. Acima dessa temperatura limite, a mistura apresentou um aumento linear da tensão de escoamento com o tempo ou para a duração do desenvolvimento do ensaio.

${ }^{[5.7]}$ WALLEVIK, O.H. Private communication apud TATTERSALL, G.H. Workability and quality control of concrete. London: E \& FN SPON, 1991b. 262p. 
Porém, o valor da temperatura limite não foi o mesmo para as diversas amostras ensaiadas.

\subsubsection{Tixotropia}

A tixotropia pode ser entendida como uma redução, dependente do tempo, da viscosidade aparente do material sob a aplicação de uma tensão de cisalhamento (GHIO, 1993), seguida por uma recuperação gradual quando o material é deixado em repouso. Esse fenômeno é considerado reversível, mas raramente para fluidos à base de cimento, uma vez que existe uma segunda fonte dependente do tempo: as reações químicas contínuas que modificam as propriedades da pasta de cimento com o tempo de maneira irreversível (MOULIN, BLANC \& SORRENTINO, 2001).

Para pequenos intervalos de tempo, os processos de floculação e de defloculação dominam, resultando nos efeitos tixotrópicos (reversíveis), enquanto que para maiores intervalos de tempo, o processo de hidratação domina, resultando em evoluções irreversíveis do comportamento do fluido. De fato, esses dois efeitos podem agir em qualquer momento, porém eles parecem ter tempos característicos bastante diferentes. Como conseqüência, é razoável considerar que existe um período intermediário (cerca de alguns minutos) para o qual os efeitos irreversíveis ainda não se tornaram significantes. Assim, parece ser possível modelar a tixotropia e apenas a tixotropia dentro de curtos períodos de tempo, para os quais as evoluções irreversíveis da hidratação podem ser desprezadas - períodos de até 30 minutos após o contato inicial entre o cimento e a água de amassamento (ROUSSEL, 2006).

Uma explicação física simples do comportamento tixotrópico pode ser encontrada em Coussot (2005) apud Roussel (2006) ${ }^{[5.8]}$. As forças de interação entre as partículas determinam uma energia potencial ótima para cada partícula, isto é, existe uma posição de equilíbrio para cada partícula onde a energia é mínima. Contanto que a energia dada a um sistema seja menor que um determinado valor, a partícula não deixa sua posição de equilíbrio. Quando a tensão ou a deformação aplicada é interrompida, a partícula retorna para sua posição inicial (comportamento de um sólido elástico). Porém, se a energia dada a

\footnotetext{
[5.8] COUSSOT, P. Rheometry of pastes, suspensions and granular materials. New Jersey: John Wiley \& Sons, 2005 apud ROUSSEL, N. A thixotropy model for fresh fluid concretes: theory, validation and applications. Cement and Concrete Research, Article in Press. Disponível em:

< http://www.sciencedirect.com/science? ob=Mlmg\& imagekey=B6TWG-4KD5C0M-1$16 \&$ cdi $=5562 \&$ user $=972067 \&$ orig $=$ browse \& coverDate $=07 \% 2 F 13 \% 2 F 2006 \&$ sk $=999999999 \& v i e w=c \& w c h p=d$ GLbVzb-zSkzk\&md5=4e4aeb32b133b43e319b8b559eaea1fa\&ie=/sdarticle.pdf> Acesso em 24/08/2006.
} 
um sistema for maior do que um determinado valor, a partícula é capaz de deixar este potencial de equilíbrio ótimo, resultando no escoamento. No caso de sistemas que apresentam um comportamento tixotrópico, a profundidade do potencial de energia ótimo aumenta em repouso com o tempo devido ao movimento browniano e a uma possível evolução das interações coloidais. A energia necessária para que a partícula deixe a posição de equilíbrio aumenta (aumento da tensão de escoamento aparente). Porém, se a partícula deixar sua posição de equilíbrio, esta volta para sua profundidade inicial.

Como a areia e a brita são partículas não-coloidais "inertes", o cimento e, conseqüentemente, a pasta de cimento são as únicas fontes potenciais da tixotropia em um concreto. Assim, a maioria dos resultados obtidos tanto no concreto quanto na pasta de cimento e/ou na argamassa apresenta um comportamento reológico transitório semelhante (ROUSSEL, 2006). Na maioria das vezes, as únicas diferenças observadas decorrem do fato de que as pastas de cimento são geralmente estudadas sob taxas de cisalhamento variando entre $0 \mathrm{e}$ $100 \mathrm{~s}^{-1}$ ou entre 0 e $200 \mathrm{~s}^{-1}$, enquanto o concreto normalmente é estudado sob uma taxa de cisalhamento variando entre 0 e $10 \mathrm{~s}^{-1}$.

Porém, a taxa de cisalhamento experimentada pela pasta de cimento no concreto é maior do que a taxa de cisalhamento experimentada pelo próprio concreto quando este é considerado um fluido homogêneo. Se a pasta de cimento for misturada e medida separadamente nos mesmos misturadores ou reômetros que o concreto, seu comportamento seria diferente (provavelmente menos fluida) do que seu comportamento quando misturada junto com os agregados graúdos. Um cálculo simples das respectivas taxas de cisalhamento pode ser feito considerando-se que o cisalhamento está concentrado dentro da pasta, enquanto o esqueleto granular não é deformado pelo escoamento.

Como o comportamento tixotrópico é reversível, é necessário ter uma concordância com relação a um estado de referência em torno do qual as variações do comportamento reológico podem ser estudadas. Conforme observações feitas por Roussel (2006), o estado de referência mais adequado para um determinado concreto é o estado de floculação imediatamente após a mistura, que é o estado mais defloculado dentro da "história de cisalhamento" do material. No entanto, deve-se lembrar que, devido às limitações na velocidade de rotação dos reômetros, esse estado de referência e uma aparente evolução irreversível do material - que não seja devida ao processo de hidratação, mas às limitações do reômetro - que 
serão medidos. Claro que se a amostra for remisturada no misturador inicial entre cada determinação, esse artefato não aparecerá.

O comportamento tixotrópico do concreto causa um atraso na resposta do material ao cisalhamento. Na prática, um concreto é considerado tixotrópico se ele flocular muito rapidamente em repouso e se tornar aparentemente mais e mais fluido durante um cisalhamento com duração de alguns décimos de segundos. Para ser rigorosamente correto, Roussel (2006) considera todos os concretos tixotrópicos. De fato, um simples comportamento com tensão de escoamento pode ser considerado um comportamento tixotrópico com uma taxa de floculação bem baixa (tempo característico de floculação muito longo) e com uma taxa de defloculação muito rápida (tempo característico de defloculação muito curto), de maneira que não exista um aumento aparente da tensão de escoamento em repouso e que o estado estacionário seja alcançado quase que instantaneamente.

A principal característica dos modelos de comportamento tixotrópico é que tanto a floculação quanto a defloculação sob cisalhamento ocorrem dentro de seus respectivos tempos característicos. Quanto menor for o tempo característico, maior a influência de um ou outro fator. No campo dos materiais cimentícios, os modelos não seguem a modelagem geral encontrada na literatura. Esses modelos são menos gerais e buscam principalmente descrever os resultados dos ensaios de reometria. Na prática, um concreto tixotrópico é um concreto que apresenta um tempo característico de floculação bastante curto (normalmente de diversos minutos) e um tempo característico de defloculação de alguns centésimos de segundo sob uma taxa de cisalhamento variando entre $1 \mathrm{~s}^{-1}$ e $10 \mathrm{~s}^{-1}$ (ROUSSEL, 2006).

O fator que influencia a tensão de escoamento em um material à base de cimento é a extensão na qual as partículas estão floculadas. Geralmente, as forças responsáveis pela floculação são quebradas pelo cisalhamento, porém essa quebra não é completa e normalmente está acompanhada pela tixotropia. Shaw (1970) apud Moulin, Blanc e Sorrentino $(2001)^{[5.9]}$ considera a tixotropia como um termo usado para descrever a propriedade exibida por um sistema que é fluido sob cisalhamento, mas que desenvolve uma estrutura na forma de gel, tornando-se auto-sustentável quando em repouso. Após uma nova agitação, essa estrutura se rompe e a pasta é novamente um fluido. Então, após o término do cisalhamento, a estrutura em forma de gel reaparece com o estado auto-sustentável.

[5.9] SHAW, D.J. Introduction to colloid and surface chemistry. 2. ed. London: Butterworths, 1970. 236p. apud MOULIN,E.; BLANC, P.; SORRENTINO, D. Influence of key cement chemical parameters on the properties of metakaolin blended cements. Cement and Concrete Composites, v. 23, n. 6, p. 463-469, Dec. 2001. 
Em sistemas tixotrópicos, a tensão de escoamento seria a tensão de cisalhamento necessária para iniciar o escoamento, isto é, a tensão medida para uma taxa de cisalhamento zero. Para fluidos não-tixotrópicos, a tensão de escoamento permanece a mesma, independente se a taxa de cisalhamento aumenta ou diminui. No caso de fluidos tixotrópicos, a tensão de escoamento é observada apenas quando o cisalhamento é retirado (MOULIN, BLANC \& SORRENTINO, 2001).

Como regra geral, fluidos tixotrópicos se comportam como fluidos binghamianos sob cisalhamento e seu comportamento é definido pela tensão de escoamento e viscosidade plástica [CLEMENT (1979) apud MOULIN, BLANC \& SORRENTINO (2001)] $]^{[5.10]}$.

A tixotropia pode ser avaliada pela determinação da redução da viscosidade com o tempo mantendo-se a taxa de cisalhamento constante ou pela viscosidade recuperada ao longo do tempo depois que a pasta tiver sido misturada sob a ação de uma alta taxa de cisalhamento (GHIO, 1993). Durante os últimos cinqüenta anos, a tixotropia de materiais cimentícios vem sendo quantificada pela medida de superfície do que é denominado "volta tixotrópica" ou, pelo menos, a superfície ligada a essa volta tixotrópica, embora Banfill e Saunders (1981) apud Roussel $(2006)^{[5.11]}$ já tenham alertado de que esse método mostrou-se muito dependente do equipamento e do procedimento de ensaio. Esse método é baseado no fato de que, devido à natureza transitória da tixotropia e à dependência da resposta reológica na "história de cisalhamento", as curvas "tensão de cisalhamento versus taxa de cisalhamento" medidas sucessivamente em um viscosímetro ou em um reômetro durante as seqüências crescentes e decrescentes das taxas de cisalhamento aplicadas não serão sobrepostas. A área de histerese entre as duas curvas é medida e considerada como uma representação do trabalho feito por unidade de tempo e unidade de volume pela pasta de cimento para quebrar algumas das ligações inicialmente presentes (SCHRAMM, 2006).

Porém, esse método de medida não fornece um valor intrínseco de qualquer parâmetro reológico físico. Dessa maneira, não existe nenhuma possibilidade além de relações empíricas para a utilização dos resultados medidos no estudo das

[5.10] CLEMENT, C.C. A scientific approach to the use of thixotropic cement. J Petrol Tecnol, p. 344-346. 1979 apud MOULIN,E.; BLANC, P.; SORRENTINO, D. Influence of key cement chemical parameters on the properties of metakaolin blended cements. Cement and Concrete Composites, v. 23, n. 6, p. 463-469, Dec. 2001.

[5.11] BANFILL, P.F.G.; SAUNDERS, D.C. On the viscosimetric examination of cement pastes. Cement and Concrete Research, v. 11, n. 3, p. 363-370, May. 1981 apud ROUSSEL, N. A thixotropy model for fresh fluid concretes: theory, validation and applications. Cement and Concrete Research, Article in Press. Disponível em: $<$ http://www.sciencedirect.com/science? ob=Mlmg\& imagekey=B6TWG-4KD5C0M-1$16 \&$ cdi $=5562 \&$ user $=972067 \&$ orig=browse \& coverDate $=07 \% 2 F 13 \% 2 F 2006 \&$ sk $=999999999 \&$ view $=c \& w c h p=d$ GLbVzb-zSkzk\&md5=4e4aeb32b133b43e319b8b559eaea1fa\&ie=/sdarticle.pdf> Acesso em 24/08/2006. 
conseqüências da tixotropia. Isso parece limitar a maneira de se ter uma classificação dos concretos ou de comparar qualitativamente o efeito dos diversos aditivos. Além disso, nos resultados medidos, a floculação e a defloculação não podem ser separadas.

\subsection{Fatores que influenciam o comportamento reológico do concreto fresco}

Em termos gerais, são consideradas suspensões as misturas do tipo sólido/líquido formadas por um conjunto de partículas distribuídas de forma relativamente uniforme através de um meio líquido, sem que haja dissolução significativa do material particulado em função do tempo (STEIN, 1986 apud PANDOLFELLI et al., 2000) ${ }^{[5.12]}$. Assim, o concreto no estado fresco pode ser considerado um tipo de suspensão concentrada, com a concentração de sólidos sendo maior que $5 \%$ do volume do material.

Neste caso, o comportamento reológico da suspensão se afasta do modelo newtoniano e passa a depender de fatores como a concentração volumétrica de sólidos, a característica do meio líquido, a temperatura, as características físicas das partículas e o tipo de interação entre elas. Quando agentes dispersantes são incorporados, o comportamento se torna ainda mais complexo e outros fatores também devem ser considerados - a concentração de moléculas de dispersante no meio líquido, o peso molecular, a conformação espacial da molécula de dispersante e a espessura da camada de moléculas de dispersante adsorvidas em torno das partículas (PANDOLFELLI et al., 2000).

Assim, dependendo das particularidades de cada suspensão e da magnitude da taxa de cisalhamento aplicada, um ou mais fatores pode prevalecer e comandar o comportamento reológico do fluido.

Ao considerar o concreto fresco como uma suspensão densa de partículas, três efeitos podem influenciar seu comportamento reológico (De LARRARD et al., 1996). Primeiro, o agregado pode ser poroso e o concreto pode ser preparado com um agregado não-saturado. No momento em que esse agregado entra em contato com a pasta de cimento, ele tende a absorver água da pasta para atingir o estado saturado. O efeito na reologia é semelhante ao observado quando uma série de

${ }^{[5.12]}$ STEIN, H.N. Rheological behavior of suspensions. Encyclopedia of fluid mechanics: slurry flow technology, Houston, v. 5, p. 3-47. 1986 apud PANDOLFELLI et al. Dispersão e empacotamento de partículas. São Paulo: Fazendo Arte, 2000. 195p.

Aplicação de conceitos reológicos na tecnologia dos concretos de alto desempenho 
lotes é produzida com uma dosagem de água decrescente: tanto a tensão de escoamento quanto a viscosidade plástica aumentam.

Segundo, o concreto, que é homogêneo após uma mistura eficiente, pode segregar por várias razões:

- em repouso - a gravidade pode promover uma segregação do agregado graúdo caso a fração desse agregado não esteja bem proporcionada, especialmente quando ele apresenta deficiência na granulometria. Essa segregação pode ser considerada como uma contração da fase granular;

- Sob vibração - o fenômeno da segregação é ampliado;

- sob cisalhamento - se o teor de agregado graúdo for alto (próximo do valor de empacotamento), a fase agregado tende a expandir.

Terceiro, pode existir uma atividade química anormal no concreto fresco. cimento, ao entrar em contato com a água, produz alguns hidratos e, mesmo durante o período de indução, alguns fenômenos químicos ocorrem. Além disso, em algumas situações, o gesso adicionado ao cimento Portland tem dificuldade em controlar a hidratação inicial do $\mathrm{C}_{3} \mathrm{~A}$ na presença de $\mathrm{SP}$, promovendo a adsorção do aditivo. O efeito sobre o comportamento reológico do material é o mesmo do observado quando a quantidade inicial de aditivo é reduzida em uma mistura fresca: a tensão de escoamento aumenta, enquanto a viscosidade plástica praticamente não é influenciada.

A partir das considerações apresentadas, De Larrard et al. (1996) desenvolveram um guia para a interpretação das mudanças do comportamento reológico dos concretos (tabela 5.2).

Tabela 5.2 - Evolução dos parâmetros reológicos durante a utilização do concreto fresco. Interpretação e correção do problema encontrado.

\begin{tabular}{c|c|c|c|c|c|c}
\hline Caso & $\begin{array}{c}\text { Tensão de } \\
\text { escoamento }\end{array}$ & $\begin{array}{c}\text { Viscosidade } \\
\text { plástica }\end{array}$ & Abatimento & $\begin{array}{c}\text { Superfície } \\
\text { da amostra }\end{array}$ & Interpretação & $\begin{array}{c}\text { Correção do } \\
\text { problema }\end{array}$ \\
\hline I & $\rightarrow$ & $\rightarrow$ & $\rightarrow$ & --- & Mistura estável & -- \\
\hline II & $\uparrow$ & $\rightarrow$ & $\downarrow$ & --- & Atividade química & $\begin{array}{c}\text { Adição de um } \\
\text { retardador de pega } \\
\text { ou mudança do } \\
\text { sistema cimento/SP }\end{array}$ \\
\hline III & $\uparrow$ & $\uparrow$ & $\downarrow$ & --- & Absorção de água & $\begin{array}{c}\text { Agregados pré- } \\
\text { saturados }\end{array}$ \\
\hline & $\downarrow$ & $\rightarrow \downarrow$ & $\rightarrow / \downarrow$ & $\begin{array}{c}\text { Ascendência } \\
\text { de agregado } \\
\text { graúdo }\end{array}$ & $\begin{array}{c}\text { Segregação entre } \\
\text { a argamassa e o } \\
\text { agregado graúdo }\end{array}$ & $\begin{array}{c}\text { Mudança da } \\
\text { granulomegado ou adição } \\
\text { de um agente de } \\
\text { viscosidade }\end{array}$ \\
\hline
\end{tabular}

Obs.: as setas indicam o aumento $(\uparrow)$, a redução $(\downarrow)$ ou a manutenção $(\rightarrow)$ do valor do parâmetro medido (tensão de escoamento, viscosidade plástica e abatimento) ao longo do tempo. 


\subsubsection{Reologia da pasta de cimento}

De um ponto de vista prático, o concreto fresco pode ser considerado como um material bifásico, composto por uma fase matriz (pasta de cimento) e uma fase partícula (agregados). Assim, seu comportamento do escoamento pode ser considerado dependente principalmente da viscosidade da matriz e da porcentagem volumétrica de agregado [CHAPPUIS (1991); YEN et al. (1999); RAGO (1999)].

Como a pasta de cimento envolve os agregados em um concreto, ao manter constante a dimensão máxima característica e a quantidade de agregados presentes na mistura, relacionam-se as propriedades reológicas do concreto às propriedades reológicas da pasta de cimento (GHIO, 1993), além do que a pasta é responsável pela maior parte da área superficial do concreto. Agulló et al. (1999) consideram a pasta de cimento como a responsável pela fluidez e a coesão do concreto, fazendo com que a trabalhabilidade e outras propriedades reológicas desse material se tornem dependentes de suas características.

Assim, ao verificar a grande influência que a pasta de cimento exerce sobre o comportamento reológico dos concretos no estado fresco, diversos autores utilizam o estudo de sua reologia com o objetivo de melhor compreender as propriedades empíricas determinadas ao longo do tempo. Powers (1968), por exemplo, considera vantajoso conhecer as características reológicas da pasta de cimento antes de se discutir sobre as características reológicas do concreto, uma vez que as características da pasta dependem da natureza e da extensão de algumas reações químicas do cimento com a água que ocorrem durante o período de mistura.

As pastas de cimento têm sido matéria de estudo da maior parte das investigações reológicas, pois parecem ser o fator reológico principal em um concreto. Ainda assim, existe uma percepção geral de que estabelecer uma conexão entre a reologia de um concreto e a reologia de uma pasta de cimento está muito além de nossa capacidade (TATTERSALL \& BANFILL, 1983). Embora os ensaios em pastas de cimento possam ser executados para imitar o ensaio de abatimento de tronco de cone em menor escala (ensaio de miniabatimento), os resultados são de utilidade limitada, pois o abatimento de um concreto depende de outros fatores além da reologia da pasta de cimento que o compõe (FERRARIS \& GAIDIS, 1992).

As propriedades reológicas do concreto e da pasta de cimento no estado fresco são complexas em diferentes maneiras e medidas em pastas nem sempre 
predizem as determinações nos concretos correspondentes (FERRARIS \& GAIDIS, 1992). Porém, com o estudo das propriedades reológicas das pastas de cimento é possível obter informações valiosas sobre o comportamento reológico do concreto fresco [BANFILL (1990); GHIO (1993)]. Além disso, os estudos em pastas podem ser realizados com o auxílio de equipamentos comercialmente disponíveis (com geometrias de medida já bem estabelecidas) e são mais simples e fáceis de serem executados do que os estudos em concretos.

As novas aplicações das pastas de cimento, como o CAD, necessitam de um melhor controle de suas propriedades reológicas e do fenômeno da segregação. A tendência geral leva à formulação de pastas muito concentradas, apesar de bastante fluidas, com baixas tensões de escoamento, mediante o controle de sua composição química - especialmente com relação aos teores de aluminatos e sulfatos do cimento - distribuição granulométrica dos concretos e, finalmente, das interações interpartículas pela adsorção do SP (MANSOUTRE, COLOMBET \& VAN DAMME, 1999). Simultaneamente, a homogeneidade da mistura deve ser mantida a fim de se evitar a segregação.

As características reológicas da pasta de cimento no estado fresco podem ser influenciadas por diversos fatores, tais como: relação água/cimento, idade da pasta, características do cimento (finura, área superficial, composição e processo de hidratação), natureza das adições químicas e minerais incorporadas à mistura e procedimento de mistura empregado na sua produção. Além desses, o comportamento do escoamento das pastas de cimento são influenciadas pelas condições de ensaio durante as determinações (dependência do tempo e da intensidade de mistura) e pela temperatura (CLAISSE, LORIMER \& AL OMARI, 2001); uma influência especialmente importante é exercida pela combinação do tipo e quantidade de sulfato de cálcio com os componentes aluminatos do clínquer (SUHR, 1991).

A pasta de cimento, considerada o lubrificante entre os agregados de um concreto, influencia bastante a fluidez do mesmo. Sabe-se que fatores que compõem a pasta de cimento (por exemplo, a relação água/cimento e a presença de aditivos) influenciam a trabalhabilidade do concreto e que uma mudança da fração volumétrica de pasta na mistura é suficiente para mudar sua fluidez, mesmo quando a composição da pasta permanece a mesma (FERRARIS \& GAIDIS, 1992).

A pasta de cimento pode apresentar uma maior trabalhabilidade quando se utiliza uma alta relação água/cimento, um cimento com pequena área superficial e uma alta velocidade de mistura. Estudos realizados em pastas produzidas com 
cimentos de composições químicas diferentes indicaram que esses fatores têm uma influência menor sobre a reologia desses materiais do que a relação água/cimento e/ou a finura do cimento (CLAISSE, LORIMER \& AL OMARI, 2001). Esses fatores também são influenciados pela proporção $C_{2} S / C_{3} S$.

As adições influenciam o comportamento do escoamento da pasta de cimento sem qualquer alteração da composição ou das características dos agregados. Assim, parece razoável tentar selecionar adições químicas e minerais apenas ensaiando a pasta de cimento. Os resultados estarão relacionados com a trabalhabilidade do concreto, mas, infelizmente, a relação entre a reologia da pasta de cimento e a reologia do concreto nem sempre pode ser completamente estabelecida, uma vez que a reologia da pasta é tipicamente medida sob condições nunca experimentadas pela mesma no concreto. Dessa maneira, os parâmetros reológicos medidos para a pasta de cimento poderão diferir dos parâmetros estimados para o concreto (FERRARIS, OBLA \& HILL, 2001). Os valores usualmente relatados na literatura para pastas de cimento não consideram a participação dos agregados [BARTOS (1992) apud FERRARIS, OBLA \& HILL $(2001)]^{[5.13]}$, que agem como redutores de calor e cisalham a pasta de cimento durante o processo de mistura do concreto. Porém, as propriedades de escoamento da pasta de cimento, se medidas corretamente, podem ser usadas para controlar a utilização das adições químicas e minerais.

As pastas de cimento sem o uso de qualquer ação mecânica ou presença de aditivo SP apresentam uma estrutura floculada; sem vibração, são consideradas materiais viscoplásticos (CYR, LEGRAND \& MOURET, 2000). Para que elas escoem, são necessárias forças cisalhantes capazes de quebrar as ligações entre os grãos de cimento, daí o surgimento de um valor de escoamento inicial (tensão de escoamento). De acordo com Banfill (1990), para se obter mais informação sobre o comportamento do material é preciso observá-lo sob uma taxa de cisalhamento ou sob uma tensão de cisalhamento constante: sob taxas de cisalhamento constantes, a tensão de cisalhamento diminui exponencialmente com o tempo até um mínimo (que pode ser de até um décimo da tensão inicial), enquanto que no caso de uma tensão controlada, a taxa de cisalhamento aumenta até um máximo. Depois que estrutura é destruída, o efeito do processo de reconstrução se torna nítido e a pasta de cimento endurece com o tempo.

${ }^{[5.13]}$ BARTOS, P. Fresh concrete: properties and tests. New York: Elsevier, 1992 apud FERRARIS, C.F.; OBLA, K.H.; HILL, R. The influence of mineral admixtures on the rheology of cement paste and concrete. Cement and Concrete Research, v. 31, n. 2, p. 245-255, Feb. 2001. 
Se o escoamento for facilitado pelo cisalhamento ou pela vibração, a viscosidade aparente da pasta de cimento quase sempre diminui com o aumento da taxa de cisalhamento (fluido pseudoplástico). A incorporação de SP causa uma importante redução da tensão de escoamento inicial sem a ação de qualquer mecanismo externo. Esse efeito é físico-químico e consiste da repulsão das forças interpartículas que tendem a mudar o estado de floculado para disperso. Isto resulta em suspensões concentradas e dispersas que podem apresentar um aumento na viscosidade aparente com o aumento da taxa de cisalhamento (fluido dilatante), levando a conseqüências inesperadas sobre a trabalhabilidade dos concretos. Quando se incorporam adições minerais, a intensidade deste fenômeno varia de acordo com sua origem; no caso da incorporação de sílica ativa, o fenômeno da dilatação pode ser reduzido (CYR, LEGRAND \& MOURET, 2000).

A reologia e a estabilidade de pastas de cimento muito concentradas, em um regime onde o volume de líquidos está próximo do necessário para preencher os vazios do empacotamento das partículas, podem se aproximar tanto de conceitos desenvolvidos para a reologia de suspensões extrapoladas para uma fração de empacotamento máximo quanto de conceitos físicos e mecânicos de materiais granulares (MANSOUTRE, COLOMBET \& VAN DAMME, 1999).

Assim, diversos modelos empíricos e teóricos têm sido usados para descrever o comportamento de pastas de cimento no estado fresco. Entre os mais utilizados estão os modelos de Bingham e de Herschel-Bulkley, que leva em consideração o comportamento pseudoplástico dessas suspensões concentradas. Se a tensão de escoamento estimada for pequena, um modelo puramente viscoso (caso particular do modelo binghamiano) pode ser suficiente para descrever corretamente 0 comportamento de pastas frescas (ROUSSEL \& Le ROY, 2005). Ainda, dependendo do teor de água da mistura, o comportamento da pasta de cimento pode ser do tipo viscoplástico, com pseudoplasticidade ou dilatação.

Por se tratar de um sistema complexo, as pastas de cimento podem apresentar outros comportamentos reológicos, os quais dependem de condições de ensaio tais como a composição da pasta, o estado de dispersão e o histórico de cisalhamento. Como observado por Curcio e DeAngelis (1998), as pastas incorporadas com adições minerais podem apresentar comportamentos de fluidos dilatantes e tixotrópicos. A dilatação é causada pelo atrito entre as partículas sólidas quando a amostra é cisalhada e aumentada por um grande volume de fração de sólidos e por partículas de formas não-esféricas; ocorre em pastas com alto grau de dispersão e com grande empacotamento de partículas, ou seja, pastas 
de cimento incorporadas com SP são fortes candidatas a apresentarem comportamento dilatante. Por outro lado, a tixotropia ocorre devido à presença de uma estrutura originada a partir das ligações entre as partículas, mesmo mecanismo que dá origem à tensão de escoamento; a constante formação de produtos de hidratação é um fator adicional que leva ao aumento desse fenômeno. Assim, a dilatação e a tixotropia tendem a se excluírem.

A tensão de escoamento das pastas de cimento tem sido determinada por meio de modelos empíricos e teóricos baseados em dados obtidos a partir das curvas de escoamento do material. Embora esses modelos possam fornecer uma estimativa razoável da tensão de escoamento, as determinações são bastante dependentes de considerações do modelo, da precisão dos dados experimentais e das especificações do reômetro; em adição, grandes erros na determinação da tensão de escoamento podem resultar em uma escolha errada da variação da taxa de cisalhamento para ajustar os modelos (SAAK, JENNINGS \& SHAH, 2001a).

O papel desempenhado pelas condições experimentais (tais como o tempo e a intensidade de mistura, a duração do ciclo, o número de repetições e a geometria do sistema de medida) na determinação dos parâmetros reológicos da pasta de cimento mostra que diferenças freqüentemente grosseiras e, em alguns casos, até mesmo contraditórias, podem surgir nos resultados obtidos (ATZENI, MASSIDDA \& SANNA, 1985). Conseqüentemente, qualquer contribuição para a compreensão da reologia das pastas de cimento deve seguir necessariamente condições de ensaio padronizadas.

\subsubsection{Microestrutura da pasta de cimento}

Qualquer discussão sobre a relação entre a reologia e a microestrutura da pasta de cimento deve considerar a formação instantânea de uma camada ou membrana de minerais hidratados ao redor das partículas de cimento em água, assim como a explicação da quebra estrutural. A estrutura tridimensional criada surge a partir de uma combinação de forças coloidais (por exemplo, forças de Van der Waals, atração e repulsão eletrostática), hidrodinâmicas e reações químicas que produzem o silicato de cálcio hidratado (TATTERSALL \& BANFILL, 1983). Em repouso, a pasta tem uma estrutura rígida que pode ser superada pelo cisalhamento, mas que se recompõe instantaneamente quando o cisalhamento é interrompido (BANFILL, 1990). Essa estrutura resulta em propriedades 
viscoelásticas, comum em suspensões cerâmicas [LANGE (1989) apud SAAK, JENNINGS \& SHAH (2001a) $]^{[5.14]}$.

Quando o cimento em pó entra em contato com a água, uma camada ou membrana hidratada se forma ao redor dos pares ou grupos de partículas. Quando a camada é quebrada pelo cisalhamento e as partículas se separam, a região de uma partícula que estava em contato com outra partícula é exposta e os hidratos corrigem a camada rompida. Essas ligações entre as partículas não podem ser reformadas da mesma maneira de quando a estrutura estava em repouso, pois a quebra da camada de junção é irreversível (BANFILL, 1990).

Sob baixas tensões de cisalhamento, a pasta de cimento é muito viscosa, parecendo-se com um sólido elástico. Para uma pequena variação de tensão, a viscosidade diminui em várias ordens de magnitude e um escoamento macroscópico é observado. A variação da tensão crítica é muito pequena e freqüentemente designada como um ponto simples, denominada tensão de escoamento aparente (SAAK, JENNINGS \& SHAH, 2001a).

A viscosidade e demais propriedades da pasta de cimento durante $\mathrm{O}$ escoamento são controladas pela forma em que se apresentam as partículas, isto é, pelo seu estado de dispersão ou floculação [GHIO (1993); RAGO (1999)]. Este fato também foi observado por Asaga e Roy (1980), onde os autores afirmam que as mudanças das propriedades reológicas de misturas à base de cimento resultam de mudanças da estrutura dispersa de suas partículas.

Muito do que se sabe sobre a microestrutura floculada das pastas de cimento no estado fresco é decorrente do trabalho desenvolvido por Powers (1968). Nele, o autor distingue dois estados possíveis de comportamento para microestrutura das pastas: o floculado, onde se observam agrupamentos isolados de partículas; e o floculento, onde a grande concentração dos flocos permite a observação de uma massa contínua, dando a impressão de que todo o sistema é constituído por um único grande floco. Ainda, considera a pasta como floculada se diluída e floculenta se concentrada (relação água/cimento menor que 0,40).

Em estudos realizados por Nachbaur et al. (2001) foi possível observar a evolução da estrutura da pasta de cimento e as forças responsáveis por suas propriedades mecânicas através de ensaios reológicos realizados dinamicamente desde sua mistura até sua pega. Com isso, os pesquisadores verificaram que a

[5.14] LANGE, F.F. Powder processing science and technology for increased reliability. Journal of the American Ceramic Society, v. 72, n. 1, p. 3-15. Jan. 1989 apud SAAK, A.W.; JENNINGS, H.M.; SHAH, S.P. The influence of wall slip on yield stress and viscoelastic measurements of cement paste. Cement and Concrete Research, v. $31, n$. 2, p. 205-212, Feb. 2001a. 
principal evolução da estrutura das pastas de cimento ocorre logo durante os primeiros minutos que seguem o fim da mistura, não sendo observada qualquer mudança durante as próximas horas, pelo menos até o início de pega.

A pasta de cimento é considerada uma suspensão densa de partículas de cimento, onde, devido ao pequeno tamanho das partículas, as forças entre elas e da gravidade exercem, na mesma magnitude, influência sobre a suspensão e desempenham um papel importante sobre as características macroscópicas das mesmas (CHAPPUIS, 1991). As forças entre as partículas presentes na suspensão podem ser de dois tipos: forças de van der Waals e dupla camada elétrica.

As forças de van der Waals geram atração entre os átomos de duas partículas quaisquer de cimento e, ainda, entre moléculas neutras quimicamente saturadas. Shaw (1980) apud Ghio (1993) ${ }^{[5.15]}$ reconhece três tipos de atração intermolecular: duas moléculas com bipolos permanentes orientados mutuamente de tal maneira que, em média, resulta em atração; moléculas bipolares induzem os bipolos de outras moléculas resultando em atração entre elas; e as forças de atração também operam entre moléculas não polares (forças de dispersão), promovendo a polarização de uma molécula pela variação na distribuição de carga de uma segunda molécula e vice-versa.

Com exceção dos materiais altamente polares, as forças de dispersão são consideradas para quase todas as forças de atração de van der Waals que estão em operação. A energia de atração entre duas moléculas é muito pequena e varia inversamente à sexta potência da distância intermolecular. Para um grupo de moléculas, as forças de dispersão são, em uma primeira aproximação, adicionais e a energia de interação de van der Waals entre duas partículas pode ser calculada pela soma das forças de atração entre todos os pares de moléculas, resultando em uma energia de atração que varia inversamente com o quadrado da distância de separação entre elas (GHIO, 1993).

As partículas coloidais geram atrito ao se movimentarem, resultando em cargas elétricas nas suas superfícies e na ocorrência da dupla camada elétrica. Uma das camadas tem aproximadamente a espessura dos íons, permanecendo praticamente fixa à superfície da partícula, enquanto a outra se estende até certa distância da superfície do sólido dentro do meio disperso (camada difusa) (RAGO, 1999). Existe, assim, uma queda acentuada de potencial através camada fixa, caindo gradualmente na camada difusa.

[5.15] SHAW, D. J. Introduction to colloid and surface chemistry. London, 1980 apud GHIO, V. A. The rheology of fresh concrete and its effect on the shotcrete process. 1993. 193p. Tese (Doutorado) em Engenharia Civil pela Divisão de Graduação da Universidade da Califórnia em Berkeley. 28/04/1993.

Aplicação de conceitos reológicos na tecnologia dos concretos de alto desempenho 
As cargas das partículas na dupla camada elétrica podem ser tanto de atração como de repulsão e as interações entre elas têm origem nas cargas elétricas superficiais das partículas ao entrarem em contato com o meio aquoso [CHAPPUIS (1991); GHIO (1993); RAGO (1999)].

Diz-se que uma suspensão é dispersa quando a forças repulsivas da dupla camada elétrica forem maior que as forças de Van der Waals; para situação contrária, observa-se a floculação. Chappuis (1991) define o exposto anteriormente como: quando as forças de repulsão da dupla camada elétrica forem superiores, a suspensão apresenta escoamento facilitado - suspensão defloculada - e, quando as forças de atração de Van der Waals forem dominantes, as partículas sólidas formam uma estrutura que deixa a suspensão mais coesa, com escoamento dificultado. Ainda segundo o autor, a relação entre as forças entre as partículas, o estado de dispersão e a reologia da suspensão pode ser resumida segundo a tabela 5.3.

Tabela 5.3 - Relação entre as forças entre as partículas, o estado de dispersão e a reologia das suspensões (CHAPPUIS, 1991).

\begin{tabular}{c|c|c}
\hline Forças entre as partículas & Atração & Repulsão \\
\hline Estado de dispersão da suspensão & Floculado & Disperso \\
\hline Reologia da suspensão & Coesa & Fluida \\
\hline
\end{tabular}

Em contraste com outros materiais que possuem uma superfície bem definida em uma solução aquosa, o cimento reage com a água e, portanto, possui uma área e uma composição superficial que varia com o tempo (RAGO, 1999). Assim, a composição da dupla camada elétrica no cimento deve ser bastante influenciada por sua reação de hidratação.

\subsubsection{Interação cimento-aditivo}

A natureza química do SP pode ter um efeito sobre o comportamento reológico de materiais à base de cimento. Porém, nenhuma tendência definitiva pode ser identificada a partir de uma pesquisa bibliográfica sobre as propriedades do material, como, por exemplo, a trabalhabilidade e sua perda ao longo do tempo, o retardamento de pega, o teor de ar incorporado etc. Isso indica claramente que diversas propriedades intrínsecas do SP podem influenciar seu desempenho (AÏTCIN, JOLICOEUR \& MacGREGOR, 1994).

Segundo estudos feitos por Erdogdu (2000), o fator principal que controla o comportamento do SP é a composição do cimento (tipo de clínquer e produtos de 
hidratação) e não a quantidade de cimento usada, pois o efeito positivo do SP só acontece quando ele reage com os produtos de hidratação do cimento. Por um lado, isso ocorre por meio dos efeitos de defloculação e dispersão do SP sobre as partículas de cimento, enquanto que, por outro lado, o SP influencia as taxas de reação do $\mathrm{C}_{3} \mathrm{~A}$ e do $\mathrm{C}_{3} \mathrm{~S}$ - uma melhoria na fluidez de um concreto é acompanhada pelo retardamento do pico inicial da evolução do calor e da hidratação do $\mathrm{C}_{3} \mathrm{~S}$ (BONEN \& SARKAR, 1995).

Assim, como os aditivos incorporados a uma mistura à base de cimento interagem com os vários constituintes do cimento e influenciam as reações de hidratação do mesmo, é necessário estudar o processo de hidratação do cimento para uma melhor compreensão da interferência do SP na mistura.

Na figura 5.3 é apresentado um esquema adaptado de Jawed, Skalny e Young (1983) apud Melo (2000) $)^{[5.16]}$, onde se observam cinco estágios distintos da hidratação: I - Reação inicial (pré-indução), II - Período de indução, III - Período de aceleração, IV - Período de desaceleração e endurecimento, V - Período de reação lenta e contínua (difusão).

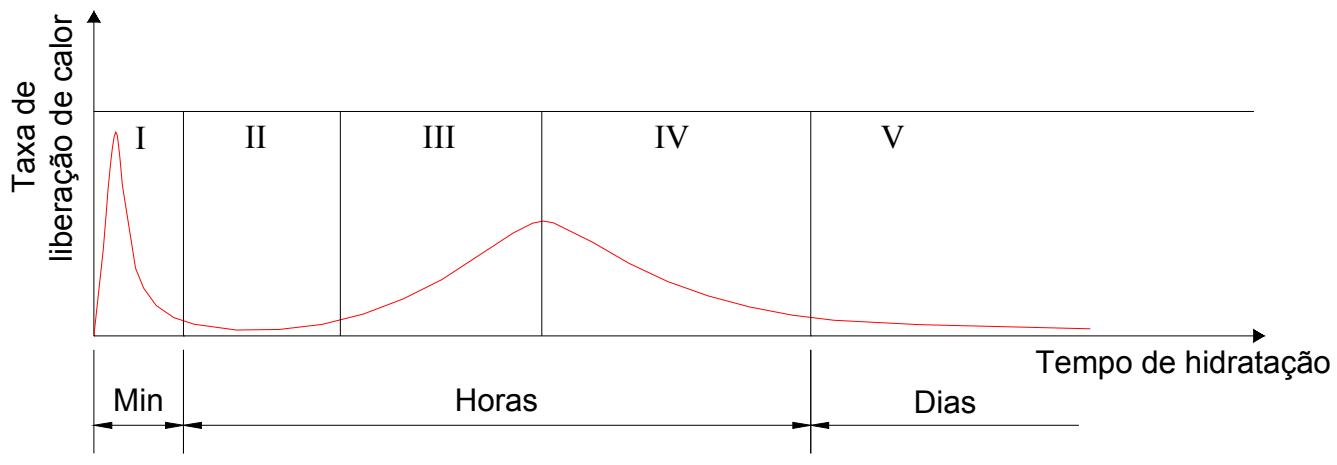

Figura 5.3 - Adaptação de uma representação gráfica da hidratação do cimento pelo método da calorimetria (JAWED, SKALNY \& YOUNG, 1983 apud MELO, 2000) ${ }^{[5.17]}$.

Será dada ênfase às etapas em que o SP influencia o processo de hidratação, ou seja, aos estágios I, II e III da figura 5.3. No estágio I, a presença do $\mathrm{SP}$, que interfere nos processos de nucleação e/ou crescimento dos produtos de hidratação, influencia a taxa da reação de hidratação, os produtos da reação ou ambos. No estágio II, a quantidade de íons $\mathrm{SO}_{4}{ }^{2-}$ disponível é que determina o comportamento do sistema cimentício, particularmente suas propriedades reológicas e seu tempo de início de pega. No estágio III, pode-se verificar uma

[5.16] JAWED, I.; SKALNY, J.; YOUNG, J. F. Hydratation of Portland cement. In: Structures and Performance of Cements. London: P. Barnes, 1983 apud MELO, A. B. Influência da cura térmica (vapor) sob pressão atmosférica no desenvolvimento da microestrutura dos concretos de cimento Portland. 2000. 245p. Tese (Doutorado) em Interunidades em Ciência e Engenharia de Materiais, Universidade de São Paulo. São Carlos. $10 / 03 / 2000$.

[5.17] Op cit. nota de rodapé [5.16].

Aplicação de conceitos reológicos na tecnologia dos concretos de alto desempenho 
situação de auto-inibição no comportamento da hidratação do cimento, explicada pelos fenômenos que ocorreram nos estágios I e II do processo de hidratação (JOLICOEUR \& SIMARD, 1998).

Assim, o tempo de adição do SP constitui um dos fatores que influenciam a fluidez de uma mistura à base de cimento que o contém. Quando a relação água/cimento é suficiente para tornar a pasta fluida, dificilmente o aditivo contribuirá na sua fluidez. Porém, quando essa adição é feita de maneira parcelada ou atrasada, a viscosidade da mistura diminui ou, em outras palavras, existe uma maior dispersão da pasta de cimento (maior fluidez).

Quando SP é adicionado ao cimento, ele é fortemente ligado à mistura de $\mathrm{C}_{3} \mathrm{~A}$ e gesso, deixando apenas pequenas quantidades para a dispersão das fases de CS-H. Porém, quando uma adição parcelada ou atrasada é feita, o SP é adsorvido em uma menor extensão pela mistura de $\mathrm{C}_{3} \mathrm{~A}$ e gesso já submetida à hidratação $\mathrm{e}$ à formação da etringita, deixando aditivo suficiente para promover a dispersão das fases de C-S-H e reduzir a viscosidade do sistema [PENTTALA (1990); MASOOD \& AGARWAL (1994)].

Com relação à influência do SP sobre a morfologia dos produtos de hidratação, diversos autores têm mostrado que a morfologia da etringita produzida durante a hidratação do cimento é alterada na presença de SP: ao invés de serem em forma de agulha, os cristais formados são bem pequenos, aproximadamente cúbicos (AÏTCIN, JOLICOEUR \& MacGREGOR, 1994). Essa mudança na morfologia certamente pode contribuir com o mecanismo de fluidificação, mas ainda não está claro em que extensão.

A adsorção do aditivo pelos grãos de cimento durante a hidratação pode reduzir a floculação da pasta de pelo menos três formas (MANNONEN \& PENTTALA, 1996). A primeira se dá pelo aumento da magnitude do potencial zeta $^{[5.18]}$, ou seja, se todas as partículas de uma superfície forem carregadas com cargas de mesmo sinal e com intensidade suficiente, elas irão se repelir. Segundo, o SP gera um aumento na afinidade entre sólidos e líquidos, isto é, caso as partículas estejam mais fortemente atraídas pela fase líquida do que entre si, a tendência será de dispersão. A terceira corresponde ao impedimento estérico; a adsorção orientada de um polímero não-iônico pode enfraquecer a atração entre as partículas sólidas.

[5.18] O potencial zeta é definido como o potencial no plano de cisalhamento entre a camada fixa de líquido adjacente da fase sólida e o líquido constituinte da fase líquida (NÄGELE, 1985). 
De acordo com Erdogdu (2000), a maioria dos aditivos orgânicos (com características poliméricas) adicionados aos materiais produzidos à base de cimento apresenta uma grande afinidade com a superfície das partículas de cimento ou com os produtos da hidratação do mesmo, o que pode resultar tanto em uma interação física quanto química. A interação física surge a partir da adsorção das moléculas de aditivo na superfície das partículas de cimento junto ao efeito estérico existente entre as moléculas poliméricas adsorvidas e as partículas de cimento vizinhas defloculadas e dispersas. O aditivo adsorvido pelas partículas de cimento gera forças de repulsão entre elas, de forma que a floculação seja evitada e que as partículas de cimento estejam homogeneamente dispersas no concreto fresco. O atrito interno existente entre as partículas de cimento é reduzido em função do efeito estérico, resultando em melhores trabalhabilidades.

Aïtcin (2000) evidencia a interação entre o cimento e o SP devido às interações simultâneas entre o cimento e os sulfatos e entre os sulfatos e o SP (figura 5.4).

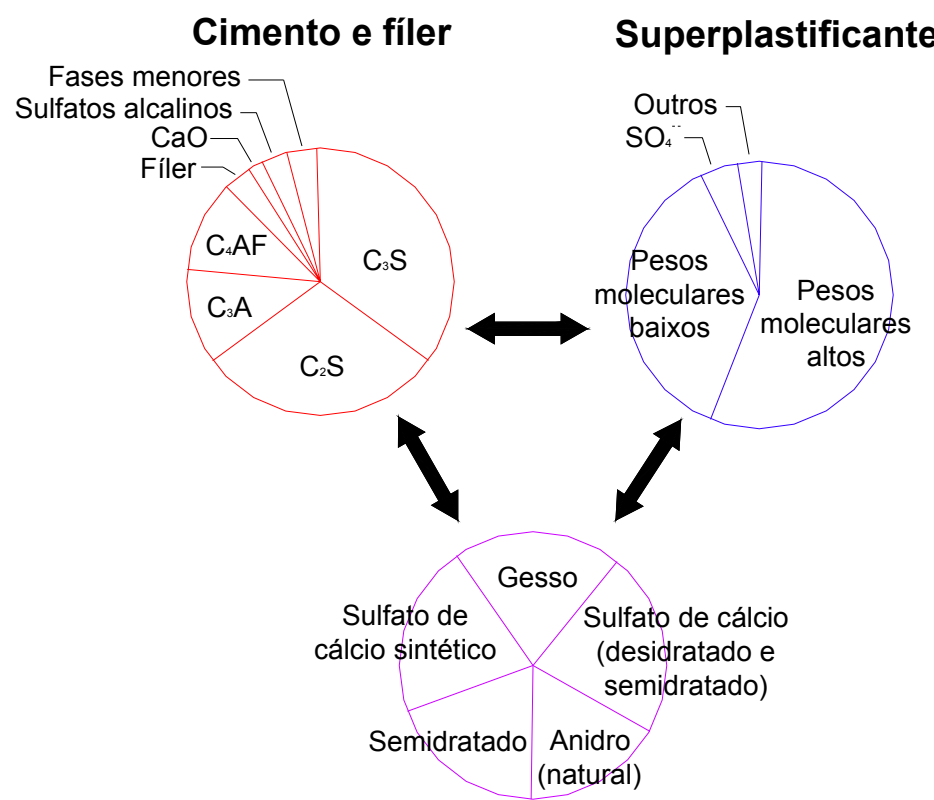

Sulfato de cálcio

Figura 5.4 - Interações entre cimento Portland, sulfato de cálcio e SP (AÏTCIN, 2000).

Além disso, o autor relata que os SP não interferem apenas na hidratação do cimento, mas também nos sulfatos em dissolução e no valor da relação $\mathrm{SO}_{4}{ }^{2-} / \mathrm{AlO}_{2}$. O grau de solubilidade dos sulfatos presentes no cimento não é igual e pode ser bastante modificado na presença de um SP; com isso, o equilíbrio do grau de solubilidade da fase $\mathrm{C}_{3} \mathrm{~A}$ e do sulfato de cálcio do cimento também é alterado. Isso pode levar um sistema com perda normal de trabalhabilidade para uma situação de pega instantânea ou, ainda, para uma situação de falsa pega. 
A ação do SP sobre um cimento em particular também depende de fatores que não estão relacionados com as propriedades físico-químicas desses dois materiais, mas na maneira com que eles são adicionados ou misturados. Como exemplo, Aïtcin, Jolicoeur e MacGregor (1994) citam o tipo de equipamento utilizado na produção da mistura e a forma de adição do SP (adições múltiplas desse aditivo resultam em uma redução de sua quantidade necessária para se alcançar uma determinada trabalhabilidade).

Aditivos SP à base de policarboxilatos constituem uma nova geração de aditivos no mercado dos concretos com alta fluidez e alta resistência. Eles surgiram a partir de novas tecnologias e são caracterizados por evitarem a perda da trabalhabilidade. Geralmente possuem um alto peso molecular e são formados por longas cadeias de copolímeros.

Seu efeito dispersante depende, principalmente, do impedimento estérico do que da repulsão eletrostática. Assim, tal como todo agente estéricamente adsorvido na superfície das partículas de cimento, esse tipo de aditivo possui um período onde está totalmente introduzido nos hidratos, tornando possível a manutenção do efeito dispersante mesmo após os hidratos estarem parcialmente cobertos com ele (OKAMURA, HARADA \& DAIMON, 1998). Esse tempo de permanência do efeito estérico, que interfere na perda da trabalhabilidade do material, poderá ser diferente em cada caso, variando de acordo com o tipo, a quantidade, o tamanho e a morfologia dos hidratos.

A interação de um aditivo SP à base de policarboxilato (como o usado na presente pesquisa) com o cimento Portland se dá da seguinte maneira: durante o processo de hidratação do cimento, as moléculas de SP, atraídas pelos grânulos de cimento amolecidos, envolvem-nos imediatamente após a mistura, aumentando as cargas negativas da superfície das partículas de cimento e, com isso, provocando uma repulsão eletrostática. Assim, resulta uma notável dispersão dos grânulos, que proporciona uma trabalhabilidade elevada do concreto mesmo com o baixo consumo de água. Esse efeito da dispersão é melhorado devido ao efeito estérico gerado pelas longas cadeias laterais das moléculas do SP, o que melhora substancialmente a capacidade das partículas de cimento se distanciarem. A segunda fase da ação desse tipo de SP sobre o cimento ocorre quando uma segunda molécula de aditivo é ativada devido ao aumento da alcalinidade da pasta de cimento que ocorre durante a mistura e a aplicação do material; esta segunda molécula reforça e substitui a primeira molécula (que perde gradualmente a sua 
eficiência), permitindo uma trabalhabilidade mais longa do concreto fresco sem os indesejáveis efeitos secundários de retardamento de pega.

A eficiência de um SP à base de policarboxilato na redução da demanda de água de uma pasta de cimento é influenciada pela composição da mistura e pelo procedimento de mistura. Uma concentração relativamente alta de íons sulfato na solução intersticial pode resultar em uma incompatibilidade entre o aglomerante e o $\mathrm{SP}$, influenciando, assim, a adsorção do aditivo sobre as partículas de cimento. $\mathrm{O}$ nível de incompatibilidade entre os materiais cimentícios e os diversos aditivos também é influenciado pela temperatura (PETIT, KHAYAT \& WIRQUIN, 2006).

Segundo Hanehara e Yamada (1999), um problema de interação do SP à base de policarboxilato está relacionado ao fato de que a quantidade de aditivo adicionado à mistura varia bastante em função da composição do cimento empregado. Como este tipo de aditivo é usado em concretos preparados com baixa relação água/aglomerante, qualquer diferença na dispersão do mesmo pode acarretar mudanças significativas na fluidez total do sistema.

\subsubsection{Estudo do escoamento de pastas de cimento através dos ensaios de miniabatimento e cone de Marsh - compatibilidade entre os materiais}

Controlar o comportamento ao escoamento das pastas de cimento é fundamental para uma produção bem sucedida de materiais à base de cimento, incluindo os concretos e as argamassas.

O comportamento reológico das pastas de cimento em função do tempo e da dosagem de SP fornece informações relevantes sobre alguns de seus parâmetroschave, como o abatimento e a perda desse abatimento, os quais podem ser transferidos para o concreto (JIANG, KIM \& AÏTCIN, 1999). A compatibilidade de um determinado par cimento-aditivo, em termos de perda de abatimento, pode e deve ser inicialmente estudada a partir de medidas de fluidez da pasta com auxílio de ensaios simples e de fácil execução.

Como as propriedades reológicas da pasta de cimento e, conseqüentemente, do concreto no estado fresco são influenciadas pela combinação cimento-aditivo, forma de adição do aditivo e relação água/aglomerante, muitas vezes observa-se problemas na sua fluidez. Diversos problemas têm sido relatados, tais como o baixo efeito de fluidificação, a rápida perda de trabalhabilidade, a segregação severa, o super-retardamento da pega e a perda de ar incorporado (AÏTCIN, JOLICOEUR \& 
MacGREGOR, 1994). Nesses casos verifica-se o fenômeno denominado incompatibilidade entre o cimento e o aditivo.

Como os aditivos são indispensáveis no preparo de misturas de alto desempenho, os problemas de interação entre o cimento e o aditivo podem ser divididos em dois grupos (HANEHARA \& YAMADA, 1999):

1. problemas causados pelo efeito da adição do aditivo na reação de hidratação do cimento;

2. problemas gerados pela adsorção do aditivo nas partículas de cimento.

A quantidade de álcalis solúveis que entram em solução durante os primeiros minutos da hidratação do cimento também pode ser considerada um ponto fundamental na compatibilidade cimento-aditivo, ou seja, no controle da trabalhabilidade e da perda da trabalhabilidade de pastas de cimento com a incorporação de SP (JIANG, KIM \& AÏTCIN, 1999). Em alguns casos, a adição de pequenas quantidades de $\mathrm{Na}_{2} \mathrm{SO}_{4}$ é capaz de reduzir essa perda de trabalhabilidade e, para um teor ótimo de álcalis solúveis, essa perda é mínima.

A compatibilidade cimento-SP é tão crítica quando se produz um CAD que alguns cimentos têm sido rejeitados devido à impossibilidade de se manter a trabalhabilidade por tempo suficiente para que o material seja lançado adequadamente. Ao se deparar com um problema de incompatibilidade entre os materiais, uma atitude prática é tentar identificar se o problema ocorreu devido à alta reatividade do cimento ou ao pobre desempenho do aditivo através do cruzamento de resultados de ensaios com amostras de outros tipos de SP e cimentos (AÏTCIN, JOLICOEUR \& MacGREGOR, 1994).

Para misturas com baixa relação água/aglomerante, a compatibilidade cimento-aditivo não pode ser determinada somente a partir das especificações de cada material. É necessária a verificação experimental da mistura devido aos complexos fenômenos químicos envolvidos.

Para isso, diversos métodos de ensaio foram desenvolvidos. São ensaios de fácil implementação e que envolvem pequenas quantidades de materiais. Geralmente, são baseados no estudo do comportamento reológico de pastas de cimento no estado fresco.

Quando esses ensaios são empregados de maneira adequada, é possível fazer uma primeira escolha do aditivo a ser usado, de modo a determinar as combinações eficientes e ineficientes. De acordo com sua experiência profissional, Aïtcin (2000) constata que estes métodos não são à prova de erros: algumas combinações que trabalham otimamente com uma pasta de cimento podem não ser 
tão eficientes com o concreto, enquanto outras podem apresentar um comportamento razoável com a pasta e um ótimo desempenho com o concreto, uma vez que os procedimentos de mistura dos dois materiais são diferentes. Ele também relata nunca ter descoberto uma combinação que não funcionasse com a pasta de cimento, mas que produzisse um concreto com bom comportamento reológico.

Dentre os vários métodos desenvolvidos, os mais utilizados são o ensaio de miniabatimento e o método do cone de Marsh. O ensaio de miniabatimento está relacionado com a tensão de escoamento das pastas de cimento para baixas taxas de cisalhamento, demanda pouco material e avalia a pasta a partir de um comportamento muito "estático". O método do cone de Marsh está relacionado com a viscosidade plástica para maiores taxas de cisalhamento, demanda uma quantidade um pouco maior de material e avalia a pasta em condições mais "dinâmicas". A escolha entre os dois métodos é pessoal, porém o uso simultâneo de ambos é interessante, uma vez que diferentes parâmetros reológicos são predominantes em cada um dos ensaios.

\section{Ensaio de miniabatimento}

O ensaio de miniabatimento foi desenvolvido por Kantro (1980) apud Bucher $(1988)^{[5.19]}$ e, como o próprio nome sugere, consiste em determinar o abatimento de pequenas quantidades de pasta de cimento usando o minitronco de cone apresentado na figura 5.5 .
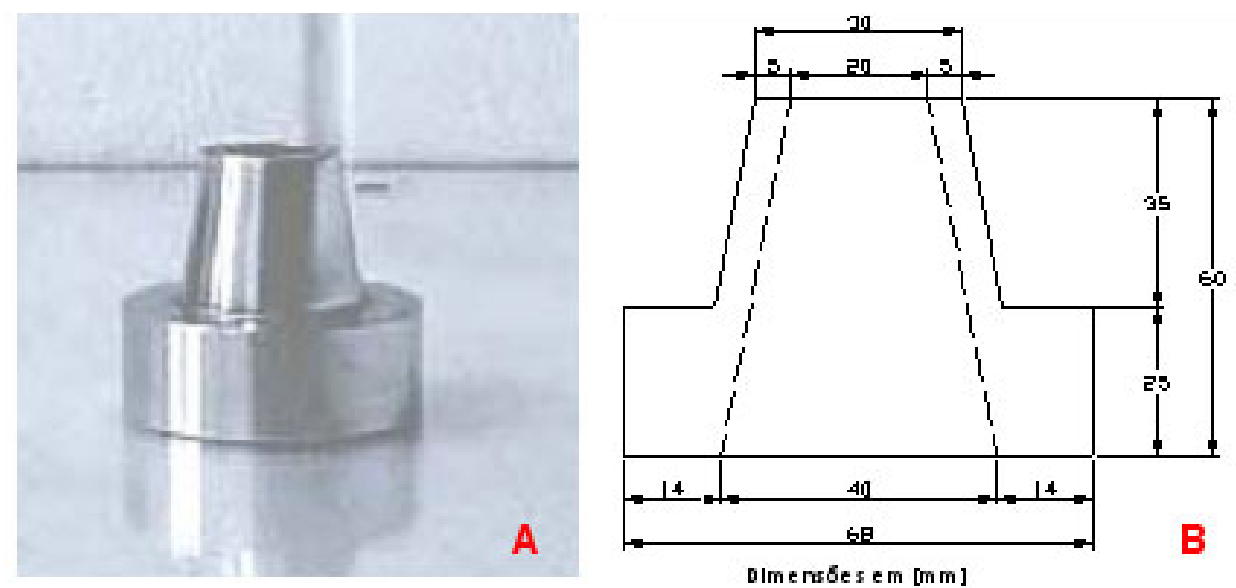

Figura 5.5 - Foto $(A)$ e esquema com as dimensões $(B)$ do minitronco de cone.

\footnotetext{
[5.19] KANTRO, D.L. Influence of water-reducing admixtures on properties of cement paste - A miniature slump test. Cement, Concrete and Aggregates, v. 2, n. 2, p. 95-102. 1980 apud BUCHER, H.R.E. Desempenho de aditivos redutores de água de alta eficiência em pastas, argamassas ou concretos. In: REIBRAC, 30., Rio de Janeiro, 1988. p. $609-625$.
} 
O ensaio consiste em determinar dois diâmetros perpendiculares de pasta abatida e, a partir do diâmetro médio, calcular a área ocupada pela pasta, considerando-a circular. Este ensaio tem sido utilizado na avaliação da influência de aditivos e/ou outras adições na fluidez da pasta de cimento e da compatibilidade entre o cimento e o SP.

Segundo Gomes (2002), as principais vantagens deste ensaio são: a utilização de um equipamento leve, barato, portátil e de fácil manutenção; e a adoção de um procedimento de ensaio simples, rápido e que envolve uma pequena quantidade de material. Uma desvantagem observada é a limitação deste ensaio para pastas que não apresentem alta fluidez.

De uma maneira geral, o ensaio pode ser desenvolvido seguindo os seguintes passos:

1) preparar uma base de vidro sem inclinação;

2) lubrificar a placa de vidro e o molde metálico do minitronco de cone;

3) preencher o molde com a amostra de pasta;

4) nivelar o topo do molde do minitronco de cone com o auxílio de uma pequena espátula (o material em excesso é coletado pela borda ampliada do molde metálico);

5) levantar o minitronco de cone suavemente, mantendo-o na posição vertical;

6) finalmente, medir os dois diâmetros perpendiculares de pasta de cimento espalhada.

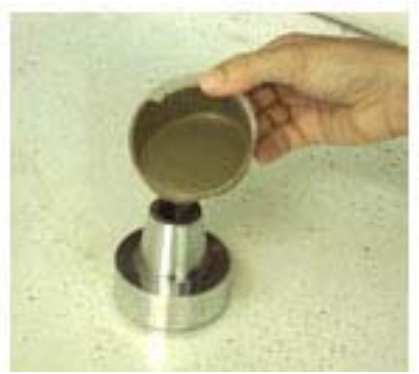

Figura 5.6a - Preenchimento do minitronco de cone com a pasta de cimento.

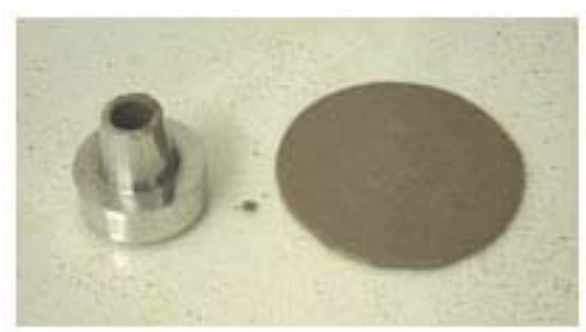

Figura 5.6c - Pasta de cimento espalhada sobre a placa de vidro.

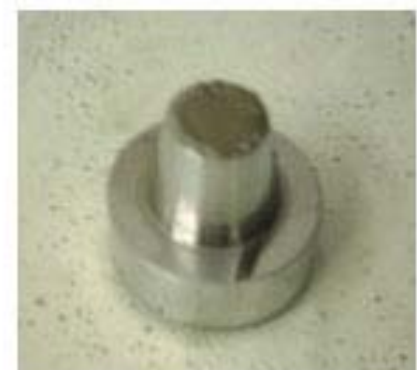

Figura 5.6b - Minitronco de cone preenchido com a pasta de cimento.

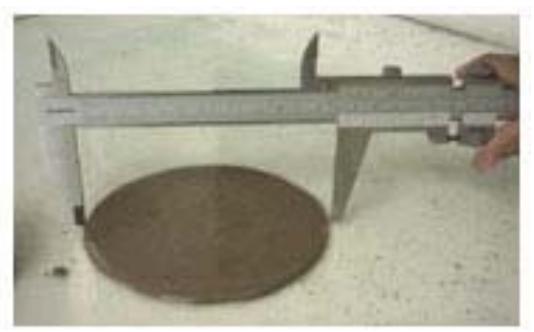

Figura 5.6d - Leitura de um dos diâmetros ortogonais da pasta de cimento espalhada.

Figura 5.6 - Exemplo de execução do ensaio de miniabatimento. 


\section{Ensaio do cone de Marsh}

O ensaio do cone de Marsh é um ensaio bastante simples que tem sido usado para a especificação, controle da qualidade e estudo da fluidez de pastas de cimento e argamassas e para a determinação do teor ótimo de SP para misturas de CAD.

Inicialmente, o método foi usado em diversos setores industriais para avaliar a fluidez de diferentes tipos de grautes e lamas, tais como as lamas de perfuração na indústria de petróleo, os grautes de injeção em rochas e em solos e os grautes de injeção para bainhas de protensão (AÏTCIN, 2000). A aplicação do ensaio de cone de Marsh na tecnologia do concreto iniciou nos anos 90 com o aumento da utilização do CAD, onde o ensaio faz parte do processo de desenvolvimento da mistura (determinação do traço). Considerando que a alta trabalhabilidade desses concretos é determinada pela composição das pastas e argamassas que o constitui, a utilização deste ensaio é de fundamental importância no estudo da reologia dos concretos.

Segundo Gomes (2002), as principais vantagens deste ensaio são: a necessidade de um equipamento simples e portátil; a utilização de pequenas quantidades de material para a sua realização; e o emprego de um procedimento de ensaio fácil de ser executado e repetido. Dentre as desvantagens estão a sensibilidade quanto a rugosidade da superfície do cone e a não utilização deste ensaio para a avaliação de pastas com baixa fluidez.

No estudo desenvolvido por Agulló et al. (1999), os autores apresentaram outras desvantagens. Primeiro, o ensaio considera a pasta de cimento como um fluido newtoniano, o que nem sempre é verdade. Como dito anteriormente, a pasta se comporta como um fluido binghamiano e, ao incorporar SP, a tensão de escoamento é reduzida sem qualquer mudança significativa da viscosidade plástica. Dessa maneira, considera-se que o tempo de escoamento determinado através do ensaio de cone de Marsh terá a mesma tendência da tensão de cisalhamento, como no caso da trabalhabilidade do concreto determinada a partir do ensaio de abatimento de tronco de cone. Segundo, a reologia da pasta no concreto poderá ser diferente da reologia da pasta preparada separadamente, sugerindo que a composição ideal final seja determinada a partir de ensaios realizados diretamente em concretos.

Do ponto de vista prático, observa-se que o cone de Marsh possui duas limitações (ROUSSEL \& Le ROY, 2005). Por um lado, se a viscosidade do fluido testado for muito baixa, não existe uma relação linear entre a viscosidade e o tempo 
de escoamento - para fluidos com baixa viscosidade, o tempo de escoamento não é uma medida significativa do ponto de vista reológico. Por outro lado, se o fluido testado possui uma tensão de escoamento, o escoamento poderá não ocorrer, isto é, o gradiente de pressão criado pelo peso do fluido acima da abertura do cone poderá não ser suficiente para que a tensão de cisalhamento exceda a tensão de escoamento na abertura; neste caso, o cone de Marsh se torna inútil.

O princípio do método consiste em medir o tempo que certa quantidade de pasta de cimento leva para escoar através de um funil com um dado diâmetro. Dessa forma, o tempo de escoamento está relacionado com a fluidez do material ensaiado, sendo considerado como o inverso de uma medida relativa da fluidez, isto é, quanto menor o tempo de escoamento, maior a fluidez do material [GOMES (2002); ROUSSEL \& Le ROY (2005); Le ROY \& ROUSSEL (2005)]. O tempo de escoamento depende do fluido ensaiado, mas também é influenciado pela geometria do cone.

$O$ ensaio é regulamentado pelas normas francesa (NF $P$ 18-358/85) e européia (EN 445/96). Uma aproximação semelhante foi padronizada pela norma americana ASTM C 939/87. No Brasil, este ensaio é regulamentado pela NBR 7682/83 - Calda de cimento para injeção - Determinação do índice de fluidez.

Basicamente, o cone de Marsh (figura 5.7) consiste de um cone plástico ou metálico com cavidade invertida, aberto na parte superior e com uma pequena abertura variável na parte inferior. Certo volume de material é colocado dentro do cone e o tempo gasto para que um volume pré-estabelecido escoe através do mesmo é monitorado. Na literatura, o diâmetro da abertura inferior pode variar entre $5 \mathrm{~mm}$ e $12,5 \mathrm{~mm}$ e o volume de pasta ou de argamassa inicial utilizado pode variar entre $800 \mathrm{ml}$ e $2000 \mathrm{ml}$. Como exemplos da variação do diâmetro e do volume de material podem ser citados trabalhos elaborados por Toralles-Carbonari et al. (1996) apud GOMES (2002) $)^{[5.20]}$, De Larrard et al. (1997b) e Aïtcin (2000): no primeiro, o cone utilizado apresentava abertura inferior com $8 \mathrm{~mm}$ de diâmetro e o ensaio foi realizado com volumes de pasta iguais a $200 \mathrm{ml}$ e $800 \mathrm{ml}$; o segundo trabalho, para a análise em argamassas, empregou um cone de Marsh com diâmetro de $12,5 \mathrm{~mm}$ e volume de material de $500 \mathrm{ml}$ e $1000 \mathrm{ml}$; por fim, o estudo

[5.20] TORALLES-CARBONARI, B. M. et al. A synthetic approach for the experimental optimization of high strength concrete. In: INTENATIONAL SYMPOSIUM ON UTILIZATION OF HIGH STRENGTH/ HIGH PERFORMANCE CONCRETE, 4. Paris: Eds. F. De Larrard and R. Lacroix, p. 161-167. 1996 apud GOMES, P. C. C. Optimization and characterization of high-strength self-compacting concrete. 2002. 139p. Tese (Doutorado) na Escola Tècnica Superior D'Enginyers de Camins, Canals i Ports de Barcelona, Universitat Politècnica de Catalunya, Barcelona. Setembro/2002. 
feito por Aïtcin (2000) utilizou um cone de Marsh com abertura inferior igual a $5 \mathrm{~mm}$ e volumes de pastas iguais a $500 \mathrm{ml} \mathrm{e} 1200 \mathrm{ml}$.
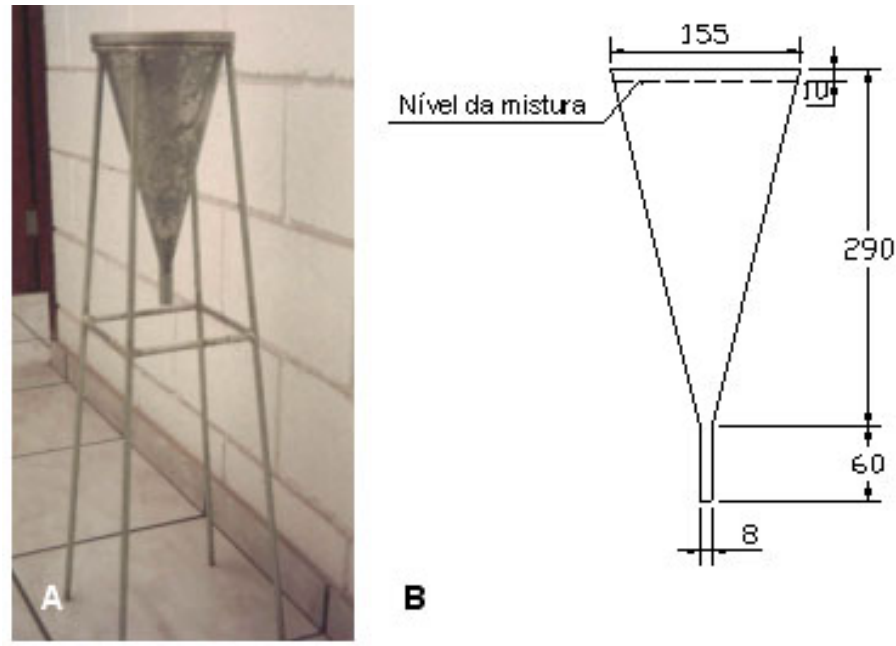

B

Figura 5.7 - Foto do equipamento completo $(A)$ e esquema detalhado do funil $(B)$ do ensaio do cone de Marsh empregado na presente pesquisa (dimensões em [mm]).

Segundo a NBR $7682 / 83$, os passos para a execução do ensaio do cone de Marsh são:

1) umedecer o interior do cone antes de cada medida;

2) posicionar o cone corretamente em seu suporte, de maneira que ele permaneça nivelado e livre de vibrações;

3) alinhar a proveta com o eixo do funil;

4) fechar a abertura inferior do cone com o dedo ou registro e lançar a amostra para dentro do cone até atingir a marca estabelecida;

5) abrir a abertura inferior e, no momento em que a calda atingir o fundo da proveta, acionar o cronômetro;

6) parar o cronômetro quando o béquer graduado for preenchido com o volume de pasta predeterminado.

Quando se mede o tempo de escoamento de uma pasta incorporada com SP através do cone de Marsh, é interessante seguir a mudança do tempo de escoamento durante a primeira hora que segue a mistura. Esses resultados fornecem uma indicação do comportamento de uma combinação cimento-SP durante o período crítico em que um concreto é transportado e lançado. O método do miniabatimento também pode ser usado para esse propósito (AÏTCIN, JOLICOEUR \& MacGREGOR, 1994).

Para uma determinada geometria e um dado procedimento de ensaio, o tempo de escoamento pode ser calculado em termos da tensão de escoamento e da viscosidade plástica para um determinado volume de pasta de cimento. O tempo 
de escoamento é proporcional à viscosidade, mas a tensão de escoamento tem que ser considerada para predeterminar o tempo de escoamento de um fluido em particular (ROUSSEL \& Le ROY, 2005). Porém, mesmo quando calibrado, o cone de Marsh não fornece dados suficientes para medir os dois parâmetros reológicos.

Assim, como o concreto se move através do orifício do funil, a tensão aplicada é maior que a tensão de escoamento. Portanto, relaciona-se este ensaio com a viscosidade do material. Caso o concreto não se mova através do funil, verifica-se uma tensão de escoamento maior que o peso do volume de material usado (FERRARIS, 1999).

\subsubsection{Ponto de saturação do aditivo}

Ultimamente, o desempenho de um concreto incorporado com SP é estabelecido em campo. Porém, muitos ensaios em pequena escala têm sido realizados em pastas de cimento e argamassas para se obter rapidamente informações do desempenho de diversas combinações cimento-SP e para determinar a concentração ótima de SP.

Geralmente, o tempo de escoamento diminui com o aumento do teor de SP. Porém, para um determinado teor de aditivo, o tempo de escoamento já não diminui significantemente. Esta dosagem é definida como ponto de saturação ou dosagem ótima, ou seja, é o ponto em que, nas condições experimentais consideradas para medir o tempo de escoamento, qualquer aumento na dosagem do aditivo não produz nenhum efeito significativo na reologia da pasta de cimento (AÏTCIN, 2000).

Não existe qualquer benefício em se utilizar mais SP do que a dosagem correspondente ao ponto de saturação. $\mathrm{Na}$ verdade, seria prejudicial usar uma dosagem mais alta. Após a introdução de uma dosagem excessiva de SP, a pasta de cimento se torna bastante fluida e não consegue mais manter o agregado graúdo (ou mesmo o agregado miúdo) em suspensão, resultando em uma severa segregação. Também podem surgir problemas de retardamento excessivo na pega do concreto caso o SP seja acidentalmente superdosado ou caso a composição do cimento seja mudada após a dosagem da mistura ter sido estabelecida (AïTCIN, JOLICOEUR \& MacGREGOR, 1994).

O ponto de saturação de um SP varia de um cimento para outro, quando usado o mesmo SP, e de um SP para outro, quando usado o mesmo cimento. Ele depende do tipo de cimento (finura, quantidade e reatividade do $\mathrm{C}_{3} \mathrm{~A}$, do teor e da taxa de dissolução dos sulfatos), da relação água/cimento, do tipo de SP, do tipo e 
da dosagem das adições minerais e da seqüência e tempo de mistura dos materiais constituintes [AÏTCIN, JOLICOEUR \& MacGREGOR (1994); AGULLÓ et al. (1999)]. Assim, com tantos fatores influenciando o comportamento dos SP na presença de um determinado cimento, já se compreende que a simples dosagem recomendada por um produtor de aditivo faz pouco sentido. Para cada combinação cimento-SP e dosagem de mistura existirá uma dosagem ótima de SP.

Usualmente, a determinação do ponto de saturação ou dosagem ótima de um aditivo é feita de forma subjetiva, dependendo da forma da curva obtida e do critério utilizado pelo pesquisador (GOMES, 2002). Dentre os vários métodos existentes, destacam-se os propostos por Aiticn (2000) e De Larrard et al. (1997b).

No primeiro procedimento de determinação, Aiticn (2000) considera como ponto de saturação a dosagem de aditivo onde as curvas "tempo de escoamento versus dosagem do SP" para tempos de medida de 5 minutos e 60 minutos se interceptam (figura 5.8). O ensaio analisa $500 \mathrm{ml}$ de pasta de cimento escoando por um cone de Marsh com abertura inferior de $5 \mathrm{~mm}$. Do ponto de vista prático, esse procedimento é válido ao considerar que o concreto não exibirá uma grande perda de escoamento ao longo do tempo; porém, esse procedimento pode levar à determinação de dosagens excessivas de SP (GOMES, 2002).

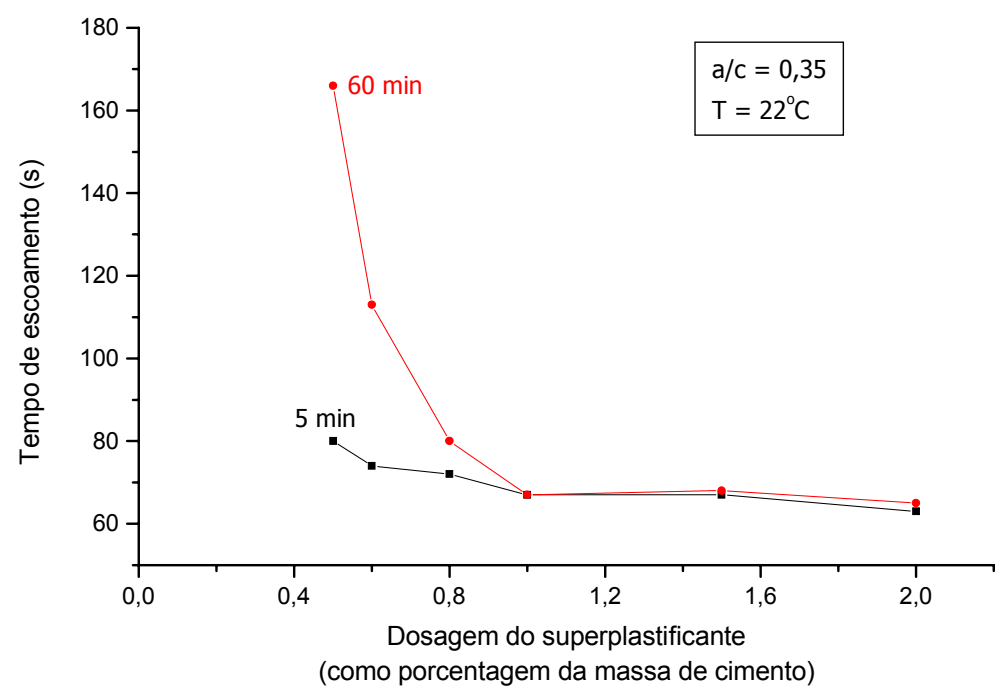

Figura 5.8 - Determinação do ponto de saturação do aditivo superplastificante pelo método apresentado por Aïtcin (2000).

O segundo método citado corresponde ao método AFREM desenvolvido por De Larrard et al. (1997b). O método avalia o tempo de escoamento de $500 \mathrm{ml}$ de argamassa através de um cone com abertura inferior igual a 12,5 mm. Neste método, o ponto de saturação do aditivo SP é considerado como o teor de aditivo onde uma reta com inclinação de 2:5 tangencia a curva "logaritmo do tempo de escoamento versus teor de SP" (figura 5.9). De acordo com os autores, a escolha 
da inclinação de 2:5 é arbitrária, porém foi adotada em função das proporções adequadas de aditivo determinadas a partir da mesma. Ainda, eles citam que a vantagem de se usar o logaritmo do tempo de escoamento está relacionada ao fato de que esse critério depende das características intrínsecas do material ensaiado.

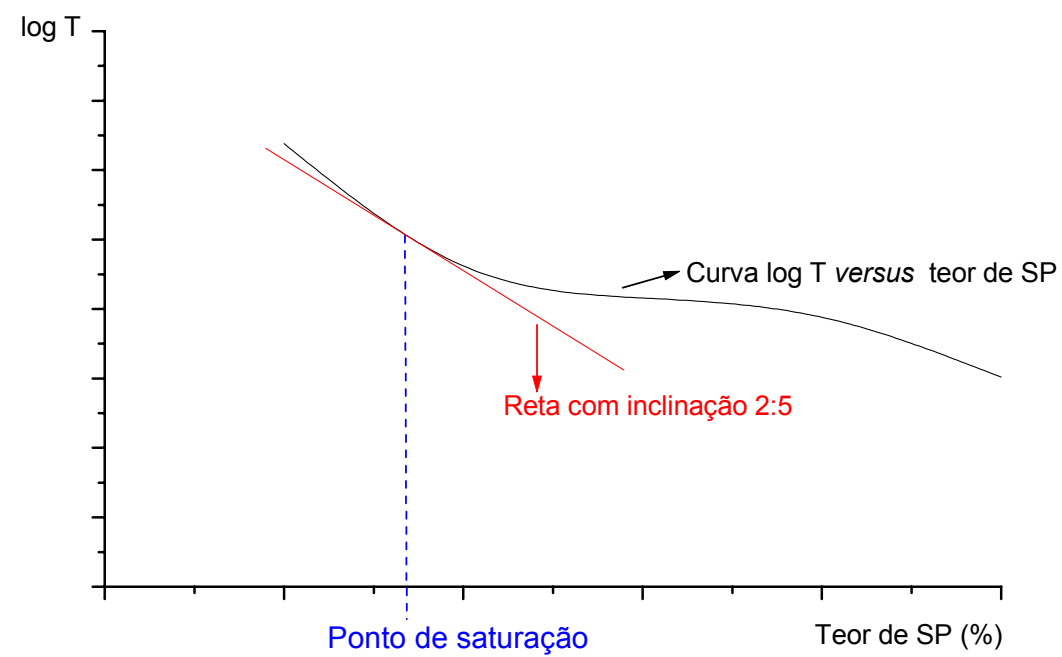

Figura 5.9 - Determinação do ponto de saturação do aditivo superplastificante pelo método AFREM desenvolvido por De Larrard et al. (1997b).

\subsubsection{Distribuição e empacotamento de partículas}

A fluidez inicial de soluções fortemente suspensas, tais como a pasta de cimento e o concreto, depende principalmente de considerações físicas, isto é, da distribuição granulométrica, do índice de forma e da textura superficial das partículas (BONEN \& SARKAR, 1995). Sendo assim, o projeto da distribuição de tamanho de partículas é de fundamental importância, pois promove o empacotamento e, juntamente com o fluido, define as características reológicas do material durante o processo de mistura e quando no estado fresco.

Segundo McGeary (1961) apud Pandolfelli et al. (2000) ${ }^{[5.21]}$, o estudo de empacotamento de partículas pode ser definido como "o problema da correta seleção da proporção e do tamanho adequado dos materiais particulados, de forma que os vazios maiores sejam preenchidos com partículas menores, cujos vazios serão novamente preenchidos com partículas ainda menores e assim sucessivamente".

Uma série de fatores pode alterar o empacotamento de um determinado conjunto de partículas. O primeiro a ser considerado é a existência de diversas distribuições granulométricas alterando a condição de dispersão inicial. Com isso,

[5.21] MCGEARY. R.K. Mechanical packing of spherical particles. Journal of the American Ceramic Society, v. 44, p. 513-522. 1961 apud PANDOLFELLI, V.C. et al. Dispersão e empacotamento de partículas: Princípios e aplicações em processamento cerâmico. São Paulo: Fazendo Arte, 2000. 195p. 
pode-se obter sistemas com fatores de empacotamento elevados - próximos de 1 até misturas onde esse fator se aproxima do nível das monodispersões (PANDOLFELLI et al., 2000).

O outro fator que pode alterar a condição de empacotamento é a morfologia das partículas. Quanto menos esférica for a partícula, menor será a densidade de empacotamento de uma distribuição que a contenha, pois ocorre o atrito entre as partículas a partir do contato das superfícies irregulares das mesmas. Quanto menor o tamanho das partículas irregulares, maior será esse efeito, devido à maior área superficial específica (PANDOLFELLI et al., 2000).

A porosidade interna das partículas também altera a densidade de um material. As partículas podem ser totalmente densas, com porosidade interna fechada ou com porosidade aberta. Para efeito de distribuição granulométrica, as partículas que apresentam porosidade fechada são semelhantes às densas, mas resultam em misturas com densidade menor. Já as partículas que apresentam porosidade aberta perturbam o empacotamento devido ao seu formato irregular e também resultam em misturas com menores densidades de empacotamento (PANDOLFELLI et al, 2000).

Empacotamentos com menor porosidade podem ser obtidos se os vazios existentes entre as partículas de uma dispersão forem preenchidos por partículas menores que os mesmos. Porém, caso sejam introduzidas partículas maiores que os vazios existentes, essas promoverão o surgimento de novos vazios, levando a um aumento na porosidade e redução da eficiência do empacotamento. Assim, a seqüência de preenchimento dos vazios existentes entre as partículas, ou melhor, a distribuição granulométrica do sistema determina o aumento ou não da densidade de empacotamento da monodispesão (PANDOLFELLI et al., 2000).

A granulometria melhorada do aglomerante e o efeito lubrificante imposto pelas partículas finas possivelmente reduzem o imbricamento entre os agregados e, conseqüentemente, a resistência ao escoamento: quanto mais fino e mais esférico for o material cimentício, maior a redução da resistência ao escoamento. $\mathrm{Na}$ presença de sílica ativa, onde mais aditivo torna-se necessário, a resistência ao escoamento será menor. Assim, de acordo com Nehdi, Mindess e Aïtcin (1998), uma determinada granulometria e finura que garantem o empacotamento ótimo das partículas de aglomerantes podem acentuar o escoamento do concreto.

A quantidade e o tipo de agregado desempenham um papel importante na trabalhabilidade do concreto fresco, em particular para a produção de CAD com baixa relação água/aglomerante. Os agregados possuem um efeito principal na 
reologia do concreto, aumentando consideravelmente tanto a viscosidade plástica quanto a tensão de escoamento.

\subsubsection{Segregação e exsudação}

Para uma completa abordagem da trabalhabilidade do concreto, deve-se considerar a estabilidade da mistura, isto é, sua capacidade de resistir à segregação e à exsudação. Para isso, é importante que, durante todo o processo de mistura, transporte e lançamento de um concreto, este mantenha uniformidade em sua composição (TATTERSALL, 1991b).

Porém, sabe-se que, no concreto fresco lançado, os agregados graúdos mais pesados sedimentam enquanto os elementos mais leves - como o ar incorporado, a água e a argamassa - tendem a subir, resultando em alguns efeitos indesejáveis, tal como a segregação e a exsudação (PETROU et al., 2000b).

A segregação é definida como a separação dos componentes do concreto fresco de maneira que sua distribuição não seja mais uniforme (MEHTA \& MONTEIRO, 1994). Existem dois tipos de segregação: o primeiro, que é uma característica das misturas secas, corresponde à separação dos agregados da argamassa do concreto; e o segundo, que é uma característica das misturas muito fluidas, corresponde à exsudação.

A exsudação é definida como um fenômeno cuja manifestação externa é o aparecimento de água na superfície do concreto após ele ter sido lançado e adensado, porém antes de ocorrer o início de pega [TATTERSALL (1991b); MEHTA \& MONTEIRO (1994)]. Ela resulta da incapacidade dos materiais constituintes de uma mistura de concreto em reter toda a água de amassamento em estado disperso enquanto os agregados mais pesados estiverem assentando.

Como causas da segregação e da exsudação estão a combinação de consistência inadequada, uma quantidade excessiva de partículas do agregado graúdo com massa específica muito alta ou muito baixa, a utilização de partículas com diâmetro máximo maior que $25 \mathrm{~mm}$, pouca quantidade de partículas finas, uma mudança desfavorável na forma das partículas, uma redução do teor de cimento, uma mudança no teor de água fazendo com que a mistura se torne muito seca ou muito fluida e os métodos impróprios de lançamento e adensamento do material [TATTERSALL (1991b); MEHTA \& MONTEIRO (1994)]. Segundo Aïtcin (2000), a segregação em um CAD pode ser produzida por um aumento acidental da 
dosagem de SP, ou seja, quando a dosagem estiver muito acima do ponto de saturação de um determinado cimento para a relação água/aglomerante escolhida.

Esses problemas podem ser reduzidos ou eliminados mediante um maior controle da dosagem e dos métodos de manuseio e lançamento do concreto. Aumentar a viscosidade de uma mistura melhora sua estabilidade e, conseqüentemente, reduz a segregação. Isso pode ser conseguido reduzindo-se a quantidade de água ou de SP do concreto, pela adição de pozolanas, pelo aumento do teor de cimento, pela adição de um aditivo incorporador de ar ou de aditivos que melhoram a viscosidade do material [TATTERSALL (1991b); AïTCIN (2000)].

Sabe-se que o concreto fresco apresenta uma tensão de escoamento abaixo da qual ele se comporta como um sólido e acima da qual ele flui como um líquido. A presença de uma tensão de escoamento em um meio retarda e pode até evitar a sedimentação natural dos agregados mais pesados [BERIS et al. (1985) apud PETROU et al. (2000b)] ${ }^{[5.22]}$. Um sólido pode ou não sedimentar em um meio dependendo do seu tamanho, da magnitude da tensão de escoamento do meio e da diferença de densidade entre o sólido e o meio (PETROU et al., 2000a). No caso do concreto fresco, o material apresenta uma tensão de escoamento que, sob determinadas condições, evita a segregação do agregado graúdo, embora sua densidade seja muito maior que a da argamassa.

Sendo assim, a densidade, a tensão de escoamento e a viscosidade de uma matriz pasta de cimento controlam a resistência à segregação para uma determinada distribuição de agregados em um concreto (SAAK, JENNINGS \& SHAH, 2001b). Uma tensão de escoamento e uma viscosidade mínimas são necessárias a uma pasta de cimento para evitar a segregação sob condições estática e dinâmica, respectivamente. Porém, os valores exatos desses parâmetros são dependentes da diferença de densidade entre a pasta e o agregado.

Se a tensão de escoamento ou a viscosidade for suficientemente alta, as partículas nunca segregarão; porém, o material também apresentará uma baixa trabalhabilidade. Assim, existe uma variação crítica para os parâmetros reológicos onde a segregação é minimizada.

Infelizmente não existe nenhum modelo teórico para a determinação da segregação de partículas em suspensão altamente concentradas como o concreto (SAAK, JENNINGS \& SHAH, 2001b). A influência das interações hidrodinâmicas, assim como a distribuição granulométrica e a morfologia das partículas estão entre

[5.22] BERIS, A.N. et al. Creeping motion of a sphere through a Bingham plastic. Journal of Fluid Mechanics, v. 158, p. 219-244, 1985 apud PETROU, M.F. et al. Influence of mortar rheology on aggregate settlement. ACI Materials Journal, v. 97, n. 4, p. 479-485, Jul.-Aug. 2000b.

Aplicação de conceitos reológicos na tecnologia dos concretos de alto desempenho 
os efeitos que levam às dificuldades na elaboração de tal modelo. Assim, a melhor maneira de determinar a resistência à segregação de tais materiais é através de métodos experimentais.

\subsubsection{Estado de dispersão das partículas}

As partículas de cimento apresentam uma grande tendência à floculação quando entram em contato com um líquido tão polar como a água, devido a vários tipos de interações: forças de Van der Waals entre as partículas, forças eletrostáticas entre posições de sítios com cargas opostas e forte interação ou ligação envolvendo as moléculas de água ou hidratos. Assumir tal estrutura floculada implica na retenção de certa quantidade da água de amassamento dentro dos flocos e, com isso, gera uma rede aberta de canais entre as partículas. Essa rede de vazios pode aprisionar parte da água que, por essa razão, fica indisponível para hidratar a superfície das partículas de cimento e para fluidificar a mistura (AïTCIN, JOLICOEUR \& MacGREGOR, 1994).

As forças responsáveis pela floculação são geralmente bastante fracas e se quebram facilmente por cisalhamento; assim, a tensão de escoamento promove o rompimento do conjunto floculado de maneira que a suspensão começa a escoar. Normalmente essa quebra não é completa e a floculação remanescente é rompida progressivamente à medida que a taxa de cisalhamento é aumentada, levando a um comportamento pseudoplástico geralmente acompanhado pela tixotropia (STRUBLE et al., 1998).

Essa aglomeração, permanente ou não, pode interferir no empacotamento e, conseqüentemente, na reologia das suspensões, visto que as partículas se juntam formando unidades móveis de tamanho efetivo maior (aglomerados). Esses aglomerados geralmente são porosos, proporcionando uma maior demanda de água para a mistura e uma maior instabilidade dos sistemas, gerando, assim, produtos com maior incidência de defeitos e com microestruturas heterogêneas.

A eliminação dos aglomerados de partículas pode resultar em uma série de vantagens com relação à reologia das suspensões. Verifica-se que a redução da distância de separação entre as partículas finas, provocada pelo aprisionamento de água no interior dos aglomerados, eleva o número de colisões entre elas e, com isso, a viscosidade da suspensão (PANDOLFELLI et al., 2000). Neste caso, a sedimentação dos aglomerados é favorecida, promovendo uma rápida separação 
entre as fases sólida e líquida da suspensão e, assim, prejudicando sua homogeneidade e estabilidade.

Para se conseguir uma distribuição homogênea da água e um ótimo contato água/cimento, as partículas de cimento deverão estar corretamente defloculadas e conservadas em um alto estado de dispersão. Além de apresentarem baixa viscosidade, as suspensões dispersas permitem a utilização de maiores concentrações de sólidos. Nelas, as partículas encontram-se individualizadas e, por isso, são pouco influenciadas pela força da gravidade (PANDOLFELLI et al., 2000). Dessa maneira, a homogeneidade e a estabilidade das suspensões são mantidas por um período maior.

Para se obter suspensões dispersas, as forças de repulsão entre as partículas devem exceder as forças de atração. Assim, o uso de dispersantes tornase necessário para evitar a sedimentação das partículas e conseqüente segregação de fases, o que possibilita a preparação de suspensões homogêneas com alta concentração de sólidos. Esses aditivos são eficientes na quebra das estruturas de partículas de cimento e em sua dispersão, evitando uma ligação prematura, minimizando a quantidade de água necessária para a suspensão e resultando em misturas mais trabalháveis pelo intervalo de tempo desejado (DAIMON \& ROY, 1978).

A fluidez melhorada do concreto pela adição de um aditivo orgânico é considerada como a causa principal da dispersão das partículas sólidas através das forças de repulsão eletrostática - devido ao aumento do potencial de superfície causado pelo aditivo adsorvido na superfície das partículas de cimento - e das forças de repulsão estéricas - baseadas na interação entre as camadas de adsorção do aditivo (UCHIKAWA, HANEHARA \& SAWAKI, 1997), embora outros mecanismos, como a liberação da água armazenada nos flocos de cimento e a inibição da hidratação da superfície das partículas de cimento, possam aumentar a fluidez de uma mistura. Fisicamente, isso significa que uma menor viscosidade e, conseqüentemente, um maior abatimento são obtidos (ANDERSEN, 1986).

As condições em uma suspensão de cimento e água podem ser modificadas de algumas maneiras a fim de evitar a formação de uma estrutura floculada. Dentre elas estão: a afinidade sólido-líquido (a separação das partículas ocorre quando a afinidade da superfície dessas partículas com a fase líquida excede as forças de atração entre elas); a expansão ou a contração da dupla camada elétrica ao redor das partículas; a geração de forças elétricas de repulsão entre as partículas por meio da adsorção de componentes ionizados (potencial zeta); e a construção de 
barreiras estéricas de proteção da floculação [DAIMON \& ROY (1978); TATTERSALL \& BANFILL (1983)]. Pandolfelli et al. (2000) apresentam três mecanismos básicos de dispersão (figura 5.10):

- eletrostático $\rightarrow$ desenvolvimento de cargas elétricas na partícula em decorrência da interação da sua superfície com o meio líquido;

- $\quad$ estérico $\rightarrow$ adsorção superficial de polímeros de cadeias longas que dificultam a aproximação das partículas por impedimento mecânico;

- $\quad$ eletroestérico $\rightarrow$ adsorção específica de moléculas com grupos ionizáveis ou polieletrólitos nas superfície das partículas, no qual os íons provenientes da dissociação desses grupos ionizáveis somam uma barreira eletrostática ao efeito estérico.
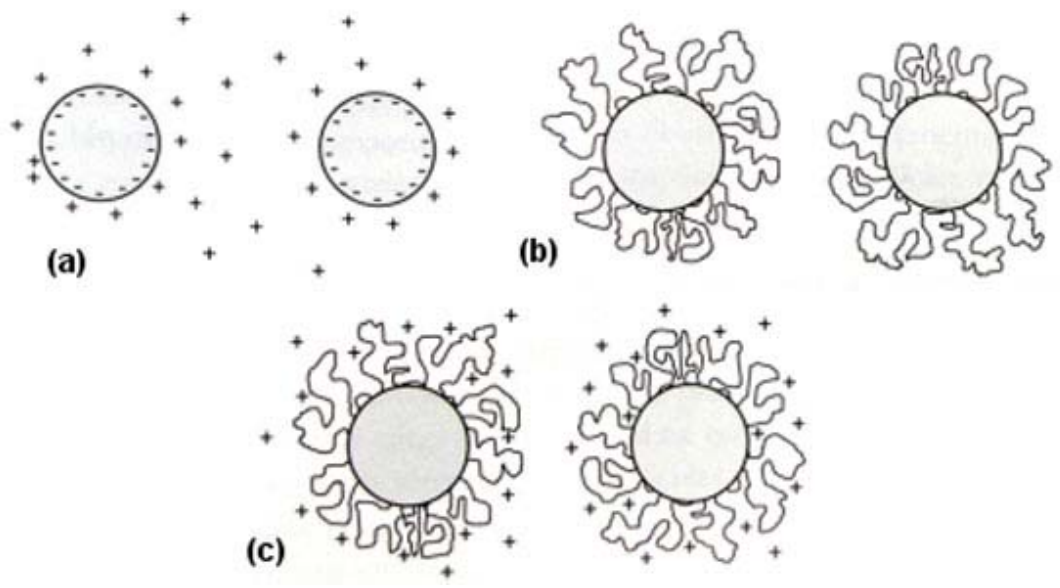

Figura 5.10 - llustração dos mecanismos de estabilização de suspensões: (a) estabilização eletrostática, (b) estabilização estérica e (c) estabilização eletroestérica

(PANDOLFELLI et al., 2000).

Em geral, a intensidade dos efeitos eletrostático e estérico na repulsão entre as partículas de cimento dependerá tanto da natureza química do polímero composição e estrutura - quanto do seu peso molecular (JOLICOUER \& SIMARD, 1998). Alguns estudos realizados mostraram que SP com maiores pesos moleculares são mais eficientes no aumento da fluidez de pastas de cimento do que os de menor peso molecular - fenômeno relacionado com o aumento do potencial zeta e com a adsorção de polímeros responsáveis pelo impedimento estérico - ou seja, são SP com maiores capacidades dispersantes [ANDERSEN, ROY \& GAIDIS (1988); MANNONEN \& PENTTALA (1996)].

Em misturas com alto teor de sólidos, tais como os concretos com baixa relação água/aglomerante (CAD), a defloculação e a ação dispersante dos SP desempenham um papel importante no efeito da fluidificação da mistura. Porém, outros fenômenos também poderão estar presentes e diferentes pesquisadores têm proposto uma variedade de efeitos ou mecanismos para explicar as propriedades 
combinadas de dispersão desses aditivos nos concretos. São elas: redução da tensão de superfície da água; repulsão eletrostática induzida entre as partículas; filme lubrificante entre as partículas de cimento; dispersão dos grãos de cimento, liberando a água aprisionada entre os flocos; inibição da reação de hidratação na superfície das partículas de cimento, deixando mais água livre para fluidificar a mistura; mudança na morfologia dos produtos de hidratação; impedimento estérico induzido evitando o contato partícula-partícula (AÏTCIN, JOLICOEUR \& MacGREGOR, 1994).

Assim, vários tipos de forças coexistem em uma suspensão à base de cimento. Existem forças de origem coloidal que surgem a partir das interações mútuas entre as partículas e que são influenciadas pela polarização da água. Quando a força de atração de van der Waals entre os grãos de cimento e a atração eletrostática entre cargas opostas na superfície das partículas são dominantes, o conjunto resulta em uma atração e as partículas tendem a flocular. Porém, na presença de materiais dispersantes, o conjunto resulta em uma repulsão e as partículas permanecem separadas. Com relação a isto, os materiais cimentícios suplementares podem influenciar as forças eletrostáticas dependendo de sua origem mineralógica e do estado das cargas da superfície de suas partículas. Como as forças coloidais também dependem da distância média entre as partículas vizinhas, a interposição de grãos desses materiais mais finos entre as partículas de cimento pode interferir na atração eletrostática e, conseqüentemente, na estrutura floculada. Igualmente, substituindo o cimento por um material com área específica diferente, muda-se a área superficial molhável e a quantidade de água adsorvida. Alguns finos, contendo uma determinada solubilidade em água, podem modificar a solução eletrolítica e, assim, as forças eletrostáticas (NEHDI, MINDESS \& AïTCIN, 1998).

Existem também forças viscosas que são proporcionais à diferença de velocidade de deslocamento entre as partículas de cimento e a água circundante e entre um agregado e a pasta de cimento que o envolve. Como os materiais à base de cimento estão dentro da faixa de suspensões densas, as partículas têm que se afastar, especialmente quando flocos são formados. O efeito fíler sobre a reologia depende da finura do material, de sua distribuição granulométrica e da forma de suas partículas. A viscosidade das suspensões geralmente aumenta à medida que se aumenta a divergência da granulometria ideal e atinge um mínimo para um determinado volume de água e para um arranjo de partículas mais compacto. Além do mais, qualquer divergência da forma esférica implica no aumento da viscosidade 
para um volume de pasta constante. Assim, na presença de SP, quanto mais fino e mais esférico for o material cimentício utilizado, melhores serão as propriedades reológicas da mistura. Esses materiais também podem apresentar diferentes eficiências para a adsorção do aditivo. Eles podem ser solúveis e introduzir íons que influenciam a cinética da reação de hidratação e a nucleação dos produtos da hidratação (NEHDI, MINDESS \& AïTCIN, 1998).

\subsubsection{Vibração}

A grande quantidade de trabalhos publicados nas décadas de 50 e 60 foi desenvolvida como uma tentativa para se decidir a freqüência e a amplitude ótimas de um equipamento de vibração, período em que se pensava que o parâmetro importante na avaliação da eficiência de um vibrador era a aceleração. Segundo esses estudos, para um vibrador senoidal, a aceleração era igual ao produto da amplitude e do quadrado da freqüência. Porém, essa afirmação simples foi rapidamente modificada e algumas exigências, como a amplitude mínima, foram sugeridas (TATTERSALL \& BANFILL, 1983).

A maior parte desses trabalhos foi feita com mesa vibratória e, na maioria deles, a eficiência de vibração foi avaliada pela medida das propriedades do concreto no estado endurecido para a verificação do grau de compactação alcançado. Evidentemente, é desejável fazer medidas no concreto fresco, isto é, examinar o efeito da vibração sobre a trabalhabilidade do material. Assim, embora seja a qualidade do material endurecido o objetivo final da produção de um concreto, uma melhor compreensão do processo de vibração será obtida a partir de estudos diretos do comportamento do concreto no estado fresco e, em particular, pela investigação da natureza de sua curva de escoamento.

Uma observação inicial do comportamento do concreto fresco sugere que o material possui uma tensão de escoamento e que a aplicação de uma força vibratória reduz essa tensão consideravelmente, pelo menos, em uma extensão tal que o material possa escoar sob a influência do seu peso próprio (TATTERSALL, 1991b).

Quando o concreto fresco é submetido à vibração, observam-se mudanças significativas em suas propriedades reológicas. Existe um indício de que a curva de escoamento do concreto vibrado passa através da origem, isto é, que o material efetivamente não possui mais uma tensão de escoamento, no entanto, sua curva não é mais uma relação linear simples (TATTERSALL \& BANFILL, 1983). Sob 
vibração, pode-se dizer que o concreto fresco se comporta como um fluido pseudoplástico e possui tensão de escoamento igual à zero, desde que certas condições limites de vibração não sejam excedidas (TATTERSALL, 1990).

Em um estudo desenvolvido com pastas de cimento por Dimond (1980) apud Tattersall e Baker (1988) ${ }^{[5.23]}$, o autor verificou que a vibração teve um efeito considerável sobre a tensão de escoamento desses materiais, sendo esse efeito imediato e também instantaneamente reversível. Em outras palavras, ao iniciar a vibração, observou-se uma queda imediata no torque e, ao desligá-la, o torque retornou imediatamente ao seu valor inicial.

Usando um equipamento conhecido como ensaio de dois pontos da trabalhabilidade (two-point workability apparatus), Tattersall (1991a) concluiu que o concreto sob vibração perde sua tensão de escoamento. Com um equipamento semelhante, Kakuta e Kojima (1991) verificaram que o concreto sob vibração muda de um material plástico com tensão de escoamento para um material pseudoplástico com pequena ou nenhuma tensão de escoamento. De Larrard et al. (1997a), usando um reômetro, observaram que, sob vibração, a tensão de escoamento das misturas de concreto estudadas caíram pela metade, tornado-se desprezível em alguns casos.

As causas da redução da tensão de escoamento devido à vibração ainda não são totalmente compreendidas. Petrou et al. (2000a; 2000b) especulam que a vibração deflocula os grãos de cimento e também rompe as fracas ligações químicas iniciais resultantes da gelificação da pasta de cimento fresco; também pode fazer com que o agregado graúdo se agite, destruindo o esqueleto inicialmente conectado. Dessa maneira, a redução da tensão de escoamento do concreto submetido à vibração pode estar relacionada com o enfraquecimento das ligações físicas e químicas entre os materiais constituintes da mistura.

Com relação à viscosidade plástica, Tattersall (1991a), Kakuta e Kojima (1991) verificaram que, através do ensaio de dois pontos da trabalhabilidade sob vibração, esse parâmetro reológico do concreto muda e o material se torna pseudoplástico. Porém, De Larrard et al. (1997a) não observaram qualquer mudança na viscosidade plástica quando o concreto foi submetido à vibração em um reômetro. Portanto, mesmo que a viscosidade plástica de uma mistura não seja modificada sob vibração, o concreto se tornará ainda mais trabalhável devido à redução de sua tensão de escoamento.

[5.23] DIMOND, C.R. Unpublished internal report, Department of Building Science, University of Sheffield, Feb. 1980 apud TATTERSALL, G.H.; BAKER, P.H. The effect of vibration on the rheological properties of fresh concrete. Magazine of Concrete Research, v. 40, n. 143, p. 79-89, Jun. 1988. 
Através do ensaio de dois pontos da trabalhabilidade, Tattersall e Baker (1988; 1989) verificaram que, quando a vibração é aplicada, as propriedades ao escoamento do concreto não são mais representadas pelo modelo binghamiano linear simples, mas que elas se aproximam da lei de potências de um fluido pseudoplástico sem tensão de escoamento. Além disso, sob baixas taxas de cisalhamento, o concreto vibrado pode ser considerado como um fluido newtoniano, pois dentro de uma variação restrita da taxa de cisalhamento, a curva de escoamento pode ser aproximada por uma linha reta que passa através da origem (TATTERSALL, 1991a; 1991b), cuja viscosidade não depende apenas da composição da misturas, mas também dos parâmetros de vibração e, em particular, da velocidade máxima de vibração (TATTERSALL, 1990). Essas considerações são válidas para condições de ensaio semelhantes às utilizadas no experimento (mesa vibratória), sendo que, no caso de vibradores internos, outros fatores também deverão ser considerados.

O comportamento semelhante ao de um fluido newtoniano permitiu o desenvolvimento de métodos de ensaio mais simples do que os métodos até então existentes. Nesse contexto, Kakuta e Kojima (1989) apud Tattersall (1991b) ${ }^{[5.24]}$ desenvolveram estudos para avaliar o efeito da vibração sobre as propriedades do concreto fresco e comprovaram que, sob baixas taxas de cisalhamento aplicadas durante a vibração, o material se comporta como um líquido newtoniano simples. Durante a vibração, existe uma amplitude e uma freqüência limites abaixo e acima das quais, respectivamente, a vibração não tem qualquer efeito prático sobre a tensão de escoamento. Assim, observa-se que a fluidez e, conseqüentemente, a trabalhabilidade de um concreto vibrado não depende apenas das propriedades e da proporção dos materiais constituintes da mistura, mas também dos parâmetros da vibração aplicada.

Segundo Börgesson e Fredriksson (1991), a vibração reduz a resistência ao cisalhamento de materiais à base de cimento se uma combinação correta da freqüência e da amplitude de oscilação da taxa de cisalhamento for aplicada. No estudo feito pelos autores, quando a freqüência e a amplitude foram aumentadas, a resistência ao cisalhamento foi reduzida. Em outra observação, eles verificaram que o efeito da mudança na freqüência foi maior do que o efeito relacionado com a mudança da amplitude, isto é, ao dobrar o valor da freqüência, seu efeito sobre o

[5.24] KAKUTA, S.; KOJIMA, T. Effect of chemical admixtures on the rheology of fresh concrete during vibration. In: INTERNATIONAL CONFERENCE ON SUPERPLASTICIZERS AND OTHER CHEMICAL ADMIXTURES IN CONCRETE, 3., 1989, Ottawa. Proceedings... p. 4-6, Oct. 1989 apud TATTERSAL, G.H. Workability and quality control of concrete. London: E \& FN SPON, 1991b. 262p. 
comportamento do material foi maior do que quando a amplitude foi dobrada. Porém, a energia necessária mostrou-se diretamente proporcional ao cubo da freqüência e ao quadrado da amplitude de oscilação, indicando que mais energia se torna necessária quando a freqüência for aumentada afim de se alcançar a mesma redução na resistência ao cisalhamento.

De acordo com Tarttersall e Baker (1988), a eficiência da vibração depende da velocidade máxima da vibração, sendo independente da relação água/cimento da pasta e, como inicialmente esperado, completa e instantaneamente reversível.

\subsection{Medição das propriedades reológicas do concreto fresco}

Quando as propriedades reológicas são determinadas em laboratório, diz-se que se está realizando ensaios de reometria. Para isso, existem diversas técnicas experimentais disponíveis que variam de acordo com o material a ser ensaiado.

No caso particular do concreto fresco, os métodos de ensaio para determinação de suas propriedades reológicas são divididos em dois grupos, os quais são separados de acordo com os resultados fornecidos: um ou dois parâmetros reológicos.

Os ensaios mais comuns medem apenas um parâmetro reológico e a relação entre o parâmetro medido e o segundo não é simples. Na maioria das vezes, é impossível calcular o parâmetro fundamental a partir do resultado obtido, podendo apenas garantir uma correlação entre eles.

A dimensão do maior agregado em um concreto impossibilita o uso de reômetros tradicionais, tais como o viscosímetro capilar ou o viscosímetro cilíndrico. Devido à dificuldade na identificação do real comportamento reológico dos concretos, alguns ensaios comparativos são utilizados. Alguns deles podem ser padronizados e são facilmente implementados e baratos. Eles apresentam, aproximadamente, o comportamento estático ou dinâmico da pasta de cimento através de valores globais (pega, espalhamento, duração do escoamento), os quais dificilmente estão relacionados aos valores específicos do material ensaiado (LANOS, LAQUERBE \& CASANDJIAN, 1996).

Para o CAD, a trabalhabilidade é avaliada por meio dos mesmos ensaios usados para o concreto convencional, mas suas características específicas impedem uma correta interpretação dos resultados (FERRARIS, 1999). Como exemplo, cita-se o ensaio de abatimento de tronco de cone, que é amplamente utilizado na prática das construções para determinação da trabalhabilidade dos 
concretos. Como esse método de ensaio fornece apenas um único valor (abatimento), críticas baseadas no argumento de que um mesmo valor de abatimento pode ser obtido por dois concretos com comportamentos reológicos diferentes têm sido feitas. A partir desse ensaio pode-se demonstrar que a tensão de escoamento está dentro da variação desejada, mas a viscosidade, que não é medida pelo ensaio, pode ser tão alta que a mistura rotulada como "pegajosa" torna-se difícil de ser moldada mesmo sob vibração.

Assim, tem sido amplamente discutida a necessidade pela descrição das propriedades reológicas do concreto fresco em termos de quantidades físicas fundamentais, independentes de detalhes do equipamento utilizado para sua caracterização. Qualquer ensaio que descreva o comportamento do escoamento do concreto fresco deve medir, pelo menos, os dois parâmetros reológicos. A exigência pelas duas constantes não é apenas uma questão de precisão científica, mas também de grande importância prática para o próprio controle e uso do concreto.

Infelizmente, a maioria dos ensaios existentes mede apenas um desses parâmetros, relacionado com a tensão de escoamento ou com a viscosidade plástica do material. De fato, os métodos de ensaio que medem somente um dos parâmetros reológicos podem apenas refletir a resposta do concreto fresco a uma taxa de cisalhamento em particular. Para se obter uma caracterização mais pertinente do comportamento do escoamento desse material, é necessário ensaiar as propriedades sobre certa variação da taxa de cisalhamento enquanto o concreto escoa (YEN et al., 1999).

Ao considerar a semelhança entre o comportamento do concreto fresco e um fluido binghamiano, verificam-se as vantagens em se utilizar de um ensaio capaz de medir os dois parâmetros reológicos sobre os ensaios padrões, que medem apenas um deles. As vantagens são: possibilidade de diferenciar concretos que poderiam ser erroneamente considerados iguais em termos de trabalhabilidade; abranger quase toda variação da trabalhabilidade (baixa até muito alta) em uma escala simples de medida; estimar um erro experimental para os resultados de cada ensaio; fornecer informações sobre as possíveis causas da variação de uma trabalhabilidade especificada e, dessa maneira, constatar os fatores que podem interferir nas propriedades do concreto quando no estado endurecido; fornecer informações sobre a tendência de uma determinada mistura à exsudação e à segregação (TATTERSALL, 1990; 1991b). Além disso, esses ensaios são menos influenciados pelo operador. 
Um ensaio no qual as determinações são feitas sob uma única taxa de cisalhamento, ou sob um único conjunto de condições de cisalhamento, não pode, em princípio, fornecer informação suficiente para descrever a trabalhabilidade, não importando quão complicado seja o ensaio nem quão sofisticado seja o tratamento dos resultados obtidos (TATTERSALL \& BANFILL, 1983). Assim, não é possível obter a curva de cisalhamento ou deduzir os valores das duas constantes reológicas que caracterizam o comportamento do concreto fresco; em outras palavras, não é possível finalizar o ensaio com mais informação do que quando ele foi iniciado. Neste caso, tudo o que pode ser feito é citar o valor único obtido ou tratar o material como um fluido newtoniano, mesmo quando ele não o é, isto é, dar o valor da inclinação da reta obtida a partir do único ponto experimental ligado à origem (TATTERSALL, 1991b). A inclinação dessa reta é a medida da viscosidade aparente, ou seja, é a viscosidade de um fluido newtoniano que se comportaria de maneira semelhante a um fluido binghamiano sob uma taxa de cisalhamento em particular.

Na seqüência são apresentados os métodos de ensaio e os equipamentos capazes de medir os parâmetros reológicos do concreto fresco segundo levantamento do estado da arte sobre o assunto feito por Ferraris (1996; 1999), dando-se ênfase aos equipamentos a serem utilizados na presente pesquisa.

\subsubsection{Ensaios que medem apenas um parâmetro reológico}

Os ensaios de abatimento de tronco de cone, penetração (Kelly ball, Vicat, ensaio Wigmore), viscosímetro de tubo rotativo e ensaio de K-slump estão relacionados com a tensão de escoamento, pois medem a capacidade do concreto iniciar o escoamento.

Já os ensaios consistômetro de Ve-Be, LCL, ensaio de vibração, cone de escoamento (Cone de Marsh), capacidade de preenchimento (caixa L) e aparelhagem Orimet estão associados à viscosidade plástica, pois medem a capacidade do concreto escoar depois que a tensão ultrapassa a tensão de escoamento. A tensão aplicada pode ser tanto por vibração quanto por gravidade.

\subsubsection{Ensaio de abatimento de tronco de cone}

O ensaio de abatimento de tronco de cone é bastante usado no cotidiano devido a sua simplicidade de execução. Ele é usado como uma boa ferramenta 
para o controle da qualidade do concreto, pois pode detectar pequenas mudanças na composição da mistura, isto é, o ensaio pode detectar variações no teor de água a partir da especificação original.

Esse método de ensaio pode fornecer respostas diferentes para uma mesma amostra de concreto quando realizado por diferentes operadores e mesmo quando repetido por um mesmo operador (DAY, 1996), verificando-se uma grande dispersão entre suas medidas. Os resultados desse ensaio não classificam as diferentes misturas de concreto em uma ordem correta de trabalhabilidade, permitindo que resultados de abatimentos semelhantes possam ser obtidos para misturas com trabalhabilidades diferentes. O ensaio é incapaz de diferenciar entre os concretos com níveis de trabalhabilidade muito baixa - aqueles onde o abatimento é zero - ou entre os concretos com níveis de trabalhabilidade muito alta - aqueles onde se observa o colapso durante o ensaio.

O equipamento utilizado consiste, basicamente, de um tronco de cone metálico aberto em ambas as extremidades (altura de $300 \mathrm{~mm}$, diâmetro inferior de $200 \mathrm{~mm}$ e diâmetro superior de $100 \mathrm{~mm}$ ), que é mantido firmemente apoiado sobre uma placa metálica não-absorvente (de $500 \mathrm{~mm} \times 500 \mathrm{~mm}$ ) por meio do posicionamento do operador sobre os apoios laterais fixados ao molde metálico. Ele é preenchido com concreto seguindo um procedimento padrão e, em seguida, levantado verticalmente. Com isso, o concreto sofre um abatimento, o qual é medido.

No Brasil, este ensaio é regulamentado pela NBR NM 67/98 - Concreto Determinação da consistência pelo abatimento do tronco de cone. Para a execução do ensaio, a norma prescreve os seguintes passos:

1) após a correta limpeza e umedecimento interno do molde, este deve ser colocado sobre a placa metálica de base, igualmente limpa e umedecida, que, por sua vez, deve apoiar-se em uma superfície rígida, plana e horizontal;

2) o molde é fixado através de suas aletas pelos pés do operador e preenchido em três camadas de volume aproximadamente iguais, com o auxílio do complemento troncocônico sendo que, na última camada, o concreto deve preenchê-lo totalmente. Cada camada deve ser adensada com 25 golpes uniformemente distribuídos aplicados com a haste de socamento e, durante o adensamento das camadas restantes, a haste deve penetrar até que a camada inferior subjacente seja atingida;

3) após o adensamento, retira-se o complemento troncocônico e remove-se o excesso de concreto com o auxílio da própria haste de socamento, que deve 
respaldar a superfície do concreto, deslizando sobre as bordas do molde. Imediatamente após, faz-se a limpeza da placa metálica de base em torno do molde;

4) em seguida, faz-se a desmoldagem elevando-se cuidadosamente o molde pelas alças na posição vertical, com velocidade constante e uniforme, num tempo de $(10 \pm 2) \mathrm{s}$;

5) por fim, mede-se o abatimento do tronco de cone. Ele corresponde à distância entre o plano correspondente à base superior do molde e o centro da base superior da amostra abatida, medida com régua metálica (figura 5.11).

Neste ensaio, a tensão consiste no peso próprio do concreto por área. concreto apenas se move caso a tensão de escoamento seja excedida e, assim que a tensão aplicada for menor que a tensão de escoamento do mesmo, ele estabiliza.

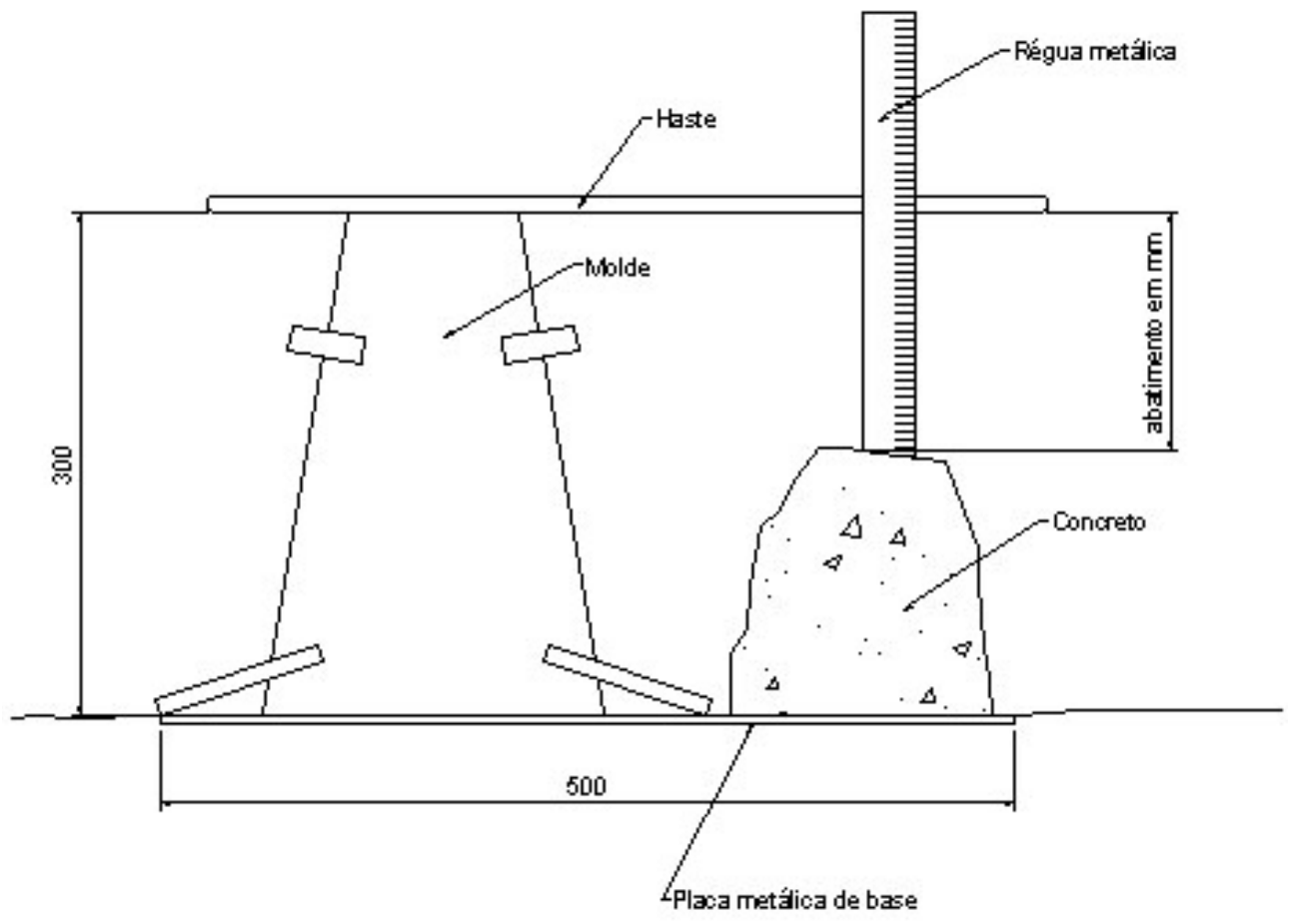

Figura 5.11 - Ensaio de abatimento de tronco de cone.

Segundo Tattersall (1991b), existem vários tipos de abatimento possíveis (figura 5.12): o abatimento verdadeiro, o colapso e o abatimento cisalhado (quando uma metade do cone de concreto cisalha sobre um plano inclinado). As normas especificam que o ensaio só é válido se o concreto apresentar um abatimento verdadeiro, onde o material permanece substancialmente intacto e simétrico. Caso o material apresente o abatimento cisalhado ou o colapso, outra amostra deverá ser tomada e o ensaio repetido. 


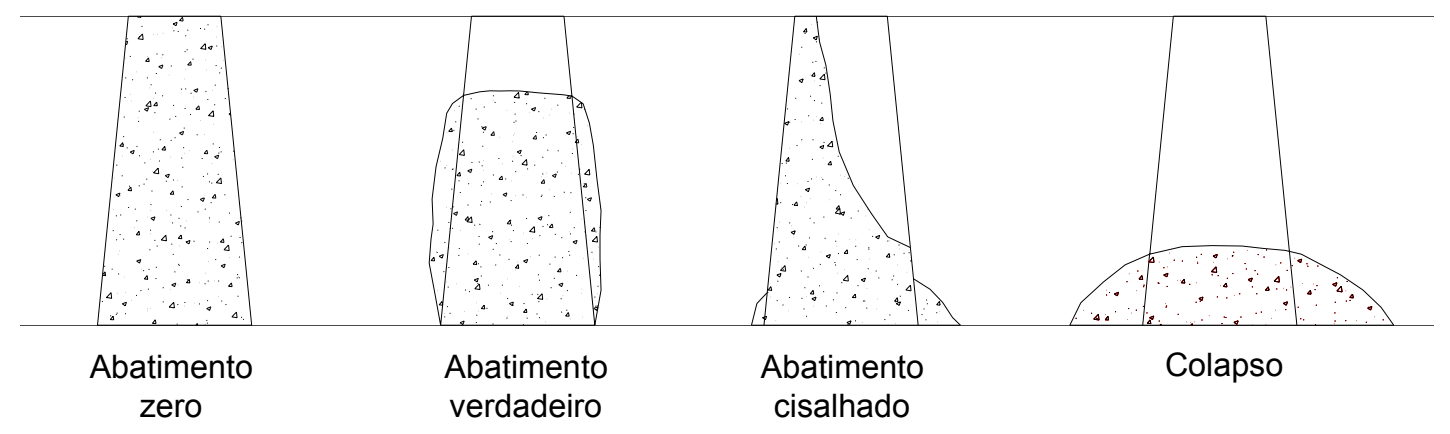

Figura 5.12 - Tipos de abatimento (TATTERSALL, 1991b).

No relatório do ensaio, deve-se apresentar a forma de abatimento exibida pelo material e, caso seja um abatimento verdadeiro, o valor desse abatimento. $\mathrm{Na}$ prática, é bastante comum observar o que seria considerado um caso contrário do abatimento verdadeiro definido pela normatização, isto é, um abatimento assimétrico por meio de uma leve inclinação de um de seus lados, de maneira que a superfície superior não fosse mais horizontal. Neste caso, a medida para o ponto mais alto seria normalmente determinada.

\subsubsection{Consistômetro de Ve-Be}

O ensaio de consistômetro de $\mathrm{Ve}-\mathrm{Be}$, inicialmente proposto por Bahrner (1940) apud Tattersall (1991b) ${ }^{[5.25]}$ - cujo objetivo era fornecer um ensaio capaz de avaliar o comportamento de concretos lançados sob vibração - corresponde a um ensaio de remodelagem desenvolvido por Powers (1932) apud Tattersall $(1991 b)^{[5.26]}$.

Este ensaio visa a determinação da consistência do concreto fresco pela avaliação da capacidade desse concreto mudar de forma quando submetido à vibração com o auxílio do consistômetro de Ve-Be (figura 5.13). De uma maneira geral, o ensaio consiste em determinar o tempo necessário para que um tronco de cone de concreto fresco se transforme em um cilindro sob a ação de uma vibração padronizada (freqüência de $50 \mathrm{~Hz}$, com amplitude de $0,35 \mathrm{~mm}$ sem concreto).

O emprego da vibração é necessário para que o concreto, em forma de tronco de cone abatido, seja remodelado e atinja a forma do cilindro, um processo que é observado através do disco transparente.

[5.25] BAHRNER, V. The Vebe consistency testing apparatus. Zement, v. 29, n. 9, p. 102-106. 1940; Betong, v. 25, n. 1, p. 27-38. 1940 apud TATTERSALL, G.H. Workability and quality control of concrete. London: E \& FN Spon, 1991b. 262p.

${ }^{[5.26]}$ POWERS, T.C. Studies of workability of concrete. Journal of the American Concrete Institute, p. 419-448, Feb. 1932; p. 693-708, June. 1932 apud TATTERSALL, G.H. Workability and quality control of concrete. London: E \& FN Spon, 1991b. 262p. 

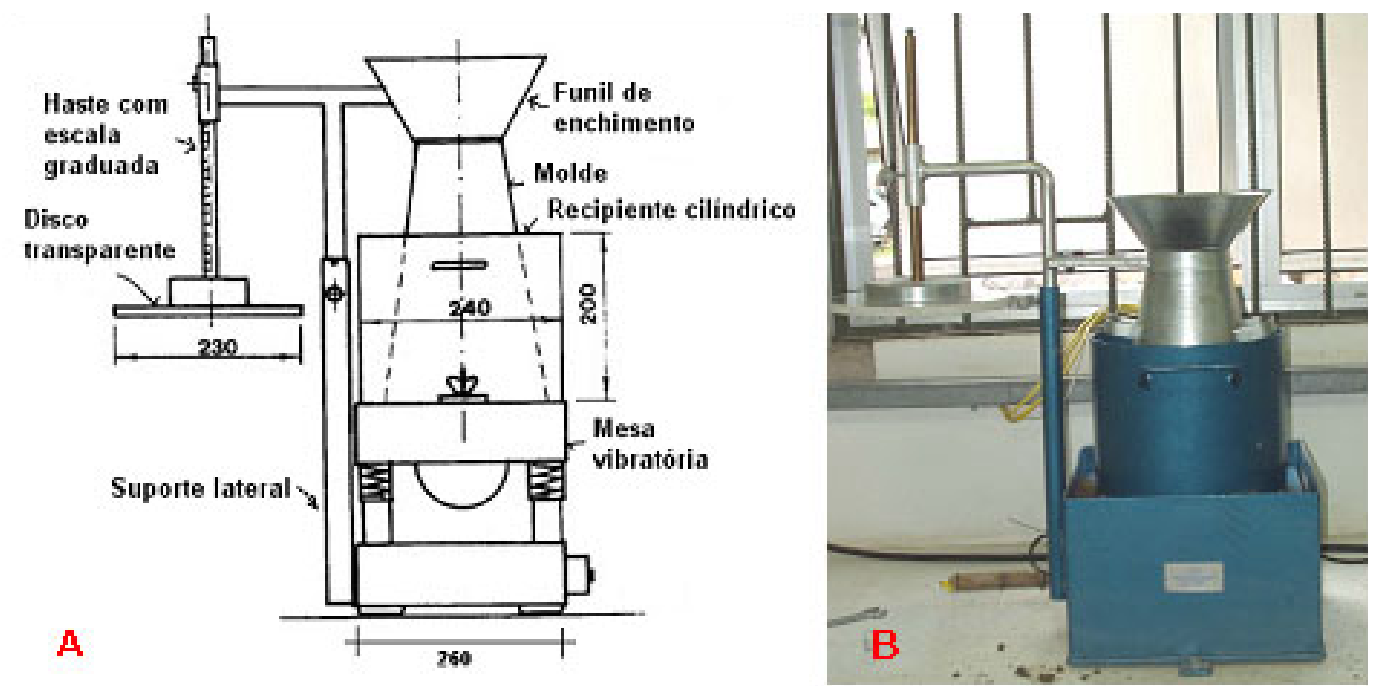

Figura 5.13 - (A) Esquema do consistômetro de Ve-Be (DNER-ME 094, 1994) e (B) foto do equipamento utilizado na presente pesquisa.

No Brasil, este ensaio é executado de acordo com a norma DNER-ME 094/94

- Concreto - Determinação da consistência pelo consistômetro de Ve-Be. O procedimento de ensaio segue as seguintes etapas:

1) inicialmente, deve-se molhar as superfícies com as quais o concreto entrará em contato;

2) em seguida, deve-se fixar o recipiente à mesa vibratória;

3) monta-se o molde centrado dentro do recipiente, adaptando o funil de enchimento e fixando o conjunto por meio de dispositivo adequado contido no suporte lateral;

4) preencher o molde com concreto, retirar o funil de enchimento e fazer a desmoldagem como especificado pela NBR NM 67/98;

5) mover o suporte lateral para permitir que o disco transparente, centrado com o recipiente, seja depositado sobre o concreto;

6) fazer a leitura do abatimento com o auxílio da escala da haste graduada;

7) acionar, simultaneamente, a mesa vibratória e o cronômetro;

8) por fim, quando o concreto preencher todo o espaço abaixo do disco, deve-se parar o cronômetro e desligar a mesa vibratória. Fazer a leitura do tempo decorrido.

Quando o tempo de vibração observado for menor ou igual a 3 segundos, o resultado do ensaio não é considerado significativo e a consistência deverá ser determinada por outro método de ensaio.

Neste ensaio, devido à vibração, o concreto só inicia seu escoamento quando a tensão de escoamento for ultrapassada. Assim, diz-se que este ensaio está 
relacionado com a viscosidade do material, porém essa relação não é direta (FERRARIS, 1996; 1999).

A vantagem do ensaio de remodelagem é que ele simula o lançamento de um concreto sob vibração, relacionando-se com sua aplicação em campo. Segundo Tattersall (1991b), a principal crítica a este ensaio é que o seu início e o seu final são mal definidos: no início, a vibração padrão leva um certo tempo para ser atingida, enquanto no final, como a taxa de umedecimento do disco pelo material diminui com o tempo, ela pode atingir um valor zero antes que toda a área seja coberta.

\subsubsection{Caixa $L$}

Este ensaio é utilizado para a determinação da capacidade de passagem do concreto, ou seja, mede a capacidade do concreto escoar dentro de um molde retangular com barras de diâmetro pré-estabelecido devido apenas ao seu peso próprio.

Em muitos países o ensaio da caixa $L$ é usado para a aceitação do concreto auto-adensável. Segundo Nguyen, Roussel e Coussot (2006), o ensaio exibe todos os fenômenos que ocorrem durante o lançamento do concreto: é uma superfície escoante livre tridimensional de um fluido não-newtoniano entre barras de aço que servem como obstáculos. Além disso, como o espaçamento entre as barras de aço é da mesma ordem da maior partícula presente na mistura de concreto ensaiada, o ensaio se mostra sensível a uma possível segregação dinâmica (contrária à segregação estática devido à ação da gravidade). Assim, o resultado do ensaio depende tanto do comportamento reológico do concreto fresco quanto da sua capacidade de permanecer homogêneo.

Os requisitos medidos são os tempos necessários para o concreto escoar até as marcas de $20 \mathrm{~cm}\left(T_{L 20}\right)$ e $40 \mathrm{~cm}\left(T_{L 40}\right)$ e a razão entre as alturas de concreto no fim e no início da caixa após o término do escoamento $\left(h_{2} / h_{1}\right)$, denominada de razão de bloqueio $(\mathrm{RB})$.

O ensaio consiste de uma caixa retangular (figura 5.14), provida de uma porta deslizante e de uma grade com barras de aço que ilustram a armadura utilizada em obras de concreto armado. A porta deslizante permanece fechada e a coluna da caixa é preenchida com concreto. Ao levantar a porta, aciona-se o cronômetro e mede-se o tempo necessário para o concreto, sob ação de seu peso próprio, atingir 
as marcas de $20 \mathrm{~cm}$ e $40 \mathrm{~cm}$, bem como a altura da camada de material nas extremidades da caixa.

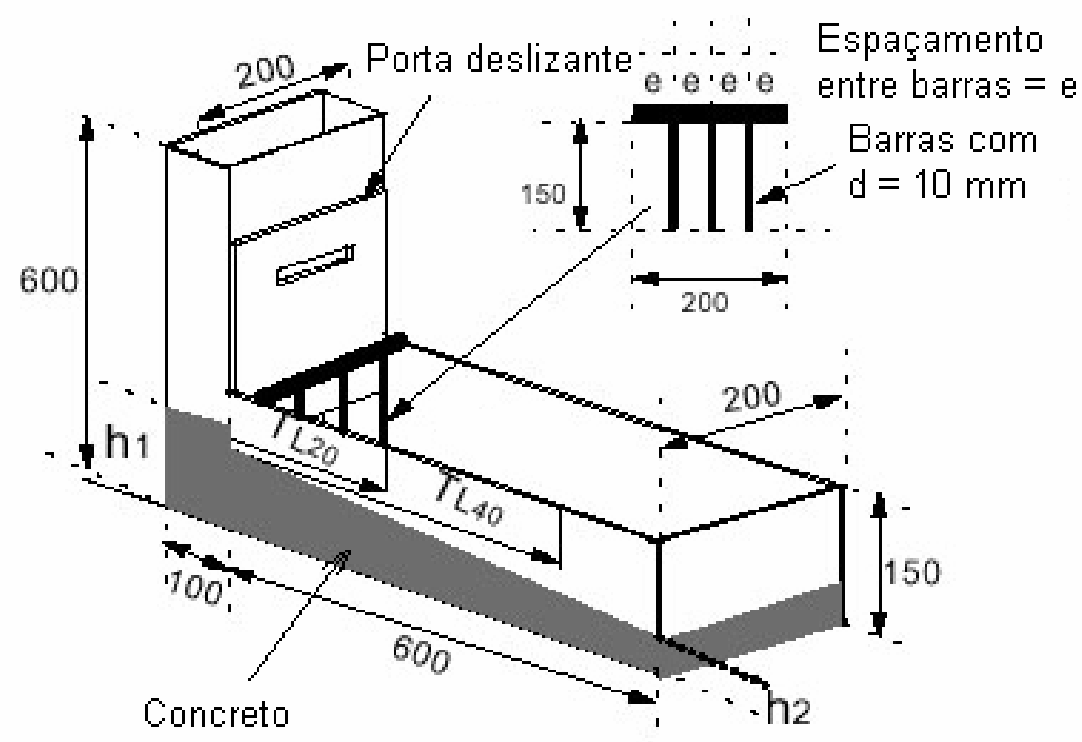

Figura 5.14 - Caixa L (GOMES, 2002).

medidas em [mm]

Para o espaçamento entre as barras, serão considerados os valores limites recomendados para o espaçamento mínimo livre entre as faces das barras longitudinais no sentido horizontal da NBR 6118/2003, ou seja, será adotado o maior valor entre $20 \mathrm{~mm}$, diâmetro da barra ou 1,2 vez o diâmetro máximo do agregado. O esquema das grades utilizado na presente pesquisa é mostrado a seguir (figura 5.15).

Grade para concreto com

$D_{\text {máx }} \leq 9,5 \mathrm{~mm}$

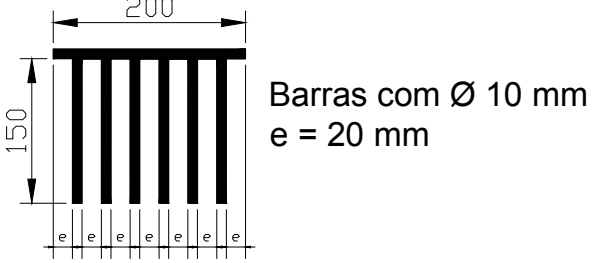

Grade para concreto com $D_{\text {máx }} \leq 25 \mathrm{~mm}$

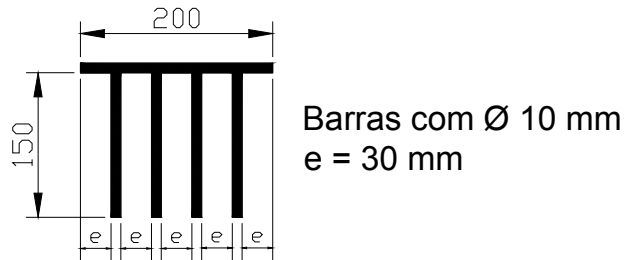

Figura 5.15 - Detalhe das grades a serem utilizadas no ensaio da Caixa $L$.

De acordo com Nguyen, Roussel e Coussot (2006), a porta da caixa $L$ deve ser aberta lentamente, de maneira que o resultado do ensaio dependa apenas da tensão de escoamento do material, que é o parâmetro mais importante quando se controla a capacidade de um concreto preencher uma determinada fôrma. Caso contrário, o resultado do ensaio torna-se dependente de uma combinação das propriedades intrínsecas da amostra (tensão de escoamento, viscosidade plástica, 
densidade) e de parâmetros externos (como, por exemplo, a taxa de levantamento da porta).

\subsubsection{Ensaios que medem os dois parâmetros reológicos}

Atualmente, existem ensaios capazes de fornecer os dois parâmetros reológicos que caracterizam o comportamento de um concreto no estado fresco, porém eles não necessariamente permitem um cálculo direto da viscosidade plástica nem da tensão de escoamento. Os valores determinados nestes ensaios estão relacionados com os dois parâmetros reológicos que caracterizam o comportamento do material.

Quando a dimensão máxima de uma partícula é pequena, como no caso das pastas de cimento, a curva de cisalhamento completa pode ser obtida em um reômetro com um espaçamento de poucos milímetros entre as superfícies cisalhantes e os parâmetros reológicos - tensão de escoamento e viscosidade plástica - podem ser determinadas através de análises convencionais considerando o escoamento laminar (DOMONE, YONGMO \& BANFILL, 1999). As argamassas, compostas por partículas de diâmetro máximo igual a $2 \mathrm{~mm}$, têm sido satisfatoriamente ensaiadas com reômetros de cilindros coaxiais com um espaçamento de $20 \mathrm{~mm}$.

No caso dos concretos, a avaliação reológica desses materiais tem encontrado alguns problemas. De acordo com Ferraris (1996; 1999), a dificuldade em desenvolver ensaios capazes de medir diretamente os valores corretos destes parâmetros está relacionada à dimensão máxima característica do agregado graúdo, à tendência à segregação a aos efeitos do tempo. Caso os agregados possuam dimensões iguais ou superiores a $10 \mathrm{~mm}$, as dimensões dos instrumentos de medida deverão ser imensas, pois as dimensões mínimas entre as superfícies de cisalhamento deverão ser de pelo menos 2 ou 3 vezes o diâmetro máximo desses agregados.

Porém, algumas soluções alternativas têm sido utilizadas com grande sucesso. Dentre os métodos de ensaio desenvolvidos, destaca-se: o ensaio de dois pontos da trabalhabilidade (two-point workability test), o mecanismo Bertta e o reômetro. Recentemente, uma modificação no ensaio de abatimento de tronco de cone tem sido usada como um método de ensaio capaz de determinar os dois parâmetros reológicos do concreto. 


\subsubsection{Ensaio de abatimento de tronco de cone modificado}

O ensaio de abatimento de tronco tradicional é capaz de medir apenas propriedades relacionadas com a tensão de escoamento do concreto fresco. Assim, recentemente, uma modificação neste método de ensaio tornou possível obter medidas relacionadas com a viscosidade plástica do material.

Para caracterizar a viscosidade plástica, os autores da mudança no ensaio decidiram se basear em uma taxa média de abatimento durante o ensaio. Dessa maneira, intervalos de tempo necessários para se alcançar uma altura intermediária entre os valores inicial e final de abatimento pareceram, a priori, uma boa maneira para se descrever a viscosidade dos concretos.

Segundo Ferraris e De Larrard (1998b), durante a escolha da altura intermediária de abatimento, dois problemas potenciais foram levados em consideração: primeiro, abatimentos muito baixos poderiam levar a tempos de abatimento muito pequenos e, assim, resultariam em baixa precisão nas medidas; e segundo, um abatimento parcial que fosse muito alto poderia excluir todos os concretos com abatimentos finais menores. Assim, como a variação de abatimento dos concretos capazes de serem avaliados com reômetros é maior que $100 \mathrm{~mm}$, este valor foi adotado como o valor do abatimento parcial.

Dessa maneira, o uso de um disco deslizante por uma haste localizada centralmente na placa de base horizontal foi adotado como um meio de monitorar o tempo gasto para se atingir o abatimento de $100 \mathrm{~mm}$ (figura 5.16). A haste foi colocada de acordo com o eixo de simetria do tronco de cone e, como o eixo de simetria do concreto não muda significantemente durante o escoamento, nenhum distúrbio significativo provocado pela haste foi verificado no abatimento.

A fim de se medir o tempo de abatimento parcial, utilizou-se um cronômetro controlado por um operador. Este cronômetro é iniciado no momento em que o molde de tronco de cone é retirado e parado quando o disco deslizante colocado sobre o concreto fresco atinge a marca de $100 \mathrm{~mm}$, sendo travado nessa posição (figura 5.17). A precisão da medida de tempo é da ordem de décimos de segundos devido ao tempo de reação do operador. 


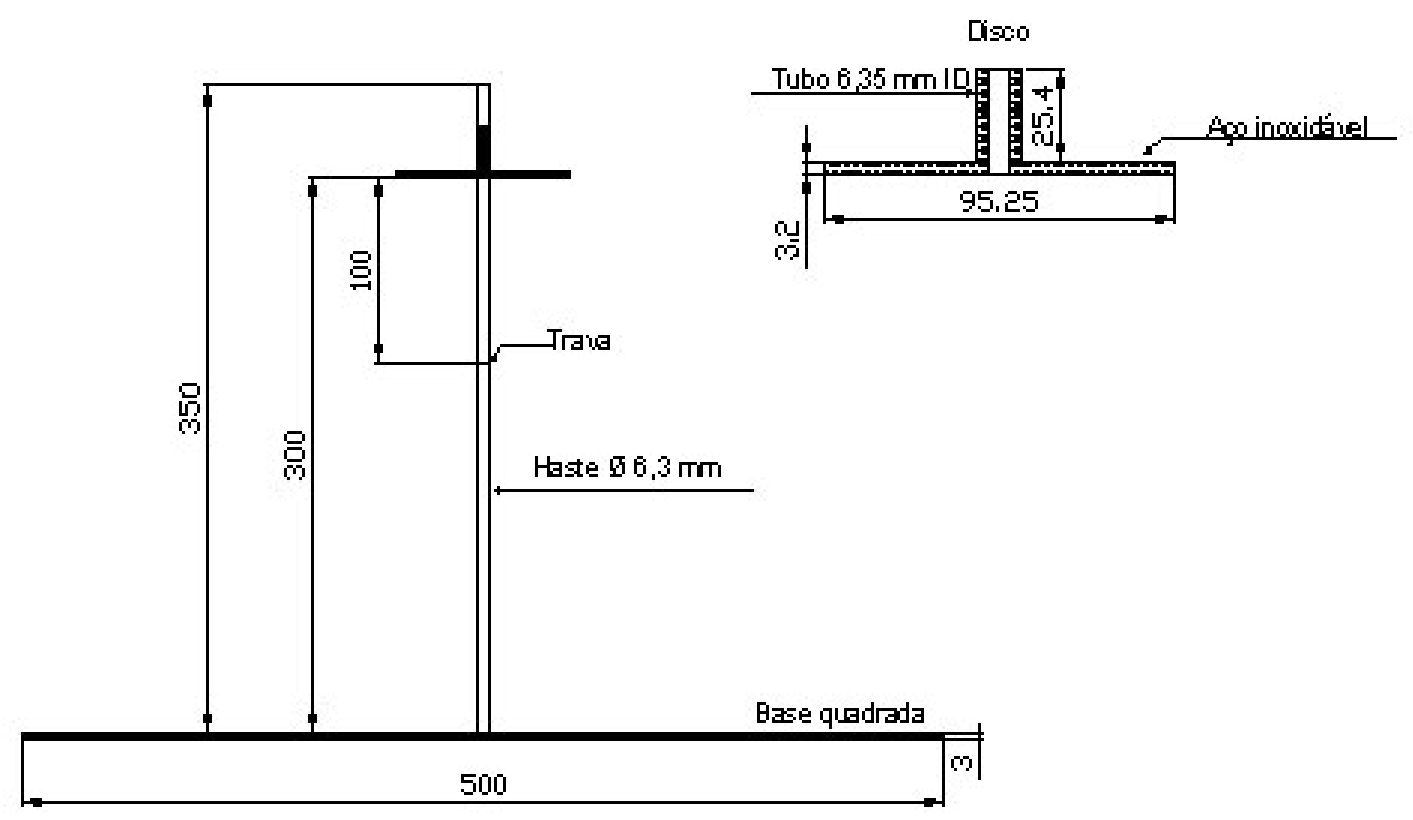

Medices em [Trm]

Figura 5.16 - Haste para a realização do ensaio de abatimento modificado. Disco deslizante no detalhe (FERRARIS \& De LARRARD, 1998b).

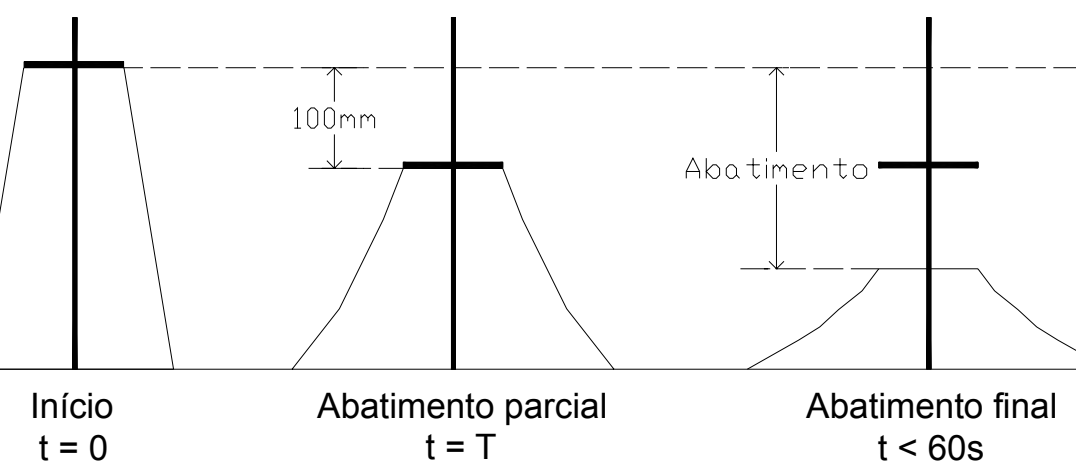

Figura 5.17 - Esquema do ensaio de abatimento de tronco de cone modificado (FERRARIS \& De LARRARD, 1998b).

O procedimento de ensaio para medir o tempo de abatimento (slump time) é bastante simples. Os passos para a execução do ensaio são:

1) limpar cuidadosamente a haste e revestí-la com desmoldante;

2) com o auxílio de uma esponja, umedecer a placa de base horizontal e o interior do molde de tronco de cone;

3) colocar o molde sobre a base garantindo que seu eixo coincida com o da haste;

4) enquanto o molde é mantido firme sobre a base, preso com o auxílio dos pés do operador, preenchê-lo de acordo com as recomendações da NBR NM 67/98;

5) alisar a superfície do concreto com uma colher de pedreiro;

6) limpar a parte da haste localizada acima da amostra de concreto; 
7) deslizar o disco pela haste até que este entre em contato com a superfície do concreto;

8) levantar o molde verticalmente e, simultaneamente, acionar o cronômetro;

9) enquanto o concreto é abatido, observar o disco continuamente (desde o topo do molde) e parar o cronômetro assim que o mesmo atingir a marca de abatimento de $100 \mathrm{~mm}$, travando nessa posição;

10) uma vez estabilizado o abatimento, ou não depois de um minuto após o início do ensaio, remover o disco deslizante e medir o abatimento com uma régua.

Para o cálculo dos parâmetros reológicos, tensão de escoamento e viscosidade plástica, a partir dos dados obtidos neste ensaio, foram desenvolvidas equações onde a tensão de escoamento e a viscosidade plástica estão relacionadas com o abatimento final e com o tempo de abatimento parcial do concreto fresco, respectivamente.

No caso da tensão de escoamento $\left(\tau_{0}\right)$, um modelo proposto por $\mathrm{Hu}$ [De LARRARD et al. (1994) apud FERRARIS \& De LARRARD (1998b)] ${ }^{[5.27]}$ foi adaptado pelos autores por não apresentar boa precisão nos resultados em situações onde a viscosidade plástica do material fosse maior que 300 Pa.s. Empiricamente, o modelo de Hu foi melhorado pela adição de uma constante e pela modificação no termo de inclinação da reta, resultando na seguinte equação:

$$
\tau_{o}=\frac{\rho}{347}(300-S)+212
$$

onde $\rho$ é a densidade do concreto em $\left[\mathrm{kg} / \mathrm{m}^{3}\right]$ e $S$ é o abatimento final em [mm].

Considerando concretos com abatimentos inferiores a $260 \mathrm{~mm}$, as equações empíricas para o cálculo da viscosidade plástica são (FERRARIS \& De LARRARD, 1998b):

$$
\begin{array}{llrl}
\mu & =1,08.10^{-3}(S-175) \rho T & & \text { para } 200 \mathrm{~mm}<S<260 \mathrm{~mm} \\
\mu & =25.10^{-3} \rho T & & \text { para } S<200 \mathrm{~mm}
\end{array}
$$

onde $\mu$ é a viscosidade plástica em [Pa.s] e $T$ é o tempo de abatimento parcial em [s].

A fim de se evitar cálculos, a tensão de escoamento e a viscosidade plástica podem ser calculadas com o auxílio de ábacos (figura 5.18). O cálculo é feito a partir de medidas de abatimentos finais e tempos de abatimentos parciais para concretos com massa unitária de $2400 \mathrm{~kg} / \mathrm{m}^{3}$.

${ }^{[5.27]}$ De LARRARD, F. et al. Design of a rheometer for fluid concretes. In: INTERNATIONAL RILEM WORKSHOP ON SPECIAL CONCRETES: WORKABILITY AND MIXING, p. 201-208, 1994 apud FERRARIS, C. F.; De LARRARD, F. Modified slump test to measure rheological parameters of fresh concrete. Cement, Concrete and Aggregates, v. 20, n. 2, p. 241-247, Dec. 1998b. 

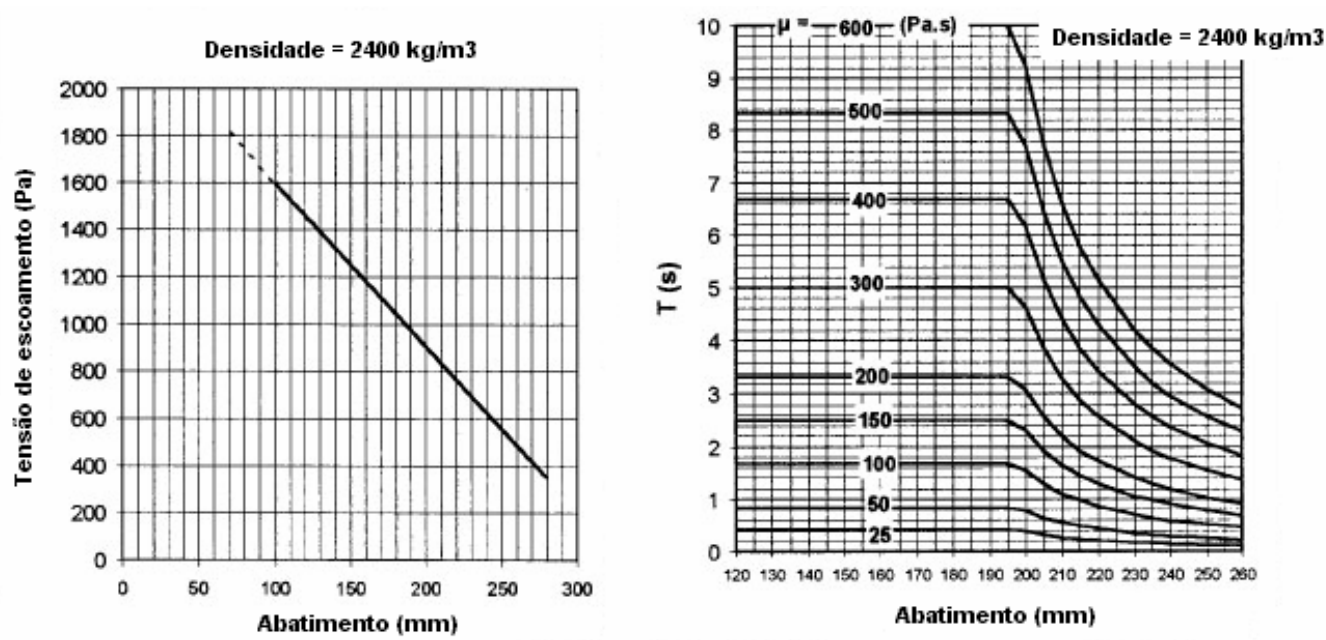

Figura 5.18 - Ábacos para estimativa da tensão de escoamento e da viscosidade plástica do concreto a partir dos resultados do ensaio de abatimento modificado (para concretos com densidade de $2400 \mathrm{~kg} / \mathrm{m}^{3}$ ) (FERRARIS \& de LARARRD, 1998b).

\subsubsection{Reômetro}

Reômetros são equipamentos direcionados à avaliação das propriedades reológicas de fluidos e suspensões. Eles permitem estudar o comportamento da tensão de escoamento e da viscosidade plástica em função de outras variáveis, como tempo, temperatura etc.

Os reômetros são equipamentos precisos não apenas para pesquisa, mas também para estudos práticos e medidas de controle de qualidade do material. Eles dão muito mais informações dos que os ensaios empíricos convencionais, reduzindo os custos com material e mão-de-obra. Também, as informações obtidas são mais objetivas, uma vez que o ensaio é totalmente automatizado e controlado por computador (De LARRARD et al., 1996).

O primeiro reômetro desenvolvido especificamente para a caracterização de concretos foi concebido por Powers (1968), no conceito de cilindros coaxiais (figura 5.19). Baseado nesse modelo, diversos outros equipamentos foram desenvolvidos. Com a evolução tecnológica dos reômetros, surgiram equipamentos que utilizam novos conceitos para o cisalhamento do material, dentre os quais se destaca o reômetro BTRHEOM (figura 5.20) desenvolvido no Laboratoire Central des Ponts et Chaussées (LCPC), França (De LARRARD et al., 1997a). Esse reômetro é baseado no conceito placa/placa, no qual um anel de concreto de eixo vertical é cisalhado, sendo sua seção inferior fixa e sua seção superior rotativa em torno do eixo. 


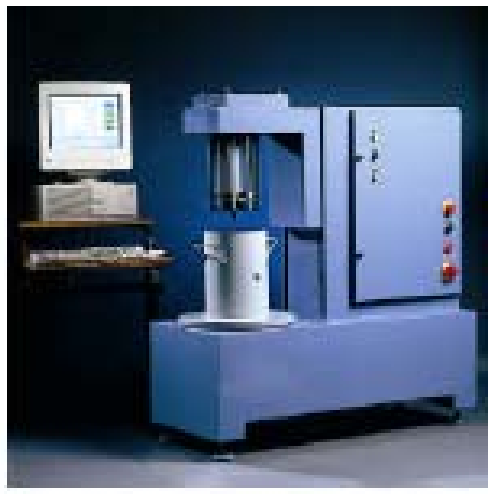

Figura 5.19 - Reômetro BML, baseado no conceito de cilindros coaxiais (BANFILL et al., 2001).
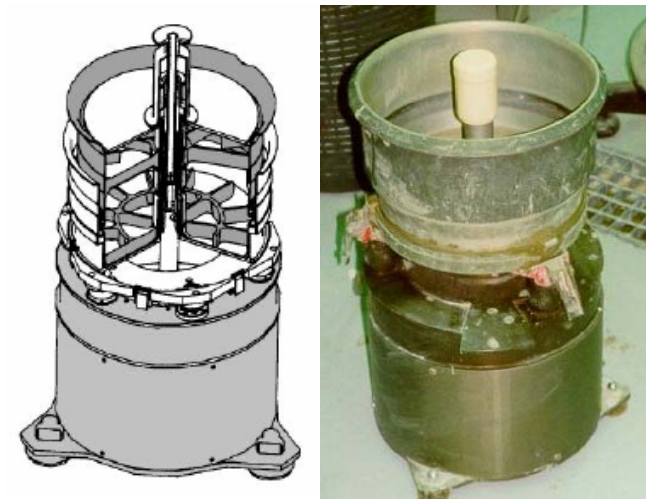

Figura 5.20 - Reômetro BTRHEOM, baseado no conceito placa/placa (BANFILL et al., 2001).

Os diversos reômetros disponíveis comercialmente se baseiam em apenas dois princípios básicos de funcionamento [STEIN (1986) apud PILEGGI (2001)] ${ }^{[5.28]}$ : reômetro em que o torque aplicado ao fluido é controlado, sendo avaliado o cisalhamento resultante - indicado para avaliações em que a tensão de escoamento é a principal propriedade a ser determinada; e reômetro em que o cisalhamento aplicado ao material é controlado, sendo registrada a força necessária para tal - indicado para avaliações do comportamento da viscosidade do material sob diversas taxas de cisalhamento.

As medidas obtidas a partir de um reômetro só podem ser interpretadas caso o fluido avaliado seja homogêneo. Devido à extensa variação da distribuição granulométrica das partículas presentes em uma mistura de concreto, esse material não pode ser considerado como tal. Assim, a descrição das características dessa classe de material em termos de tensão de cisalhamento e taxa de cisalhamento é imprecisa. Uma aproximação mais precisa seria a análise direta das forças (torque) que resultam do cisalhamento (velocidade de rotação) do concreto (PILEGGI et al., 2000).

No caso dos concretos, os reômetros são indicados para materiais com consistência fluida. Além de determinar o comportamento reológico desses materiais, os reômetros apresentam geometrias que são especialmente adequadas para a avaliação de formulações durante a mistura e o transporte, simulando condições de escoamento turbulento.

O reômetro usado foi desenvolvido na Universidade Federal de São Carlos e destinado à avaliação reológica de concretos refratários. O projeto foi baseado em

[5.28] STEIN, H.N. Rheological behavior of suspensions. In: ENCYCLOPEDIA OF FLUID MECHANICS - SLURRY FLOW TECHNOLOGY, v. 5. Houston: Gulf Publishing, 1986. p. 3-47 apud PILEGGI, R.G. Ferramentas para o estudo e desenvolvimento de concretos refratários. 2001. 187p. Tese (Doutorado) em Ciência e Engenharia de Materiais, Universidade Federal de São Carlos. São Carlos. 21/08/2001. 
um misturador planetário originalmente composto por um motor de corrente alternada (1 CV e 1140 RPM), um câmbio de quatro velocidades (28, 48, 80 e 132 RPM no eixo de saída para o planetário) e uma cuba cilíndrica com capacidade para misturar até $10 \mathrm{~kg}$ de concreto (PILEGGI, 2001).

A vantagem da consideração do modelo planetário é que este permite que tanto concretos com alta fluidez quanto concretos com fluidez reduzida e sem coesão sejam avaliados. Essa possibilidade amplia o campo de utilização do equipamento quando comparado aos reômetros de cilindros concêntricos, além de permitir o estudo da mistura e a simulação de diversas técnicas de aplicação dos concretos, dentre outras coisas (PILEGGI, 2001).

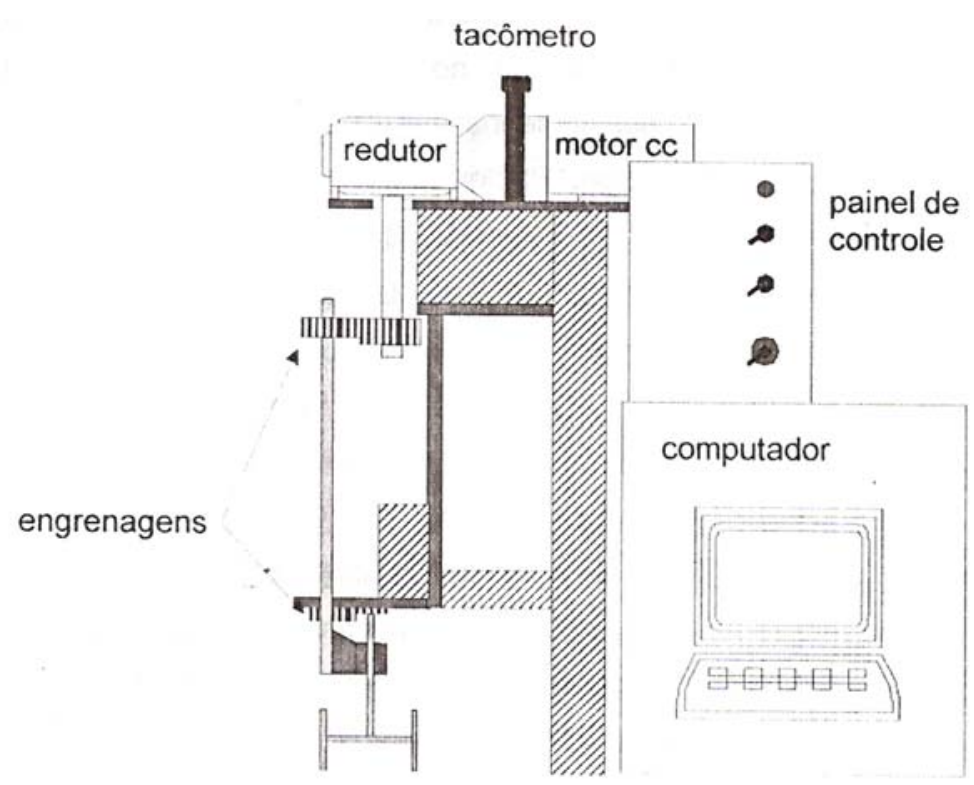

Figura 5.21 - Diagrama esquemático do reômetro planetário usado na presente pesquisa (PILEGGI, 2001).

As peças do dispositivo planetário e a pá misturada foram construídas em aço inox, sendo dimensionadas para que a distância entre o elemento móvel e a parede da cuba seja de $10 \mathrm{~mm}$. O sistema de fixação das pás é feito através de rosca, proporcionando o travamento efetivo durante o funcionamento do equipamento. É possível acoplar um dispositivo adaptador para a fixação de elementos móveis centrais no eixo central do planetário, permitindo que o equipamento também opere como um reômetro de cilindros concêntricos (PILEGGI, 2001).

O sistema de redução original do misturador foi mantido para transferir a rotação do motor para o planetário. O câmbio de quatro velocidades permite adequar a relação força/velocidade de rotação para cada ensaio em particular, sendo possível trabalhar desde baixas até muito elevadas rotações com precisão (PILEGGI, 2001). 
Porém algumas mudanças foram feitas no misturador original. A primeira alteração consistiu na redução da capacidade da cuba de mistura de $10 \mathrm{~kg}$ para 4 kg e na instalação de entradas para sensores de $\mathrm{pH}$ e temperatura. Para o controle da rotação do equipamento e, conseqüentemente, aplicação do cisalhamento desejado ao concreto, um servo-motor de corrente contínua de 2 CV substituiu o motor original e a velocidade de rotação tornou-se variável (entre 0 e 3000 RPM, na qual é atingido o torque máximo de $7 \mathrm{Nm}$ ) [PILEGGI et al. (2000); PILEGGI (2001)].

O controle da rotação é feito pela variação da voltagem de alimentação, que é diretamente proporcional à rotação. O motor também é ligado a um tacômetro, permitindo uma maior confiabilidade na rotação medida. Assim, esse motor mais potente e capaz de atingir rotações mais elevadas permite que as misturas de concreto sejam estudadas sob condições extremas de cisalhamento (PILEGGI, 2001).

A introdução de um servo-motor de corrente contínua exigiu a construção de um painel de controle, no qual estão contidos um conversor de corrente alternada para contínua, um sistema de segurança que limita a corrente máxima que pode ser fornecida ao motor, um controlador de rotação do motor, além de pontos de conexão para a comunicação com um computador (PILEGGI, 2001). O painel de controle foi conectado a um computador e um software específico também foi desenvolvido para controlar o reômetro e analisar os dados coletados (PILEGGI et al., 2000).

As leituras do $\mathrm{pH}$ e da temperatura da amostra de concreto durante o desenvolvimento do ensaio no reômetro são feitas por meio de sondas fixadas nos dispositivos anexados à cuba de mistura, permitindo sua fácil remoção para limpeza e manutenção. O eletrodo de $\mathrm{pH}$ (vidro) foi colocado dentro de um sistema protetor de aço inox, evitando que partículas grosseiras constituintes do concreto o atinjam, porém permitindo o escoamento da matriz ao seu redor. $O$ sensor de temperatura foi introduzido dentro de uma cápsula de aço inox, que é colocada diretamente dentro da cuba, não necessitando do sistema de proteção. Ambas as sondas são acopladas a um sistema digital de leitura de $\mathrm{pH}$ e temperatura, o qual é conectado a um computador, sendo os resultados também registrados pelo software do reômetro (PILEGGI, 2001).

O equipamento controla a velocidade de rotação (cisalhamento) da pá usada para misturar o concreto e para medir a força (torque) necessária para manter a pá movendo sob uma determinada rotação. Assim, o reômetro (figura 5.22-A), em sua arquitetura final, é um equipamento que possui força, velocidade e precisão 
suficientes para estudar os mais variados tipos de concretos. Ele permite o estudo de diferentes aspectos da preparação desse material, incluindo o procedimento de mistura, a influência das adições e o comportamento reológico, entre outros. É uma ferramenta eficiente para a caracterização de concretos e, o mais importante, ele contribui para o preenchimento do espaço entre a tecnologia dos concretos e sua caracterização (PILEGGI et al., 2000).

Na mesma figura, é apresentado um outro reômetro que também foi utilizado na pesquisa (figura 5.22-B). Esse equipamento constitui uma evolução do primeiro reômetro desenvolvido no laboratório e é composto com os mesmo detalhes técnicos, mecânicos e de funcionamento descritos anteriormente, porém possui alguns fatores adicionais em sua concepção: apresenta uma arquitetura específica para ensaios de reometria (arquitetura helicoidal planetária) e o controle pode ser microprocessado tanto por rotação quanto por torque (controle: Plataforma Linux que permite precisão no posicionamento e na automatização dos ensaios).

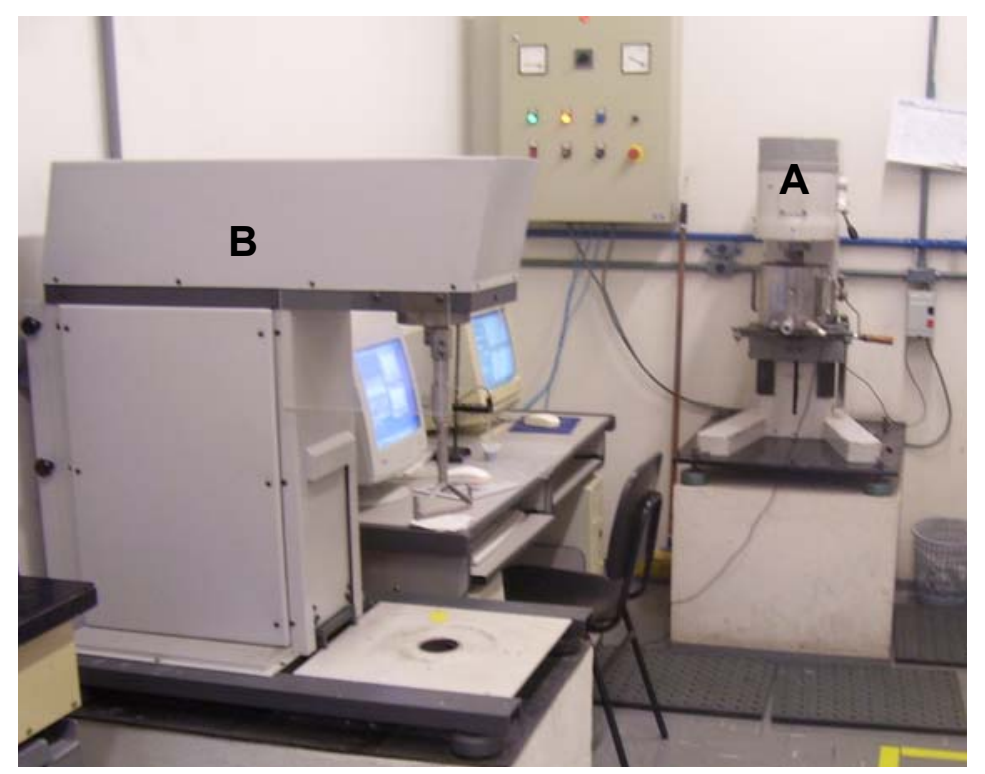

Figura 5.22 - Fotografia dos reômetros usados na presente pesquisa.

\section{Curvas de cisalhamento}

As propriedades reológicas do concreto fresco são determinadas a partir da plotagem de curvas de cisalhamento com o auxílio de um reômetro. Dessa maneira é possível determinar a relação entre a tensão de cisalhamento e a taxa de cisalhamento sob condições definidas fisicamente.

A condição experimental (ciclo de cisalhamento) deve ser definida antes do cálculo dos parâmetros reológicos. Embora não exista nenhuma restrição quanto à seleção da condição de cisalhamento, uma condição complicada geralmente é evitada e condições mais simples são frequentemente adotadas (HATTORI \& 
IZUMI, 1991). De acordo com Wallevik e GjØrv (1990a), para uma suspensão à base de cimento, onde certos fenômenos dependentes do tempo também estão envolvidos, a mudança na velocidade de rotação (taxa de cisalhamento) deve ser feita em escada e não continuamente.

As curvas de cisalhamento são necessárias para caracterizar adequadamente materiais à base de cimento como fluidos não-newtonianos, uma vez que sua viscosidade depende tanto da taxa de cisalhamento quanto da duração do cisalhamento (SUHR, 1991).

Quando um concreto é submetido a uma taxa de cisalhamento gradualmente crescente e, posteriormente, essa taxa é uniformemente reduzida à zero, a curva resultante (curva descendente) poderá ou não coincidir com a curva anterior (curva ascendente). A esse gráfico dá-se o nome de curva de histerese, construída quando o material sofre uma quebra estrutural sob a ação de um cisalhamento (TATTERSALL \& BANFILL, 1983). Esse volume de histerese, cuja área representa o trabalho relacionado com o volume cisalhado, permite uma análise qualitativa do cisalhamento, sendo possível, então, tirar conclusões quanto à estabilidade da estrutura desses materiais (SUHR, 1991).

Os tipos das curvas de cisalhamento de suspensões usadas para classificar os fluidos variam entre si em função da influência das condições de ensaio. A forma exata dessa curva para um determinado material não depende apenas de suas propriedades, mas também da maneira com que a curva é obtida e, em particular, da taxa de acréscimo e de redução da taxa de cisalhamento (TATTERSALL \& BANFILL, 1983). As curvas de histerese são úteis como um indicador preliminar do comportamento, porém elas não fornecem uma boa base para a análise quantitativa desse comportamento. Uma técnica alternativa é estudar a taxa de quebra estrutural com o tempo sob uma taxa de cisalhamento constante ou, mais precisamente, sob uma velocidade constante.

As formas das curvas de histerese variam dependendo do tempo total do ciclo de cisalhamento e do "ponto de virada" dos ensaios - momento em que a taxa de cisalhamento crescente começa a diminuir. Em um estudo feito por Hattori e Izumi (1991), os pesquisadores verificaram que, dentre os parâmetros que promovem variações na forma das curvas de cisalhamento das suspensões, a taxa de coagulação das partículas é o único fator relacionado com sua composição química; como os outros parâmetros não estão relacionados com a composição e são simples condições experimentais, é importante observar que a variação da 
forma das curvas de cisalhamento nem sempre descrevem diferenças quanto à qualidade da amostra ensaiada.

Dentre os modelos propostos, o caso onde a curva de escoamento é côncava com relação ao eixo da taxa de cisalhamento é de grande interesse para a tecnologia dos concretos (TATTERSALL \& BANFILL, 1983). A inclinação aumenta à medida que a taxa de cisalhamento aumenta, isto é, o inverso da inclinação - que é uma medida da "viscosidade instantânea" - diminui. A explicação para isso é que as forças de cisalhamento destroem, ou tendem a destruir, alguma estrutura existente no material quando ele permanece em repouso, sendo o progresso da destruição superior a maior taxa de cisalhamento. 



\section{CAPÍTUL口 6 PROCEDIMENTO EXPERIMENTAL}

A presente pesquisa visa a avaliação da trabalhabilidade de concretos de alto desempenho por meio de sua caracterização reológica, ou seja, determinação dos parâmetros que definem o comportamento do escoamento do material - tensão de escoamento e viscosidade plástica.

Serão estudados concretos constituídos de cimento e sílica ativa disponíveis comercialmente e de agregados utilizados na região de São Carlos/SP.

A seguir, um esquema do procedimento experimental empregado é apresentado (figura 6.1).

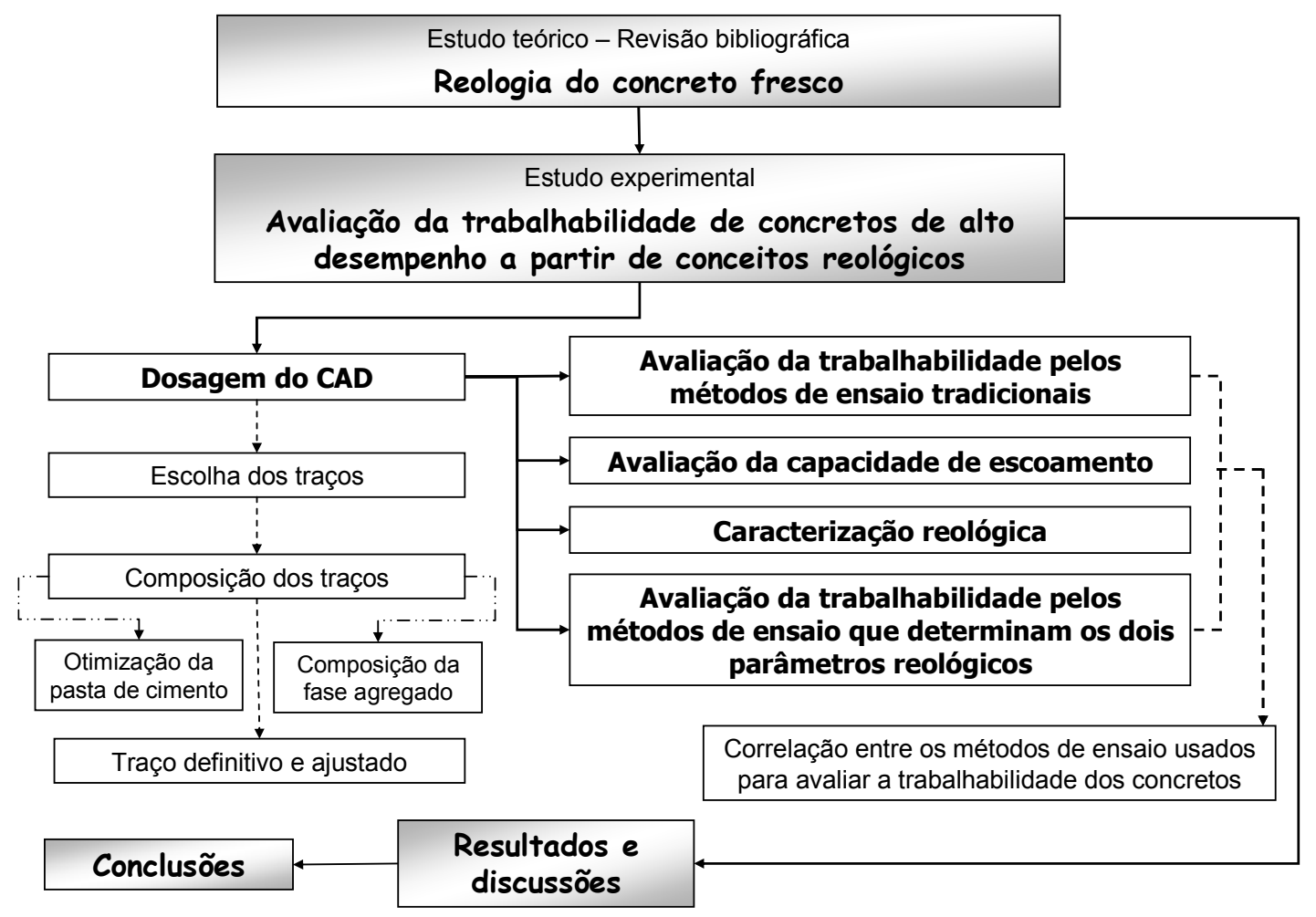

Figura 6.1 - Esquema da metodologia utilizada na presente pesquisa. 


\subsection{Dosagem do concreto}

\subsubsection{Escolha dos traços estudados}

Os traços adotados na presente pesquisa (tabela 6.1) foram baseados em trabalhos desenvolvidos por Silva (2000) e Melo (2000), que avaliaram várias dosagens de concreto quanto aos aspectos relacionados ao desempenho mecânico e à durabilidade. Os traços escolhidos correspondem aos que apresentaram melhores resultados quando avaliados, porém, foram feitos ajustes para adequá-los aos materiais utilizados.

Tabela 6.1 - Traços a serem analisados na pesquisa.

\begin{tabular}{|c|c|c|c|c|c|}
\hline Misturas & Tipo de cimento & $\begin{array}{l}\text { Traço } \\
(1: \mathrm{m})\end{array}$ & $\begin{array}{c}\text { a/agl } \\
(\mathrm{kg} / \mathrm{kg})\end{array}$ & $\begin{array}{c}\text { Teor de sílica }{ }^{\otimes} \\
(\%)\end{array}$ & $\begin{array}{c}\text { Abatimento } \\
(\mathrm{mm})\end{array}$ \\
\hline \multicolumn{6}{|c|}{ MICROCONCRETO $\left(D_{\text {máx }} \leq 9,5 \mathrm{~mm}\right)$} \\
\hline $\begin{array}{l}\text { MCAD1 } \\
\text { MCAD2 } \\
\text { MCAD3 }\end{array}$ & $\begin{array}{l}\text { CPV ARI Plus } \\
\text { CPV ARI RS }\end{array}$ & $\begin{array}{c}1: 3,5 \\
1: 3,5 \mathrm{SP} \\
1: 3,5 \mathrm{SP}\end{array}$ & $\begin{array}{l}0,40 \\
0,40 \\
0,40\end{array}$ & $\begin{array}{l}--- \\
--- \\
10\end{array}$ & $160 \pm 20$ \\
\hline \multicolumn{6}{|c|}{ CONCRETO $\left(D_{\text {máx }} \leq 25 \mathrm{~mm}\right)$} \\
\hline $\begin{array}{l}\text { CAD1 } \\
\text { CAD2 } \\
\text { CAD3 }\end{array}$ & $\begin{array}{l}\text { CPV ARI Plus } \\
\text { CPV ARI RS }\end{array}$ & $\begin{array}{c}1: 3,5 \\
1: 3,5 \mathrm{SP} \\
1: 3,5 \mathrm{SP}\end{array}$ & $\begin{array}{l}0,40 \\
0,40 \\
0,40\end{array}$ & $\begin{array}{l}--- \\
--- \\
10\end{array}$ & $160 \pm 20$ \\
\hline
\end{tabular}

${ }^{\otimes}$ Sílica ativa adicionada em substituição volumétrica ao cimento.

\subsubsection{Composição dos traços de concreto}

Inicialmente, foram escolhidos e caracterizados todos os materiais constituintes do concreto: cimento, agregados miúdo e graúdo, aditivo e sílica ativa. As características desses materiais encontram-se detalhadas no anexo A deste trabalho.

Para que a temperatura da pasta no final da mistura se mantivesse entre $20^{\circ} \mathrm{C}$ e $23^{\circ} \mathrm{C}$ (valores recomendados por Aïtcin (2000) para se produzir as condições normais de hidratação inicial do cimento), foi utilizada água gelada para a produção de todas as misturas.

A fim de não ampliar as variáveis envolvidas durante o estudo, alguns cuidados foram tomados com relação aos materiais utilizados. Buscou-se utilizar os mesmos lotes dos materiais, determinar o menor índice de vazios nas proporções entre os agregados de cada mistura, fixar a relação água/aglomerante e adotar as 
mesmas proporções entre os diversos materiais, variando-se apenas o tipo de cimento e a dosagem de SP necessária para se atingir o abatimento estabelecido. Além disso, as condições de ensaio foram mantidas constantes: umidade relativa do ar superior a $65 \%$ e temperatura ambiente de $23^{\circ} \mathrm{C} \pm 3^{\circ} \mathrm{C}$.

Para um melhor aproveitamento dos materiais, realizou-se um estudo das fases que compõem o concreto: pasta de cimento e agregados.

O estudo da matriz pasta de cimento a ser incorporada à mistura de concreto de alto desempenho se deu para a avaliação da compatibilidade entre os materiais aglomerantes e o SP e da trabalhabilidade das pastas ao longo do tempo, bem como a determinação do ponto de saturação do aditivo (teor considerado ótimo). Este estudo foi feito porque as pastas que apresentam bons comportamentos do escoamento resultam em concretos com fluidez e consistência satisfatórias.

Como as propriedades reológicas das pastas de cimento são sensíveis à seqüência e intensidade de mistura, o procedimento de mistura empregado na sua produção foi inicialmente avaliado através do ensaio de cone de Marsh. Quatro procedimentos foram avaliados, sendo a diferença entre eles relacionada com a ordem de incorporação dos materiais constituintes da mistura (tabela 6.2). O procedimento adotado nas avaliações seguintes foi o que manteve o menor tempo de escoamento durante uma hora, uma vez que o tempo de escoamento corresponde ao inverso da fluidez da pasta, ou seja, quanto menor o tempo de escoamento medido, maior a fluidez da pasta.

Definido o procedimento de mistura para a produção das pastas, o teor ótimo de SP para cada combinação de materiais aglomerantes foi determinado pelo ensaio de cone de Marsh. A compatibilidade do pares cimento-superplastificante usados e a trabalhabilidade das pastas ao longo do tempo foram avaliadas através do ensaio miniabatimento. 
Tabela 6.2 - Procedimentos de mistura avaliados para a produção das pastas de cimento.

\begin{tabular}{|c|c|c|c|c|c|}
\hline \multirow[b]{2}{*}{ Seqüência } & \multicolumn{5}{|c|}{ Procedimento } \\
\hline & Passo & Material incorporado & $\begin{array}{l}\text { Tempo de } \\
\text { repouso (s) }\end{array}$ & $\begin{array}{l}\text { Tempo de } \\
\text { mistura (s) }\end{array}$ & $\begin{array}{l}\text { Velocidade } \\
\text { de mistura }\end{array}$ \\
\hline \multirow{4}{*}{1} & 1 & Cimento, SP e água (90\%) & --- & 60 & baixa \\
\hline & 2 & Sílica & 60 & 60 & baixa \\
\hline & \multirow{2}{*}{3} & \multirow{2}{*}{ água restante } & 60 & 30 & baixa \\
\hline & & & --- & 150 & alta \\
\hline \multirow{4}{*}{2} & 1 & Cimento, $1 / 2$ SP e água $(90 \%)$ & --- & 60 & baixa \\
\hline & 2 & Sílica & 60 & 60 & baixa \\
\hline & \multirow{2}{*}{3} & \multirow{2}{*}{$1 / 2$ SP e água restante } & 60 & 30 & baixa \\
\hline & & & --- & 150 & alta \\
\hline \multirow{4}{*}{3} & 1 & Cimento e água $(90 \%)$ & --- & 60 & baixa \\
\hline & 2 & Sílica & 60 & 60 & baixa \\
\hline & \multirow{2}{*}{3} & \multirow{2}{*}{ SP e água restante } & 60 & 30 & baixa \\
\hline & & & --- & 150 & alta \\
\hline \multirow{5}{*}{4} & 1 & Cimento e Sílica & -- & 30 & baixa \\
\hline & \multirow{2}{*}{2} & \multirow{2}{*}{ água (90\%) } & -- & 60 & baixa \\
\hline & & & 30 & 60 & baixa \\
\hline & \multirow{2}{*}{3} & \multirow{2}{*}{ SP e água restante } & 60 & 30 & baixa \\
\hline & & & --- & 150 & alta \\
\hline
\end{tabular}

A fase agregado foi estudada a fim de se buscar o melhor empacotamento das partículas mediante a determinação da composição ideal entre eles. Essa composição ideal foi determinada de acordo com o recomendado por Helene e Terzian (1992): dois agregados com distribuições granulométricas diferentes são combinados em diversas frações e a massa unitária no estado compactado de cada combinação é determinada de acordo com as especificações da NBR 7810/83. A composição é considerada ideal quando o valor obtido para a massa unitária é máximo. Como orientação, a tabela 6.3 apresenta um exemplo do procedimento adotado.

Tabela 6.3 - Exemplo da determinação da composição ideal entre dois agregados de granulometrias diferentes através da massa unitária no estado compactado.

\begin{tabular}{c|c|c|c|c|c}
\hline $\begin{array}{c}\text { Composição entre } \\
\text { os agregados 2/1 } \\
\mathbf{( \% )}\end{array}$ & $\begin{array}{c}\text { Agregado } \\
\mathbf{2} \\
\mathbf{( k g )}\end{array}$ & $\begin{array}{c}\text { Agregado } \\
\mathbf{1} \\
\mathbf{( k g )}\end{array}$ & $\begin{array}{c}\text { Acréscimo de } \\
\text { agregado 1 } \\
\mathbf{( k g )}\end{array}$ & $\begin{array}{c}\text { Massa total } \\
\text { (agregados + } \\
\text { tara) } \\
\mathbf{( k g )}\end{array}$ & $\begin{array}{c}\text { Massa unitária no } \\
\text { estado compactado } \\
\mathbf{( k g / d m}^{\mathbf{3}} \mathbf{)}\end{array}$ \\
\hline 100 & 25,0 & ---- & ---- & 28,622 & 1,624 \\
\hline $90 / 10$ & 25,0 & 2,78 & 2,78 & 28,665 & 1,627 \\
\hline $80 / 20$ & 25,0 & 6,25 & 3,47 & 28,911 & 1,644 \\
\hline $70 / 30$ & 25,0 & 10,71 & 4,46 & 28,934 & 1,646 \\
\hline $60 / 40$ & $\mathbf{2 5 , 0}$ & $\mathbf{1 6 , 6 7}$ & $\mathbf{5 , 9 6}$ & $\mathbf{2 9 , 0 3 3}$ & $\mathbf{1 , 6 5 3}$ \\
\hline $50 / 50$ & 25,0 & 25,00 & 8,33 & 28,923 & 1,645 \\
\hline
\end{tabular}


No caso dos microconcretos, a composição ideal foi determinada entre a areia e a brita 0 , enquanto que, para os concretos, a combinação foi feita para as britas 1 e 2 .

\subsubsection{Traço definitivo e ajustado}

Definidas as duas fases que compõem o concreto, matriz pasta de cimento e agregados, a composição final dos traços, bem como os ajustes necessários foram realizados.

Para os microconcretos, cujo diâmetro máximo do agregado graúdo era menor ou igual a $9,5 \mathrm{~mm}$, as proporções entre os materiais foram determinadas diretamente após a composição ideal entre os agregados. Caso fosse necessário, o teor de SP seria ajustado para se alcançar o abatimento desejado.

Já para os concretos, cujo diâmetro máximo do agregado graúdo era menor ou igual a $25 \mathrm{~mm}$, o traço definitivo foi determinado de acordo com o procedimento de dosagem estabelecido por Helene e Terzian (1992). O teor ideal de argamassa foi determinado através de um estudo experimental e, em seguida, as corretas proporções entre os materiais constituintes da mistura foram estabelecidas a partir da equação:

$$
\alpha=\frac{1+a}{1+m}
$$

onde: $\alpha=$ teor ideal de argamassa; $a$ = relação agregado miúdo seco/cimento em massa; $m=a+p=$ relação agregados secos/cimento em massa; $p=$ relação agregado graúdo seco/cimento em massa.

Como a relação água/aglomerante foi mantida constante, os ajustes necessários para se obter o abatimento estabelecido foram feitos pelo aditivo.

\subsubsection{Procedimento de mistura do concreto de alto desempenho}

Como as propriedades do concreto no estado fresco são bastante dependentes da seqüência e intensidade do processo de mistura adotado, a influência do procedimento de mistura foi considerada.

Para essa avaliação, seis procedimentos diferentes foram adotados (figura 6.2), cuja ordem de colocação dos materiais constituintes foi variada. Eles foram baseados no processo de mistura amplamente utilizado na prática (procedimento A) e uma variação do tempo da adição do SP foi considerada (procedimentos B e C). 
Nos procedimentos $\mathrm{D}$ e $\mathrm{E}$, buscou-se saturar os agregados antes da adição dos materiais aglomerantes; a diferença entre eles está no momento de adição do SP. No procedimento $\mathrm{F}$, os materiais aglomerantes foram inicialmente homogeneizados e só em seguida os agregados, a água de amassamento e o SP foram adicionados.

O tempo de mistura total foi mantido constante para todos os procedimentos adotados. Foi considerado um tempo de 9 minutos para a completa produção do concreto.

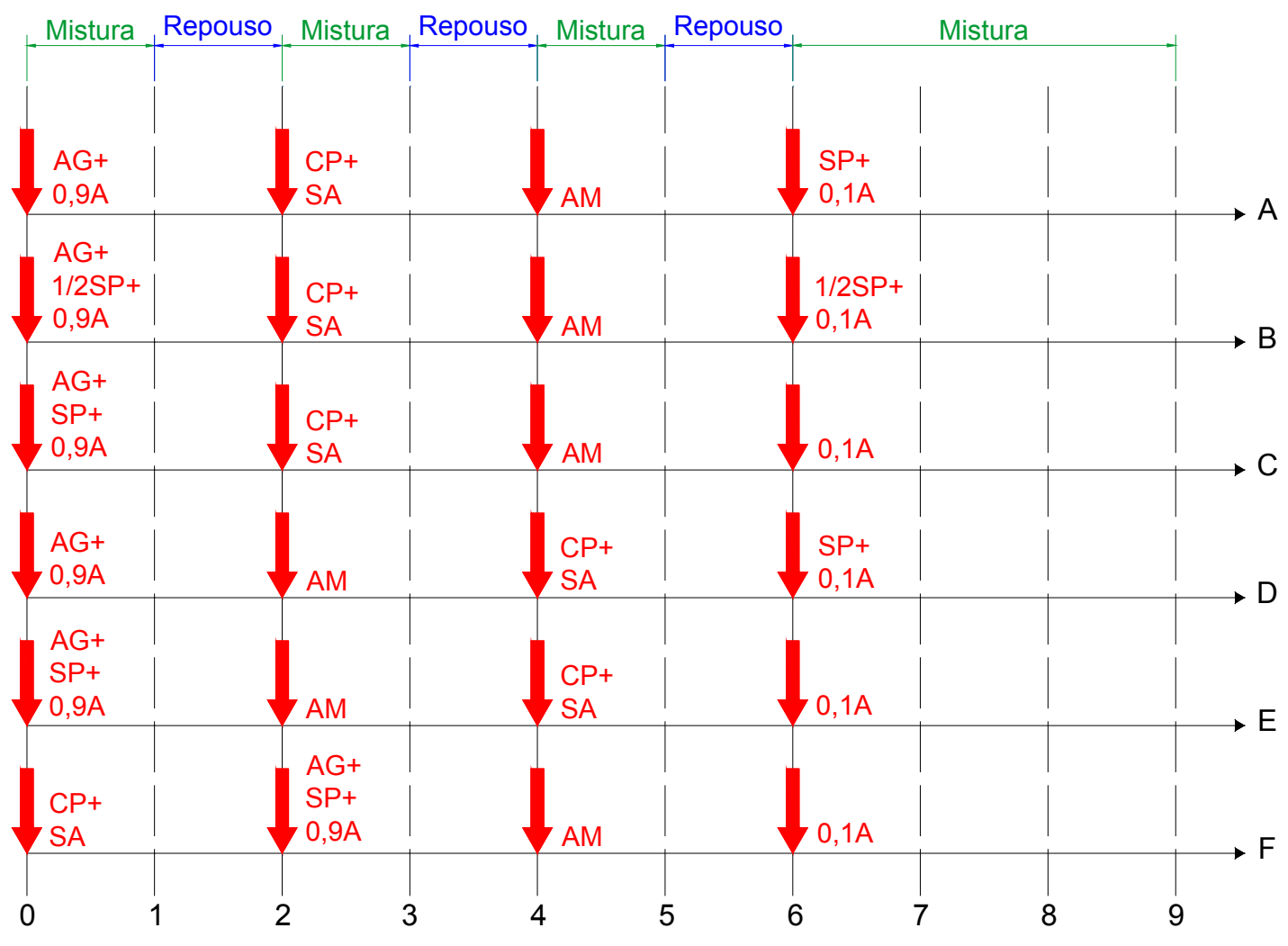

Tempo (min)

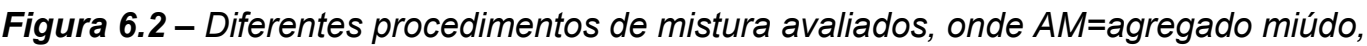
$A G=$ agregado graúdo, $C P=$ cimento, $S A=$ sílica ativa, $A=a ́ g u a$ e $S P=$ superplastificante .

\subsection{Avaliação da trabalhabilidade pelos métodos de ensaio tradicionais}

A trabalhabilidade dos CAD foi medida de acordo com dois métodos de ensaio: o ensaio de abatimento de tronco de cone e o consistômetro de Ve-Be.

O comportamento desses materiais ao longo do tempo foi analisado tomandose medidas do abatimento e tempo Ve-Be aos 10, 30, 60, 90 e 120 minutos após o cimento ter entrado em contato com a água. Assim, a perda de trabalhabilidade das misturas pode ser medida por um período de até duas horas após o início da hidratação do cimento. 
Entre as sucessivas determinações realizadas ao longo do tempo, o material permaneceu dentro do misturador, sendo a abertura do mesmo protegida com pano úmido para evitar a perda de água por evaporação.

\subsection{Avaliação da capacidade de escoamento}

A capacidade de escoamento do CAD foi avaliada através do ensaio com a caixa L. Para o espaçamento entre as barras foi considerado o estabelecido pela NBR 6118/2003. As leituras do escoamento do material por entre as barras de aço foram feitas imediatamente após o fim do processo de mistura.

\subsection{Caracterização reológica dos concretos de alto desempenho}

A caracterização reológica das misturas de alto desempenho foi realizada por meio de ensaios de cisalhamento executados com o auxílio de um reômetro. Para isso, as misturas foram submetidas a ciclos de cisalhamento em escada, com velocidade de rotação variando entre 5 RPM e 80 RPM após a mistura. Esse tipo de ensaio gera curvas de cisalhamento que permitem verificar a eficiência de dispersão das partículas (eficiência do misturador) e identificar a natureza reológica de uma mistura de concreto.

Para a identificação do comportamento reológico das misturas, as curvas de cisalhamento obtidas foram ajustadas por dois modelos reológicos - Bingham e lei das potências. Tanto a parte ascendente quanto a parte descendente da curva de cisalhamento foram avaliadas.

Assim, a natureza reológica da mistura foi identificada pelo modelo que melhor se ajustou à curva de cisalhamento, ou seja, pelo modelo que permitiu obter o maior coeficiente de correlação entre os dados obtidos pelo reômetro e a reta que caracteriza o modelo.

\subsection{Avaliação da trabalhabilidade pelos métodos de ensaio que determinam os dois parâmetros reológicos}

Os dois métodos de ensaio utilizados que permitem a determinação dos dois parâmetros reológicos que caracterizam o comportamento de um concreto foram o ensaio de abatimento de tronco de cone modificado e o reômetro. Porém, nesses 
ensaios, as constantes reológicas foram determinadas de maneiras indiretas, isto é, elas foram determinadas a partir de outros parâmetros medidos pelo ensaio.

A trabalhabilidade, bem como sua perda ao longo do tempo, foi relacionada com a evolução dos parâmetros reológicos. Assim, qualquer alteração ou diferença entre as determinações feitas para as várias misturas ao longo do tempo poderiam ser detectadas com facilidade.

A avaliação do comportamento de concretos sob uma taxa de cisalhamento contínua ou, mais precisamente, sob uma velocidade de rotação constante constitui uma técnica alternativa às curvas de cisalhamento para a avaliação preliminar desse comportamento. Assim, o processo de endurecimento das misturas também foi acompanhado durante o período compreendido desde o fim da mistura até a total perda de trabalhabilidade do material (falta de coesão da mistura).

Como a utilização de um reômetro para a avaliação da trabalhabilidade de concretos de alto desempenho não é uma prática comum nas construções de concreto, foram feitas correlações entre os diversos parâmetros medidos com os métodos de ensaio propostos na pesquisa, como uma tentativa de facilitar o estudo da trabalhabilidade de concretos a partir de conceitos reológicos.

As técnicas experimentais adotadas na pesquisa, assim como os intervalos entre as leituras, foram mantidas constantes dentro dos métodos de ensaio propostos, para se evitar que qualquer fator extra influenciasse na análise do comportamento dos concretos no estado fresco. 


\section{CAPÍTUL口 7 RESULTADOS E DISCUSSÕES}

Neste capítulo são apresentados os resultados e as discussões de todo o estudo experimental idealizado e realizado em pastas de cimento, fase agregado e concretos.

Os resultados dos ensaios básicos necessários para a implementação da presente pesquisa estão apresentados em anexo, sendo a caracterização dos materiais no anexo A e a caracterização dos concretos de alto desempenho estudados no anexo $B$.

Inicialmente, será apresentado o estudo feito nas fases que compõem uma mistura de concreto, bem como os traços definitivos e seus respectivos ajustes. Em seguida, serão apresentados os estudos em concreto: avaliação da trabalhabilidade e sua perda ao longo do tempo; avaliação da capacidade de escoamento; e caracterização reológica das misturas de alto desempenho.

As avaliações realizadas tiveram como objetivo analisar a influência dos parâmetros listados a seguir sobre as propriedades reológicas dos CAD:

- o ponto de saturação do aditivo (teor considerado ótimo) para as combinações de materiais aglomerantes, SP e relação água/aglomerante utilizadas;

- a pasta de cimento otimizada para cada mistura;

- o tipo de cimento;

- a dimensão máxima característica do agregado graúdo;

- a incorporação de uma adição química - aditivo superplastificante;

- a incorporação de uma adição mineral - sílica ativa;

- o procedimento de mistura utilizado na produção dos concretos. 


\subsection{Dosagem dos concretos de alto desempenho}

O processo de dosagem dos CAD foi dividido em duas partes: a primeira corresponde ao estudo da matriz pasta de cimento; e a segunda, relacionada com a fase agregado, visa a determinação do melhor empacotamento de partículas, isto é, a determinação da composição ideal entre os agregados que compõem cada mistura.

\subsubsection{Estudo da matriz pasta de cimento}

O estudo da matriz pasta de cimento consistiu na avaliação da compatibilidade entre o cimento e o SP, na determinação do ponto de saturação do aditivo (teor considerado ótimo) e na avaliação da trabalhabilidade das pastas e sua perda ao longo do tempo.

Ao iniciar a otimização das pastas de cimento que constituíram as misturas de alto desempenho, ou seja, aquelas incorporadas com sílica ativa, foi necessário avaliar o procedimento de mistura a ser empregado na sua produção, pois as propriedades reológicas das pastas de cimento no estado fresco são bastante influenciadas pelo mesmo. Foram avaliados quatro procedimentos diferentes, onde a ordem de colocação dos materiais constituintes da mistura foi variada (tabela 7.1).

Para a determinação do procedimento capaz de produzir pastas de cimento mais fluidas, considerou-se mais adequado aquele em que o tempo de escoamento fosse mantido o menor possível por um período de até 1 hora, uma vez que o tempo de escoamento corresponde ao inverso da fluidez da pasta; então, quanto menor o tempo de escoamento medido, maior a fluidez da pasta. O método de ensaio empregado foi o cone de Marsh.

Os resultados determinados para cada procedimento e tipo de cimento utilizado são apresentados na tabela 7.1. Nas figuras 7.1 e 7.2 são apresentadas as curvas "tempo de escoamento versus tempo" para as pastas de cimento produzidas com ambos os cimentos. A partir das figuras pode-se observar que, para cada pasta de cimento estudada, um procedimento de mistura mostrou-se mais adequado, ou seja, para cada situação em particular uma determinada seqüência de mistura produziu pastas que se mantiveram mais trabalháveis por um intervalo de tempo maior. 
Tabela 7.1 - Variação do procedimento de mistura e os correspondentes tempos de escoamento para as pastas de cimento produzidas com sílica ativa.

\begin{tabular}{|c|c|c|c|c|c|c|c|c|}
\hline \multirow{3}{*}{ Seq. } & \multicolumn{5}{|c|}{ Procedimento } & \multirow{3}{*}{$\begin{array}{c}\text { Tempo de } \\
\text { medida } \\
(\min )\end{array}$} & \multirow{2}{*}{\multicolumn{2}{|c|}{$\begin{array}{c}\text { Tempo de } \\
\text { escoamento (s) }\end{array}$}} \\
\hline & \multirow[b]{2}{*}{ Passo } & \multirow[b]{2}{*}{ Material incorporado } & \multirow[b]{2}{*}{$T_{R}(s)$} & \multirow[b]{2}{*}{$T_{m}(\mathbf{s})$} & \multirow[b]{2}{*}{$\mathbf{V}_{\mathrm{m}}$} & & & \\
\hline & & & & & & & $\begin{array}{l}\text { CPV ARI } \\
\text { Plus }\end{array}$ & $\begin{array}{l}\text { CPV ARI } \\
\text { RS }\end{array}$ \\
\hline \multirow{4}{*}{1} & 1 & $\mathrm{CP}, \mathrm{SP}$ e água $(\mathrm{a} / \mathrm{c}=0,36)$ & --- & 60 & baixa & 10 & 59,25 & 47,95 \\
\hline & 2 & Sílica & 60 & 60 & baixa & 30 & 68,29 & 58,33 \\
\hline & \multirow{2}{*}{3} & \multirow{2}{*}{ água restante } & 60 & 30 & baixa & 40 & 74,23 & 61,02 \\
\hline & & & -- & 150 & alta & 60 & 90,80 & 65,95 \\
\hline \multirow{4}{*}{2} & 1 & $\mathrm{CP}, 1 / 2 \mathrm{SP}$ e água $(\mathrm{a} / \mathrm{c}=0,36)$ & -- & 60 & baixa & 10 & 43,27 & 37,52 \\
\hline & 2 & Sílica & 60 & 60 & baixa & 30 & 55,70 & 45,25 \\
\hline & \multirow{2}{*}{3} & \multirow{2}{*}{$1 / 2 \mathrm{SP}$ e água restante } & 60 & 30 & baixa & 40 & 60,53 & 49,35 \\
\hline & & & -- & 150 & alta & 60 & 80,41 & 56,97 \\
\hline \multirow{4}{*}{3} & 1 & $\mathrm{CP}$ e água $(\mathrm{a} / \mathrm{c}=0,36)$ & --- & 60 & baixa & 10 & 37,91 & 33,42 \\
\hline & 2 & Sílica & 60 & 60 & baixa & 30 & 63,09 & 39,88 \\
\hline & \multirow{2}{*}{3} & \multirow{2}{*}{$\mathrm{SP}$ e água restante } & 60 & 30 & baixa & 40 & 76,08 & 41,53 \\
\hline & & & -- & 150 & alta & 60 & 107,32 & 45,26 \\
\hline \multirow{5}{*}{4} & 1 & CP e Sílica & -- & 30 & baixa & 10 & 40,26 & 35,57 \\
\hline & \multirow{2}{*}{2} & \multirow{2}{*}{ água $(\mathrm{a} / \mathrm{c}=0,36)$} & -- & 60 & baixa & 30 & 68,55 & 42,99 \\
\hline & & & 30 & 60 & baixa & 40 & 79,19 & 47,35 \\
\hline & \multirow{2}{*}{3} & \multirow{2}{*}{ SP e água restante } & 60 & 30 & baixa & \multirow{2}{*}{60} & \multirow{2}{*}{106,53} & \multirow{2}{*}{55,15} \\
\hline & & & --- & 150 & alta & & & \\
\hline
\end{tabular}

onde: $\mathrm{T}_{\mathrm{r}}=$ tempo de repouso; $\mathrm{T}_{\mathrm{m}}=$ tempo de mistura; $\mathrm{V}_{\mathrm{m}}=$ velocidade de mistura $($ baixa $\approx 65 \mathrm{RPM} ;$ alta $\approx 130 \mathrm{RPM}$ ).

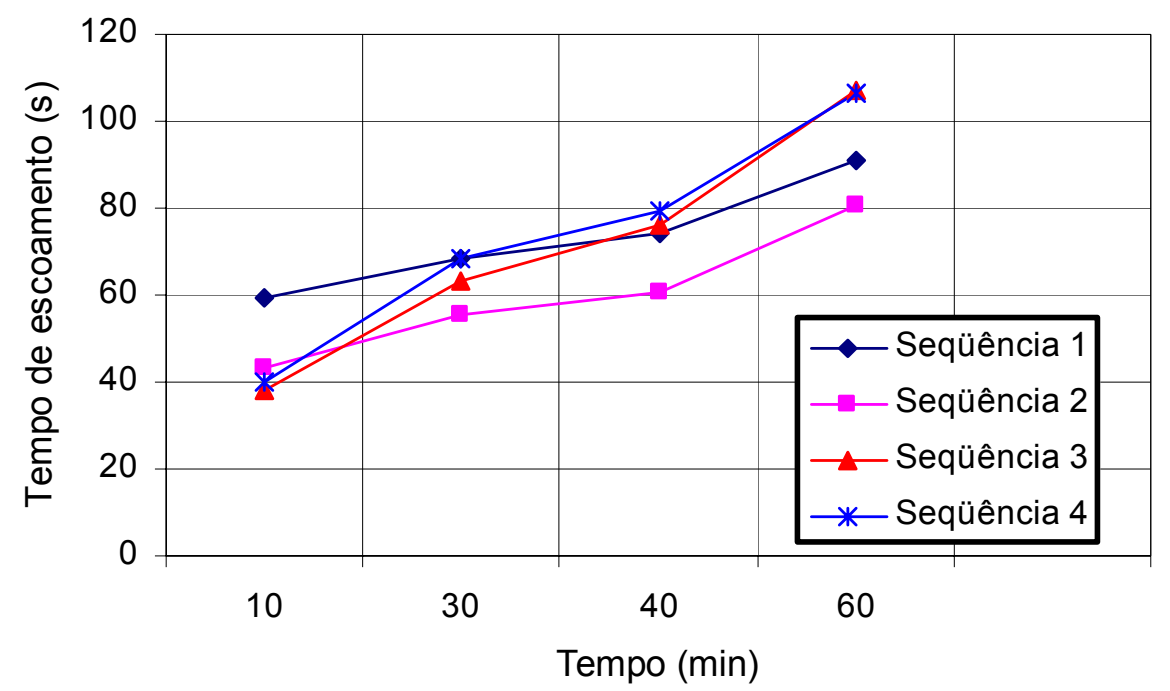

Figura 7.1 - Curva do tempo de escoamento versus tempo para pastas de cimento produzidas com CPV ARI Plus em função da seqüência de mistura adotada. 


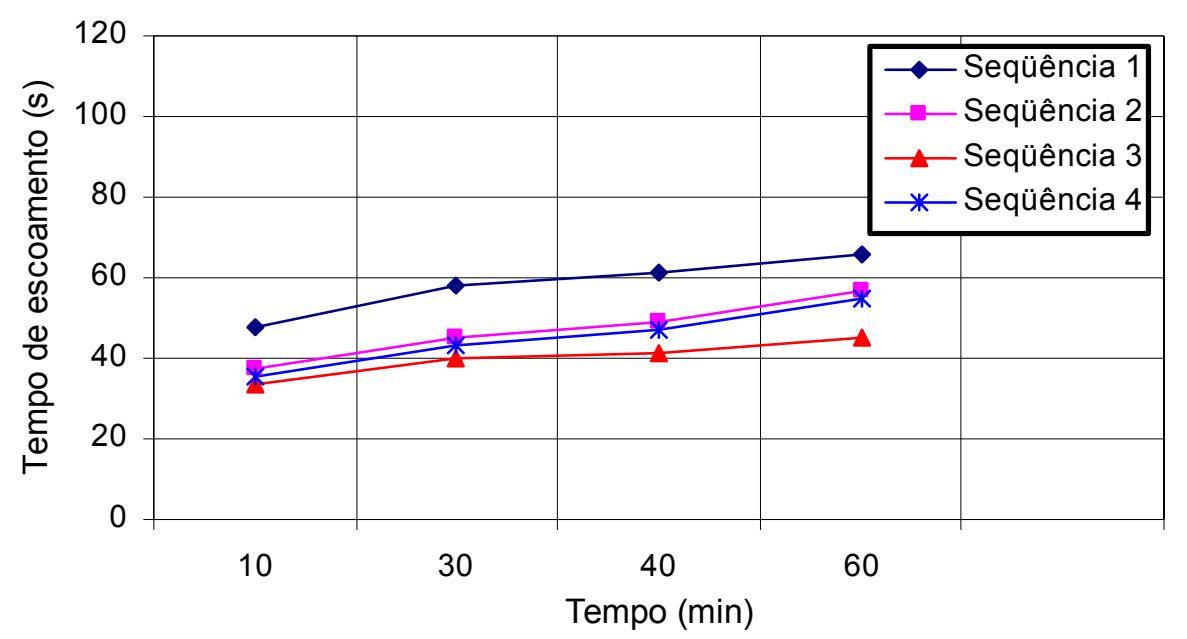

Figura 7.2 - Curva do tempo de escoamento versus tempo para pastas de cimento produzidas com CPV ARI RS em função da seqüência de mistura adotada.

Assim, para a avaliação da compatibilidade entre os materiais, avaliação da trabalhabilidade ao longo do tempo e determinação do ponto de saturação do SP, os procedimentos adotados na produção das pastas de aglomerantes produzidas com CPV ARI Plus e CPV ARI RS foram, respectivamente, os correspondentes às seqüências 2 e 3 da tabela 7.1 .

A seqüência 2 adotada na produção de pastas produzidas com CPV ARI Plus segue as seguintes etapas:

- primeiro, o cimento, metade do SP e $90 \%$ da água de amassamento total foram misturados por 1 minuto na velocidade baixa;

- o misturador foi parado por mais 1 minuto enquanto as laterais da cuba eram raspadas com uma espátula para eliminar o material retido. Adicionou-se, então, a sílica e a pasta foi novamente misturada por mais 1 minuto na velocidade baixa;

- mais uma vez a mistura foi interrompida por 1 minuto para que as laterais da cuba fossem limpadas. Neste intervalo adicionou-se o restante da água e do $\mathrm{SP}$;

- a pasta foi misturada por mais 30 segundos na velocidade baixa, seguido de mais $2 \frac{1}{2}$ minutos na velocidade alta.

No caso das pastas produzidas com CPV ARI RS, o procedimento de mistura seguiu a seqüência 3 :

- primeiro, o cimento e $90 \%$ da água de amassamento foram misturados por 1 minuto na velocidade baixa;

- o misturador foi parado por 1 minuto enquanto as laterais da cuba eram raspadas com uma espátula para eliminar o material retido. Adicionou-se, 
então, a sílica e a pasta foi novamente misturada por mais 1 minuto na velocidade baixa;

- mais uma vez a mistura foi interrompida por 1 minuto para que as laterais da cuba fossem limpadas. Neste intervalo adicionou-se o SP e a água restante;

- a pasta foi misturada por mais 30 segundos na velocidade baixa, seguido de mais $2 \frac{1}{2}$ minutos na velocidade alta.

Com os procedimentos de mistura definidos, deu-se início ao estudo das pastas de cimento incorporadas com SP e sílica ativa. Primeiro determinou-se o teor ótimo de aditivo através do ensaio de cone de Marsh e com o auxílio do método AFREM - nesse método, o ponto de saturação (PS) do aditivo é determinado como o ponto no qual uma reta com inclinação de 2:5 tangencia a curva "logaritmo do tempo de escoamento versus teor de SP". Em seguida, avaliouse a perda da trabalhabilidade da pasta através do ensaio de miniabatimento e a compatibilidade entre o cimento e o SP.

$\mathrm{Na}$ tabela 7.2 são apresentados os tempos de escoamento determinados para as pastas de cimento produzidas com ambos os cimentos através do ensaio de cone de Marsh. Os tempos de escoamento foram adotados como o valor médio de três determinações, pois se trata de ensaios bastante sensíveis.

$\mathrm{Na}$ figura 7.3, observam-se as curvas "logaritmo do tempo de escoamento versus teor de SP" para as pastas avaliadas e seus correspondentes pontos de saturação do SP. Foi considerado o tempo de 30 minutos para a construção das curvas porque, para algumas misturas, a curva correspondente à primeira determinação (10 minutos) não apresentou nenhum ponto de tangência com a reta de inclinação 2:5. 
Tabela 7.2 - Tempos de escoamento para pastas de aglomerantes incorporadas com SP determinados através do ensaio de cone de Marsh.

\begin{tabular}{|c|c|c|c|c|c|c|c|c|c|c|c|}
\hline \multirow{2}{*}{\multicolumn{2}{|c|}{$\frac{\text { Cimento }}{\text { SP (\%) }}$}} & \multicolumn{5}{|c|}{ CPV ARI Plus } & \multicolumn{5}{|c|}{ CPV ARI RS } \\
\hline & & 0,20 & 0,40 & 0,60 & 0,80 & 1,0 & 0,20 & 0,40 & 0,60 & 0,80 & 1,0 \\
\hline \multirow{3}{*}{$10 \mathrm{~min}$} & $\mathbf{T}_{\mathbf{m}}$ & --- & 41,63 & 41,77 & 38,16 & 37,76 & 50,40 & 33,12 & 30,36 & 26,91 & 25,98 \\
\hline & $\log \left(T_{m}\right)$ & --- & 1,619 & 1,621 & 1,582 & 1,577 & 1,702 & 1,520 & 1,482 & 1,430 & 1,415 \\
\hline & Desvio & --- & 3,55 & 0,40 & 3,05 & 0,91 & 0,96 & 0,65 & 0,68 & 0,56 & 0,55 \\
\hline \multirow{3}{*}{$30 \mathrm{~min}$} & $\mathbf{T}_{\mathbf{m}}$ & --- & 64,23 & 59,18 & 47,94 & 44,46 & 80,51 & 39,43 & 34,06 & 29,53 & 27,58 \\
\hline & $\log \left(T_{m}\right)$ & --- & 1,808 & 1,772 & 1,681 & 1,645 & 1,906 & 1,596 & 1,532 & 1,470 & 1,441 \\
\hline & Desvio & --- & 4,09 & 0,28 & 2,30 & 1,90 & 2,66 & 0,06 & 0,98 & 0,42 & 0,92 \\
\hline \multirow{3}{*}{$40 \mathrm{~min}$} & $\mathbf{T}_{\mathrm{m}}$ & --- & 69,10 & 62,41 & 49,98 & 46,94 & 90,72 & 42,04 & 34,14 & 30,10 & 27,81 \\
\hline & $\log \left(T_{m}\right)$ & --- & 1,839 & 1,795 & 1,699 & 1,672 & 1,958 & 1,624 & 1,533 & 1,479 & 1,444 \\
\hline & Desvio & --- & 2,63 & 0,99 & 2,24 & 2,34 & 1,55 & 0,72 & 0,96 & 0,51 & 0,62 \\
\hline \multirow{3}{*}{$60 \mathrm{~min}$} & $\mathrm{~T}_{\mathrm{m}}$ & -- & 81,53 & 70,43 & 56,10 & 49,94 & 127,93 & 45,03 & 35,07 & 30,40 & 28,05 \\
\hline & $\log \left(T_{m}\right)$ & --- & 1,911 & 1,848 & 1,749 & 1,698 & 2,107 & 1,654 & 1,545 & 1,483 & 1,448 \\
\hline & Desvio & --- & 3,06 & 1,27 & 2,22 & 2,29 & 1,89 & 0,36 & 1,02 & 0,43 & 0,75 \\
\hline \multirow{3}{*}{$90 \mathrm{~min}$} & $\mathbf{T}_{\mathrm{m}}$ & -- & 106,08 & 82,99 & 64,16 & 55,80 & --- & 50,62 & 38,93 & 31,11 & 28,43 \\
\hline & $\log \left(T_{m}\right)$ & --- & 2,026 & 1,919 & 1,807 & 1,747 & --- & 1,704 & 1,590 & 1,493 & 1,454 \\
\hline & Desvio & --- & 2,88 & 4,42 & 1,36 & 3,11 & --- & 1,12 & 1,34 & 0,83 & 0,53 \\
\hline \multirow{3}{*}{$120 \mathrm{~min}$} & $\mathbf{T}_{\mathrm{m}}$ & -- & 151,15 & 102,27 & 75,00 & 63,47 & -- & 64,70 & 44,18 & 32,51 & 29,24 \\
\hline & $\log \left(T_{m}\right)$ & -- & 2,179 & 2,010 & 1,875 & 1,803 & -- & 1,811 & 1,645 & 1,512 & 1,466 \\
\hline & Desvio & --- & 3,20 & 4,75 & 1,59 & 3,06 & --- & 1,10 & 0,36 & 0,70 & 0,60 \\
\hline
\end{tabular}

onde: $T_{m}=$ tempo de escoamento; $\log \left(T_{m}\right)=$ logaritmo do tempo de escoamento.

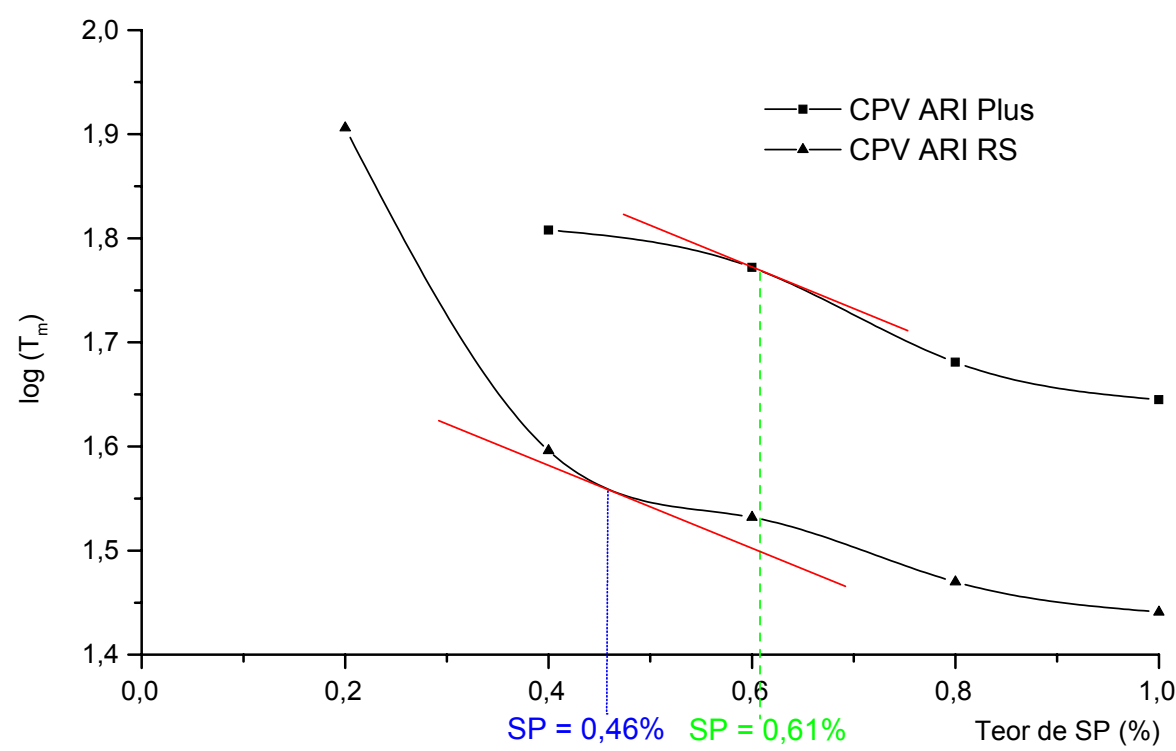

Figura 7.3 - Curvas "logaritmo do tempo de escoamento versus teor de SP" e pontos de saturação do SP para pastas de aglomerantes incorporadas com SP. 
A partir da figura 7.3, pode-se observar que os teores de SP considerados ótimos variaram com o tipo de cimento. Os pontos de saturação determinados para as pastas produzidas com CPV ARI Plus e CPV ARI RS foram de 0,61\% e 0,46\%, respectivamente.

Como a ação do SP sobre um cimento é função da quantidade de $C_{3} A$ existente na composição do cimento, espera-se que cimentos com maiores teores de $\mathrm{C}_{3} \mathrm{~A}$ exijam maiores quantidades de SP para manter uma determinada trabalhabilidade. A diferença entre os teores de SP considerados ótimos para ambos os cimento estudados deve-se a esse fator, ou seja, como o CPV ARI Plus possui uma maior quantidade de $\mathrm{C}_{3} \mathrm{~A}$ na sua composição $(7,36 \%)$ do que o $\mathrm{CPV}$ ARI RS (4,92\%), a demanda de SP do primeiro cimento é maior que a do segundo. Além disso, a área superficial dos cimentos é diferente: por apresentar uma área superficial maior (4457 $\mathrm{cm}^{2} / \mathrm{g}$ contra $3293 \mathrm{~cm}^{2} / \mathrm{g}$ ), o CPV ARI Plus demanda uma quantidade maior de SP para envolver suas pequenas partículas quando as demais proporções dos materiais constituintes são mantidas constantes.

O estudo da trabalhabilidade das pastas de cimento foi feito com o auxílio do ensaio de miniabatimento (ensaio de Kantro). As áreas de espalhamento obtidas para as pastas estudadas são apresentadas na tabela 7.3 e as correspondentes curvas "área de espalhamento versus tempo" na figura 7.4. O teor de SP utilizado na produção de cada mistura corresponde ao teor ótimo determinado pelo método AFREM com auxílio do ensaio de cone de Marsh.

Tabela 7.3 - Áreas de espalhamento obtidas a partir do ensaio de miniabatimento para pastas de cimento com e sem a adição de sílica ativa.

\begin{tabular}{|c|c|c|c|c|}
\hline \multirow{2}{*}{$\begin{array}{c}\text { Cimento } \\
\text { Sílica }\end{array}$} & \multicolumn{2}{|c|}{ CPV ARI Plus } & \multicolumn{2}{|c|}{ CPV ARI RS } \\
\hline & SSA & SFS & SSA & SFS \\
\hline SP (\%) & 0,61 & 0,61 & 0,46 & 0,46 \\
\hline Tempo (min) & Área $\left(\mathrm{cm}^{2}\right)$ & Área $\left(\mathrm{cm}^{2}\right)$ & Área $\left(\mathrm{cm}^{2}\right)$ & Área $\left(\mathrm{cm}^{2}\right)$ \\
\hline 10 & 315,10 & 332,00 & 252,21 & 222,46 \\
\hline 30 & 332,97 & 276,12 & 264,46 & 175,30 \\
\hline 40 & 324,61 & 249,69 & 279,66 & 156,81 \\
\hline 60 & 322,38 & 215,64 & 265,04 & 135,61 \\
\hline 90 & 319,52 & 183,37 & 246,61 & 110,85 \\
\hline 120 & 300,18 & 144,63 & 215,90 & 91,95 \\
\hline
\end{tabular}

SSA = pasta sem adição de sílica ativa; SFS = pasta com adição de sílica ativa. 


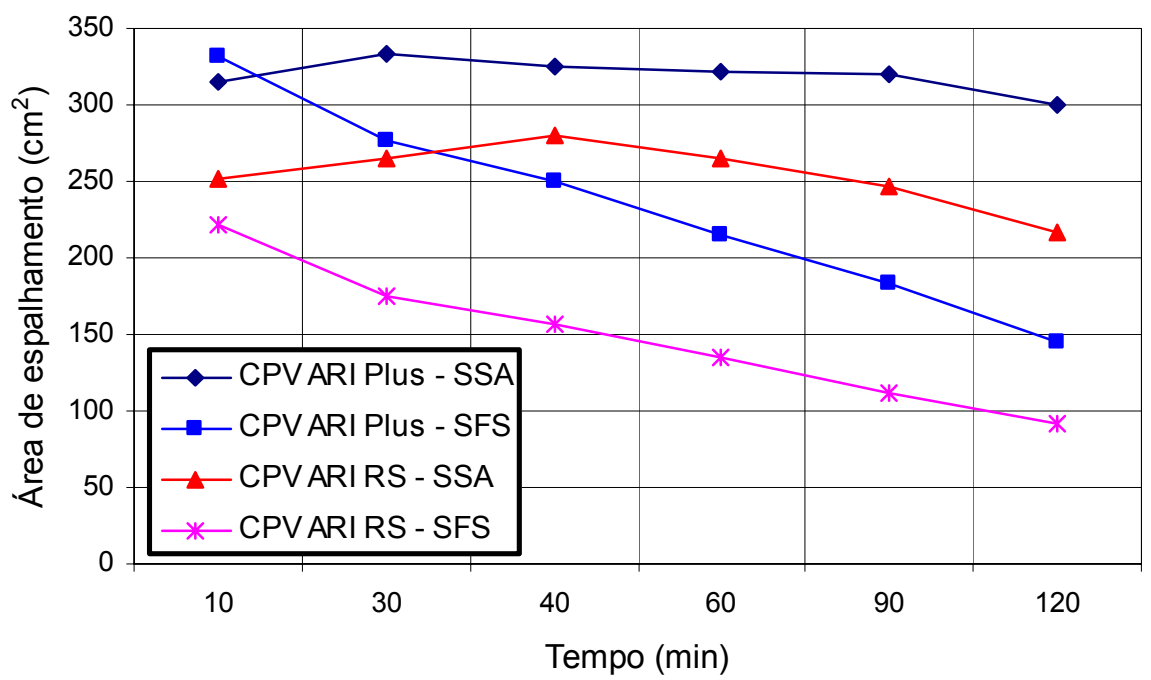

Figura 7.4 - Curva "área de espalhamento versus tempo" para pastas de cimento com e sem a adição de sílica ativa.

A compatibilidade entre o cimento e o SP pode ser observada através da figura 7.4. Como as pastas de cimento simples de ambos os cimento praticamente mantém sua trabalhabilidade durante o período de execução do ensaio, para as dosagens determinadas como teores ótimos de SP, pode-se constatar a compatibilidade entre os materiais.

A partir da figura 7.4, observa-se uma queda constante e gradual da trabalhabilidade das pastas de cimento incorporadas com sílica ativa, qualquer que fosse o cimento utilizado em sua produção, durante todo o período em que o ensaio foi realizado. O comportamento é semelhante entre as pastas produzidas com ambos os cimentos considerados.

Quando comparada à pasta com incorporação única de SP, mantendo-se o teor de SP e a relação água/aglomerante constantes, verifica-se um comportamento diferente entre elas: a pasta de cimento simples mantém sua trabalhabilidade praticamente constante durante todo o ensaio, enquanto a pasta com adição de sílica perde constante e gradualmente sua trabalhabilidade ao longo das duas horas de ensaio. Novamente, pode-se observar que a pasta de cimento com adição de sílica ativa mostrou-se menos trabalhável que a pastas de cimento simples (áreas de espalhamento menores). Essa diferença está relacionada com a incorporação de sílica, que aumenta a quantidade de finos da mistura e, com isso, aumenta a demanda de água para total envolvimento das partículas.

Assim, a otimização das pastas de cimento definiu as matrizes detalhadas na tabela 7.4 para os concretos de alto desempenho a serem produzidos. 
Tabela 7.4 - Características das matrizes pasta de cimento e/ou de aglomerantes a serem incorporadas às misturas de concretos de alto desempenho.

\begin{tabular}{c|c|c}
\hline Cimento & CPV ARI Plus & CPV ARI RS \\
\hline Teor de sílica & $10 \%$ & $10 \%$ \\
\hline Relação a/agl & 0,40 & 0,40 \\
\hline Teor de SP & $0,61 \%$ & $0,46 \%$ \\
\hline
\end{tabular}

\subsubsection{Estudo da fase agregado}

No estudo da fase agregado foi determinado o melhor empacotamento entre as partículas de cada mistura. Para isso, determinou-se a composição ideal entre os agregados através do método recomendado por Helene e Terzian (1992).

A composição foi feita tanto para a combinação de areia e brita 0 (microconcreto) e de britas 1 e 2 (concreto). Nas tabelas 7.5 e 7.6 são apresentadas as diversas combinações realizadas, bem como a massa unitária no estado compactado para cada uma delas.

Tabela 7.5 - Composição ideal entre areia e brita 0 (microconcreto).

\begin{tabular}{|c|c|c|c|c|c|c|}
\hline $\begin{array}{c}\text { Composição } \\
\text { entre brita } \\
\text { 0/areia } \\
(\%) \\
\end{array}$ & $\begin{array}{c}\text { Brita } 0 \\
\text { (kg) }\end{array}$ & $\begin{array}{c}\text { Areia } \\
(\mathbf{k g})\end{array}$ & $\begin{array}{c}\text { Acréscimo } \\
\text { de areia } \\
\text { (kg) }\end{array}$ & $\begin{array}{c}\text { Massa total } \\
\text { (agregado + tara) } \\
(\mathrm{kg})\end{array}$ & $\begin{array}{c}\text { Massa unitária } \\
\text { no estado } \\
\text { compactado } \\
\left(\mathbf{k g} / \mathrm{dm}^{3}\right) \\
\end{array}$ & $\begin{array}{c}\text { Índice de } \\
\text { vazios }\end{array}$ \\
\hline 100 & 10,0 & ---- & ---- & 8,230 & 1,668 & 0,72 \\
\hline $90 / 10$ & 10,0 & 1,11 & 1,11 & 8,500 & 1,758 & 0,62 \\
\hline $80 / 20$ & 10,0 & 2,50 & 1,39 & 8,750 & 1,842 & 0,53 \\
\hline $70 / 30$ & 10,0 & 4,28 & 1,78 & 8,990 & 1,922 & 0,45 \\
\hline $60 / 40$ & 10,0 & 6,66 & 2,38 & 9,050 & 1,942 & 0,42 \\
\hline $50 / 50$ & 10,0 & 10,00 & 3,34 & 9,050 & 1,942 & 0,41 \\
\hline $40 / 60$ & 10,0 & 15,00 & 5,00 & 8,940 & 1,905 & 0,42 \\
\hline
\end{tabular}

Tabela 7.6 - Composição ideal entre britas 1 e 2 (concreto).

\begin{tabular}{c|c|c|c|c|c|c}
\hline $\begin{array}{c}\text { Composição } \\
\text { entre B2/B1 } \\
(\%)\end{array}$ & $\begin{array}{c}\text { Brita 2 } \\
\mathbf{( k g )}\end{array}$ & $\begin{array}{c}\text { Brita 1 } \\
\mathbf{( k g )}\end{array}$ & $\begin{array}{c}\text { Acréscimo } \\
\text { de brita 1 } \\
\mathbf{( k g )}\end{array}$ & $\begin{array}{c}\text { Massa total } \\
\text { (agregado + tara) } \\
\mathbf{( k g )}\end{array}$ & $\begin{array}{c}\text { Massa unitária } \\
\text { no estado } \\
\text { compactado } \\
\left(\mathbf{k g} / \mathbf{d m}^{3}\right)\end{array}$ & $\begin{array}{c}\text { índice de } \\
\text { vazios }\end{array}$ \\
\hline 100 & 25,0 & ---- & ---- & 28,622 & 1,624 & 0,77 \\
\hline $90 / 10$ & 25,0 & 2,78 & 2,78 & 28,665 & 1,627 & 0,77 \\
\hline $80 / 20$ & 25,0 & 6,25 & 3,47 & 28,911 & 1,644 & 0,75 \\
\hline $70 / 30$ & 25,0 & 10,71 & 4,46 & 28,934 & 1,646 & 0,75 \\
\hline $\mathbf{6 0 / 4 0}$ & $\mathbf{2 5 , 0}$ & $\mathbf{1 6 , 6 7}$ & $\mathbf{5 , 9 6}$ & $\mathbf{2 9 , 0 3 3}$ & $\mathbf{1 , 6 5 3}$ & $\mathbf{0 , 7 4}$ \\
\hline $50 / 50$ & 25,0 & 25,00 & 8,33 & 28,923 & 1,645 & 0,75 \\
\hline
\end{tabular}


A partir das tabelas 7.5 e 7.6, pode-se observar que as massas unitárias no estado compactado determinadas para combinação de agregados aumentaram até atingir um valor máximo, reduzindo em seguida. Assim, as combinações entre a areia e a brita 0 e entre as britas 1 e 2 que forneceram essas massas unitárias máximas foram adotadas na produção dos microconcretos e concretos de alto desempenho, respectivamente.

Para a verificação da quantidade de vazios presente em cada combinação, o índice de vazios foi calculado de acordo com a equação 7.1. A partir da figura 7.5 pode-se observar que o índice de vazios atinge um valor mínimo e depois volta a aumentar. Considera-se ideal a combinação de agregados que forneceu esse valor mínimo.

$$
\text { Índice de vazios }=\frac{\gamma_{\text {real }}}{\rho}-1
$$

onde:

$\gamma_{\text {real }}=$ massa específica real da combinação de agregados;

$\rho=$ massa unitária da combinação no estado compactado.

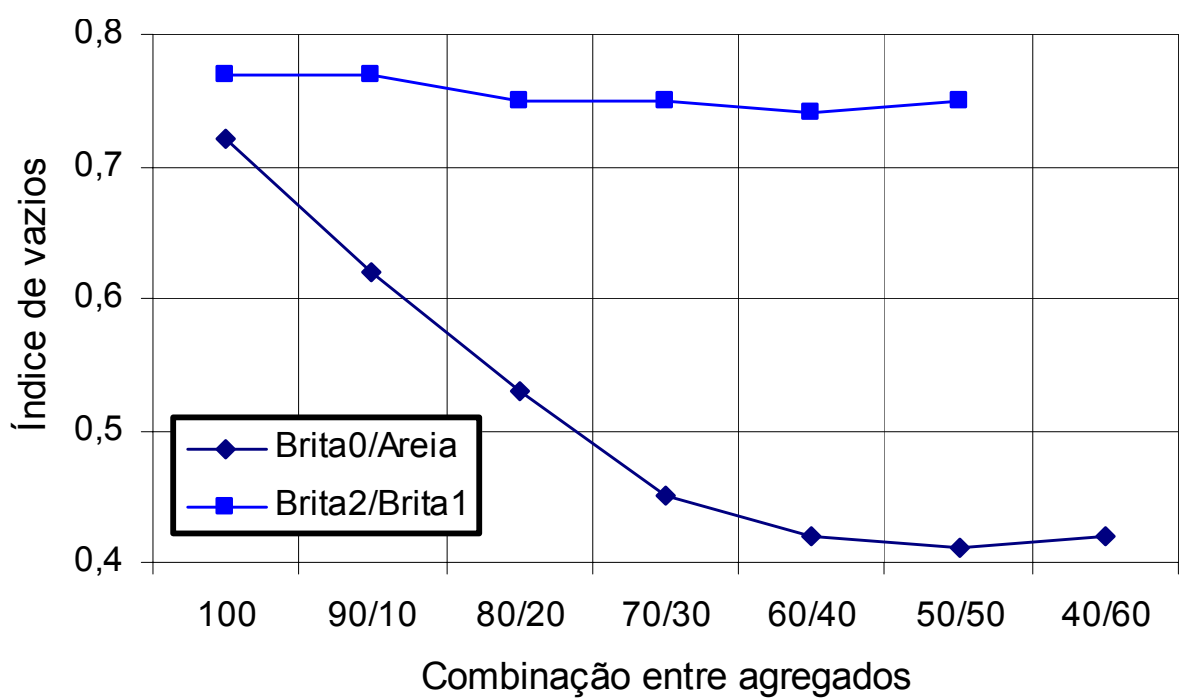

Figura 7.5 - Gráfico da combinação entre os agregados versus índice de vazios para as composições estudadas.

Assim, uma combinação de agregados pode ser considerada ideal quando o índice de vazios for mínimo e a massa unitária no estado compactado for máxima.

Para os concretos estudados, as combinações de $50 \%$ de areia e $50 \%$ de brita 0 e de $40 \%$ de brita 1 e $60 \%$ de brita 2 foram adotadas para a produção dos microconcretos e concretos de alto desempenho, respectivamente. 


\subsubsection{Traço definitivo e ajustado}

Definidas as duas fases que compõem o concreto, matriz pasta de cimento e agregados, a composição final dos traços foi realizada.

Para os microconcretos de alto desempenho (MCAD - $D_{\text {Máx }} \leq 9,5 \mathrm{~mm}$ ), as proporções entre os materiais foram determinadas diretamente após definidas as características das fases da mistura. Os traços finais definidos para cada mistura são apresentados na tabela 7.7 .

O teor de SP determinado a partir da otimização da pasta de cimento mostrou-se bem adequado às misturas de concreto. Para os MCAD produzidos com CPV ARI Plus, os abatimentos atingidos com o teor de SP igual a 0,61\% ponto de saturação do SP determinado através do ensaio de cone de Marsh com o auxílio do método AFREM - ficaram entre $175 \mathrm{~mm}$ e $225 \mathrm{~mm}$, valores que vão além do inicialmente proposto $(160 \mathrm{~mm} \pm 20 \mathrm{~mm}$ ). Como as misturas se mostraram bem coesos e trabalháveis, esse teor foi mantido para os ensaios posteriores.

Já para os MCAD produzidos com CPV ARI RS, o teor de SP igual a 0,46\% determinado durante o estudo da fase pasta de aglomerantes produziu misturas com abatimentos variando entre $80 \mathrm{~mm}$ e $145 \mathrm{~mm}$, considerados abaixo do desejado. Assim, um ajuste no aditivo foi realizado. O novo teor de $0,50 \%$ permitiu que abatimentos entre $175 \mathrm{~mm}$ e $210 \mathrm{~mm}$ fossem atingidos, adequando-se ao inicialmente proposto.

Para os concretos de alto desempenho (CAD $-D_{\text {máx }} \leq 25 \mathrm{~mm}$ ), o traço definitivo foi determinado de acordo com o método de dosagem proposto por Helene e Terzian (1992). Um teor de argamassa igual a $51 \%$ foi considerado ideal para as misturas produzidas com ambos os cimentos, porém o teor considerado ótimo para o aditivo determinado a partir da otimização da matriz pasta não se mostrou adequado.

As misturas produzidas com os teores determinados pelo estudo da pasta de aglomerantes segregaram após a mistura. Uma grande quantidade de argamassa migrou para a superfície do material, enquanto o agregado graúdo era depositado no fundo do recipiente que armazenava o concreto. Assim, um novo estudo do teor de SP foi realizado.

O teor de argamassa e a relação água/aglomerante foram mantidos constantes em $51 \%$ e 0,40 , respectivamente, variando-se apenas o teor de SP. Iniciou-se com o teor mínimo de 0,20\% estabelecido pelo fabricante, com 
acréscimos de $0,05 \%$ até que o abatimento de $160 \mathrm{~mm} \pm 20 \mathrm{~mm}$ inicialmente fixado fosse atingido.

Os teores finais que permitiram atingir a variação de abatimento fixada sem qualquer segregação do agregado graúdo foram de $0,25 \%$ e $0,20 \%$ para os CAD produzidos com CPV ARI Plus e CPV ARI RS, respectivamente. Os abatimentos determinados através do ensaio de abatimento de tronco de cone variaram entre $140 \mathrm{~mm}$ e $185 \mathrm{~mm}$.

Os traços finais estabelecidos para os CAD também são apresentados na tabela 7.7 .

Tabela 7.7 - Traços definitivos e ajustados para os concretos de alto desempenho estudados na pesquisa.

\begin{tabular}{|c|c|c|c|c|c|c|}
\hline Mistura & $\begin{array}{l}\text { Traço } \\
\text { (1:a:p) }\end{array}$ & Cimento & $\begin{array}{c}\text { Relação } \\
\text { a/agl } \\
\text { (kg/kg) }\end{array}$ & $\begin{array}{c}\text { Teor de SP } \\
(\%)\end{array}$ & $\begin{array}{c}\text { Teor de sílica } \\
(\%)\end{array}$ & $\begin{array}{c}\text { Abatimento } \\
(\mathrm{mm})\end{array}$ \\
\hline \multicolumn{7}{|c|}{ MICROCONCRETO $\left(D_{\text {máx }} \leq 9,5 \mathrm{~mm}\right)$} \\
\hline MCAD1 & \multirow{3}{*}{$1: 1,75: 1,75$} & $\begin{array}{l}\text { CPV ARI Plus } \\
\text { CPV ARI RS }\end{array}$ & $\begin{array}{l}0,40 \\
0,40\end{array}$ & ---- & ---- & \multirow{3}{*}{$160 \pm 20$} \\
\hline MCAD2 & & $\begin{array}{l}\text { CPV ARI Plus } \\
\text { CPV ARI RS }\end{array}$ & $\begin{array}{l}0,40 \\
0,40\end{array}$ & $\begin{array}{l}0,61 \\
0,50\end{array}$ & ---- & \\
\hline MCAD3 & & $\begin{array}{l}\text { CPV ARI Plus } \\
\text { CPV ARI RS }\end{array}$ & $\begin{array}{l}0,40 \\
0,40\end{array}$ & $\begin{array}{l}0,61 \\
0,50\end{array}$ & $\begin{array}{l}10 \\
10\end{array}$ & \\
\hline \multicolumn{7}{|c|}{ CONCRETO $\left(D_{\text {máx }} \leq 25 \mathrm{~mm}\right)$} \\
\hline CAD1 & \multirow{3}{*}{$1: 1,30: 2,20$} & $\begin{array}{l}\text { CPV ARI Plus } \\
\text { CPV ARI RS }\end{array}$ & $\begin{array}{l}0,40 \\
0,40\end{array}$ & ---- & ---- & \multirow{3}{*}{$160 \pm 20$} \\
\hline CAD2 & & $\begin{array}{l}\text { CPV ARI Plus } \\
\text { CPV ARI RS }\end{array}$ & $\begin{array}{l}0,40 \\
0,40\end{array}$ & $\begin{array}{l}0,25 \\
0,20\end{array}$ & $\begin{array}{l}---- \\
----\end{array}$ & \\
\hline CAD3 & & $\begin{array}{l}\text { CPV ARI Plus } \\
\text { CPV ARI RS }\end{array}$ & $\begin{array}{l}0,40 \\
0,40\end{array}$ & $\begin{array}{l}0,25 \\
0,20\end{array}$ & $\begin{array}{l}10 \\
10\end{array}$ & \\
\hline
\end{tabular}

onde: $a$ = relação agregado miúdo seco/cimento em massa; $p$ = relação agregado graúdo/cimento em massa; a/agl = relação água/aglomerante.

\subsection{Avaliação da trabalhabilidade pelos métodos de ensaio tradicionais}

A trabalhabilidade de um concreto pode ser influenciada por diversos fatores e a situação é posteriormente complicada pelo fato de que existem interações entre eles, isto é, os fatores não são independentes um dos outros em seus efeitos.

Foram consideradas as influências do tipo de cimento, do diâmetro máximo característico do agregado graúdo, da incorporação de adições químicas e minerais e do procedimento de mistura empregado na produção do concreto. 
A trabalhabilidade das misturas de alto desempenho foi medida através do ensaio de abatimento de tronco de cone e do consistômetro de Ve-Be e dada em termos de abatimento e tempo Ve-Be (ou de vibração), respectivamente.

Nos tópicos seguintes, os tempos correspondentes a 30 e 60 minutos estão realçados por se tratarem dos tempos máximos que seriam praticados em obras com qualidade técnica e viáveis economicamente às indústrias de pré-moldados e obras convencionais, respectivamente. Ressalta-se que, quando esses tempos são ultrapassados, faz-se a necessidade de se utilizar de plastificantes e/ou superplastificantes retardadores de pega e endurecimento - situações não abrangidas nessa pesquisa, mas que serão recomendadas no seu prosseguimento.

\subsubsection{Ensaio de abatimento de tronco de cone}

$\mathrm{Na}$ tabela 7.8 são apresentados os valores dos abatimentos de MCAD determinados através do ensaio de abatimento de tronco de cone. Nas figuras $7.6 \mathrm{e}$ 7.7 são apresentados os comportamentos desses materiais ao longo do tempo.

Tabela 7.8 - Resultados do ensaio de abatimento de tronco de cone para os microconcretos de alto desempenho. Abatimentos em [mm].

\begin{tabular}{c|c|c|c|c|c|c|c|c|c|c}
\hline Cimento & \multicolumn{4}{c|}{ CPV ARI Plus } & \multicolumn{5}{c}{ CPV ARI RS } \\
\hline \multirow{2}{*}{ Microconcreto } & \multicolumn{4}{|c|}{ Tempo de medida (min) } & \multicolumn{5}{c}{ Tempo de medida (min) } \\
\cline { 2 - 13 } & $\mathbf{1 0}$ & $\mathbf{3 0}$ & $\mathbf{6 0}$ & $\mathbf{9 0}$ & $\mathbf{1 2 0}$ & $\mathbf{1 0}$ & $\mathbf{3 0}$ & $\mathbf{6 0}$ & $\mathbf{9 0}$ & $\mathbf{1 2 0}$ \\
\hline MCADI & 20 & ----- & ----- & ----- & ---- & 20 & ---- & ---- & ----- & ----- \\
\hline MCAD2 & 240 & 190 & 130 & 60 & 30 & 230 & 190 & 125 & 80 & 50 \\
\hline MCAD3/A & 190 & 135 & 80 & 60 & 15 & 210 & 165 & 135 & 100 & 55 \\
\hline MCAD3/B & 175 & 125 & 100 & 50 & 0 & 195 & 155 & 130 & 105 & 80 \\
\hline MCAD3/C & 190 & 165 & 110 & 55 & 10 & 180 & 145 & 110 & 90 & 65 \\
\hline MCAD3/D & 210 & 175 & 120 & 75 & 45 & 200 & 145 & 115 & 65 & 40 \\
\hline MCAD3/E & 225 & 190 & 130 & 70 & 50 & 190 & 140 & 120 & 75 & 35 \\
\hline MCAD3/F & 205 & 150 & 90 & 50 & 15 & 175 & 140 & 120 & 90 & 55 \\
\hline
\end{tabular}

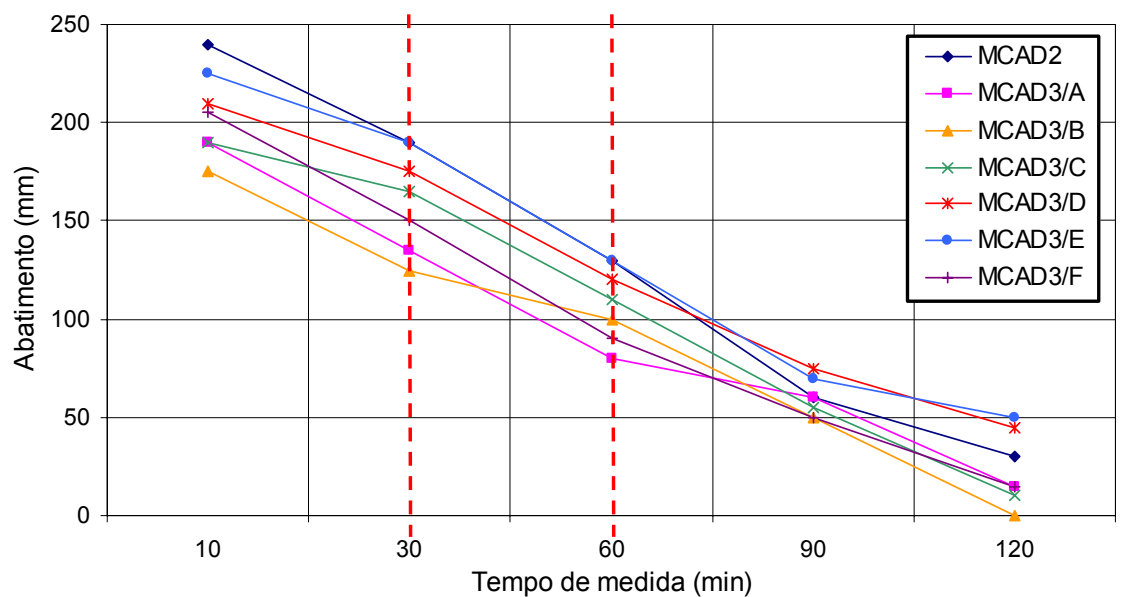

Figura 7.6 - Curvas "abatimento de tronco de cone versus tempo" para os microconcretos de alto desempenho produzidos com CPV ARI Plus. 


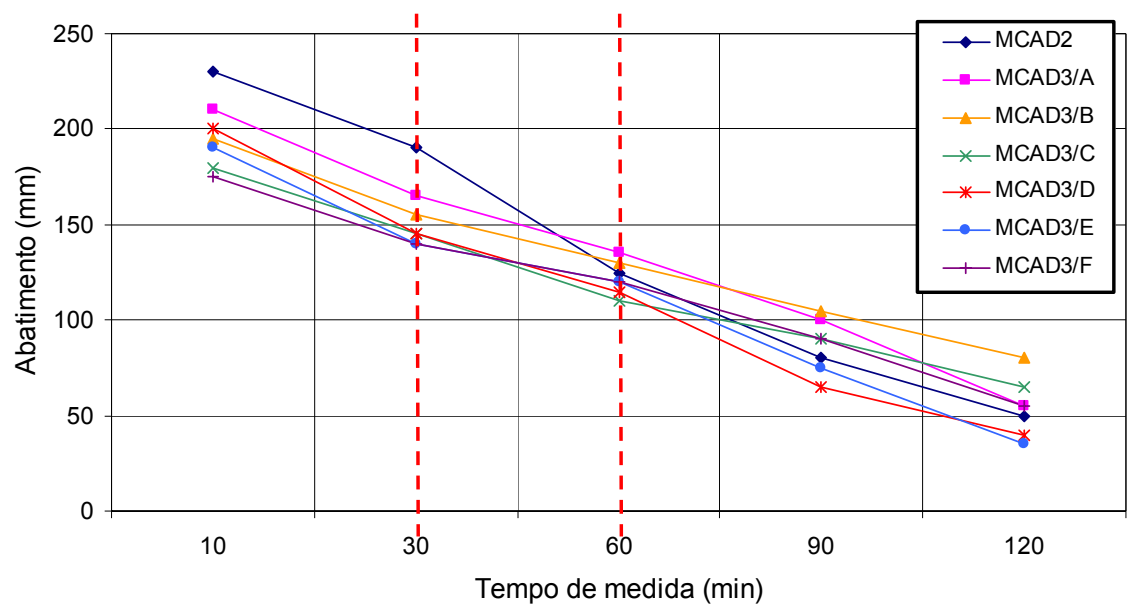

Figura 7.7 - Curvas "abatimento de tronco de cone versus tempo" para os microconcretos de alto desempenho produzidos com CPV ARI RS.

Os MCAD1, misturas sem a incorporação de aditivos químicos e adições minerais, não apresentaram abatimentos suficientes para a avaliação do comportamento ao longo do tempo. Os abatimentos iniciais obtidos foram de apenas $20 \mathrm{~mm}$ para as misturas produzidas com ambos os cimentos.

As demais misturas (MCAD2 e MCAD3) apresentaram altos valores de abatimento, sendo consideradas misturas fluidas. Porém, esse comportamento não é mantido durante todo o ensaio. Observou-se uma perda contínua e gradual do abatimento ao longo do ensaio para todas as misturas, conforme ilustrado na figura 7.8 .
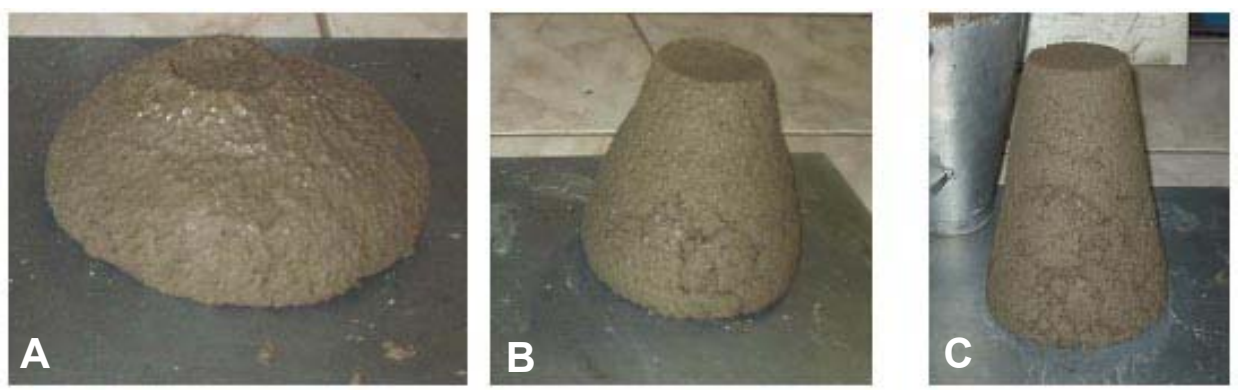

Figura 7.8 - Ensaio de abatimento de tronco de cone para microconcretos de alto desempenho: avaliação da perda da trabalhabilidade ao longo do tempo: $(A)$ aos 10 minutos; (B) aos 60 minutos; e (C) aos 120 minutos.

A mudança no comportamento do concreto fresco ao longo do tempo deve-se especialmente ao cimento, que constitui o principal componente reativo da mistura (HANKE, 1991). Dentre os fatores mais importantes desse constituinte da mistura de concreto, o teor de $\mathrm{C}_{3} \mathrm{~A}$ e a quantidade e condição dos sulfatos, além da proporção de partículas com tamanhos entre $10 \mu \mathrm{m}$ e $30 \mu \mathrm{m}$ (TATTERSALL, 1991b) são destacados pelas pesquisas mais recentes. De acordo com Aïtcin e Neville (2003), para misturas com baixas relações água/aglomerante, como o CAD, 
deve-se dar preferência para a utilização de cimentos que contêm baixos teores de $\mathrm{C}_{3} \mathrm{~A}$ e $\mathrm{C}_{3} \mathrm{~S}$.

Apesar das diferenças nos teores de $\mathrm{C}_{3} \mathrm{~A}$ que compõe o cimento $(7,36 \% \mathrm{e}$ 4,92\%, respectivamente, para o CPV ARI Plus e CPV ARI RS), para as misturas avaliadas, o tipo de cimento que compõe o concreto não influenciou no abatimento medido no início do ensaio. Também, a perda de abatimento observada nos primeiros trinta minutos após o contato água-cimento foi semelhante entre os dois cimentos. Diferenças entre os comportamentos das misturas produzidas com ambos os cimentos foram observadas depois de 60 minutos de ensaio: após esse período, as misturas produzidas com CPV ARI Plus apresentaram maiores perdas de abatimento que o CPV ARI RS ( $90 \%$ contra $70 \%$, em média, respectivamente).

Como a perda de abatimento nos primeiros trinta minutos é semelhante, a diferença entre as perdas de abatimento observadas após esse período está relacionada com o $\mathrm{C}_{3} \mathrm{~S}$ do cimento: como o CPV ARI Plus possui uma quantidade de $\mathrm{C}_{3} \mathrm{~S}$ muito maior que o CPV ARI RS (58,95\% contra 38,26\%, respectivamente), a maior perda de abatimento das misturas produzidas com o primeiro cimento devese à hidratação desse componente para o desenvolvimento da resistência mecânica nas primeiras idades.

Como não foi possível determinar o abatimento para as misturas de referência (MCAD1), a influência do SP sobre a trabalhabilidade (em termos de abatimento de tronco de cone) não pode ser devidamente avaliada. Porém, sabe-se da literatura que essa adição química resulta em um aumento do abatimento medido e, consequentemente, em misturas mais trabalháveis.

Para ambos os tipos de cimento utilizados, a incorporação de sílica ativa reduziu os abatimentos iniciais das misturas, mas ao longo do tempo, a tendência do comportamento foi semelhante, ou seja, a perda de abatimento se deu de maneira contínua e gradual durante o ensaio. Porém, ao final do ensaio, algumas misturas incorporadas com sílica (MCAD3) apresentaram-se mais trabalháveis que os concretos com adição única de SP (MCAD2), mostrando que a sílica, apesar de reduzir a trabalhabilidade inicial, melhora o desempenho das misturas ao longo do tempo.

A principal razão para essa menor trabalhabilidade deve-se à adição de materiais muito finos que aumentam a demanda de água em função do aumento da área específica. $O$ efeito positivo da adição de sílica ativa é observado quando suas minúsculas partículas esféricas dispersas no sistema promovem o deslocamento das moléculas de água vizinhas aos grãos de cimento. Com isso, as moléculas de 
água presas entre as partículas de cimento floculadas podem ser liberadas e contribuir com a fluidificação da mistura.

O procedimento de mistura considerado na produção de um concreto de alto desempenho tem se mostrado muito importante sobre o comportamento desses materiais, particularmente o tempo de incorporação do SP. Para as misturas estudadas (produzidas de acordo com os seis procedimentos propostos), os desvios de abatimentos medidos variaram, em termos de determinações absolutas, em aproximadamente $50 \mathrm{~mm}$ e $35 \mathrm{~mm}$ para as misturas produzidas com CPV ARI Plus e CPV ARI RS, respectivamente.

Os maiores abatimentos iniciais foram determinados para as misturas produzidas com CPV ARI Plus e CPV ARI RS e de acordo com os procedimentos $E$ e $A$, respectivamente. Até os 60 minutos de ensaio, os mesmo procedimentos mantiveram o melhor desempenho com relação à determinação do maior abatimento para as misturas estudadas. Depois desse momento e até o fim do ensaio, o procedimento $B$ foi o que melhor se ajustou às misturas produzidas com CPV ARI RS, enquanto o procedimento $E$ se manteve como o mais adequado para as misturas produzidas com CPV ARI Plus.

Nos procedimentos $A$ e $B$, o SP foi incorporado no final do processo de mistura (um atraso de quatro minutos com relação ao contato inicial entre o cimento e a água) e dividido em duas parcelas (metade no início da mistura junto com a água de amassamento e a outra metade quatro minutos após o contato cimentoágua), respectivamente. De acordo com a literatura, essa forma de adição atrasada e/ou parcelada - do aditivo permite obter melhores trabalhabilidades ao longo do tempo do que quando o material é incorporado no início da mistura junto com a água de amassamento. Porém, no procedimento $\mathrm{E}$, que resultou em maiores abatimentos para as misturas produzidas com CPV ARI Plus, o SP foi incorporado no início da mistura, junto com a água de amassamento. Assim, o melhor desempenho desse procedimento pode ser relacionado com a saturação inicial dos agregados antes da incorporação dos materiais aglomerantes, evitando a absorção de parte da água da matriz pelos agregados que resulta em uma redução da trabalhabilidade de um concreto.

Concretos produzidos com agregados graúdos de $D_{\text {máx }} \leq 25 \mathrm{~mm}$ também foram avaliados. Os valores dos abatimentos para as várias misturas são apresentados na tabela 7.9 e a evolução dos comportamentos ao longo do tempo é ilustrada na figuras 7.9 e 7.10 . 
Tabela 7.9 - Resultados do ensaio de abatimento de tronco de cone para os concretos de alto desempenho. Abatimentos em [mm].

\begin{tabular}{c|c|c|c|c|c|c|c|c|c|c}
\hline Cimento & \multicolumn{4}{|c|}{ CPV ARI Plus } & \multicolumn{5}{c}{ CPV ARI RS } \\
\hline \multirow{2}{*}{ Concreto } & \multicolumn{4}{|c|}{ Tempo de medida (min) } & \multicolumn{5}{c}{ Tempo de medida (min) } \\
\cline { 2 - 12 } & $\mathbf{1 0}$ & $\mathbf{3 0}$ & $\mathbf{6 0}$ & $\mathbf{9 0}$ & $\mathbf{1 2 0}$ & $\mathbf{1 0}$ & $\mathbf{3 0}$ & $\mathbf{6 0}$ & $\mathbf{9 0}$ & $\mathbf{1 2 0}$ \\
\hline CADI & 130 & 100 & 85 & 75 & 55 & 150 & 135 & 105 & 80 & 75 \\
\hline CAD2 & 215 & 125 & 90 & 80 & 50 & 220 & 160 & 115 & 95 & 80 \\
\hline CAD3/A & 165 & 120 & 105 & 85 & 55 & 170 & 135 & 115 & 80 & 55 \\
\hline CAD3/B & 160 & 125 & 110 & 95 & 80 & 150 & 120 & 100 & 70 & 45 \\
\hline CAD3/C & 140 & 100 & 100 & 75 & 50 & 140 & 110 & 90 & 75 & 50 \\
\hline CAD3/D & 170 & 120 & 95 & 50 & 20 & 150 & 120 & 110 & 85 & 65 \\
\hline CAD3/E & 140 & 100 & 70 & 45 & 20 & 140 & 120 & 95 & 80 & 70 \\
\hline CAD3/F & 145 & 125 & 90 & 70 & 50 & 170 & 140 & 105 & 95 & 60 \\
\hline
\end{tabular}

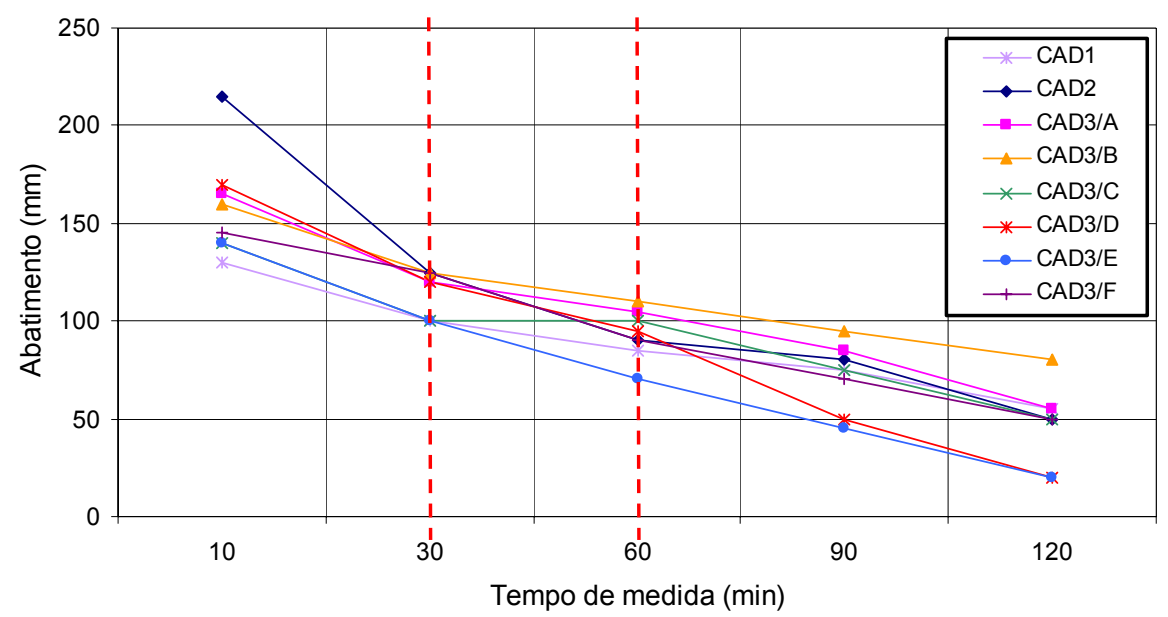

Figura 7.9 - Curvas "abatimento de tronco de cone versus tempo" para os concretos de alto desempenho produzidos com CPV ARI Plus.

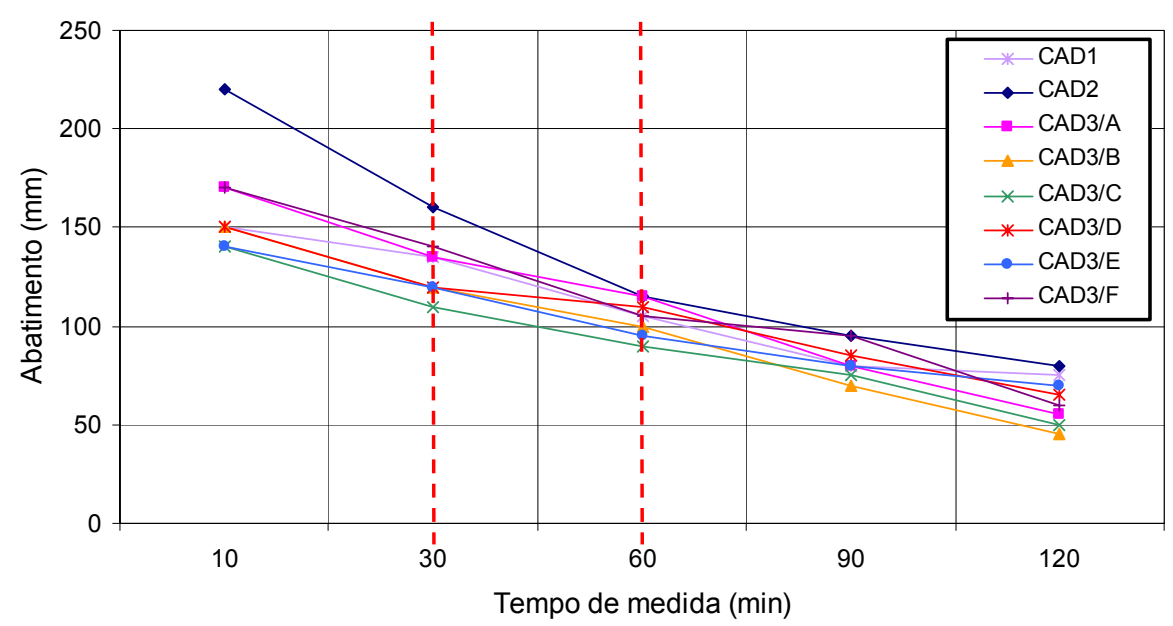

Figura 7.10 - Curvas "abatimento de tronco de cone versus tempo" para os concretos de alto desempenho produzidos com CPV ARI RS.

Como para os MCAD, ao manter as proporções entre os materiais constituintes da mistura e a relação água/aglomerante constantes e variando-se o tipo de cimento e o teor de SP adequado para cada combinação cimento-SP, os 
CAD produzidos com ambos os cimentos apresentaram abatimentos semelhantes no início da avaliação, porém, ao longo do tempo, a perda novamente foi maior para as misturas produzidas com o CPV ARI Plus (em média, 70\%) do que para os CAD produzidos com o CPV ARI RS (em média, 62\%). Assim, mais uma vez, as misturas produzidas com CPV ARI Plus, que possui uma maior quantidade de $C_{3} A$ e $\mathrm{C}_{3} \mathrm{~S}$ na sua composição, apresentaram maiores perdas de abatimento do que as misturas produzidas com um cimento com menor quantidade desses componentes (CPV ARI RS).

A incorporação de SP resultou em misturas mais trabalháveis quando comparado às misturas convencionais (CAD1), com abatimentos $36 \%$ maiores, porém a perda de abatimento observada para os CAD2 foi maior. Enquanto os CAD1 perderam aproximadamente $54 \%$ do seu abatimento ao longo do ensaio, os CAD2 apresentaram perda média de $70 \%$, sendo a perda da mistura produzida com o CPV ARI Plus maior que a da mistura produzida com o CPV ARI RS. Esse fato mostra que misturas incorporadas com SP apresentam maiores perdas de abatimento quando comparadas com as misturas convencionais, produzidas sem a incorporação de qualquer adição química ou mineral e que, quanto maior o abatimento inicial, maior sua perda ao longo do tempo.

Para ambos os cimentos utilizados, a incorporação de sílica ativa reduziu os abatimentos iniciais dos CAD3 quando comparado com os CAD2 (adição única de $\mathrm{SP})$, mas ao longo do tempo, a tendência do comportamento foi semelhante, ou seja, a perda de abatimento se deu de maneira contínua e gradual durante o ensaio. Deve-se observar que, apesar do menor abatimento inicial dessas misturas, a perda de abatimento ao longo do tempo foi menor.

Assim como para os MCAD, o procedimento de mistura influenciou o comportamento dos CAD no estado fresco. A variação dos abatimentos medidos foi, em determinações absolutas, de $41 \mathrm{~mm}$ e $27 \mathrm{~mm}$ para as misturas produzidas com CPV ARI Plus e CPV ARI RS, respectivamente.

Com a mudança na dimensão máxima característica do agregado graúdo e, consequentemente, na composição da mistura, o procedimento de mistura mais adequado também mudou. Para os CAD3 produzidos com CPV ARI Plus, o maior abatimento inicial foi obtido com o procedimento de mistura $D$, porém, o melhor desempenho ao longo do tempo foi observado para as misturas produzidas segundo o procedimento $B$. Para os CAD3 produzidos com CPV ARI RS, os maiores abatimentos foram obtidos para a ordem de incorporação dos materiais ditada pelo procedimento $\mathrm{F}$, durante praticamente todo o ensaio. 
No procedimento $\mathrm{B}$, a incorporação do SP foi feita em duas partes (metade no início da mistura junto com a água de amassamento e a outra metade aproximadamente quatro minutos após o contato entre o cimento e a água) durante o processo de mistura. Esse melhor desempenho do comportamento verificado pela adição parcelada durante o processo de mistura está de acordo com o apresentado na literatura. No procedimento $F$, que se ajustou melhor aos valores determinados para as misturas produzidas com o CPV ARI RS, a adição do SP foi realizada junto com água de amassamento, dois minutos após a homogeneização dos materiais aglomerantes. Sempre que um SP é adicionado junto com a água de amassamento, ele perde seu caráter superplastificante, comportando-se apenas como um plastificante. As moléculas do aditivo são então absorvidas pelos agregados, competindo com água para a saturação de sua superfície. Assim, as moléculas de SP só serão liberadas posteriormente para contribuir com a fluidificação da mistura, resultando em melhores trabalhabilidades com o decorrer do tempo.

A trabalhabilidade do concreto também depende do teor de argamassa presente na mistura. Em um concreto, o teor de argamassa deve ser o mínimo necessário para preencher os vazios entre o agregado graúdo e ligá-lo de maneira a formar um material resistente quando no estado endurecido (YEN et al., 1999). Porém, um concreto trabalhável requer uma quantidade suficiente de argamassa para preencher os vazios entre os agregados e para lubrificar a superfície dos mesmos durante o seu lançamento. Quanto maior o teor de argamassa no concreto, maior será o abatimento e a extensão de fluxo (slump flow) do material.

Ambas as séries de concreto (MCAD e CAD) foram produzidas com teores de argamassa ideais para cada composição, resultando em trabalhabilidades adequadas. Apesar dos maiores teores de argamassa ( $\alpha=61 \%$ ) e SP, os MCAD apresentaram perda de trabalhabilidade média de aproximadamente $80 \%$, enquanto os CAD produzidos com menores teores de argamassa ( $\alpha=51 \%$ ) e SP apresentaram perda de trabalhabilidade média de $65 \%$. Isso pode estar relacionado com a área específica dos agregados graúdos. Para uma dada partícula, a área específica é inversamente proporcional à sua dimensão linear, de maneira que quanto mais finas as partículas, maior a área específica para uma determinada massa. No concreto, isso significa que a utilização de um agregado com área superficial maior necessitará de uma maior quantidade de matriz pasta de cimento ou de argamassa para o completo revestimento e lubrificação das partículas, 
resultando em misturas menos trabalháveis, considerando-se constante as demais características e materiais.

O efeito da dimensão máxima característica do agregado pode ser observado sobre a demanda do teor ideal de argamassa e, conseqüentemente, sobre a quantidade de SP necessária para se manter uma mesma trabalhabilidade medida em termos de abatimento de tronco de cone. Agregados com dimensões menores necessitam de maiores teores de argamassa e SP que os agregados com dimensões maiores, o que implica em misturas menos econômicas. Porém, a escolha de um agregado deve ser feita de acordo com outros parâmetros de projetos como, por exemplo, o espaçamento entre as armaduras.

\subsubsection{Consistômetro de Ve-Be}

As trabalhabilidades dos concretos também foram analisadas em temos do tempo Ve-Be. Na tabela 7.10 são apresentados os valores dos tempos de vibração de MCAD determinados através do consistômetro de Ve-Be. Nas figuras $7.11 \mathrm{e}$ 7.12 são apresentados os comportamentos desses materiais ao longo do tempo.

Tabela 7.10 - Resultados do ensaio de consistômetro de Ve-Be para os microconcretos de alto desempenho. Tempos em [s].

\begin{tabular}{c|c|c|c|c|c|c|c|c|c|c}
\hline Cimento & \multicolumn{4}{|c|}{ CPV ARI Plus } & \multicolumn{5}{c}{ CPV ARI RS } \\
\hline \multirow{2}{*}{ Microconcreto } & \multicolumn{4}{|c|}{ Tempo de medida (min) } & \multicolumn{5}{c}{ Tempo de medida (min) } \\
\cline { 2 - 12 } & $\mathbf{1 0}$ & $\mathbf{3 0}$ & $\mathbf{6 0}$ & $\mathbf{9 0}$ & $\mathbf{1 2 0}$ & $\mathbf{1 0}$ & $\mathbf{3 0}$ & $\mathbf{6 0}$ & $\mathbf{9 0}$ & $\mathbf{1 2 0}$ \\
\hline MCADI & 10,91 & ----- & ----- & ----- & ----- & 9,75 & ----- & ----- & ----- & ---- \\
\hline MCAD2 & 2,84 & 3,88 & 4,62 & 4,96 & 7,22 & 1,67 & 2,53 & 2,64 & 3,07 & 3,99 \\
\hline MCAD3/A & 3,03 & 4,29 & 4,81 & 5,72 & 8,87 & 2,63 & 2,71 & 2,92 & 3,68 & 4,31 \\
\hline MCAD3/B & 3,77 & 4,01 & 4,07 & 6,09 & 8,89 & 2,70 & 2,86 & 2,97 & 3,01 & 3,95 \\
\hline MCAD3/C & 2,89 & 3,07 & 3,88 & 6,00 & 9,69 & 2,59 & 2,67 & 2,93 & 3,05 & 3,62 \\
\hline MCAD3/D & 2,81 & 3,32 & 3,70 & 4,24 & 5,63 & 2,27 & 2,43 & 2,87 & 4,26 & 4,63 \\
\hline MCAD3/E & 2,66 & 2,90 & 3,03 & 4,57 & 5,56 & 2,57 & 2,63 & 2,91 & 3,43 & 4,49 \\
\hline MCAD3/F & 2,51 & 2,83 & 3,71 & 5,02 & 8,14 & 2,32 & 2,44 & 2,63 & 3,12 & 3,91 \\
\hline
\end{tabular}




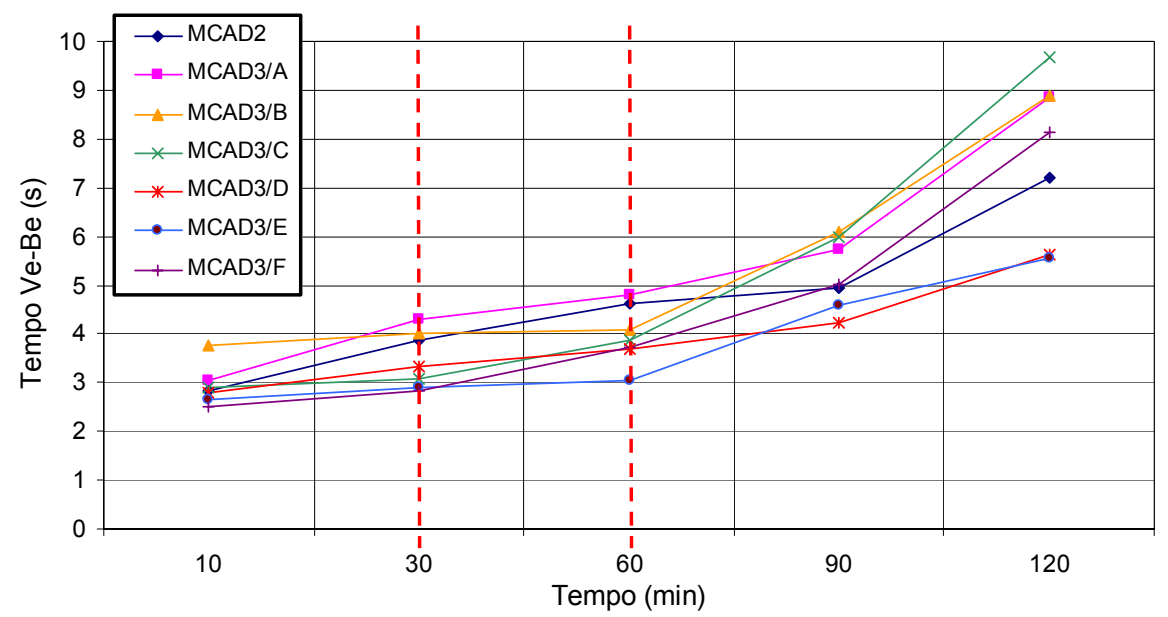

Figura 7.11 - Curvas "tempo Ve-Be versus tempo" para os microconcretos de alto desempenho produzidos com CPV ARI Plus.

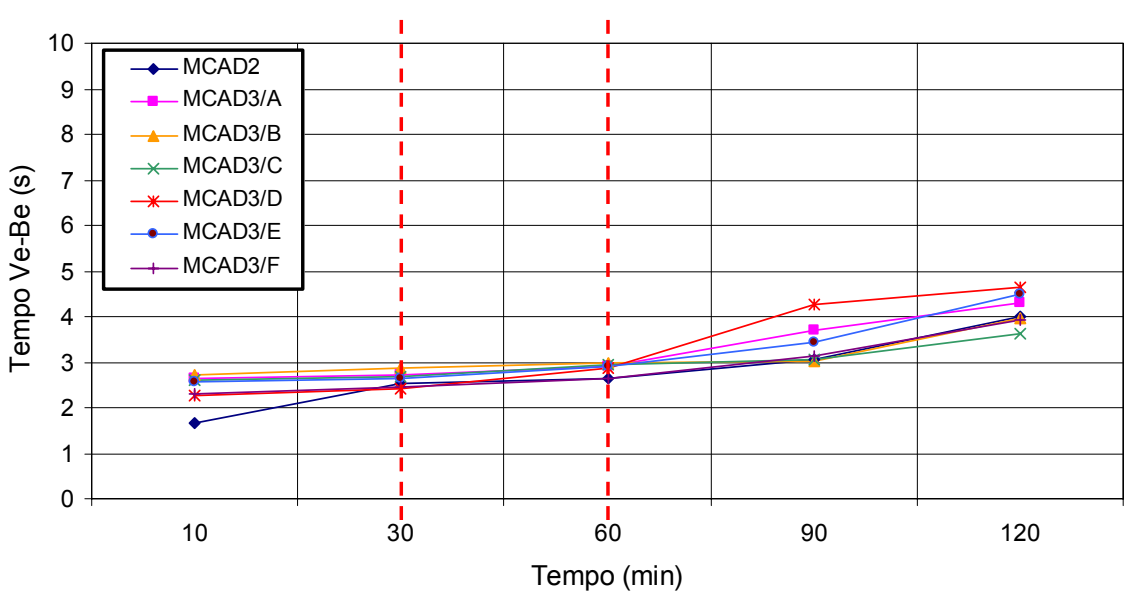

Figura 7.12 - Curvas "tempo Ve-Be versus tempo" para os microconcretos de alto desempenho produzidos com CPV ARI RS.

Os MCAD1, misturas produzidas sem a incorporação de adições químicas e minerais, apresentaram trabalhabilidades insuficientes para serem avaliados. Pelo ensaio de consistômetro de $\mathrm{Ve}-\mathrm{Be}$, os tempos de vibração medidos logo aos 10 minutos foram de 10,91 s e 9,75 s para os MCAD produzidos com CPV ARI Plus e CPV ARI RS, respectivamente.

As demais misturas apresentaram-se bastante fluidas, com tempos Ve-Be variando entre 1,67 s e 3,77 s aos 10 minutos de ensaio. Com o decorrer do ensaio, os tempos de vibração medidos aumentaram de maneiras diferentes para os dois cimentos estudados. Os MCAD produzidos com CPV ARI Plus apresentaram grandes aumentos do tempo de vibração (cerca de 170\%), enquanto que nas misturas produzidas com CPV ARI RS, esse acréscimo foi bem menor (aproximadamente 66\%). Esse aumento no tempo Ve-Be indica uma perda da trabalhabilidade desses materiais, uma vez que o tempo necessário para que uma mesma massa de concreto leva para preencher um cilindro aumenta. 
A diferença no comportamento observado para as misturas produzidas com os dois cimentos se deve à composição do cimento, particularmente a quantidade de $\mathrm{C}_{3} \mathrm{~A}$ e $\mathrm{C}_{3} \mathrm{~S}$. Como os tempos de vibração medidos aos 10 minutos de ensaio foram semelhantes para as misturas produzidas com ambos os cimentos, a diferença entre a evolução dos tempos está relacionada com a hidratação do $\mathrm{C}_{3} \mathrm{~S}$ : como o CPV ARI Plus possui uma maior quantidade de $\mathrm{C}_{3} \mathrm{~S}$ em sua composição $(58,95 \%)$, uma maior quantidade de produtos hidratados será formada nas misturas produzidas com esses cimentos do que com o CPV ARI RS (38,26\%), resultando em maiores reduções da trabalhabilidade dessas misturas ao longo do tempo.

Como não foi possível determinar o abatimento para os concretos de referência (MCAD1), a influência do SP sobre a trabalhabilidade (em termos de tempo de vibração) não pode ser devidamente avaliada. Porém, da literatura sabese que a incorporação desse aditivo a uma mistura de concreto resulta em misturas mais trabalháveis e, consequentemente, com menores tempos $\mathrm{Ve}-\mathrm{Be}$.

A incorporação de sílica ativa às misturas praticamente não influenciou o tempo Ve-Be medido. A diferença entre os concretos produzidos com e sem a incorporação da adição mineral está no comportamento apresentado ao longo do tempo: para os MCAD produzidos com CPV ARI Plus, o aumento do tempo medido foi semelhante para todas as misturas (154\% para o MCAD2 e média de 166\% para o CAD3), independente da sua composição; porém, para os MCAD produzidos com CPV ARI RS, as misturas incorporadas com sílica apresentaram aumentos bem menores no tempo medido do que as misturas com incorporação única de SP (66\% contra $139 \%$, respectivamente).

Apesar de reduzir a trabalhabilidade inicial dos concretos aos quais a sílica ativa é incorporada, o uso dessa adição mineral resulta em misturas mais coesas (sem exsudação ou segregação) e é muito eficiente na produção de concretos fluidos. As pequenas partículas de sílica agem como esferas rolantes no concreto e passam a fazer parte da solução de água do poro, o que, conseqüentemente, promove o aumento da fluidez da mistura. Com a aplicação da vibração, o deslocamento relativo entre as partículas de sílica é facilitado, mantendo o comportamento da mistura e resultando pequenas variações entre as determinações (pequenos aumentos ao longo do tempo).

Quanto à influência do procedimento de mistura, pode-se observar que uma mudança na ordem de incorporação dos materiais constituintes da mistura resultou em pequenas variações na determinação do tempo Ve-Be. Com exceção dos tempos medidos aos 120 minutos para as misturas produzidas com CPV ARI Plus, 
cujas diferenças foram de até quatro segundos, as demais misturas apresentaram variações de máximo 1,5 segundo entre as determinações. Ao longo do tempo, a influência do procedimento de mistura empregado na produção dos MCAD3 se deu de maneira diferenciada para os dois cimentos.

Para os MCAD3 produzidos com CPV ARI Plus, o menor tempo Ve-Be foi medido para a mistura produzida de acordo com o procedimento $F$, que manteve o desempenho aos 30 minutos de ensaio. Aos 60 minutos, o menor tempo foi observado para o concreto produzido de acordo com o procedimento E. Nas determinações seguintes, os procedimentos que apresentaram os melhores desempenhos foram os procedimentos D e E aos 90 e 120 minutos, respectivamente. No caso dos MCAD3 produzidos com CPV ARI RS, os menores tempos de vibração foram obtidos com os procedimentos $D$ (aos 10 e 30 minutos), F (aos 60 minutos), B (aos 90 minutos) e C (aos 120 minutos).

Como a determinação dos menores tempos de vibração apresentou uma grande dispersão entre os procedimentos de mistura testados, foi considerado mais adequado o procedimento que apresentou menores acréscimos para os tempos de vibração medidos ao longo do ensaio. Sendo assim, para os MCAD3 produzidos com CPV ARI Plus e CPV ARI RS, os menores aumentos dos tempos de vibração foram observados para as misturas produzidas de acordo com os procedimentos $E$ e $\mathrm{C}$, respectivamente. Em ambos os procedimentos, o SP foi adicionado junto com a água de amassamento no início do processo de mistura. A diferença entre eles está na ordem de incorporação do agregado miúdo e dos aglomerantes: no procedimento de mistura $\mathrm{C}$, os aglomerantes foram incorporados dois minutos após o início da mistura, enquanto que no procedimento $E$, os agregados foram inicialmente saturados e só depois de quatro minutos do início do processo de mistura que os aglomerantes foram incorporados.

Sabe-se que para a adição do SP junto com a água de amassamento, esse aditivo perde seu caráter superplastificante, comportando-se apenas como um plastificante. As moléculas do aditivo são então absorvidas pelos agregados, competindo com água para a saturação de sua superfície. Assim, as moléculas de SP só serão liberadas posteriormente para contribuir com a fluidificação da mistura, resultando em melhores trabalhabilidades com o decorrer do tempo.

De acordo com a norma brasileira DNER-ME 094/94, quando o tempo de vibração medido for menor ou igual a 3 segundos, o resultado do ensaio é considerado não significativo e a consistência deverá ser determinada por outro método de ensaio. Assim, como a grande maioria das determinações apresentou 
tempos Ve-Be menores que $3 \mathrm{~s}$, esse método de ensaio não deve ser considerado para a avaliação da trabalhabilidade dos MCAD estudados.

$\mathrm{Na}$ figura 7.13 são apresentadas as etapas para a execução do ensaio de consistômetro de Ve-Be, antes e após a aplicação da vibração.

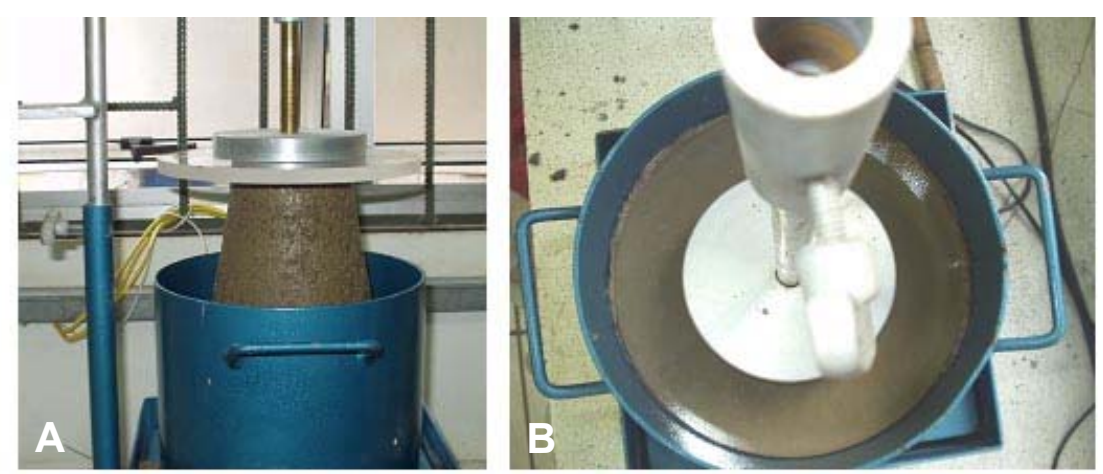

Figura 7.13 - Etapas do ensaio para determinação do tempo Ve-Be: (A) tronco de cone de concreto com disco transparente posicionado par ao início do ensaio; e (B) concreto ocupando o formato cilíndrico da cuba do equipamento, o que caracteriza o fim do ensaio.

$\mathrm{O}$ ensaio de consistômetro de $\mathrm{Ve}-\mathrm{Be}$ foi repetido para os concretos produzidos com agregados graúdos de $D_{\text {máx }} \leq 25 \mathrm{~mm}$. Os valores dos tempos de vibração medidos para as várias misturas são apresentados na tabela $7.11 \mathrm{e} \mathrm{a}$ evolução dessas determinações ao longo do tempo é apresentada na figura $7.14 \mathrm{e}$ 7.15 .

Tabela 7.11 - Resultados do ensaio de consistômetro de Ve-Be para os concretos de alto desempenho. Tempos em [s].

\begin{tabular}{c|c|c|c|c|c|c|c|c|c|c}
\hline Cimento & \multicolumn{4}{|c|}{ CPV ARI PIus } & \multicolumn{5}{c}{ CPV ARI RS } \\
\hline \multirow{2}{*}{ Concreto } & \multicolumn{4}{|c|}{ Tempo de medida (min) } & \multicolumn{5}{c}{ Tempo de medida (min) } \\
\cline { 2 - 12 } & $\mathbf{1 0}$ & $\mathbf{3 0}$ & $\mathbf{6 0}$ & $\mathbf{9 0}$ & $\mathbf{1 2 0}$ & $\mathbf{1 0}$ & $\mathbf{3 0}$ & $\mathbf{6 0}$ & $\mathbf{9 0}$ & $\mathbf{1 2 0}$ \\
\hline CADI & 2,76 & 3,87 & 5,33 & 6,76 & 7,93 & 3,21 & 3,71 & 4,25 & 5,90 & 6,81 \\
\hline CAD2 & 2,26 & 2,93 & 4,90 & 6,69 & 7,95 & 2,32 & 2,49 & 4,03 & 4,95 & 6,57 \\
\hline CAD3/A & 2,10 & 3,19 & 4,77 & 7,76 & 9,65 & 3,33 & 4,59 & 5,23 & 5,88 & 8,44 \\
\hline CAD3/B & 2,67 & 3,17 & 4,42 & 4,42 & 5,70 & 3,76 & 4,38 & 5,67 & 6,63 & 9,06 \\
\hline CAD3/C & 2,77 & 3,69 & 4,33 & 5,45 & 7,76 & 3,93 & 4,63 & 5,43 & 6,49 & 7,49 \\
\hline CAD3/D & 3,49 & 3,76 & 6,69 & 7,60 & 12,93 & 3,15 & 4,95 & 5,08 & 5,62 & 7,41 \\
\hline CAD3/E & 3,49 & 4,98 & 6,00 & 8,43 & 12,39 & 3,59 & 4,09 & 4,75 & 5,77 & 7,03 \\
\hline CAD3/F & 2,74 & 3,49 & 5,16 & 5,33 & 7,17 & 2,56 & 4,15 & 4,60 & 5,88 & 7,23 \\
\hline
\end{tabular}




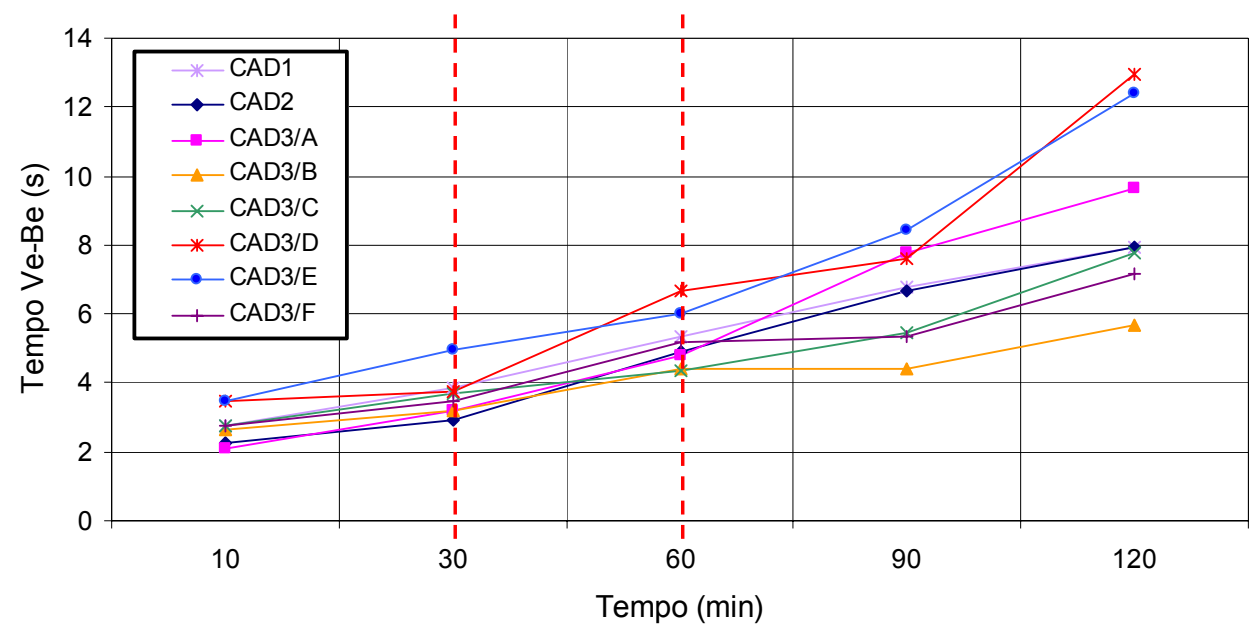

Figura 7.14 - Curvas "tempo Ve-Be versus tempo" para os concretos de alto desempenho produzidos com CPV ARI Plus.

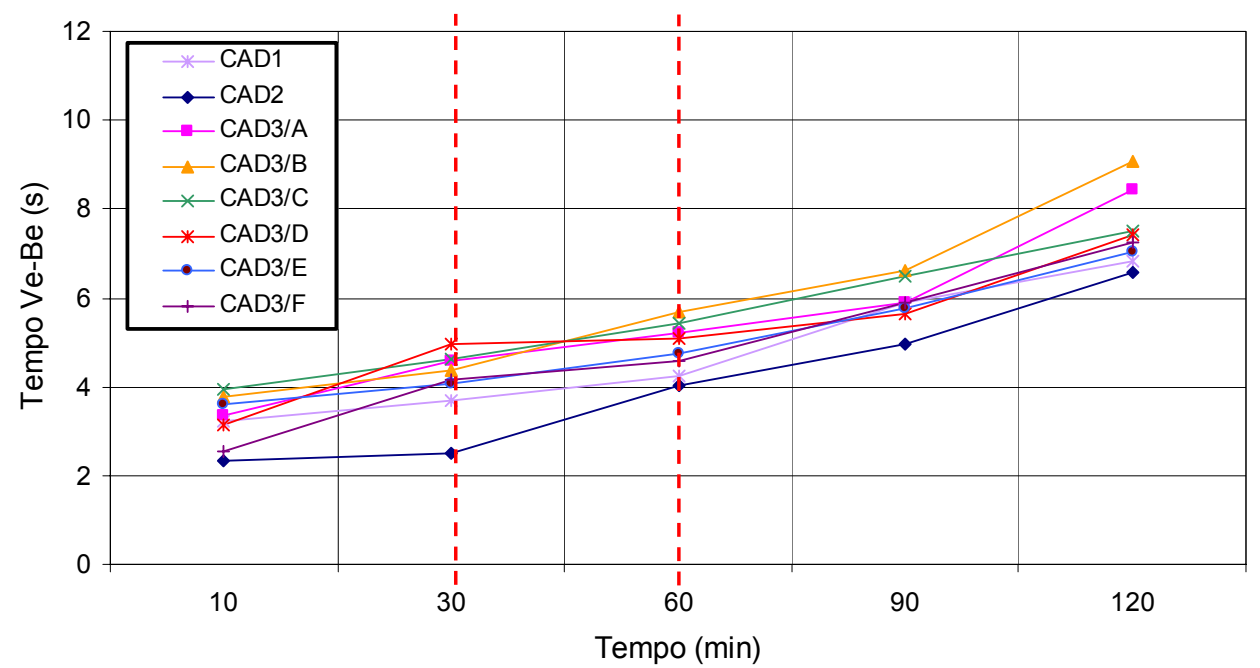

Figura 7.15 - Curvas "tempo Ve-Be versus tempo" para os concretos de alto desempenho produzidos com CPV ARI RS.

Os tempos de vibração medidos a partir do consistômetro de Ve-Be variaram entre 2,10 s e 3,93 s aos 10 minutos de ensaio. Com o decorrer do ensaio, esses tempos aumentaram para os dois cimentos estudados, sendo que os CAD produzidos com CPV ARI Plus apresentaram aumentos do tempo Ve-Be de cerca de $220 \%$, enquanto que nas misturas produzidas com CPV ARI RS esse acréscimo foi de aproximadamente $140 \%$. Esse aumento no tempo Ve-Be indica uma perda da trabalhabilidade desses materiais, uma vez que o tempo necessário para que uma mesma massa de concreto mude do formato de um tronco de cone em cilindro e, assim preencher a cuba de ensaio, aumenta.

Mais uma vez, os teores de $\mathrm{C}_{3} \mathrm{~A}$ e $\mathrm{C}_{3} \mathrm{~S}$ presentes na composição dos cimentos podem ser relacionados com a diferença observada no comportamento das misturas produzidas com ambos os cimentos ao longo do tempo. 
A incorporação do SP implicou na redução do tempo Ve-Be dos concretos estudados (CAD2), porém a perda da trabalhabilidade, relacionada com o aumento do tempo de vibração medido com o consistômetro de Ve-Be, foi maior para essas misturas do que para as misturas de concretos convencionais (CAD1).

As misturas com a incorporação de sílica ativa (CAD3) apresentaram tempos de vibração médios maiores que as outras duas misturas (CAD1 e CAD2), sendo, assim, consideradas menos trabalháveis. Porém, a perda de trabalhabilidade observada, em termos de aumento do tempo de vibração, foi novamente menor do que a perda observada para o CAD2 e maior do que para o CAD1.

Com a mudança do agregado graúdo, verificaram-se mudanças no comportamento das misturas frescas em função do procedimento de mistura empregado na sua produção. Mais uma vez, o menor tempo de vibração variou ao longo do tempo entre os procedimentos de mistura considerados e, assim, o desempenho geral foi considerado. Para os CAD3 produzidos com o CPV ARI Plus, o menor aumento do tempo de vibração medido foi para a mistura produzida de acordo com o procedimento $B$, enquanto que para os concretos produzidos com o CPV ARI RS, o melhor desempenho foi da mistura produzida de acordo com o procedimento $\mathrm{E}$. No procedimento $\mathrm{B}, \mathrm{o} \mathrm{SP}$ foi adicionado à mistura em duas partes (a primeira metade no início da mistura junto com a água e com o agregado graúdo e a outra metade no final do processo - quatro minutos após o contato cimentoágua). No procedimento $\mathrm{E}$, o aditivo foi adicionado no começo da mistura, entrando em contato com o cimento quatro minutos após o início do processo de mistura. Porém, o efeito positivo desse procedimento de mistura pode estar relacionado com a saturação inicial dos agregados antes da incorporação dos aglomerantes, evitando a absorção de parte da água da matriz pelos agregados.

Como a grande maioria dos tempos de vibração é maior que 3 segundos, o ensaio de consistômetro de Ve-Be pode ser considerado satisfatório para a avaliação da trabalhabilidade de concretos com $D_{\text {máx }} \leq 25 \mathrm{~mm}$.

Os CAD apresentaram aumento médio no tempo de vibração de cerca de $180 \%$ ao longo do intervalo de tempo medido, enquanto o aumento médio observado para os MCAD foi de $130 \%$. Essa diferença pode ser explicada pela perda de argamassa do concreto durante o ensaio. Como essa perda foi maior para os CAD, o tempo de vibração necessário para o completo adensamento do material (transformação de um tronco de cone em um cilindro) foi maior, isto é, com uma menor quantidade de argamassa, maior o tempo de vibração para que os agregados sejam totalmente envolvidos. 


\subsection{Avaliação da capacidade de escoamento do CAD fresco}

A avaliação da capacidade de escoamento dos concretos por entre uma grade com barras, se seguida a recomendação crítica da NBR 6118/2003, é um parâmetro que não está inexoravelmente ligado à busca de um concreto autoadensável, mas também à facilidade de agregados ultrapassar barreiras com energia de vibração. Ainda assim, verificou-se essa condição quando se utiliza o ensaio da caixa L, utilizada nas análises de concretos auto-adensáveis. Os resultados obtidos, bem como as observações feitas durante o ensaio para os MCAD são apresentados nas tabelas 7.12 e 7.13 .

Conforme observado nas tabelas 7.12 e 7.13 , nenhuma das misturas apresentou escoamento suficiente que a caracterizasse como um concreto autoadensável, mesmo com os altos valores de abatimento determinados pelo ensaio de abatimento de tronco de cone.

Tabela 7.12 - Resultados obtidos e observações feitas para a avaliação da capacidade de escoamento de MCAD produzidos com CPV ARI Plus através da caixa $L$.

\begin{tabular}{|c|c|c|c|c|c|c|}
\hline \multirow{2}{*}{ Concreto } & \multicolumn{5}{|c|}{ Parâmetros da caixa $L$} & \multirow{2}{*}{ Observações feitas durante o ensaio } \\
\hline & $\mathbf{T}_{20}$ & $\mathbf{T}_{40}$ & $\mathbf{h}_{1}$ & $\mathbf{h}_{2}$ & $h_{2} / h_{1}$ & \\
\hline MCAD1 & -- & -- & --- & --- & --- & $\begin{array}{l}\text { Não foi possível fazer qualquer medida. O material não } \\
\text { apresentou qualquer trabalhabilidade. }\end{array}$ \\
\hline MCAD2/1 & 1,10 & 6,25 & 10,5 & --- & --- & $\begin{array}{l}\text { O material escoou pela caixa } L \text {, porém não atingiu o fim da } \\
\text { caixa. Assim, não foi possível determinar a altura final }\left(h_{2}\right) \text { e, } \\
\text { conseqüentemente, a razão de bloqueio. }\end{array}$ \\
\hline MCAD3/1A & --- & --- & 48 & --- & --- & $\begin{array}{l}\text { O material escoou pela caixa } L \text { até atingir a marca de } 15 \mathrm{~cm} \\
\text { (distância entre as barras e o ponto final atingindo pelo } \\
\text { material). }\end{array}$ \\
\hline MCAD3/1B & --- & --- & 57,5 & --- & --- & $\begin{array}{l}\text { O material escoou pela caixa } L \text { até atingir a marca de } 3 \mathrm{~cm} \\
\text { (distância entre as barras e o ponto final atingindo pelo } \\
\text { material). }\end{array}$ \\
\hline MCAD3/1C & --- & --- & 52 & --- & --- & $\begin{array}{l}\text { O material escoou pela caixa } L \text { até atingir a marca de } 12 \mathrm{~cm} \\
\text { (distância entre as barras e o ponto final atingindo pelo } \\
\text { material). }\end{array}$ \\
\hline MCAD3/1D & --- & --- & 57 & --- & --- & $\begin{array}{l}\text { O material escoou pela caixa } \mathrm{L} \text { até atingir a marca de } 3 \mathrm{~cm} \\
\text { (distância entre as barras e o ponto final atingindo pelo } \\
\text { material). }\end{array}$ \\
\hline MCAD3/1E & --- & --- & 51 & --- & --- & $\begin{array}{l}\text { O material escoou pela caixa } L \text { até atingir a marca de } 12 \mathrm{~cm} \\
\text { (distância entre as barras e o ponto final atingindo pelo } \\
\text { material). }\end{array}$ \\
\hline MCAD3/1F & --- & --- & 53 & --- & --- & $\begin{array}{l}\text { O material escoou pela caixa } L \text { até atingir a marca de } 10 \mathrm{~cm} \\
\text { (distância entre as barras e o ponto final atingindo pelo } \\
\text { material). }\end{array}$ \\
\hline
\end{tabular}

$\mathrm{RB}=\mathrm{h}_{2} / \mathrm{h}_{1} ; \mathrm{T}_{20}$ e $\mathrm{T}_{40}$ em [s]; $h_{1}$ e $h_{2}$ em [cm]. 
Tabela 7.13 - Resultados obtidos e observações feitas para a avaliação da capacidade de escoamento de MCAD produzidos com CPV ARI RS através da caixa $L$.

\begin{tabular}{|c|c|c|c|c|c|c|}
\hline \multirow{2}{*}{ Concreto } & \multicolumn{5}{|c|}{ Parâmetros da caixa $L$} & \multirow{2}{*}{ Observações feitas durante o ensaio } \\
\hline & $\mathbf{T}_{20}$ & $\mathrm{~T}_{40}$ & $\mathbf{h}_{1}$ & $\mathbf{h}_{\mathbf{2}}$ & $\mathbf{h}_{2} / \mathbf{h}_{1}$ & \\
\hline MCAD1 & --- & --- & --- & --- & --- & $\begin{array}{l}\text { Não foi possível fazer qualquer medida. O material não } \\
\text { apresentou qualquer trabalhabilidade. }\end{array}$ \\
\hline MCAD2/1 & 2,53 & ----- & 50 & ----- & ----- & $\begin{array}{l}\text { O material escoou pela caixa } \mathrm{L} \text {, mas atingiu a marca de } 27 \\
\mathrm{~cm} \text {. Assim, não foi possível determinar a altura final }\left(\mathrm{h}_{2}\right) \text { e, } \\
\text { conseqüentemente, a razão de bloqueio. }\end{array}$ \\
\hline MCAD3/1A & ----- & ----- & 57,5 & ----- & ----- & $\begin{array}{l}\text { O material escoou pela caixa } \mathrm{L} \text { até atingir a marca de } 3 \mathrm{~cm} \\
\text { (distância entre as barras e o ponto final atingindo pelo } \\
\text { material). }\end{array}$ \\
\hline MCAD3/1B & ----- & ----- & ----- & ----- & ----- & $\begin{array}{l}\text { O material não escoou pela caixa L. Não passou qualquer } \\
\text { material por entre as barras para condição considerada. }\end{array}$ \\
\hline MCAD3/1C & ----- & ----- & 58 & ----- & ----- & $\begin{array}{l}\text { O material escoou pela caixa } L \text { até atingir a marca de } 2,5 \mathrm{~cm} \\
\text { (distância entre as barras e o ponto final atingindo pelo } \\
\text { material). }\end{array}$ \\
\hline MCAD3/1D & ----- & ----- & ----- & ----- & ----- & $\begin{array}{l}\text { O material não escoou pela caixa L. Não passou qualquer } \\
\text { material por entre as barras para condição considerada. }\end{array}$ \\
\hline MCAD3/1E & ----- & ----- & 58 & ----- & ----- & $\begin{array}{l}\text { O material escoou pela caixa } L \text { até atingir a marca de } 3,5 \mathrm{~cm} \\
\text { (distância entre as barras e o ponto final atingindo pelo } \\
\text { material). }\end{array}$ \\
\hline MCAD3/1F & ----- & ----- & ---- & ----- & ---- & $\begin{array}{l}\text { O material não escoou pela caixa L. Não passou qualquer } \\
\text { material por entre as barras para condição considerada. }\end{array}$ \\
\hline
\end{tabular}

$\mathrm{RB}=\mathrm{h}_{2} / \mathrm{h}_{1} ; \mathrm{T}_{20}$ e $\mathrm{T}_{40}$ em $[\mathrm{s}] ; \mathrm{h}_{1}$ e $\mathrm{h}_{2}$ em $[\mathrm{cm}]$.

A capacidade de escoamento dos concretos produzidos com agregados de $D_{\text {máx }} \leq 25 \mathrm{~mm}$ também foi avaliada. Nas tabelas 7.14 e 7.15 são apresentados os resultados e as observações feitas durante os ensaios.

Tabela 7.14 - Resultados obtidos e observações feitas para a avaliação da capacidade de escoamento de CAD produzidos com CPV ARI Plus através da caixa $\mathrm{L}$.

\begin{tabular}{|c|c|c|c|c|c|c|}
\hline \multirow{2}{*}{ Concreto } & \multicolumn{5}{|c|}{ Parâmetros da caixa $L$} & \multirow{2}{*}{ Observações feitas durante o ensaio } \\
\hline & $\mathrm{T}_{20}$ & $\mathbf{T}_{40}$ & $\mathbf{h}_{1}$ & $\mathbf{h}_{2}$ & $\mathrm{~h}_{2} / \mathrm{h}_{1}$ & \\
\hline CAD1 & ---- & ----- & 58,5 & ----- & ------ & $\begin{array}{l}\text { O material não escoou pela caixa L. Não passou qualquer } \\
\text { material por entre as barras para condição considerada. }\end{array}$ \\
\hline CAD2 & ----- & ----- & 57 & ----- & ----- & $\begin{array}{l}\text { O material escoou pouco pela caixa } L \text {, atingindo a marca de } 7 \\
\mathrm{~cm} \text { (distância entre as barras e o ponto atingido pelo material). }\end{array}$ \\
\hline CAD3/A & ----- & ----- & 58,5 & ----- & ----- & $\begin{array}{l}\text { O material não escoou pela caixa L. Não passou qualquer } \\
\text { material por entre as barras para condição considerada. }\end{array}$ \\
\hline CAD3/B & . & ----- & 58 & ----- & ----- & $\begin{array}{l}\text { O material não escoou pela caixa L. Não passou qualquer } \\
\text { material por entre as barras para condição considerada. }\end{array}$ \\
\hline CAD3/C & ----- & ----- & 58,5 & ----- & - & $\begin{array}{l}\text { O material não escoou pela caixa L. Não passou qualquer } \\
\text { material por entre as barras para condição considerada. }\end{array}$ \\
\hline CAD3/D & ----- & ----- & 59 & ----- & ----- & $\begin{array}{l}\text { O material não escoou pela caixa L. Não passou qualquer } \\
\text { material por entre as barras para condição considerada. }\end{array}$ \\
\hline CAD3/E & ---- & ----- & 59 & ----- & --- & $\begin{array}{l}\text { O material não escoou pela caixa L. Não passou qualquer } \\
\text { material por entre as barras para condição considerada. }\end{array}$ \\
\hline CAD3/F & ----- & ----- & 59,5 & ----- & & $\begin{array}{l}\text { O material não escoou pela caixa L. Não passou qualquer } \\
\text { material por entre as barras para condição considerada. }\end{array}$ \\
\hline
\end{tabular}


Tabela 7.15 - Resultados obtidos e observações feitas para a avaliação da capacidade de escoamento de CAD produzidos com CPV ARI RS através da caixa $L$.

\begin{tabular}{|c|c|c|c|c|c|c|}
\hline \multirow{2}{*}{ Concreto } & \multicolumn{5}{|c|}{ Parâmetros da caixa $L$} & \multirow{2}{*}{ Observações feitas durante o ensaio } \\
\hline & $\mathbf{T}_{20}$ & $T_{40}$ & $\mathbf{h}_{1}$ & $\mathbf{h}_{2}$ & $\mathrm{~h}_{2} / \mathrm{h}_{1}$ & \\
\hline CAD1 & ---- & ---- & ---- & ---- & ---- & $\begin{array}{l}\text { O material não escoou pela caixa L. Não passou qualquer } \\
\text { material por entre as barras para condição considerada. }\end{array}$ \\
\hline CAD2 & -- & ----- & 54,5 & ----- & ----- & $\begin{array}{l}\text { O material escoou pouco pela caixa } \mathrm{L} \text {, atingindo a marca de } \\
10 \mathrm{~cm} \text { (distância entre as barras e o ponto atingido pelo } \\
\text { material). }\end{array}$ \\
\hline CAD3/A & ----- & ----- & ----- & ----- & ----- & $\begin{array}{l}\text { O material não escoou pela caixa L. Não passou qualquer } \\
\text { material por entre as barras para condição considerada. }\end{array}$ \\
\hline CAD3/B & - & ----- & - & - & & $\begin{array}{l}\text { O material não escoou pela caixa L. Não passou qualquer } \\
\text { material por entre as barras para condição considerada. }\end{array}$ \\
\hline CAD3/C & --- & ----- & ----- & --- & -- & $\begin{array}{l}\text { O material não escoou pela caixa L. Não passou qualquer } \\
\text { material por entre as barras para condição considerada. }\end{array}$ \\
\hline CAD3/D & -- & ----- & $--\cdot$ & --- & -- & $\begin{array}{l}\text { O material não escoou pela caixa L. Não passou qualquer } \\
\text { material por entre as barras para condição considerada. }\end{array}$ \\
\hline CAD3/E & --- & ----- & ----- & --- & ----- & $\begin{array}{l}\text { O material não escoou pela caixa L. Não passou qualquer } \\
\text { material por entre as barras para condição considerada. }\end{array}$ \\
\hline CAD3/F & ----- & ----- & --- & --- & --- & $\begin{array}{l}\text { O material não escoou pela caixa L. Não passou qualquer } \\
\text { material por entre as barras para condição considerada. }\end{array}$ \\
\hline
\end{tabular}

$R B=h_{2} / h_{1} ; T_{20}$ e $T_{40}$ em $[s] ; h_{1}$ e $h_{2}$ em [cm].

Pode-se observar que a situação é ainda mais complicada do que para os MCAD. O escoamento desses materiais através da caixa $L$ foi menor do que o escoamento dos MCAD, porque nenhuma das misturas estudadas apresentou qualquer escoamento por entre as barras de aço, nem mesmo as misturas incorporadas apenas com SP (CAD2).

O comportamento observado foi semelhante ao apresentado na figura 7.16 para todas as misturas, seja microconcreto ou concreto de alto desempenho. Em nenhuma delas o material sequer atingiu o fim da caixa de ensaio, evidenciando a necessidade de uma força vibratória para o correto e completo adensamento desse material quando lançado em moldes de elementos de estruturas de concreto.
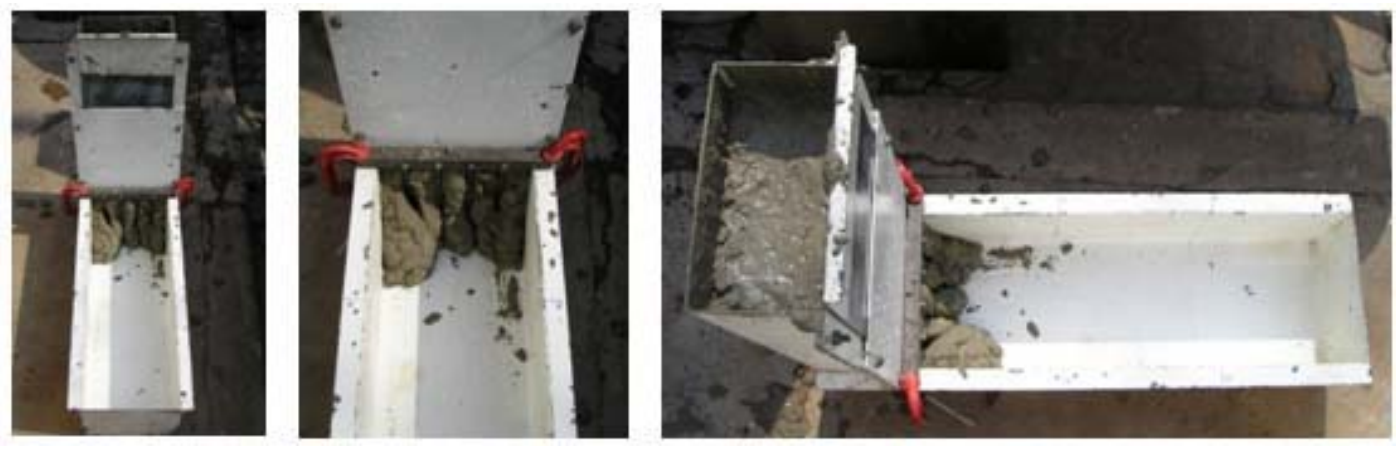

Figura 7.16 - Ensaio de caixa L para as misturas ensaiadas.

Assim, para a verificação do comportamento ao escoamento desses materiais por entre barras de aço simulando a armadura em elementos de concreto armado quando submetidos à vibração, o ensaio foi repetido para a situação mais crítica, ou seja, para a mistura de concreto que apresentou o menor escoamento. Na figura 7.17 , observa-se que, quando uma força vibratória é aplicada ao concreto, esse 
escoa completamente por entre as barras de aço, preenchendo a parte horizontal da caixa L.
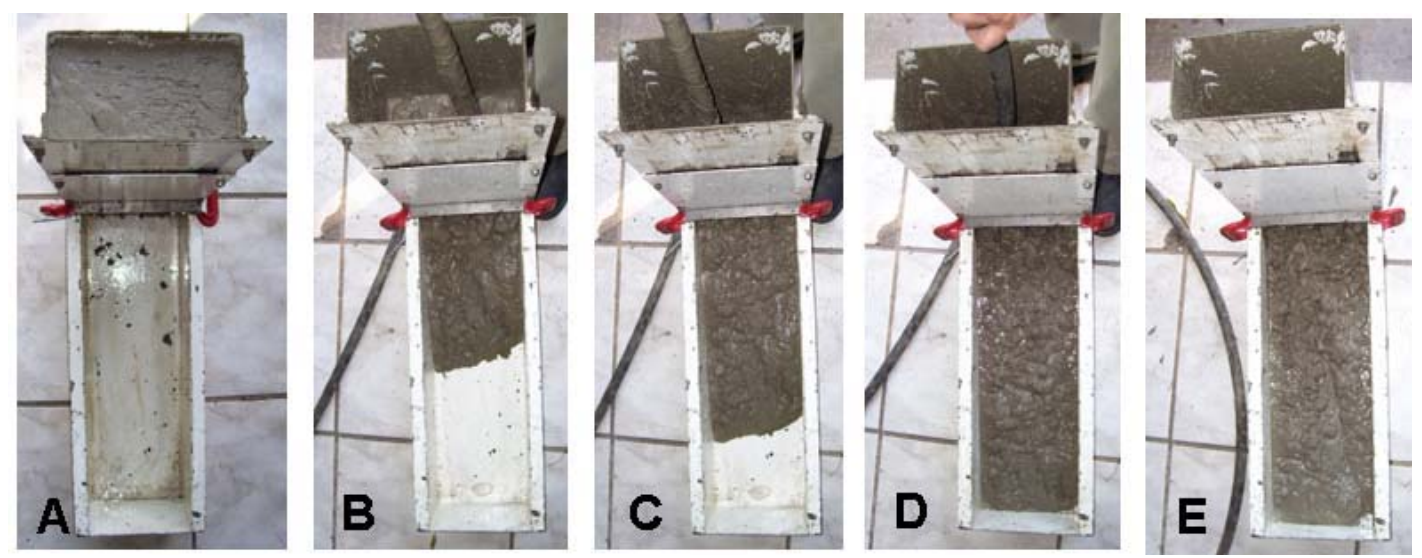

Figura 7.17 - Ensaio da caixa $L$ com a aplicação de uma força vibratória para o completo adensamento do concreto. As letras indicam a seqüência da evolução do adensamento.

\subsection{Avaliação da trabalhabilidade pelos métodos de ensaio que determinam os dois parâmetros reológicos}

\subsubsection{Ensaio de abatimento de tronco de cone modificado}

Para a caracterização reológica inicial das misturas de alto desempenho utilizou-se o ensaio de abatimento de tronco de cone modificado desenvolvido por Ferraris e De Larrard (1998b). Neste ensaio, através da determinação do abatimento de tronco de cone e do tempo de abatimento parcial (anexo D.1), foi possível determinar, respectivamente, a tensão de escoamento $\left(\tau_{0}\right)$ e a viscosidade plástica $(\mu)$ do material por meio das equações:

$$
\begin{gathered}
\tau_{o}=\frac{\rho}{347}(300-S)+212 \\
\mu=25 \times 10^{-3} \rho T
\end{gathered}
$$

onde $\rho$ é a densidade do concreto em $\left[\mathrm{kg} / \mathrm{m}^{3}\right]$, S é o abatimento final em [mm] e $T$ é o tempo de abatimento parcial em [s].

A equação elaborada pelos autores responsáveis pela modificação no ensaio de abatimento de tronco de cone para o cálculo da viscosidade de concretos com abatimento variando entre $200 \mathrm{~mm}$ e $260 \mathrm{~mm}$ não se ajustou às misturas estudadas. Quando utilizada, ela forneceu valores para a viscosidade plástica que não se adequaram ao comportamento dos materiais, isto é, o valor da viscosidade calculado a partir desta equação foi superestimado com relação ao seu 
desenvolvimento ao longo do tempo. Assim, adotou-se a mesma equação para todas as determinações.

Este ensaio, apesar de ser uma modificação do ensaio de abatimento de tronco de cone convencional para determinar a viscosidade plástica de um concreto, apresentou uma deficiência quanto a essa avaliação ao longo do tempo. Quando o abatimento medido foi menor que $100 \mathrm{~mm}$ - abatimento parcial estabelecido por Ferraris e De Larrard (1998b) - a leitura do tempo de abatimento parcial não pode ser feita. Assim, não foi possível analisar a evolução desse parâmetro reológico durante o todo o ensaio, isto é, por um período de até 120 minutos. Para a maioria das misturas estudadas, o acompanhamento desse parâmetro só foi possível por até 60 minutos após o início do ensaio.

Os valores dos parâmetros reológicos determinados para os MCAD a partir do ensaio de abatimento de tronco de cone modificado são apresentados na tabela 7.16. Nas figuras 7.18 e 7.19 são apresentadas as curvas "tensão de escoamento versus tempo" para os microconcretos estudados.

A influência mais significativa do cimento sobre o comportamento reológico de um concreto está relacionada com sua composição química, isto é, com o retardamento do processo de hidratação dos aluminatos causado pelo sulfato de cálcio. $\mathrm{O}$ teor e a morfologia do $\mathrm{C}_{3} \mathrm{~A}$ estão entre as características químicas do cimento mais importantes em termos de fluidez da mistura.

Apesar de possuírem teores de $\mathrm{C}_{3} \mathrm{~A}$ diferentes (7,36\% e 4,92\% para o CPV ARI Plus e CPV ARI RS, respectivamente), a trabalhabilidade inicial das misturas produzidas com ambos os cimentos foi semelhante. Porém, foi ao longo do tempo que a influência do tipo de cimento se tornou evidente. Os concretos produzidos com CPV ARI Plus apresentaram maiores aumentos da tensão de escoamento e da viscosidade plástica do que as misturas produzidas com CPV ARI RS, independente da composição da mistura e do procedimento de mistura empregado na sua produção. Esses acréscimos dos valores dos parâmetros reológicos indicam uma maior perda da trabalhabilidade para as misturas produzidas com o primeiro tipo de cimento.

Assim, a diferença entre as perdas de trabalhabilidade das misturas produzidas com os dois cimentos, associadas aos acréscimos dos parâmetros reológicos determinados, está relacionada com a quantidade de $\mathrm{C}_{3} \mathrm{~S}$ que compõe o cimento: como o CPV ARI Plus possui uma quantidade de $\mathrm{C}_{3} \mathrm{~S}$ maior que o $\mathrm{CPV}$ ARI RS (58,95\% contra 38,26\%, respectivamente), o maior acréscimo dos parâmetros das misturas produzidas com o primeiro cimento deve-se à hidratação 
desse componente para o desenvolvimento da resistência mecânica nas primeiras idades.

A influência da incorporação do SP sobre os parâmetros reológicos não pode ser verificada para os microconcretos. Como o MCAD1 - mistura de referência não apresentou abatimento suficiente para ser avaliado ao longo do tempo, não houve uma mistura de comparação para as observações pudessem ser feitas.

Tabela 7.16 - Parâmetros reológicos para os MCAD estudados.

\begin{tabular}{|c|c|c|c|c|c|c|c|c|c|c|}
\hline \multirow{3}{*}{$\begin{array}{c}\text { Cimento } \\
\begin{array}{c}\text { Micro- } \\
\text { concreto }\end{array}\end{array}$} & \multicolumn{5}{|c|}{ CPV ARI Plus (SP = 0,61\%) } & \multicolumn{5}{|c|}{ CPV ARI RS (SP = 0,50\%) } \\
\hline & \multicolumn{5}{|c|}{ Tempo de medida (min) } & \multicolumn{5}{|c|}{ Tempo de medida (min) } \\
\hline & 10 & 30 & 60 & 90 & 120 & 10 & 30 & 60 & 90 & 120 \\
\hline \multicolumn{11}{|c|}{ TENSÃO DE ESCOAMENTO [Pa] } \\
\hline MCAD I & ---- & ---- & ----- & ---- & ---- & ---- & ---- & ----- & ---- & ----- \\
\hline MCAD2 & 634,25 & 1126,87 & 1478,74 & 1900,99 & $(2112,12)$ & 660,26 & 936,11 & 1418,84 & 1694,69 & $(1936,06)$ \\
\hline MCAD3/A & 902,20 & 1385,34 & 1764,95 & $(1868,48)$ & $(2179,07)$ & 794,26 & 1102,52 & 1342,27 & 1650,53 & $(1890,29)$ \\
\hline MCAD3/B & 1074,75 & 1385,34 & 1626,91 & $(1937,50)$ & $(2282,61)$ & 931,27 & 1171,02 & 1445,03 & 1650,53 & $(1719,03)$ \\
\hline MCAD3/C & 936,71 & 1109,26 & 1523,38 & 1902,99 & $(2213,59)$ & 1102,52 & 1273,77 & 1547,78 & 1684,78 & $(1821,78)$ \\
\hline MCAD3/D & 764,16 & 1040,24 & 1454,36 & 1764,95 & $(1972,01)$ & 897,01 & 1239,52 & 1513,53 & 1856,03 & $(1993,04)$ \\
\hline MCAD3/E & 626,12 & 971,22 & 1419,85 & 1799,46 & $(1937,50)$ & 999,77 & 1342,27 & 1513,53 & 1787,53 & $(2027,29)$ \\
\hline MCAD3/F & 867,69 & 1385,34 & 1661,42 & $(1937,50)$ & $(2179,07)$ & 1034,02 & 1308,02 & 1513,53 & 1650,53 & $(1890,29)$ \\
\hline
\end{tabular}

VISCOSIDADE PLÁSTICA [Pa.s]

\begin{tabular}{|c|c|c|c|c|c|c|c|c|c|c|}
\hline MCADI & ----- & ----- & ----- & ----- & ----- & ----- & ----- & ----- & ----- & ----- \\
\hline MCAD2 & $(12,82)$ & 14,04 & 23,20 & ----- & ----- & $(13,16)$ & 14,96 & 19,14 & ----- & ----- \\
\hline MCAD3/A & 19,40 & 22,15 & ---- & ---- & ---- & $(16,64)$ & 17,83 & 24,96 & ---- & ---- \\
\hline MCAD3/B & 15,57 & 16,17 & ----- & ----- & ----- & 20,80 & 22,58 & 26,74 & ----- & ----- \\
\hline MCAD3/C & 16,77 & 17,36 & 25,75 & ----- & ----- & 19,61 & 20,80 & 23,18 & ----- & ----- \\
\hline MCAD3/D & $(14,97)$ & 16,17 & 20,36 & ----- & ---- & 14,86 & 17,83 & 19,02 & ----- & ----- \\
\hline MCAD3/E & $(13,77)$ & 14,97 & 20,96 & ----- & ----- & 16,04 & 17,83 & 20,20 & ----- & ----- \\
\hline MCAD3/F & 16,77 & 18,56 & ----- & ----- & ----- & 19,02 & 20,80 & 24,36 & ----- & ----- \\
\hline
\end{tabular}

OBS.:

1) As tensões de escoamento entre parênteses foram calculadas utilizando os abatimentos determinados a partir do ensaio de abatimento de tronco tradicional, pois o ensaio de abatimento de tronco de cone modificado apresentou uma limitação para concretos com abatimentos inferiores a $100 \mathrm{~mm}$

2) As viscosidades entre parênteses foram determinadas de acordo com a equação recomendada para concretos com abatimento inferior a $200 \mathrm{~mm}$, pois a outra equação forneceu valores que não se adequaram ao aumento da viscosidade com o tempo.

3) Os espaços marcados com traços na tabela indicam que, para essas misturas, não foi possível determinar o tempo de abatimento parcial e, consequentemente, sua viscosidade plástica (misturas com abatimentos menores que $100 \mathrm{~mm}$ ). 


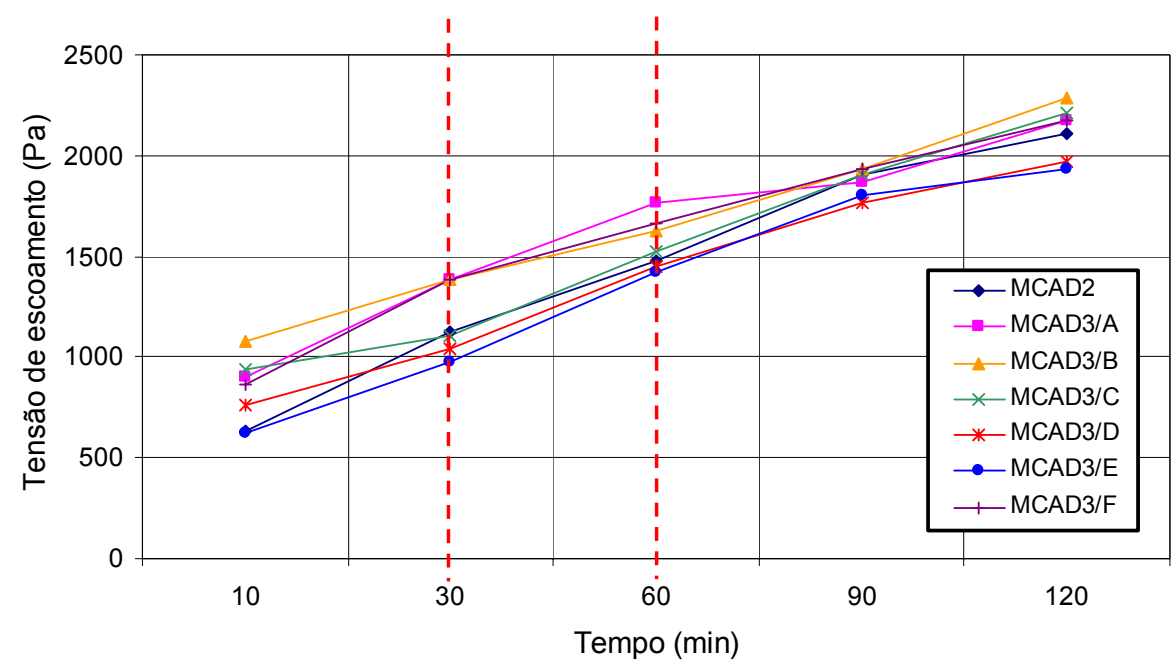

Figura 7.18 - Curva da" tensão de escoamento versus tempo" para microconcretos de alto desempenho produzidos com CPV ARI Plus.

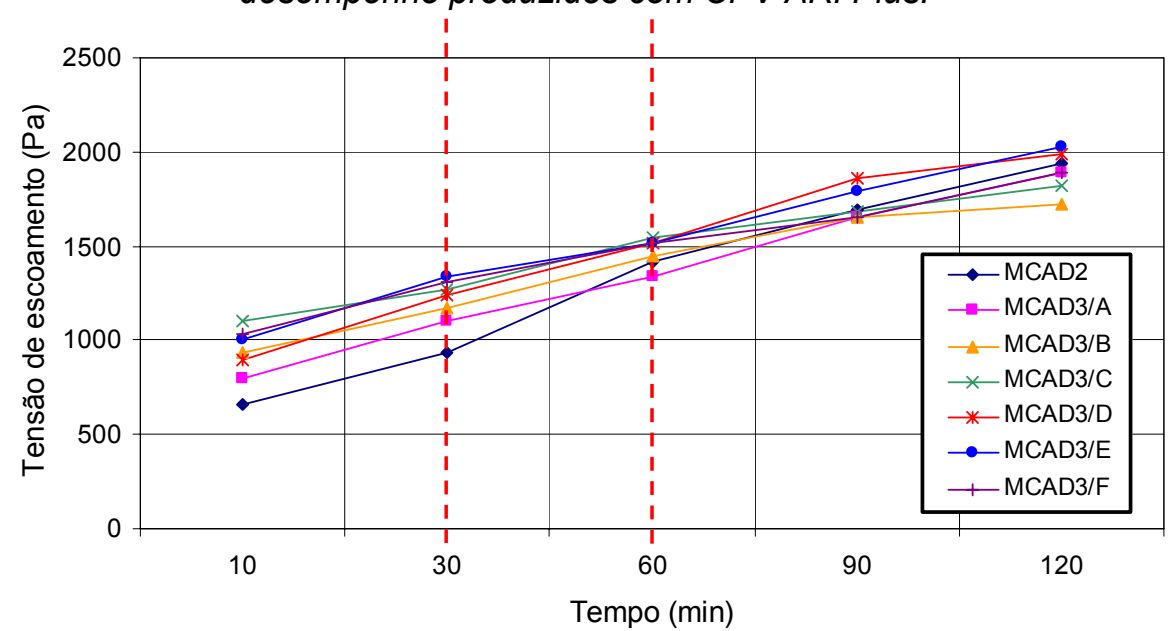

Figura 7.19 - Curva da "tensão de escoamento versus tempo" para microconcretos de alto desempenho produzidos com CPV ARI RS.

Quando a sílica ativa é incorporada a uma mistura de concreto, uma maior quantidade de superfícies sólidas é introduzida na mistura. Como a sílica constitui de partículas muito pequenas e, consequentemente, possui uma área superficial elevada, suas partículas são reativas quimicamente e adsorvem moléculas de SP. Como resultado, a tensão de escoamento e a viscosidade plástica tendem a aumentar. Porém, como as partículas de sílica são bem arredondadas, elas favorecem o empacotamento dos materiais aglomerantes e diminuem o imbricamento entre os agregados, resultando em uma redução dos parâmetros reológicos. No caso dos MCAD avaliados pelo ensaio de abatimento de tronco de cone modificado, a incorporação de sílica resultou no aumento da tensão de escoamento e da viscosidade plástica quando comparado com as misturas sem essa adição mineral (MCAD2). Porém, ao longo do tempo, os acréscimos observados para os MCAD3 foram menores do que os aumentos observados para 
os MCAD2. Isso mostra que a incorporação de sílica melhora o desempenho da mistura ao longo do tempo, mesmo reduzindo a trabalhabilidade inicial desses materiais.

As propriedades reológicas dos MCAD3 variaram de acordo com o procedimento de mistura empregado na sua produção. Para a tensão de escoamento, as variações médias absolutas foram de aproximadamente $345 \mathrm{~Pa}$ e $253 \mathrm{~Pa}$ para as misturas produzidas com CPV ARI Plus e CPV ARI RS, respectivamente. Para a viscosidade plástica, a variação média absoluta foi de aproximadamente 6 Pa.s para ambos os cimentos utilizados.

No início do ensaio, os procedimentos de mistura $E$ e $A$ resultaram em misturas com os menores valores de tensão de escoamento para os MCAD3 produzidos com CPV ARI Plus e CPV ARI RS, respectivamente, enquanto as menores viscosidades foram obtidas para as misturas produzidas segundo os procedimentos E e D respectivamente para os mesmos cimentos. Durante praticamente todo o ensaio, esses mesmos procedimentos resultaram nos menores valores medidos para ambos os parâmetros reológicos.

Essa variação entre os procedimentos de mistura que resultaram em misturas com melhores desempenhos relacionados com os dois parâmetros reológicos mostra que não existe nenhuma correlação entre eles, ou seja, uma mistura produzida de acordo com um determinado procedimento de mistura pode apresentar uma menor tensão de escoamento quando comparada com uma mistura produzida de acordo com outro procedimento, porém esse procedimento não implica necessariamente na mistura com a menor viscosidade plástica. Conforme observado por Tattersall (1990), os dois parâmetros reológicos devem ser determinados como entidades separadas.

Para a ampla literatura sobre o efeito do tempo de adição do SP, uma melhor trabalhabilidade é obtida quando o aditivo é incorporado em atraso (alguns minutos após o contato cimento-água) ou divido em parcelas durante o processo de mistura do concreto. Isso pode ser relacionado com a quantidade de $\mathrm{C}_{3} \mathrm{~A}$ - que é responsável pela redução da fluidez devido à sua rápida hidratação nas primeiras idades (dessa maneira, a quantidade de $\mathrm{C}_{3} \mathrm{~A}$ é minimizada pela hidratação antes da incorporação do SP por até 10 minutos) - e com a adsorção do SP pelo $C_{3} A$ e $C_{3} S$ não-hidratados - que é maior do que a adsorção pelas fases hidratadas, aumentando a quantidade de SP na fase intersticial e, consequentemente, levando a um aumento na trabalhabilidade dos materiais à base de cimento (AIAD, ELALEEM \& EL-DIDAMONY, 2002). 
Esse fato foi observado para as misturas produzidas com CPV ARI RS, onde os procedimentos $A$ e $D$ se mostraram mais adequados para a produção de misturas com menores valores de tensão de escoamento e viscosidade plástica, respectivamente - nesses procedimentos, o SP foi adicionado no fim do processo de mistura, aproximadamente quatro minutos após o contato entre o cimento e a água de amassamento. No caso das misturas produzidas com CPV ARI Plus, uma outra observação foi feita: os menores valores dos parâmetros reológicos foram obtidos para as misturas produzidas de acordo com o procedimento E, onde o SP foi adicionado no início do processo de mistura, porém o efeito positivo pode ser relacionado com a saturação inicial dos agregados antes da incorporação dos materiais aglomerantes, impedindo que parte da água da matriz seja absorvida pelos agregados.

Quanto menor a tensão de escoamento de um concreto, maior sua facilidade de iniciar o escoamento, maior a sua fluidez e, conseqüentemente, menor sua viscosidade. Em todas as misturas, independente da sua composição e do procedimento de mistura empregado na sua produção, observa-se um aumento tanto da tensão de escoamento quanto da viscosidade plástica com o tempo, indicando perda da trabalhabilidade, pois, com o decorrer do tempo, a fluidez da mistura diminui e a resistência a ser vencida para iniciar o escoamento aumenta. Segundo Wallevik, Saasen e Gjørv (1995) e Punkki, Golaszewski e Gjørv (1996), o aumento da tensão de escoamento é equivalente à redução da trabalhabilidade com o tempo.

As fotos da figura 7.20 mostram o desenvolvimento do ensaio de abatimento de tronco de cone modificado para misturas que permitiram ou não a determinação do abatimento e do tempo de abatimento parcial necessários para a determinação dos dois parâmetros reológicos ao longo do tempo.
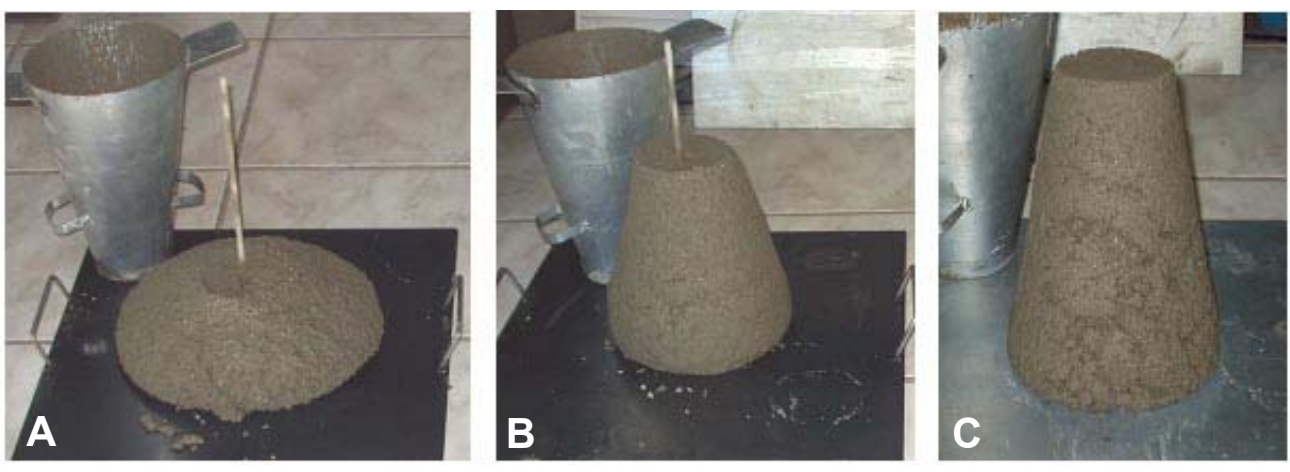

Figura 7.20 - Ensaio de abatimento de tronco de cone modificado - caracterização reológica das misturas de alto desempenho: (A) aos 10 minutos; (B) aos 60 minutos; e (C) aos 120 minutos. 
Para os concretos produzidos com agregado graúdo de $D_{\text {máx }} \leq 25 \mathrm{~mm}$, os parâmetros reológicos determinados a partir do ensaio de abatimento de tronco de cone modificado são apresentados na tabela 7.17. Nas figuras 7.21 e 7.22 são apresentadas as curvas "tensão de escoamento versus tempo" para as misturas estudadas.

Tabela 7.17 - Parâmetros reológicos para os CAD estudados.

\begin{tabular}{|c|c|c|c|c|c|c|c|c|c|c|}
\hline \multirow{3}{*}{ Concreto } & \multicolumn{5}{|c|}{ CPV ARI Plus (SP = 0,25\%) } & \multicolumn{5}{|c|}{ CPV ARI RS (SP = 0,20\%) } \\
\hline & \multicolumn{5}{|c|}{ Tempo de medida (min) } & \multicolumn{5}{|c|}{ Tempo de medida (min) } \\
\hline & 10 & 30 & 60 & 90 & 120 & 10 & 30 & 60 & 90 & 120 \\
\hline \multicolumn{11}{|c|}{ TENSÃO DE ESCOAMENTO [Pa] } \\
\hline CADI & 9 & 96 & 1730,41 & $(1838,87)$ & $(1983,48)$ & 1366,12 & 1510,39 & 165 & 183 & 8) \\
\hline CAD2 & 976,35 & 1413,12 & 1667,91 & 1886,29 & $(2031,88)$ & 793,44 & 1193,18 & 1592,92 & 1738,28 & $(1810,96)$ \\
\hline CAD3/A & 1289,67 & 1541,12 & 1648,89 & 1792,58 & $(1972,58)$ & 1285,34 & 1392,68 & 1643,12 & 1857,79 & $(1965,13)$ \\
\hline CAD3/B & 1289,67 & 1505,20 & 1648,89 & 1720,73 & $(1792,58)$ & 1321,12 & 1500,01 & 1678,90 & $(1857,79)$ & $(2036,68)$ \\
\hline $3 / C$ & 33,35 & 77,04 & 1648,89 & 1864,42 & $(2008,11)$ & 1392,68 & 1643,12 & 1786,24 & $(1822,01)$ & $(200$ \\
\hline CAD3/D & 1289,67 & 1648,89 & 1756,65 & $(2008,11)$ & $(2223,64)$ & 1356,90 & 1571,57 & 1643,12 & 1786,24 & $(1893,57)$ \\
\hline CAD3/E & 1505,20 & 1648,89 & 1936,27 & $(2044,03)$ & $(2223,64)$ & 1392,68 & 1571,57 & 1750,46 & $(1786,24)$ & $(1857,79)$ \\
\hline CAD3/F & 1361,51 & 1612,97 & 1684,81 & $(1864,42)$ & $(2008,11)$ & 1213,79 & 1464,23 & 1571,57 & 1714,68 & $(1929,35)$ \\
\hline
\end{tabular}

VISCOSIDADE PLÁSTICA [Pa.s]

\begin{tabular}{|c|c|c|c|c|c|c|c|c|c|c|}
\hline CADI & 18,19 & 21,95 & ----- & ---- & ----- & 18,15 & 21,90 & 24,40 & ---- & ---- \\
\hline CAD2 & 20,21 & 21,47 & 25,26 & ---- & ---- & $(17,65)$ & 18,92 & 22,07 & ---- & ---- \\
\hline CAD3/A & 14,96 & 18,07 & 21,81 & ---- & ----- & 17,38 & 19,24 & 22,97 & ----- & ---- \\
\hline CAD3/B & 15,58 & 18,70 & 21,81 & ---- & ---- & 18,62 & 21,11 & ---- & ---- & ---- \\
\hline CAD3/C & 18,07 & 21,19 & 24,93 & ----- & ----- & 18,00 & 21,73 & ----- & ----- & ---- \\
\hline CAD3/D & 20,57 & 23,06 & ---- & --- & ---- & 18,00 & 20,48 & 24,83 & ---- & --- \\
\hline CAD3/E & 16,83 & 19,94 & ----- & ---- & ---- & 18,00 & 19,86 & ----- & ----- & ---- \\
\hline CAD3/F & 16,83 & 20,57 & ---- & ---- & ---- & 16,14 & 18,00 & 22,35 & ---- & ---- \\
\hline
\end{tabular}

OBS:

1) As tensões de escoamento entre parênteses foram calculadas utilizando os abatimentos determinados a partir do ensaio de abatimento de tronco tradicional, pois o ensaio de abatimento de tronco de cone modificado apresentou uma limitação para concretos com abatimentos inferiores a $100 \mathrm{~mm}$.

2) As viscosidades entre parênteses foram determinadas de acordo com a equação recomendada para concretos com abatimento inferior a $200 \mathrm{~mm}$, pois a outra equação forneceu valores que não se adequaram ao aumento da viscosidade com o tempo.

3) Os espaços marcados com traços na tabela indicam que, para essas misturas, não foi possível determinar o tempo de abatimento parcial e, consequentemente, sua viscosidade plástica (misturas com abatimentos menores que 100 $\mathrm{mm})$. 


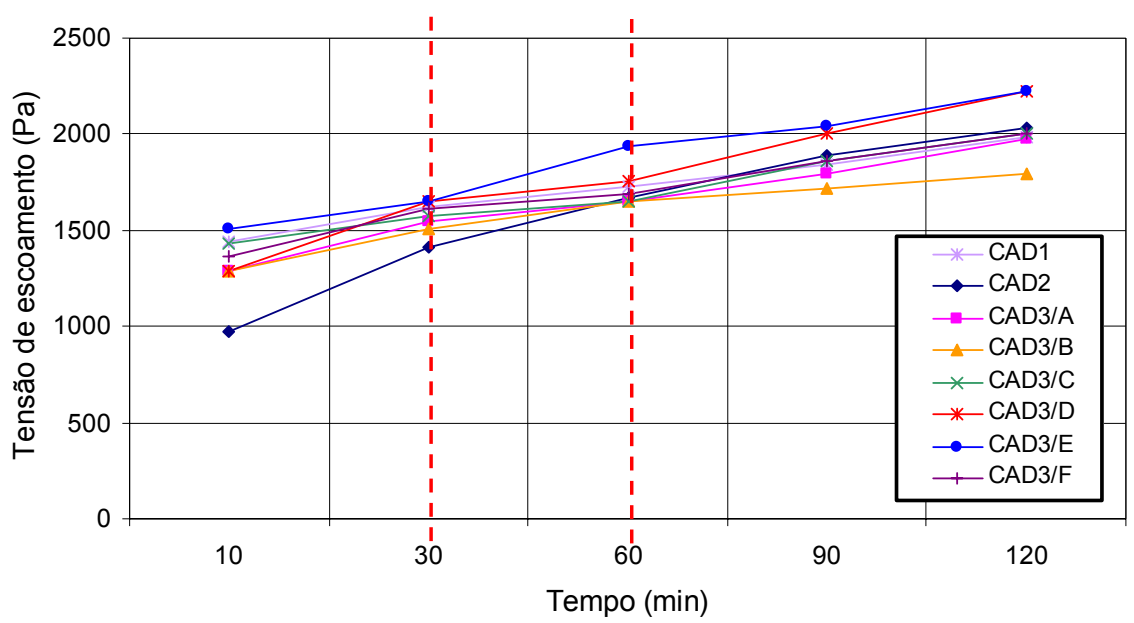

Figura 7.21 - Curva da "tensão de escoamento versus tempo" para concretos de alto desempenho produzidos com CPV ARI Plus.

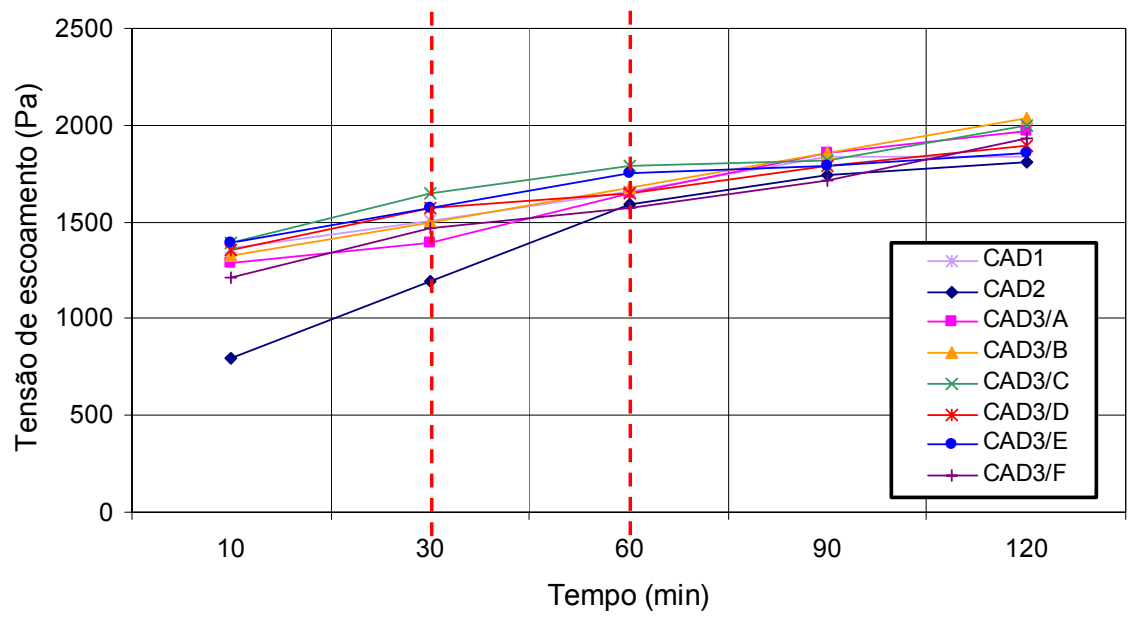

Figura 7.22 - Curva da "tensão de escoamento versus tempo" para concretos de alto desempenho produzidos com CPV ARI RS.

A influência do tipo de cimento usado na produção dos concretos foi mais evidente para as misturas incorporadas apenas com SP (CAD2), onde a diferença entre os valores determinados para a tensão de escoamento e a viscosidade plástica foi maior. Para as outras misturas (CAD1 e CAD3), as misturas produzidas com ambos os cimentos apresentaram parâmetros reológicos semelhantes.

O efeito do SP sobre as propriedades reológicas do concreto pode ser verificado ao comparar as misturas CAD1 e CAD2. Observa-se que a incorporação desse aditivo implica em uma redução de 32\% e 42\% na tensão de escoamento das misturas produzidas com CPV ARI Plus e CPV ARI RS, respectivamente, enquanto a viscosidade plástica praticamente não é influenciada. Segundo Tattersall (1991b) e Petrou et al. (2000), esse fato está relacionado com a defloculação das partículas de cimento.

Novamente o efeito esperado para a incorporação de sílica ativa foi observado. As misturas apresentaram-se menos trabalháveis que as misturas sem 
a incorporação de tal adição mineral (CAD2), com tensões de escoamento maiores. Sobre a viscosidade plástica, a influência da incorporação de sílica ativa foi diferente para os dois cimentos: para as misturas produzidas com CPV ARI Plus, a viscosidade plástica dos concretos foi reduzida com a adição de sílica; porém, para as misturam produzidas com CPV ARI RS, a diferença não foi evidente, ou seja, as misturas com a presença de sílica ativa em sua composição (CAD3) apresentaram viscosidades semelhantes ao CAD2.

Com a mudança no procedimento de mistura empregado na produção dos CAD3 foram verificadas variações entre os valores determinados para os parâmetros reológicos: para a tensão de escoamento, as variações médias absolutas foram de aproximadamente $280 \mathrm{~Pa}$ e $193 \mathrm{~Pa}$ para as misturas produzidas com CPV ARI Plus e CPV ARI RS, respectivamente; no caso da viscosidade plástica, a variação foi de 4,67 Pa.s e de 2,89 Pa.s respectivamente para os mesmos cimentos.

No início do ensaio, os procedimentos de mistura $B$ e $F$ resultaram em misturas com os menores valores de tensão de escoamento para os CAD3 produzidos com CPV ARI Plus e CPV ARI RS, respectivamente, enquanto as menores viscosidades foram obtidas para as misturas produzidas segundo os procedimentos A e F respectivamente para os mesmos cimentos. Durante praticamente todo o ensaio, esses mesmos procedimentos resultaram nos menores valores medidos para ambos os parâmetros reológicos. Mais uma vez observou-se a falta de correlação entre os parâmetros reológicos determinados, ou seja, verificou-se uma variação entre os procedimentos de mistura que resultaram em misturas com melhores desempenhos relacionados com os dois parâmetros reológicos.

Nos procedimentos A e B, o SP foi adicionado em atraso e dividido em duas parcelas, respectivamente, durante 0 processo de mistura. Esse melhor comportamento da trabalhabilidade verificado pela adição atrasada e/ou dividido durante o processo de mistura está de acordo com o apresentado na literatura. No procedimento $\mathrm{F}$, que se ajustou melhor aos parâmetros determinados para as misturas produzidas com o CPV ARI RS, a adição do SP foi realizada junto com água de amassamento, dois minutos após a homogeneização dos materiais aglomerantes. Como nesse procedimento de mistura o SP é adicionado junto com a água de amassamento, o aditivo perde seu caráter superplastificante, comportandose apenas como um plastificante. As moléculas do aditivo são então absorvidas pelos agregados, competindo com água para a saturação de sua superfície. Assim, 
as moléculas de SP só serão liberadas posteriormente para contribuir com a fluidificação da mistura, resultando em melhores trabalhabilidades com o decorrer do tempo.

A influência dos agregados sobre as propriedades reológicas do concreto fresco está relacionada principalmente com a quantidade de agregado que compõe a mistura e com a sua granulometria. Normalmente, os agregados aumentam consideravelmente a tensão de escoamento e a viscosidade plástica e esses acréscimos são maiores à medida que o teor de agregado aumenta; porém ambos os parâmetros podem ser reduzidos quando a granulometria do agregado se torna mais densa (STRUBLE et al., 1998).

Nas misturas estudadas, um aumento de $10 \%$ na fração de agregado implicou em aumentos de $58 \%$ e $38 \%$ na tensão de escoamento inicial determinada para os concretos produzidos com CPV ARI Plus e CPV ARI RS, respectivamente, enquanto a viscosidade plástica praticamente não foi influenciada. Como o concreto geralmente é idealizado por um modelo de esferas, a trabalhabilidade desses materiais depende da mobilidade de todas as partículas sólidas assim como do teor de água. Dessa maneira, apesar de serem constituídos por teores ideais de argamassa para o preenchimento dos vazios entre os agregados, as maiores tensões de escoamento decorrem do imbricamento entre os agregados.

De uma maneira geral, pode-se dizer que quanto mais esféricas forem as partículas de um agregado, mais trabalhável será a mistura na qual esse agregado é incorporado, considerando-se constante as demais características e materiais. Os agregados utilizados na pesquisa possuem índices de forma que os caracterizam como partículas angulares. Assim, para um menor teor de argamassa, o deslocamento relativo entre as partículas é dificultado, necessitando que uma tensão maior seja imposta para o início do escoamento do material.

Conforme observado por Shindoh, Yokota e Yokoi (1996), o aumento da fração de agregado graúdo que compõe uma mistura de concreto diminui a variação entre os limites inferior e superior da tensão de escoamento e viscosidade plástica de uma série de amostras ensaiadas. Essa observação foi verificada para as misturas estudadas. Quando a fração de agregados era de 39\% (MCAD3), a tensão de escoamento medida aos 10 minutos de ensaio, por exemplo, variou entre 626,12 Pa e 1074,75 Pa para os concretos produzidos com CPV ARI Plus e entre 794,26 Pa e 1102,52 Pa para as misturas produzidas com CPV ARI RS, o que corresponde a uma diferença entre as tensões mínima e máxima de 448,63 Pa e $308,26 \mathrm{~Pa}$, respectivamente. Ao aumentar a fração para 49\% (CAD3), a tensão 
variou entre 1289,67 Pa e 1505,20 Pa para os concretos produzidos com CPV ARI Plus e entre 1213,79 $\mathrm{Pa}$ e 1392,68 Pa para as misturas produzidas com CPV ARI RS, correspondendo a uma diferença entre as tensões de 215,53 Pa e 178,89 Pa, respectivamente. Para a viscosidade plástica, as variações entre as determinações não foram significativas, isto é, para todos os concretos ensaiados, independente do teor de agregado presente na sua composição, a variação entre as viscosidades determinadas foi de cerca de 2 Pa.s.

Assim como para os MCAD, a partir das figuras 7.21 e 7.22 e dos resultados apresentados na tabela 7.17, observa-se que tanto a tensão de escoamento quanto a viscosidade plástica determinadas para as misturas estudadas aumentaram com o tempo, indicando perda de sua trabalhabilidade. Mais uma vez, o método de ensaio mostrou-se ineficiente para a avaliação da viscosidade ao longo do tempo, pois a determinação do tempo de abatimento parcial relacionado com o cálculo desse parâmetro não pode ser feita após uma hora de ensaio.

\subsubsection{Reômetro}

A utilização do reômetro na avaliação do comportamento reológico das misturas de alto desempenho propostas nessa pesquisa só foi possível para os microconcretos de alto desempenho (MCAD). O equipamento disponível possuía um espaçamento entre a cuba e a pá misturadora adequado para agregados de dimensão máxima característica de $9,5 \mathrm{~mm}$, limitando sua utilização para a avaliação de concretos compostos com agregados de dimensões maiores (caso dos concretos de alto desempenho - CAD, compostos por agregado graúdo de dimensão máxima característica de $25 \mathrm{~mm}$ ).

Com o auxílio do ensaio de abatimento de tronco de cone, verificou-se que a maioria das misturas estudadas apresentou grandes perdas de abatimento após 60 minutos de ensaio, perdendo boa parte de sua trabalhabilidade.

Por outro lado, justificar valores acima de 60 minutos poderá não estar relacionado com as reais situações observadas no campo quando se faz um planejamento de concretagem. Normalmente, as reais etapas equacionadas (mistura, transporte, aplicação de aditivos, facilidade de lançamento, espalhamento, adensamento etc.) envolvem, no máximo, 60 minutos. Analogamente, em uma fábrica de pré-moldados, esse tempo nunca ultrapassa os 30 minutos.

A avaliação de resultados com uso apenas de microconcretos é mais crítica, pelo maior imbricamento entre as partículas e maior superfície exposta do material. 
Nessa situação, apenas se conseguem bons resultados com microconcretos com elevado teor de argamassa.

Se implementado um alto teor de pasta de cimento, conseguem-se bons resultados em termos da facilidade do material fluir, porém isso pode trazer outras implicações problemáticas no comportamento do concreto após seu lançamento.

Sendo assim, pelas limitações de equipamento, os resultados apresentados nessa parte do trabalho correspondem apenas à avaliação dos microconcretos de alto desempenho que compõem as misturas estudadas na presente pesquisa por um período de 60 minutos após o contato entre o cimento e a água de amassamento.

\subsubsection{Identificação da natureza reológica dos concretos de alto desempenho}

O controle dos fatores que influenciam o comportamento reológico dos concretos de alto desempenho permite determinar suas características de aplicação. Assim, dependendo da composição da mistura, a técnica de moldagem empregada pode variar desde a aplicação de uma vibração de alta energia até um auto-escoamento que preenche os moldes sob ação do seu peso próprio.

Porém, a utilização dos concretos não envolve apenas seu processo de adensamento, mas também os processos de mistura, transporte e lançamento do material. Diversos fatores, como a natureza reológica, a tendência à segregação, a coesão, o aquecimento etc., que influenciam o comportamento do concreto durante os processos de manipulação do material não são medidos pelo ensaio de abatimento de tronco de cone amplamente utilizado na prática das construções em concreto.

Como exemplo, Pileggi (2001) cita o concreto bombeável: um concreto dilatante, independente do seu nível de fluidez, apresenta dificuldades para escoar sob elevadas taxas de cisalhamento, dificultando ou impedindo seu bombeamento; por outro lado, uma mistura pseudoplástica, mesmo com baixa fluidez, poderia ser bombeada, pois quanto maior a taxa de cisalhamento aplicada, menor sua resistência ao escoamento. Com isso pode-se observar uma diferença entre o nível de fluidez (que define a característica de moldagem) e o comportamento reológico de um concreto (que determina a técnica mais adequada para sua aplicação).

A caracterização reológica dos MCAD estudados foi realizada por meio de ensaios de cisalhamento executados com o auxílio de um reômetro (figura 5.22-B). Para isso as misturas foram submetidas a ciclos de cisalhamento em escada 
(patamares), com velocidade de rotação variando entre 5 RPM e 80 RPM (que corresponde a uma variação entre 0,08 RPS e 1,33 RPS ${ }^{[7.1]}$ ) após a mistura. Esse tipo de ensaio gera curvas de "torque versus velocidade de rotação" que fornecem duas informações fundamentais: primeiro, quanto menor a área de histerese (área entre as curvas ascendente e descendente do cisalhamento), maior a eficiência da dispersão; e segundo, o perfil da curva de cisalhamento indica a natureza reológica da mistura de concreto (PILEGGI, 2001).

De acordo com Wallevik e Gjørv (1990a), o tempo para se obter o equilíbrio em cada taxa de cisalhamento será sempre mais curto partindo-se de uma maior para uma menor taxa de cisalhamento, o que significa de uma maior para um menor grau de dispersão. Dessa maneira, a parte descendente da curva de cisalhamento deve ser escolhida.

De qualquer maneira, para a identificação do comportamento reológico das misturas foram feitos ajustes tanto na parte ascendente quanto na parte descendente da curva de cisalhamento e dois modelos foram utilizados - Bingham e lei das potências. A partir dos resultados obtidos (anexo D.2), a consideração da parte ascendente da curva de cisalhamento se mostrou mais adequada (maiores coeficientes de ajuste da reta), além de corresponder ao período em que a tensão de escoamento deve ser excedida para que o escoamento inicie.

As curvas de "torque versus velocidade de rotação" ajustadas para a identificação da natureza reológica dos MCAD são apresentadas nas figuras 7.23 , $7.24,7.25$ e 7.26 . As figuras 7.23 e 7.24 apresentam as curvas obtidas para as misturas produzidas com variações na composição (MCAD1 - concreto de referência, ou seja, produzido sem a incorporação de qualquer aditivo químico ou adição mineral; MCAD2 - concreto incorporado apenas com SP; e o MCAD ${ }^{[7.2]}$ mistura de alto desempenho incorporada com aditivo químico e adição mineral), enquanto as figuras 7.25 e 7.26 apresentam as curvas resultantes para as misturas de mesma composição produzidas de acordo com os seis procedimentos propostos na pesquisa, tanto com CPV ARI Plus quanto com CPV ARI RS.

Vale lembrar que os seis procedimentos de mistura considerados foram baseados no processo de mistura amplamente utilizado na prática (procedimento $A$ ) e uma variação no tempo de adição do SP foi considerada (procedimentos B e C).

\footnotetext{
[7.1] A velocidade de rotação foi considerada em RPS - rotação por segundo - na construção das curvas de "torque versus velocidade de rotação" para que o parâmetro relacionado com a viscosidade de torque ( $h$ ), expresso em Nm.s, fosse determinado diretamente. Caso contrário, ao construir as curvas com a velocidade de rotação em RPM - rotação por minuto - esse parâmetro deveria ser corrigido na equação da reta.

${ }^{[7.2]}$ Os resultados do MCAD3 correspondem aos resultados obtidos para a mistura produzida de acordo com o procedimento de mistura $A$, pois a mesma seqüência de incorporação dos materiais constituintes foi usada na produção das duas misturas de referência (MCAD1 e MCAD2).
}

Aplicação de conceitos reológicos na tecnologia dos concretos de alto desempenho 
Nos procedimentos $\mathrm{D}$ e $\mathrm{E}$, buscou-se saturar os agregados antes da adição dos materiais aglomerantes; a diferença entre eles está no momento de adição do SP. No procedimento $F$, os materiais aglomerantes foram inicialmente homogeneizados e só em seguida os agregados, a água de amassamento e o SP foram adicionados (figura 6.2).

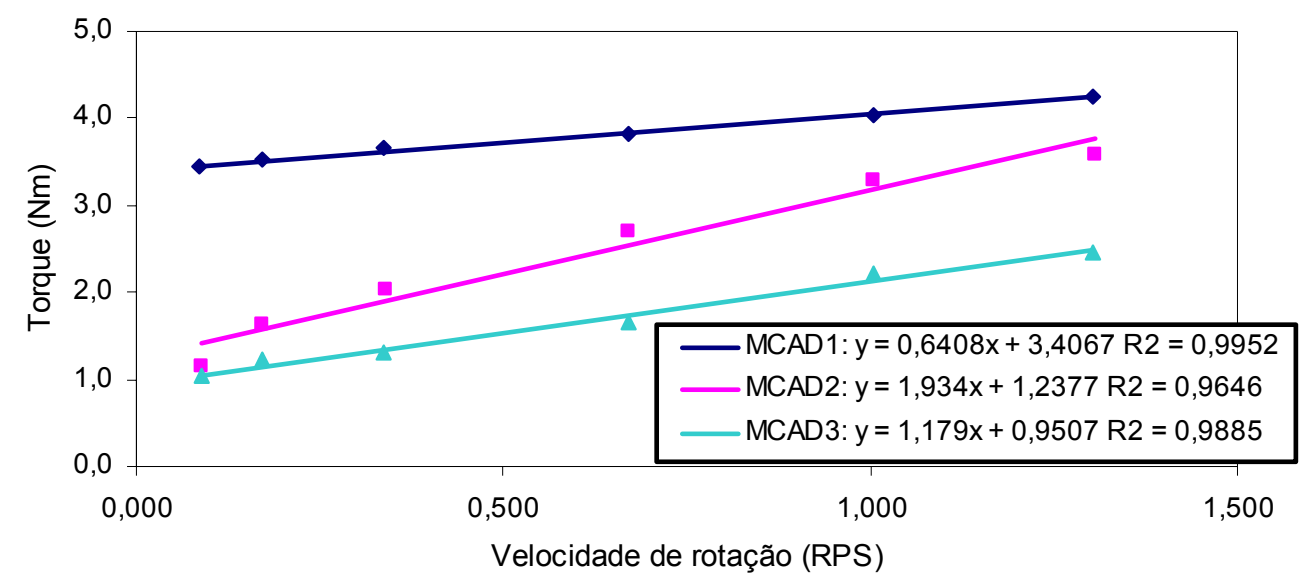

Figura 7.23 - Curvas ascendentes de cisalhamento dos MCAD produzidos com CPV ARI

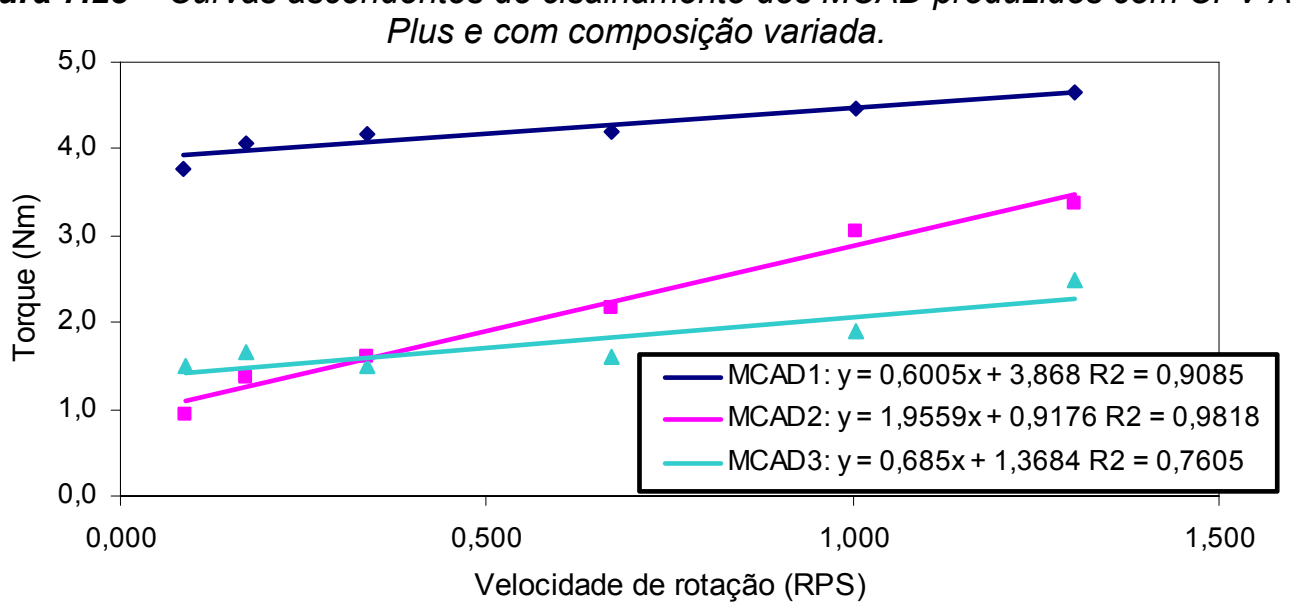

Figura 7.24 - Curvas ascendentes de cisalhamento dos MCAD produzidos com CPV ARI $R S$ e com composição variada.

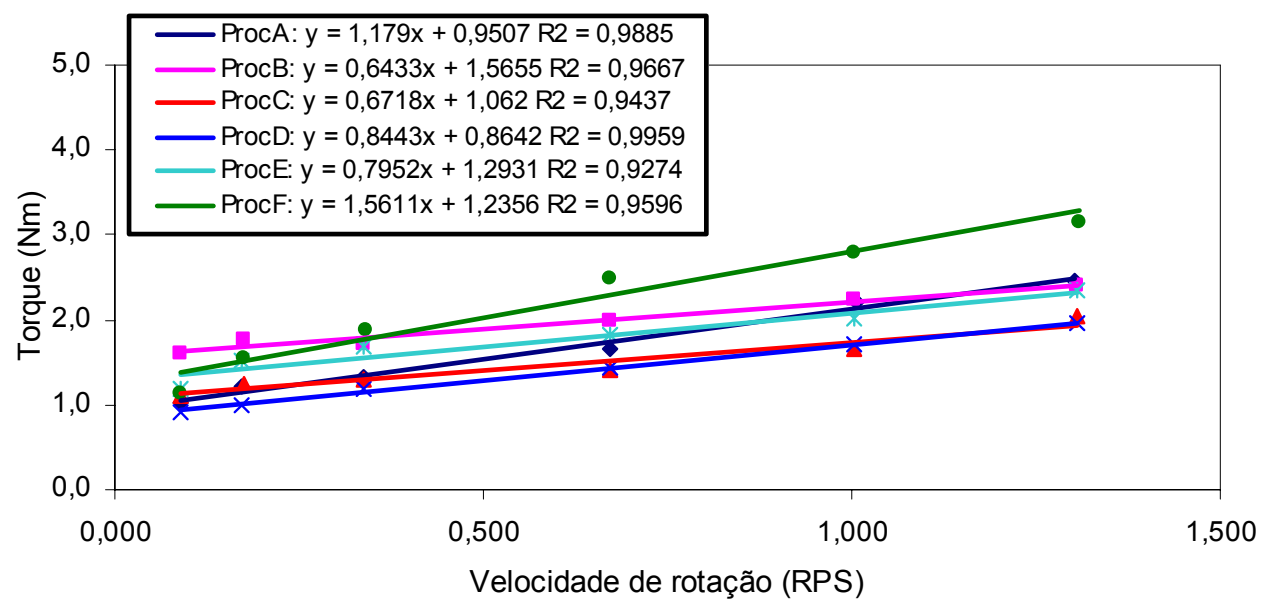

Figura 7.25 - Curvas ascendentes de cisalhamento dos MCAD produzidos com CPV ARI Plus e de acordo com os procedimentos propostos. 


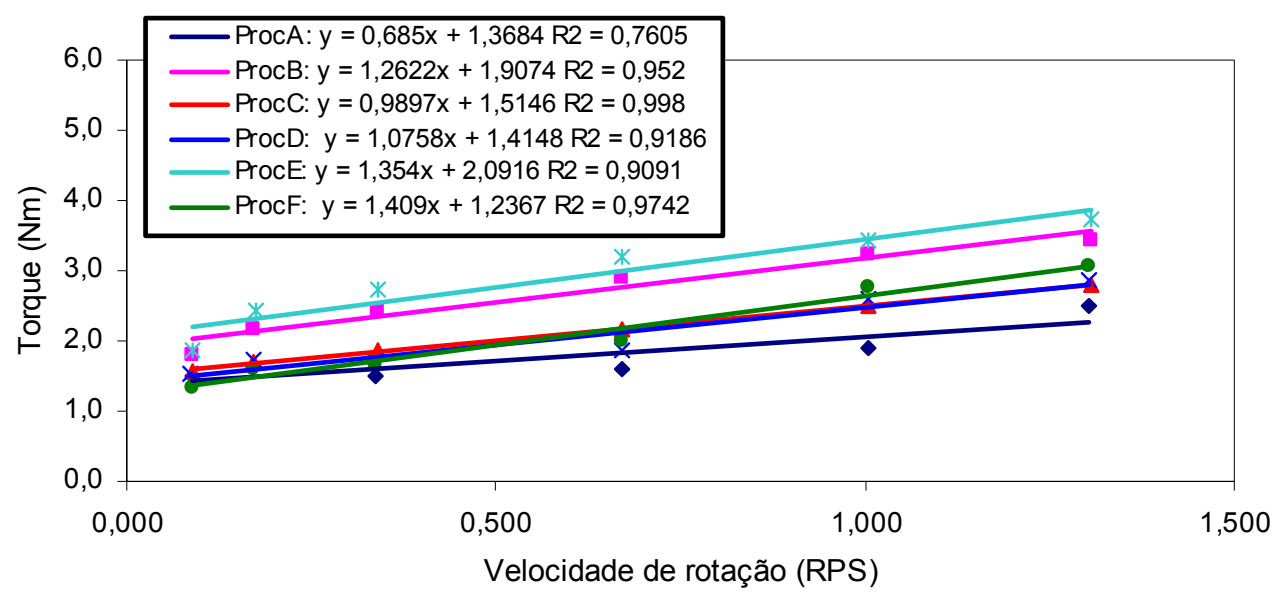

Figura 7.26 - Curvas ascendentes de cisalhamento dos MCAD produzidos com CPV ARI $R S$ e de acordo com os procedimentos propostos.

A partir das figuras $7.23,7.24,7.25$ e 7.26 , pode-se observar que todas as misturas, independente de sua composição e do procedimento de mistura empregado na sua produção, apresentam um comportamento binghamiano, indicando que o material apresenta uma tensão de cisalhamento que deve ser excedida para iniciar o escoamento (tensão de escoamento) e, depois de excedida, o material apresenta um comportamento onde a tensão de cisalhamento se torna diretamente proporcional à taxa de cisalhamento aplicada. Esse comportamento é amplamente observado para as misturas de concreto de alto desempenho estudadas nos grandes centros de pesquisa da tecnologia dos concretos e encontradas na literatura [TATTERSALL \& BANFILL (1983); TATTERSALL (1991b); FERRARIS (1996; 1999); TOUTOU \& ROUSSEL (2006)]. Vale lembrar que se trata de um modelo e que desvios da curva de preenchimento dos dados podem ocorrer.

Assim, dois parâmetros reológicos são necessários para a caracterização desses concretos: a tensão de escoamento $\left(\tau_{0}\right)$ e a viscosidade plástica $(\mu)$. Como, em reologia, esses parâmetros são normalmente medidos como parâmetros dependentes do equipamento utilizado no ensaio e expressados em unidades de torque, a relação entre o torque $(\mathrm{T})$ e a velocidade de rotação $(\mathrm{N})$ é dada segundo a equação:

$$
\mathrm{T}=g+h^{\star} \mathrm{N}
$$

onde $g$ - torque de escoamento, em [Nm] - é a intersecção com o eixo do torque e $h$ - viscosidade de torque, em [Nm.s] - é a inclinação da reta. Essas duas constantes são análogas à tensão de escoamento e a viscosidade plástica, respectivamente (YEN et al., 1999).

Nas figuras 7.27, 7.28, 7.29 e 7.30 são apresentadas as curvas completas de cisalhamento para os MCAD estudados. Pode-se verificar que as misturas 
apresentam as partes ascendente e descendente das curvas de cisalhamento distintas, gerando uma área de histerese. Essa área representa o trabalho relacionado com o volume de material cisalhado e permite uma análise qualitativa do cisalhamento, sendo possível tirar conclusões quanto à estabilidade da estrutura desses materiais (SUHR, 1991). Inicialmente, esse comportamento indica que a mistura não foi capaz de fornecer energia suficiente para quebrar os aglomerados presentes no material, porém verifica-se que essa quebra continua com o decorrer do ciclo de cisalhamento. Em algumas situações, outros fatores também podem estar relacionados com a área de histerese, como as características da matriz e fase agregado que constituem uma mistura de concreto.

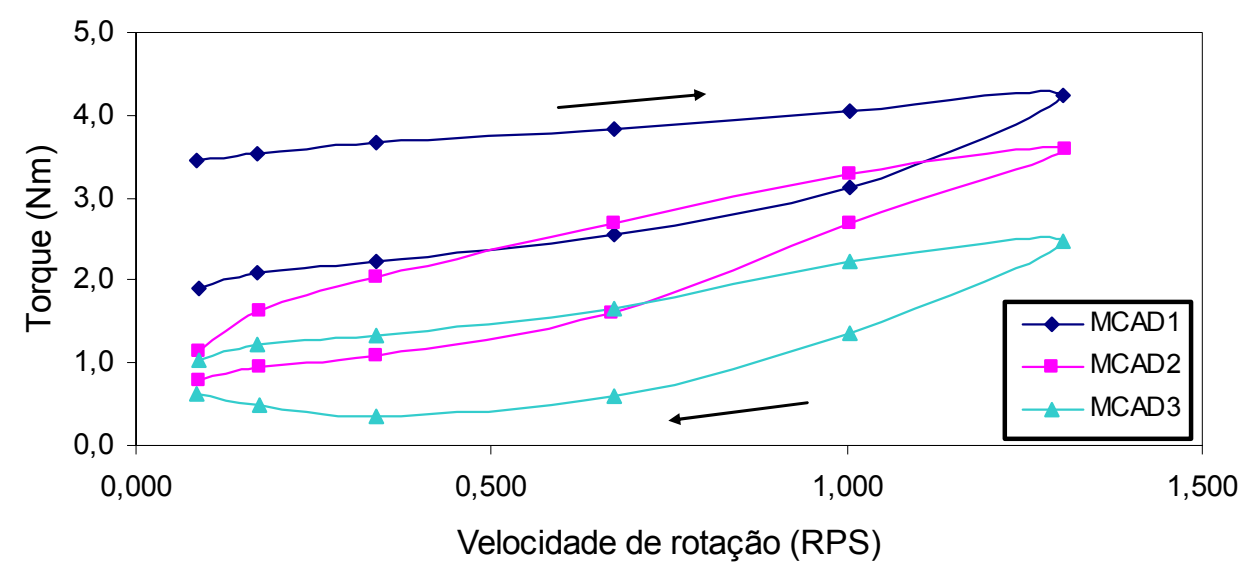

Figura 7.27 - Curvas de cisalhamento dos MCAD, com variações na composição, produzidos com CPV ARI Plus. Obs.: As setas indicam o sentido de aplicação da velocidade de cisalhamento.

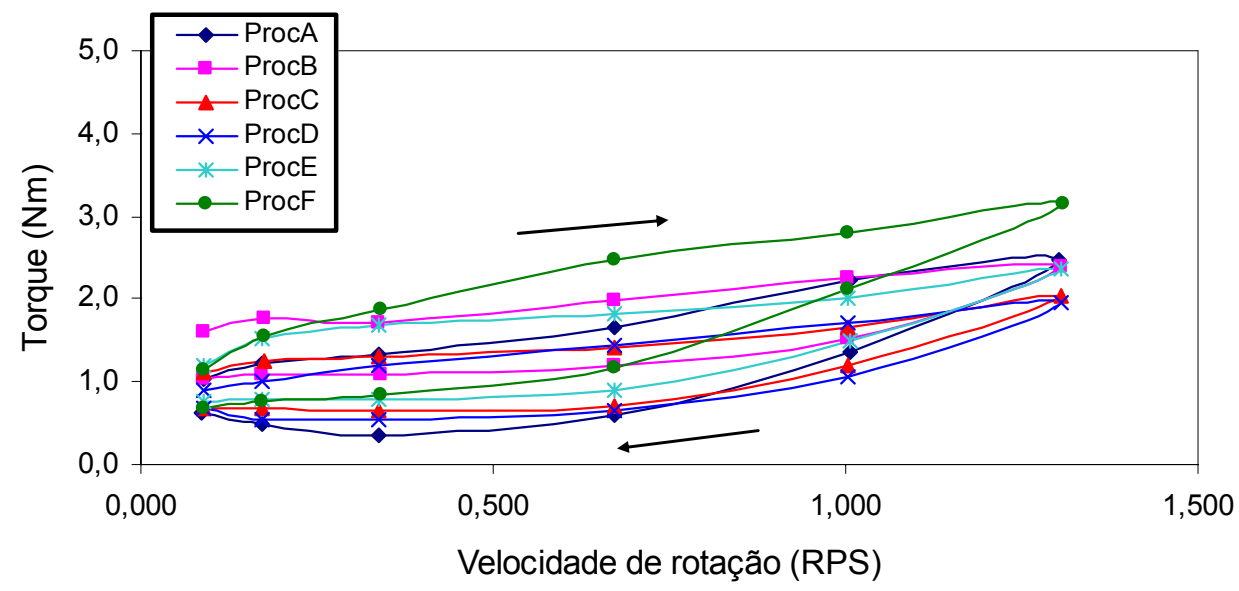

Figura 7.28 - Curvas de cisalhamento dos MCAD produzidos com CPV ARI Plus e de acordo com os procedimentos de mistura propostos na pesquisa. Obs.: As setas indicam o sentido de aplicação da velocidade de cisalhamento. 


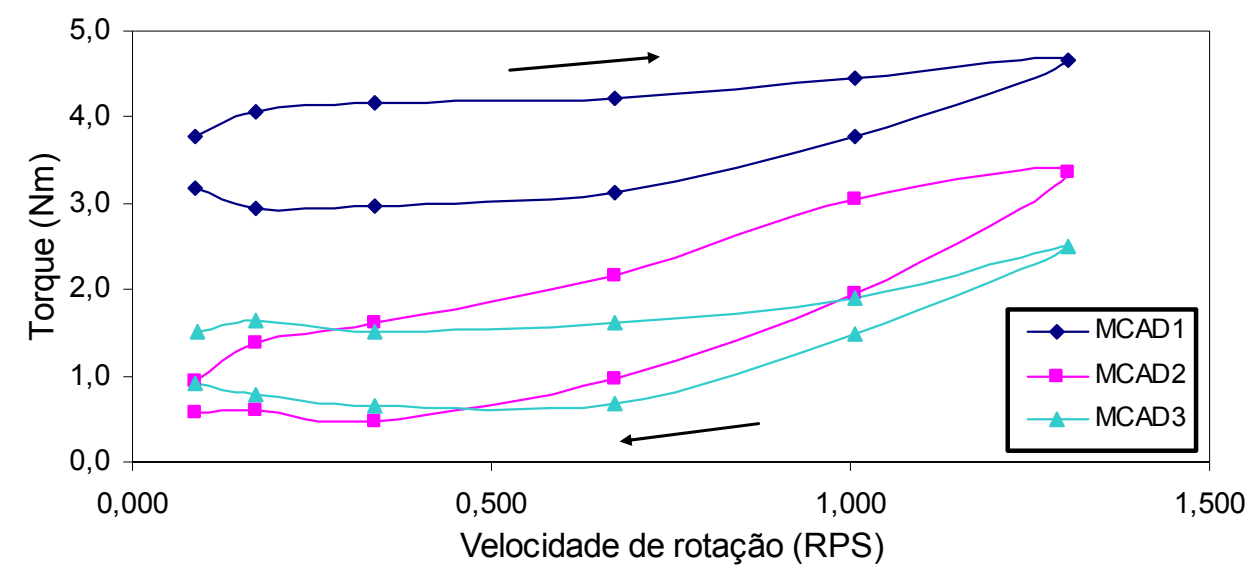

Figura 7.29 - Curvas de cisalhamento dos MCAD, com variações na composição, produzidos com CPV ARI RS. Obs.: As setas indicam o sentido de aplicação da velocidade de cisalhamento.

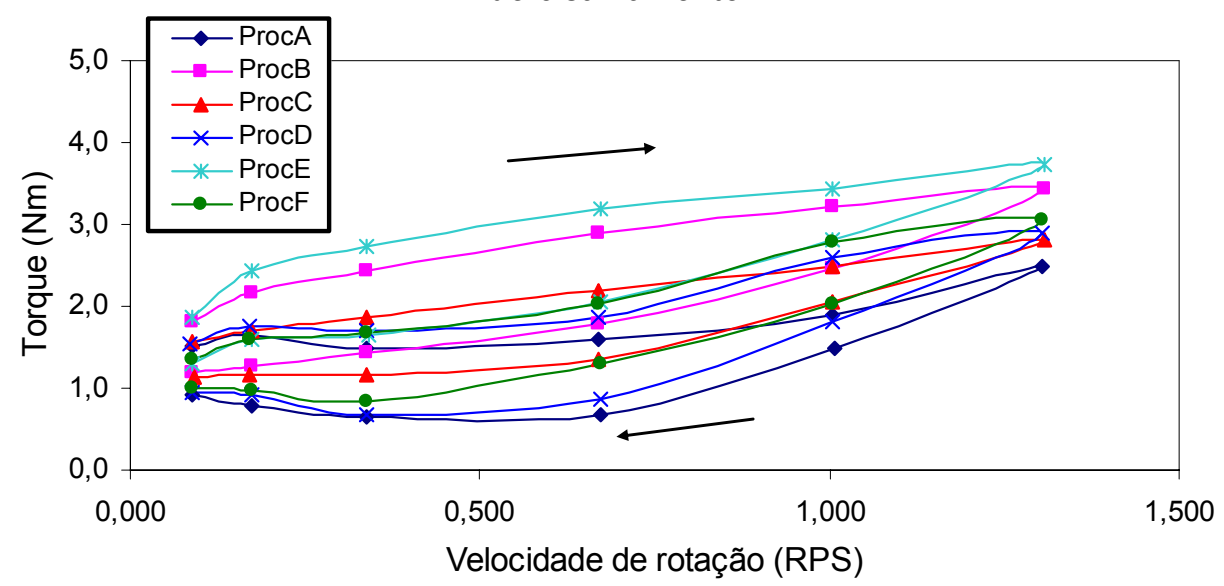

Figura 7.30 - Curvas de cisalhamento dos MCAD produzidos com CPV ARI RS e de acordo com os procedimentos de mistura propostos na pesquisa. Obs.: As setas indicam o sentido de aplicação da velocidade de cisalhamento.

$\mathrm{Na}$ tabela 7.18 são apresentados os valores da área de histerese para as curvas de cisalhamento dos MCAD estudados. Uma maior eficiência do processo de mistura está relacionada com uma menor área de histerese. Verifica-se uma variação dessas áreas em função da composição do concreto e do procedimento de mistura empregado na sua produção.

Tabela 7.18 - Área de histerese das curvas de cisalhamento dos MCAD estudados.

\begin{tabular}{c|c|c}
\hline \multirow{2}{*}{ Concreto } & \multicolumn{2}{|c}{ Área de histerese (Nm.RPS) } \\
\cline { 2 - 3 } & CPV ARI Plus & CPV ARI RS \\
\hline MCAD1 & 1,325 & 1,041 \\
\hline MCAD2 & 1,119 & 1,275 \\
\hline MCAD3/A & 1,095 & 0,787 \\
\hline MCAD3/B & 1,023 & 1,328 \\
\hline MCAD3/C & 0,804 & 0,965 \\
\hline MCAD3/D & 0,840 & 0,977 \\
\hline MCAD3/E & 1,008 & 1,366 \\
\hline MCAD3/F & 1,222 & 1,004 \\
\hline
\end{tabular}


Além disso, quando as partes ascendente e descendente da curva de cisalhamento não coincidem e nem são paralelas, ou seja, quando se verifica a presença de uma área de histerese, considera-se que o material testado tem um significante comportamento tixotrópico (WALLEVIK \& SIMMERMAN, 1996), isto é, a viscosidade aparente diminui ao longo do tempo quando esses materiais são submetidos a uma taxa de cisalhamento constante. Esse comportamento deve-se à existência de uma estrutura instável no material, que pode ser rompida com a aplicação de uma determinada energia (HU \& De LARRARD, 1996) - formação da etringita. Vale lembrar que essa quebra estrutural é reversível e recuperada rapidamente após poucos minutos.

Assim, pode-se observar que as curvas de cisalhamento obtidas para os MCAD testados apresentam uma área de histerese, comprovando o comportamento tixotrópico desses materiais. Porém, a determinação da área de histerese não fornece um valor intrínseco de qualquer parâmetro reológico. Além de correlações empíricas, não existe qualquer possibilidade de se usar o resultado obtido no estudo das conseqüências da tixotropia. Esse método parece ser uma maneira limitada de se adquirir uma classificação relativa dos concretos ou uma comparação qualitativa do efeito de diversas adições (ROUSSEL, 2006).

\subsubsection{Avaliação da trabalhabilidade dos concretos de alto desempenho através da evolução dos parâmetros reológicos}

Normalmente, a perda da trabalhabilidade de um concreto é expressa em termos de perda de abatimento, que reflete a maneira mais tradicional de descrição da trabalhabilidade desse material no estado fresco. Como métodos de ensaio - tal como o ensaio de abatimento de tronco de cone - não predetermina a resposta de compactação e capacidade de escoamento de um concreto, existe a necessidade pela descrição da trabalhabilidade baseada em termos reológicos. Particularmente isso é verdade para os concretos de alto desempenho (com alta resistência), que apresentam trabalhabilidades muito diferentes dos concretos convencionais (PUNKKI, GOLASZEWSKI \& GJøRV, 1996).

Sendo assim, os resultados do programa experimental para a avaliação da trabalhabilidade e de sua perda ao longo do tempo, com base na evolução dos parâmetros reológicos, são apresentados na seqüência. Os parâmetros reológicos - tensão de escoamento e viscosidade plástica - foram determinados a partir do ajuste da parte ascendente das curvas de cisalhamento ao modelo binghamiano 
(anexo D.2) e dados em termos de $g$ e $h$, constantes que correspondem ao torque de escoamento e à viscosidade de torque, respectivamente, em unidades de torque.

Na tabela 7.19 e nas figuras 7.31 e 7.32 , são apresentados os parâmetros reológicos determinados pelo ajuste das curvas de cisalhamento, bem como sua evolução ao longo do tempo, para a verificação da influência da composição da mistura e, consequentemente, dos materiais constituintes - adições química e mineral, além do tipo de cimento usado na composição - sobre a trabalhabilidade dos concretos.

Tabela 7.19 - Parâmetros reológicos obtidos a partir do ajuste das curvas de cisalhamento dos MCAD estudados.

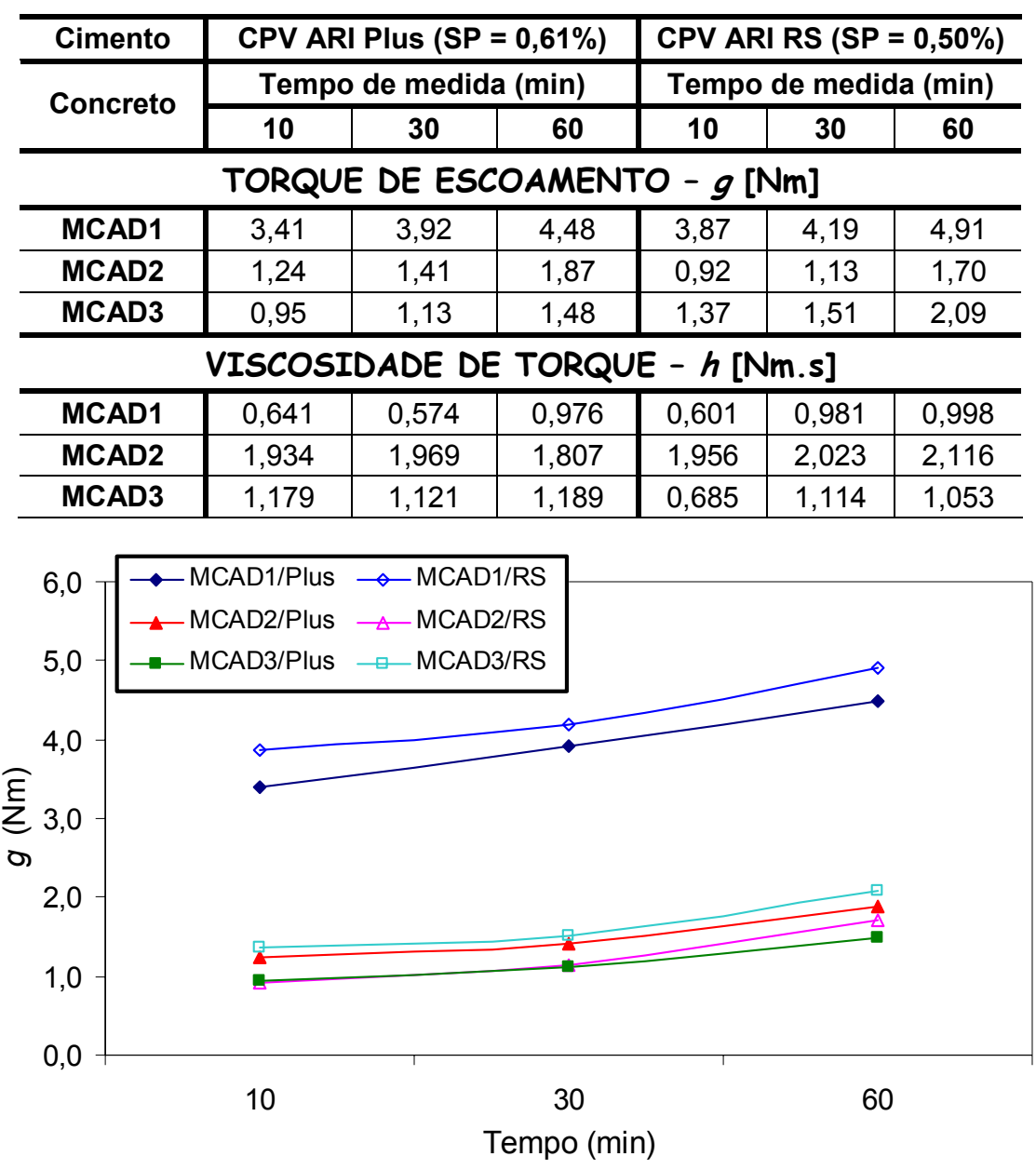

Figura 7.31 - Curva do "torque de escoamento versus tempo" para os MCAD produzidos com composições variadas. 


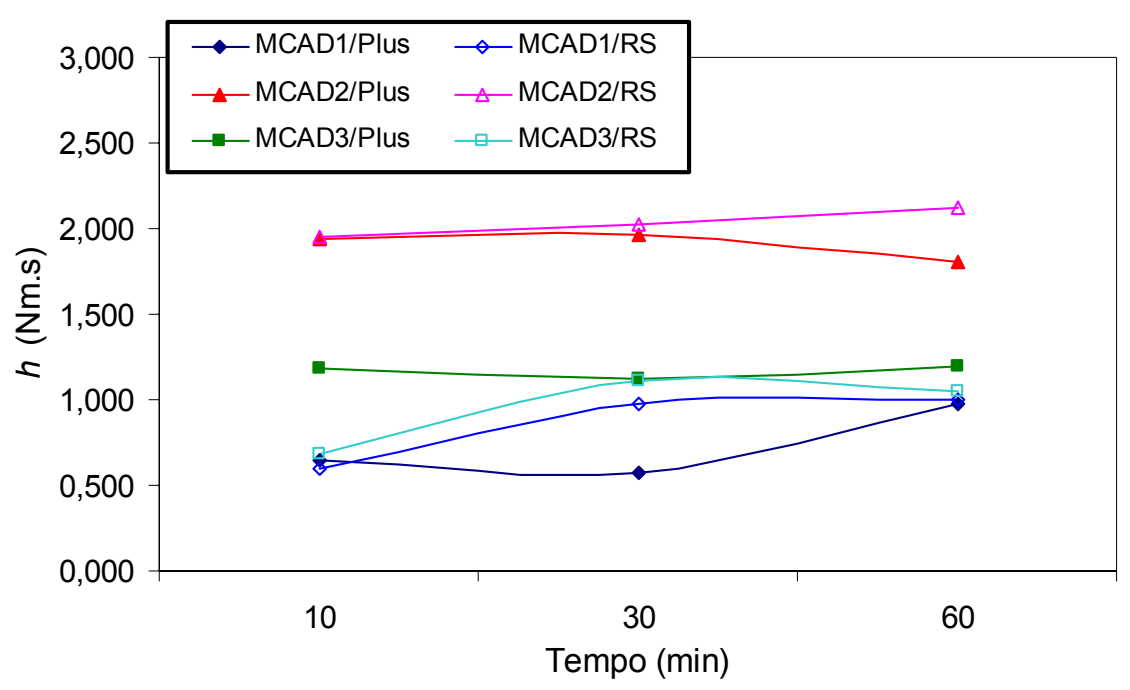

Figura 7.32 - Curva da "viscosidade de torque versus tempo" para os MCAD produzidos com composições variadas.

A influência mais significativa do cimento sobre o comportamento reológico de um concreto está relacionada com sua composição química, isto é, com o retardamento do processo de hidratação dos aluminatos causado pelo sulfato de cálcio. $\mathrm{O}$ teor e a morfologia do $\mathrm{C}_{3} \mathrm{~A}$ estão entre as características químicas do cimento mais importantes em termos de fluidez da mistura. Assim, sendo o comportamento reológico de um dado cimento determinado pelo controle do $\mathrm{C}_{3} \mathrm{~A}$ através da formação da etringita, quanto mais cúbico for esse componente, mais fácil será o controle de sua reologia. Assim, a reologia dos concretos produzidos com ambos os cimentos estudados pode ser considerada de fácil controle a partir morfologia do $C_{3} A$, pois os cimentos são constituídos por $C_{3} A$ de forma cúbica, constituindo a forma mais adequada em termos de controle da reologia desses materiais (AÏTCIN, 2000).

Apesar das diferenças nos teores de $\mathrm{C}_{3} \mathrm{~A}$ que compõe os cimentos $(7,36 \% \mathrm{e}$ 4,92\%, respectivamente, para o CPV ARI Plus e CPV ARI RS), as misturas avaliadas apresentaram trabalhabilidades iniciais semelhantes. A influência do tipo de cimento só se tornou evidente com o decorrer do ensaio: um maior aumento dos parâmetros reológicos foi verificado para as misturas produzidas com CPV ARI Plus. Assim, a diferença entre os acréscimos observados ao longo do tempo está relacionada com a quantidade de $\mathrm{C}_{3} \mathrm{~S}$ que compõe o cimento: como o CPV ARI Plus possui uma maior quantidade desse componente em sua composição que o CPV ARI RS (58,95\% contra 38,26\%, respectivamente), os maiores acréscimos e, consequentemente, a maior perda de trabalhabilidade das misturas produzidas com o primeiro cimento deve-se à hidratação desse componente para o desenvolvimento da resistência mecânica nas primeiras idades. Deve-se observar 
também que o aumento do torque de escoamento foi maior do que o aumento da viscosidade de torque, mostrando que o efeito dos produtos de hidratação sobre o torque de escoamento é mais evidente do que sobre a viscosidade de torque (KUCHARSKA, 1991).

A diferença de comportamento entre os dois cimentos ficou evidente quando o SP foi incorporado à mistura: a mistura produzida com CPV ARI RS apresentou uma maior redução do torque de escoamento do que a mistura produzida com CPV ARI Plus quando comparadas com o concreto de referência (MCAD1). O efeito sobre a viscosidade de torque não foi significativo entre as misturas, ou seja, os valores determinados para a viscosidade de torque se mostraram independente do tipo de cimento usado na produção da mistura.

Embora existam algumas exceções, a incorporação de um SP a uma mistura de concreto resulta em uma significativa redução do torque de escoamento, enquanto um pequeno ou nenhum efeito é observado sobre a viscosidade de torque do material [TATTERSALL (1991b); PETROU et al. (2000b)]. Esse comportamento está relacionado com a defloculação das partículas de cimento: os SP introduzem uma camada de adsorção que evita a aproximação entre as partículas, enfraquecendo a estrutura que pode se formar quando a mistura permanece em repouso e, assim, reduzindo o torque de escoamento do material. Como as partículas estão dispersas, existe uma pequena mudança da viscosidade de torque, porém isso depende da distribuição granulométrica, da forma e da textura superficial das partículas que constitui a mistura de concreto.

Essas observações podem ser verificadas, em parte, para as misturas estudadas. Ao comparar o MCAD1 e o MCAD2, verifica-se uma grande redução do torque de escoamento para as misturas produzidas com CPV ARI Plus e CPV ARI RS (64\% e 76\%, respectivamente) quando o SP é incorporado à mistura. Porém, essa incorporação promoveu um grande aumento da viscosidade de torque das misturas. Para os estudos desenvolvidos por Hu, De Larrard e Gjørv (1995) e Ferraris e De Larrard (1998a), esse comportamento também foi verificado, ou seja, as misturas incorporadas apenas com SP apresentaram menores torques de escoamento e maiores viscosidades de torque do que as misturas sem essa adição química e os autores relacionam essa observação com o fato dos SP terem um maior efeito sobre o torque de escoamento do que sobre a viscosidade de torque.

Do ponto de vista da reologia, a sílica ativa produz efeitos intensos sobre a trabalhabilidade dos concretos a que é incorporada. Quando a sílica é incorporada à mistura, uma maior quantidade de superfícies sólidas é introduzida. Como a sílica 
possui partículas muito pequenas e, consequentemente, uma área superficial muito alta, suas partículas são muito reativas quimicamente e adsorvem moléculas de SP [PUNKKI, GOLASZEWSKI \& GJøRV (1996); PARK, NOH \& PARK (2005)]. Como resultado, o torque de escoamento e a viscosidade de torque tendem a aumentar.

Porém, a substituição de parte do cimento por uma adição mineral também pode resultar em uma redução de ambos os parâmetros reológicos do concreto. $A$ granulometria melhorada do aglomerante, a troca de partículas angulosas (alita) por partículas esféricas (sílica ativa) e o efeito lubrificante concedido pelas pequenas partículas de sílica possivelmente reduzem o imbricamento entre os agregados e, consequentemente, o torque de escoamento e a viscosidade de torque do material. Quanto mais finas e mais esféricas forem as partículas da adição mineral, maior a redução observada para os parâmetros reológicos. Situações em que esse comportamento foi observado foram relatadas por Nehdi, Mindess e Aïtcin (1998) e Zhang e Han (2000).

Ao comparar as misturas MCAD2 e MCAD3, verifica-se que a incorporação de sílica ativa resultou em comportamentos diferentes com relação ao torque de escoamento determinado para as misturas produzidas com os dois cimentos: a mistura produzida com CPV ARI Plus apresentou uma redução do torque de escoamento quando a sílica ativa foi incorporada à mistura, enquanto que, para a mistura produzida com CPV ARI RS, esse parâmetro foi aumentado. No caso da viscosidade de torque, verificou-se uma redução da mesma com a incorporação de sílica ativa às misturas produzidas com ambos os cimentos.

Uma mistura de alto desempenho possui baixo torque de escoamento e alta viscosidade de torque comparado com uma mistura convencional (YEN et al., 1999). Um menor torque de escoamento significa que esse material está apto a escoar sob a influência do seu peso próprio, enquanto uma maior viscosidade de torque é necessária para evitar a segregação dos agregados. Assim, ao comparar os parâmetros reológicos determinados para o concreto convencional (MCAD1) e para o concreto de alto desempenho (MCAD3), essa observação é confirmada.

Um problema comum encontrado em campo é a rápida perda da trabalhabilidade das misturas de alto desempenho. A fim de se garantir um comportamento reológico estável durante um determinado intervalo de tempo, uma caracterização adequada da evolução da trabalhabilidade se torna importante. Assim, o acompanhamento do comportamento reológico dos MCAD foi feito durante 60 minutos após o contato entre a água e o cimento, ainda que em casos práticos esse tempo seja excessivamente elevado. 
Geralmente, o processo de perda da trabalhabilidade é refletido por um aumento do torque de escoamento, com uma redução correlativa do abatimento de tronco de cone; porém, na maioria dos casos, a viscosidade de torque permanece praticamente constante durante o período em que o ensaio é desenvolvido (normalmente menor que 90 minutos) [HU \& De LARRARD (1996); De LARRARD et al. (1997a)].

De acordo com Nehdi, Mindess e Aïtcin (1998), o aumento verificado para o torque de escoamento ao longo do tempo indica o endurecimento do concreto, no entanto, a viscosidade de torque não reflete esse comportamento. Como os concretos permanecem em repouso entre os consecutivos ensaios reológicos, a exigência de torque para as baixas velocidades de rotação aumenta mais do que para as altas velocidades. Isso resulta em uma redução da inclinação da curva "torque versus velocidade de rotação", o que pode explicar porque a viscosidade de torque não aumenta com o tempo, podendo até diminuir em alguns casos.

Em um concreto convencional, que não contém qualquer adição química e/ou mineral na sua composição, as propriedades reológicas são controladas principalmente pela quantidade de água de amassamento, sulfato de cálcio e reatividade do cimento. Assim, os problemas da perda de trabalhabilidade são relativamente raros e acidentais (falsa pega). Para os concretos convencionais estudados na pesquisa (MCAD1), verificou-se um aumento tanto do torque de escoamento quanto da viscosidade de torque. Esses acréscimos decorrem do processo de endurecimento normal do concreto, uma vez que não foi verificado qualquer comportamento anormal nos primeiros instantes.

Embora os SP sejam eficientes na dispersão das partículas de cimento por meio do processo de defloculação, essa ação é dependente do tempo e concretos com baixa relação água/aglomerante sofrem uma rápida perda de trabalhabilidade. Como o efeito principal da dispersão se dá sobre o torque de escoamento, esse efeito é observado por um maior aumento desse parâmetro reológico com o tempo quando comparado com a viscosidade de torque (TATTERSALL \& BANFILL, 1983). De acordo com os resultados obtidos, essas observações foram confirmadas. Verifica-se que os MCAD2 apresentaram maiores perdas de trabalhabilidade do que os outros concretos (MCAD1 e MCAD3). Essas misturas apresentaram aumentos do torque de escoamento ao longo do desenvolvimento do ensaio, porém a viscosidade de torque permaneceu praticamente constante para o período.

Os concretos incorporados com sílica ativa (MCAD3), com maior ou menor trabalhabilidade inicial, apresentaram um melhor desempenho ao longo do tempo, 
ou seja, essas misturas apresentaram menores acréscimos do torque de escoamento, com pequenas variações da viscosidade de torque. Esse comportamento está relacionado com o efeito positivo que a adição de sílica ativa promove em uma mistura: quando suas minúsculas partículas esféricas estão bem dispersas no sistema água-cimento, elas promovem o deslocamento das moléculas de água vizinhas aos grãos de cimento; com isso, as moléculas de água presas entre as partículas de cimento floculadas podem ser liberadas, contribuindo com a fluidificação da mistura.

A influência dos agregados sobre as propriedades reológicas do concreto fresco está relacionada principalmente com a quantidade de agregado que compõe a mistura e com sua a granulometria. Em um estudo desenvolvido por Struble et al. (1998), os autores observaram um aumento de ambos os parâmetros reológicos quando agregados foram incorporados à pasta de cimento para a produção do concreto.

$\mathrm{Na}$ presente pesquisa, ensaios foram realizados para a determinação do comportamento reológico de pastas de cimento e de concretos com o objetivo de verificar a influência dos agregados sobre os parâmetros reológicos que caracterizam esses materiais. Porém, os equipamentos forneceram parâmetros em unidades diferentes que impossibilitaram uma correlação entre eles: os ensaios em pasta, realizados com um reômetro de cilindros coaxiais, forneciam tensão de escoamento e viscosidade plástica em unidades do sistema internacional de medidas (SI), ou seja, em Pa e Pa.s, respectivamente; enquanto os ensaios realizados em concretos com o auxílio de um reômetro de eixo planetário forneceram parâmetros em unidades de torque, ou seja, em $\mathrm{Nm}$ e $\mathrm{Nm}$.s para o torque de escoamento e viscosidade de torque, respectivamente. Assim, não foi possível verificar a influência dos agregados sobre os parâmetros reológicos que caracterizam o comportamento de uma mistura de concreto.

Além das propriedades dos materiais constituintes da mistura, da compatibilidade entre eles e da composição do concreto, o procedimento de mistura empregado na produção desses materiais tem-se mostrado muito importante, em especial o tempo de adição do SP. Assim, para verificar a influência do procedimento de mistura sobre a trabalhabilidade dos concretos, bem como sobre sua perda ao longo do tempo, as misturas foram produzidas de acordo com os seis procedimentos propostos na pesquisa (figura 6.2) e as evoluções dos parâmetros determinados a partir do ajuste das curvas de cisalhamento ao modelo binghamiano (anexo D.2) - que caracterizam o comportamento desses materiais no 
estado fresco são apresentadas nas figuras 7.33, 7.34, 7.35 e 7.36. Um resumo dos valores determinados para cada parâmetro é apresentado na tabela 7.20.

Tabela 7.20 - Parâmetros reológicos obtidos a partir do ajuste das curvas de cisalhamento dos MCAD produzidos de acordo com os procedimentos de mistura propostos na pesquisa.

\begin{tabular}{c|c|c|c|c|c|c}
\hline Cimento & \multicolumn{2}{c|}{ CPV ARI Plus (SP = 0,61\%) } & \multicolumn{3}{c}{ CPV ARI RS (SP = 0,50\%) } \\
\hline $\begin{array}{c}\text { Procedimento } \\
\text { de mistura }\end{array}$ & \multicolumn{7}{c}{ Tempo de medida (min) } & \multicolumn{2}{c}{ Tempo de medida (min) } \\
\cline { 2 - 7 } & $\mathbf{1 0}$ & $\mathbf{3 0}$ & $\mathbf{6 0}$ & $\mathbf{1 0}$ & $\mathbf{3 0}$ & $\mathbf{6 0}$ \\
\hline \multicolumn{7}{c}{ TORQUE DE ESCOAMENTO - $\mathbf{g}$ [Nm] } \\
\hline ProcA & 0,95 & 1,13 & 1,48 & 1,37 & 1,51 & 2,09 \\
\hline ProcB & 1,57 & 1,86 & 2,31 & 1,91 & 2,12 & 2,42 \\
\hline ProcC & 1,06 & 1,44 & 1,54 & 1,51 & 1,91 & 2,30 \\
\hline ProcD & 0,86 & 1,46 & 1,76 & 1,41 & 1,43 & 2,08 \\
\hline ProcE & 1,29 & 1,52 & 1,68 & 2,09 & 2,18 & 2,33 \\
\hline ProcF & 1,24 & 1,20 & 1,68 & 1,24 & 1,44 & 1,94 \\
\hline ProcA & 1,179 & 1,121 & 1,189 & 0,685 & 1,114 & 1,053 \\
\hline ProcB & 0,643 & 0,688 & 0,663 & 1,262 & 1,420 & 1,508 \\
\hline ProcC & 0,672 & 0,673 & 0,800 & 0,990 & 1,039 & 0,983 \\
\hline ProcD & 0,850 & 0,926 & 1,070 & 1,076 & 1,347 & 1,102 \\
\hline ProcE & 0,795 & 1,051 & 1,108 & 1,354 & 1,064 & 0,906 \\
\hline ProcF & 1,561 & 1,780 & 1,746 & 1,409 & 1,686 & 1,632 \\
\hline
\end{tabular}

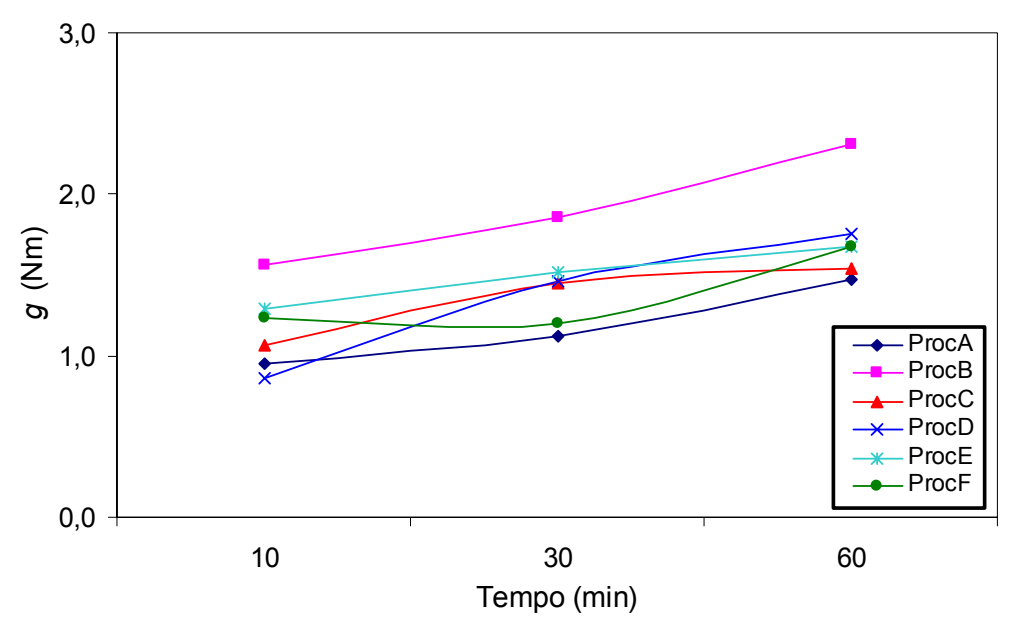

Figura 7.33 - Curva do "torque de escoamento versus tempo" para os MCAD produzidos com CPV ARI Plus e de acordo com os procedimentos de mistura propostos na pesquisa. 


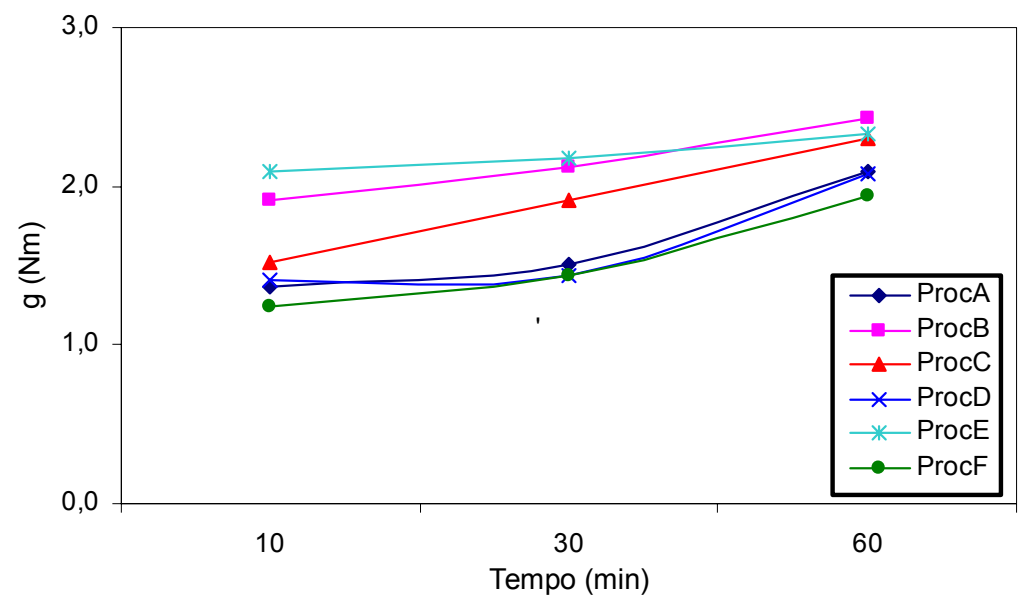

Figura 7.34 - Curva do "torque de escoamento versus tempo" para os MCAD produzidos com CPV ARI RS e de acordo com os procedimentos de mistura propostos na pesquisa.

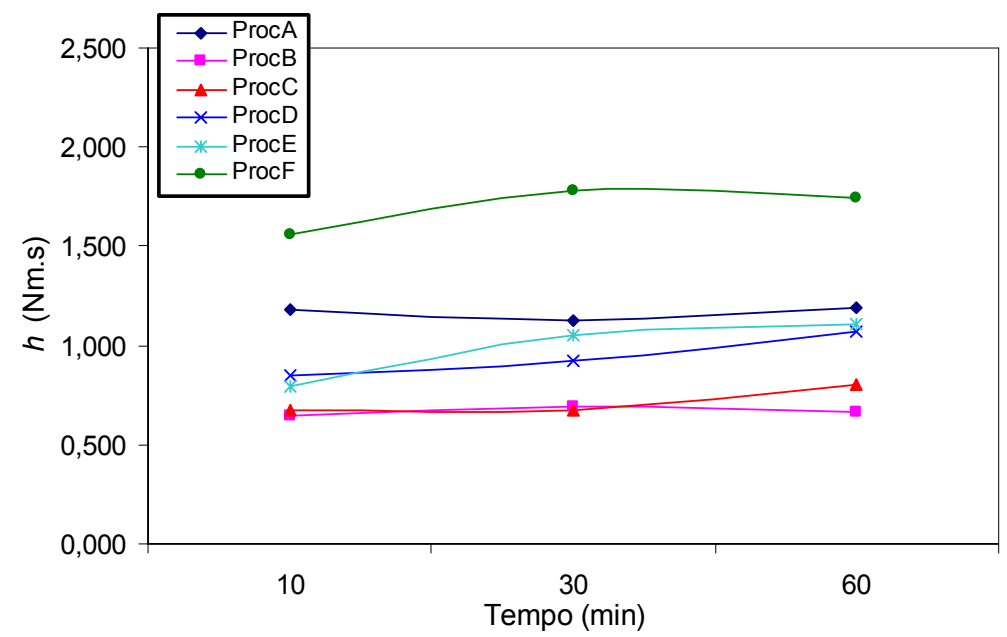

Figura 7.35 - Curva da "viscosidade de torque versus tempo" para os MCAD produzidos com CPV ARI Plus e de acordo com os procedimentos de mistura propostos na pesquisa.

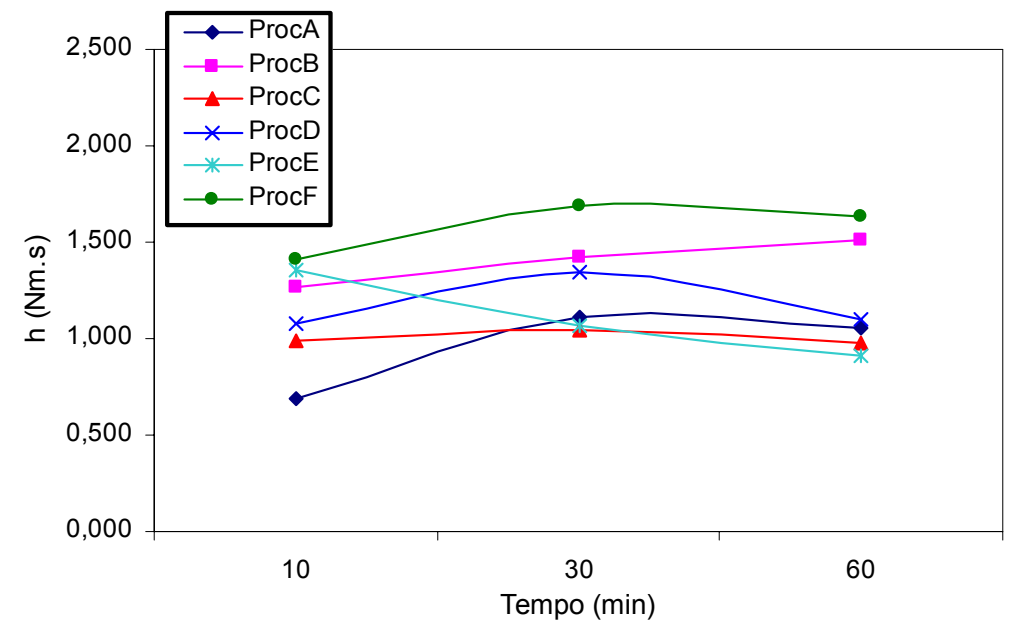

Figura 7.36 - Curva da "viscosidade de torque versus tempo" para os MCAD produzidos com CPV ARI RS e de acordo com os procedimentos de mistura propostos na pesquisa. 
Mantendo-se a composição da mistura constante e variando-se apenas o procedimento de mistura considerado na produção dos concretos, pode-se observar uma variação entre os valores dos parâmetros reológicos determinados através do ajuste da curva de cisalhamento ao modelo binghamiano. Para o torque de escoamento, os valores variaram entre 0,86 Nm e 1,57 Nm e entre 1,24 Nm e 2,09 Nm para os concretos produzidos com CPV ARI Plus e CPV ARI RS, respectivamente. Para a viscosidade de torque, a variação foi entre $0,643 \mathrm{Nm}$.s e 1,561 Nm.s para as misturas produzidas com CPV ARI Plus e entre 0,685 Nm.s e 1,409 Nm.s para os concretos produzidos com CPV ARI RS. Assim, pode-se observar que uma mudança na ordem de incorporação dos materiais constituintes durante o processo de mistura influencia as propriedades do concreto no estado fresco.

Para os MCAD produzidos com CPV ARI Plus, as misturas produzidas de acordo com os procedimentos $\mathrm{D}$ e $\mathrm{B}$ apresentaram os menores torque de escoamento e viscosidade de torque, respectivamente, no início do ensaio (10 minutos após o contato água-cimento). Após 30 minutos de ensaio, os melhores desempenhos para o torque de escoamento e para a viscosidade de torque foram observados para as misturas produzidas de acordo com os procedimentos A e C, respectivamente. Aos 60 minutos, a consideração dos procedimentos A e B resultou na produção de misturas com os menores valores de torque de escoamento e viscosidade de torque, respectivamente.

Para os MCAD produzidos com CPV ARI RS, as misturas produzidas de acordo com os procedimentos $\mathrm{F}$ e $\mathrm{A}$ apresentaram os menores torque de escoamento e viscosidade de torque, respectivamente, no início do ensaio (10 minutos após o contato água-cimento). Após 30 minutos de ensaio, os melhores desempenhos para o torque de escoamento e para a viscosidade de torque foram observados para as misturas produzidas de acordo com os procedimentos $\mathrm{D}$ e $\mathrm{C}$, respectivamente. Aos 60 minutos, a consideração dos procedimentos $\mathrm{F}$ e $\mathrm{E}$ resultou na produção de misturas com os menores valores de torque de escoamento e viscosidade de torque, respectivamente.

Devido à variação entre os procedimentos de mistura que resultaram em misturas com melhores trabalhabilidades (menores valores de torque de escoamento e de viscosidade de torque), o desempenho geral ao longo do ensaio foi considerado. Para as misturas produzidas com CPV ARI Plus, o emprego do procedimento de mistura A na produção dos concretos resultou em menores torques de escoamento ao longo do tempo, enquanto o melhor desempenho 
relacionado com a viscosidade de torque foi obtido para a mistura produzida a partir do procedimento B. Para os concretos produzidos com CPV ARI RS, os menores acréscimos no torque de escoamento e na viscosidade de torque ao longo do tempo foram obtidos para as misturas produzidas de acordo com os procedimentos F e C, respectivamente.

Mesmo com a utilização de um equipamento mais preciso para a determinação das características reológicas de uma mistura de concreto, observou-se uma variação entre os procedimentos de mistura que resultaram em misturas com melhores desempenhos relacionados com os dois parâmetros reológicos. Essa variação mostra a falta de correlação entre os parâmetros reológicos determinados, evidenciando a necessidade de se determinar os dois parâmetros reológicos como entidades separadas.

O tempo de adição do SP constitui um dos fatores que influenciam a fluidez de uma mistura à base de cimento que o contém. Quando a relação água/cimento é suficiente para tornar a pasta fluida, dificilmente o aditivo contribuirá na sua fluidez. Porém, quando essa adição é feita de maneira parcelada ou atrasada, existe uma maior dispersão da pasta de cimento (maior fluidez), pois o SP é adsorvido em uma menor extensão pela mistura de $\mathrm{C}_{3} \mathrm{~A}$ e gesso já submetida à hidratação e à formação da etringita, deixando aditivo suficiente para promover a dispersão das fases de C-S-H e reduzir a viscosidade do sistema [PENTTALA (1990); MASOOD \& AGARWAL (1994)].

No procedimento A, o SP foi incorporado no final do processo de mistura, quatro minutos depois do cimento ter entrado em contato com a água de amassamento. No procedimento $B$, a adição foi feita de maneira parcelada, sendo metade do SP adicionada junto com a água de amassamento e a outra metade no fim do processo de mistura, quatro minutos após o contato água-cimento. As misturas produzidas com CPV ARI Plus e de acordo com esses dois procedimentos de mistura resultaram em maiores trabalhabilidades, relacionadas com os menores valores de torque de escoamento e de viscosidade de torque, respectivamente. O melhor comportamento observado pela adição atrasada ou parcelada de SP está de acordo com o amplamente exposto na literatura.

Porém, para as misturas produzidas com CPV ARI RS, as maiores trabalhabilidades foram observadas quando o SP foi adicionado no início do processo de mistura, junto com a água de amassamento. Nesse caso, o melhor desempenho verificado ao longo do tempo pode estar relacionado com o fato de que a adição de SP, junto com a água de amassamento, implica em um 
comportamento semelhante ao de um aditivo plastificante. A diferença entre os procedimentos $\mathrm{F}$ e $\mathrm{C}$, que resultaram em menores torque de escoamento e viscosidade de torque, respectivamente, está na incorporação dos materiais aglomerantes: no procedimento $F$, os aglomerantes foram inicialmente homogeneizados e somente após dois minutos, o SP, a água e o agregado graúdo foram adicionados, enquanto que no procedimento C, o SP, a água e o agregado graúdo foram homogeneizados primeiramente, para posterior adição dos materiais aglomerantes.

Ao longo do desenvolvimento do ensaio, pode-se observar que os MCAD apresentaram um acréscimo contínuo e gradual dos valores do torque de escoamento (figuras 7.33 e 7.34), independente do procedimento de mistura empregado na sua produção. Isso reflete o comportamento de endurecimento do concreto (grau de estruturação que ocorre no material), indicando perda de sua trabalhabilidade ao longo do tempo, pois é necessário aplicar um torque maior para que o material inicie o escoamento. As viscosidades de torque determinadas a partir da reta que preenche o comportamento reológico dos concretos (modelo de Bingham) permaneceram praticamente constantes ao longo do tempo, sendo verificados pequenos aumentos em algumas situações.

Assim, o processo de perda da trabalhabilidade dos MCAD - de composição constante, mas produzidos de acordo com procedimentos de mistura diferentes mediante a determinação dos parâmetros reológicos, foi representado por um aumento do torque de escoamento, enquanto a viscosidade de torque permaneceu praticamente constante durante o ensaio (menores acréscimos ao longo do tempo). Esse comportamento está de acordo com os resultados observados na literatura [HU \& De LARRARD (1995); PUNKKI, GOLASZEWSKI \& GJøRV (1996); NEHDI, MINDESS \& AÏTCIN (1998); YEN et al. (1999)].

O estudo do comportamento reológico dos concretos com o auxílio de um reômetro permite que o usuário não detecte apenas as perdas de trabalhabilidade desses materiais, mas também que se conheça a origem desse fenômeno, que pode ser decorrente da absorção de água pelos agregados, segregação e/ou atividade química do sistema aglomerante/SP (incompatibilidade entre o cimento e o SP). A partir dos resultados obtidos, verifica-se que tanto o torque de escoamento quanto a viscosidade de torque apresentaram acréscimos durante o ensaio. Segundo o estudo feito por De Larrard et al. (1996), quando ambos os parâmetros reológicos apresentam acréscimos ao longo do tempo, mesmo quando esses são bem pequenos, a perda da trabalhabilidade está associada à absorção de água da 
matriz pelos agregados. Isso está de acordo com o trabalho desenvolvido, uma vez que foram utilizados agregados na condição seca para a produção dos MCAD. Para corrigir esse problema e produzir misturas estáveis, ou seja, misturas em que os dois parâmetros reológicos permanecem constantes ao longo do tempo, é necessária a utilização de agregados na condição pré-saturada.

\subsubsection{Comportamento ao cisalhamento dos concretos de alto desempenho ao longo do tempo}

A avaliação do comportamento de concretos sob uma taxa de cisalhamento contínua ou, mais precisamente, sob uma velocidade de rotação constante, mediante o estudo da taxa de quebra estrutural do material em função do tempo, constitui uma técnica alternativa às curvas de cisalhamento para a avaliação preliminar desse comportamento (TATTERSALL \& BANFILL, 1983).

Assim, o comportamento ao cisalhamento dos MCAD foi acompanhado ao longo do tempo. Para isso, as misturas foram submetidas a um cisalhamento contínuo (velocidade de rotação constante e igual a 28 RPM) no reômetro (figura 5.22-A) por um período de tempo indefinido, isto é, até que o torque limite de segurança do equipamento fosse atingido ou que a mistura se apresentasse sem coesão (pá misturadora girando no vazio). As determinações começaram imediatamente após o fim da mistura, ou seja, aproximadamente 10 minutos após o contato inicial entre a água de amassamento e o cimento. As curvas experimentais foram suavizadas para a redução do ruído e melhor visualização das tendências de endurecimento.

O comportamento ao cisalhamento dos concretos em função do tempo, bem como a influência das adições químicas e minerais sobre esse comportamento podem ser observados a partir das figuras 7.37 e 7.38. Nelas são apresentadas as curvas do "torque versus tempo" para o concreto de referência (MCAD1), o concreto com adição única de SP (MCAD2) e o concreto com ambas as adições SP e sílica ativa (MCAD3), produzidos com CPV ARI Plus e CPV ARI RS. 


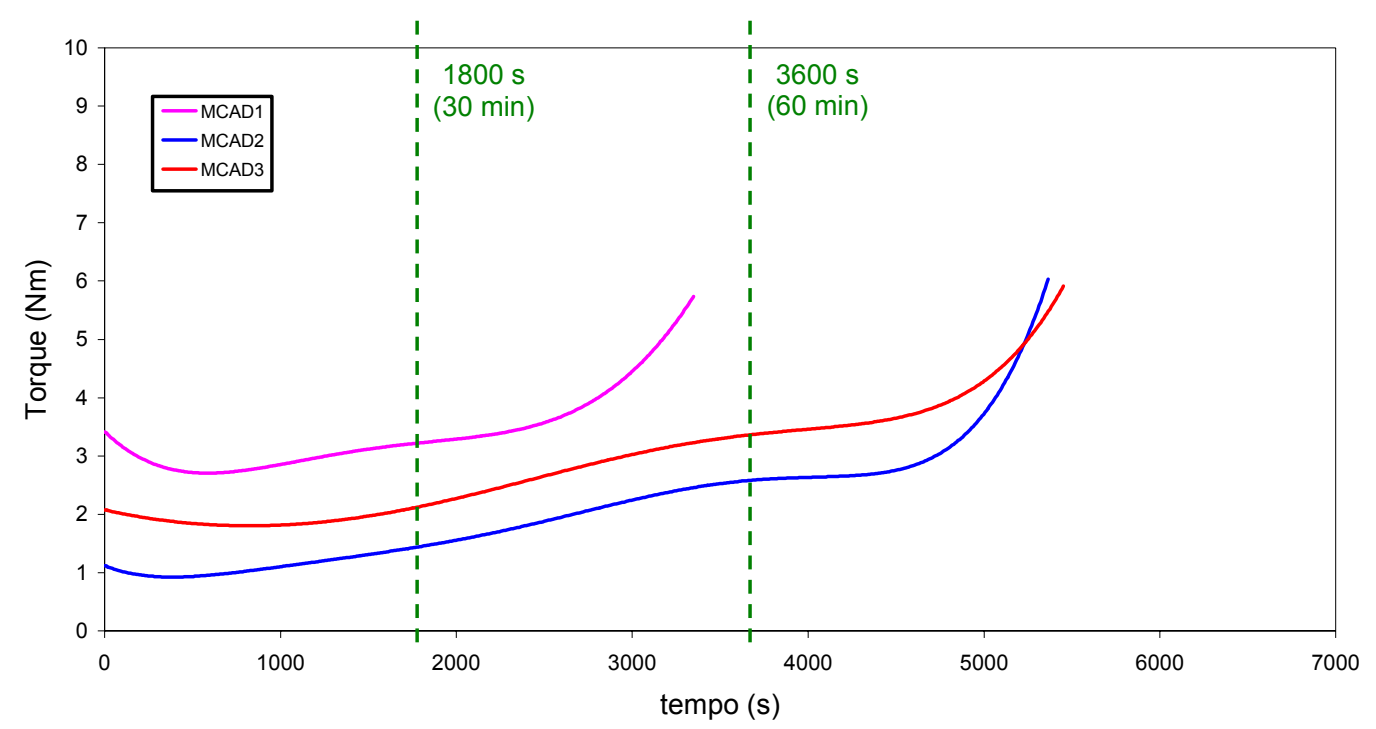

Figura 7.37 - Curvas do torque em função do tempo para as misturas produzidas com CPV ARI Plus e com composições variadas.

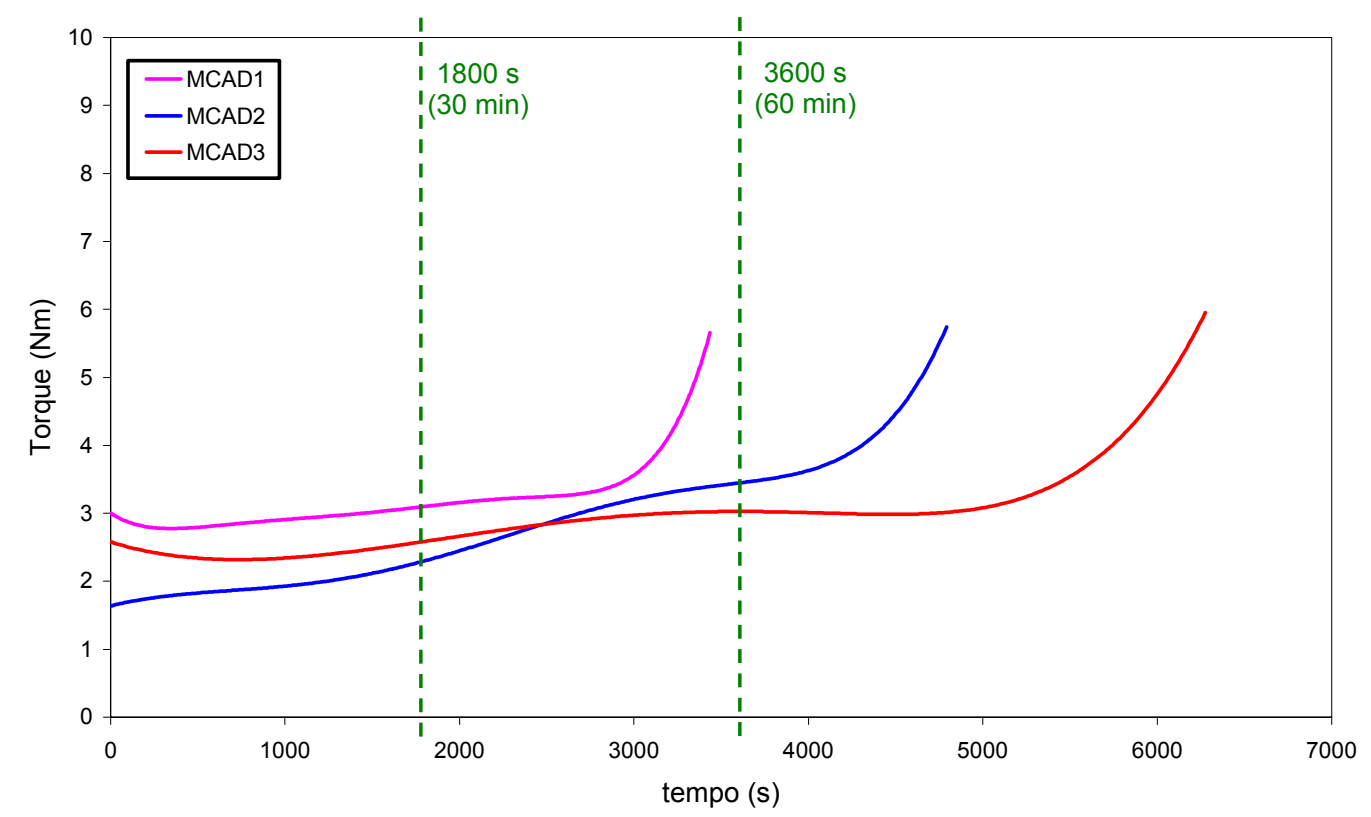

Figura 7.38 - Curvas do torque em função do tempo para as misturas produzidas com CPV $A R I R S$ e com composições variadas.

As propriedades reológicas de uma mistura variam continuamente dentro do período de início e fim de pega do concreto, com conseqüente redução progressiva da sua trabalhabilidade e do aumento do consumo de energia para o seu completo adensamento (KRUML, 1990). Para as misturas estudadas, a pega e o endurecimento ocorreram de maneira contínua e gradual até o fim do ensaio, independente da sua composição. Em todas as avaliações, o ensaio foi interrompido quando o material se apresentou sem coesão, ou seja, a pá misturadora girando no vazio. Na figura 7.39 são apresentadas fotos que mostram as etapas de desenvolvimento do ensaio. 

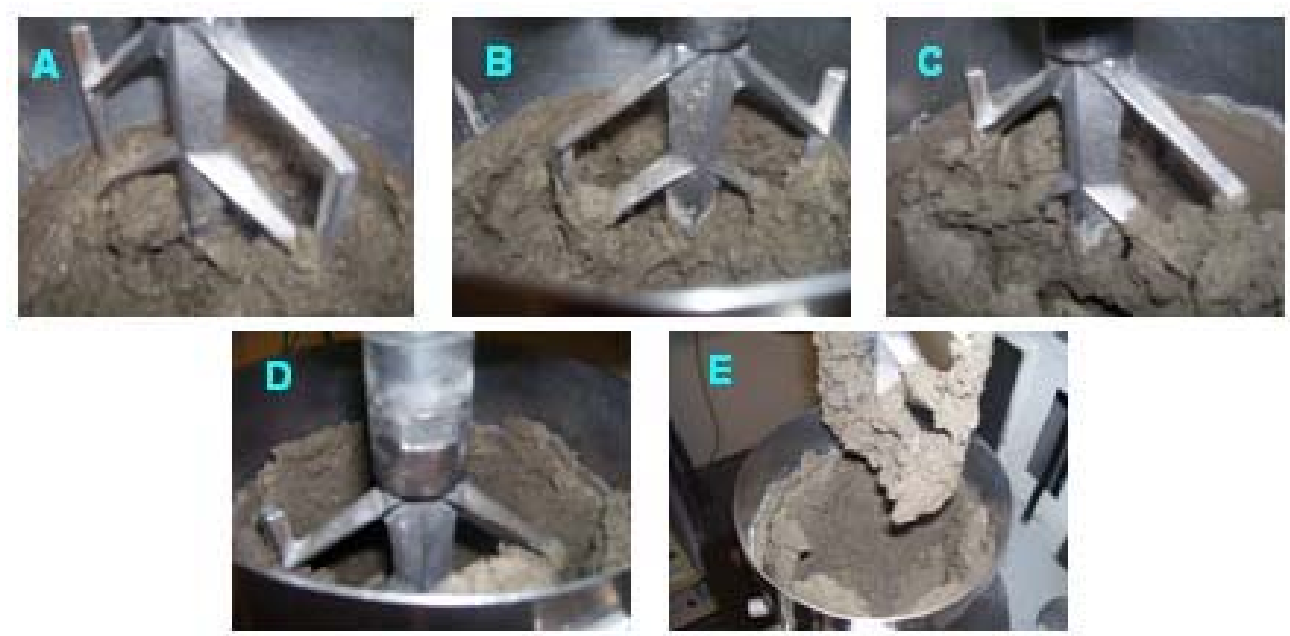

Figura 7.39 - Fotos do ensaio de cisalhamento contínuo ao longo do tempo: (A) no início do ensaio; (B) após 30 minutos; (C) após 60 minutos; (D) após 90 minutos e (E) indicando o fim do ensaio (material sem coesão aderido na parede da cuba de ensaio - pá misturadora girando no vazio).

O processo de pega e endurecimento do concreto resulta em propriedades muito complicadas devido à mudança do estado fluido para o estado sólido, causada pelo desenvolvimento da hidratação do cimento e pela sedimentação dos materiais granulares (OKAMOTO \& ENDOH, 1991). Neville (1997) atribui o endurecimento do concreto fresco à absorção de parte da água de amassamento pelos agregados (caso esse não tenha sido utilizado na condição saturada), à perda de parte da água por evaporação e ainda à remoção de parte da água pelas reações iniciais da hidratação do cimento.

Assim, o endurecimento do concreto fresco não deve ser confundido com a pega do cimento. Os tempos de pega determinados para as pastas de cimento que compõem o MCAD1, MCAD2 e MCAD3, medidos pelo ensaio de penetração com auxílio do aparelho de Vicat, foram de 152, 427 e 284 minutos, respectivamente, para as misturas produzidas com CPV ARI Plus e de 240, 571 e 395 minutos, respectivamente, para as misturas produzidas com CPV ARI RS. Os tempos de trabalhabilidade dos concretos produzidos com essas pastas verificados através do ensaio de cisalhamento contínuo foram de 48, 82 e 90 minutos para os MCAD1, MCAD2 e MCAD3 produzidos com CPV ARI Plus, respectivamente, e de 55, 76 e 98 minutos, respectivamente, para as misturas produzidas com CPV ARI RS. Como os tempos de trabalhabilidade dos concretos são bem menores que os tempos de início de pega das pastas que os compõem, confirma-se que o processo de perda da trabalhabilidade medido pelo ensaio de cisalhamento contínuo ao longo do tempo realmente está relacionado com o processo de pega e endurecimento do concreto. 
Para ambos os cimentos, o concreto de referência, MCAD1, foi a primeira mistura a endurecer e, conseqüentemente, a perder sua trabalhabilidade, ainda que esses materiais pudessem ser usados na produção de elementos pré-moldados de concreto onde o intervalo de tempo entre a mistura e a moldagem não ultrapassa 30 minutos; além disso, os valores de torque medidos ao longo do tempo foram os maiores entre as três misturas avaliadas para cada cimento. A incorporação de SP a essa mistura, MCAD2, permitiu a produção de um concreto mais fluido que manteve sua trabalhabilidade por um período mais longo e implicou em menores valores de torque durante o seu cisalhamento. Quando a sílica ativa foi incorporada ao concreto, MCAD3, a mistura se manteve trabalhável por um período de tempo ainda mais longo que os MCAD2, porém implicou em valores de torque maiores; em outras palavras, pode-se dizer que a incorporação de sílica ativa a uma mistura de concreto melhora o seu desempenho ao longo do tempo, porém diminui sua trabalhabilidade.

O MCAD1, concreto convencional, apresenta o processo de endurecimento normal desses materiais decorrente da absorção de água de amassamento pelos agregados, da evaporação de parte da água constituinte da mistura, do consumo de parte da água pelas reações iniciais da hidratação e da temperatura, uma vez que não foi observado qualquer comportamento anormal desse material.

O processo de endurecimento do MCAD2 ilustra a maior perda de trabalhabilidade sofrida pela misturas incorporadas com SP. A contribuição da sílica ativa com o desempenho do concreto é verificada pelos maiores tempos de trabalhabilidade dos MCAD3 determinados pelo ensaio de cisalhamento contínuo. As minúsculas partículas esféricas de sílica ativa, estando bem dispersas no sistema água-cimento, promovem o deslocamento das moléculas de água vizinhas aos grãos de cimento; com isso, as moléculas de água presas entre as partículas de cimento floculadas podem ser liberadas, contribuindo com a fluidificação da mistura.

A influência do procedimento de mistura sobre o comportamento de concretos no estado fresco pode ser observada a partir das curvas de "torque versus tempo" apresentadas nas figuras 7.40 e 7.41. O processo de pega e endurecimento das misturas também se deu de maneira contínua e gradual ao longo do ensaio e, para todas as amostras, o ensaio também foi interrompido quando o material apresentou falta de coesão, ou seja, a pá misturadora girando no vazio. 


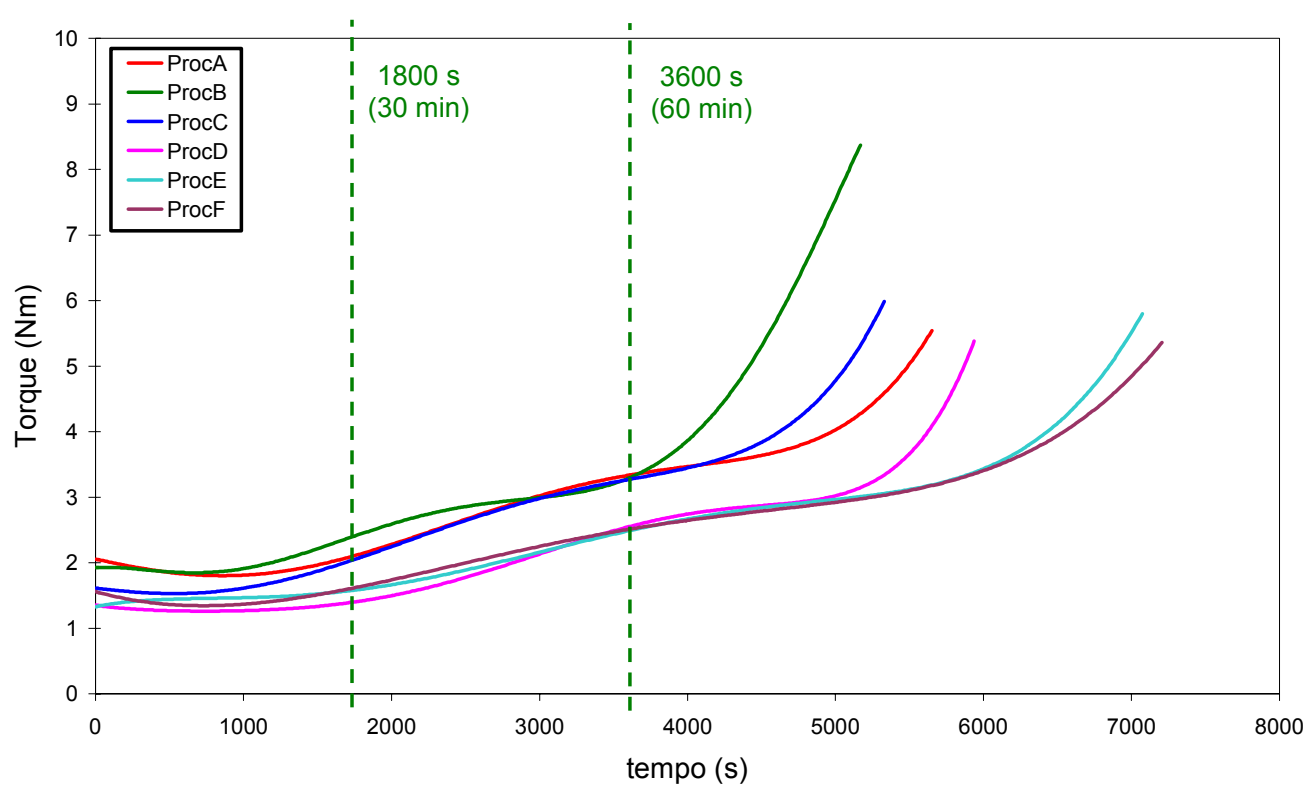

Figura 7.40 - Curvas do torque em função do tempo para as misturas produzidas com CPV ARI Plus e de acordo com os procedimentos de mistura propostos na pesquisa.

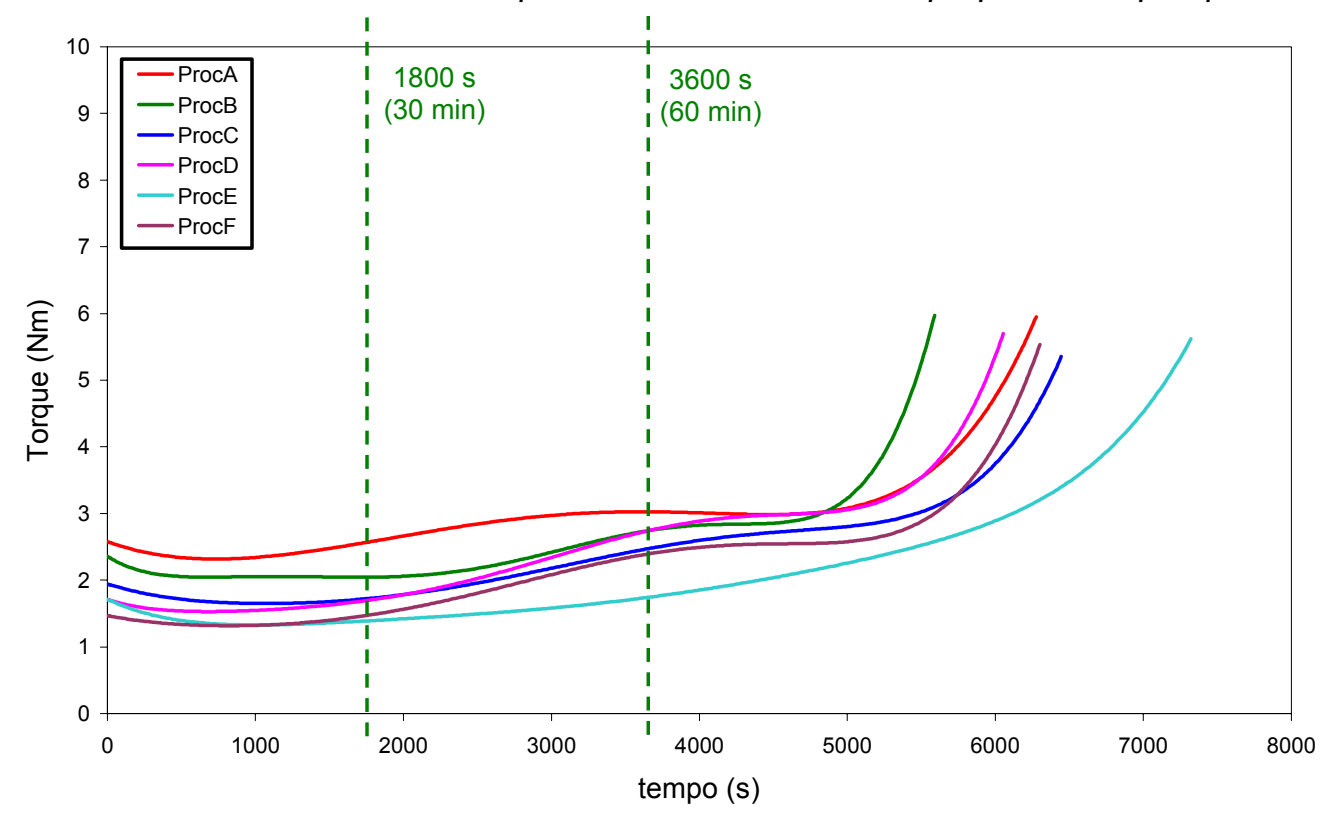

Figura 7.41 - Curvas do torque em função do tempo para as misturas produzidas com CPV $A R I R S$ e de acordo com os procedimentos de mistura propostos na pesquisa.

Mantendo-se a composição da mistura constante, pode-se observar que os concretos apresentaram tempos de trabalhabilidade variando em função do procedimento de mistura adotado na sua produção (figuras 7.40 e 7.41). Os tempos mínimo e máximo determinados a partir do ensaio de cisalhamento contínuo com o auxílio de um reômetro variaram entre 64 e 108 minutos e entre 86 e 115 minutos para os concretos produzidos com CPV ARI Plus e CPV ARI RS, respectivamente. Os procedimentos de mistura $\mathrm{F}$ e $\mathrm{E}$ resultaram nos tempos de trabalhabilidade mais longos para as misturas produzidas com CPV ARI Plus e CPV ARI RS, 
respectivamente, indicando a manutenção da trabalhabilidade dessas misturas por um maior intervalo de tempo.

Da literatura sabe-se que a adição atrasada ou parcelada do SP favorece a produção de misturas com melhores trabalhabilidades [PENTTALA (1990); MASOOD \& AGARWAL (1994)]. Porém, os resultados obtidos vão contra essas observações. Em ambos os procedimentos, o SP foi adicionado no início do processo de mistura, junto com a água de amassamento. Nesse caso, o melhor desempenho verificado ao longo do tempo pode estar relacionado com o fato de que a adição de SP, junto com a água de amassamento, implica em um comportamento semelhante ao de um aditivo plastificante, resultando em melhores trabalhabilidades ao longo do tempo.

Ao considerar o intervalo de tempo compreendido entre o início do processo de mistura e o lançamento do concreto normalmente empregado na prática das construções, as misturas produzidas de acordo com os seis procedimentos considerados na pesquisa apresentaram comportamentos semelhantes entre si, com pequenas variações nos valores de torque medidos. Vale observar também que o comportamento se manteve praticamente constante durante esse intervalo de tempo sob a ação de cisalhamento contínuo.

Para uma situação mais crítica, ou seja, para uma situação em que o intervalo de tempo compreendido entre as etapas de mistura e lançamento do concreto pode chegar a 60 minutos, a influência do procedimento de mistura adotado na produção dos concretos se tornou mais evidente. As misturas produzidas com os seis procedimentos estudados apresentaram comportamentos diferentes entre si e, para esse intervalo, o aumento do valor do torque medido e, consequentemente, a perda de trabalhabilidade do material pôde ser observada com maior significância. Assim, o intervalo de tempo no qual esse material será misturado e lançado se torna um fator importantíssimo quando da aplicação de misturas de alto desempenho.

\subsubsection{Influência da temperatura e do pH sobre o comportamento de concretos de alto desempenho}

Até o momento, as discussões envolveram os fatores que compõem uma mistura de concreto e o procedimento de mistura empregado na sua produção. Porém, alguns efeitos secundários, como a influência da variação da temperatura e do $\mathrm{pH}$ da mistura ao longo do tempo, também foram considerados durante a avaliação do comportamento dos concretos ao cisalhamento. 
Essas leituras foram realizadas durante o ensaio de cisalhamento contínuo. Para isso, os sensores medidores da temperatura e do $\mathrm{pH}$ foram inseridos na amostra através de dispositivos anexados a cuba e ambos ligados a um sistema digital de leitura conectado a um computador, sendo os dados coletados também registrados pelo software do reômetro.

A evolução da temperatura ao longo do tempo para todas as misturas estudadas é apresentada nas figuras 7.42 e 7.43 . Verifica-se que todas as misturas, independente de sua composição ou do procedimento de mistura empregado na sua produção, apresentaram um aumento dessa temperatura ao longo do desenvolvimento do ensaio. Esse aumento da temperatura está relacionado com a liberação de calor durante a evolução do processo de hidratação do cimento, particularmente com a formação da etringita nos primeiros instantes após o contato entre o cimento e a água de amassamento.

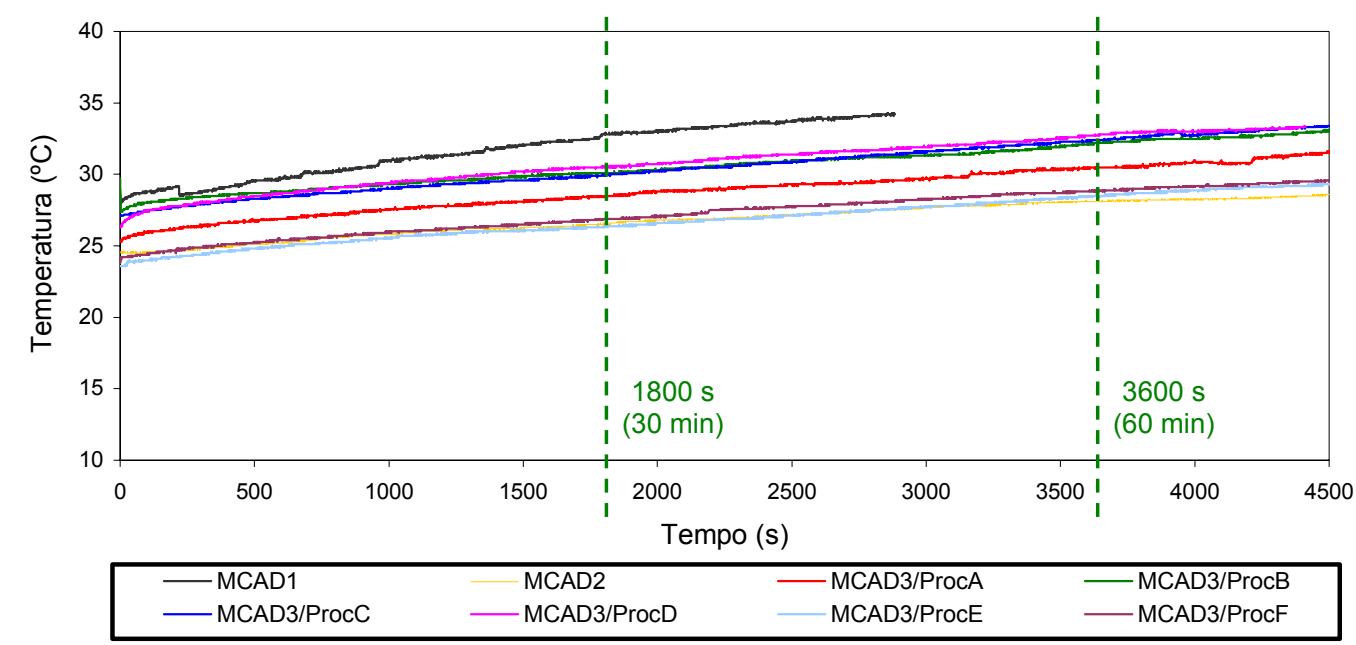

Figura 7.42 - Evolução da temperatura ao longo do tempo para os MCAD produzidos com CPV ARI Plus.

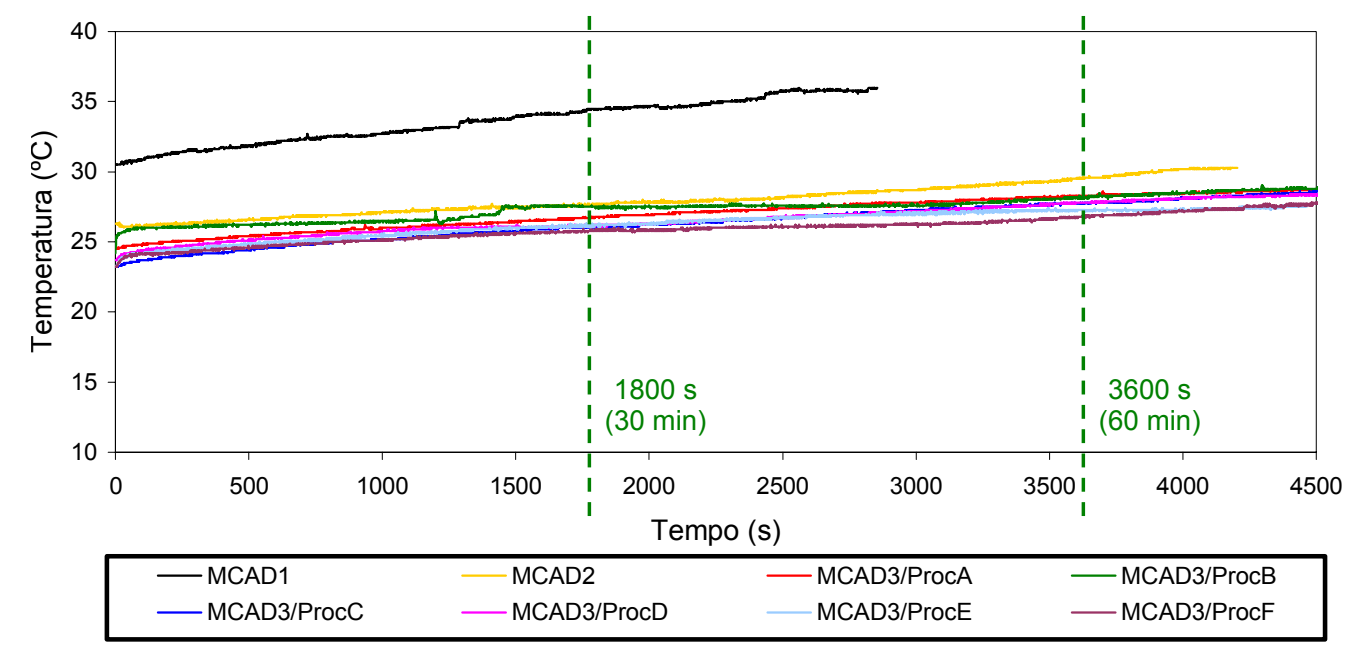

Figura 7.43 - Evolução da temperatura ao longo do tempo para os MCAD produzidos com CPV ARI RS. 
Para as misturas produzidas com CPV ARI Plus, o concreto de referência (MCAD1) apresentou a maior temperatura inicial entre as misturas ensaiadas $\left(28,1^{\circ} \mathrm{C}\right)$. A adição de SP (MCAD2) promoveu um retardamento na hidratação inicial do cimento, resultando em uma menor liberação de calor e, consequentemente, implicando em uma menor temperatura inicial da amostra $\left(24,6^{\circ} \mathrm{C}\right)$ e, quando a sílica ativa foi incorporada (MCAD3), a temperatura inicial voltou a subir (média de $25,4^{\circ} \mathrm{C}$ ). Porém, ao longo do ensaio, todas as misturas apresentaram um acréscimo de temperatura de cerca de $6^{\circ} \mathrm{C}$, independente da sua composição e do procedimento de mistura adotado na sua produção.

Para as misturas produzidas com CPV ARI RS, o concreto de referência (MCAD1) também apresentou a maior temperatura inicial entre as misturas ensaiadas $\left(30,5^{\circ} \mathrm{C}\right)$. A incorporação de SP (MCAD2) mais uma vez retardou o processo de hidratação inicial do cimento resultando em uma menor temperatura inicial da mostra $\left(26,3^{\circ} \mathrm{C}\right)$, mas quando a sílica foi incorporada, a temperatura média das seis amostras ensaiadas (MCAD3) foi ainda menor $\left(23,9^{\circ} \mathrm{C}\right)$. Porém, ao longo do ensaio, o acréscimo de temperatura foi de aproximadamente $5^{\circ} \mathrm{C}$ para os concretos testados, independente da composição da mistura e do procedimento de mistura empregado na produção desses materiais.

Essas diferenças de comportamento com relação à temperatura podem ser explicadas em termos da fase sólida que compõem o concreto. Durante o processo de mistura, os agregados trabalham como um moinho de bolas no cisalhamento da matriz de cimento. $\mathrm{O}$ atrito gerado entre as partículas é dissipado, na sua maior parte, em forma de calor, acelerando o processo de hidratação do cimento e, conseqüentemente, o endurecimento e a perda de trabalhabilidade do concreto.

No MCAD1, a matriz presente não é suficientemente fluida para dispersar as partículas sólidas presentes na mistura. Isso gera um maior atrito entre as partículas, resultando em maior liberação de calor e maiores temperaturas da mistura. Além disso, o retardamento da pega do cimento observado com a incorporação de um aditivo químico não é verificado para esse material, ou seja, a hidratação do cimento ocorre normalmente, com a liberação de calor característica de cada cimento.

Ao adicionar SP (MCAD2), a pega do cimento que compõe a mistura é retardada, fazendo com que a matriz se torne bastante fluida, dispersando melhor as partículas, reduzindo o atrito entre elas e, conseqüentemente, a liberação de calor e a temperatura da mistura. No caso do MCAD3, onde tanto o aditivo químico 
quanto a adição mineral estão presentes, observa-se uma temperatura maior ou bem próxima da temperatura do MCAD2, porém menor que a do MCAD1. Ao incorporar sílica ativa à composição do concreto, a quantidade de partículas sólidas presentes na mistura aumenta; com isso, o atrito entre as partículas novamente é aumentado, promovendo uma maior liberação de calor e, assim, aumentando a temperatura da mistura. Porém, essa temperatura se mantém abaixo da temperatura medida para o MCAD1 porque a presença de SP retarda a pega do cimento que constitui a mistura e fornece uma maior dispersão das partículas mantendo a matriz mais fluida do que no MCAD1. Quanto ao aumento de temperatura praticamente constante para todas as misturas, ele pode estar relacionado com o processo de hidratação normal do cimento adotado na produção dos concretos avaliados.

A variação do procedimento de mistura empregado na produção dos concretos implicou em pequenas variações na temperatura da mistura. Essas diferenças podem estar relacionadas principalmente com as variações da temperatura ambiente onde foram realizados os ensaios, pois o perfil da curva da evolução da temperatura em função do tempo segue a mesma tendência para os concretos produzidos com os dois tipos de cimento e de acordo com os seis procedimentos de mistura avaliados.

$\mathrm{O}$ comportamento do $\mathrm{pH}$ em função do tempo também foi avaliado. A evolução dessa característica é apresentada para todas as misturas de concreto estudadas nas figuras 7.44 e 7.45 .

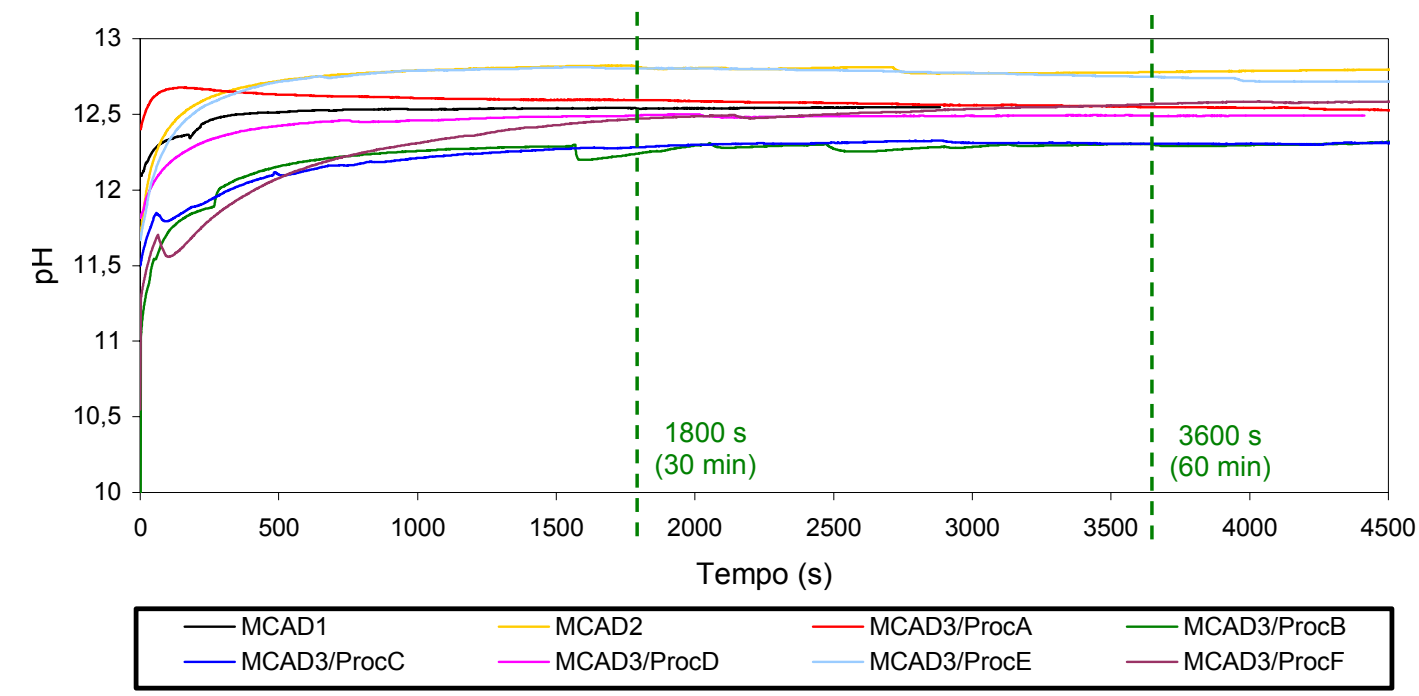

Figura 7.44 - Evolução do $\mathrm{pH}$ ao longo do tempo para os MCAD produzidos com CPV ARI Plus. 


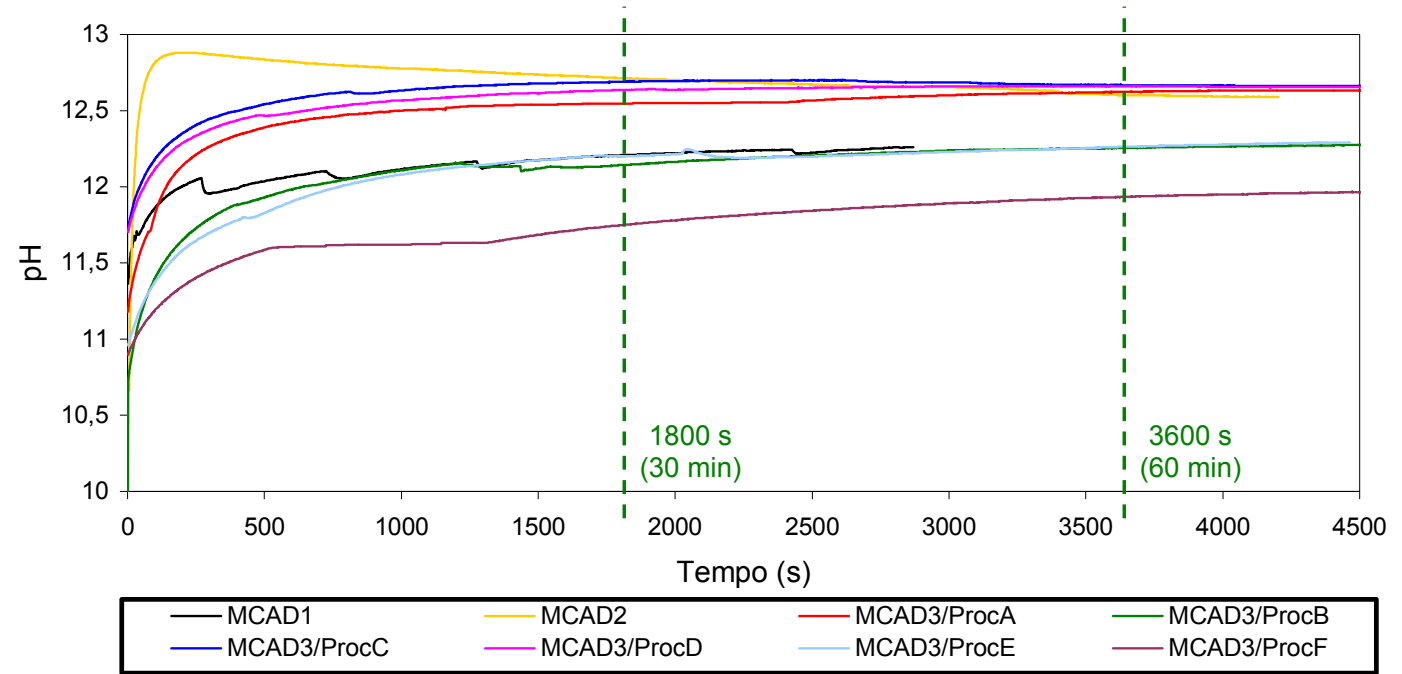

Figura 7.45 - Evolução do $\mathrm{pH}$ ao longo do tempo para os MCAD produzidos com CPV ARI $R S$.

Para os concretos produzidos com CPV ARI Plus, até aproximadamente 500 segundos de ensaio (cerca de 20 minutos após o contato inicial entre a água de amassamento e o cimento), todas as misturas apresentaram um acréscimo no valor do $\mathrm{pH}$ da água capilar; a partir desse momento, os valores mantiveram-se constantes até o fim do ensaio. Para os concretos produzidos $\mathrm{cm}$ CPV ARI RS, também se observou um aumento do $\mathrm{pH}$ até que um valor de equilíbrio fosse atingido, o que aconteceu aproximadamente 1000 segundos (cerca de 30 minutos após o contato água-cimento). Esse pH de equilíbrio, que varia entre 12,3 e 12,7 e entre 12,2 e 12,6 para as misturas produzidas com CPV ARI Plus e CPV ARI RS, respectivamente, está perfeitamente de acordo com o valor de 12,5 para o $\mathrm{pH}$ do fluido nos poros das pastas de cimento apresentados na literatura (MEHTA \& MONTEIRO, 1994). Assim, não se verifica qualquer efeito adverso da evolução do $\mathrm{pH}$ sobre o comportamento dos microconcretos de alto desempenho no estado fresco.

\subsection{Comparação dos resultados}

\subsubsection{Correlação entre o abatimento e os parâmetros reológicos}

De acordo com Tattersall (1991b), existem somente duas situações em que um método de ensaio que determina apenas um dos dois parâmetros reológicos pode ser útil: quando a taxa de cisalhamento no ensaio for igual à taxa de trabalho a qual o concreto será submetido; e quando as curvas de cisalhamento de todas as amostras de um conjunto de concreto se apresentarem de tal forma que duas linhas 
não se cruzem. Na primeira situação, o ensaio serve para classificar os concretos em uma ordem correta de trabalhabilidade que também será encontrada no campo; em outras palavras, um concreto que for classificado como mais trabalhável pelo ensaio será, de fato, o mais trabalhável em campo. A segunda situação é de grande interesse prático, pois dependendo da forma com que as curvas se apresentam uma com relação às outras, é possível detectar o fator que varia entre as amostras: um conjunto de linhas na forma de leque é obtido para uma série de concretos que se diferem apenas no teor de água; enquanto um conjunto de linhas paralelas indica que as amostras de uma série se diferem apenas com relação ao teor de aditivo.

Uma outra maneira de afirmar que as curvas de cisalhamento de uma série de concretos não se cruzam corresponde à existência de uma correlação significativa entre a tensão de escoamento e a viscosidade plástica, ou ainda, em unidades de torque, entre o torque de escoamento e a viscosidade de torque. Em geral isso não acontece para uma variedade de composições de concreto, evidenciando que ambos os parâmetros reológicos devem ser determinados como entidades separadas (TATTERSALL, 1990).

A partir das figuras $7.25,7.26,7.46$ e 7.47 , observa-se que as curvas de cisalhamento para as séries de microconcretos de alto desempenho (MCAD3) produzidos com CPV ARI Plus e CPV ARI RS se cruzam e que o coeficiente de correlação entre o torque de escoamento e a viscosidade de torque desses materiais é baixo, evidenciando que um ou mais fatores estão variando dentro dessas séries. Isso está de acordo com as variáveis consideradas no ensaio, pois os gráficos apresentam os resultados de todas as misturas para cada tipo de cimento utilizado, as quais foram produzidas de acordo com procedimentos de mistura diferentes. Assim, a utilização de qualquer método de ensaio que fornece apenas um dos parâmetros reológicos se torna totalmente inadequada.

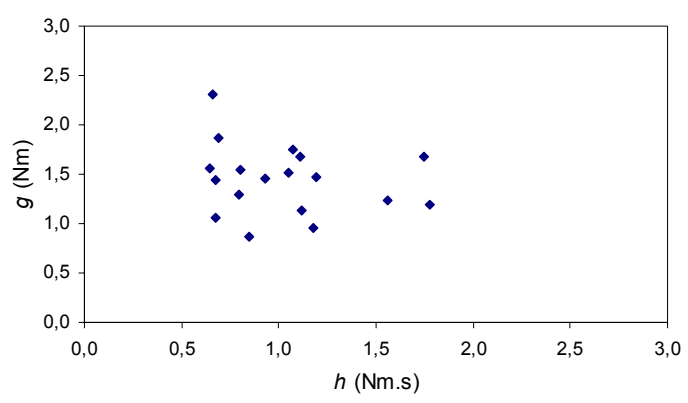

Figura 7.46 - Correlação entre $g$ versus $h$ para as misturas produzidas com CPV ARI Plus $\left(R^{2}=0,042\right)$.

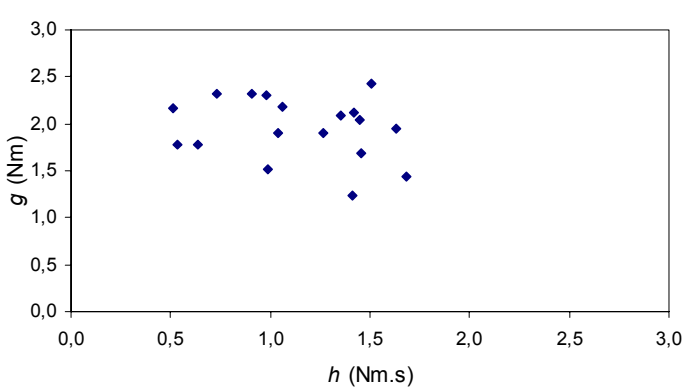

Figura 7.47 - Correlação entre $g$ versus $h$ para as misturas produzidas com CPV ARI $R S\left(R^{2}=0,050\right)$. 
Porém, como até o momento os reômetros não são utilizados em uma grande extensão, é interessante determinar correlações entre os valores obtidos com esses equipamentos e o ensaio de abatimento de tronco de cone comumente usado [BANFILL et al. (2001); WALLEVIK (2006)]. Para isso, os dois ensaios de abatimento de tronco de cone foram considerados: o tradicional (NBR NM 67/98) e o modificado (FERRARIS \& De LARRARD, 1998b). A partir dos resultados, esperase que o abatimento seja correlacionado com o torque de escoamento, enquanto a tensão de escoamento e a viscosidade plástica determinadas pelo ensaio de abatimento modificado sejam correlacionadas, respectivamente, com o torque de escoamento e com a viscosidade de torque obtidos a partir do ajuste das curvas de cisalhamento determinadas com um reômetro.

As figuras 7.48, 7.49, 7.50 e 7.51 apresentam os resultados obtidos para cada mistura em particular, ou seja, cada mistura produzida de acordo com um determinado procedimento foi considerada independente da outra. A relação entre a tensão de escoamento e o torque de escoamento apresentou coeficientes de correlação médios iguais a 0,8346 e 0,8883 para as misturas produzidas com CPV ARI Plus e CPV ARI RS, respectivamente, mostrando que esses dois parâmetros apresentam uma boa correlação, independente do método de ensaio empregado na sua determinação. A correlação entre a viscosidade plástica e a viscosidade de torque apresentou coeficientes médios iguais a 0,8474 e 0,8968 para as misturas produzidas com CPV ARI Plus e CPV ARI RS, respectivamente, mostrando também uma boa correlação entre esses dois parâmetros reológicos determinados a partir de métodos de ensaio diferentes.

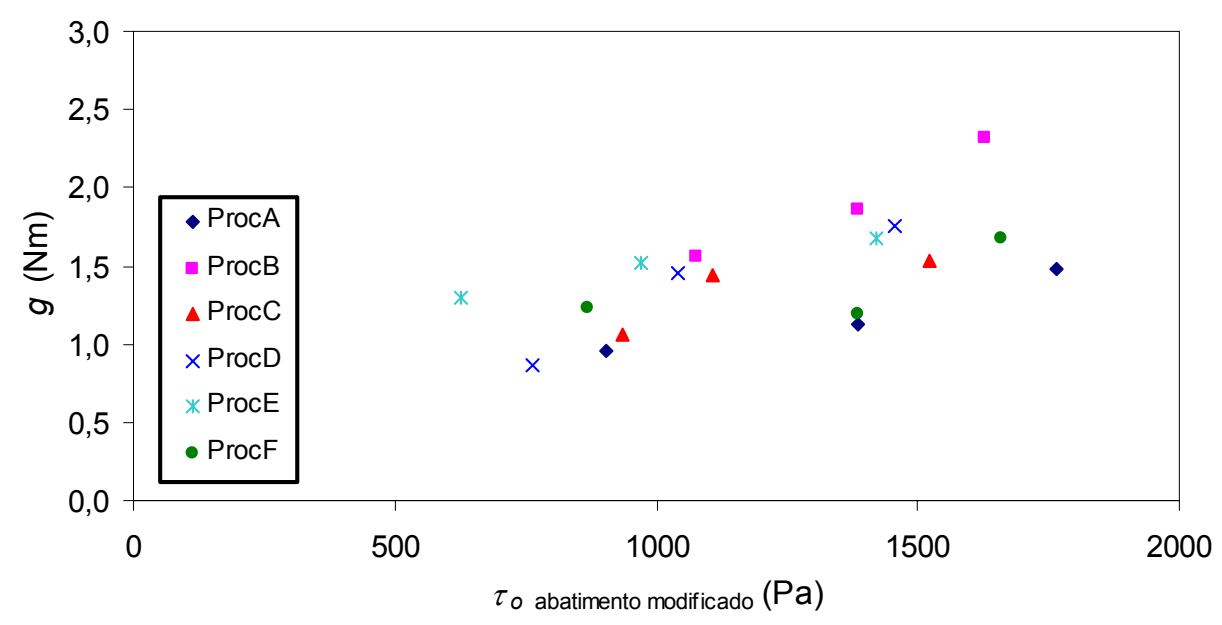

Figura 7.48 - Comparação entre a tensão de escoamento (determinada pelo ensaio de abatimento de tronco de cone modificado) e o torque de escoamento (determinado a partir do reômetro) para os MCAD3 produzidos com CPV ARI Plus. 


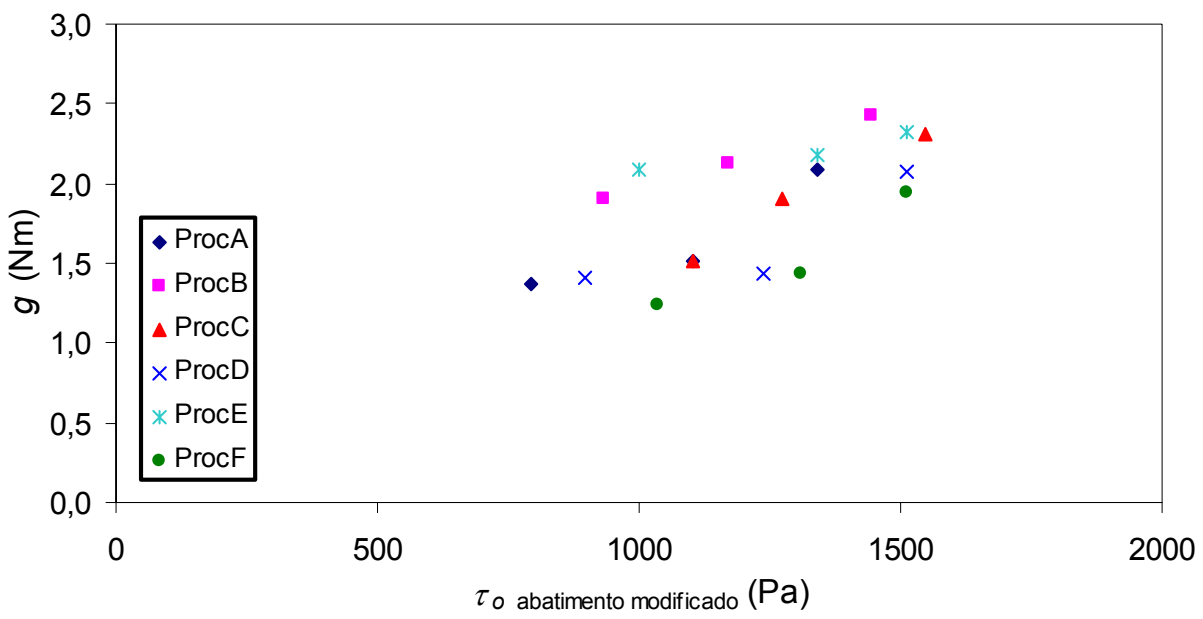

Figura 7.49 - Comparação entre a tensão de escoamento (determinada pelo ensaio de abatimento de tronco de cone modificado) e o torque de escoamento (determinado a partir do reômetro) para os MCAD3 produzidos com CPV ARI RS.

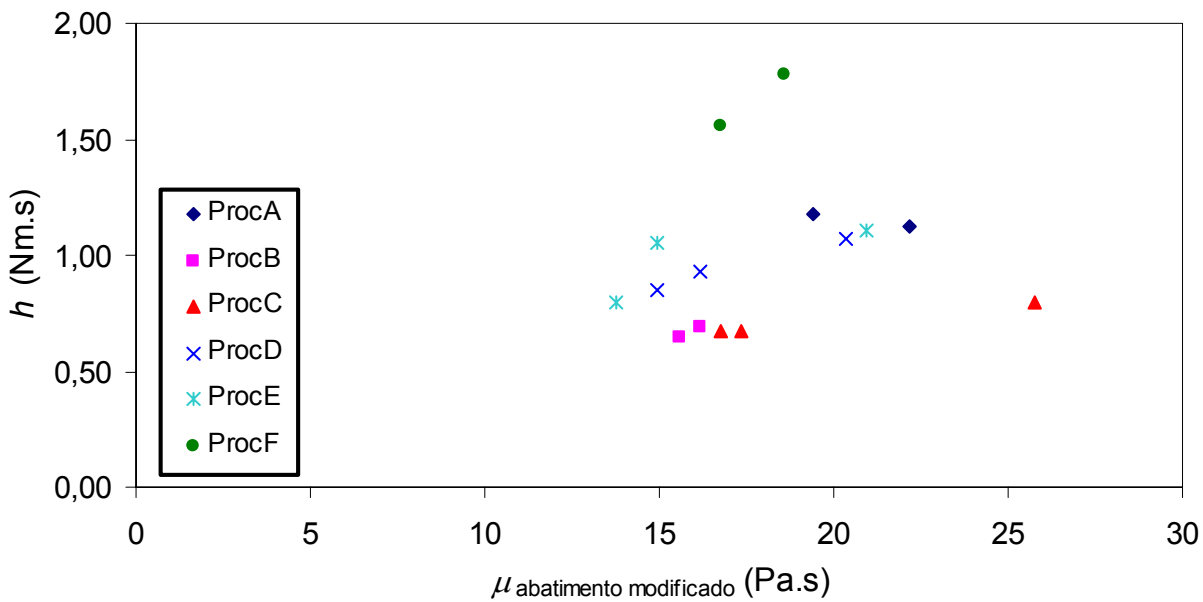

Figura 7.50 - Comparação entre a viscosidade plástica (determinada pelo ensaio de abatimento de tronco de cone modificado) e a viscosidade de torque (determinada a partir do reômetro) para os MCAD3 produzidos com CPV ARI Plus.

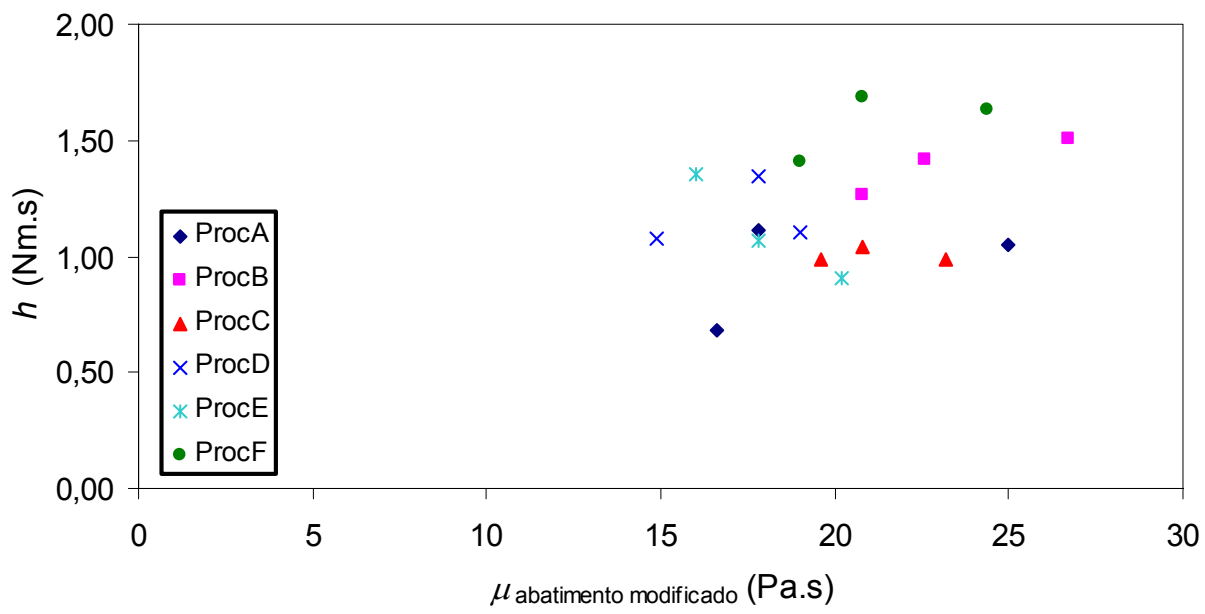

Figura 7.51 - Comparação entre a viscosidade plástica (determinada pelo ensaio de abatimento de tronco de cone modificado) e a viscosidade de torque (determinada a partir do reômetro) para os MCAD3 produzidos com CPV ARI RS. 
À medida que o molde tronco-cônico é retirado, a amostra de concreto sofre um abatimento devido à ação da gravidade. Considerando o concreto como um fluido com tensão de escoamento, o abatimento da amostra deixa de ocorrer quando a tensão de cisalhamento aplicada (pela gravidade) se torna menor do que a tensão de escoamento do material. Assim, para esses materiais, espera-se a existência de uma forte relação entre o abatimento e a tensão de escoamento ou torque de escoamento (WALLEVIK, 2006).

Diversas tentativas têm sido feitas para se encontrar uma relação entre a viscosidade plástica (ou viscosidade de torque), a tensão de escoamento (ou torque de escoamento) e o abatimento de uma mistura de concreto. Porém, a maioria dos pesquisadores concorda que o ensaio de abatimento de tronco de cone é um método de ensaio essencialmente estático, dependente principalmente da tensão de escoamento do concreto e, em uma menor extensão, da viscosidade plástica do material (HU et al., 1996).

No caso particular da correlação entre a tensão de escoamento e o abatimento, diversas tentativas para a determinação de uma equação que relacione esses dois parâmetros são encontradas na literatura [MURATA (1984); TANIGAWA, MORI \& WATANABE (1990); HU et al. (1996); SCHOWALTER \& CHRISTENSEN (1998); SAAK, JENNINGS \& SHAH (2004); WALLEVIK (2006)]. Algumas dessas equações são baseadas em simulações de elementos finitos do ensaio de abatimento de tronco de cone, enquanto outras são baseadas no preenchimento de um conjunto de dados.

No presente trabalho, as correlações entre a tensão de escoamento e o abatimento e entre o torque de escoamento e o abatimento apresentaram, respectivamente, coeficientes médios iguais a 0,9893 e 0,8590 para as misturas produzidas com CPV ARI Plus e iguais a 0,9888 e 0,8474, respectivamente, para as misturas produzidas com CPV ARI RS, mostrando que esses dois parâmetros estão correlacionados como inicialmente esperado (figuras 7.52, 7.53, 7.54 e 7.55). Para a viscosidade plástica e a viscosidade de torque, os coeficientes de correlação médios entre esses parâmetros reológicos e o abatimento foram, respectivamente, de 0,9531 e 0,6067 para as misturas produzidas com CPV ARI Plus e, respectivamente, de 0,8972 e 0,5882 para as misturas produzidas com CPV ARI RS (figuras 7.56, 7.57, 7.58 e 7.59). Assim, esse estudo indica que o abatimento é mais sensível à tensão de escoamento ou torque de escoamento do que à viscosidade plástica ou viscosidade de torque, o que está de acordo com o estudo desenvolvido por Wallevik (2006). 


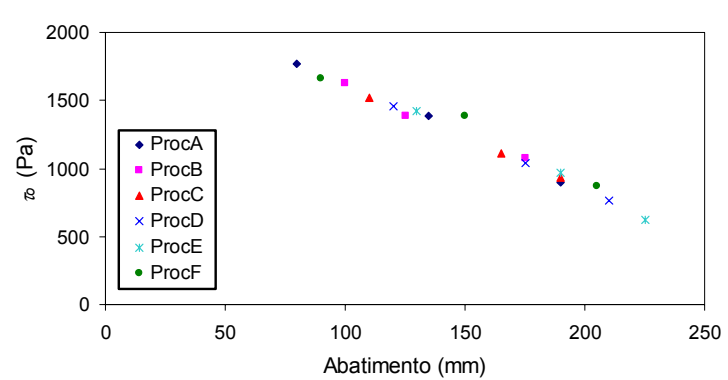

Figura 7.52 - Correlação entre o abatimento de tronco de cone tradicional e a tensão de escoamento (determinada a partir do ensaio de abatimento de tronco de cone modificado) para os MCAD3 produzidos com CPV ARI Plus.

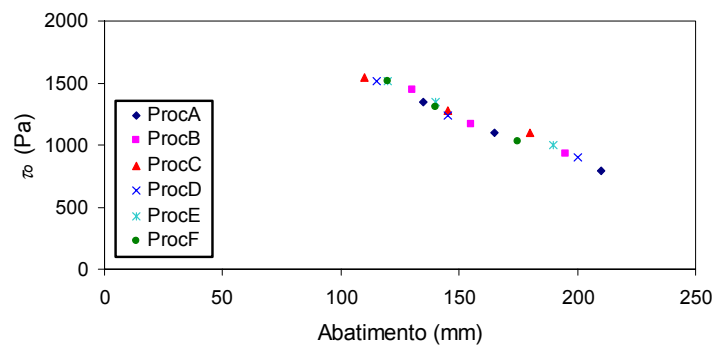

Figura 7.54 - Correlação entre o abatimento de tronco de cone tradicional e a tensão de escoamento (determinada a partir do ensaio de abatimento de tronco de cone modificado) para os MCAD3 produzidos com CPV ARI RS.

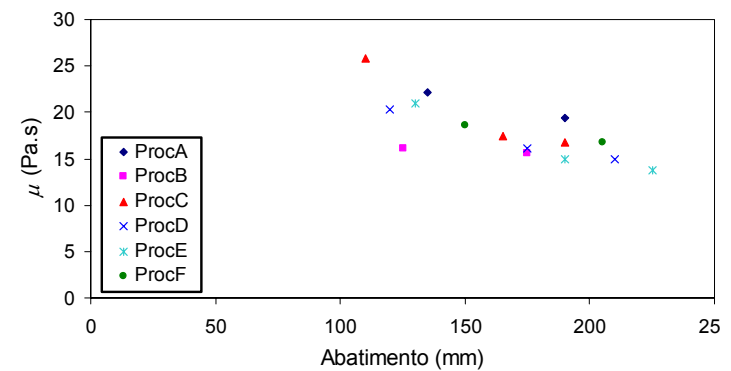

Figura 7.56 - Correlação entre o abatimento de tronco de cone tradicional e a viscosidade plástica (determinada a partir do ensaio de abatimento de tronco de cone modificado) para os MCAD3 produzidos com CPV ARI Plus.

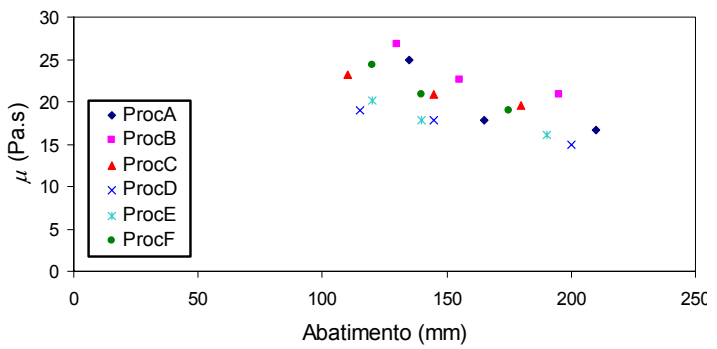

Figura 7.58 - Correlação entre o abatimento de tronco de cone tradicional e a viscosidade plástica (determinada a partir do ensaio de abatimento de tronco de cone

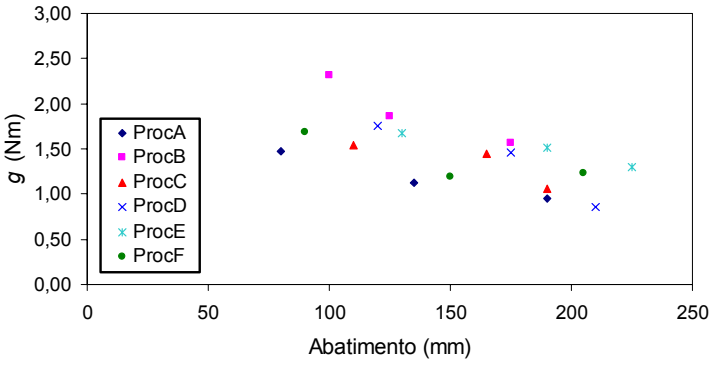

Figura 7.53 - Correlação entre o abatimento de tronco de cone tradicional e o torque de escoamento (determinado a partir do ajuste da curva de cisalhamento ao modelo binghamiano) para os MCAD3 produzidos com CPV ARI Plus.

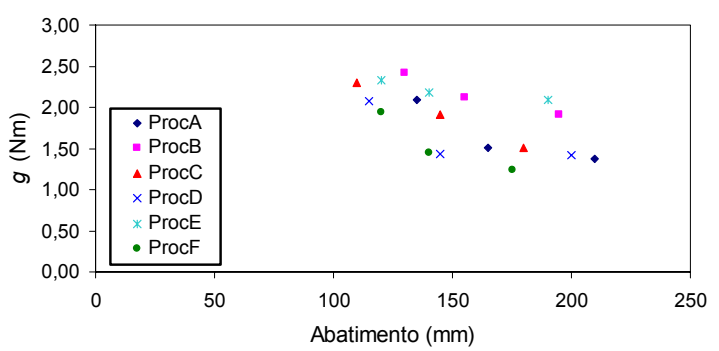

Figura 7.55 - Correlação entre o abatimento de tronco de cone tradicional e o torque de escoamento (determinado a partir do ajuste da curva de cisalhamento ao modelo binghamiano) para os MCAD3 produzidos com CPV ARI RS.

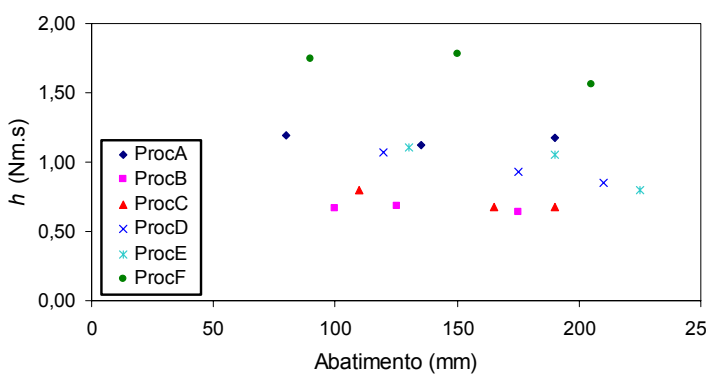

Figura 7.57 - Correlação entre o abatimento de tronco de cone tradicional e a viscosidade de torque (determinada a partir do ajuste da curva de cisalhamento ao modelo binghamiano) para os MCAD3 produzidos com CPV ARI Plus.

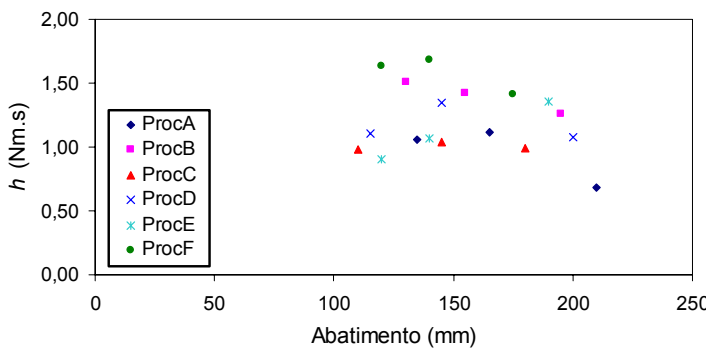

Figura 7.59 - Correlação entre o abatimento de tronco de cone tradicional e a viscosidade de torque (determinada a partir do ajuste da curva de cisalhamento ao modelo 
modificado) para os MCAD3 produzidos com CPV ARI RS. binghamiano) para os MCAD3 produzidos com CPV ARI RS.

\subsubsection{Correlação entre o abatimento, o tempo e os parâmetros reológicos}

Quando uma mistura de concreto é dosada, especialmente para um CAD, não é necessário apenas encontrar as especificações para o seu comportamento reológico inicial, mas também garantir que seu comportamento permaneça estável durante o tempo necessário para o seu lançamento (De LARRARD et al., 1997a). A partir dos comportamentos típicos observados e as interpretações desses comportamentos, um comportamento é considerado estável quando nenhuma mudança significativa dos parâmetros reológicos é observada durante a primeira hora após o contato água-cimento (De LARRARD et al., 1996).

De acordo com os resultados obtidos nessa pesquisa, a evolução dos parâmetros reológicos - determinados tanto pelo ensaio de abatimento de tronco de cone modificado quanto com o auxílio de um reômetro - foi acompanhada por um aumento da tensão de escoamento (ou torque de escoamento), enquanto a viscosidade plástica (ou viscosidade de torque) permaneceu praticamente constante durante o ensaio (menores acréscimos ao longo do tempo).

Nas figuras 7.60, 7.61, 7.62 e 7.63, as evoluções da tensão de escoamento (ou do torque de escoamento) e do abatimento ao longo do tempo são apresentadas em um único gráfico para uma melhor visualização desses comportamentos. Observa-se que, ao longo do tempo, o abatimento diminui, enquanto a tensão de escoamento e o torque de escoamento aumentam. Assim, o processo da perda de trabalhabilidade está relacionado com uma redução do abatimento e um correspondente aumento da tensão de escoamento e do torque de escoamento [WALLEVIK, SAASEN \& GJØRV (1995); PUNKKI, GOLASZEWSKI \& GJ $\varnothing R V$ (1996); De LARRARD et al. (1997a)]. 


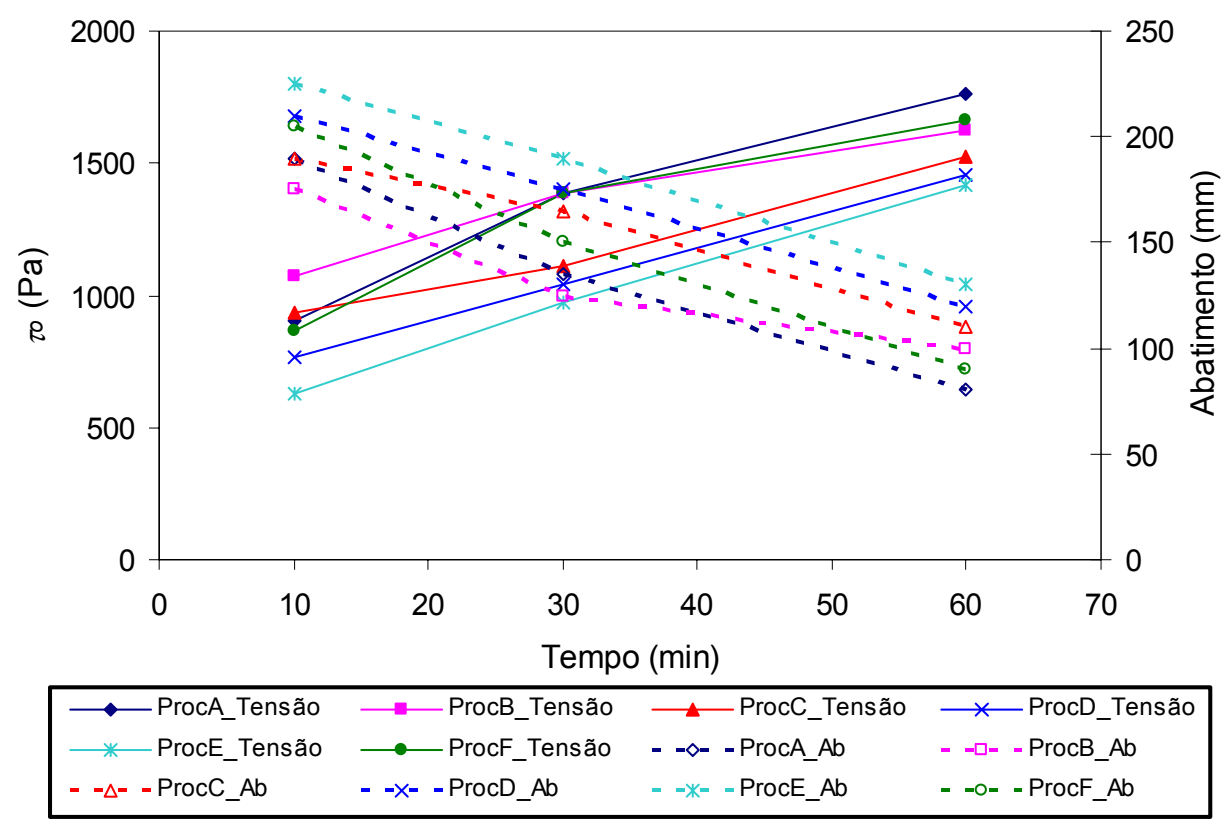

Figura 7.60 - Evolução da tensão de escoamento $\left(\tau_{0}\right)$ e do abatimento $(A b)$ com o tempo para os MCAD3 produzidos com CPV ARI Plus.

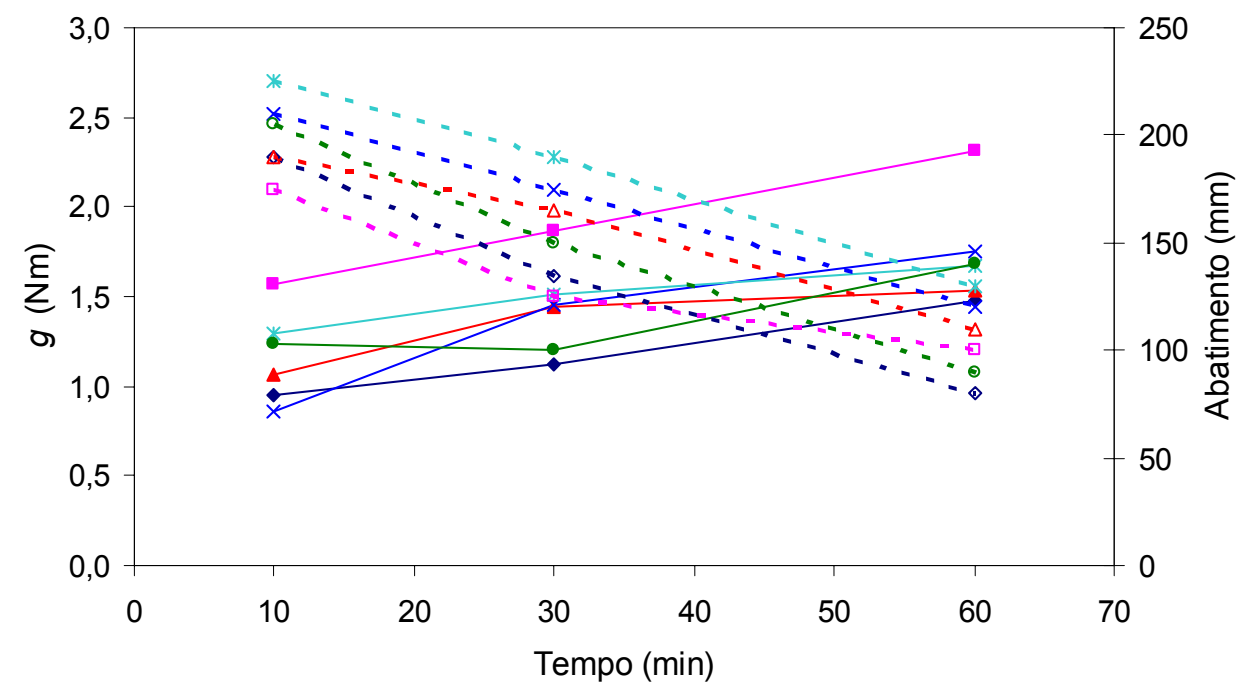

\begin{tabular}{|c|c|c|c|}
\hline$\longrightarrow$ ProcA_g & $\longrightarrow$ ProcB_g & $\longrightarrow$ ProcC_g & $\longrightarrow$ ProcD_g \\
\hline$\longrightarrow$ * ProcE_g & $\longrightarrow$ ProcF_g & - -১- - ProcA_Ab & = -D= - ProcB_Ab \\
\hline$=-\Delta=-$ ProcC_Ab & - -x- - ProcD_Ab & $=-*=-$ ProcE_Ab & - =- - - ProcF_Ab \\
\hline
\end{tabular}

Figura 7.61 - Evolução do torque de escoamento $(g)$ e do abatimento $(A b)$ com o tempo para os MCAD3 produzidos com CPV ARI Plus. 


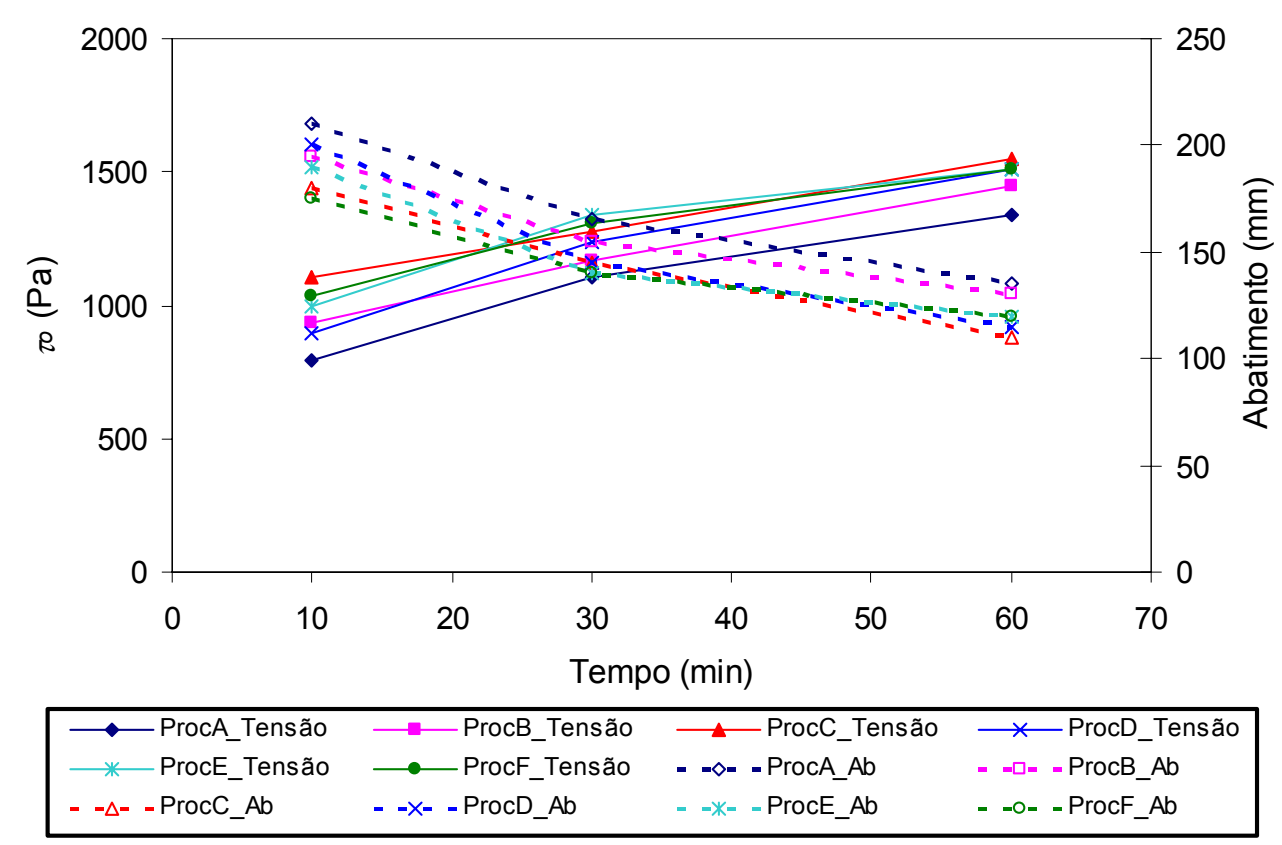

Figura 7.62 - Evolução da tensão de escoamento $\left(\tau_{0}\right)$ e do abatimento (Ab) com o tempo para os MCAD3 produzidos com CPV ARI RS.

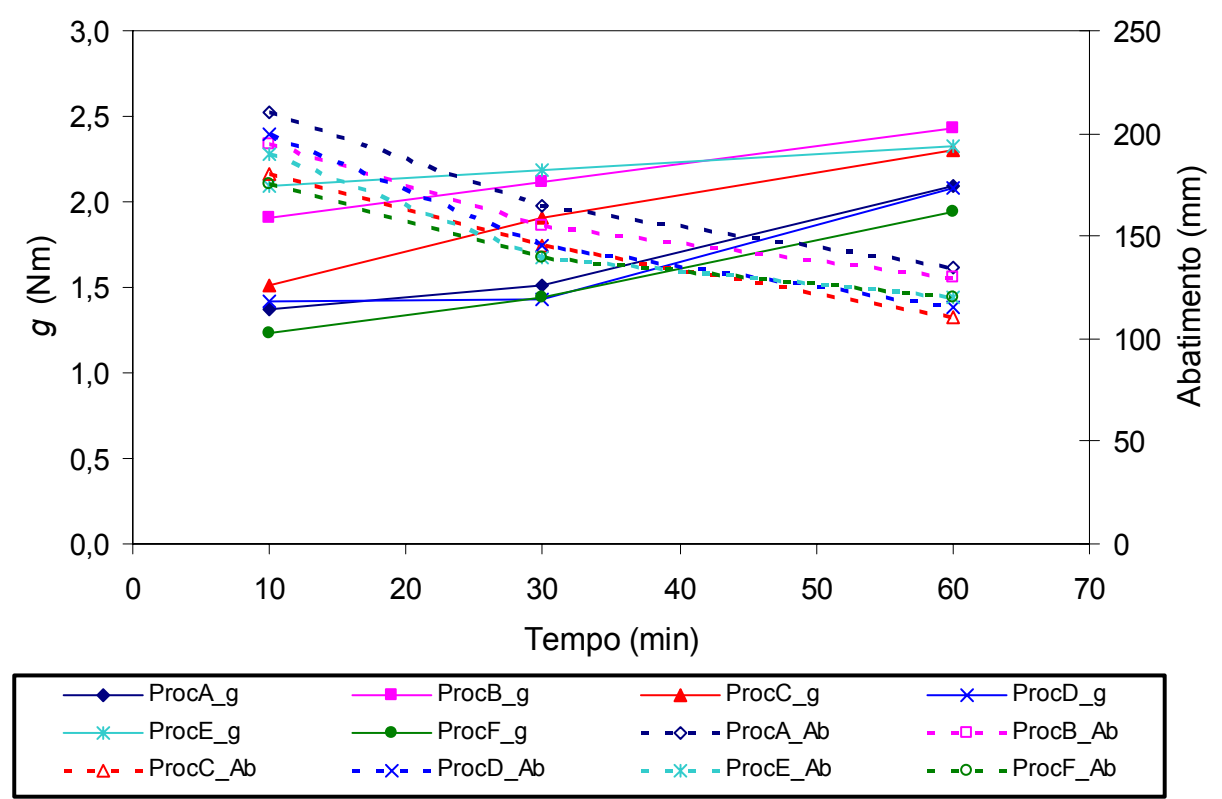

Figura 7.63 - Evolução do torque de escoamento $(g)$ e do abatimento (Ab) com o tempo para os MCAD 3 produzidos com CPV ARI RS.

No caso da viscosidade, tanto a viscosidade plástica quanto a viscosidade de torque determinadas pelo ensaio de abatimento de tronco de cone modificado e pelo reômetro, respectivamente, apresentaram pequenos acréscimos ao longo do tempo, sendo consideradas praticamente constantes durante o período de ensaio (figuras 7.64 e 7.65). Assim, a evolução desses parâmetros resulta em comportamentos semelhantes a outros resultados apresentados na literatura [HU \& De LARRARD (1995); PUNKKI, GOLASZEWSKI \& GJøRV (1996); De LARRARD et al. (1997a); NEHDI, MINDESS \& AÏTCIN (1998); YEN et al. (1999)]. 


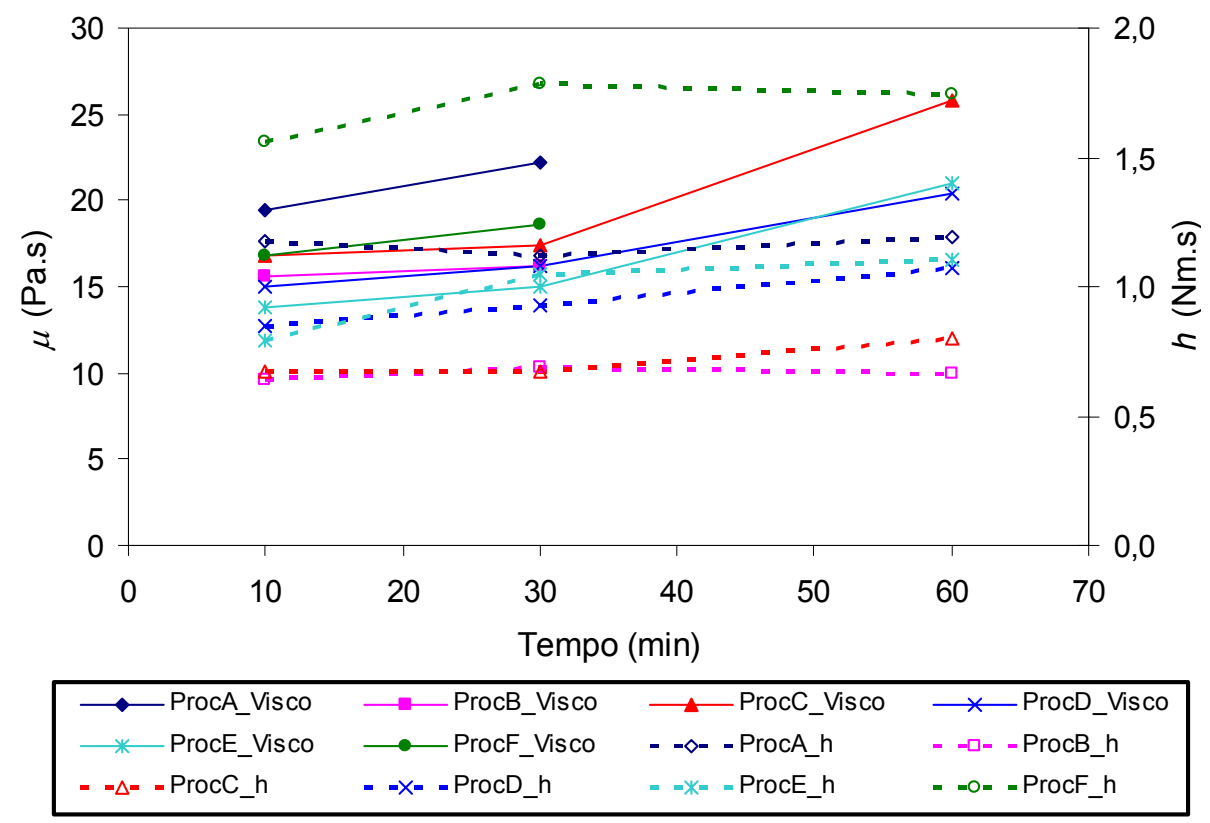

Figura 7.64 - Evolução da viscosidade plástica $(\mu)$ e da viscosidade de torque (h) com o tempo para os MCAD3 produzidos com CPV ARI Plus.

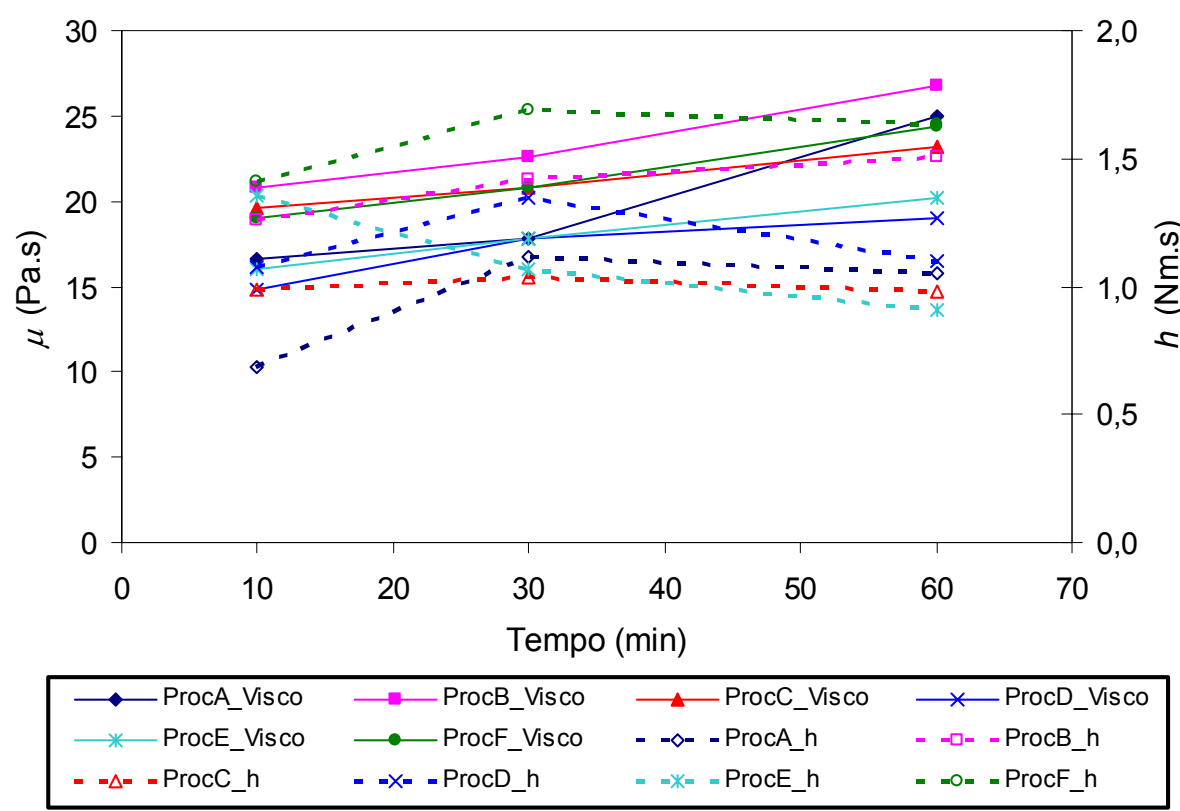

Figura 7.65 - Evolução da viscosidade plástica $(\mu)$ e da viscosidade de torque (h) com o tempo para os MCAD 3 produzidos com CPV ARI RS.

A fluidez desses concretos também foi medida antes e depois dos ciclos de cisalhamento. Os valores dos diâmetros de espalhamento obtidos para os concretos são apresentados na tabela 7.21 e sua evolução com o tempo nas figuras 7.66 e 7.67. A relação entre os valores da fluidez e do torque de escoamento também é apresentada nas figuras 7.66 e 7.67 . 
Tabela 7.21 - Valores da fluidez medida antes e após o ciclo de cisalhamento para os MCAD produzidos com CPV ARI Plus e CPV ARI RS.

\begin{tabular}{|c|c|c|c|c|c|}
\hline \multirow[b]{2}{*}{ Cimento } & \multirow[b]{2}{*}{ Concreto } & \multicolumn{4}{|c|}{ Valores da fluidez: diâmetro médio em [mm] } \\
\hline & & $\begin{array}{c}\text { Antes do } \\
\text { cisalhamento }\end{array}$ & $\begin{array}{l}\text { Após o } 1^{\circ} \\
\text { ciclo }\end{array}$ & $\begin{array}{l}\text { Após o } 2^{\circ} \\
\text { ciclo }\end{array}$ & $\begin{array}{c}\text { Após o } 3^{\circ} \\
\text { ciclo }\end{array}$ \\
\hline \multirow{6}{*}{$\begin{array}{l}\text { CPV ARI } \\
\text { Plus }\end{array}$} & MCAD3/A & 184,8 & 163,1 & 155,3 & 139,3 \\
\hline & MCAD3/B & 186,5 & 167,8 & 164,0 & 152,4 \\
\hline & MCAD3/C & 204,0 & 186,3 & 178,6 & 165,5 \\
\hline & MCAD3/D & 218,8 & 189,7 & 180,7 & 164,0 \\
\hline & MCAD3/E & 217,1 & 185,2 & 177,5 & 167,2 \\
\hline & MCAD3/F & 226,2 & 204,6 & 192,1 & 183,3 \\
\hline \multirow{6}{*}{$\begin{array}{l}\text { CPV ARI } \\
\text { RS }\end{array}$} & MCAD3/A & 204,9 & 186,3 & 178,1 & 167,3 \\
\hline & MCAD3/B & 198,4 & 188,5 & 167,9 & 164,1 \\
\hline & MCAD3/C & 199,5 & 186,7 & 176,8 & 171,0 \\
\hline & MCAD3/D & 199,3 & 181,3 & 172,4 & 160,0 \\
\hline & MCAD3/E & 196,2 & 186,8 & 179,4 & 169,3 \\
\hline & MCAD3/F & 188,8 & 176,3 & 161,7 & 156,6 \\
\hline
\end{tabular}

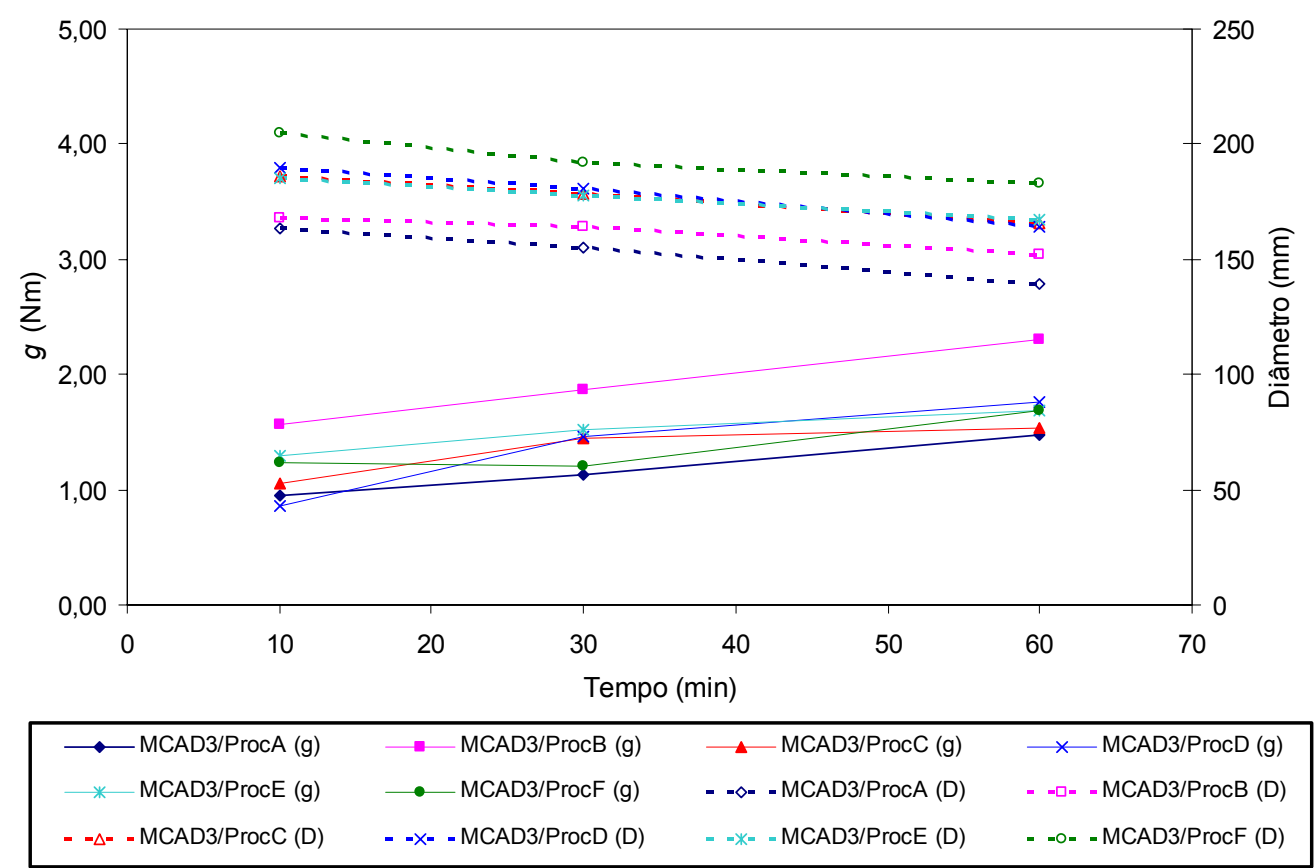

Figura 7.66 - Evolução da fluidez (diâmetro de concreto abatido - D) e do torque de escoamento (g) com o tempo para os MCAD3 produzidos com CPV ARI Plus. 


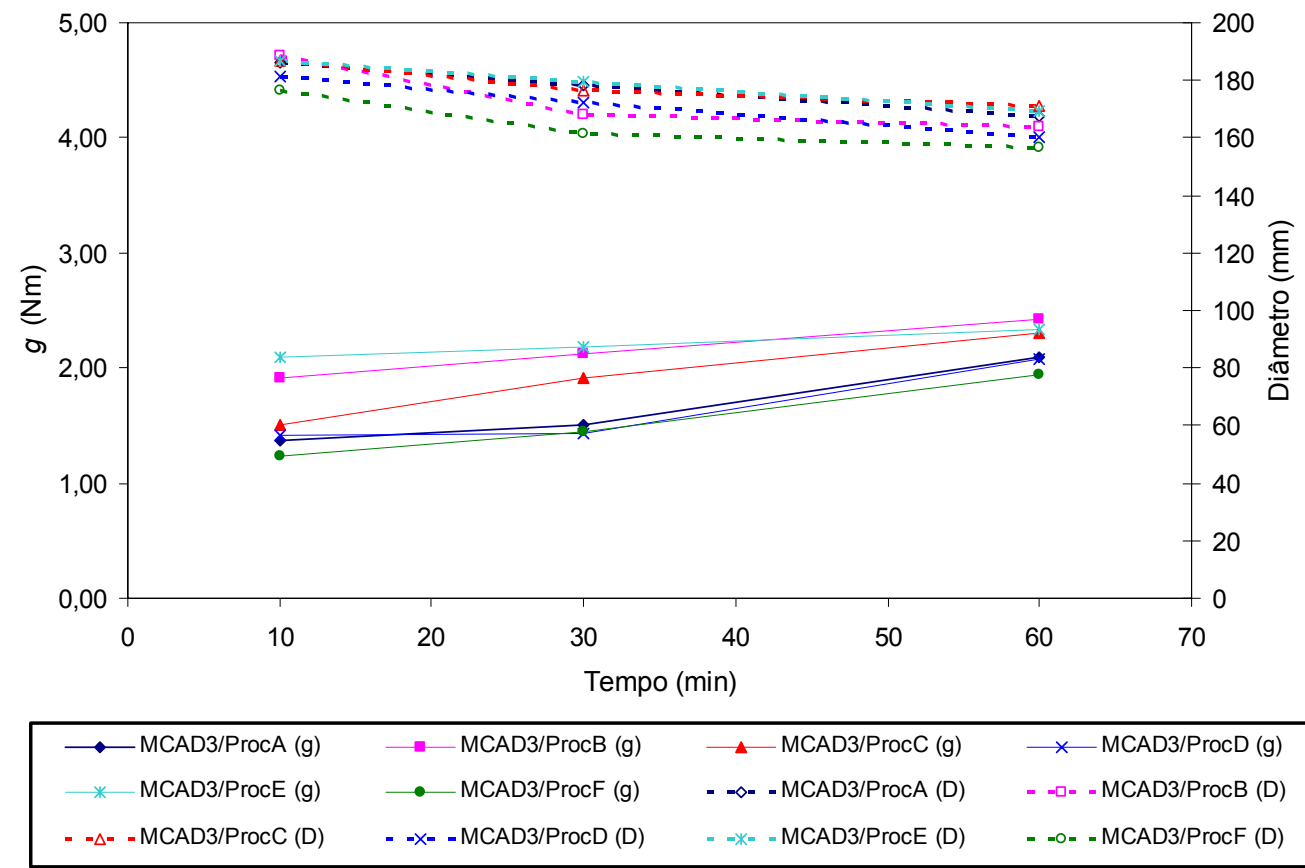

Figura 7.67 - Evolução da fluidez (diâmetro de concreto abatido - D) e do torque de escoamento $(\mathrm{g})$ com o tempo para os MCAD3 produzidos com CPV ARI RS.

Quanto menor o valor do diâmetro de espalhamento obtido para o concreto, menor sua fluidez. Assim, a correlação esperada entre o torque de escoamento e a fluidez dos concretos realmente foi observada, isto é, as misturas com menores diâmetros de espalhamento apresentaram maiores valores de torque de escoamento. Além disso, enquanto o torque de escoamento aumentava com o tempo, o diâmetro de espalhamento de concreto diminuía, indicando redução da fluidez da mistura.

Todas as misturas ensaiadas apresentaram pequenas perdas de fluidez após o ciclo de cisalhamento. Durante os 60 minutos em que o comportamento da mistura foi acompanhado, observou-se uma perda contínua e gradual da fluidez para todas as misturas estudadas (figura 7.68).
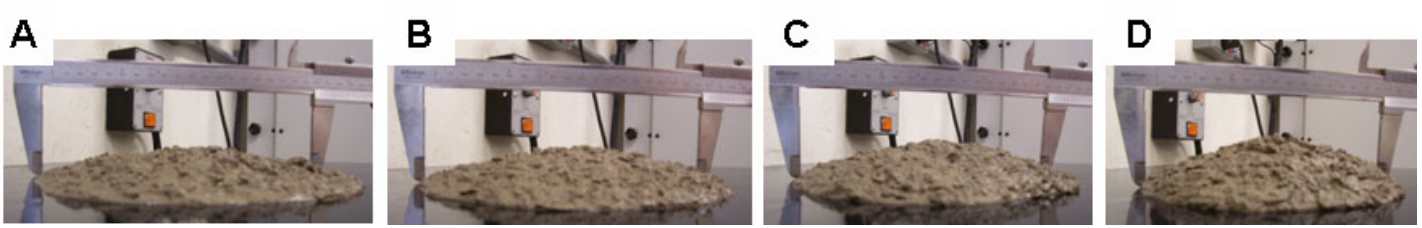

Figura 7.68 - Fotos do ensaio de fluidez ao longo do tempo: $(A)$ antes do cisalhamento (no início do ensaio), (B) após o primeiro, $(C)$ o segundo e $(D)$ o terceiro ciclos de cisalhamento. 


\subsubsection{Influência do misturador}

Um estudo da relação entre a trabalhabilidade e o processo de mistura de um concreto é importante em três aspectos: consideração das exigências de energia em usinas de concreto; possível aplicação para o controle da produção de concreto; e estudo da eficiência de misturadores específicos (TATTERSALL \& BANFILL, 1983).

A escolha de um misturador depende da natureza dos componentes a serem misturados. Em um processo de mistura ideal, o material deve estar isento de aglomerados, cada partícula deve estar envolvida com água e a mistura deve apresentar uma baixa viscosidade. Assim, o grau de uniformidade de um lote de concreto não depende apenas do projeto do misturador empregado na sua produção, mas também do método de incorporação dos vários materiais constituintes da mistura [TATTERSALL \& BANFILL (1983); TATTERSALL (1991b)].

A taxa de cisalhamento aplicada durante a mistura pode variar entre $10 \mathrm{~s}^{-1} \mathrm{e}$ $60 \mathrm{~s}^{-1}$ e constituir uma das variáveis que mais interferem nas propriedades reológicas dos materiais à base de cimento. Além disso, como a energia disponível para o equipamento de mistura diminui desde a produção do concreto (misturador da usina) até o local da construção (caminhão-betoneira), a floculação do material aumentará e sua fluidez diminuirá (ROUSSEL, 2006). Essa ocorrência, no entanto, poderá ser modificada pela complementação da dosagem do concreto (aditivos) em instante muito posterior à mistura inicial - aplicação de aditivo 30 a 40 minutos após o contato da água com o cimento, anteriormente ao lançamento do material.

As misturas de concreto foram produzidas com dois misturadores diferentes, escolhidos em função da demanda de material para a realização de cada ensaio. Para o ensaio de abatimento de tronco de cone modificado, cuja demanda de material é grande (aproximadamente $13 \mathrm{~kg}$ de concreto), as misturas foram produzidas com uma betoneira de eixo inclinado com capacidade nominal de 220 litros e velocidade de rotação constante de 34 RPM (figura 7.69). Para os ensaios com o reômetro, cuja demanda de material é pequena (3,5 $\mathrm{kg}$ de concreto), as amostras de concreto foram produzidas em uma argamassadeira de eixo planetário com capacidade nominal de 8 litros e velocidade de rotação variando entre 60 RPM e 100 RPM (figura 7.70). 


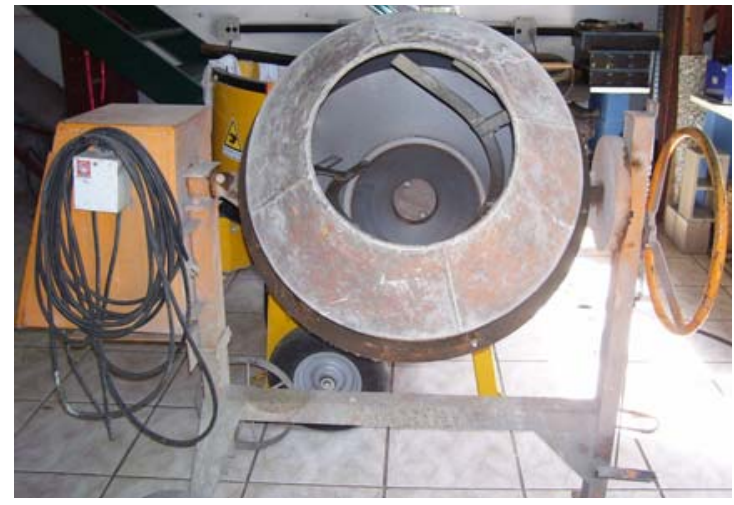

Figura 7.69 - Betoneira de eixo inclinado usada na pesquisa.

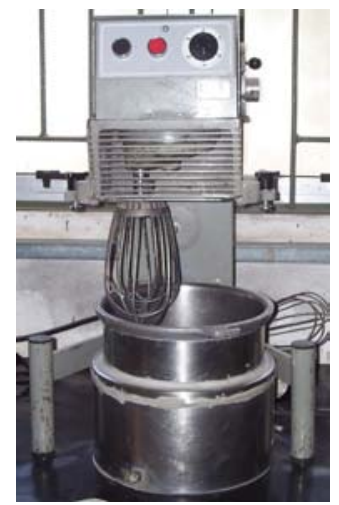

Figura 7.70 - Argamassadeira planetária usada na pesquisa.

Como as propriedades reológicas dos materiais à base de cimento são sensíveis à seqüência e intensidade de mistura, diferenças entre os valores dos parâmetros reológicos determinados a partir dos dois ensaios podem ser observadas, resultando em diferenças quanto à trabalhabilidade e à fluidez das misturas.

Porém, deve-se esperar que os dois métodos de ensaio considerados ensaio de abatimento de tronco de cone modificado e reômetro - classifiquem a tensão de cisalhamento em uma mesma ordem e, semelhantemente, a viscosidade plástica. Em outras palavras, os valores determinados a partir de cada ensaio devem ser o maior ou o menor para a mesma mistura. Assim, para verificar essa correlação, os parâmetros reológicos foram plotados em função de cada mistura (figuras 7.71 e 7.72 ).

A tensão de escoamento e a viscosidade plástica obtidas a partir das equações do ensaio de abatimento de tronco de cone modificado são expressas em unidades do sistema internacional de medidas (SI), ou seja, em Pa e Pa.s, respectivamente. No caso do reômetro, os parâmetros reológicos são dados em unidades de torque, ou seja, $\mathrm{Nm}$ e Nm.s. Apesar de existirem equações que permitem a transformação das unidades de torque em unidades do SI, essa transformação não foi possível no presente trabalho, pois as equações de transformação encontradas na literatura foram desenvolvidas para reômetros de cilindros coaxiais [YEN et al. (1999); WALLEVIK (2006)]. Dessa maneira, os gráficos possuem eixos duplos para garantir que os dados obtidos fossem corretamente representados.

Os gráficos das figuras 7.71 e 7.72 mostram a existência de alguma similaridade entre os resultados obtidos com os dois métodos de ensaio considerados. As correlações encontradas mostram que os valores da tensão de escoamento ou torque de escoamento estão melhor sincronizados entre os dois 
métodos de ensaio do que os valores obtidos para a viscosidade plástica ou viscosidade de torque.

Assim, a influência das diferentes energias de mistura sobre o comportamento reológico de materiais à base de cimento tem que ser estudada em termos qualitativos. Apesar da boa correlação encontrada entre os diversos parâmetros obtidos (abatimento e parâmetros reológicos), comportamentos diferentes foram observados para as misturas produzidas com os dois misturadores, ou seja, para cada ensaio, um procedimento de mistura diferente se mostrou mais adequado. Como exemplo, citam-se as misturas produzidas com CPV ARI Plus: de acordo com o ensaio de abatimento de tronco de cone modificado, o melhor desempenho - com relação à evolução dos parâmetros reológicos - foi observado para a mistura produzida de acordo com o procedimento $\mathrm{E}$, enquanto que o melhor desempenho das misturas avaliadas com o reômetro foi observado para o concreto produzido de acordo com o procedimento A. A mesma variação dos desempenhos entre os parâmetros determinados para cada ensaio também foi verificada para as misturas produzidas com CPV ARI RS.

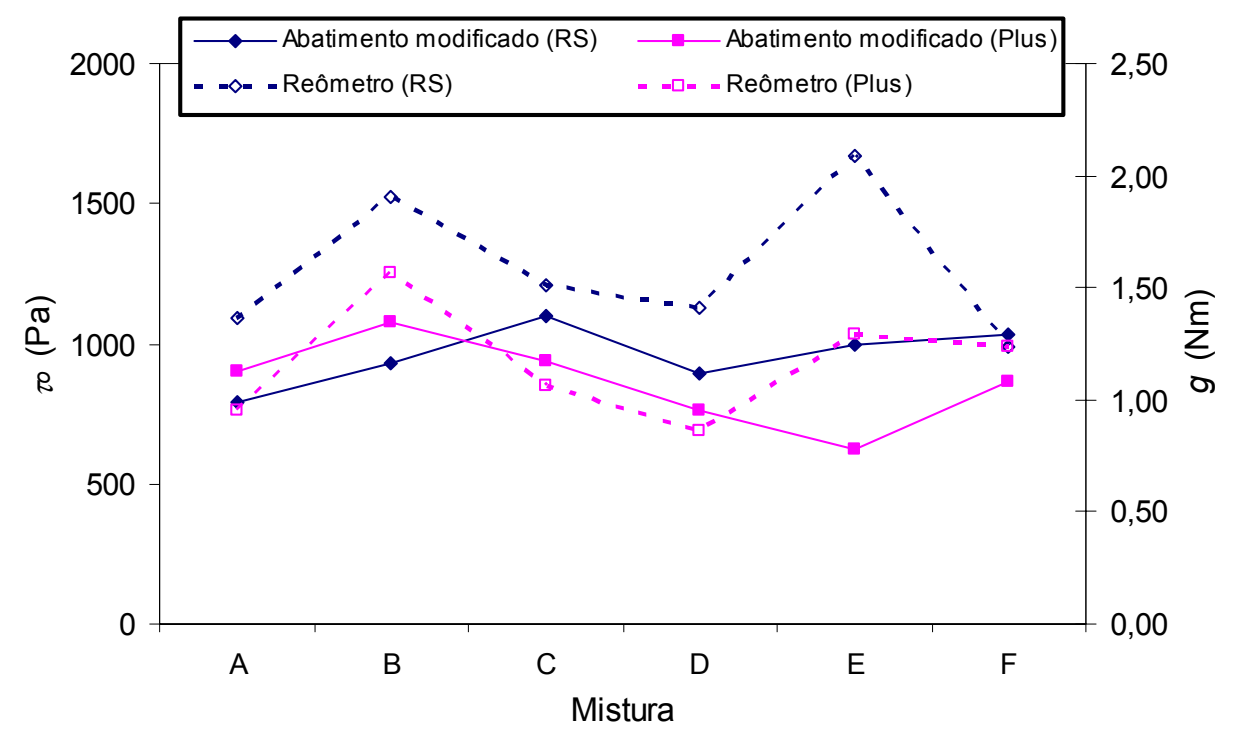

Figura 7.71 - Comparação da tensão de escoamento e do torque de escoamento medidos a partir dos métodos de ensaio considerados para cada mistura. 


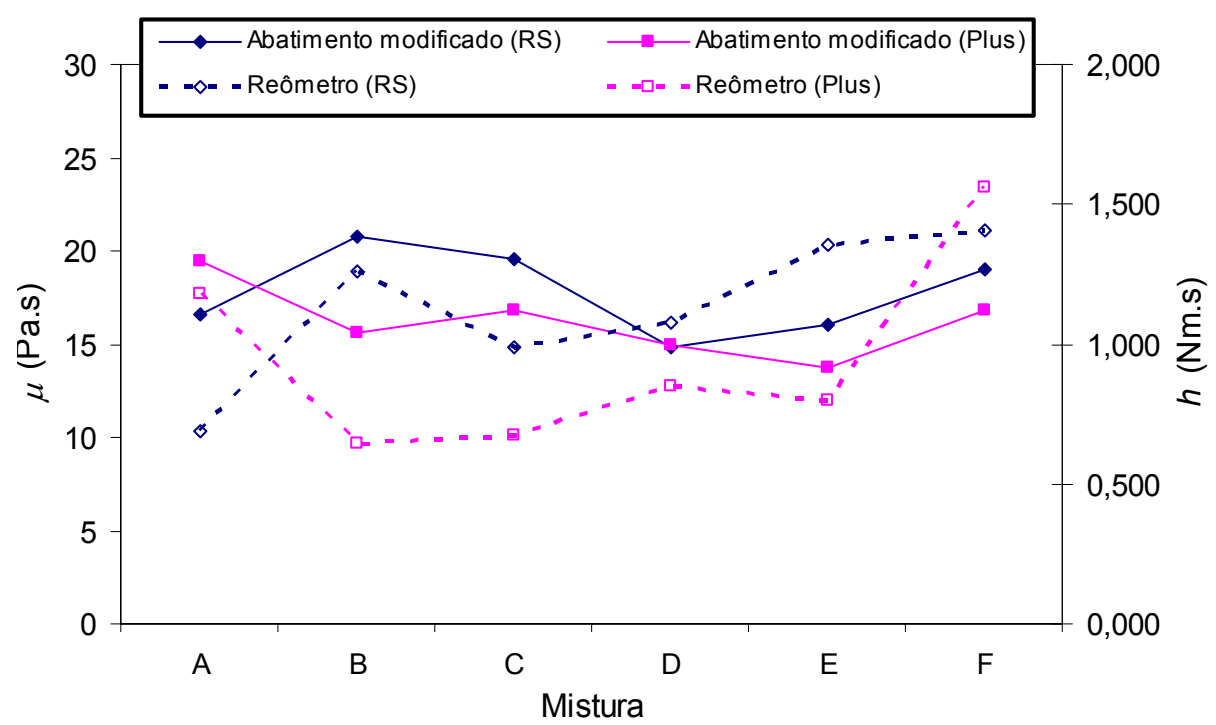

Figura 7.72 - Comparação da viscosidade plástica e da viscosidade de torque medidas a partir dos métodos de ensaio considerados para cada mistura.

A maioria das influências importantes sobre a trabalhabilidade do concreto fresco tem sido investigada através de ensaios em laboratório. Assim, as influências mais evidentes encontradas por meio dos ensaios de laboratório devem ser compensadas durante a produção na usina. Porém, dentre as condições de contorno comparáveis entre uma usina de concreto e um laboratório, a correlação dos processos de mistura do material não é possível para as duas situações (RESTORFF, 1990).

$\mathrm{Na}$ prática, durante o transporte do concreto fresco em um caminhãobetoneira, a pasta de cimento está sendo constantemente misturada pelos agregados. Assim, as propriedades de escoamento e a microestrutura de uma pasta de cimento em campo são bem diferentes das propriedades de uma pasta produzida em laboratório com o auxílio de uma argamassadeira (YANG \& JENNINGS, 1995). Além disso, nenhum dos reômetros disponíveis para ensaios em laboratório é capaz de quebrar completamente o estado de floculação do material após um período de repouso e devolvê-lo ao seu estado de floculação em um misturador, uma vez que a taxa de cisalhamento máxima que eles podem aplicar no material é sempre menor que a taxa de cisalhamento durante o processo de mistura; isso significa que o comportamento reológico observado imediatamente após a mistura não será medido novamente caso a amostra permaneça no reômetro entre as determinações (ROUSSEL, 2006). Assim, como uma grande parte dos procedimentos de mistura empregados na produção de pastas de cimento em laboratório segue, na maioria das vezes, seqüências normalizadas, 
deve-se tomar cuidado quando aplicar os resultados obtidos em laboratório no campo.

\subsubsection{Comparação do comportamento dos concretos produzidos com os diferentes procedimentos de mistura}

Durante a análise dos resultados obtidos na fase de desenvolvimento do estudo experimental sobre a reologia dos concretos de alto desempenho, observouse que, para cada fator analisado, um procedimento de mistura se adequava melhor. Além disso, o tempo no qual o ensaio foi desenvolvido se mostrou muito importante em relação ao tempo no qual a mistura foi executada e o tempo no qual ela seria utilizada.

O comportamento do concreto foi avaliado considerando-se o período compreendido desde a mistura até o lançamento do material na prática das construções, o que normalmente corresponde a um intervalo de até 40 minutos. Assim, foram considerados dois períodos: desde a mistura até 30 minutos e até 60 minutos, correlacionando as avaliações com situações reais no campo.

Para isso, os dados obtidos relacionados com a avaliação do comportamento do concreto foram reunidos em tabelas e, na seqüência, foram distribuídos pontos para cada fator avaliado. Cada método de ensaio foi considerado separadamente para verificar se o melhor desempenho geral seria obtido com o mesmo procedimento de mistura. A distribuição de pontos foi feita de acordo com o seguinte critério: quanto melhor 0 desempenho do material para 0 fator considerado, maior sua pontuação. Dessa maneira, a maior somatória dos pontos distribuídos corresponde à mistura que, produzida de acordo com o procedimento de mistura considerado, apresenta o melhor desempenho em termos de comportamento no estado fresco segundo avaliação por meio de ensaios reológicos.

Os fatores considerados para a pontuação são:

- o abatimento inicial e sua perda ao longo do período considerado;

- o tempo Ve-Be e seu acréscimo ao longo do período considerado;

- a tensão de escoamento e seu acréscimo ao longo do período considerado;

- a viscosidade plástica e seu acréscimo ao longo do período considerado;

- o torque de escoamento e seu acréscimo ao longo do período considerado;

- o torque máximo para o momento considerado no lançamento do material (30 ou 60 minutos); 
- a viscosidade de torque e seu acréscimo ao longo do período considerado;

- a área de histerese produzida durante o ensaio de cisalhamento em escada para o momento considerado no lançamento do material (30 ou 60 minutos);

- o tempo de trabalhabilidade para cada mistura, determinado pelo ensaio de cisalhamento contínuo ao longo do tempo.

Serão consideradas apenas as misturas de alto desempenho propriamente ditas, ou seja, aquelas incorporadas com ambas as adições químicas e minerais (série MCAD3) para avaliação da influência do procedimento de mistura sobre as propriedades reológicas desses materiais no estado fresco.

Para o ensaio de abatimento de tronco de cone modificado e demais fatores relacionados com esse ensaio - abatimento, tempo Ve-Be, tensão de escoamento e viscosidade plástica (tabela 7.22), pode-se verificar que as misturas produzidas com CPV ARI Plus e CPV ARI RS e de acordo com os procedimentos de mistura $E$ e $A$, respectivamente, apresentaram os melhores desempenhos em termos de trabalhabilidade e perda dessa trabalhabilidade para o período de 30 minutos compreendido entre o processo de mistura e o "lançamento" do material (maiores pontuações - tabela 7.23). Esses mesmos procedimentos também resultaram em misturas com os melhores desempenhos para o período de 60 minutos, considerando-se os mesmos fatores e método de ensaio (tabelas 7.26 e 7.27).

Com a utilização de um reômetro para a caracterização e avaliação da trabalhabilidade dessas misturas com uma maior precisão, as misturas produzidas com CPV ARI Plus e CPV ARI RS e de acordo com os procedimentos de mistura C e $A$, respectivamente, apresentaram os melhores desempenhos com relação à trabalhabilidade e sua perda ao longo do tempo, ou seja, as misturas produzidas de acordo com esses procedimentos de mistura apresentaram as maiores pontuações dos fatores relacionados com esse método de ensaio - abatimento, tempo Ve-Be, torque de escoamento, viscosidade de torque, torque máximo, área de histerese da curva de cisalhamento e tempo de trabalhabilidade (tabelas 7.24 e 7.25), considerando-se um período de 30 minutos entre a mistura e o "lançamento" do material. Para um intervalo de 60 minutos entre esses processos, os melhores desempenhos foram verificados para as misturas produzidas de acordo com os procedimentos E e A para o CPV ARI Plus e o CPV ARI RS, respectivamente, considerando-se os mesmos fatores e método de ensaio (tabelas 7.28 e 7.29).

Com exceção dos resultados obtidos para as misturas produzidas com CPV ARI Plus a partir de um reômetro no intervalo de 30 minutos entre a mistura e o "lançamento" do material, os outros melhores desempenhos foram obtidos paras as 
misturas produzidas com os mesmos procedimentos de mistura, considerando-se cada tipo de cimento utilizado, independente do período compreendido entre o processo de mistura e o "lançamento" do material. Em outras palavras, para um determinado tipo de cimento, as misturas produzidas de acordo com um determinado procedimento apresentaram os melhores desempenhos em termos de trabalhabilidade, independente do método de ensaio empregado e, consequentemente, dos fatores relacionados com cada um deles, assim como do período compreendido entre o processo de mistura e o "lançamento" do material.

Vale observar que os procedimentos que resultaram nas misturas com os melhores desempenhos variaram entre os dois tipos de cimento considerados. Para o CPV ARI Plus, a saturação inicial dos agregados e a incorporação do SP junto com a água de amassamento (funcionando apenas como um plastificante) procedimento E - resultaram na mistura com o melhor desempenho da trabalhabilidade ao longo do tempo. Já para o CPV ARI RS, o melhor desempenho foi verificado para as misturas produzidas de acordo com procedimento $A$, onde o SP foi adicionado no final do processo de mistura.

Assim, apesar dos dois métodos de ensaio utilizados fornecerem dados em unidades diferentes, os resultados obtidos mostraram uma boa correlação entre os parâmetros medidos, além de um desempenho semelhante entre as misturas avaliadas. 
Tabela 7.22 - Valores dos fatores considerados na avaliação do comportamento dos MCAD a partir do ensaio de abatimento de tronco de cone modificado (para um intervalo de 30 minutos entre a mistura e o lançamento do material).

\begin{tabular}{|c|c|c|c|c|c|c|c|c|c|c|c|c|c|}
\hline \multicolumn{2}{|c|}{ Cimento } & \multirow{2}{*}{\multicolumn{6}{|c|}{$\begin{array}{c}\text { CPV ARI Plus } \\
\text { Procedimento de mistura }\end{array}$}} & \multirow{2}{*}{\multicolumn{6}{|c|}{$\frac{\text { CPV ARI RS }}{\text { Procedimento de mistura }}$}} \\
\hline \multirow{2}{*}{$\begin{array}{c}\text { Fator } \\
\text { considerado }\end{array}$} & \multirow{2}{*}{ Unidade } & & & & & & & & & & & & \\
\hline & & A & B & C & D & $E$ & $\mathbf{F}$ & A & B & C & D & $E$ & $\mathbf{F}$ \\
\hline $\begin{array}{l}\text { Abatimento } \\
\text { inicial }\end{array}$ & $\mathrm{mm}$ & 190 & 175 & 190 & 210 & 225 & 205 & 210 & 195 & 180 & 200 & 190 & 175 \\
\hline $\begin{array}{l}\text { Variação do } \\
\text { abatimento }\end{array}$ & $\%$ & -29 & -29 & -13 & -17 & -16 & -27 & -21 & -21 & -19 & -28 & -26 & -20 \\
\hline Tempo Ve-Be & $\mathrm{s}$ & 3,03 & 3,77 & 2,89 & 2,81 & 2,66 & 2,51 & 2,63 & 2,70 & 2,59 & 2,27 & 2,57 & 2,32 \\
\hline $\begin{array}{l}\text { Variação do } \\
\text { tempo Ve-Be }\end{array}$ & $\%$ & +42 & +6 & +6 & +18 & +9 & +13 & +3 & +6 & +3 & +7 & +2 & +5 \\
\hline $\begin{array}{l}\text { Tensão de } \\
\text { escoamento }\end{array}$ & $\mathrm{Pa}$ & 902,20 & 1074,75 & 936,71 & 764,16 & 626,12 & 867,69 & 794,26 & 931,27 & 1102,52 & 897,01 & 999,77 & 1034,02 \\
\hline $\begin{array}{c}\text { Variação da } \\
\text { tensão de } \\
\text { escoamento }\end{array}$ & $\%$ & +54 & +29 & +18 & +36 & +55 & +60 & +39 & +26 & +16 & +38 & +34 & +26 \\
\hline $\begin{array}{l}\text { Viscosidade } \\
\text { plástica }\end{array}$ & Pa.s & 19,40 & 15,57 & 16,77 & 14,97 & 13,77 & 16,77 & 16,64 & 20,80 & 19,61 & 14,86 & 16,04 & 19,02 \\
\hline $\begin{array}{c}\text { Variação da } \\
\text { viscosidade } \\
\text { plástica }\end{array}$ & $\%$ & +14 & +4 & +4 & +8 & +9 & +11 & +7 & +9 & +6 & +20 & +11 & +9 \\
\hline
\end{tabular}

Obs.: sinal (+) indica aumento do valor do parâmetro para o período considerado; sinal (-) indica redução do valor do parâmetro para o período considerado. 
Tabela 7.23 - Pontuação dos fatores considerados na avaliação do comportamento dos MCAD a partir do ensaio de abatimento de tronco de cone modificado (para um intervalo de 30 minutos entre a mistura e o lançamento do material).

\begin{tabular}{|c|c|c|c|c|c|c|c|c|c|c|c|c|c|}
\hline \multicolumn{2}{|l|}{ Cimento } & \multirow{2}{*}{\multicolumn{6}{|c|}{$\frac{\text { CPV ARI Plus }}{\text { Procedimento de mistura }}$}} & \multirow{2}{*}{\multicolumn{6}{|c|}{$\frac{\text { CPV ARI RS }}{\text { Procedimento de mistura }}$}} \\
\hline \multirow{2}{*}{ Fator considerado } & \multirow{2}{*}{ Unidade } & & & & & & & & & & & & \\
\hline & & A & B & C & D & $\mathbf{E}$ & $\mathbf{F}$ & A & B & C & D & $\mathbf{E}$ & $\mathbf{F}$ \\
\hline Abatimento inicial & $\mathrm{mm}$ & 2 & 1 & 2 & 5 & 6 & 4 & 6 & 4 & 2 & 5 & 3 & 1 \\
\hline Variação do abatimento & $\%$ & 1 & 1 & 6 & 4 & 5 & 3 & 3 & 3 & 6 & 1 & 2 & 5 \\
\hline Tempo Ve-Be & $\mathrm{s}$ & 2 & 1 & 3 & 4 & 5 & 6 & 2 & 1 & 3 & 6 & 4 & 5 \\
\hline Variação do tempo Ve-Be & $\%$ & 1 & 5 & 5 & 2 & 4 & 3 & 4 & 2 & 4 & 1 & 6 & 3 \\
\hline Tensão de escoamento & $\mathrm{Pa}$ & 3 & 1 & 2 & 5 & 6 & 4 & 6 & 4 & 1 & 5 & 3 & 2 \\
\hline Variação da tensão de escoamento & $\%$ & 3 & 5 & 6 & 4 & 2 & 1 & 1 & 4 & 6 & 2 & 3 & 4 \\
\hline Viscosidade plástica & Pa.s & 1 & 4 & 2 & 5 & 6 & 2 & 4 & 1 & 2 & 6 & 5 & 3 \\
\hline Variação da viscosidade plástica & $\%$ & 1 & 5 & 5 & 4 & 3 & 2 & 5 & 3 & 6 & 1 & 2 & 3 \\
\hline PONTL & O TOTAL & 14 & 23 & 31 & 33 & 37 & 25 & 31 & 22 & 30 & 27 & 28 & 26 \\
\hline
\end{tabular}


Tabela 7.24 - Valores dos fatores considerados na avaliação do comportamento dos MCAD a partir do reômetro (para um intervalo de 30 minutos entre a mistura e o lançamento do material).

\begin{tabular}{|c|c|c|c|c|c|c|c|c|c|c|c|c|c|}
\hline \multicolumn{2}{|l|}{ Cimento } & \multirow{2}{*}{\multicolumn{6}{|c|}{$\frac{\text { CPV ARI Plus }}{\text { Procedimento de mistura }}$}} & \multirow{2}{*}{\multicolumn{6}{|c|}{$\frac{\text { CPV ARI RS }}{\text { Procedimento de mistura }}$}} \\
\hline \multirow{2}{*}{ Fator considerado } & \multirow{2}{*}{ Unidade } & & & & & & & & & & & & \\
\hline & & A & B & C & D & $\mathbf{E}$ & $\mathbf{F}$ & A & B & C & D & $\mathbf{E}$ & $\mathbf{F}$ \\
\hline Abatimento inicial & $\mathrm{mm}$ & 190 & 175 & 190 & 210 & 225 & 205 & 210 & 195 & 180 & 200 & 190 & 175 \\
\hline Variação do abatimento & $\%$ & -29 & -29 & -13 & -17 & -16 & -27 & -21 & -21 & -19 & -28 & -26 & -20 \\
\hline Tempo Ve-Be & s & 3,03 & 3,77 & 2,89 & 2,81 & 2,66 & 2,51 & 2,63 & 2,70 & 2,59 & 2,27 & 2,57 & 2,32 \\
\hline $\begin{array}{l}\text { Variação do tempo Ve- } \\
\qquad \mathrm{Be}^{-}\end{array}$ & $\%$ & +42 & +6 & +6 & +18 & +9 & +13 & +3 & +6 & +3 & +7 & +2 & +5 \\
\hline Torque de escoamento & $\mathrm{Nm}$ & 0,95 & 1,57 & 1,06 & 0,86 & 1,29 & 1,24 & 1,37 & 1,91 & 1,51 & 1,41 & 2,09 & 1,24 \\
\hline $\begin{array}{c}\text { Variação do torque de } \\
\text { escoamento }\end{array}$ & $\%$ & +18 & +19 & +36 & +69 & +17 & -3 & +10 & +11 & +26 & +1 & +4 & +17 \\
\hline Viscosidade de torque & Nm.s & 1,179 & 0,643 & 0,672 & 0,850 & 0,795 & 1,561 & 0,685 & 1,262 & 0,990 & 1,076 & 1,354 & 1,409 \\
\hline $\begin{array}{c}\text { Variação da } \\
\text { viscosidade de torque }\end{array}$ & $\%$ & -5 & +7 & 0 & +9 & +32 & +14 & +63 & +13 & +5 & +25 & -21 & +20 \\
\hline Torque máximo & $\mathrm{Nm}$ & 2,71 & 2,81 & 2,46 & 2,67 & 2,86 & 3,45 & 3,20 & 3,90 & 3,22 & 3,35 & 3,53 & 3,59 \\
\hline Área de histerese & Nm.RPS & 0,689 & 1,084 & 1,060 & 1,083 & 1,131 & 1,020 & 0,758 & 0,837 & 0,842 & 0,738 & 0,973 & 0,634 \\
\hline $\begin{array}{c}\text { Tempo de } \\
\text { trabalhabilidade }\end{array}$ & $S$ & 5382 & 3819 & 4948 & 5576 & 6405 & 6493 & 5895 & 5157 & 6155 & 5655 & 6884 & 5731 \\
\hline
\end{tabular}

Obs.: sinal (+) indica aumento do valor do parâmetro para o período considerado;

sinal (-) indica redução do valor do parâmetro para o período considerado. 
Tabela 7.25 - Pontuação dos fatores considerados na avaliação do comportamento dos MCAD a partir do reômetro (para um intervalo de 30 minutos entre a mistura e o lançamento do material).

\begin{tabular}{|c|c|c|c|c|c|c|c|c|c|c|c|c|c|}
\hline \multicolumn{2}{|l|}{ Cimento } & \multirow{2}{*}{\multicolumn{6}{|c|}{$\begin{array}{c}\text { CPV ARI Plus } \\
\text { Procedimento de mistura }\end{array}$}} & \multirow{2}{*}{\multicolumn{6}{|c|}{$\frac{\text { CPV ARI RS }}{\text { Procedimento de mistura }}$}} \\
\hline \multirow{2}{*}{ Fator considerado } & \multirow{2}{*}{ Unidade } & & & & & & & & & & & & \\
\hline & & A & B & C & D & $\mathbf{E}$ & $\mathbf{F}$ & A & B & C & D & $\mathbf{E}$ & $\mathbf{F}$ \\
\hline Abatimento inicial & $\mathrm{mm}$ & 2 & 1 & 2 & 5 & 6 & 4 & 6 & 4 & 2 & 5 & 3 & 1 \\
\hline Variação do abatimento & $\%$ & 1 & 1 & 6 & 4 & 5 & 3 & 3 & 3 & 6 & 1 & 2 & 5 \\
\hline Tempo Ve-Be & $\mathrm{s}$ & 2 & 1 & 3 & 4 & 5 & 6 & 2 & 1 & 3 & 6 & 4 & 5 \\
\hline Variação do tempo Ve-Be & $\%$ & 1 & 5 & 5 & 2 & 4 & 3 & 4 & 2 & 4 & 1 & 6 & 3 \\
\hline Torque de escoamento & $\mathrm{Nm}$ & 5 & 1 & 4 & 6 & 2 & 3 & 5 & 2 & 3 & 4 & 1 & 6 \\
\hline Variação do torque de escoamento & $\%$ & 4 & 3 & 2 & 1 & 5 & 6 & 4 & 3 & 1 & 6 & 5 & 2 \\
\hline Viscosidade de torque & Nm.s & 2 & 6 & 5 & 3 & 4 & 1 & 6 & 3 & 5 & 4 & 2 & 1 \\
\hline Variação da viscosidade de torque & $\%$ & 6 & 4 & 5 & 3 & 1 & 2 & 1 & 4 & 5 & 2 & 6 & 3 \\
\hline Torque máximo & $\mathrm{Nm}$ & 4 & 3 & 6 & 5 & 2 & 1 & 6 & 1 & 5 & 4 & 3 & 2 \\
\hline Área de histerese & Nm.RPS & 6 & 2 & 4 & 3 & 1 & 5 & 4 & 3 & 2 & 5 & 1 & 6 \\
\hline Tempo de trabalhabilidade & $\mathrm{s}$ & 3 & 1 & 2 & 4 & 5 & 6 & 4 & 1 & 5 & 2 & 6 & 3 \\
\hline & ÇÃO TOTAL & 36 & 28 & 44 & 40 & 40 & 40 & 45 & 27 & 41 & 40 & 39 & 37 \\
\hline
\end{tabular}


Tabela 7.26 - Valores dos fatores considerados na avaliação do comportamento dos MCAD a partir do ensaio de abatimento de tronco de cone modificado (para um intervalo de 60 minutos entre a mistura e o lançamento do material).

\begin{tabular}{|c|c|c|c|c|c|c|c|c|c|c|c|c|c|}
\hline \multicolumn{2}{|c|}{ Cimento } & \multirow{2}{*}{\multicolumn{6}{|c|}{$\frac{\text { CPV ARI Plus }}{\text { Procedimento de mistura }}$}} & \multirow{2}{*}{\multicolumn{6}{|c|}{$\begin{array}{c}\text { CPV ARI RS } \\
\text { Procedimento de mistura }\end{array}$}} \\
\hline \multirow{2}{*}{$\begin{array}{c}\text { Fator } \\
\text { considerado }\end{array}$} & \multirow{2}{*}{ Unidade } & & & & & & & & & & & & \\
\hline & & A & B & C & D & $E$ & $F$ & A & B & C & D & $\mathbf{E}$ & $\mathbf{F}$ \\
\hline $\begin{array}{l}\text { Abatimento } \\
\text { inicial }\end{array}$ & $\mathrm{mm}$ & 190 & 175 & 190 & 210 & 225 & 205 & 210 & 195 & 180 & 200 & 190 & 175 \\
\hline $\begin{array}{l}\text { Variação do } \\
\text { abatimento }\end{array}$ & $\%$ & -58 & -43 & -42 & -43 & -42 & -56 & -36 & -33 & -39 & -43 & -37 & -31 \\
\hline Tempo Ve-Be & $\mathrm{s}$ & 3,03 & 3,77 & 2,89 & 2,81 & 2,66 & 2,51 & 2,63 & 2,70 & 2,59 & 2,27 & 2,57 & 2,32 \\
\hline $\begin{array}{l}\text { Variação do } \\
\text { tempo Ve-Be }\end{array}$ & $\%$ & +59 & +8 & +34 & +32 & +14 & +48 & +11 & +10 & +13 & +26 & +13 & +13 \\
\hline $\begin{array}{l}\text { Tensão de } \\
\text { escoamento }\end{array}$ & $\mathrm{Pa}$ & 902,20 & 1074,75 & 936,71 & 764,16 & 626,12 & 867,69 & 794,26 & 931,27 & 1102,52 & 897,01 & 999,77 & 1034,02 \\
\hline $\begin{array}{c}\text { Variação da } \\
\text { tensão de } \\
\text { escoamento }\end{array}$ & $\%$ & +96 & +51 & +63 & +90 & +127 & +91 & +69 & +55 & +40 & +69 & +51 & +46 \\
\hline $\begin{array}{l}\text { Viscosidade } \\
\text { plástica }\end{array}$ & Pa.s & 19,40 & 15,57 & 16,77 & 14,97 & 13,77 & 16,77 & 16,64 & 20,80 & 19,61 & 14,86 & 16,04 & 19,02 \\
\hline $\begin{array}{l}\text { Variação da } \\
\text { viscosidade } \\
\text { plástica }\end{array}$ & $\%$ & ----- & ----- & +54 & +36 & +52 & ----- & +50 & +29 & +18 & +28 & +26 & +28 \\
\hline
\end{tabular}

Obs.: sinal (+) indica aumento do valor do parâmetro para o período considerado; sinal (-) indica redução do valor do parâmetro para o período considerado.

Os espaços tracejados indicam que a viscosidade plástica não pode ser determinada para o período considerado. 
Tabela 7.27 - Pontuação dos fatores considerados na avaliação do comportamento dos MCAD a partir do ensaio de abatimento de tronco de cone modificado (para um intervalo de 60 minutos entre a mistura e o lançamento do material).

\begin{tabular}{|c|c|c|c|c|c|c|c|c|c|c|c|c|c|}
\hline \multicolumn{2}{|l|}{ Cimento } & \multicolumn{6}{|c|}{$\frac{\text { CPV ARI Plus }}{\text { Procedimento de mistura }}$} & \multicolumn{6}{|c|}{$\frac{\text { CPV ARI RS }}{\text { Procedimento de mistura }}$} \\
\hline Fator considerado & Unidade & A & B & C & D & $\mathbf{E}$ & $\mathbf{F}$ & A & B & C & D & E & $\mathbf{F}$ \\
\hline Abatimento inicial & $\mathrm{mm}$ & 2 & 1 & 2 & 5 & 6 & 4 & 6 & 4 & 2 & 5 & 3 & 1 \\
\hline Variação do abatimento & $\%$ & 1 & 3 & 5 & 3 & 5 & 2 & 4 & 5 & 2 & 1 & 3 & 6 \\
\hline Tempo Ve-Be & $\mathrm{s}$ & 2 & 1 & 3 & 4 & 5 & 6 & 2 & 1 & 3 & 6 & 4 & 5 \\
\hline Tensão de escoamento & $\mathrm{Pa}$ & 3 & 1 & 2 & 5 & 6 & 4 & 6 & 4 & 1 & 5 & 3 & 2 \\
\hline $\begin{array}{l}\text { Variação da tensão de } \\
\text { escoamento }\end{array}$ & $\%$ & 2 & 6 & 5 & 4 & 1 & 3 & 1 & 3 & 6 & 1 & 4 & 5 \\
\hline Viscosidade plástica & Pa.s & 1 & 4 & 2 & 5 & 6 & 2 & 4 & 1 & 2 & 6 & 5 & 3 \\
\hline $\begin{array}{c}\text { Variação da viscosidade } \\
\text { plástica }\end{array}$ & $\%$ & --- & --- & --- & --- & --- & --- & 1 & 2 & 6 & 3 & 5 & 3 \\
\hline
\end{tabular}

Obs.: A variação da viscosidade plástica para as misturas produzidas com CPV ARI Plus não foram consideradas na pontuação porque a viscosidade de algumas dessas misturas não pode ser determinada a partir do ensaio de abatimento de tronco de cone modificado (abatimento $<100 \mathrm{~mm}$ ). 
Tabela 7.28 - Valores dos fatores considerados na avaliação do comportamento dos MCAD a partir do reômetro (para um intervalo de 60 minutos entre a mistura e o lançamento do material).

\begin{tabular}{|c|c|c|c|c|c|c|c|c|c|c|c|c|c|}
\hline \multicolumn{2}{|l|}{ Cimento } & \multirow{2}{*}{\multicolumn{6}{|c|}{$\frac{\text { CPV ARI Plus }}{\text { Procedimento de mistura }}$}} & \multirow{2}{*}{\multicolumn{6}{|c|}{$\frac{\text { CPV ARI RS }}{\text { Procedimento de mistura }}$}} \\
\hline \multirow{2}{*}{ Fator considerado } & \multirow{2}{*}{ Unidade } & & & & & & & & & & & & \\
\hline & & A & B & C & D & $\mathbf{E}$ & $\mathbf{F}$ & A & B & C & D & $\mathbf{E}$ & $\mathbf{F}$ \\
\hline Abatimento inicial & $\mathrm{mm}$ & 190 & 175 & 190 & 210 & 225 & 205 & 210 & 195 & 180 & 200 & 190 & 175 \\
\hline Variação do abatimento & $\%$ & -29 & -29 & -13 & -17 & -16 & -27 & -21 & -21 & -19 & -28 & -26 & -20 \\
\hline Tempo Ve-Be & $\mathrm{s}$ & 3,03 & 3,77 & 2,89 & 2,81 & 2,66 & 2,51 & 2,63 & 2,70 & 2,59 & 2,27 & 2,57 & 2,32 \\
\hline Variação do tempo Ve-Be & $\%$ & +42 & +6 & +6 & +18 & +9 & +13 & +3 & +6 & +3 & +7 & +2 & +5 \\
\hline Torque de escoamento & $\mathrm{Nm}$ & 0,95 & 1,57 & 1,06 & 0,86 & 1,29 & 1,24 & 1,37 & 1,91 & 1,51 & 1,41 & 2,09 & 1,24 \\
\hline $\begin{array}{l}\text { Variação do torque de } \\
\text { escoamento }\end{array}$ & $\%$ & +55 & +48 & +45 & +104 & +30 & +36 & +53 & +27 & +52 & +47 & +11 & +57 \\
\hline Viscosidade de torque & Nm.s & 1,179 & 0,643 & 0,672 & 0,850 & 0,795 & 1,561 & 0,685 & 1,262 & 0,990 & 1,076 & 1,354 & 1,409 \\
\hline $\begin{array}{c}\text { Variação da viscosidade } \\
\text { de torque }\end{array}$ & $\%$ & +1 & +3 & +19 & +26 & +39 & +12 & +54 & +19 & -1 & +2 & -33 & +16 \\
\hline Torque máximo & $\mathrm{Nm}$ & 3,17 & 3,25 & 2,63 & 3,12 & 3,11 & 3,85 & 3,76 & 4,33 & 3,51 & 3,74 & 3,53 & 4,13 \\
\hline Área de histerese & Nm.RPS & 0,966 & 1,260 & 1,058 & 1,243 & 1,114 & 1,211 & 0,752 & 0,890 & 0,909 & 0,760 & 0,947 & 0,705 \\
\hline $\begin{array}{c}\text { Tempo de } \\
\text { trabalhabilidade }\end{array}$ & $s$ & 5382 & 3819 & 4948 & 5576 & 6405 & 6493 & 5895 & 5157 & 6155 & 5655 & 6884 & 5731 \\
\hline
\end{tabular}

Obs.: sinal (+) indica aumento do valor do parâmetro para o período considerado;

sinal (-) indica redução do valor do parâmetro para o período considerado. 
Tabela 7.29 - Pontuação dos fatores considerados na avaliação do comportamento dos MCAD a partir do reômetro (para um intervalo de 60 minutos entre a mistura e o lançamento do material).

\begin{tabular}{|c|c|c|c|c|c|c|c|c|c|c|c|c|c|}
\hline \multicolumn{2}{|l|}{ Cimento } & \multirow{2}{*}{\multicolumn{6}{|c|}{$\frac{\text { CPV ARI Plus }}{\text { Procedimento de mistura }}$}} & \multirow{2}{*}{\multicolumn{6}{|c|}{$\frac{\text { CPV ARI RS }}{\text { Procedimento de mistura }}$}} \\
\hline \multirow{2}{*}{ Fator considerado } & \multirow{2}{*}{ Unidade } & & & & & & & & & & & & \\
\hline & & A & B & C & D & $\mathbf{E}$ & $\mathbf{F}$ & A & B & C & D & $\mathbf{E}$ & $\mathbf{F}$ \\
\hline Abatimento inicial & $\mathrm{mm}$ & 2 & 1 & 2 & 5 & 6 & 4 & 6 & 4 & 2 & 5 & 3 & 1 \\
\hline Variação do abatimento & $\%$ & 1 & 3 & 5 & 3 & 5 & 2 & 4 & 5 & 2 & 1 & 3 & 6 \\
\hline Tempo Ve-Be & $\mathrm{s}$ & 2 & 1 & 3 & 4 & 5 & 6 & 2 & 1 & 3 & 6 & 4 & 5 \\
\hline Variação do tempo Ve-Be & $\%$ & 1 & 6 & 3 & 4 & 5 & 2 & 5 & 6 & 2 & 1 & 2 & 2 \\
\hline Torque de escoamento & $\mathrm{Nm}$ & 5 & 1 & 4 & 6 & 2 & 3 & 5 & 2 & 3 & 4 & 1 & 6 \\
\hline Variação do torque de escoamento & $\%$ & 2 & 3 & 4 & 1 & 6 & 5 & 2 & 5 & 3 & 4 & 6 & 1 \\
\hline Viscosidade de torque & $\mathrm{Nm} . \mathrm{s}$ & 2 & 6 & 5 & 3 & 4 & 1 & 6 & 3 & 5 & 4 & 2 & 1 \\
\hline Variação da viscosidade de torque & $\%$ & 6 & 5 & 3 & 1 & 2 & 4 & 1 & 2 & 5 & 4 & 6 & 3 \\
\hline Torque máximo & $\mathrm{Nm}$ & 3 & 2 & 6 & 4 & 5 & 1 & 3 & 1 & 6 & 4 & 5 & 2 \\
\hline Área de histerese & Nm.RPS & 6 & 1 & 5 & 2 & 4 & 3 & 5 & 3 & 2 & 4 & 1 & 6 \\
\hline Tempo de trabalhabilidade & $\mathrm{s}$ & 3 & 1 & 2 & 4 & 5 & 6 & 4 & 1 & 5 & 2 & 6 & 3 \\
\hline & ÇÃO TOTAL & 33 & 30 & 42 & 37 & 49 & 37 & 43 & 33 & 38 & 39 & 39 & 36 \\
\hline
\end{tabular}




\section{CAPÍTUL口 8 CONCLUSÕES}

Após o término das atividades planejadas para o estudo da trabalhabilidade a partir de conceitos reológicos, os ensaios realizados durante a investigação experimental permitem destacar alguns pontos importantes do trabalho:

\section{Avaliação da trabalhabilidade pelos métodos de ensaio tradicionais}

As misturas de alto desempenho apresentaram perda da trabalhabilidade, relacionada com a perda de abatimento medido pelo ensaio de abatimento de tronco de cone. Essa perda foi contínua e gradual durante o tempo de execução do ensaio, independente da composição e do procedimento de mistura empregado na produção.

Com relação à trabalhabilidade medida em termos de tempo Ve-Be ou tempo de vibração, observou-se um aumento desse parâmetro com o tempo, indicando perda da trabalhabilidade desses materiais, uma vez que o tempo necessário para que uma mesma massa de concreto leva para preencher um cilindro aumenta.

\section{Caracterização reológica dos concretos de alto desempenho}

A identificação do comportamento reológico das misturas foi feita por meio de ajustes das partes ascendente e descendente da curva de cisalhamento a dois modelos reológicos - Bingham e lei das potências. A consideração da parte ascendente da curva de cisalhamento se mostrou mais adequada por apresentar os maiores coeficientes de ajuste da reta, além de corresponder ao período em que a tensão de escoamento deve ser excedida para que o escoamento inicie.

Independente da sua composição e do procedimento de mistura empregado na sua produção, as misturas apresentam um comportamento binghamiano, 
indicando que o material possui uma tensão de cisalhamento que deve ser excedida para iniciar o escoamento (tensão de escoamento) e, depois de excedida, o material apresenta um comportamento onde a tensão de cisalhamento se torna diretamente proporcional à taxa de cisalhamento aplicada. Esse comportamento é amplamente observado para as misturas de concreto de alto desempenho estudadas nos grandes centros de pesquisa da tecnologia dos concretos e encontradas na literatura.

Além disso, pode-se observar que as partes ascendente e descendente das curvas de cisalhamento das misturas testadas não coincidem, formando uma área de histerese entre elas. Isso comprova o comportamento tixotrópico desses materiais.

\section{Avaliação da trabalhabilidade pelos métodos de ensaio que determinam os dois parâmetros reológicos}

O processo de perda da trabalhabilidade das misturas de alto desempenho, mediante a determinação dos parâmetros reológicos, foi representado por um aumento da tensão de escoamento e do torque de escoamento, enquanto a viscosidade plástica e a viscosidade de torque permaneceram praticamente constantes durante o ensaio (menores acréscimos ao longo do tempo). Esses aumentos indicam perda da trabalhabilidade dessas misturas, pois, com o decorrer do tempo, a fluidez da mistura diminui e a resistência a ser vencida para iniciar o escoamento aumenta. O comportamento observado está de acordo com os resultados divulgados na literatura.

\section{Avaliação da trabalhabilidade pelo ensaio de cisalhamento contínuo}

Esse método de ensaio mostrou que o processo de perda da trabalhabilidade das misturas ocorreu de maneira contínua e gradual ao longo do tempo. Além disso, pode-se verificar a influência da composição da mistura e do procedimento de mistura empregado na produção desses concretos sobre os tempos de trabalhabilidade.

Observou-se um aumento da temperatura das misturas de concretos ao longo do tempo, relacionado principalmente com o atrito gerado entre as partículas angulosas que compõem a fase de agregados das misturas de concreto. Os acréscimos de temperatura são semelhantes entre as misturas, relacionando-se 
com o processo de hidratação do cimento que as constitui. Entre as misturas produzidas de acordo com os procedimentos de mistura considerados, observaramse pequenas variações entre as leituras que podem estar relacionadas com a temperatura ambiente do local onde os ensaios foram realizados.

$\mathrm{O}$ acompanhamento da evolução do $\mathrm{pH}$ com o tempo não evidencia qualquer efeito adverso desse fator sobre o comportamento dos concretos no estado fresco. Observou-se um acréscimo do $\mathrm{pH}$ até que um valor de equilíbrio fosse atingido. Esse valor de equilíbrio corresponde ao valor de $\mathrm{pH}$ normalmente medido para o fluido presente nos poros do concreto no estado endurecido.

\section{Correlação entre os métodos de ensaio usados para avaliar a trabalhabilidade dos concretos}

A variação entre os procedimentos de mistura resultou em misturas com desempenhos diferentes relacionados com os dois parâmetros reológicos, mostrando a inexistência de correlação entre eles.

As correlações obtidas entre a tensão de escoamento ou o torque de escoamento e o abatimento apresentaram coeficientes superiores a 0,80 , enquanto que os coeficientes de correlação obtidos entre a viscosidade plástica ou a viscosidade de torque e o abatimento foram bem menores, mostrando que o abatimento é mais sensível ao primeiro parâmetro reológico do que ao segundo.

A correlação entre a tensão de escoamento e o torque de escoamento apresentou coeficientes superiores 0,80 , enquanto a correlação obtida entre a viscosidade plástica e a viscosidade de torque apresentou coeficientes superiores a 0,85, mostrando uma boa correlação entre os parâmetros reológicos determinados a partir desses dois métodos de ensaio. Com isso, o ensaio de abatimento de tronco de cone modificado pode ser uma alternativa ao reômetro.

A influência de diferentes energias de mistura sobre o comportamento reológico de materiais à base de cimento deve ser estudada em termos qualitativos. Para as misturas estudadas, observou-se alguma similaridade entre os resultados obtidos com os dois métodos de ensaio usados na avaliação da trabalhabilidade a partir da evolução dos parâmetros reológicos. As correlações encontradas mostram que os valores da tensão de escoamento ou torque de escoamento estão melhor sincronizados entre os dois métodos de ensaio do que os valores obtidos para a viscosidade plástica ou viscosidade de torque.

Durante a análise dos resultados obtidos na fase de desenvolvimento do estudo experimental sobre a reologia das misturas de alto desempenho, observou- 
se que, para cada fator analisado, um procedimento de mistura se adequava melhor. Além disso, o tempo no qual o ensaio foi desenvolvido se mostrou muito importante em relação ao tempo no qual a mistura foi executada e o tempo no qual ela seria utilizada.

Assim, cada método de ensaio foi analisado separadamente para a verificação do desempenho das misturas avaliadas com cada um deles. Observouse que o melhor desempenho geral das misturas produzidas com cada tipo de cimento foi obtido pelo mesmo procedimento de mistura, independente do método de ensaio utilizado na determinação dos parâmetros reológicos e do intervalo de tempo considerado entre a mistura e o "lançamento" do material.

Portanto, o ensaio de abatimento de tronco de cone modificado corresponde a uma boa alternativa para o reômetro na avaliação da trabalhabilidade de misturas de alto desempenho em campo.

O tempo no qual o ensaio é desenvolvido mostrou-se um fator muito importante com relação à trabalhabilidade dos concretos. Para os intervalos de tempo considerados - 30 e 60 minutos entre os processos de mistura e de "lançamento" do concreto - as misturas apresentaram comportamentos diferentes. Relacionado com a prática da construção, dependendo do tempo necessário para a aplicação do concreto, um determinado procedimento de mistura resulta em uma mistura com trabalhabilidade mais adequada para a finalidade desejada do que outra e, com a utilização do reômetro, essas diferenças se tornam ainda mais evidentes.

O fato de terem sidos estudadas apenas misturas compostas com agregado graúdo de dimensão máxima característica menor ou igual a 9,5 mm não significa que, ao avaliar o comportamento de concretos produzidos com agregados de dimensões maiores (25 mm, por exemplo), o material apresente a mesma tendência do comportamento. Muito provavelmente esse comportamento será diferente em função da maior capacidade de defloculação dos finos pelas partículas de agregados de dimensões maiores que compõem essa mistura.

$\mathrm{Na}$ fabricação dos materiais aglomerantes - cimento Portland e sílica ativa que compõem uma mistura de concreto de alto desempenho existe uma grande variação entre as propriedades desses materiais ao longo do tempo, resultando em grandes variações entre as análises realizadas em épocas diferentes. Assim, devese ter em mente que, na tecnologia dos concretos, cada situação em particular deve ser avaliada. A mudança de qualquer um dos materiais constituintes da 
mistura implica em mudanças no comportamento do concreto no estado fresco. Portanto, cada dosagem deve ser estudada cuidadosamente, considerando os diversos fatores que influenciam o comportamento de uma mistura de concreto no estado fresco.

A finalização dessa pesquisa indica claramente que há necessidade de se limitar as variáveis para se fazer uma correlação entre as experimentações em laboratório e as atividades desenvolvidas no campo. Em função do grande número de variáveis envolvidas, a produção de um concreto de alto desempenho - projeto do concreto, efetiva escolha de materiais, escolha dos misturadores, processos de transporte, redosagem, lançamento, adensamento, acabamento e cura do material - não pode ser limitado simplesmente às análises únicas em laboratório, devendo as equipes envolvidas em todos os processos serem também de alto desempenho.

\subsection{Sugestões para pesquisas futuras}

Apesar do extenso trabalho desenvolvido durante essa pesquisa, alguns pontos relacionados com o estudo da trabalhabilidade de misturas de alto desempenho em termos da evolução de parâmetros reológicos ainda precisam ser verificados:

- a caracterização reológica de concretos compostos por agregados de dimensão máxima característica maior que $9,5 \mathrm{~mm}$;

- a influência de agregados sobre os parâmetros reológicos que caracterizam o comportamento de uma mistura de concreto no estado fresco;

- a avaliação do comportamento de concretos compostos com outros tipos de adições químicas e minerais, que são amplamente utilizados na prática das construções;

- a avaliação da influência da vibração sobre os parâmetros reológicos que caracterizam o comportamento de concretos nos estado fresco;

- o desenvolvimento de equações que permitam a transformação dos parâmetros reológicos fornecidos por um reômetro de eixo planetário, dados em unidades de torque, em parâmetros expressados em unidades do sistema internacional de medidas. 



\section{Anexo A - Caracterização dos materiais}

\section{A.1 Cimento}

Análises químicas:

A análise química dos cimentos utilizados na pesquisa foi feita por fluorescência de raios-X no Centro de Caracterização e Desenvolvimento de Materiais da Universidade Federal de São Carlos (CCDM/UFSCar).

\section{Massa específica:}

Corresponde à relação entre a massa de uma determinada quantidade de material e o volume ocupado por ela. Para o cimento, o ensaio, que se dá por meio do frasco volumétrico de "Le Chatelier", segue as especificações da NBR 6474/84 Cimento Portland e outros materiais em pó - determinação da massa específica.

\section{Área específica Blaine:}

Resultados fornecidos pelo fabricante dos cimentos (Holcim Brasil S/A).

\section{Água da pasta de consistência normal:}

Com este ensaio determinou-se o teor de água que confere consistência normal à pasta de cimento Portland. Este ensaio foi realizado seguindo as especificações da NBR 11580/91 (MB-3433) - Cimento Portland - Determinação da água da pasta de consistência normal. 


\section{Início e fim de pega:}

O ensaio para determinação dos tempos de início e fim de pega dos cimentos foi realizado de acordo com as especificações da NBR 11581/91 (MB-3434) Cimento Portland - Determinação dos tempos de pega.

\section{Resistência à compressão:}

Resultados fornecidos pelo fabricante dos cimentos (Holcim Brasil S/A).

Na presente pesquisa foram utilizados os cimentos CPV ARI Plus e CPV ARI RS, todos do fabricante Holcim Brasil S/A. Os ensaios de caracterização realizados para esses cimentos forneceram os dados apresentados nas tabelas A.1 e A.2.

Tabela A.1 - Propriedades químicas e composição potencial dos cimentos utilizados na pesquisa.

\begin{tabular}{|c|c|c|}
\hline \multirow{2}{*}{ Óxidos } & \multicolumn{2}{|c|}{ Resultado (\%) } \\
\hline & CPV ARI Plus & CPV ARI RS \\
\hline $\mathrm{SiO}_{2}$ & 21,16 & 22,32 \\
\hline $\mathrm{Al}_{2} \mathrm{O}_{3}$ & 4,71 & 5,50 \\
\hline $\mathrm{Fe}_{2} \mathrm{O}_{3}$ & 1,89 & 1,72 \\
\hline $\mathrm{TiO}_{2}$ & 0,15 & 0,17 \\
\hline $\mathrm{CaO}$ & 68,08 & 63,61 \\
\hline $\mathrm{MgO}$ & 0,48 & 1,45 \\
\hline $\mathrm{Na}_{2} \mathrm{O}$ & 0,29 & 0,25 \\
\hline $\mathrm{K}_{2} \mathrm{O}$ & 0,56 & 0,63 \\
\hline $\mathrm{P}_{2} \mathrm{O}_{5}$ & 0,28 & 0,19 \\
\hline $\mathrm{MnO}$ & Traços & Traços \\
\hline $\mathrm{Cr}_{2} \mathrm{O}_{5}$ & Traços & Traços \\
\hline Perda ao fogo & 2,39 & 4,15 \\
\hline \multicolumn{3}{|c|}{ Composição potencial $(\%)^{(\propto)}$} \\
\hline $\mathrm{C}_{3} \mathrm{~S}$ & 58,95 & 38,26 \\
\hline $\mathrm{C}_{2} \mathrm{~S}$ & 10,15 & 7,66 \\
\hline $\mathrm{C}_{3} \mathrm{~A}$ & 7,36 & 4,92 \\
\hline $\mathrm{C}_{4} \mathrm{AF}$ & 9,46 & 6,32 \\
\hline
\end{tabular}


Tabela A.2 - Propriedades físicas dos cimentos utilizados na pesquisa.

\begin{tabular}{r|c|c}
\hline \multicolumn{1}{c|}{ Propriedades físicas } & CPV ARI Plus & CPV ARI RS \\
\hline Massa específica $\left(\mathrm{g} / \mathrm{cm}^{3}\right)$ & 3,12 & 3,08 \\
\hline Blaine $\left(\mathrm{cm}^{2} / \mathrm{g}\right)^{*}$ & 4457 & 3293 \\
\hline Início de pega $(\mathrm{min})$ & 98 & 137 \\
\hline Fim de pega $(\mathrm{min})$ & 188 & 277 \\
\hline$\# 200(\%)^{*}$ & 0,2 & 1,4 \\
\hline$\# 325(\%)^{*}$ & 2,7 & 10,6 \\
\hline Resistência à compressão (MPa) & & 16,9 \\
1 dia & 28,4 & 29,6 \\
3 dias & 43,2 & 36,6 \\
7 dias & 48,4 & 46,4 \\
28 dias & 56,8 &
\end{tabular}

Também foi realizado o ensaio para a determinação do teor de água de consistência normal para pastas dos cimentos utilizados na pesquisa. Os valores obtidos foram:

- $\quad$ CPV ARI Plus $\rightarrow \mathbf{a} / \mathbf{c}=\mathbf{0 , 3 0}(\mathbf{7} \mathrm{mm})$

- $\quad$ CPV ARI RS $\rightarrow \mathbf{a} / \mathbf{c}=\mathbf{0 , 3 2}(\mathbf{5} \mathrm{mm})$.

\section{A.2 Agregados}

\section{A.2.1 Agregado miúdo}

\section{Composição granulométrica:}

A determinação da composição granulométrica da areia (dimensão máxima característica e módulo de finura) foi realizada de acordo com a NBR 7217/87 Agregados - Determinação da composição granulométrica.

\section{Massa unitária:}

Definida como o quociente entre a massa de agregado lançado no recipiente e o volume desse recipiente, a massa unitária foi determinada de acordo com as especificações da NBR 7251/82 - Agregado em estado solto - Determinação da massa unitária.

\section{Massa específica:}

Definida como a relação entre a massa do agregado seco em estufa e o volume igual do sólido, a massa específica da areia foi determinada de acordo com 
a NBR 9776/87 - Agregados - Determinação da massa específica de agregados miúdos por meio do frasco Chapman.

\section{Teor de materiais pulverulentos:}

Materiais pulverulentos são definidos como as partículas minerais com dimensão inferior a $0,075 \mathrm{~mm}$, inclusive os materiais solúveis em água, presentes nos agregados. A determinação da quantidade desses materiais presentes na areia seguiu as especificações da NBR 7219/87 - Agregados - Determinação do teor de materiais pulverulentos.

\section{Teor de argila em torrões e materiais friáveis:}

São consideradas argila em torrões e materiais friáveis as partículas presentes nos agregados que são suscetíveis de serem desfeitas pela pressão entre os dedos polegar e indicador. A determinação do teor desses materiais presentes na areia seguiu as especificações da NBR 7218/87 - Agregados Determinação do teor de argila em torrões e materiais friáveis.

\section{Impurezas orgânicas:}

Este ensaio foi realizado de acordo com as recomendações da NM 49/2001 Agregado miúdo - Determinação de impurezas orgânicas. O ensaio determina a presença de impurezas orgânicas na areia através do método colorimétrico.

\section{Número de angulosidade:}

O conceito de angulosidade está relacionado com a norma inglesa BS812/85. O número de angulosidade corresponde à diferença da subtração entre 67 (porcentagem de volume sólido do agregado mais arredondado) e a porcentagem de volume de sólidos em um recipiente preenchido com agregado segundo um procedimento estabelecido. Quanto maior o número (diferença entre as porcentagens de volume), mais anguloso é o agregado. O número de angulosidade varia entre 0 e 11 .

Os ensaios com agregado miúdo (areia quartzosa de cava retirada de uma jazida próxima cidade de São Carlos) conduziram aos seguintes resultados:

- o módulo de finura e a dimensão máxima do agregado determinados a partir do ensaio de composição granulométrica (NBR 7217/87) são 2,34 e 4,8 mm, 
respectivamente, e apresentados na tabela A.3 e figura A.1. A areia é classificada como areia fina (zona 2);

- $\quad$ massa unitária $(N B R 7251 / 82)=1,67 \mathrm{~kg} / \mathrm{dm}^{3}$;

- $\quad$ massa específica $(N B R$ 9776/87) = 2,61 kg/dm

- $\quad$ teor de materiais pulverulentos $(\operatorname{NBR} 7219 / 87)=\mathbf{0 , 5 8 \%}$;

- teor de argila em torrões e materiais friáveis $(\operatorname{NBR} 7218 / 87)=\mathbf{1 , 1 9 \%}$;

- determinação de impurezas orgânicas (NM 49/2001) $\rightarrow$ solução com agregado mais clara que a solução padrão;

- $\quad$ número de angulosidade médio = 0 (BS-812).

Tabela A.3 - Composição granulométrica do agregado miúdo.

\begin{tabular}{c|c|c|c|c}
\hline $\begin{array}{c}\text { Peneiras } \\
(\mathbf{m m})\end{array}$ & $\begin{array}{c}\text { Massa retida } \\
\mathbf{( g )}\end{array}$ & $\begin{array}{c}\text { Massa } \\
\text { acumulada } \mathbf{( g )}\end{array}$ & $\begin{array}{c}\text { \% retida } \\
\mathbf{( \% )}\end{array}$ & $\begin{array}{c}\text { \% acumulada } \\
\mathbf{( \% )}\end{array}$ \\
\hline 9,5 & 2,7 & 2,7 & 0 & 0 \\
\hline $6,3^{*}$ & 6,5 & 9,2 & 1 & 1 \\
\hline $\mathbf{4 , 8}$ & $\mathbf{8 , 5}$ & $\mathbf{1 7 , 7}$ & $\mathbf{2}$ & $\mathbf{3}$ \\
\hline 2,4 & 19,7 & 37,4 & 4 & 7 \\
\hline 1,2 & 38,1 & 75,5 & 8 & 15 \\
\hline 0,6 & 69,9 & 145,4 & 14 & 29 \\
\hline 0,3 & 262,7 & 408,1 & 53 & 82 \\
\hline 0,15 & 81,5 & 489,6 & 16 & 98 \\
\hline Fundo & 10,4 & 500,0 & 2 & 100 \\
\hline Total & 500,0 & --- & 100 & 234 \\
\hline
\end{tabular}

Diâmetro máximo = 4,8 $\mathrm{mm}$; Módulo de finura $=2,34$.

* Peneira intermediária.

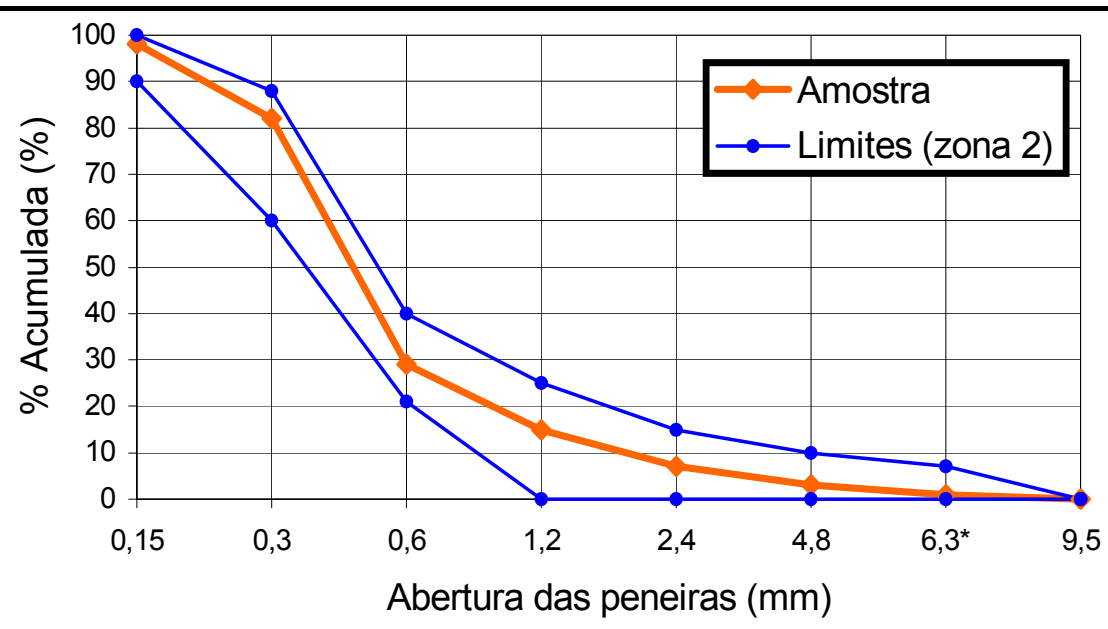

Figura A.1 - Curva granulométrica da areia. 


\section{A.2.2 Agregado graúdo}

\section{Composição granulométrica:}

A composição granulométrica dos agregados graúdos (dimensão máxima característica e módulo de finura) foi realizada de acordo com a NBR 7217/87 Agregados - Determinação da composição granulométrica.

\section{Massa unitária:}

Para os agregados graúdos, foram calculadas duas massas unitárias: no estado solto e no estado compactado. No estado solto, ela é definida como o quociente entre a massa de agregado lançado no recipiente e o volume desse recipiente e sua determinação segue as especificações da NBR 7251/82 Agregado em estado solto - Determinação da massa unitária. No estado compactado, a massa unitária corresponde ao quociente entre a massa do agregado lançado e compactado em um recipiente e o volume do mesmo e sua determinação está de acordo com as recomendações da NBR 7810/83 - Agregado em estado compactado seco - Determinação da massa unitária.

\section{Massa específica:}

Definida como a relação entre a massa do agregado seco e seu volume, excluídos os vazios permeáveis (descontinuidades ligadas diretamente à superfície externa do agregado que, na condição saturada superfície seca, são passíveis de reter água), a massa específica de cada agregado graúdo foi determinada de acordo com a NBR 9937/87 - Agregados - Determinação da absorção e da massa específica de agregado graúdo.

\section{Massa específica na condição saturada superfície seca:}

Corresponde à relação entre a massa do agregado na condição saturada superfície seca e o seu volume, excluídos os vazios permeáveis. A determinação dessa massa específica seguiu as especificações da NBR 9937/87 - Agregados Determinação da absorção e da massa específica de agregado graúdo.

\section{Absorção:}

Determinada de acordo com as especificações da NBR 9937/87 - Agregados - Determinação da absorção e da massa específica de agregado graúdo, a 
absorção corresponde ao aumento da massa do agregado devido ao preenchimento de seus poros por água e é expressa em termos de porcentagem da massa seca desse agregado.

\section{Teor de materiais pulverulentos:}

Materiais pulverulentos são as partículas minerais com dimensão inferior a 0,075 mm, inclusive os materiais solúveis em água, presentes nos agregados. A determinação da quantidade desses materiais presentes nos agregados graúdos seguiu as especificações da NBR 7219/87 - Agregados - Determinação do teor de materiais pulverulentos.

\section{Índice de forma:}

O método utilizado na determinação do índice de forma dos agregados graúdos foi o prescrito pela norma francesa NF EN 933-4/2000. Este método consiste em determinar um coeficiente volumétrico médio de uma amostra obtida a partir do quarteamento de um lote representativo de agregado, até obter-se uma massa de $250 \mathrm{~g}$. Inicialmente, calcula-se o volume da amostra pelo deslocamento de um líquido de volume previamente estabelecido $(\mathrm{V})$ e, a seguir, mede-se o diâmetro "d" de cada partícula pertencente à amostra para depois calcular o coeficiente volumétrico médio $\left(\mathrm{C}_{\mathrm{v}}\right.$, médio $)$ através da expressão abaixo. Quanto maior o coeficiente volumétrico, mais esférico é o agregado.

$$
\mathrm{C}_{\mathrm{v}, \text { médio }}=\frac{\mathrm{V}}{\left(\frac{\pi}{6} \Sigma \mathrm{d}^{3}\right)} \geq 0,2
$$

Os agregados graúdos utilizados na pesquisa foram as britas de graduação 0 , 1 e 2 , todas de origem basáltica. Os ensaios para os diversos agregados resultaram nas seguintes características:

- o módulo de finura e a dimensão máxima dos agregados determinados a partir da composição granulométrica são apresentados nas tabelas A.4, A.5 e A.6;

- massa unitária nos estados solto (NBR 7251/87) e compactado (NBR $7810 / 83) \rightarrow$ tabela A.7;

- $\quad$ massa específica (NBR 9937/87 - Britas 0, 1 e 2) $\rightarrow$ tabela A.7; 
- $\quad$ massa específica na condição saturada superfície seca - $\gamma_{\text {sss }}$ (NBR 9937/87)

$\rightarrow$ tabela A.7;

- $\quad$ absorção (NBR 9937/87) $\rightarrow$ tabela A.7;

- $\quad$ teor de materiais pulverulentos (NBR 7219/87) $\rightarrow$ tabela A.7;

- $\quad$ número de angulosidade médio (BS-812 - Brita 0) $\rightarrow$ tabela A.7;

- $\quad$ índice de forma (AFNOR P-18-301 - Britas 1 e 2) $\rightarrow$ tabela A.7.

Tabela A.4 - Composição granulométrica do agregado graúdo (brita 0).

\begin{tabular}{c|c|c|c|c}
\hline $\begin{array}{c}\text { Peneiras } \\
(\mathbf{m m})\end{array}$ & $\begin{array}{c}\text { Massa retida } \\
\mathbf{( g )}\end{array}$ & $\begin{array}{c}\text { Massa } \\
\text { acumulada (g) }\end{array}$ & $\begin{array}{c}\text { \% retida } \\
(\mathbf{\%})\end{array}$ & $\begin{array}{c}\text { \% acumulada } \\
(\mathbf{\%})\end{array}$ \\
\hline $12,5^{*}$ & 7,6 & 7,6 & 0 & 0 \\
\hline $\mathbf{9 , 5}$ & $\mathbf{3 4 , 0}$ & $\mathbf{4 1 , 6}$ & $\mathbf{1}$ & $\mathbf{1}$ \\
\hline $6,3^{*}$ & 1418,1 & 1459,7 & 28 & 29 \\
\hline 4,8 & 1287,8 & 2747,5 & 26 & 55 \\
\hline 2,4 & 1601,6 & 4349,1 & 32 & 87 \\
\hline 1,2 & 327,9 & 4677,0 & 6 & 93 \\
\hline 0,6 & 131,4 & 4808,4 & 3 & 96 \\
\hline 0,3 & 101,4 & 4909,8 & 2 & 98 \\
\hline 0,15 & 57,9 & 4967,7 & 1 & 99 \\
\hline Fundo & 57,8 & 5025,5 & 1 & 100 \\
\hline Total & 5025,5 & & 100 & 529 \\
\hline
\end{tabular}

Diâmetro máximo = 9,5 mm; Módulo de finura = 5,29.

* Peneiras intermediárias

Tabela A.5 - Composição granulométrica do agregado graúdo (brita 1).

\begin{tabular}{c|c|c|c|c}
\hline $\begin{array}{c}\text { Peneiras } \\
(\mathbf{m m})\end{array}$ & $\begin{array}{c}\text { Massa retida } \\
\mathbf{( g )}\end{array}$ & $\begin{array}{c}\text { Massa } \\
\text { acumulada }(\mathbf{g})\end{array}$ & $\begin{array}{c}\text { \% retida } \\
\mathbf{( \% )}\end{array}$ & $\begin{array}{c}\text { \% acumulada } \\
\mathbf{( \% )}\end{array}$ \\
\hline $25^{*}$ & 0 & 0 & 0 & 0 \\
\hline $\mathbf{1 9}$ & $\mathbf{7 5 , 5}$ & $\mathbf{7 5 , 5}$ & $\mathbf{2}$ & $\mathbf{2}$ \\
\hline $12,5^{\star}$ & 4220,5 & 4296,0 & 84 & 86 \\
\hline 9,5 & 413,0 & 4709,0 & 8 & 94 \\
\hline $6,3^{*}$ & 245,5 & 4954,5 & 5 & 99 \\
\hline 4,8 & 30,5 & 4985,0 & 1 & 100 \\
\hline 2,4 & 6,0 & 4991,0 & 0 & 100 \\
\hline 1,2 & 1,5 & 4992,5 & 0 & 100 \\
\hline 0,6 & 0 & 4992,5 & 0 & 100 \\
\hline 0,3 & 0 & 4992,5 & 0 & 100 \\
\hline 0,15 & 0 & 4992,5 & 0 & 100 \\
\hline Fundo & 7,5 & 5000,0 & 0 & 100 \\
\hline Total & 5000,0 & & 100 & 696 \\
\hline
\end{tabular}

Diâmetro máximo = $19 \mathrm{~mm}$; Módulo de finura = 6,96.

* Peneiras intermediárias 
Tabela A.6 - Composição granulométrica do agregado graúdo (brita 2).

\begin{tabular}{c|c|c|c|c}
\hline $\begin{array}{c}\text { Peneiras } \\
(\mathbf{m m})\end{array}$ & $\begin{array}{c}\text { Massa retida } \\
\mathbf{( g )}\end{array}$ & $\begin{array}{c}\text { Massa } \\
\text { acumulada }(\mathbf{g})\end{array}$ & $\begin{array}{c}\text { \% retida } \\
\mathbf{( \% )}\end{array}$ & $\begin{array}{c}\text { \% acumulada } \\
\mathbf{( \% )}\end{array}$ \\
\hline $32^{*}$ & 18,5 & 18,5 & 0 & 0 \\
\hline $\mathbf{2 5}^{*}$ & $\mathbf{2 1 3 , 0}$ & $\mathbf{2 3 1 , 5}$ & $\mathbf{4}$ & $\mathbf{4}$ \\
\hline 19 & 3598,5 & 3830,0 & 67 & 71 \\
\hline $12,5^{*}$ & 1431,0 & 5261,0 & 27 & 98 \\
\hline 9,5 & 68,0 & 5329,0 & 1 & 99 \\
\hline $6,3^{*}$ & 26,5 & 5355,5 & 1 & 100 \\
\hline 4,8 & 4,0 & 5359,5 & 0 & 100 \\
\hline 2,4 & 0,5 & 5360,0 & 0 & 100 \\
\hline 1,2 & 0,0 & 5360,0 & 0 & 100 \\
\hline 0,6 & 0,0 & 5360,0 & 0 & 100 \\
\hline 0,3 & 0,0 & 5360,0 & 0 & 100 \\
\hline 0,15 & 0,0 & 5360,0 & 0 & 100 \\
\hline Fundo & 1,5 & 5361,5 & 0 & 100 \\
\hline Total & 5361,5 & & 100 & 770 \\
\hline
\end{tabular}

Diâmetro máximo = 25 mm; Módulo de finura = 7,70.

* Peneiras intermediárias

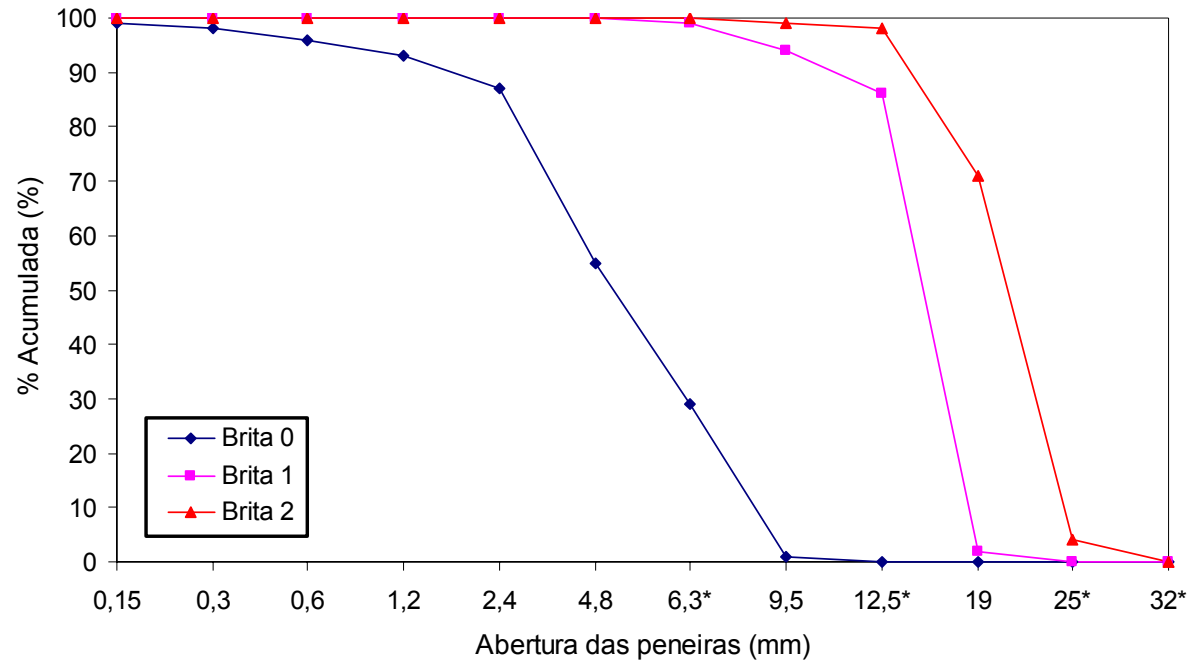

Figura A.2 - Curvas granulométricas das britas 0,1 e 2.

Tabela A.7 - Massa unitária, massa específica, absorção, teor de materiais pulverulentos, número de angulosidade e índice de forma (agregados graúdos).

\begin{tabular}{c|c|c|c}
\hline & Brita 0 & Brita 1 & Brita 2 \\
\hline Massa unitária no estado solto $\left(\mathrm{kg} / \mathrm{dm}^{3}\right)$ & 1,49 & 1,52 & 1,53 \\
\hline Massa unitária no estado compactado $\left(\mathrm{kg} / \mathrm{dm}^{3}\right)$ & 1,67 & 1,68 & 1,62 \\
\hline Massa específica $\left(\mathrm{kg} / \mathrm{dm}^{3}\right)$ & 2,87 & 2,88 & 2,88 \\
\hline$\gamma_{\text {sss }}\left(\mathrm{kg} / \mathrm{dm}^{3}\right)$ & 2,89 & 2,89 & 2,89 \\
\hline Absorção $(\%)$ & 0,53 & 0,33 & 0,31 \\
\hline Teor de materiais pulverulentos $(\%)$ & 0,90 & 0,84 & 0,37 \\
\hline Número de angulosidade & 9,3 & --- & --- \\
\hline Índice de forma & --- & 0,24 & 0,23 \\
\hline
\end{tabular}




\section{A.3 Água de amassamento}

\section{Ensaio de qualidade e teores de substâncias agressivas:}

As características da água destinada à preparação de concretos são especificadas na NM 137/97 - Argamassa e concreto - Água para amassamento e cura de argamassa e concreto de cimento Portland. Porém, no caso da água de amassamento ser proveniente do abastecimento público, o controle de sua aceitação se torna dispensável. A água utilizada na presente pesquisa atende às especificações da norma, conforme controle periódico feito por órgão competente.

\section{A.4 Aditivo}

\section{Teor de sólidos:}

Este ensaio determina a quantidade de sólidos presente no aditivo em termos de porcentagem da composição total do material. $O$ ensaio seguiu as especificações da NBR 10908/90 - Aditivos para argamassa e concreto - Ensaios de uniformidade.

$O$ aditivo utilizado na pesquisa foi 0 ADVA ${ }^{\mathrm{TM}}$ Cast, um aditivo do tipo superplastificante que permite uma grande redução na água de amassamento sem provocar o retardamento de pega. É um aditivo constituído por éster-carboxílico modificado. As características fornecidas pelo fabricante foram:

- $\quad$ massa específica $=1,08 \mathrm{~g} / \mathrm{cm}^{3}$;

- dosagens recomendadas: $\mathbf{0 , 2}$ I a 1,0 I/100 kg de cimento $(0,20 \%$ a 1,0\%).

O teor de sólidos presente neste aditivo foi determinado no laboratório com o auxílio da NBR 10908/90. O valor encontrado para a constituição sólida/líquida do superplastificante foi: $\mathbf{3 0} \%$ de sólidos e $\mathbf{7 0} \%$ de água.

\section{A.4 Sílica ativa}

\section{Análises químicas:}

A análise química dos cimentos utilizados na pesquisa foi feita por fluorescência de raios- $X$ no Centro de Caracterização e Desenvolvimento de Materiais da Universidade Federal de São Carlos (CCDM/UFSCar). 


\section{Massa específica:}

Corresponde à relação entre a massa de uma determinada quantidade de material e o volume ocupado por ela. Para a sílica ativa utilizou-se o mesmo ensaio empregado na determinação da massa específica do cimento, o qual se dá por meio do frasco volumétrico de "Le Chatelier" e segue as especificações da NBR 6474/84 - Cimento Portland e outros materiais em pó - determinação da massa específica.

A massa específica da sílica de ferro-silício ou silício metálico (SFS) foi determinada seguindo as especificações da NBR 6474/84. Assim, o valor encontrado para a massa específica foi de $2,10 \mathrm{~g} / \mathrm{cm}^{3}$.

A composição química da sílica empregada na pesquisa foi determinada por fluorescência de raios- $X$ e os valores encontrados são apresentados na tabela a seguir.

Tabela A.8 - Composição química e perda ao fogo da SFS empregada na pesquisa.

\begin{tabular}{l|c}
\hline \multicolumn{1}{c|}{ Elementos } & Resultados (\%) \\
\hline Sílica amorfa $\left(\mathrm{SiO}_{2}\right)$ & 95,92 \\
\hline $\mathrm{Fe}_{2} \mathrm{O}_{3}$ & 1,33 \\
\hline $\mathrm{Al}_{2} \mathrm{O}_{3}$ & ---- \\
\hline $\mathrm{TiO}_{2}$ & 0,01 \\
\hline $\mathrm{CaO}$ & 0,36 \\
\hline $\mathrm{P}_{2} \mathrm{O}_{5}$ & ----- \\
\hline $\mathrm{MnO}$ & ---- \\
\hline $\mathrm{MgO}$ & 0,38 \\
\hline $\mathrm{Na}{ }_{2} \mathrm{O}$ & 0,12 \\
\hline $\mathrm{K}_{2} \mathrm{O}$ & 0,30 \\
\hline $\mathrm{Cr} \mathrm{O}_{5}$ & ---- \\
\hline $\mathrm{Perda}$ ao fogo & 1,58 \\
\hline
\end{tabular}




\section{Anexo B - Caracterização dos concretos estudados}

\section{B.1 Microconcretos de alto desempenho}

São considerados microconcretos de alto desempenho aqueles em que o agregado graúdo empregado na mistura possui dimensão máxima característica menor ou igual a $9,5 \mathrm{~mm}$, isto é, brita 0 .

A caracterização desses concretos será feita em termos da massa específica, das resistências mecânicas e do módulo de elasticidade. O consumo de material empregado em cada mistura também será apresentado.

Para os ensaios mecânicos, foram moldados corpos-de-prova cilíndricos com $50 \mathrm{~mm}$ de diâmetro e $100 \mathrm{~mm}$ de altura. Após a desmoldagem, eles foram submetidos à cura úmida até as idades de ensaio (3, 7, 28, 63 e 91 dias).

A nomenclatura designada aos microconcretos estudados nesta pesquisa é:

- MCAD1: microconcreto de alto desempenho sem qualquer adição química ou mineral;

- MCAD2: microconcreto de alto desempenho incorporado apenas com SP (teor adicionado igual ao teor ótimo determinado na otimização de pastas incorporadas com SFS);

- $\quad \operatorname{MCAD3/(A,~B,~C,~D,~E~ou~F):~microconcreto~de~alto~desempenho~incorporado~}$ com SP e SFS em substituição volumétrica ao cimento. As letras A, B, C, D, E e $\mathrm{F}$ indicam o procedimento de mistura empregado na produção do material.

Tabela B.1 - Massa específica e consumo de materiais para microconcretos de alto desempenho produzidos com CPV ARI Plus.

\begin{tabular}{|c|c|c|c|c|c|c|c|c|c|}
\hline \multirow{3}{*}{$\begin{array}{l}\text { Micro- } \\
\text { concreto }\end{array}$} & \multirow{3}{*}{$\begin{array}{c}\text { Massa } \\
\text { específica } \\
\left(\mathbf{k g} / \mathrm{dm}^{3}\right)\end{array}$} & \multicolumn{8}{|c|}{ Consumo de material ( $\mathrm{kg} / \mathrm{m}^{3}$ de microconcreto) } \\
\hline & & \multirow{2}{*}{ Cimento } & \multirow{2}{*}{ Sílica } & \multirow{2}{*}{$\begin{array}{l}\text { Agregado } \\
\text { miúdo }\end{array}$} & \multicolumn{3}{|c|}{ Agregado graúdo } & \multirow{2}{*}{ Água } & \multirow{2}{*}{ SP } \\
\hline & & & & & Brita 0 & Brita 1 & Brita 2 & & \\
\hline MCAD1 & 2,419 & 494 & --- & 864 & 864 & --- & --- & 197 & --- \\
\hline MCAD2 & 2,442 & 498 & --- & 872 & 872 & --- & --- & 197 & 3,04 \\
\hline $\mathrm{MCAD}^{\otimes}$ & 2,395 & 458 & 31 & 855 & 855 & --- & --- & 193 & 2,98 \\
\hline
\end{tabular}

${ }^{\otimes}$ A massa específica e o consumo de material são iguais, ou seja, não variam de acordo com o procedimento de mistura empregado na produção do material. 
Tabela B.2 - Massa específica e consumo de materiais para microconcretos de alto desempenho produzidos com CPV ARI RS.

\begin{tabular}{|c|c|c|c|c|c|c|c|c|c|}
\hline \multirow{3}{*}{$\begin{array}{c}\text { Micro- } \\
\text { concreto }\end{array}$} & \multirow{3}{*}{$\begin{array}{c}\text { Massa } \\
\text { específica } \\
\left(\mathrm{kg} / \mathrm{dm}^{3}\right)\end{array}$} & \multicolumn{8}{|c|}{ Consumo de material $\left(\mathrm{kg} / \mathrm{m}^{3}\right.$ de microconcreto) } \\
\hline & & \multirow{2}{*}{ Cimento } & \multirow{2}{*}{ Sílica } & \multirow{2}{*}{$\begin{array}{l}\text { Agregado } \\
\text { miúdo }\end{array}$} & \multicolumn{3}{|c|}{ Agregado graúdo } & \multirow{2}{*}{ Água } & \multirow{2}{*}{ SP } \\
\hline & & & & & Brita 0 & Brita 1 & Brita 2 & & \\
\hline MCAD1 & 2,393 & 488 & --- & 855 & 855 & --- & --- & 195 & --- \\
\hline MCAD2 & 2,393 & 488 & --- & 855 & 855 & --- & --- & 194 & 2,25 \\
\hline MCAD3 $^{\otimes}$ & 2,377 & 454 & 31 & 849 & 849 & --- & --- & 192 & 2,43 \\
\hline
\end{tabular}

${ }^{\otimes}$ A massa específica e o consumo de material são iguais, ou seja, não variam de acordo com o procedimento de mistura empregado na produção do material.

Tabela B.3 - Tempos de início e fim de pega das pastas de cimento que compõem os microconcretos de alto desempenho (em [min]).

\begin{tabular}{c|c|c|c|c}
\hline \multirow{2}{*}{ Microconcreto } & \multicolumn{2}{|c|}{ CPV ARI Plus } & \multicolumn{2}{c}{ CPV ARI RS } \\
\cline { 2 - 5 } & Início & Fim & Início & Fim \\
\hline MCAD1 & 152 & 362 & 240 & 525 \\
\hline MCAD2 & 427 & 577 & 571 & 841 \\
\hline MCAD3/A & 284 & 479 & 395 & 635 \\
\hline MCAD3/B & 246 & 396 & 427 & 667 \\
\hline MCAD3/C & 212 & 437 & 376 & 661 \\
\hline MCAD3/D & 228 & 408 & 335 & 530 \\
\hline MCAD3/E & 291 & 486 & 336 & 561 \\
\hline MCAD3/F & 344 & 509 & 348 & 558 \\
\hline
\end{tabular}

Tabela B.4 - Resistência à compressão, resistência à tração e módulo de elasticidade dos microconcretos de alto desempenho produzidos com CPV ARI Plus.

\begin{tabular}{c|c|c|c|c|c|c|c}
\hline \multirow{2}{*}{$\begin{array}{c}\text { Micro- } \\
\text { concreto }\end{array}$} & \multicolumn{5}{|c|}{ Resistência à compressão simples (MPa) } & $\begin{array}{c}\text { Resistência à } \\
\text { tração (MPa) }\end{array}$ & $\begin{array}{c}\text { Módulo de } \\
\text { elasticidade } \\
\text { (GPa) }\end{array}$ \\
\cline { 2 - 8 } & 3 dias & 7 dias & 28 dias & 63 dias & 91 dias & 28 dias & 46 \\
\hline MCAD1 & 54,9 & 59,9 & 63,9 & 66,7 & 74,8 & 6,0 & 44 \\
\hline MCAD2 & 54,1 & 59,1 & 63,7 & 71,6 & 77,9 & 5,7 & 42 \\
\hline MCAD3/A & 51,6 & 57,8 & 65,4 & 81,2 & 84,4 & 5,7 & 41 \\
\hline MCAD3/B & 52,0 & 61,5 & 69,3 & 78,8 & 80,4 & 5,8 & 43 \\
\hline MCAD3/C & 53,5 & 63,7 & 64,4 & 79,5 & 82,8 & 6,5 & 50 \\
\hline MCAD3/D & 55,1 & 65,0 & 69,1 & 76,9 & 81,8 & 6,2 & 58 \\
\hline MCAD3/E & 51,8 & 63,0 & 68,3 & 74,4 & 77,7 & 5,0 & 57 \\
\hline MCAD3/F & 51,4 & 60,1 & 64,6 & 72,8 & 81,9 & 6,0 & 57 \\
\hline
\end{tabular}

OBS.: Os valores apresentados correspondem à média de três determinações - critério de Chauvenet. 
Tabela B.5 - Resistência à compressão, resistência à tração e módulo de elasticidade dos microconcretos de alto desempenho produzidos com CPV ARI RS.

\begin{tabular}{c|c|c|c|c|c|c|c}
\hline \multirow{2}{*}{$\begin{array}{c}\text { Micro- } \\
\text { concreto }\end{array}$} & \multicolumn{5}{|c|}{ Resistência à compressão simples (MPa) } & $\begin{array}{c}\text { Resistência à } \\
\text { tração (MPa) }\end{array}$ & $\begin{array}{c}\text { Módulo de } \\
\text { elasticidade } \\
\text { (GPa) }\end{array}$ \\
\cline { 2 - 7 } & 3 dias & 7 dias & 28 dias & $\mathbf{6 3}$ dias & 91 dias & 28 dias & 46 \\
\hline MCAD1 & 42,6 & 57,2 & 60,2 & 66,4 & 67,2 & 5,6 & 42 \\
\hline MCAD2 & 42,8 & 62,4 & 65,9 & 72,4 & 74,5 & 5,0 & 46 \\
\hline MCAD3/A & 41,9 & 50,9 & 60,7 & 70,5 & 72,8 & 6,1 & 42 \\
\hline MCAD3/B & 42,5 & 56,3 & 67,4 & 70,3 & 72,2 & 6,6 & 44 \\
\hline MCAD3/C & 44,0 & 51,1 & 66,0 & 65,0 & 72,0 & 5,9 & 42 \\
\hline MCAD3/D & 46,1 & 55,3 & 72,7 & 73,4 & 80,6 & 6,3 & 41 \\
\hline MCAD3/E & 43,1 & 56,7 & 66,7 & 69,7 & 76,3 & 6,0 & 40 \\
\hline MCAD3/F & 41,0 & 55,4 & 66,8 & 70,7 & 75,0 & 5,2 & 4 \\
\hline
\end{tabular}

OBS.: Os valores apresentados correspondem à média de três determinações - critério de Chauvenet.

\section{B. 2 Concretos de alto desempenho}

São considerados concretos de alto desempenho aqueles em que o agregado graúdo empregado na mistura possui dimensão máxima característica menor ou igual a $25 \mathrm{~mm}$, isto é, brita 2 .

A caracterização desses concretos será feita em termos da massa específica, das resistências mecânicas e do módulo de elasticidade. O consumo de material empregado em cada mistura também será apresentado.

Para os ensaios mecânicos, foram moldados corpos-de-prova cilíndricos com $100 \mathrm{~mm}$ de diâmetro e $200 \mathrm{~mm}$ de altura. Após a desmoldagem, eles foram submetidos à cura úmida até as idades de ensaio $(3,7,28,63$ e 91 dias).

A nomenclatura designada aos concretos estudados nesta pesquisa é:

- CAD1: concreto de alto desempenho sem qualquer adição química ou mineral;

- CAD2: concreto de alto desempenho incorporado apenas com SP (teor adicionado igual ao teor ótimo determinado na otimização de pastas incorporadas com SFS);

- $\quad C A D 3 /(A, B, C, D, E$ ou F): concreto de alto desempenho incorporado com SP e SFS em substituição volumétrica ao cimento. As letras A, B, C, D, E e F indicam o procedimento de mistura empregado na produção do material. 
Tabela B.6 - Massa específica e consumo de materiais para concretos de alto desempenho produzidos com CPV ARI Plus.

\begin{tabular}{|c|c|c|c|c|c|c|c|c|c|}
\hline \multirow{3}{*}{ Concreto } & \multirow{3}{*}{$\begin{array}{c}\text { Massa } \\
\text { específica } \\
\left(\mathbf{k g} / \mathrm{dm}^{3}\right)\end{array}$} & \multicolumn{8}{|c|}{ Consumo de material $\left(\mathrm{kg} / \mathrm{m}^{3}\right.$ de concreto) } \\
\hline & & \multirow{2}{*}{ Cimento } & \multirow{2}{*}{ Sílica } & \multirow{2}{*}{$\begin{array}{l}\text { Agregado } \\
\text { miúdo }\end{array}$} & \multicolumn{3}{|c|}{ Agregado graúdo } & \multirow{2}{*}{ Água } & \multirow{2}{*}{ SP } \\
\hline & & & & & Brita 0 & Brita 1 & Brita 2 & & \\
\hline CAD1 & 2,509 & 512 & --- & 665 & --- & 450 & 676 & 205 & --- \\
\hline CAD2 & 2,526 & 516 & --- & 671 & --- & 454 & 681 & 205 & 1,29 \\
\hline $\mathrm{CAD3}^{\otimes}$ & 2,493 & 477 & 32 & 662 & --- & 448 & 672 & 203 & 1,27 \\
\hline
\end{tabular}

${ }^{\otimes}$ A massa específica e o consumo de material são iguais, ou seja, não variam de acordo com o procedimento de mistura empregado na produção do material.

Tabela B.7 - Massa específica e consumo de materiais para concretos de alto desempenho produzidos com CPV ARI RS.

\begin{tabular}{|c|c|c|c|c|c|c|c|c|c|}
\hline \multirow{3}{*}{ Concreto } & \multirow{3}{*}{$\begin{array}{c}\text { Massa } \\
\text { específica } \\
\left(\mathbf{k g} / \mathbf{d m}^{3}\right)\end{array}$} & \multicolumn{8}{|c|}{ Consumo de material $\left(\mathrm{kg} / \mathrm{m}^{3}\right.$ de concreto) } \\
\hline & & \multirow{2}{*}{ Cimento } & \multirow{2}{*}{ Sílica } & \multirow{2}{*}{$\begin{array}{l}\text { Agregado } \\
\text { miúdo }\end{array}$} & \multicolumn{3}{|c|}{ Agregado graúdo } & \multirow{2}{*}{ Água } & \multirow{2}{*}{ SP } \\
\hline & & & & & Brita 0 & Brita 1 & Brita 2 & & \\
\hline CAD1 & 2,503 & 511 & --- & 664 & --- & 452 & 677 & 204 & --- \\
\hline CAD2 & 2,522 & 515 & --- & 669 & --- & 455 & 682 & 205 & 1,03 \\
\hline $\mathrm{CAD}^{\otimes}$ & 2,483 & 474 & 32 & 659 & --- & 448 & 672 & 202 & 1,01 \\
\hline
\end{tabular}

${ }^{\otimes}$ A massa específica e o consumo de material são iguais, ou seja, não variam de acordo com o procedimento de mistura empregado na produção do material.

Tabela B.8 - Tempos de início e fim de pega das pastas de cimento que compõem os concretos de alto desempenho (em [min]).

\begin{tabular}{c|c|c|c|c}
\hline \multirow{2}{*}{ Concreto } & \multicolumn{2}{|c|}{ CPV ARI Plus } & \multicolumn{2}{c}{ CPV ARI RS } \\
\cline { 2 - 5 } & Início & Fim & Início & Fim \\
\hline CAD1 & 152 & 362 & 240 & 525 \\
\hline CAD2 & 347 & 542 & 345 & 585 \\
\hline CAD3/A & 292 & 457 & 241 & 451 \\
\hline CAD3/B & 293 & 458 & 257 & 452 \\
\hline CAD3/C & 275 & 395 & 260 & 425 \\
\hline CAD3/D & 260 & 395 & 217 & 427 \\
\hline CAD3/E & 236 & 386 & 247 & 457 \\
\hline CAD3/F & 214 & 349 & 260 & 470 \\
\hline
\end{tabular}


Tabela B.9 - Resistência à compressão, resistência à tração e módulo de elasticidade dos concretos de alto desempenho produzidos com CPV ARI Plus.

\begin{tabular}{|c|c|c|c|c|c|c|c|}
\hline \multirow{2}{*}{ Concreto } & \multicolumn{5}{|c|}{ Resistência à compressão simples (MPa) } & \multirow{2}{*}{$\begin{array}{c}\text { Resistência à } \\
\text { tração (MPa) }\end{array}$} & \multirow{2}{*}{$\begin{array}{c}\text { Módulo de } \\
\text { elasticidade } \\
\text { (GPa) }\end{array}$} \\
\hline & 3 dias & 7 dias & 28 dias & 63 dias & 91 dias & & \\
\hline CAD1 & 33,4 & 38,9 & 44,1 & 52,0 & 57,1 & 3,7 & 40 \\
\hline CAD2/1 & 33,2 & 36,0 & 40,0 & 47,2 & 54,8 & 3,5 & 40 \\
\hline CAD3/1A & 31,0 & 35,5 & 50,5 & 57,5 & 62,8 & 3,4 & 46 \\
\hline $\mathrm{CAD} 3 / 1 \mathrm{~B}$ & 30,3 & 38,0 & 48,0 & 56,1 & 63,3 & 3,5 & 42 \\
\hline $\mathrm{CAD} 3 / 1 \mathrm{C}$ & 31,1 & 40,1 & 49,1 & 54,0 & 60,7 & 3,2 & 46 \\
\hline CAD3/1D & 33,8 & 42,6 & 49,8 & 56,0 & 62,3 & 3,5 & 41 \\
\hline CAD3/1E & 34,2 & 38,6 & 47,7 & 51,1 & 61,1 & 3,4 & 45 \\
\hline $\mathrm{CAD} 3 / 1 \mathrm{~F}$ & 36,7 & 39,6 & 49,6 & 54,2 & 62,5 & 2,9 & 48 \\
\hline
\end{tabular}

OBS.: Os valores apresentados correspondem à média de três determinações - critério de Chauvenet.

Tabela B.10 - Resistência à compressão, resistência à tração e módulo de elasticidade dos concretos de alto desempenho produzidos com CPV ARI RS.

\begin{tabular}{|c|c|c|c|c|c|c|c|}
\hline \multirow{2}{*}{ Concreto } & \multicolumn{5}{|c|}{ Resistência à compressão simples (MPa) } & \multirow{2}{*}{$\begin{array}{c}\text { Resistência à } \\
\text { tração (MPa) }\end{array}$} & \multirow{2}{*}{$\begin{array}{c}\text { Módulo de } \\
\text { elasticidade } \\
\text { (GPa) }\end{array}$} \\
\hline & 3 dias & 7 dias & 28 dias & 63 dias & 91 dias & & \\
\hline CAD1 & 33,9 & 36,0 & 48,2 & 51,3 & 58,0 & 3,4 & 48 \\
\hline CAD2/1 & 30,8 & 34,1 & 42,8 & 47,5 & 57,9 & 3,4 & 45 \\
\hline CAD3/1A & 39,4 & 40,9 & 46,7 & 53,5 & 61,6 & 3,1 & 42 \\
\hline CAD3/1B & 36,5 & 42,6 & 49,7 & 57,9 & 59,0 & 2,7 & 46 \\
\hline CAD3/1C & 37,5 & 38,6 & 49,9 & 59,9 & 66,1 & 3,0 & 48 \\
\hline CAD3/1D & 38,6 & 41,0 & 43,6 & 57,0 & 62,9 & 2,9 & 44 \\
\hline CAD3/1E & 32,3 & 36,6 & 43,1 & 54,6 & 60,3 & 3,0 & 42 \\
\hline CAD3/1F & 32,6 & 34,5 & 45,2 & 53,8 & 62,6 & 3,2 & 45 \\
\hline
\end{tabular}

OBS.: Os valores apresentados correspondem à média de três determinações - critério de Chauvenet.

\section{Anexo C - Estudo da pasta de cimento}

Neste anexo são apresentados os resultados gerais determinados durante os ensaios de cone de Marsh e de miniabatimento. No capítulo correspondente aos resultados e discussões as tabelas apresentadas foram resumidas para um melhor entendimento e maior rapidez na análise dos resultados obtidos.

Na tabela C.1 são apresentados os tempos de escoamento medidos através do ensaio de cone de Marsh para as pastas de cimento e/ou de aglomerantes. Eles correspondem às três determinações feitas durante o ensaio, bem como os desvios para cada determinação - determinação do ponto de saturação do SP. 
Na tabela C.2 são apresentados os dois diâmetros ortogonais e o diâmetro médio das pastas de cimento espalhadas, com e sem a adição de sílica ativa, determinados a partir do ensaio de miniabatimento - avaliação da trabalhabilidade das pastas ao longo do tempo e da compatibilidade entre os materiais empregados na produção das misturas.

Tabela C.1 - Tempos de escoamento determinados a partir do ensaio de cone de Marsh para as pastas de cimento incorporadas com sílica ativa.

\begin{tabular}{|c|c|c|c|c|c|c|c|c|c|c|c|}
\hline \multirow{2}{*}{\multicolumn{2}{|c|}{$\begin{array}{c}\text { Cimento } \\
\text { SP (\%) }\end{array}$}} & \multicolumn{5}{|c|}{ CPV ARI Plus } & \multicolumn{5}{|c|}{ CP ARI RS } \\
\hline & & 0,20 & 0,40 & 0,60 & 0,80 & 1,0 & 0,20 & 0,40 & 0,60 & 0,80 & 1,0 \\
\hline \multirow{5}{*}{$10 \mathrm{~min}$} & Ensaio 1 & --- & 45,53 & 41,54 & 35,75 & 38,71 & 50,18 & 33,83 & 29,96 & 26,93 & 26,43 \\
\hline & Ensaio 2 & --- & 40,76 & 41,53 & 41,59 & 37,67 & 51,45 & 32,99 & 31,14 & 27,45 & 25,37 \\
\hline & Ensaio 3 & --- & 38,59 & 42,23 & 37,14 & 36,90 & 49,57 & 32,55 & 29,97 & 26,34 & 26,15 \\
\hline & Média & --- & 41,63 & 41,77 & 38,16 & 37,76 & 50,40 & 33,12 & 30,36 & 26,91 & 25,98 \\
\hline & Desvio & --- & 3,55 & 0,40 & 3,05 & 0,91 & 0,96 & 0,65 & 0,68 & 0,56 & 0,55 \\
\hline \multirow{5}{*}{$30 \mathrm{~min}$} & Ensaio 1 & --- & 68,77 & 58,94 & 45,46 & 42,31 & 80,11 & 39,43 & 33,14 & 29,47 & 28,35 \\
\hline & Ensaio 2 & --- & 63,08 & 59,49 & 49,99 & 45,92 & 83,35 & 39,49 & 35,09 & 29,97 & 26,56 \\
\hline & Ensaio 3 & --- & 60,84 & 59,10 & 48,37 & 45,15 & 78,07 & 39,37 & 33,94 & 29,14 & 27,83 \\
\hline & Média & --- & 64,23 & 59,18 & 47,94 & 44,46 & 80,51 & 39,43 & 34,06 & 29,53 & 27,58 \\
\hline & Desvio & --- & 4,09 & 0,28 & 2,30 & 1,90 & 2,66 & 0,06 & 0,98 & 0,42 & 0,92 \\
\hline \multirow{5}{*}{$40 \mathrm{~min}$} & Ensaio 1 & --- & 72,13 & 62,88 & 48,25 & 44,38 & 91,12 & 42,86 & 33,21 & 29,96 & 28,38 \\
\hline & Ensaio 2 & --- & 67,50 & 63,07 & 52,51 & 47,47 & 92,03 & 41,54 & 35,13 & 30,67 & 27,15 \\
\hline & Ensaio 3 & --- & 67,67 & 61,27 & 49,18 & 48,97 & 89,01 & 41,71 & 34,09 & 29,67 & 27,90 \\
\hline & Média & --- & 69,10 & 62,41 & 49,98 & 46,94 & 90,72 & 42,04 & 34,14 & 30,10 & 27,81 \\
\hline & Desvio & --- & 2,63 & 0,99 & 2,24 & 2,34 & 1,55 & 0,72 & 0,96 & 0,51 & 0,62 \\
\hline \multirow{5}{*}{$60 \mathrm{~min}$} & Ensaio 1 & --- & 85,03 & 71,89 & 54,11 & 47,32 & 127,45 & 44,87 & 34,08 & 29,97 & 28,53 \\
\hline & Ensaio 2 & --- & 80,22 & 69,88 & 58,49 & 50,98 & 130,01 & 44,78 & 36,11 & 30,82 & 27,19 \\
\hline & Ensaio 3 & --- & 79,35 & 69,53 & 55,71 & 51,53 & 126,33 & 45,44 & 35,01 & 30,41 & 28,44 \\
\hline & Média & --- & 81,53 & 70,43 & 56,10 & 49,94 & 127,93 & 45,03 & 35,07 & 30,40 & 28,05 \\
\hline & Desvio & --- & 3,06 & 1,27 & 2,22 & 2,29 & 1,89 & 0,36 & 1,02 & 0,43 & 0,75 \\
\hline \multirow{5}{*}{$90 \mathrm{~min}$} & Ensaio 1 & --- & 109,06 & 87,63 & 62,83 & 52,45 & --- & 50,04 & 37,38 & 30,50 & 28,69 \\
\hline & Ensaio 2 & --- & 103,32 & 82,50 & 65,54 & 58,60 & --- & 49,91 & 39,67 & 32,06 & 27,82 \\
\hline & Ensaio 3 & --- & 105,86 & 78,83 & 64,12 & 56,36 & --- & 51,92 & 39,74 & 30,78 & 28,79 \\
\hline & Média & --- & 106,08 & 82,99 & 64,16 & 55,80 & --- & 50,62 & 38,93 & 31,11 & 28,43 \\
\hline & Desvio & --- & 2,88 & 4,42 & 1,36 & 3,11 & --- & 1,12 & 1,34 & 0,83 & 0,53 \\
\hline \multirow{5}{*}{$120 \mathrm{~min}$} & Ensaio 1 & --- & 148,64 & 106,61 & 73,51 & 60,73 & --- & 64,85 & 43,78 & 31,95 & 28,92 \\
\hline & Ensaio 2 & --- & 150,06 & 103,01 & 76,67 & 66,77 & --- & 63,54 & 44,32 & 33,29 & 28,87 \\
\hline & Ensaio 3 & --- & 154,76 & 97,19 & 74,81 & 62,92 & --- & 65,72 & 44,45 & 32,29 & 29,94 \\
\hline & Média & --- & 151,15 & 102,27 & 75,00 & 63,47 & --- & 64,70 & 44,18 & 32,51 & 29,24 \\
\hline & Desvio & --- & 3,20 & 4,75 & 1,59 & 3,06 & --- & 1,10 & 0,36 & 0,70 & 0,60 \\
\hline
\end{tabular}


Tabela C.2 - Diâmetros das pastas de cimento abatidas, com e sem a adição de sílica ativa, determinados através do ensaio de miniabatimento.

\begin{tabular}{|c|c|c|c|c|c|c|c|c|c|c|c|c|}
\hline \multirow{2}{*}{$\begin{array}{c}\text { Cimento } \\
\text { SP (\%) }\end{array}$} & \multicolumn{6}{|c|}{ CPV ARI Plus } & \multicolumn{6}{|c|}{ CPV ARI RS } \\
\hline & \multicolumn{3}{|c|}{0,61} & \multicolumn{3}{|c|}{0,61} & \multicolumn{3}{|c|}{0,46} & \multicolumn{3}{|c|}{0,46} \\
\hline Sílica & \multicolumn{3}{|c|}{ SSA } & \multicolumn{3}{|c|}{ SFS } & \multicolumn{3}{|c|}{ SSA } & \multicolumn{3}{|c|}{ SFS } \\
\hline $\begin{array}{c}\text { Tempo } \\
\text { (min) }\end{array}$ & $\mathbf{D}_{1}$ & $\mathbf{D}_{2}$ & $D_{m}$ & $\mathbf{D}_{1}$ & $\mathbf{D}_{2}$ & $D_{m}$ & $\mathbf{D}_{1}$ & $\mathbf{D}_{2}$ & $\mathbf{D}_{\mathrm{m}}$ & $D_{1}$ & $D_{2}$ & $D_{m}$ \\
\hline 10 & 198,0 & 202,5 & 200,3 & 206,5 & 204,7 & 205,6 & 178,9 & 179,5 & 179,2 & 167,3 & 169,2 & 168,3 \\
\hline 30 & 205,4 & 206,4 & 205,9 & 189,2 & 185,8 & 187,5 & 183,0 & 183,9 & 183,5 & 148,1 & 150,6 & 149,4 \\
\hline 40 & 202,0 & 204,6 & 203,3 & 180,0 & 176,5 & 178,3 & 188,7 & 188,6 & 188,7 & 140,9 & 141,7 & 141,3 \\
\hline 60 & 200,6 & 204,6 & 202,6 & 165,9 & 165,4 & 165,7 & 184,1 & 183,2 & 183,7 & 130,3 & 132,5 & 131,4 \\
\hline 90 & 194,1 & 209,3 & 201,7 & 149,1 & 156,5 & 152,8 & 175,6 & 178,8 & 177,2 & 117,4 & 120,2 & 118,8 \\
\hline 120 & 192,3 & 198,6 & 195,5 & 136,5 & 134,9 & 135,7 & 165,0 & 166,5 & 165,8 & 107,1 & 109,2 & 108,2 \\
\hline
\end{tabular}

SSA = pasta sem adição de sílica ativa; SFS = pasta com adição de sílica ativa.

D1 e D2 = diâmetros ortogonais em [mm]; Dm = diâmetro médio em [mm].

\section{Anexo D - Caracterização reológica do concreto fresco}

\section{D.1 Ensaio de abatimento de tronco de cone modificado}

Os valores dos abatimentos de tronco de cone e dos tempos de abatimento parcial dos MCAD e dos CAD, utilizados no cálculo dos parâmetros reológicos tensão de escoamento e viscosidade plástica - são apresentados nas tabelas D.1 e D.2, respectivamente.

Tabela D.1 - Valores dos abatimentos de tronco de cone e dos tempos de abatimento parcial determinados através do ensaio de abatimento de tronco modificado para os MCAD.

\begin{tabular}{c|c|c|c|c|c|c|c|c|c|c}
\hline Cimento & \multicolumn{4}{|c|}{ CPV ARI Plus } & \multicolumn{5}{c}{ CPV ARI RS } \\
\hline \multirow{2}{*}{ Microconcreto } & \multicolumn{4}{c|}{ Tempo de medida (min) } & \multicolumn{5}{c}{ Tempo de medida (min) } \\
\cline { 2 - 10 } & 10 & 30 & 60 & 90 & 120 & 10 & 30 & 60 & 90 & 120 \\
\hline
\end{tabular}

ABATIMENTO DE TRONCO DE CONE [mm]

\begin{tabular}{c|c|c|c|c|c|c|c|c|c|c}
\hline MCAD1 & ---- & ---- & ---- & ---- & ---- & ---- & ---- & ---- & ----- & ----- \\
\hline MCAD2 & 240 & 170 & 120 & 60 & $(30)$ & 235 & 195 & 125 & 85 & $(50)$ \\
\hline MCAD3/A & 200 & 130 & 75 & $(60)$ & $(15)$ & 215 & 170 & 135 & 90 & $(55)$ \\
\hline MCAD3/B & 175 & 130 & 95 & $(50)$ & $(10)$ & 195 & 160 & 120 & 90 & $(80)$ \\
\hline MCAD3/C & 195 & 170 & 110 & 55 & $(10)$ & 170 & 145 & 105 & 85 & $(65)$ \\
\hline MCAD3/D & 220 & 180 & 120 & 75 & $(45)$ & 200 & 150 & 110 & 60 & $(40)$ \\
\hline MCAD3/E & 240 & 190 & 125 & 70 & $(50)$ & 185 & 135 & 110 & 70 & $(35)$ \\
\hline MCAD3/F & 205 & 130 & 90 & $(50)$ & $(15)$ & 180 & 140 & 110 & 90 & $(55)$ \\
\hline
\end{tabular}


Tabela D.1 - Valores dos abatimentos de tronco de cone e dos tempos de abatimento parcial determinados através do ensaio de abatimento de tronco modificado para os MCAD (continuação).

\begin{tabular}{|c|c|c|c|c|c|c|c|c|c|c|}
\hline Cimento & & & ARI & & & & & $\mathrm{AR}$ & & \\
\hline \multirow{2}{*}{ Microconcreto } & \multicolumn{5}{|c|}{ Tempo de medida (min) } & \multicolumn{5}{|c|}{ Tempo de medida ( $\mathrm{min}$ ) } \\
\hline & 10 & 30 & 60 & 90 & 120 & 10 & 30 & 60 & 90 & 120 \\
\hline
\end{tabular}

TEMPO DE ABATIMENTO PARCIAL [s]

\begin{tabular}{|c|c|c|c|c|c|c|c|c|c|c|}
\hline MCAD1 & ---- & ---- & ---- & ----- & ----- & ---- & ---- & ---- & ----- & ---- \\
\hline MCAD2 & 0,21 & 0,23 & 0,38 & ----- & ----- & 0,22 & 0,25 & 0,32 & ----- & ---- \\
\hline MCAD3/A & 0,30 & 0,37 & ---- & ----- & ----- & 0,28 & 0,30 & 0,42 & ----- & ---- \\
\hline MCAD3/B & 0,26 & 0,27 & ----- & ----- & ----- & 0,35 & 0,38 & 0,45 & ----- & ----- \\
\hline MCAD3/C & 0,28 & 0,29 & 0,43 & ---- & ---- & 0,33 & 0,35 & 0,39 & ----- & $\begin{array}{l}--- \\
--\end{array}$ \\
\hline MCAD3/D & 0,25 & 0,27 & 0,34 & ----- & ----- & 0,25 & 0,30 & 0,32 & ----- & ---- \\
\hline MCAD3/E & 0,23 & 0,25 & 0,35 & ----- & ----- & 0,27 & 0,30 & 0,34 & ----- & ---- \\
\hline MCAD3/F & 0,28 & 0,31 & ---- & ----- & ----- & 0,32 & 0,35 & 0,41 & ----- & ---- \\
\hline
\end{tabular}

OBS.: Os abatimentos entre parênteses correspondem aos valores dos abatimentos determinados a partir do ensaio de abatimento de tronco convencional. Eles foram utilizados no cálculo da tensão de escoamento porque o ensaio de abatimento de tronco de cone modificado apresentou uma limitação para concretos com abatimentos inferiores a $100 \mathrm{~mm}$.

Tabela D.2 - Valores dos abatimentos de tronco de cone e dos tempos de abatimento parcial determinados através do ensaio de abatimento de tronco modificado para os CAD.

\begin{tabular}{|c|c|c|c|c|c|c|c|c|c|c|}
\hline Cimento & & & ARI & & & & & AR & & \\
\hline \multirow{2}{*}{ Concreto } & \multicolumn{5}{|c|}{ Tempo de medida (min) } & \multicolumn{5}{|c|}{ Tempo de medida (min) } \\
\hline & 10 & 30 & 60 & 90 & 120 & 10 & 30 & 60 & 90 & 120 \\
\hline \multicolumn{11}{|c|}{ ABATIMENTO DE TRONCO DE CONE [mm] } \\
\hline CAD1 & 130 & 105 & 90 & (75) & (55) & 140 & 120 & 100 & 75 & $(75)$ \\
\hline CAD2 & 195 & 135 & 100 & 70 & $(50)$ & 220 & 165 & 110 & 90 & $(80)$ \\
\hline CAD3/A & 150 & 115 & 100 & 80 & $(55)$ & 150 & 135 & 100 & 70 & (55) \\
\hline CAD3/B & 150 & 120 & 100 & 90 & (80) & 145 & 120 & 95 & (70) & (45) \\
\hline CAD3/C & 130 & 110 & 100 & 70 & (50) & 135 & 100 & 80 & (75) & (50) \\
\hline CAD3/D & 150 & 100 & 85 & (50) & (20) & 140 & 110 & 100 & 80 & (65) \\
\hline CAD3/E & 120 & 100 & 60 & (45) & (20) & 135 & 110 & 85 & (80) & (70) \\
\hline CAD3/F & 140 & 105 & 95 & (70) & (50) & 160 & 125 & 110 & 90 & (60) \\
\hline
\end{tabular}

TEMPO DE ABATIMENTO PARCIAL [s]

\begin{tabular}{|c|c|c|c|c|c|c|c|c|c|c|}
\hline CAD1 & 0,29 & 0,35 & ----- & ----- & ----- & 0,29 & 0,35 & 0,39 & ----- & ----- \\
\hline CAD2 & 0,32 & 0,34 & 0,40 & ----- & ----- & 0,28 & 0,30 & 0,35 & ----- & ----- \\
\hline CAD3/A & 0,24 & 0,29 & 0,35 & ----- & ----- & 0,28 & 0,31 & 0,37 & ----- & ----- \\
\hline CAD3/B & 0,25 & 0,30 & 0,35 & ----- & ----- & 0,30 & 0,34 & ---- & ---- & ---- \\
\hline CAD3/C & 0,29 & 0,34 & 0,40 & ----- & ----- & 0,29 & 0,35 & ---- & ----- & ----- \\
\hline CAD3/D & 0,33 & 0,37 & ----- & ----- & ----- & 0,29 & 0,33 & 0,40 & ----- & ----- \\
\hline CAD3/E & 0,27 & 0,32 & ---- & ----- & ----- & 0,29 & 0,32 & ---- & ----- & ----- \\
\hline CAD3/F & 0,27 & 0,33 & ----- & ----- & ----- & 0,26 & 0,29 & 0,36 & ----- & ----- \\
\hline
\end{tabular}

OBS.: Os abatimentos entre parênteses correspondem aos valores dos abatimentos determinados a partir do ensaio de abatimento de tronco convencional. Eles foram utilizados no cálculo da tensão de escoamento porque o ensaio de abatimento de tronco de cone modificado apresentou uma limitação para concretos com abatimentos inferiores a $100 \mathrm{~mm}$. 


\section{D.2 Reômetro}

O ajuste das curvas de cisalhamento (ascendente e descendente) foi feito para os dois modelos mais utilizados na descrição do comportamento de concretos de alto desempenho encontrados na literatura: Bingham e lei das potências. As curvas ascendente e descendente são mostradas separadamente para cada mistura ensaiada nas figuras seguintes. Os coeficientes de ajuste de cada modelo são resumidos na tabela D.3, sendo considerado mais adequado o modelo que apresentou o maior coeficiente.

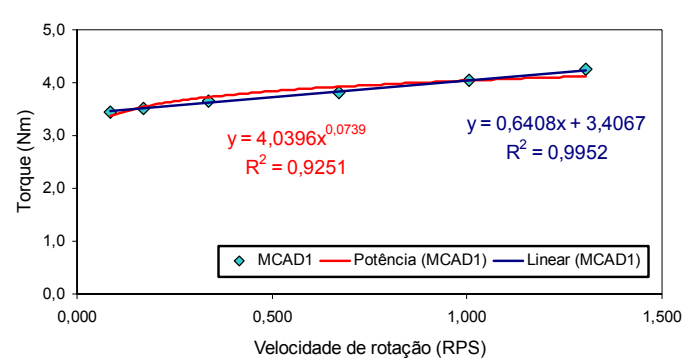

Figura D.1 - Parte ascendente da curva de cisalhamento do MCAD1 produzido com CPV ARI Plus (10 minutos).

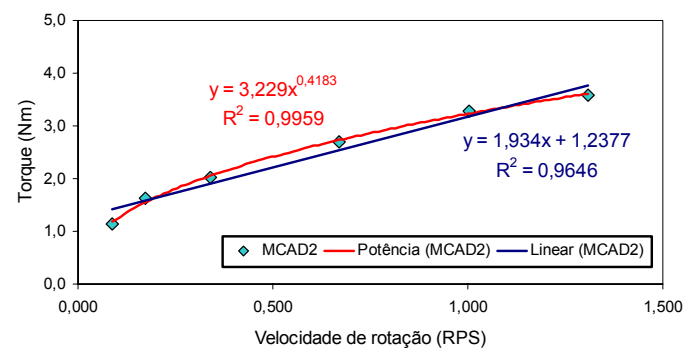

Figura D.3 - Parte ascendente da curva de cisalhamento do MCAD2 produzido com CPV ARI Plus (10 minutos).

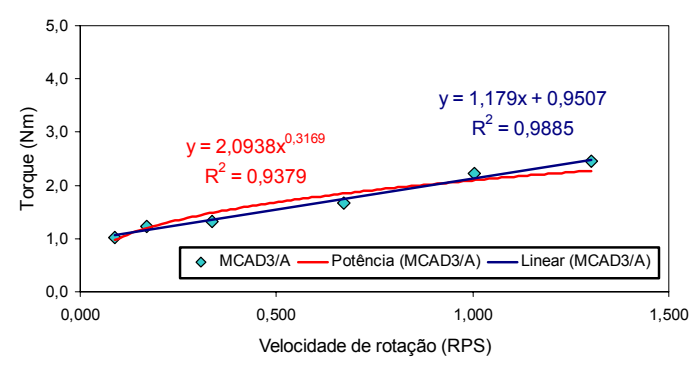

Figura D.5 - Parte ascendente da curva de cisalhamento do MCAD3/A produzido com CPV ARI Plus (10 minutos).

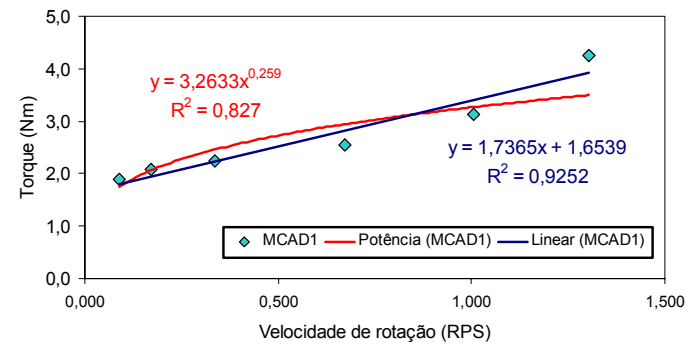

Figura D.2 - Parte descendente da curva de cisalhamento do MCAD1 produzido com CPV ARI Plus (10 minutos).

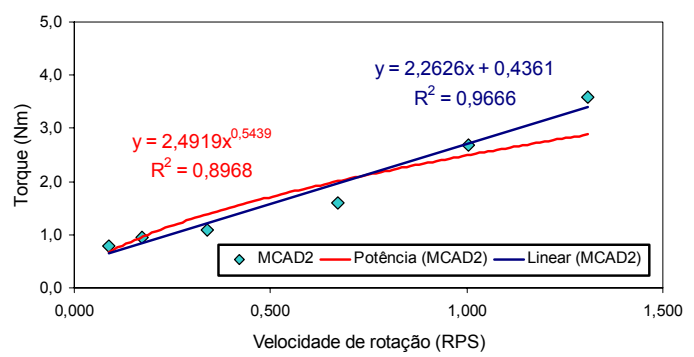

Figura D.4 - Parte descendente da curva de cisalhamento do MCAD2 produzido com CPV ARI Plus (10 minutos).

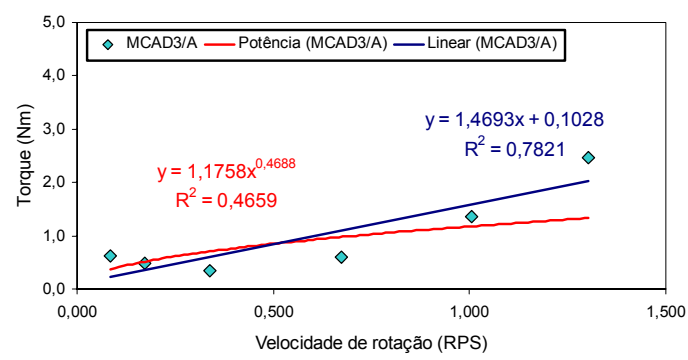

Figura D.6 - Parte descendente da curva de cisalhamento do MCAD3/A produzido com CPV ARI Plus (10 minutos). 


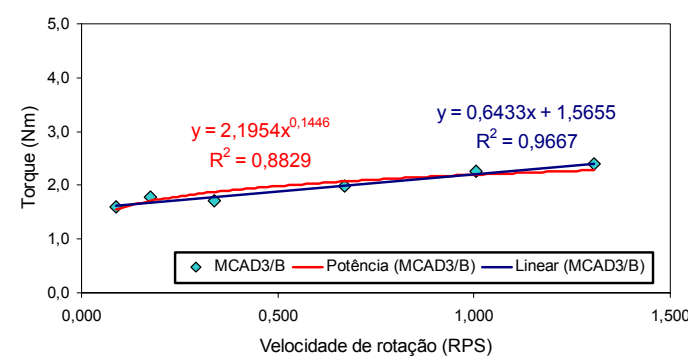

Figura D.7 - Parte ascendente da curva de cisalhamento do MCAD3/B produzido com CPV ARI Plus (10 minutos).

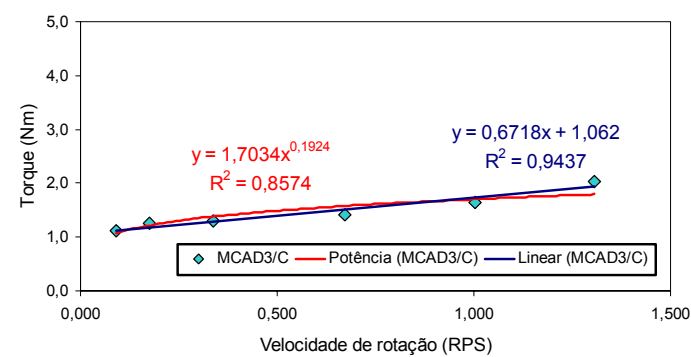

Figura D.9 - Parte ascendente da curva de cisalhamento do MCAD3/C produzido com CPV ARI Plus (10 minutos).

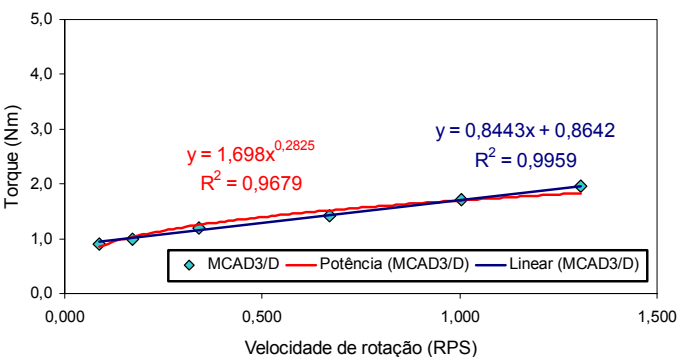

Figura D.11 - Parte ascendente da curva de cisalhamento do MCAD3/D produzido com CPV ARI Plus (10 minutos).

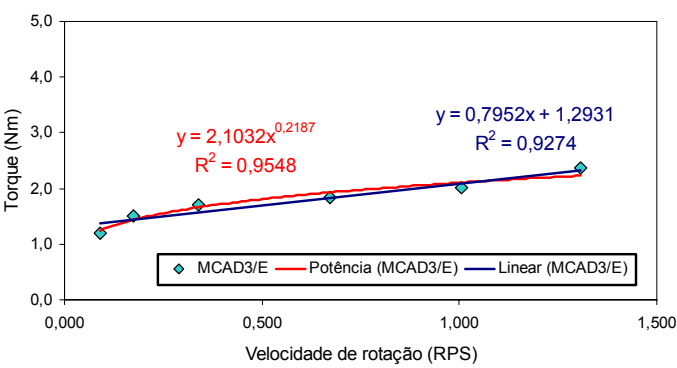

Figura D.13 - Parte ascendente da curva de cisalhamento do MCAD3/E produzido com CPV ARI Plus (10 minutos).

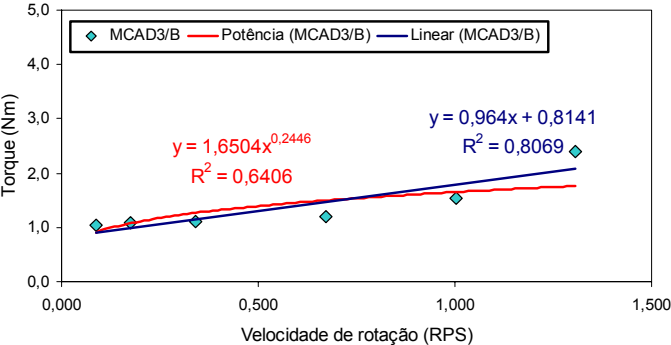

Figura D.8 - Parte descendente da curva de cisalhamento do MCAD3/B produzido com CPV ARI Plus (10 minutos).

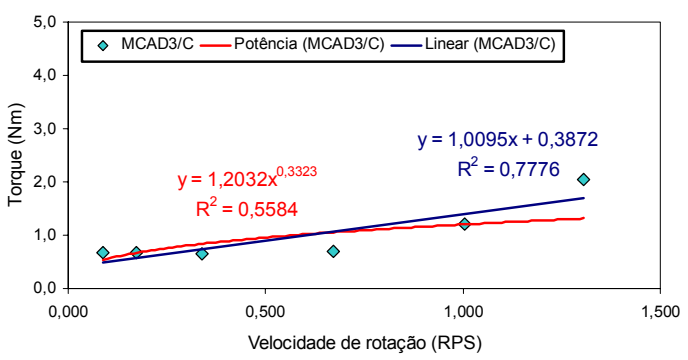

Figura D.10 - Parte descendente da curva de cisalhamento do MCAD3/C produzido com CPV ARI Plus (10 minutos).

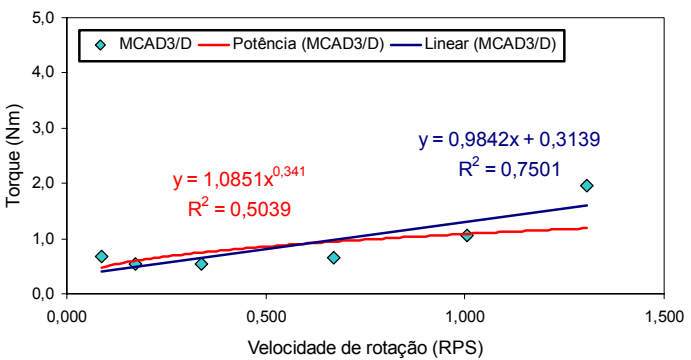

Figura D.12 - Parte descendente da curva de cisalhamento do MCAD3/D produzido com CPV ARI Plus (10 minutos).

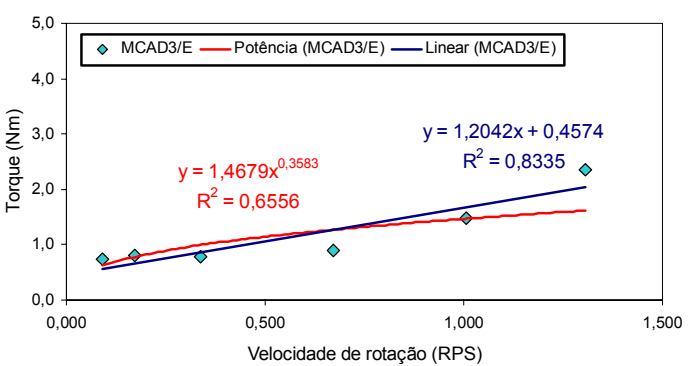

Figura D.14 - Parte descendente da curva de cisalhamento do MCAD3/E produzido com CPV ARI Plus (10 minutos). 


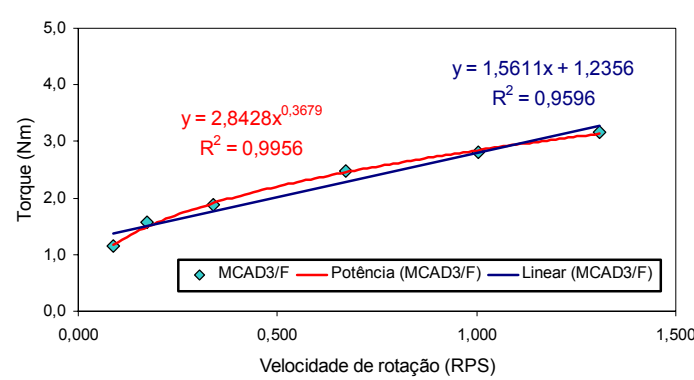

Figura D.15 - Parte ascendente da curva de cisalhamento do MCAD3/F produzido com CPV ARI Plus (10 minutos).

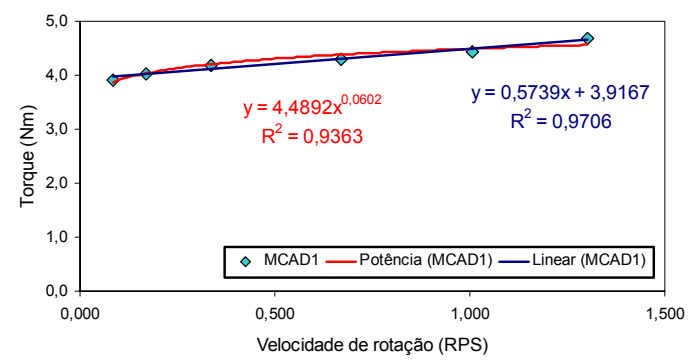

Figura D.17 - Parte ascendente da curva de cisalhamento do MCAD1 produzido com CPV ARI Plus (30 minutos).

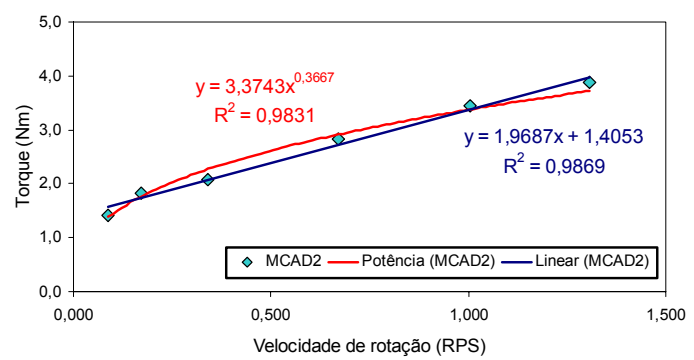

Figura D.19 - Parte ascendente da curva de cisalhamento do MCAD2 produzido com CPV ARI Plus (30 minutos).

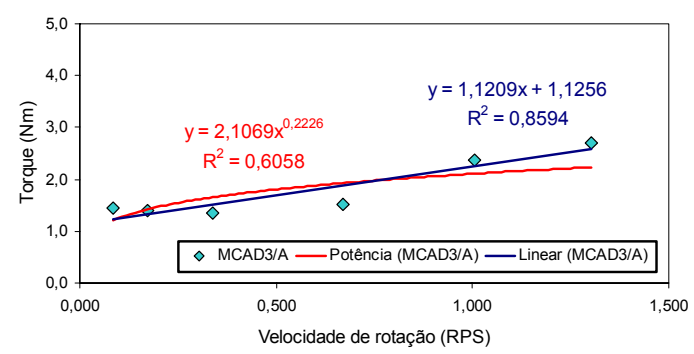

Figura D.21 - Parte ascendente da curva de cisalhamento do MCAD3/A produzido com CPV ARI Plus (30 minutos).

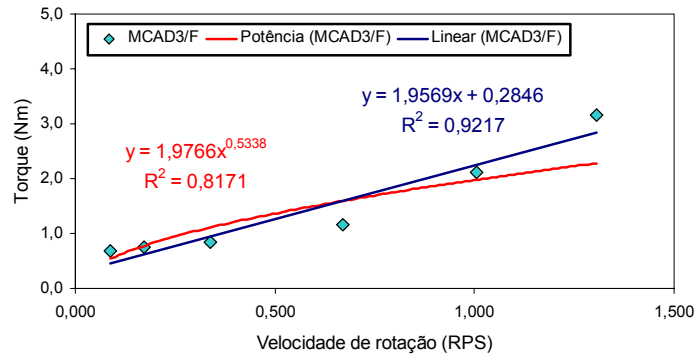

Figura D.16 - Parte descendente da curva de cisalhamento do MCAD3/F produzido com CPV ARI Plus (10 minutos).

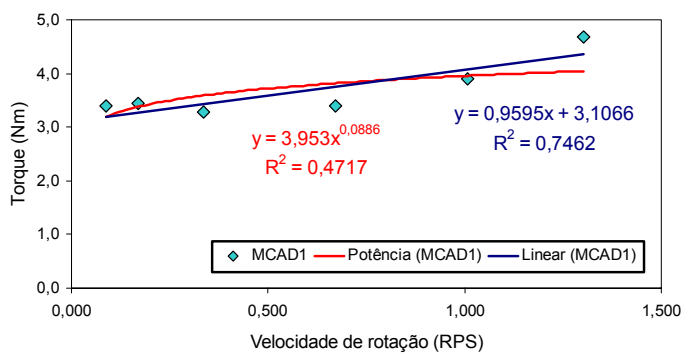

Figura D.18 - Parte descendente da curva de cisalhamento do MCAD1 produzido com CPV ARI Plus (30 minutos).

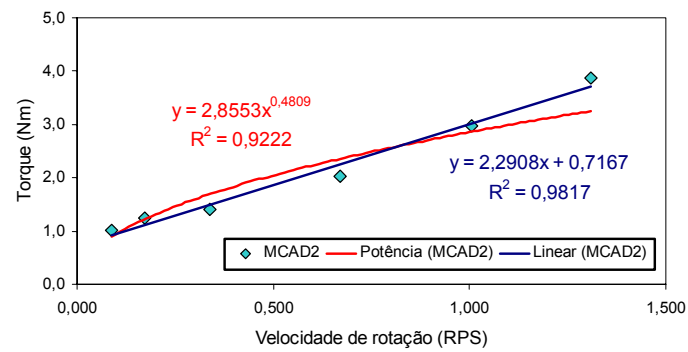

Figura D.20 - Parte descendente da curva de cisalhamento do MCAD2 produzido com CPV ARI Plus (30 minutos).

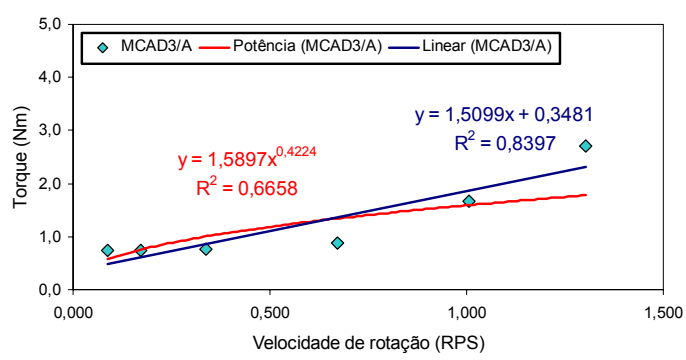

Figura D.22 - Parte descendente da curva de cisalhamento do MCAD3/A produzido com CPV ARI Plus (30 minutos). 


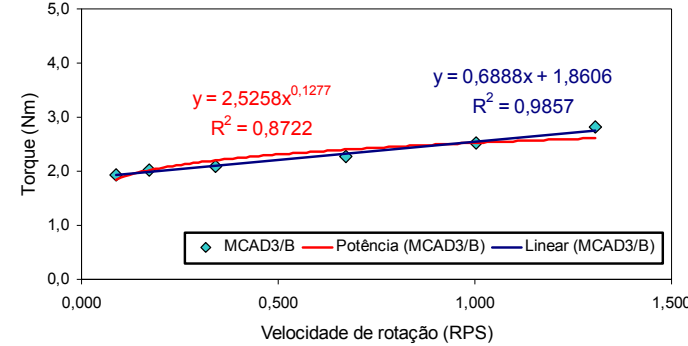

Figura D.23 - Parte ascendente da curva de cisalhamento do MCAD3/B produzido com CPV ARI Plus (30 minutos).

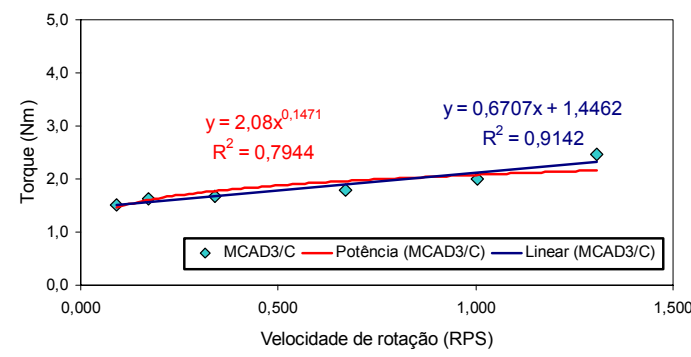

Figura D.25 - Parte ascendente da curva de cisalhamento do MCAD3/C produzido com CPV ARI Plus (30 minutos).

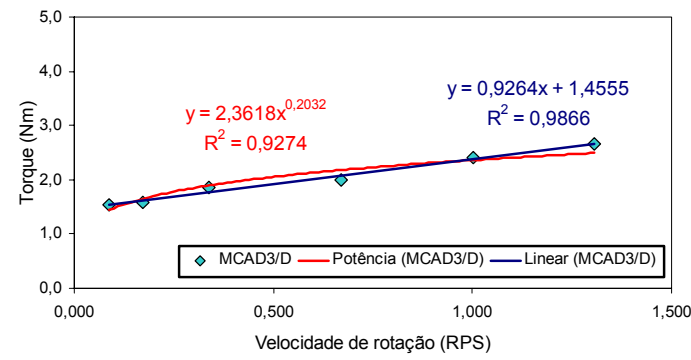

Figura D.27 - Parte ascendente da curva de cisalhamento do MCAD3/D produzido com CPV ARI Plus (30 minutos).

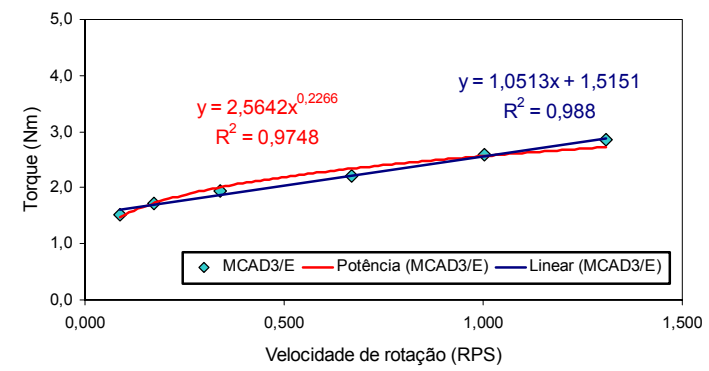

Figura D.29 - Parte ascendente da curva de cisalhamento do MCAD3/E produzido com CPV ARI Plus (30 minutos).

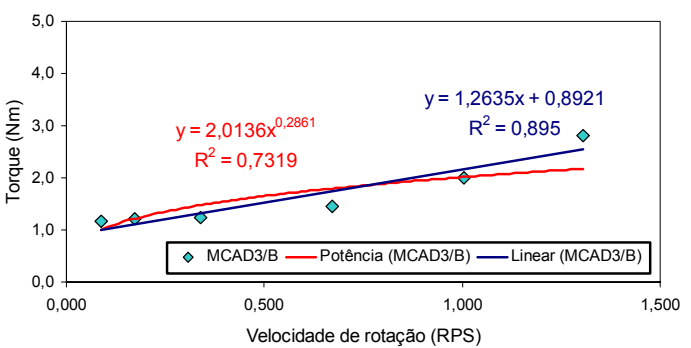

Figura D.24 - Parte descendente da curva de cisalhamento do MCAD3/B produzido com CPV ARI Plus (30 minutos).

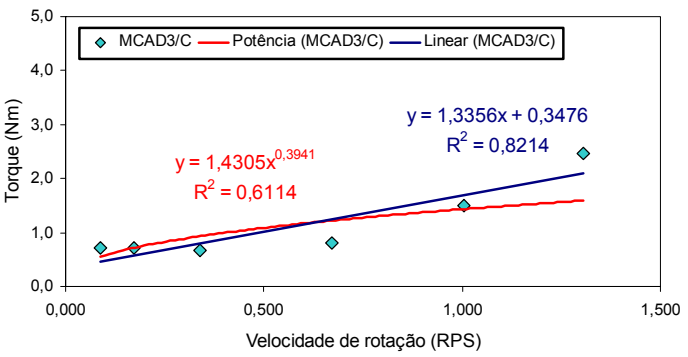

Figura D.26 - Parte descendente da curva de cisalhamento do MCAD3/C produzido com CPV ARI Plus (30 minutos).

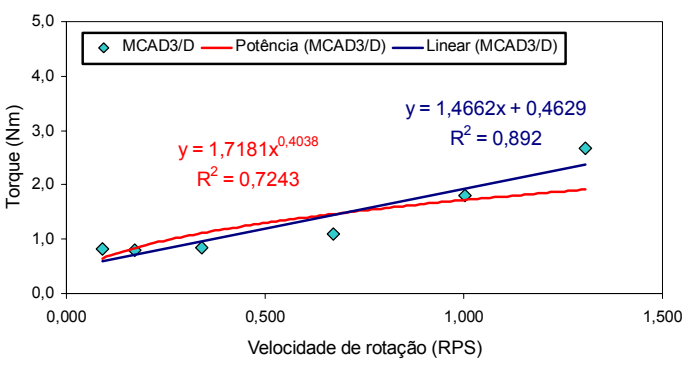

Figura D.28 - Parte descendente da curva de cisalhamento do MCAD3/D produzido com CPV ARI Plus (30 minutos).

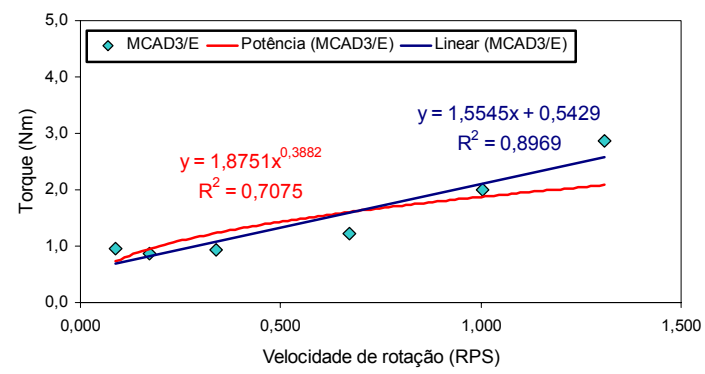

Figura D.30 - Parte descendente da curva de cisalhamento do MCAD3/E produzido com CPV ARI Plus (30 minutos). 


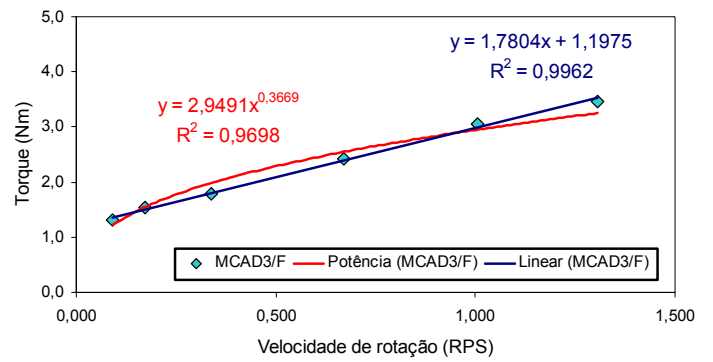

Figura D.31 - Parte ascendente da curva de cisalhamento do MCAD3/F produzido com CPV ARI Plus (30 minutos).

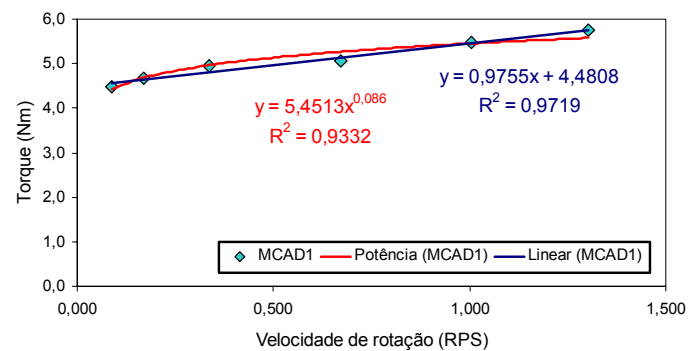

Figura D.33 - Parte ascendente da curva de cisalhamento do MCAD1 produzido com CPV ARI Plus (60 minutos).

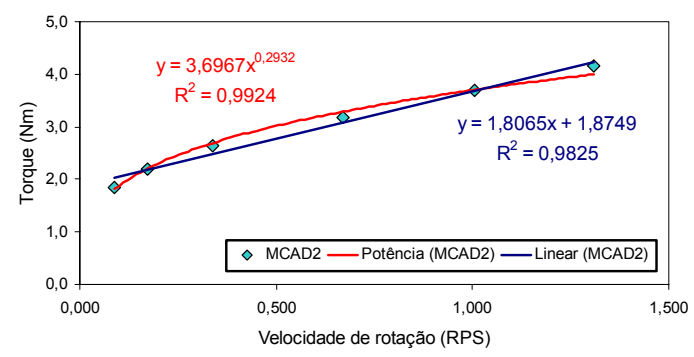

Figura D.35 - Parte ascendente da curva de cisalhamento do MCAD2 produzido com CPV ARI Plus (60 minutos).

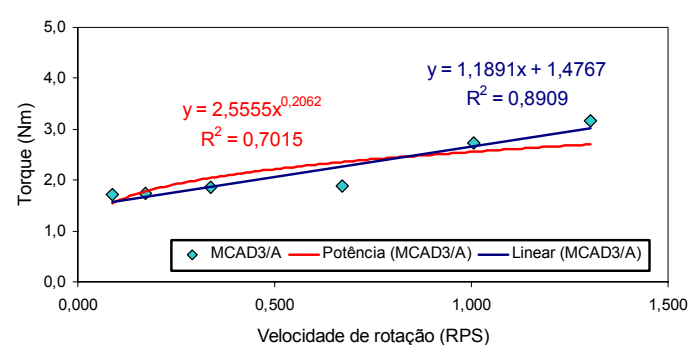

Figura D.37 - Parte ascendente da curva de cisalhamento do MCAD3/A produzido com CPV ARI Plus (60 minutos).

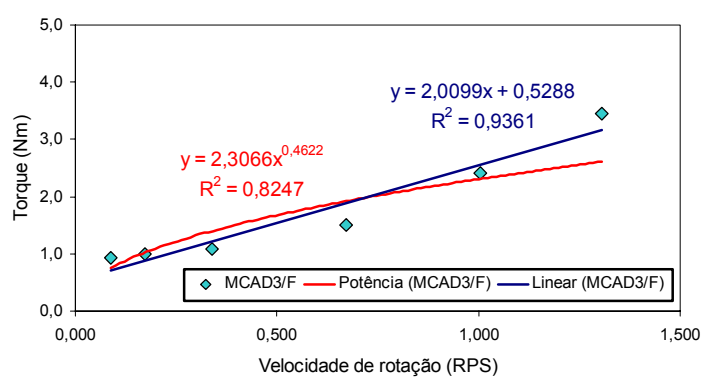

Figura D.32 - Parte descendente da curva de cisalhamento do MCAD3/F produzido com CPV ARI Plus (30 minutos).

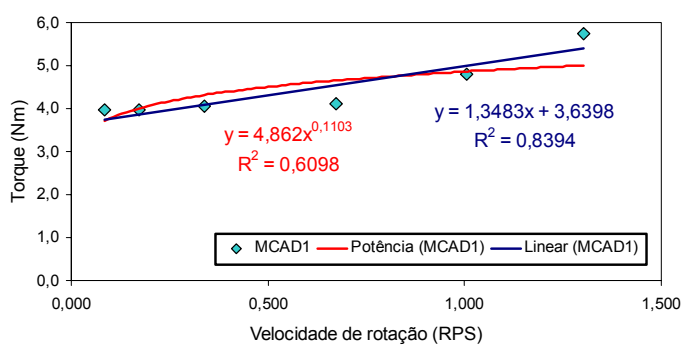

Figura D.34 - Parte descendente da curva de cisalhamento do MCAD1 produzido com CPV ARI Plus (60 minutos).

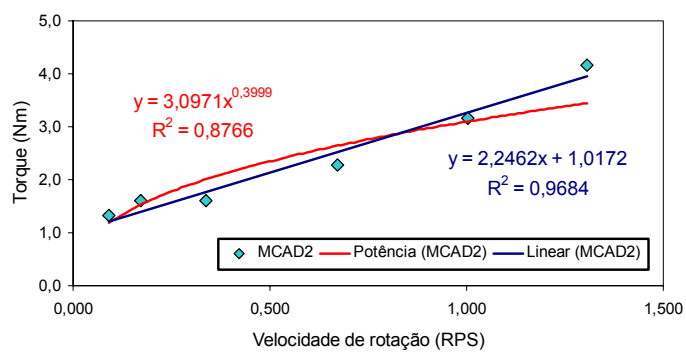

Figura D.36 - Parte descendente da curva de cisalhamento do MCAD2 produzido com CPV ARI Plus (60 minutos).

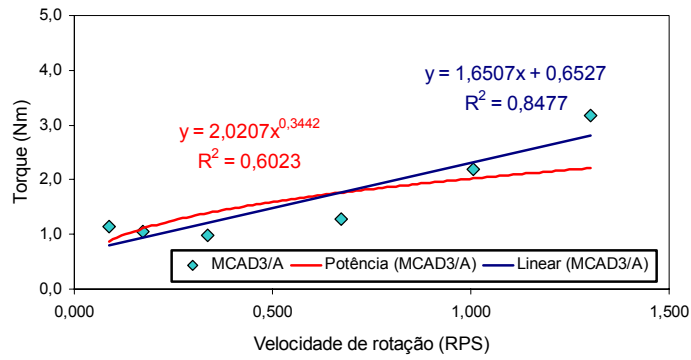

Figura D.38 - Parte descendente da curva de cisalhamento do MCAD3/A produzido com CPV ARI Plus (60 minutos). 


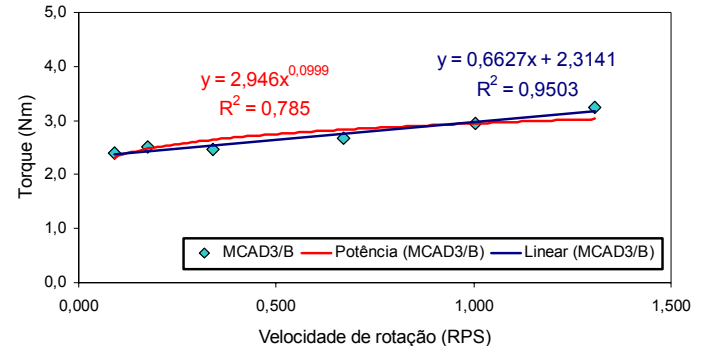

Figura D.39 - Parte ascendente da curva de cisalhamento do MCAD3/B produzido com CPV ARI Plus (60 minutos).

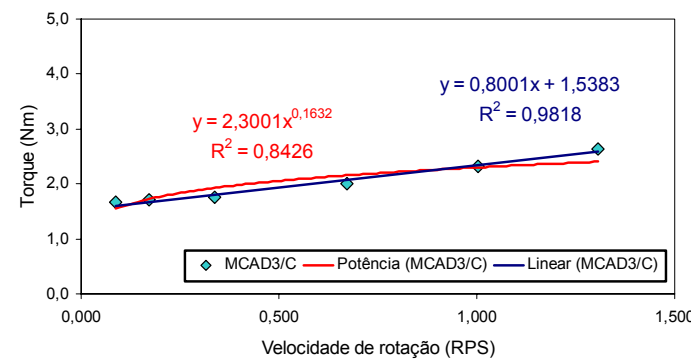

Figura D.41 - Parte ascendente da curva de cisalhamento do MCAD3/C produzido com CPV ARI Plus (60 minutos).

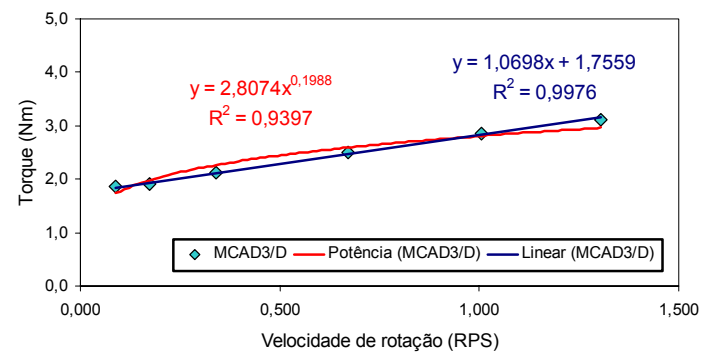

Figura D.43 - Parte ascendente da curva de cisalhamento do MCAD3/D produzido com CPV ARI Plus (60 minutos).

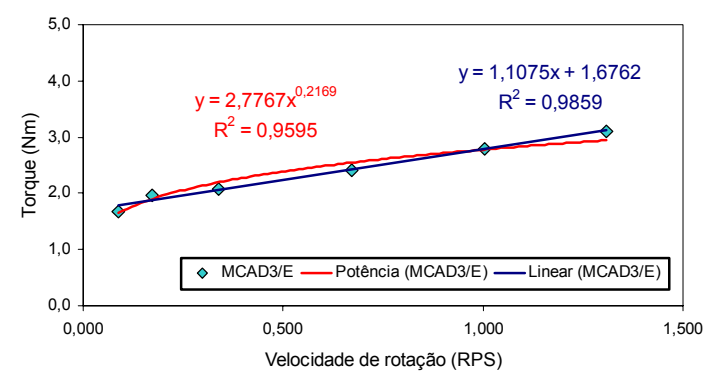

Figura D.45 - Parte ascendente da curva de cisalhamento do MCAD3/E produzido com CPV ARI Plus (60 minutos).

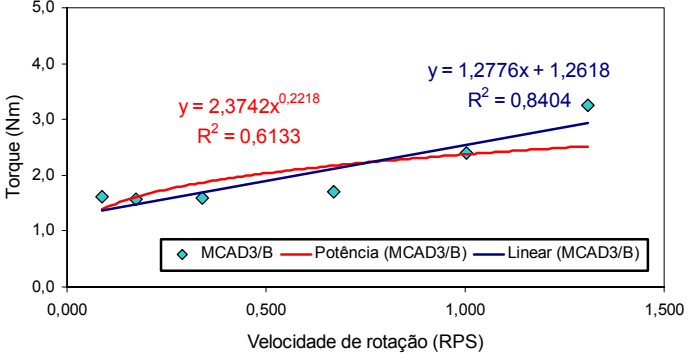

Figura D.40 - Parte descendente da curva de cisalhamento do MCAD3/B produzido com CPV ARI Plus (60 minutos).

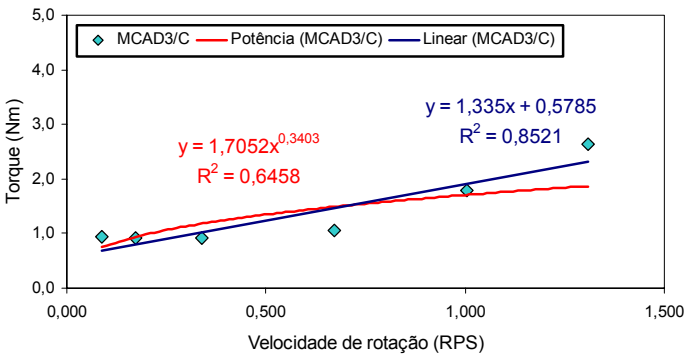

Figura D.42 - Parte descendente da curva de cisalhamento do MCAD3/C produzido com CPV ARI Plus (60 minutos).

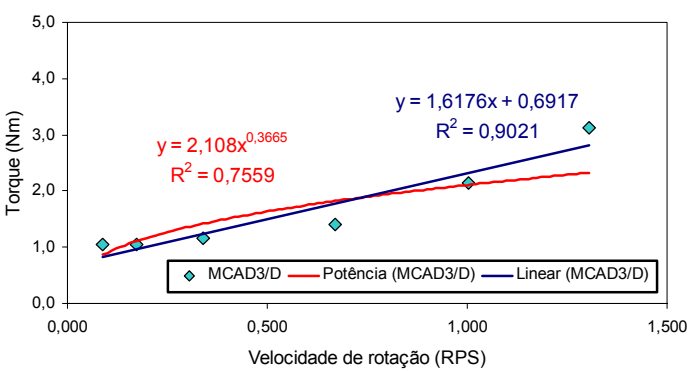

Figura D.44 - Parte descendente da curva de cisalhamento do MCAD3/D produzido com CPV ARI Plus (60 minutos).

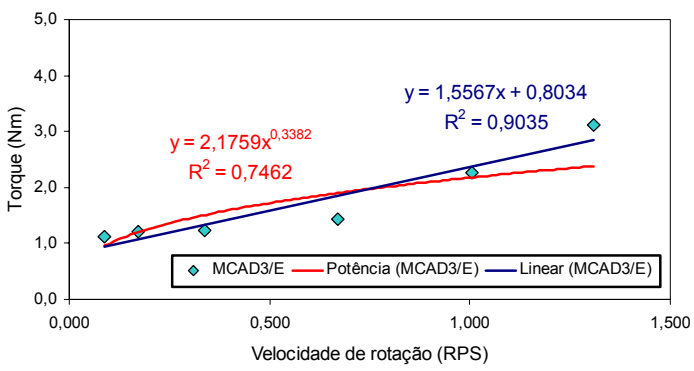

Figura D.46 - Parte descendente da curva de cisalhamento do MCAD3/E produzido com CPV ARI Plus (60 minutos). 


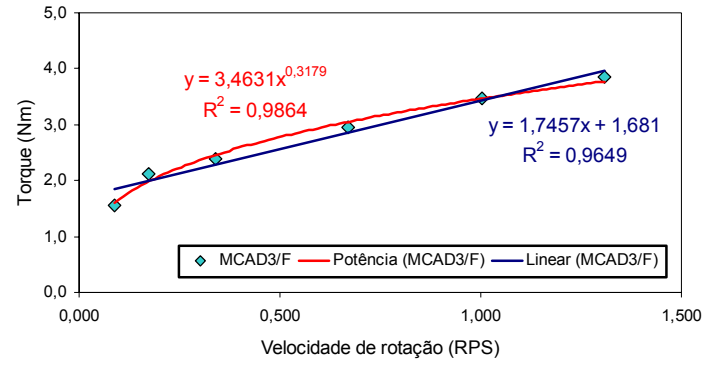

Figura D.47 - Parte ascendente da curva de cisalhamento do MCAD3/F produzido com CPV ARI Plus (60 minutos).

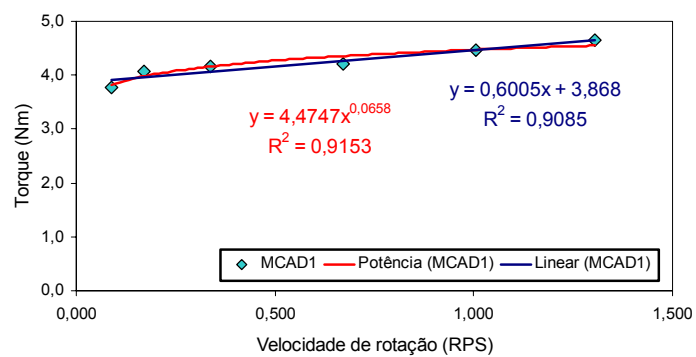

Figura D.49 - Parte ascendente da curva de cisalhamento do MCAD1 produzido com CPV ARI RS (10 minutos).

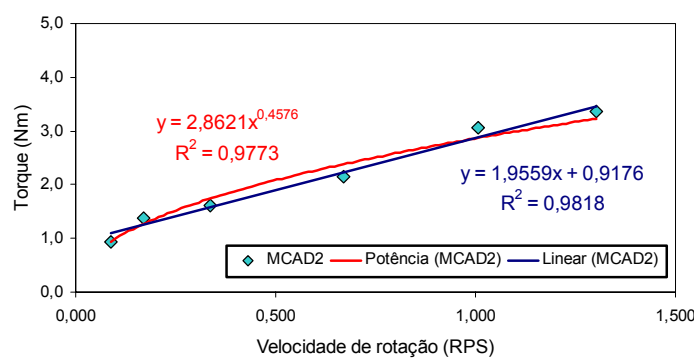

Figura D.51 - Parte ascendente da curva de cisalhamento do MCAD2 produzido com CPV ARI RS (10 minutos).

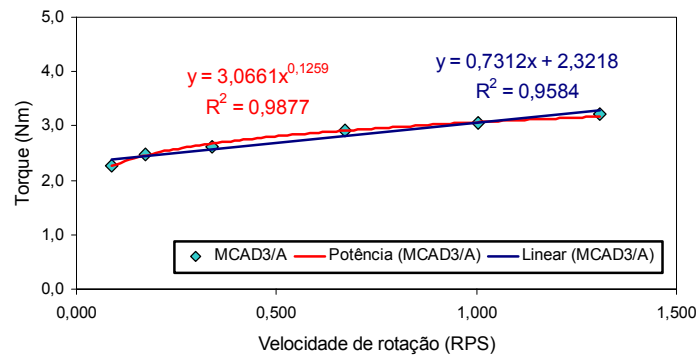

Figura D.53 - Parte ascendente da curva de cisalhamento do MCAD3/A produzido com CPV ARI RS (10 minutos).

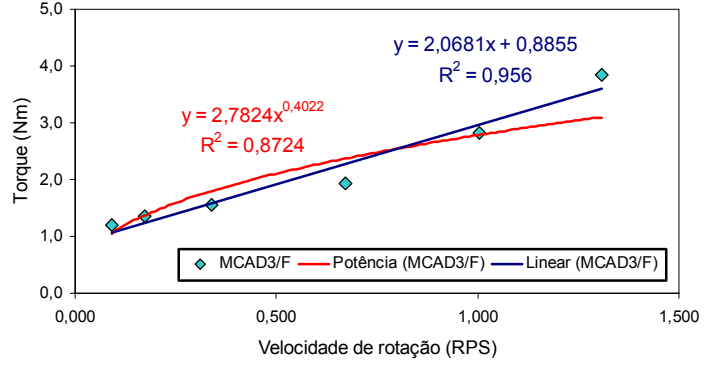

Figura D.48 - Parte descendente da curva de cisalhamento do MCAD3/F produzido com CPV ARI Plus (60 minutos).

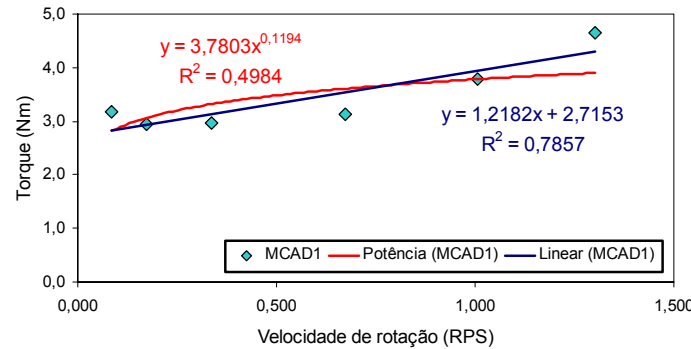

Figura D.50 - Parte descendente da curva de cisalhamento do MCAD1 produzido com CPV ARI RS (10 minutos).

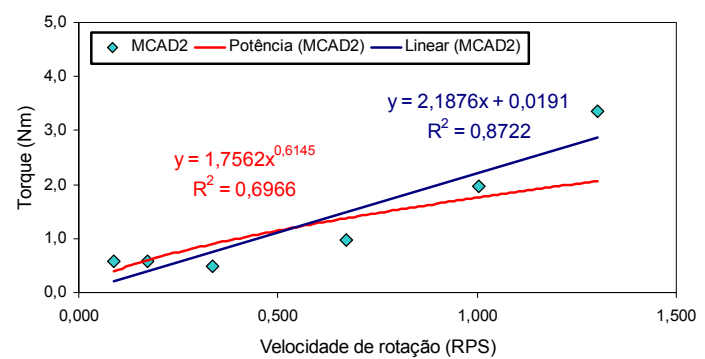

Figura D.52 - Parte descendente da curva de cisalhamento do MCAD2 produzido com CPV ARI RS (10 minutos).

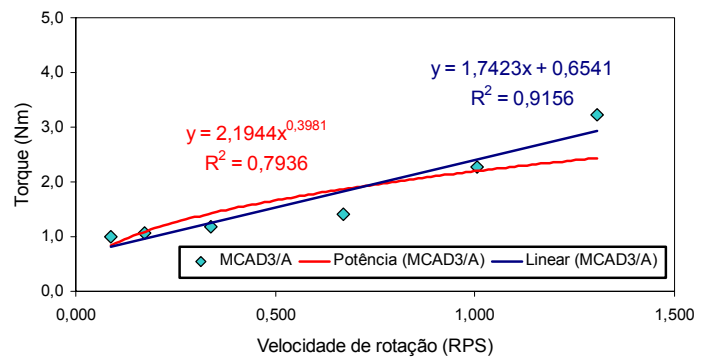

Figura D.54 - Parte descendente da curva de cisalhamento do MCAD3/A produzido com CPV ARI RS (10 minutos). 


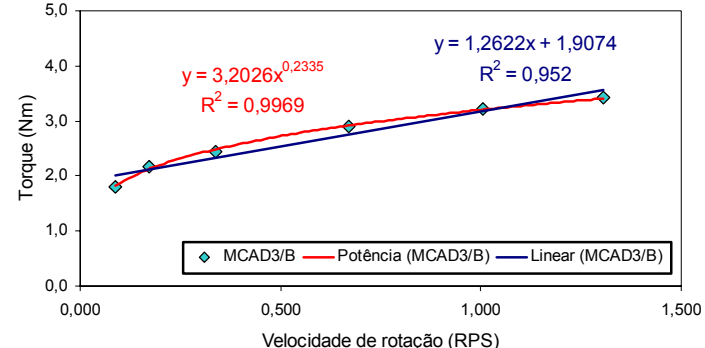

Figura D.55 - Parte ascendente da curva de cisalhamento do MCAD3/B produzido com CPV ARI RS (10 minutos).

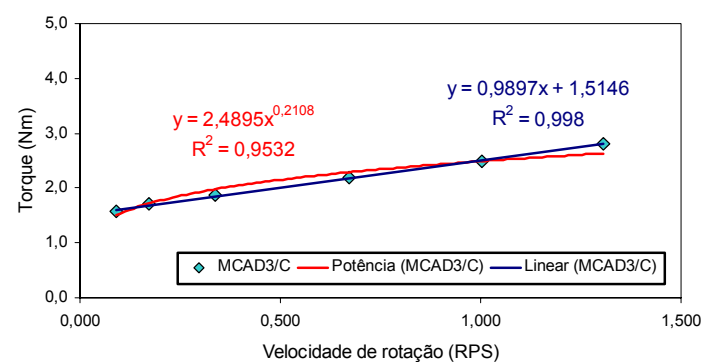

Figura D.57 - Parte ascendente da curva de cisalhamento do MCAD3/C produzido com CPV ARI RS (10 minutos).

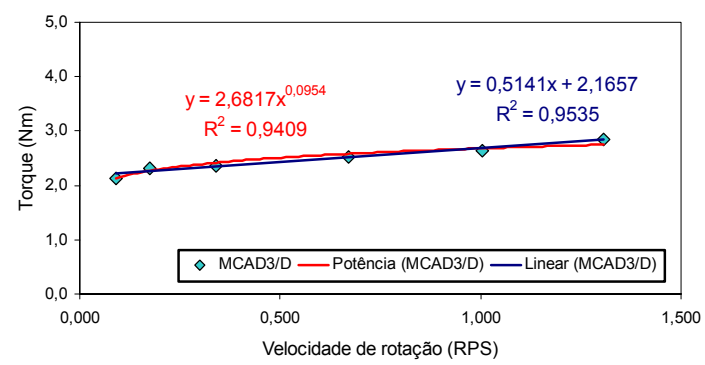

Figura D.59 - Parte ascendente da curva de cisalhamento do MCAD3/D produzido com CPV ARI RS (10 minutos).

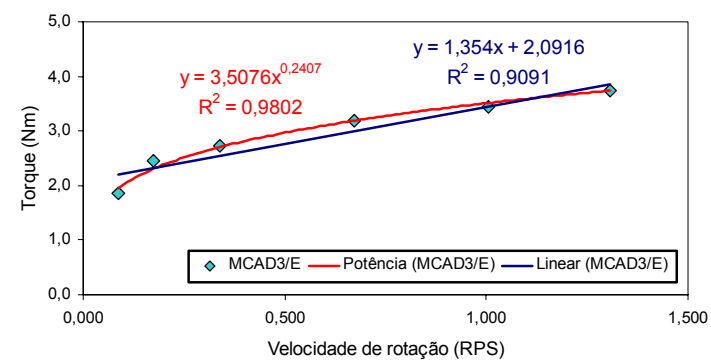

Figura D.61 - Parte ascendente da curva de cisalhamento do MCAD3/E produzido com CPV ARI RS (10 minutos).

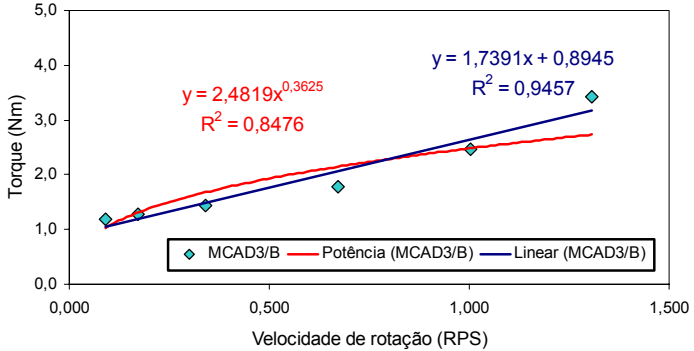

Figura D.56 - Parte descendente da curva de cisalhamento do MCAD3/B produzido com CPV ARI RS (10 minutos).

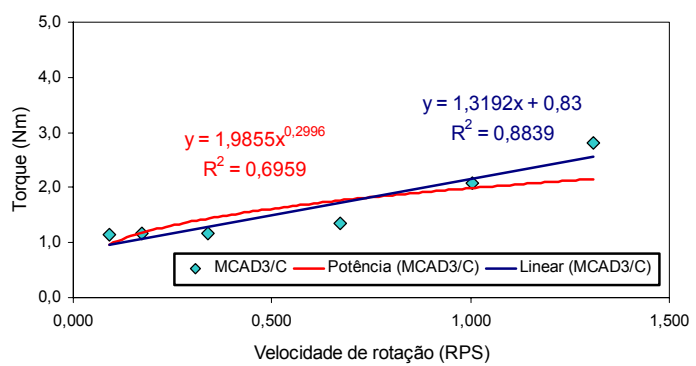

Figura D.58 - Parte descendente da curva de cisalhamento do MCAD3/C produzido com CPV ARI RS (10 minutos).

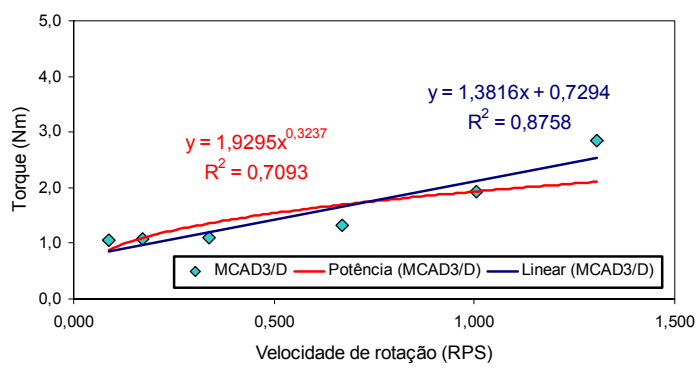

Figura D.60 - Parte descendente da curva de cisalhamento do MCAD3/D produzido com CPV ARI RS (10 minutos).

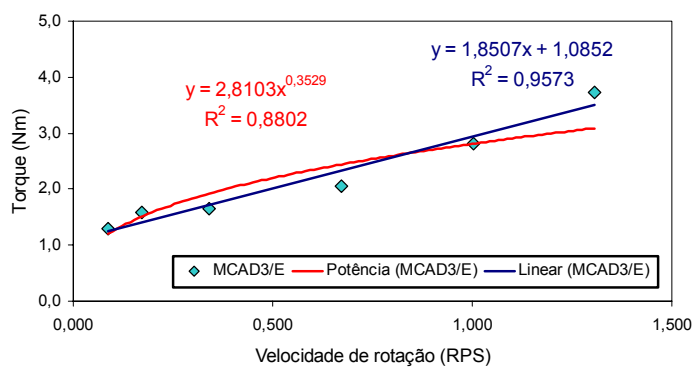

Figura D.62 - Parte descendente da curva de cisalhamento do MCAD3/E produzido com CPV ARI RS (10 minutos). 


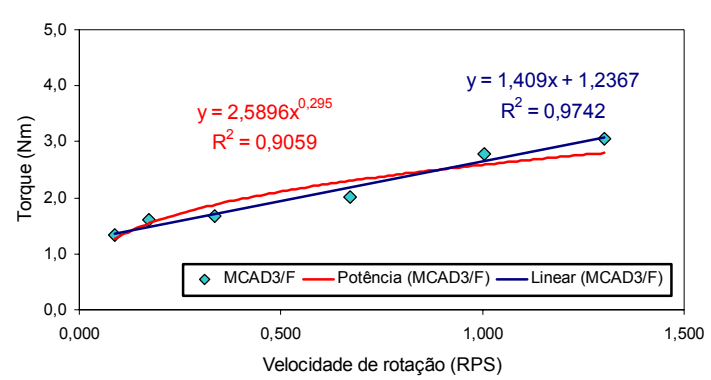

Figura D.63 - Parte ascendente da curva de cisalhamento do MCAD3/F produzido com CPV ARI RS (10 minutos).

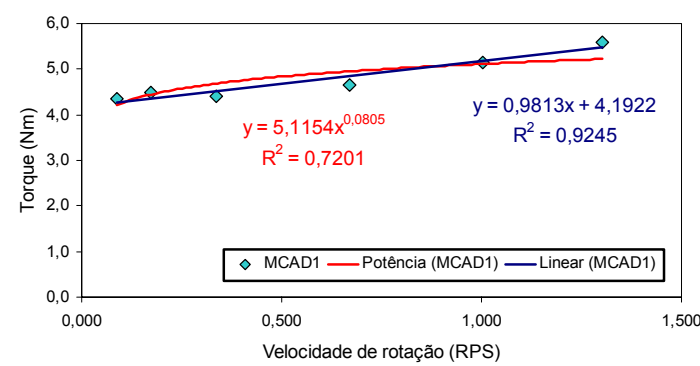

Figura D.65 - Parte ascendente da curva de cisalhamento do MCAD1 produzido com CPV ARI RS (30 minutos).

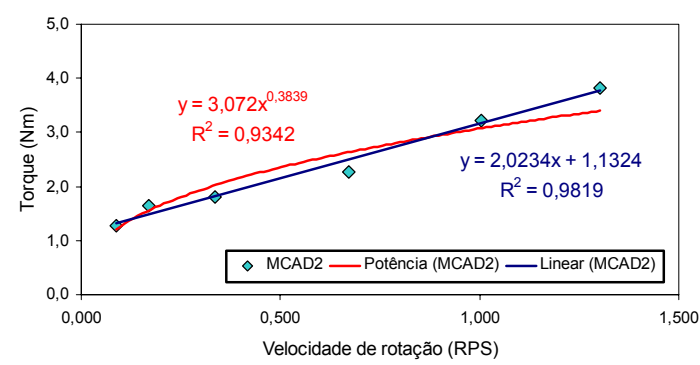

Figura D.67 - Parte ascendente da curva de cisalhamento do MCAD2 produzido com CPV ARI RS (30 minutos).

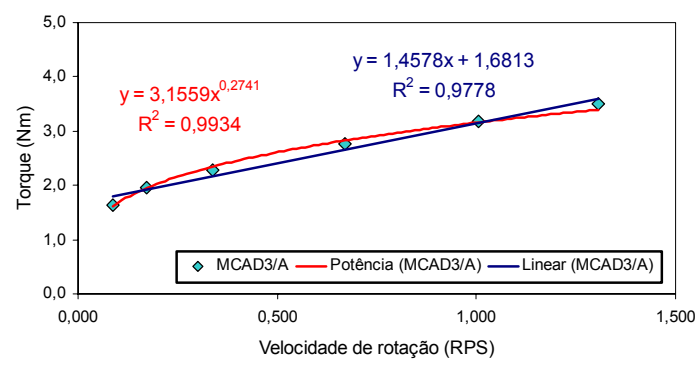

Figura D.69 - Parte ascendente da curva de cisalhamento do MCAD3/A produzido com CPV ARI RS (30 minutos).

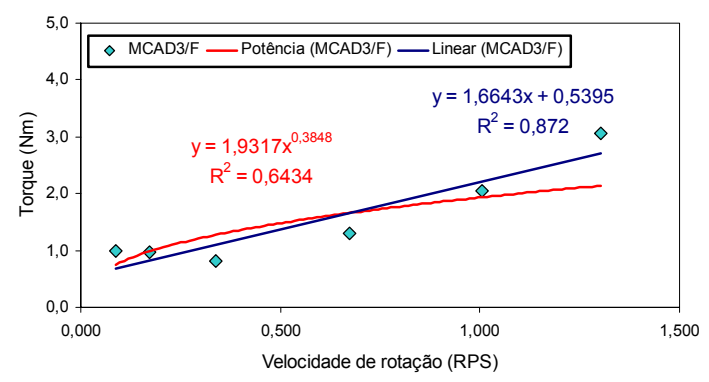

Figura D.64 - Parte descendente da curva de cisalhamento do MCAD3/F produzido com CPV ARI RS (10 minutos).

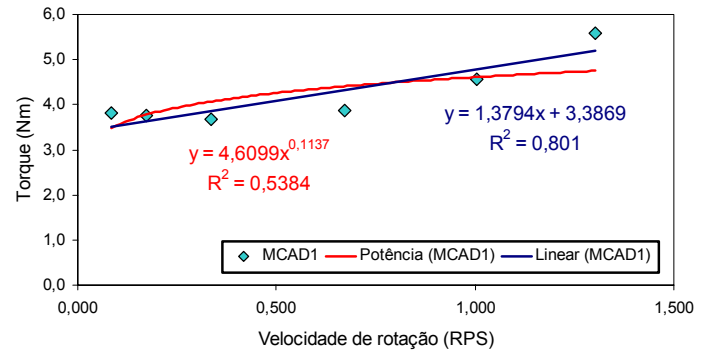

Figura D.66 - Parte descendente da curva de cisalhamento do MCAD1 produzido com CPV ARI RS (30 minutos).

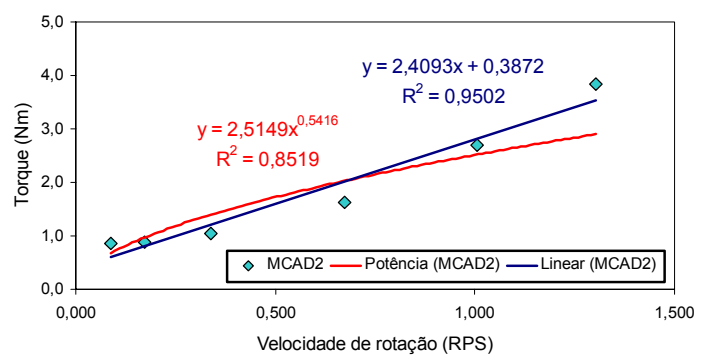

Figura D.68 - Parte descendente da curva de cisalhamento do MCAD2 produzido com CPV ARI RS (30 minutos).

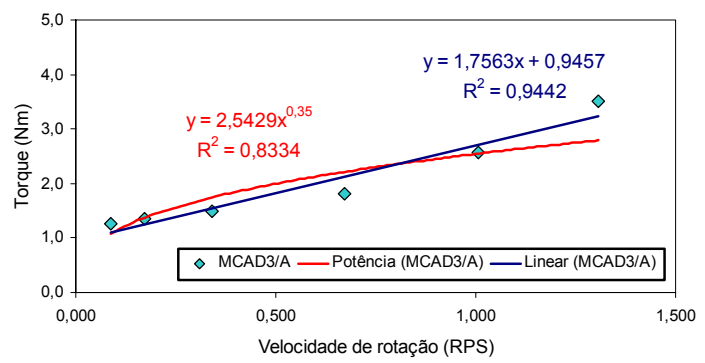

Figura D.70 - Parte descendente da curva de cisalhamento do MCAD3/A produzido com CPV ARI RS (30 minutos). 


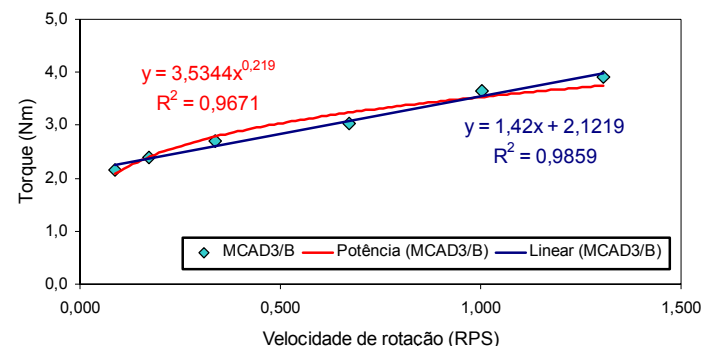

Figura D.71 - Parte ascendente da curva de cisalhamento do MCAD3/B produzido com CPV ARI RS (30 minutos).

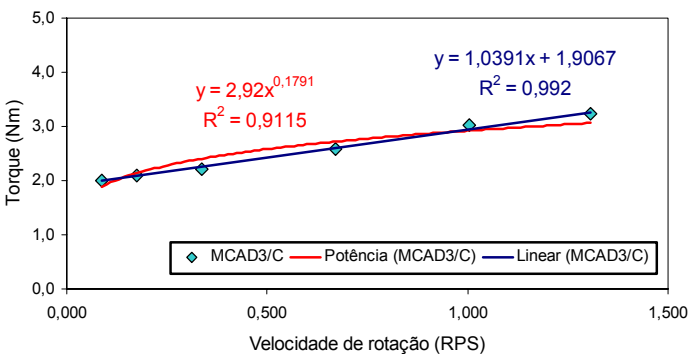

Figura D.73 - Parte ascendente da curva de cisalhamento do MCAD3/C produzido com CPV ARI RS (30 minutos).

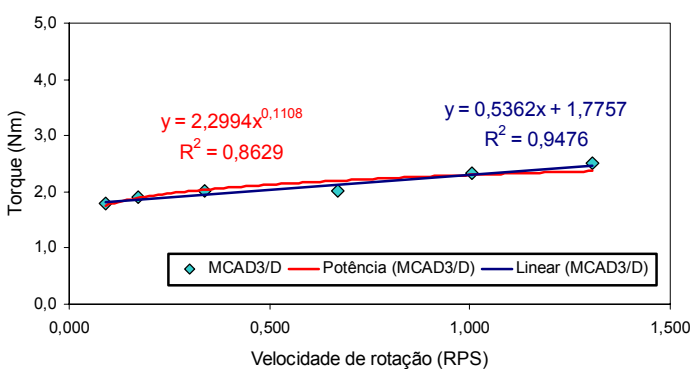

Figura D.75 - Parte ascendente da curva de cisalhamento do MCAD3/D produzido com CPV ARI RS (30 minutos).

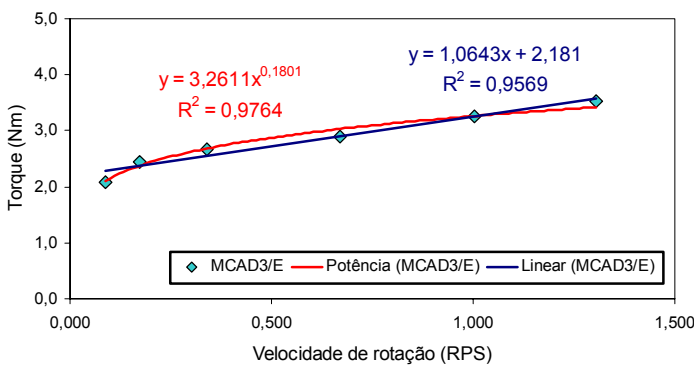

Figura D.77 - Parte ascendente da curva de cisalhamento do MCAD3/E produzido com CPV ARI RS (30 minutos).

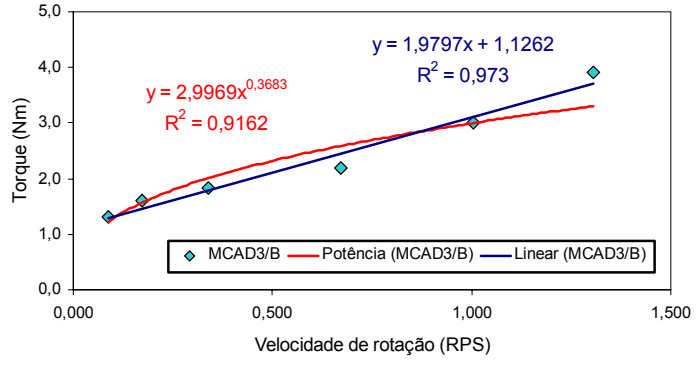

Figura D.72 - Parte descendente da curva de cisalhamento do MCAD3/B produzido com CPV ARI RS (30 minutos).

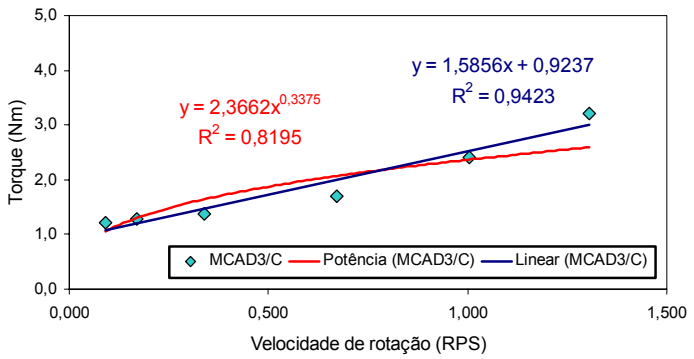

Figura D.74 - Parte descendente da curva de cisalhamento do MCAD3/C produzido com CPV ARI RS (30 minutos).

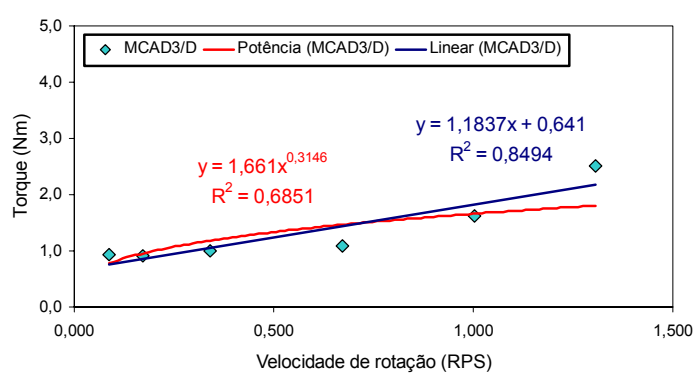

Figura D.76 - Parte descendente da curva de cisalhamento do MCAD3/D produzido com CPV ARI RS (30 minutos).

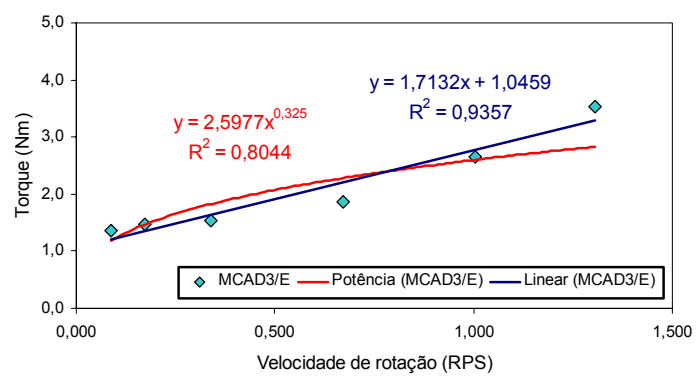

Figura D.78 - Parte descendente da curva de cisalhamento do MCAD3/E produzido com CPV ARI RS (30 minutos). 


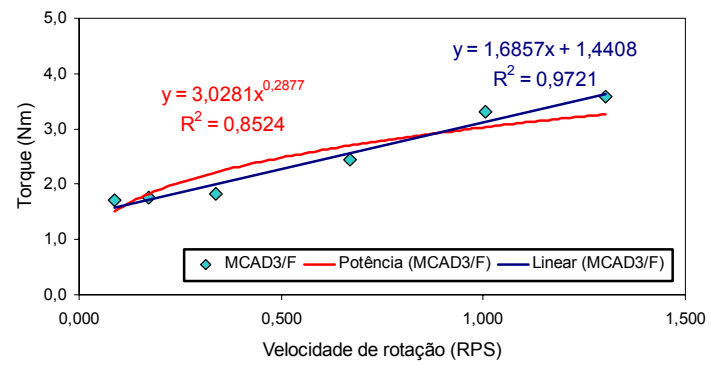

Figura D.79 - Parte ascendente da curva de cisalhamento do MCAD3/F produzido com CPV ARI RS (30 minutos).

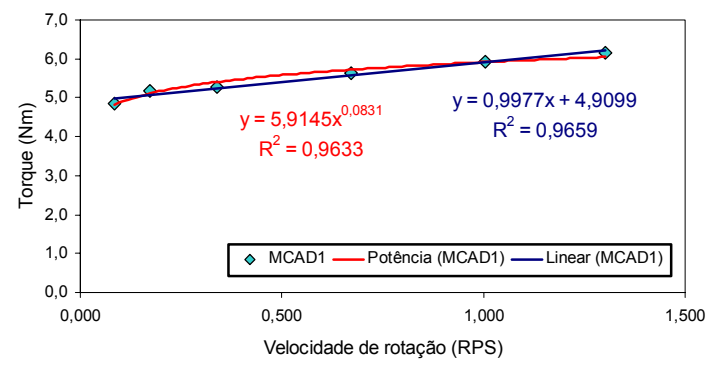

Figura D.81 - Parte ascendente da curva de cisalhamento do MCAD1 produzido com CPV ARI RS (60 minutos).

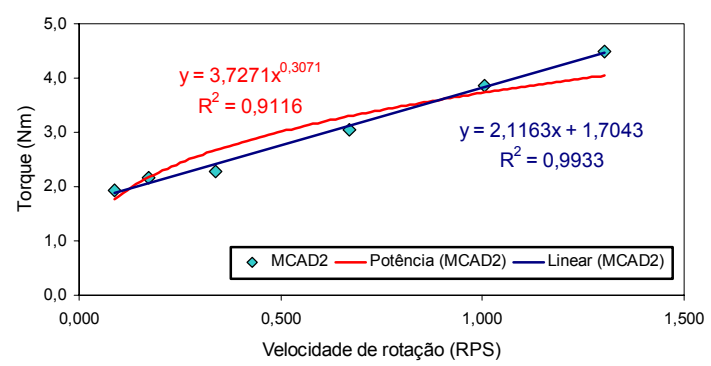

Figura D.83 - Parte ascendente da curva de cisalhamento do MCAD2 produzido com CPV ARI RS (60 minutos).

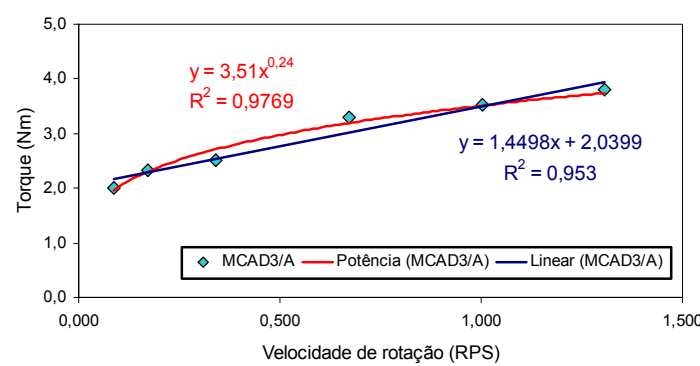

Figura D.85 - Parte ascendente da curva de cisalhamento do MCAD3/A produzido com CPV ARI RS (60 minutos).

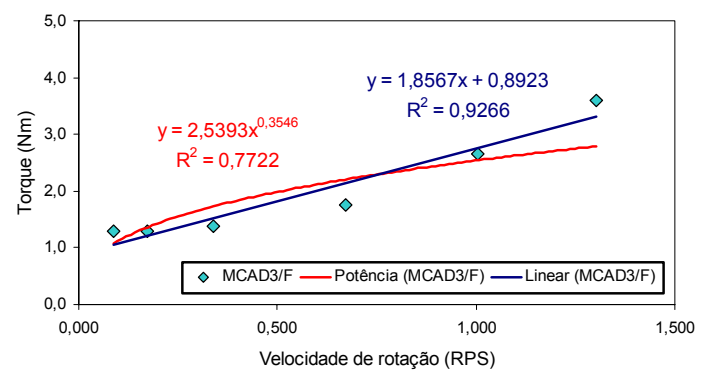

Figura D.80 - Parte descendente da curva de cisalhamento do MCAD3/F produzido com CPV ARI RS (30 minutos).

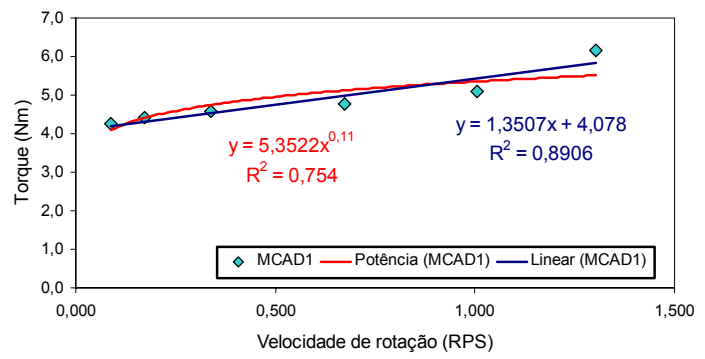

Figura D.82 - Parte descendente da curva de cisalhamento do MCAD1 produzido com CPV ARI RS (60 minutos).

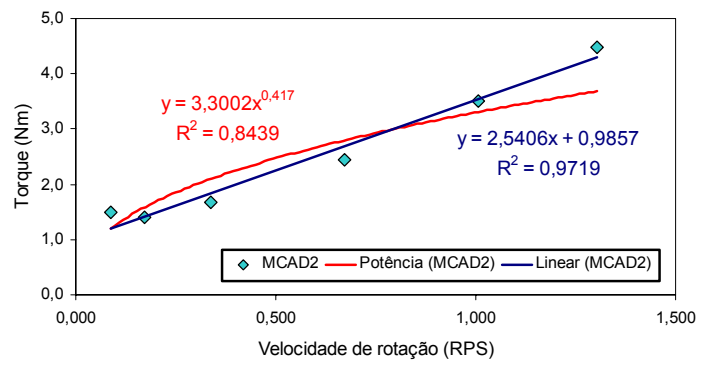

Figura D.84 - Parte descendente da curva de cisalhamento do MCAD2 produzido com CPV ARI RS (60 minutos).

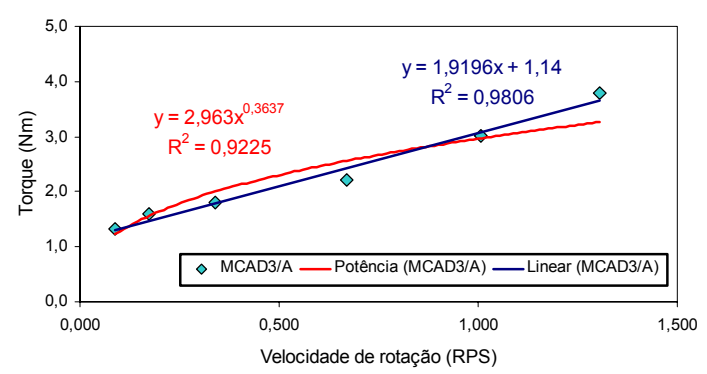

Figura D.86 - Parte descendente da curva de cisalhamento do MCAD3/A produzido com CPV ARI RS (60 minutos). 


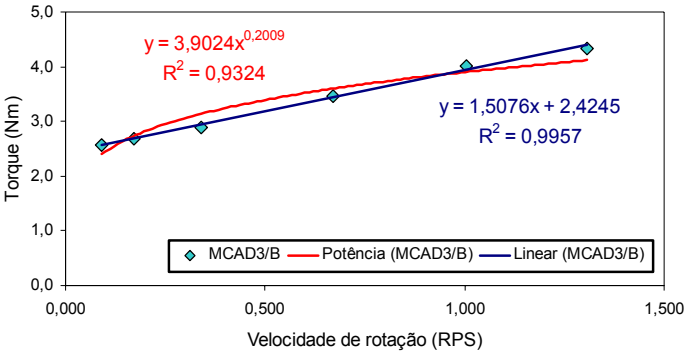

Figura D.87 - Parte ascendente da curva de cisalhamento do MCAD3/B produzido com CPV ARI RS (60 minutos).

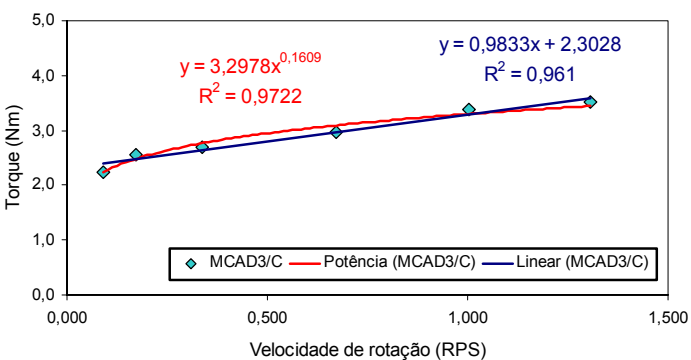

Figura D.89 - Parte ascendente da curva de cisalhamento do MCAD3/C produzido com CPV ARI RS (60 minutos).

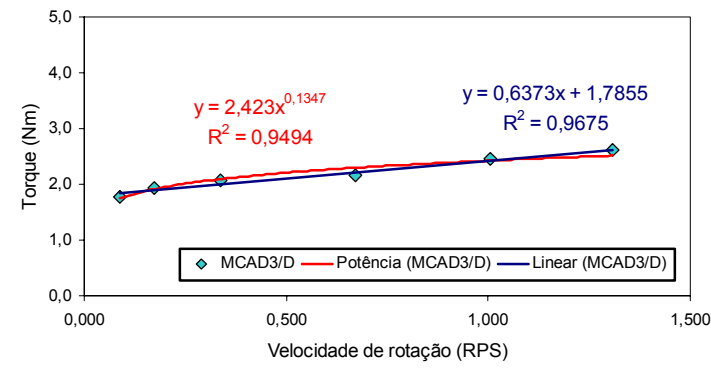

Figura D.91 - Parte ascendente da curva de cisalhamento do MCAD3/D produzido com CPV ARI RS (60 minutos).

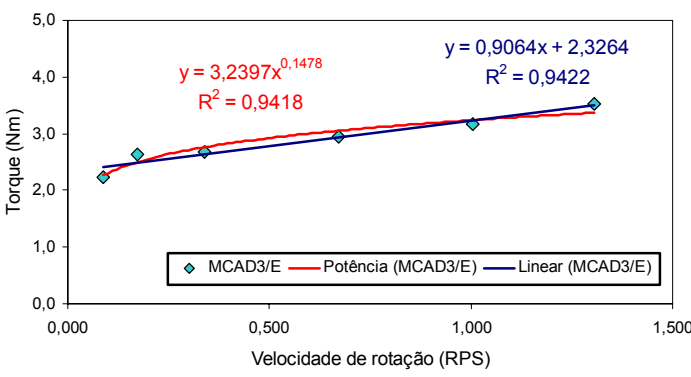

Figura D.93 - Parte ascendente da curva de cisalhamento do MCAD3/E produzido com CPV ARI RS (60 minutos).

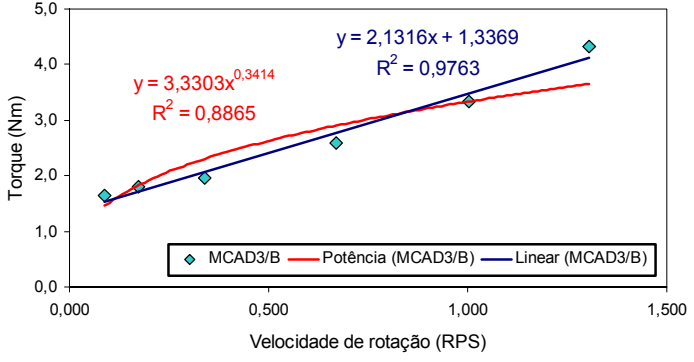

Figura D.88 - Parte descendente da curva de cisalhamento do MCAD3/B produzido com CPV ARI RS (60 minutos).

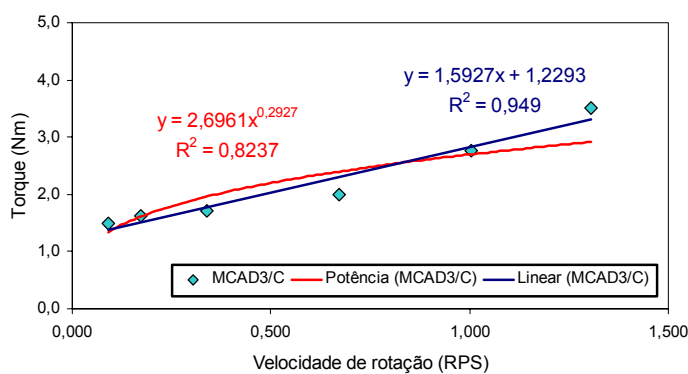

Figura D.90 - Parte descendente da curva de cisalhamento do MCAD3/C produzido com CPV ARI RS (60 minutos).

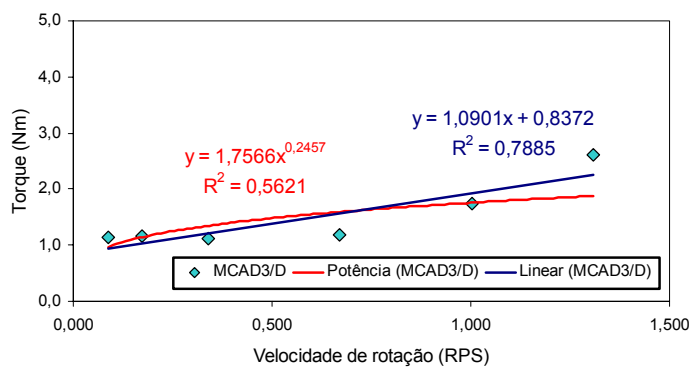

Figura D.92 - Parte descendente da curva de cisalhamento do MCAD3/D produzido com CPV ARI RS (60 minutos).

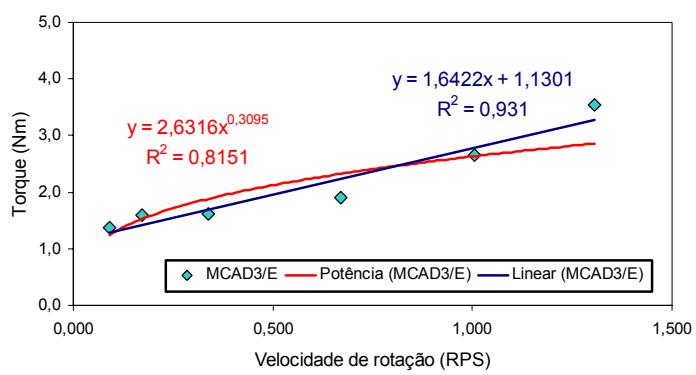

Figura D.94 - Parte descendente da curva de cisalhamento do MCAD3/E produzido com CPV ARI RS (60 minutos). 


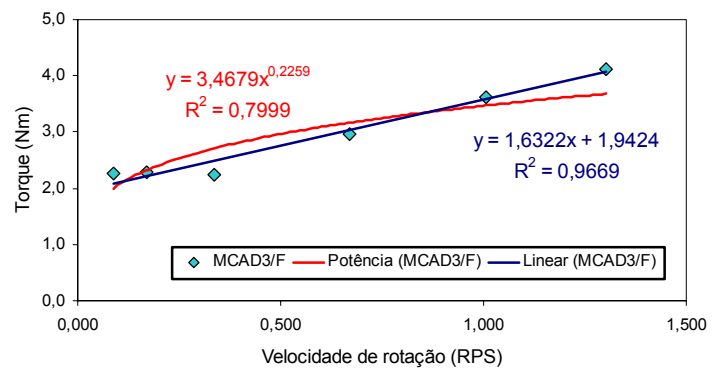

Figura D.95 - Parte ascendente da curva de cisalhamento do MCAD3/F produzido com CPV ARI RS (60 minutos).

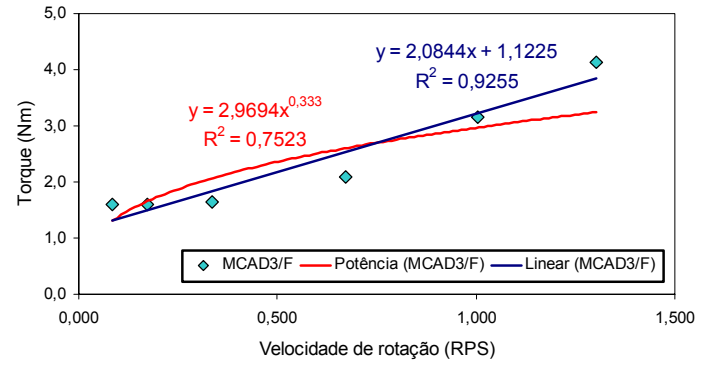

Figura D.96 - Parte descendente da curva de cisalhamento do MCAD3/F produzido com CPV ARI RS (60 minutos).

Tabela D.3 - Resumo dos coeficientes de ajuste dos modelos reológicos considerados.

\begin{tabular}{|c|c|c|c|c|c|c|c|c|c|}
\hline \multirow{2}{*}{\multicolumn{2}{|c|}{$\frac{\text { Cimento }}{\text { Modelo }}$}} & \multicolumn{4}{|c|}{ CPV ARI Plus } & \multicolumn{4}{|c|}{ CPV ARI RS } \\
\hline & & Linear & Potência & Linear & Potência & Linear & Potência & Linear & Potência \\
\hline \multicolumn{2}{|c|}{ Mistura } & \multicolumn{2}{|c|}{ Curva ascendente } & \multicolumn{2}{|c|}{ Curva descendente } & \multicolumn{2}{|c|}{ Curva ascendente } & \multicolumn{2}{|c|}{ Curva descendente } \\
\hline \multirow{4}{*}{ MCAD1 } & $10 \mathrm{~min}$ & 0,9952 & 0,9409 & 0,9252 & 0,827 & 0,9085 & 0,9153 & 0,7857 & 0,4984 \\
\hline & $30 \mathrm{~min}$ & 0,9706 & 0,9363 & 0,7462 & 0,4717 & 0,9245 & 0,7201 & 0,801 & 0,5384 \\
\hline & $60 \mathrm{~min}$ & 0,9719 & 0,9332 & 0,8394 & 0,6098 & 0,9659 & 0,9633 & 0,8906 & 0,754 \\
\hline & Média & 0,9792 & 0,9368 & 0,8369 & 0,6362 & 0,9330 & 0,8662 & 0,8258 & 0,5969 \\
\hline \multirow{4}{*}{ MCAD2 } & $10 \mathrm{~min}$ & 0,9646 & 0,9959 & 0,9666 & 0,8968 & 0,9818 & 0,9773 & 0,8717 & 0,6966 \\
\hline & $30 \mathrm{~min}$ & 0,9869 & 0,983 & 0,9817 & 0,9222 & 0,9819 & 0,9342 & 0,9502 & 0,8519 \\
\hline & $60 \mathrm{~min}$ & 0,9825 & 0,9924 & 0,9682 & 0,8763 & 0,9933 & 0,9116 & 0,9721 & 0,8454 \\
\hline & Média & 0,9780 & 0,9904 & 0,9722 & 0,8984 & 0,9857 & 0,9410 & 0,9313 & 0,7980 \\
\hline \multirow{3}{*}{ MCAD3/A } & $10 \mathrm{~min}$ & 0,9885 & 0,9379 & 0,7821 & 0,4659 & 0,7605 & 0,536 & 0,6952 & 0,3523 \\
\hline & $30 \mathrm{~min}$ & 0,8594 & 0,6058 & 0,8397 & 0,6658 & 0,8807 & 0,6802 & 0,8445 & 0,6105 \\
\hline & $60 \mathrm{~min}$ & 0,8909 & 0,7015 & 0,8477 & 0,6023 & 0,835 & 0,5965 & 0,8154 & 0,5511 \\
\hline \multirow{3}{*}{ MCAD3/B } & $10 \mathrm{~min}$ & 0,9667 & 0,8829 & 0,8069 & 0,6406 & 0,952 & 0,9969 & 0,9457 & 0,8476 \\
\hline & $30 \mathrm{~min}$ & 0,9845 & 0,8742 & 0,895 & 0,7319 & 0,9859 & 0,9671 & 0,973 & 0,9162 \\
\hline & $60 \mathrm{~min}$ & 0,9503 & 0,785 & 0,8404 & 0,6133 & 0,9957 & 0,9324 & 0,9763 & 0,8865 \\
\hline \multirow{3}{*}{ MCAD3/C } & $10 \mathrm{~min}$ & 0,9437 & 0,8574 & 0,7776 & 0,5584 & 0,998 & 0,8651 & 0,8839 & 0,6959 \\
\hline & $30 \mathrm{~min}$ & 0,9131 & 0,794 & 0,8214 & 0,6114 & 0,992 & 0,9115 & 0,9423 & 0,8195 \\
\hline & $60 \mathrm{~min}$ & 0,9818 & 0,8426 & 0,8521 & 0,6458 & 0,961 & 0,9722 & 0,949 & 0,8237 \\
\hline \multirow{3}{*}{ MCAD3/D } & $10 \mathrm{~min}$ & 0,9958 & 0,9677 & 0,7501 & 0,5039 & 0,9186 & 0,7728 & 0,765 & 0,454 \\
\hline & $30 \mathrm{~min}$ & 0,9866 & 0,9274 & 0,892 & 0,7243 & 0,9544 & 0,8043 & 0,804 & 0,5338 \\
\hline & $60 \mathrm{~min}$ & 0,9976 & 0,9397 & 0,9021 & 0,7559 & 0,8478 & 0,5816 & 0,8104 & 0,5301 \\
\hline \multirow{3}{*}{ MCAD3/E } & $10 \mathrm{~min}$ & 0,9274 & 0,9548 & 0,8335 & 0,6559 & 0,9091 & 0,9802 & 0,9573 & 0,8802 \\
\hline & $30 \mathrm{~min}$ & 0,988 & 0,9748 & 0,8969 & 0,7075 & 0,9569 & 0,9764 & 0,9357 & 0,8044 \\
\hline & $60 \mathrm{~min}$ & 0,9859 & 0,9595 & 0,9035 & 0,7462 & 0,9422 & 0,9418 & 0,931 & 0,8151 \\
\hline \multirow{3}{*}{ MCAD3/F } & $10 \mathrm{~min}$ & 0,9596 & 0,9956 & 0,9217 & 0,8171 & 0,9742 & 0,9059 & 0,872 & 0,6434 \\
\hline & $30 \mathrm{~min}$ & 0,9962 & 0,9698 & 0,9361 & 0,8247 & 0,9721 & 0,8524 & 0,9266 & 0,7722 \\
\hline & $60 \mathrm{~min}$ & 0,9649 & $0,9864$. & 0,956 & 0,8724 & 0,9669 & 0,7999 & 0,9255 & 0,7523 \\
\hline \multicolumn{2}{|c|}{ Média (MCAD3) } & 0,9601 & 0,8865 & 0,8586 & 0,6746 & 0,9335 & 0,8374 & 0,8863 & 0,7049 \\
\hline
\end{tabular}




\section{REFERÊNCIAS BIBLIOGRÁFICAS}

AGULLÓ, L. et al. Fluidity of cement pastes with mineral admixtures and superplasticizer - a study based on the Marsh cone test. Materials and Structures, v. 32, n. 221, p. 479-485, Aug.-Sept. 1999.

AIAD, I. Influence of time addition of superplasticizers on the rheological properties of fresh cement pastes. Cement and Concrete Research, v. 33, n. 8, p. 1229-1234, Aug. 2003.

AIAD, I.; EL-ALEEM, S. A.; EL-DIDAMONY, H. Effect of delaying addition of some concrete admixtures on the rheological properties of cement pastes. Cement and Concrete Research, v. 32, n. 11, p. 1839-1843, Nov. 2002.

AïTCIN, P. C. Concreto de alto desempenho. Tradução de Geraldo G. Serra. São Paulo: PINI, 2000. 667p.

AIITCIN, P.-C.; JOLICOEUR, C.; MacGREGOR, J. G. Superplasticizers: how they work and why they occasionally don't. Concrete International, v. 16, n. 5, p. 45-52, May. 1994.

AÏTCIN, P.-C.; NEVILLE, A. How the water-cement ratio affects concrete strength. Concrete International, v. 25, n. 8, p. 51-58, Aug. 2003.

AL-KUBAISY, M. A.; PALANJIAN, A. S. K. Retempering studies of concrete in hot weather. In: PROPERTIES OF FRESH CONCRETE, 1990, Hanover/Germany. Proceedings... London: Chapman and Hall, 1990. p. 83-91.

ANDERSEN, P. J. The effect of superplasticizers and air-entraining agents on the zeta potential of cement particles. Cement and Concrete Research, v. 16, n. 6, p. 931-940, Nov. 1986.

ANDERSEN, P. J.; ROY, D. M.; GAIDIS, J. M. The effect of superplasticizer molecular weight in its adsorption on, and dispersion of, cement. Cement and Concrete Research, v. 18, n. 6 , p. 980-986, Nov. 1988.

ASAGA, K.; ROY, D. M. Rheological properties of cement mixes: IV. Effects of superplasticizers on viscosity and yield stress. Cement and Concrete Research, v. 10, n. 2, p. 287-295. 1980.

ASSOCIAÇÃO BRASILEIRA DE NORMAS TÉCNICAS. NBR 5732: cimento Portland comum. Rio de Janeiro, 1991.

NBR 6118: projeto de estruturas de concreto. Rio de Janeiro, 2003. 
NBR 6474: cimento Portland e outros materiais em pó - determinação da massa específica. Rio de Janeiro, 1984.

Janeiro, 1987.

NBR 7217: agregados - determinação da composição granulométrica. Rio de

NBR 7218: agregados - determinação do teor de argila em torrões e materiais friáveis. Rio de Janeiro, 1987.

NBR 7219: agregados - determinação do teor de materiais pulverulentos. Rio de Janeiro, 1987.

. NBR 7251: agregado em estado solto - determinação da massa unitária. Rio de Janeiro, 1982

NBR 7682: calda de cimento para injeção - determinação do índice de fluidez. Rio de Janeiro, 1983.

. NBR 7810: agregado em estado compactado seco - determinação da massa unitária. Rio de Janeiro, 1983.

. NBR 9776 : agregados - determinação da massa específica de agregados miúdos por meio do frasco Chapman. Rio de Janeiro, 1987.

NBR 9937: agregados - determinação da absorção e da massa específica de agregado graúdo. Rio de Janeiro, 1987.

NBR 10342: concreto - perda de abatimento. Rio de Janeiro, 1992.

. NBR 10908 (MB-2645): aditivos para argamassa e concreto - ensaios de uniformidade. Rio de Janeiro, 1990.

NBR 11580 (MB-3433): cimento Portland - determinação da água da pasta de consistência normal. Rio de Janeiro, 1991.

NBR 11581 (MB-3434): cimento Portland - determinação dos tempos de pega. Rio de Janeiro, 1991. 1992.

NBR 11768 (EB-1763): aditivos para concreto de cimento Portland. Rio de Janeiro,

. NBR NM 67: concreto - determinação da consistência pelo abatimento do tronco de cone. Rio de Janeiro, 1998. 2001.

NM 49: agregado miúdo - determinação de impurezas orgânicas. Rio de Janeiro,

NM 137: argamassa e concreto - água para amassamento e cura de argamassa e concreto de cimento Portland. Rio de Janeiro, 1997.

ASSOCIATION FRANÇAISE DE NORMALISATION. NF EN 933-4 - Essais pour déterminer les caractéristiques géométriques des granulats - Partie 4 : détermination de la forme des grains - Indice de forme. 2000. 
ATZENI, C.; MASSIDDA, L.; SANNA, U. Comparison between rheological models for portland cement pastes. Cement and Concrete Research, v. 15, n. 3, p. 511-519, May. 1985.

BANFILL, P. F. G. The rheology of cement paste: progress since 1973. In: PROPERTIES OF FRESH CONCRETE, 1990, Hanover/Germany. Proceedings... London: Chapman and Hall, 1990. p. 3-9.

BANFILL, P. F. G. A coaxial cylinders viscosimeter for mortar: design and experimental validation. In: RHEOLOGY OF FRESH CEMENT AND CONCRETE, 1990, London. Proceedings... London: E \& FN Spon, 1991. p. 217-226.

BANFILL, P. et al. Comparison of concrete rheometers: international tests at LCPC (Nantes, France) in October, 2000. NISTIR 6819, Sept. 2001.

BARTOS, P. J. M. Workability of special fresh concretes. In: INTERNATIONAL RILEM WORKSHOP - SPECIAL CONCRETES: WORKABILITY AND MIXING, 1993, Paisley/Scotland. Proceedings... London: E \& FN Spon, 1994. p. 3-6.

BEITZEL, $H$. Automation of concrete construction site. In: INTERNATIONAL RILEM WORKSHOP - SPECIAL CONCRETES: WORKABILITY AND MIXING, 1993, Paisley/Scotland. Proceedings... London: E \& FN Spon, 1994. p. 7-13.

BENTZ, D. P.; GARBOCZI, E. J. Percolation of phases in a three-dimensional cement paste microstructural model. Cement and Concrete Research, v. 21, n. 2-3, p. 325-344, Mar.May. 1991.

BONEN, D.; SARKAR, S. L. The superplasticizer adsorption capacity of cement pastes, pore solution composition, and parameters affecting flow loss. Cement and Concrete Research, v. 25, n. 7, p. 1423-1434, Oct. 1995.

BÖRGESSON, L.; FREDRIKSSON, A. Influence of vibrations on the rheological properties of cement. In: RHEOLOGY OF FRESH CEMENT AND CONCRETE, 1990, London. Proceedings... London: E \& FN Spon, 1991. p. 313-322.

BRETAS, R. E. S.; D' AVILA, M. A. Reologia de polímeros fundidos. São Carlos/SP: Editora da UFSCar, 2000. 196p.

BRITISH STANDARDS. BS 812 (Pt. 105): method for determination of particle shape. 1985.

BUCHER, H. R. E. Desempenho de aditivos redutores de água de alta eficiência em pastas, argamassas ou concretos. In: REUNIAO ANUAL DO IBRACON, REIBRAC, 30., Rio de Janeiro, 1988. v. 2, p. 609-625.

CHAPPUIS, J. Rheological measurements with cement pastes in viscosimeters: a comprehensive approach. In: RHEOLOGY OF FRESH CEMENT AND CONCRETE, 1990, London. Proceedings... London: E \& FN Spon, 1991. p. 3-12.

CHIDIAC, S. E. et al. Controlling the quality of fresh concrete - a new approach. Magazine of Concrete Research, v. 52, n. 5, p. 353-363, Oct. 2000.

CHIOCCHIO, G.; PAOLINI, A. E. Optimum time for adding superplasticizers to portland cement pastes. Cement and Concrete Research, v. 15, n. 5, p. 901-908, Sept. 1985.

CHOPIN, D.; De LARRARD, F.; CAZACLIU, B. Why do HPC and SCC require a longer mixing time? Cement and Concrete Research, v. 34, n. 12, p. 2237-2243, Dec. 2004. 
CLAISSE, P. A.; LORIMER, O.; AL OMARI, M. Workability of cement pastes. ACI Materials Journal, v. 98, n. 6, p. 476-482, Nov.-Dec. 2001.

CURCIO, F.; DeANGELIS, B. A. Dilatant behavior of superplasticized cement pastes containing matakaolin. Cement and Concrete Research, v. 28, n. 5, p. 629-634, May. 1998.

CYR, M.; LEGRAND, C.; MOURET, M. Study of the shear thickening effect of superplsticizers on the rheological behaviour of cement pastes containing or not mineral additives. Cement and Concrete Research, v. 30, n. 9, p. 1477-1483, Sept. 2000.

DAIMON, M.; ROY, D. M. Rheological properties of cement mixes: I. methods, preliminary experiments, and adsorption studies. Cement and Concrete Research, v. 8, n. 6, p. 753764, Nov. 1978.

DAY, K. W. Equivalent slump. In: INTERNATIONAL RILEM CONFERENCE PRODUCTION METHODS AND WORKABILITY OF CONCRETE, 1996, Paisley/Scotland. Proceedings... London: E \& FN Spon, 1996. p. 357-364.

De LARRARD, F. et al. Design of a rheometer for fluid concretes. In: INTERNATIONAL RILEM WORKSHOP - SPECIAL CONCRETES: WORKABILITY AND MIXING, 1993, Paisley/Scotland. Proceedings... London: E \& FN Spon, 1994. p. 201-208.

De LARRARD, F. et al. Evolution of the workability of superplasticized concretes: assessment with the BTRHEOM rheometer. In: INTERNATIONAL RILEM CONFERENCE - PRODUCTION METHODS AND WORKABILITY OF CONCRETE, 1996, Paisley/Scotland. Proceedings... London: E \& FN Spon, 1996. p. 377-388.

De LARRARD, F. et al. A new rheometer for soft-to-fluid concrete. ACl Materials Journal, v. 94, n. 3, p. 234-243, May-June. 1997a.

De LARRARD, F. et al. The AFREM method for the mix-design of high performance concrete. Materials and Structures, v. 30, p. 439-446, Aug.-Sept. 1997b.

De LARRARD, F.; FERRARIS, C. F.; SEDRAN, T. Fresh concrete: a Herschel-Bulkley material. Materials and Structures, v. 31, p. 494-498, Aug.-Sept. 1998.

De LARRARD, F.; SEDRAN, T. Mixture-proportioning of high-performance concrete. Cement and Concrete Research, v. 32, n. 11, p. 1699-1704, Nov. 2002.

DEPARTAMENTO NACIONAL DE ESTRADAS DE RODAGEM. DNER-ME 094 : concreto determinação da consistência pelo consistômetro Ve-Be. Rio de Janeiro:I PR,1994.

DOMONE, P.; HSI-WEN, C. Testing of binders for high performance concrete. Cement and Concrete Research, v. 27, n. 8, p. 1141-1147, Aug. 1997.

DOMONE, P. L.; THURAIRATNAM, H. The relationship between early age property measurements on cement pastes. In: RHEOLOGY OF FRESH CEMENT AND CONCRETE, 1990, London. Proceedings... London: E \& FN Spon, 1991. p. 181-191.

DOMONE, P. L. J.; YONGMO, X.; BANFILL, P. F. G. Developments of the two-point workability test for high-performance concrete. Magazine of Concrete Research, v. 51, n. 3, p. 171-179, June. 1999.

ERDOGDU, S. Compatibility of superplasticizers with cements different in composition. Cement and Concrete Research, v. 30, n. 5, p. 767-773, May. 2000. 
ERDOGDU, S. Effect of retempering with superplasticizer admixtures on slump loss and compressive strength of concrete subjected to prolonged mixing. Cement and Concrete Research, v. 35, n. 5, p. 907-912, May. 2005.

FERRARIS, C. F. Measurement of rheological properties of high performance concrete: state of the art report. NISTIR 5869, July. 1996.

FERRARIS, C. F. Measurement of rheological properties of high performance concrete: state of the art report. Journal of Research of the National Institute of Standards and Technology, v.104, n. 5, p. 461-478, Sept.-Oct. 1999.

FERRARIS, C. F.; De LARRARD, F. Testing and modeling of fresh concrete rheology. NISTIR 6094, Feb. 1998a.

FERRARIS, C. F.; De LARRARD, F. Modified slump test to measure rheological parameters of fresh concrete. Cement, Concrete and Aggregates, v. 20, n. 2, p. 241-247, Dec. 1998b.

FERRARIS, C. F.; GAIDIS, J. M. Connection between the rheology of concrete and rheology of cement paste. ACl Materials Journal, v. 89, n. 4, p. 388-393, July.-Aug. 1992.

FERRARIS, C. F.; OBLA, K. H.; HILL, R. The influence of mineral admixtures on the rheology of cement paste and concrete. Cement and Concrete Research, v. 31, n. 2, p. 245-255, Feb. 2001.

FOX, R. W.; McDONALD, A. T. Introdução à mecânica dos fluidos. Tradução de Alexandre Matos de Souza Melo. 4 ed. Rio de Janeiro: LTC - Livros Técnicos e Científicos, 1998. $662 p$.

GHIO, V. A. The rheology of fresh concrete and its effect on the shotcrete process. 1993. 193p. Tese (Doutorado em Engenharia Civil), Universidade da Califórnia, Berkeley. 1993.

GOMES, P. C. C. Optimization and characterization of high-strength self-compacting concrete. 2002. 139p. Tese (Doutorado), Escola Tècnica Superior D'Enginyers de Camins, Canals i Ports de Barcelona, Universitat Politècnica de Catalunya, Barcelona. 2002.

GRZESZCZYK, G.; KUCHARSKA, L. Hydrative reactivity of cement and rheological properties of fresh cement pastes. Cement and Concrete Research, v. 20, n. 2, p. 165174, Mar. 1990.

GRESZCZYK, S.; KUCHARSKA, L. The influence of chemical composition of cement on the rheological properties. In: RHEOLOGY OF FRESH CEMENT AND CONCRETE, 1990, London. Proceedings... London: E \& FN Spon, 1991. p. 27-36.

HANEHARA, S.; YAMADA, K. Interaction between cement and chemical admixture from the point of cement hydration, absorption behaviour of admixture, and paste rheology. Cement and Concrete Research, v. 29, n. 8, p. 1159-1165, Aug. 1999.

HANKE, V. Prediction of consistency of concrete by using key properties of raw materials and mix composition. In: RHEOLOGY OF FRESH CEMENT AND CONCRETE, 1990, London. Proceedings... London: E \& FN Spon, 1991. p. 303-309.

HATTORI, K.; IZUMI, K. A new viscosity equation for non-Newtonian suspensions and its application. In: RHEOLOGY OF FRESH CEMENT AND CONCRETE, 1990, London. Proceedings... London: E \& FN Spon, 1991. p. 83-92. 
HELENE, P. R. L. Récord mundial en el uso del concreto de alto desempeño - Edifício eTower. In: CONCRETO COLOQUIA 2003, São Carlos/SP. Anais... São Carlos/SP: CDROM.

HELENE, P. R. L.; TERZIAN, P. Manual de dosagem e controle do concreto. São Paulo: PINI; Brasília: SENAI, 1992. 349p.

$\mathrm{HU}, \mathrm{C}$. et al. Validation of BTRHEOM, the new rheometer for soft-to-fluid concrete. Materials and Structures, v. 29, n. 194, p. 620-631, Dec. 1996.

HU, C.; De LARRARD, F. The rheology of fresh high-performance concrete. Cement and Concrete Research, v. 26, n. 2, p. 283-294, Feb. 1996.

HU, C.; De LARRARD, F.; GJ $\varnothing R V$, O. E. Rheological testing and modeling of fresh high performance concrete. Materials and Structures, v. 28, n. 175, p. 1-7, Jan.-Feb. 1995.

IVANOV, Y. P.; ROSHAVELOV, T. T. The effect of condensed silica fume on the rheological behaviour of cement pastes. In: RHEOLOGY OF FRESH CEMENT AND CONCRETE, 1990, London. Proceedings... London: E \& FN Spon, 1991. p. 23-26.

JIANG, S.; KIM, B.-G.; AÏTCIN, P.-C. Importance of adequate soluble alkali content to ensure cement/superpalsticizer compatibility. Cement and Concrete Research, v. 29, n. 1, p. 71-78, Jan. 1999.

JIANG, S.; KIM, B.-G.; AIITCIN, P.-C. A practical method to solve slump loss problem in PNS superplasticized high-performance concrete. Cement, Concrete and Aggregates, v. 22, n. 1, p. 10-15, June. 2000.

JOHNSTON, C. D. Influence of aggregate void condition and particle size on the workability and water requirement of single-sized aggregate-paste mixtures. In: PROPERTIES OF FRESH CONCRETE, 1990, Hanover/Germany. Proceedings... London: Chapman and Hall, 1990. p. 67-76.

JOLICOEUR, C.; SIMARD, M. A. Chemical admixture-cement interactions: phenomenology and physico-chemical concepts. Cement and Concrete Composites, v. 20, n. 2-3, p. 87101, Apr. 1998.

KAKUTA, S.; KOJIMA, T. Rheology of fresh concrete under vibration. In: RHEOLOGY OF FRESH CEMENT AND CONCRETE, 1990, London. Proceedings... London: E \& FN Spon, 1991. p. 339-342.

KRUML, F. Setting process of concrete. In: PROPERTIES OF FRESH CONCRETE, 1990, Hanover/Germany. Proceedings... London: Chapman and Hall, 1990. p. 10-16.

KUCHARSKA, L. Effect of products of the hydration of $\mathrm{C}_{3} \mathrm{~A}$ on rheology of clinker and cement pastes. In: RHEOLOGY OF FRESH CEMENT AND CONCRETE, 1990, London. Proceedings... London: E \& FN Spon, 1991. p. 47-54.

LANOS, C.; LAQUERBE, M.; CASANDJIAN, C. Rheological behaviours of mortars and concretes: experimental approach. In: INTERNATIONAL RILEM CONFERENCE PRODUCTION METHODS AND WORKABILITY OF CONCRETE, 1996, Paisley/Scotland. Proceedings... London: E \& FN Spon, 1996. p. 343-353.

Le ROY, R.; ROUSSEL, N. The Marsh cone as a viscosimeter: theoretical analysis and practical limits. Materials and Structures, v. 38, n. 275, p. 25-30, Jan.-Feb. 2005.

Aplicação de conceitos reológicos na tecnologia dos concretos de alto desempenho 
LEGRAND, C. Workability and rheology. In: INTERNATIONAL RILEM WORKSHOP SPECIAL CONCRETES: WORKABILITY AND MIXING, 1993, Paisley/Scotland. Proceedings... London: E \& FN Spon, 1994. p. 51-54.

LIBORIO, J. B. L. Desenvolvimento de fôrmas metálicas para a construção de elementos estruturais - avaliação das técnicas para uma produção em escala industrial. Relatório Técnico apresentado à $\mathrm{CDH}$ - Companhia do Desenvolvimento Habitacional do Estado de São Paulo. $1^{\text {a }}$ Fase. 1985/1986.

LIBORIO, J. B. L. Conferência sobre concreto de alto desempenho. In: SIMPÓSIO INTERNACIONAL SOBRE CONCRETOS ESPECIAIS. Sobral/CE, mar., 2002.

LIBORIO, J. B. L.; CASTRO, A. L.; SILVA, F. G. Potencialidade de uso de concretos especiais em obras marítimas. In: SEMINÁRIO E WORKSHOP EM ENGENHARIA OCEÂNICA, 2004, Rio Grande/RS. Anais... CD-ROM.

LIBORIO, J. B. L. et al. Demystifying the production processof high performance and high strength concretes - Design considerations. In: IV HIGH PERFORMANCE CONCRETE STRUCTURES - IV ACI/CANMET CONFERENCE ON QUALITY OF CONCRETE STRUCTURES AND RECENT ADVANCES IN CONCRETE MATERIALS AND TESTING, 2005, Olinda/PE. Proceedings... CD-ROM.

LIM, G.-G. et al. Slump loss control of cement paste by adding polycarboxylic type slumpreleasing dispersant. Cement and Concrete Research, v. 29, n. 2, p. 223-229, Feb. 1999.

MANNONEN, R.; PENTTALA, V. The efficiency of SNF-type superplasticiser in Portland cement pastes. In: INTERNATIONAL RILEM CONFERENCE - PRODUCTION METHODS AND WORKABILITY OF CONCRETE, 1996, Paisley/Scotland. Proceedings... London: E \& FN Spon, 1996. p. 327-341.

MANRICH, S.; PESSAN, L. A. Reologia: conceitos básicos. São Carlos: Gráfica UFSCar, 1987.

MANSOUTRE, S.; COLOMBET, P.; VAN DAMME, H. Water retention and granular rheological behavior of fresh $\mathrm{C}_{3} \mathrm{~S}$ paste as a function of concentration. Cement and Concrete Research, v. 29, n. 9, p. 1441-1453, Sept. 1999.

MASOOD, I.; AGARWAL, S. K. Effect of various superplasticizers on rheological properties of cement paste and mortars. Cement and Concrete Research, v. 24, n. 2, p. 291-302, 1994.

MEHTA, P. K.; MONTEIRO, P. J. M. Concreto: estrutura, propriedades e materiais. São Paulo: PINI, 1994. 573p.

MELO, A. B. Influência da cura térmica (vapor) sob pressão atmosférica no desenvolvimento da microestrutura dos concretos de cimento Portland. 2000. 245p. Tese (Doutorado em Interunidades em Ciência e Engenharia de Materiais), Universidade de São Paulo. São Carlos/SP. 2000.

MOULIN, E.; BLANC, P.; SORRENTINO, D. Influence of key cement chemical parameters on the properties of metakaolin blended cements. Cement and Concrete Composites, v. 23, n. 6, p. 463-469, Dec. 2001.

MURATA, J. Flow and deformation of fresh concrete. Materials and Structures, v. 17, n. 98 , p. 117-129, Mar.-Apr. 1984. 
MфRTSELL, E.; MAAGE, M.; SMEPLASS, S. A particle-matrix model for prediction of workability of concrete. In: INTERNATIONAL RILEM CONFERENCE - PRODUCTION METHODS AND WORKABILITY OF CONCRETE, 1996, Paisley/Scotland. Proceedings... London: E \& FN Spon, 1996 p. 429-438.

NACHBAUR, L. et al. Dynamic mode rheology of cement and tricalcium silicate pastes from mixing to setting. Cement and Concrete Research, v. 31, n. 2, p. 183-192, Feb. 2001.

NÄGELE, E. The zeta-potential of cement. Cement and Concrete Research, v. 15, n. 3, p. 453-462, May. 1985.

NEHDI, M. Why some carbonate fillers cause rapid increases of viscosity in dispersed cement-based materials. Cement and Concrete Research, v. 30, n. 10, p. 1663-1669, Oct. 2000.

NEHDI, M.; MINDESS, S.; AÏTCIN, P.-C. Rheology of high-performance concrete: effect of ultrafine particles. Cement and Concrete Research, v. 28, n. 5, p. 687-697, May. 1998.

NEVILLE, A. M. Propriedades do concreto. Tradução de Salvador E. Giammusso. 2 ed. São Paulo: PINI, 1997. 828p.

NGUYEN, T. L. H.; ROUSSEL, N.; COUSSOT, P. Correlation between L-box test and rheological parameters of a homogeneous yield stress fluid. Cement and Concrete Research,. Article in Press. Disponível <http://www.sciencedirect.com/science?_ob=Mlmg\&_imagekey=B6TWG-4K9C5K0-2R\&_cdi=5562\&_user=972067\&_orig=browse\&_coverDate=06\%2F30\%2F2006\&_sk=999 999999\&view $=\bar{c} \& w c h p=d G L b V z b-$ zSkzk\&md5=d3678cbca908322abf03630a5ca3cee0\&ie=/sdarticle.pdf>Acesso em $: 24 / 08 / 2006$.

NISHIBAYASHI, S. et al. Effect of properties of mix constituents on rheological constants of self-compacting concrete. In: INTERNATIONAL RILEM CONFERENCE - PRODUCTION METHODS AND WORKABILITY OF CONCRETE, 1996, Paisley/Scotland. Proceedings... London: E \& FN Spon, 1996. p. 255-262.

OKAMOTO, H.; ENDOH, T. Modeling in analysis of deformation of very early age concrete subject to construction load. In: RHEOLOGY OF FRESH CEMENT AND CONCRETE, 1990, London. Proceedings... London: E \& FN Spon, 1991. p. 113-122.

OKAMURA, T.; HARADA, H.; DAIMON, M. Influence of calcium sulfate in belite-rich cement on the change in fluidity of mortar with time. Cement and Concrete Research, v. 28, n. 9, p. 1297-1308, Sept. 1998.

PANDOLFELLI, V. C. et al. Dispersão e empacotamento de partículas: princípios e aplicações em processamento cerâmico. São Paulo: Fazendo Arte, 2000. 195p.

PARK, C. K.; NOH, M. H.; PARK, T. H. Rheological properties of cimentitious materials containing mineral admixtures. Cement and Concrete Research, v. 35, n. 5, p. 842-849, May. 2005.

PENTTALA, V. Possibilities of increasing the workability time of high strength concretes. In: PROPERTIES OF FRESH CONCRETE, 1990, Hanover/Germany. Proceedings... London: Chapman and Hall, 1990. p. 92-100. 
PETIT, J.-Y.; KHAYAT, K. H.; WIRQUIN, E. Coupled effect of time and temperature on variations of yield value of highly flowable mortar. Cement and Concrete Research, v. 36, n. 5, p. 832-841, May. 2006.

PETROU, M. F. et al. A unique experimental method for monitoring aggregate settlement in concrete. Cement and Concrete Research, v. 30, n. 5, p. 809-816, May. 2000a.

PETROU, M. F. et al. Influence of mortar rheology on aggregate settlement. ACl Materials Journal, v. 97, n. 4, p. 479-485, July.-Aug. 2000b.

PILEGGI, R. G. Ferramentas para o estudo e desenvolvimento de concretos refratários. 2001. 187p. Tese (Doutorado em Ciência e Engenharia de Materiais), Universidade Federal de São Carlos. São Carlos/SP. 2001.

PILEGGI, R. G. et al. Novel rheometer for refractory castables. American Ceramic Society Bulletin, v. 79, n. 1, p. 54-58, Jan. 2000.

POWERS, T. C. The properties of fresh concrete. New York: John Wiley \& Sons, 1968. $664 p$.

PUNKKI, J.; GOLASZEWSKI, J.; GJØRV, O. E. Workability loss of high-strength concrete. ACl Materials Journal, v. 93, n. 5, p. 427-431, Sept.-Oct. 1996.

RAGO, F. Características reológicas de pastas de cales hidratadas normalizadas e de cimento. 1999. 207p. Dissertação (Mestrado em Engenharia de Construção Civil e Urbana) - Escola Politécnica, Universidade de São Paulo. São Paulo/SP. 1999.

RAVINA, D.; SOROKA, I. Slump loss and compressive strength of concrete made with WRR and HRWR admixtures and subjected to prolonged mixing. Cement and Concrete Research, v. 24, n. 8, p. 1455-1462. 1994.

RESTORFF, B. Consistency and stiffening of fresh concrete: Relationships between results of laboratory and field tests. In: PROPERTIES OF FRESH CONCRETE, 1990, Hanover/Germany. Proceedings... London: Chapman and Hall, 1990. p. 17-23.

ROSHAVELOV, T. Prediction of fresh concrete flow behavior based on analytical model for mixture proportioning. Cement and Concrete Research, v. 35, n. 5, p. 831-835, May. 2005.

ROUSSEL, N. A thixotropy model for fresh fluid concrete: theory, validation and applications. Cement and Concrete Research, Article in Press. Disponível em: <http://www.sciencedirect.com/science?_ob=Mlmg\&_imagekey=B6TWG-4KD5C0M-1$16 \&$ cdi $=5562 \&$ user $=972067 \&$ orig $=$ browse\&_coverDate $=07 \% 2 F 13 \% 2 F 2006 \&$ sk $=999$ 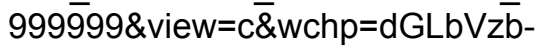

zSkzk\&md5=4e4aeb32b133b43e319b8b559eaea1fa\&ie=/sdarticle.pdf $>$ Acesso em: 24/08/2006.

ROUSSEL, N.; Le ROY, R. The Marsh cone: a test or a rheological apparatus? Cement and Concrete Research, v. 35, n. 5, p. 823-830, May. 2005.

SAAK, A. W.; JENNINGS, H. M.; SHAH, S. P. The influence of wall slip on yield stress and viscoelastic measurements of cement paste. Cement and Concrete Research, v. 31, n. 2, p. 205-212, Feb. 2001a.

SAAK, A. W.; JENNINGS, H. M.; SHAH, S. P. New methodology for designing selfcompacting concrete. ACI Materials Journal, v. 98, n. 6, p. 429-439, Nov.-Dec. 2001b. 
SAAK, A. W.; JENNINGS, H. M.; SHAH, S. P. A generalized approach for the determination of yield stress by slump and slump flow. Cement and Concrete Research, v. 34, n. 3, p. 363-371, Mar. 2004.

SASIADEK, S.; SLIWINSKI, M. Means of prolongation of workability of fresh concrete in hot climate conditions. In: PROPERTIES OF FRESH CONCRETE, 1990, Hanover/Germany. Proceedings... London: Chapman and Hall, 1990. p. 109-115.

SCHOWALTER, W. R.; CHRISTENSEN, G. Toward a rationalization of the slump test for fresh concrete: comparisons of calculations and experiments. Journal of Rheology, v. 42, n. 4, p. 865-870, July. 1998.

SCHRAMM, G. Reologia e reometria: fundamentos teóricos e práticos. Tradução de Cheila G. Mothé; Denise Z. Correia; Hans M. Petri; Michelle Gonçalves; Tatiana Carestiato. São Paulo: Artliber Editora, 2006. 234p.

SCRIVENER, K. L. The microstructure of concrete. In: ; Jan P. Skalny. Materials Science of Concrete I. Westerville/USA: The American Ceramic Society, 1989. p. 127161.

SEDRAN, T. et al. Mix design of self-compacting concrete (SCC). In: INTERNATIONAL RILEM CONFERENCE - PRODUCTION METHODS AND WORKABILITY OF CONCRETE, 1996, Paisley/Scotland. Proceedings... London: E \& FN Spon. p. 439-450.

SHINDOH, T.; YOKOTA, K.; YOKOI, K. Effect of mix constituents on rheological properties of super workable concrete. In: INTERNATIONAL RILEM CONFERENCE PRODUCTION METHODS AND WORKABILITY OF CONCRETE, 1996, Paisley/Scotland. Proceedings... London: E \& FN Spon, 1996. p. 263-270.

SILVA , I. J. Contribuição ao estudo dos concretos de elevado desempenho: propriedades mecânicas, durabilidade e microestrutura. 2000. 279p. Tese (Doutorado em Interunidades em Ciência e Engenharia de Materiais), Universidade de São Paulo. São Carlos/SP. 2000.

STRUBLE, L. et al. Rheology of cement paste and concrete. Cement, Concrete and Aggregates, v. 20, n. 2, p. 269-277, Dec. 1998.

SUHR, S. Interactions between sulphates minerals and $\mathrm{C}_{3} \mathrm{~A}$ in cement paste rheology. In: RHEOLOGY OF FRESH CEMENT AND CONCRETE, 1990, London. Proceedings... London: E \& FN Spon, 1991. p. 37-46.

SVERMOVA, L.; SONEBI, M.; BARTOS, P. J. M. Influence of mix proportions on rheology of cement grouts containing limestone powder. Cement and Concrete Composites, v. 25, n. 7, p. 737-749, 2003.

SZWABOWSKI, J. Influence of three-phase structure on the yield stress of fresh concrete. In: RHEOLOGY OF FRESH CEMENT AND CONCRETE, 1990, London. Proceedings... London: E \& FN Spon, 1991. p. 241-248.

TANIGAWA, Y.; MORI, H.; WATANABE, K. Computer simulation of consistency and rheology tests of fresh concrete by viscoplastic finite element method. In: PROPERTIES OF FRESH CONCRETE, 1990, Hanover/Germany. Proceedings... London: Chapman and Hall, 1990. p. 301-308.

TANNER, R. I. Engineering rheology. ed. rev. New York: Oxford University Press, 1988. $451 \mathrm{p}$.

Aplicação de conceitos reológicos na tecnologia dos concretos de alto desempenho 
TATTERSALL, G. H. Progress in measurement of workability by two-point test. In: PROPERTIES OF FRESH CONCRETE, 1990, Hanover/Germany. Proceedings... London: Chapman and Hall, 1990. p. 203-212.

TATTERSALL, G. H. Effect of vibration on the rheological properties of fresh cement pastes and concretes. In: RHEOLOGY OF FRESH CEMENT AND CONCRETE, 1990, London. Proceedings... London: E \& FN Spon, 1991a. p. 323-338.

TATTERSALL, G. H. Workability and quality control of concrete. London: E \& FN Spon, 1991b. 262p.

TATTERSALL, G. H. Application of rheological measurements to practical control of concrete. In: RHEOLOGY OF FRESH CEMENT AND CONCRETE, 1990, London. Proceedings... London: E \& FN Spon, 1991c. p. 270-280.

TATTERSALL, G. H.; BAKER, P. H. The effect of vibration on the rheological properties of fresh concrete. Magazine of Concrete Research, v. 40, n. 143, p. 79-89, June. 1988.

TATTERSALL, G. H.; BAKER, P. H. An investigation on the effect of vibration on the workability of fresh concrete using a vertical pipe apparatus. Magazine of Concrete Research, v. 41, n. 146, p. 3-9, Mar. 1989.

TATTERSALL, G. H.; BANFILL, P. F.G. The rheology of fresh concrete. London: Pitman, 1983. 347p.

TOPCU, I. B.; KOCATASKIN, F. A two-phase composite materials approach to the workability of concrete. Cement and Concrete Composites, v.17, n. 4, p. 319-325, Dec. 1995.

TOUTOU, Z.; ROUSSEL, N. Multiscale experimental study of concrete rheology: from water scale to gravel scale. Materials and Structures, v. 39, n. 2, Mar. 2006.

UCHIKAWA, $\mathrm{H}$. et al. Effect of admixture on hydration of cement, adsorptive behavior of admixture and fluidity and setting of fresh cement paste. Cement and Concrete Research, v. 22, n. 6, p. 1115-1129, Nov. 1992.

UCHIKAWA, H.; HANEHARA, S.; SAWAKI, D. The role of steric repulsive force in the dispersion of cement particles in fresh paste prepared with organic admixture. Cement and Concrete Research, v. 27, n. 1, p. 37-50, Jan. 1997.

VAN WAZER, J. R. et al. Viscosity and flow measurement: a laboratory handbook of rheology. 2.ed. New York: Interscience Publishers, 1966. 406p.

VIEIRA, M. C. et al. Dispersing agents for cement based on modified polysaccharides. Cement and Concrete Research, v. 35, v. 5, p. 883-890, May. 2005.

WALLEVIK, J. E. Relationship between the Bingham parameters and slump. Cement and Concrete Research, v. 36, n. 7, p. 1214-1221, July. 2006.

WALLEVIK, O. H.; GJØRV, O. E. Development of a coaxial cylinders viscometer for fresh concrete. In: PROPERTIES OF FRESH CONCRETE, 1990, Hanover/Germany. Proceedings... London: Chapman and Hall, 1990a. p. 213-224.

WALLEVIK, O. H.; GJøRV, O. E. Modification of the two-point workability apparatus. Magazine of Concrete Research, v. 42, n. 152, p. 135-142, Sept. 1990b. 
WALLEVIK, O. H.; SAASEN, A.; GJØRV, O. E. Effect of filler materials on the rheological properties of fresh concrete. ACl Materials Journal, v. 92, n. 5, p. 524-528, Sept.-Oct. 1995.

WEST, R. P. Concrete retempering without strength loss. In: PROPERTIES OF FRESH CONCRETE, 1990, Hanover/Germany. Proceedings... London: Chapman and Hall, 1990. p. 134-141.

WILLIAMS, D. A.; SAAK, A. W.; JENNINGS, H. M. The influence of mixing on the rheology of fresh cement paste. Cement and Concrete Research, v. 29, n. 9, p. 1491-1496, Sept. 1999.

YAHIA, A.; KHAYAT, K. H. Analytical models for estimating yield stress of high-performance pseudoplastic grout. Cement and Concrete Research, v. 31, n. 5, p. 731-738, May. 2001.

YAHIA, A.; KHAYAT, K. H. Applicability of rheological models to high-performance grouts containing supplementary cimentitious materials and viscosity enhancing admixture. Materials and Structures, v. 36, n. 260, p. 402-412, July. 2003.

YANG, M.; JENNINGS, H. M. Influences of mixing methods on the microstructure and rheological behavior of cement paste. Advanced Cement Based Materials, v. 2, n. 2, p. 70-78, Mar. 1995.

YEN, T. et al. Flow behaviour of high strength high-performance concrete. Cement and Concrete Composites, v. 21, n. 5-6, p. 413-424, Dec. 1999.

ZAIN, M. F. M.; SAFIUDDIN, M.; YUSOF, K. M. A study on the properties of freshly mixed high performance concrete. Cement and Concrete Research, v. 29, n. 9, p. 1427-1432, Sept. 1999.

ZHANG, X.; HAN, J. The effect of ultra-fine admixture on the rheological property of cement paste. Cement and Concrete Research, v. 30, n. 5, p. 827-830, May. 2000. 